\title{
CREATE A CONSORTIUM AND DEVELOP PREMIUM CARBON PRODUCTS FROM COAL
}

TECHNICAL PROGRESS REPORT

January 1, 2000 - December 31, 2000

FRANK RUSINKO, JR.

November 2001

DE-FC26-98FT40350

The Pennsylvania State University

Office of Sponsored Programs

110 Technology Center

University Park, PA 16802

West Virginia University

Office of Sponsored Programs

886b Chestnut Ridge Road, Room 202

Morgantown, W 26506-6845

R. Kevomen 1121102

Assistant Vice President for Research 


\section{DISCLAIMER}

This report was prepared as an account of work sponsored by an agency of the United States Government. Neither the United States Government or any agency thereof, nor any of their employees, makes any warranty, express or implied, or assumes any legal liability or responsibility for the accuracy, completeness, or usefulness of any information, apparatus, product, or process disclosed, or represents that its use would not infringe privately owned rights. Reference herein to any specific commercial product, process, or service by trade name, trademark, manufacturer or otherwise does not necessarily constitute or imply its endorsement, recommendation, or favoring by the United States Government or any agency thereof. The views and opinions of authors expressed herein do not necessarily state or reflect those of the United States Government or any agency thereof. 


\title{
Technical Progress Report \\ Budget Period 3
}

\begin{abstract}
The Consortium for premium Carbon Products from Coal, with funding from the U.S. Department of Energy, National Energy Technology Laboratory continue with the development of innovative technologies that will allow coal or coal-derived feedstocks to be used in the production of value-added carbon materials.

In addition to supporting eleven independent projects during budget period 3 , three meeting were held at two separate locations for our membership. The first was held at Nemacolin Woodlands Resort on May 15-16, 2000. This was followed by two meetings at Penn State, a tutorial on August 11,2000 and a technical progress meeting on October 26-27.
\end{abstract}

Dr. Charles E. Bakis, Associate Professor in the Penn State Composites Manufacturing Technology Center was the guest speaker at our Nemacolin Meeting. Dr. Bakis presented a paper on Carbon Fiber Reinforced Composites.

This year's tutorial was held to familiarize the carbon and graphite interests with the coal industry. The program was well received and guest speakers included individuals from the anthracite and bituminous coal industries.

The final meeting of the year was held October 26-27. Four new Council Members were elected and presentations on projects proposals submitted for potential 2001 funding were presented. Dr. Eva Pell, Vice President for Research and Dean of the Graduate School at Penn State discussed the importance of research and the role of technology transfer.

Enclosed are copies of the final project reports for projects funded during Budget Period 3. 


\section{Table of Contents}

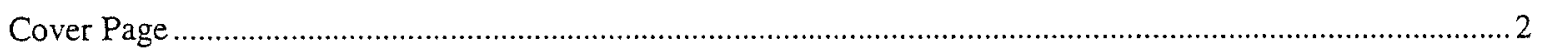

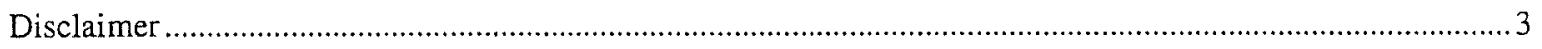

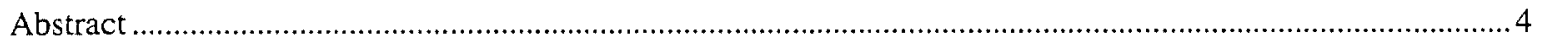

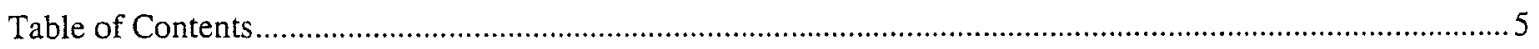

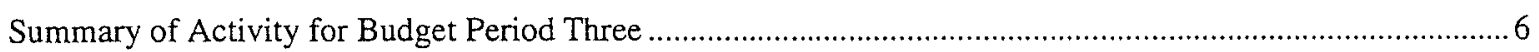

"Coal Derived Matrix Pitches for Carbon-Carbon Composite Manufacture/Production

of Fibers and Composites from Coal-Based Precursors", Principal Investigator:

Dr. John Zondlo, West Virginia University, Morgantown, WV.

"Anthracite Feedstocks for Specialty Graphite Production", Principal Investigator:

Mr. Bruce Conrad, Cornerstone Technology, Inc., Wilkes-Barre, PA.

"Comparison of Bituminous Coal Pyrolysis Tar and By-product Coke Oven Tar as

Premium Feedstock for Carbon Black Production", Principal Investigator: Dr. Semih Eser,

The Pennsylvania State University, University Park, PA.

"Anthracite Feedstocks for Binder Pitches for Carbon Fibers", Principal Investigator:

Mr. Bruce Conrad, Cornerstone Technology, Inc., Wilkes-Barre, PA

"Recovery and Utilization of Carbon from Coal-Fired Power Plant Fly Ash", Principal

Investigator: Dr. Mercedes Maroto-Valer, The Pennsylvania State University, University Park, PA.

"Low Cost Carbon Fibers from Coal-Based Precursors", Principal Investigator: Dr. Jim Withers,

MER Corporation, Tucson, AZ......

"Characterization of Coal-Derived Mercury Sorbents", Principal Investigator: Dr. Steve Benson,

University of North Dakota, Grand Forks, ND.

"Solvent Extracted Coal Tar Pitch for Nanofiber Production", Principal Investigator: Mr. Elliot

Kennel, Applied Sciences, Cedarville, OH.

"Coal Derived Cokes for the Production of Anodes for the Aluminum Industry", Principal

Investigator: Dr. John Zondlo, West Virginia University, Morgantown, WV.

"Understanding Microstructural Development in Coal-Derived Foams during Thermal

Processing", Principal Investigator: Dr. Darren Rogers, Touchstone Research Laboratory, Ltd.,

Triadelphia, WV.

"Development of Binder Pitches from Direct Coal Liquefaction and Coal-Tar Pitch

Blends", Principal Investigator: Dr. Peter Stansberry, West Virginia University,

Morgantown, WV. 


\section{Summary}

As we move into a new budget year we will continue to improve efforts to increase our membership. It is important that we get more exposure for the Consortium.

A Tutorial Workshop and two technical meeting will be scheduled during the year. Our first technical review meeting has tentatively been scheduled in St. Marys, PA for the March-April timeframe. We would like to schedule the tutorial workshop in the Pittsburgh area and include visits to one or two industrial sites.

Proposals will again be solicited from our membership for the next budget period. We will continue to encourage our membership to become more active in the Consortium, either with individual projects or working as a collaborative effort. 
Coal Derived Matrix Pitches for Carbon-Carbon Composite Manufacture/Production of Fibers and Composites from Coal-Based Precursors

\title{
FINAL REPORT
}

Reporting Period Start Date: January 1, 2000

Reporting Period End Date: June 30, 2001

Report Prepared by

Peter G. Stansberry

$\&$

John W. Zondlo

Department of Chemical Engineering

College of Engineering and Mineral Resources

P. O. Box 6102

West Virginia University

Morgantown, WV 26506-6102

Report Issued

July 2001

DOE Award Number DE-FC26-98FT40350

\author{
Other Contributors \\ Rodney Andrews \\ CAER \\ University of Kentucky \\ 2540 Research Park Drive \\ Lexington, KY 40511 \\ $\&$ \\ James C. Withers \\ MER Corporation \\ 7960 S. Kolb Road \\ Tucson, AZ 85760
}




\section{DISCLAIMER}

This report was prepared as an account of work sponsored by an agency of the United States Government. Neither the United States Government nor any agency thereof, nor any of their employees, makes any warranty, expressed or implied, or assumes any legal liability or responsibility for the accuracy, completeness, or usefulness of any information, apparatus, product, or process disclosed, or represents that its use would not infringe privately owned rights. Reference herein to any specific commercial product process, or service by trade name, trademark, manufacturer, or otherwise does not necessarily constitute or imply its endorsement, recommendation, or favoring by the United States Government or any agency thereof. The views and opinions of authors expressed herein do not necessarily state or reflect those of the United States Government or any agency thereof. 


\section{ABSTRACT}

The focus of the current project is the development of pitches for spinning isotropic fibers from coal by means of hydrotreatment and solvent extraction. The bulk of the fibers have been produced from the coal-derived pitches by conventional melt-spinning out of a single-hole spinneret. In addition, the pitches have been successfully tested in the novel centrifugal melt spinning (CMS) apparatus developed at the University of Kentucky. The fibers were oxygen stabilized in air at heating rates up to $1 \ldots \mathrm{C} / \mathrm{min}$ with good results and finally carbonized at $1100 \ldots$. C. The resulting fibers had a mean diameter of 27.9_m and a average tensile strength of $809 \mathrm{MPa}$. The fibers were then fabricated with coal-tar pitch into a C-C composite using two impregnation steps. The composite had a fiber volume of roughly $50 \%$, a density of $1.78 \mathrm{~g} / \mathrm{cm}^{3}$, and a flexural strength of $60 \mathrm{MPa}$. Finally, the carbonized coal-derived fibers were steam activated at $800 \ldots \mathrm{C}$ at a $33 \%$ burnoff, producing a surface area of $178 \mathrm{~m}^{2} / \mathrm{g}$ and a total pore volume of $0.396 \mathrm{~mL} / \mathrm{g}$. Interestingly, over half of the pore volume was in mesopores which may allow for applications not usually found for microporous fibers. 


\section{TABLE OF CONTENTS}

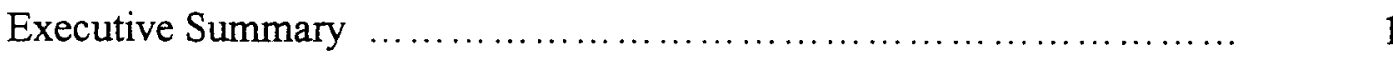

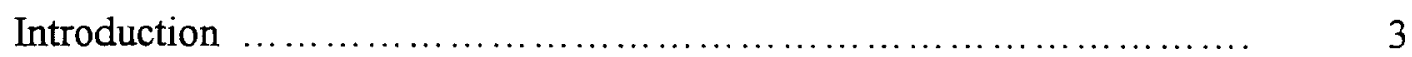

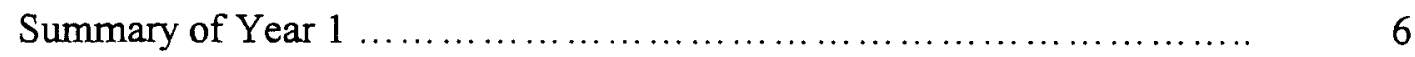

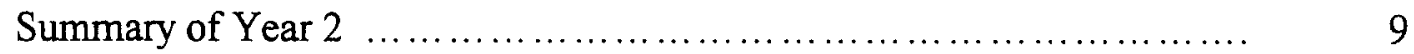

Coal-Derived Pitch Development $\quad$............................ 9

Fiber Spinning, Processing, and Composite Testing $\ldots \ldots \ldots \ldots \ldots \ldots .12$

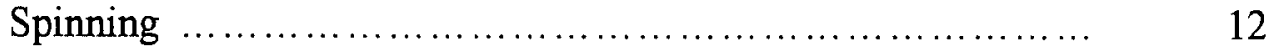

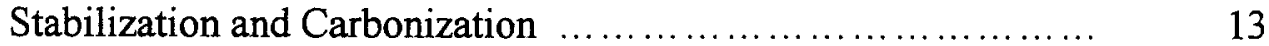

Composite Fabrication and Testing $\ldots \ldots \ldots \ldots \ldots \ldots \ldots \ldots \ldots . \ldots \ldots$

Activation of Coal-Based Carbon Fibers $\ldots \ldots \ldots \ldots \ldots \ldots \ldots \ldots . . \ldots 17$

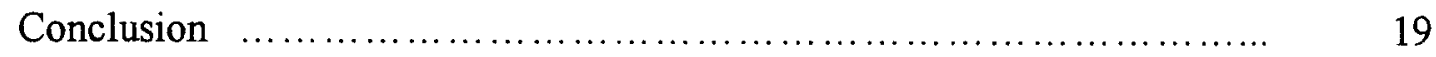

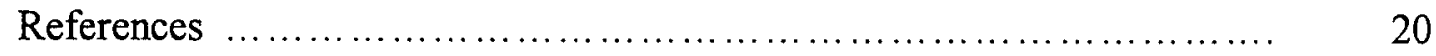




\section{LIST OF TABLES}

$1 \quad$ Yield of Isotropic Pitches Suitable for Carbon Fiber Production $\ldots \ldots \ldots . \quad \frac{\text { Page }}{4}$

2 Properties of Coal-Derived Fiber Precursor Developed in Year $1 \ldots \ldots$.... 6

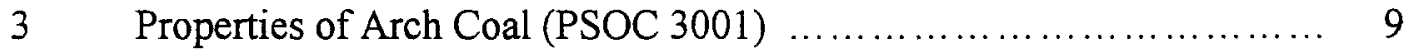

4 Product Yield and Pitch Properties from Hydrogenation of PSOC 3001 .. 10

5 Properties of Initial Coal-Derived Isotropic Pitch Sample ............. 11

6 Properties of Larger Size Coal-Derived Isotropic Pitch Sample .......... 11

$7 \quad$ Properties of Coal-Derived Matrix Pitch $\ldots \ldots \ldots \ldots \ldots \ldots \ldots \ldots \ldots \ldots \ldots \ldots \ldots \ldots \ldots$

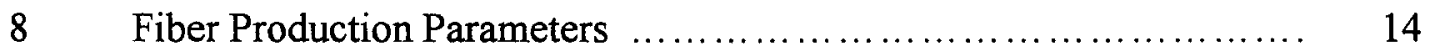

9 Characteristics of Individual Coal-Derived Carbon Fibers $\ldots \ldots \ldots \ldots \ldots \ldots$ 


\section{LIST OF FIGURES}

1 Processing Steps in Pitch Fiber Manufacture …................. $\frac{\text { Page }}{4}$

2 Relationship Between Stabilization Rate and Softening Point ......... 5

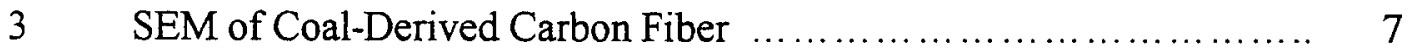

4 Fracture Surface of the Coal-Derived C-C Composite …............. 9

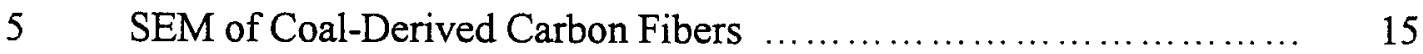

6 SEM of Fraction Surface of a Coal-Derived C-C Composite $\ldots \ldots \ldots \ldots \quad 17$ 


\section{EXECUTIVE SUMMARY}

Several coal-derived pitches were prepared for use as fiber precursors and the matrix binder for carbon-carbon composites. The pitches were produced from an Arch Coal (PSOC 3001) supplied by a CPCPC member company. Through a combination of hydrogenation, solvent extraction, filtration and heat treatment, three pitch samples were formulated: two samples for fiber spinning and the third for use as a matrix pitch in $\mathrm{C}-\mathrm{C}$ composites. Continuous fibers were easily spun from the pitches using a conventional single-hole spinneret. They were then stabilized in air using heating rates of up to $1 \ldots \mathrm{C} / \mathrm{min}$ to $310 \ldots \mathrm{C}$ and subsequently carbonized at $1100 \ldots \mathrm{C}$ in an inert atmosphere. Moreover, one of the pitches was successfully fed to the novel centrifugal melt spinning (CMS) apparatus where short, non-uniform fibers of variable diameter are spun into a mat-like material in short time.

The continuous fibers resulted in a mean diameter of 27.9_m and had an average tensile strength of $809 \mathrm{MPa}$. They were then placed in a closed die and matrix pitch was added under an applied pressure of 200psi. After heating and carbonization to $1200 \ldots \mathrm{C}$ in nitrogen, an impregnation step was performed, followed by another heat treatment to $1200 \ldots$ C. The resulting composite had a fiber volume of around $50 \%$, a density of $1.78 \mathrm{~g} / \mathrm{cm}^{3}$, and a flexural strength of $60 \mathrm{MPa}$. These properties are considered quite good when compared to comparable commercial C-C composites.

A final investigation studied the ability of the coal-derived fibers to be steam activated. The carbonized fibers were heated in steam for $0.25 \mathrm{hr}$ at $800 \ldots \mathrm{C}$ to yield a carbon burn-off

of about $33 \%$. The BET surface area using $\mathrm{N}_{2}$ was found to be $178 \mathrm{~m}^{2} / \mathrm{g}$ with a total pore 
volume of $0.396 \mathrm{~mL} / \mathrm{g}$. It was observed that the activation rate was faster than that observed for other extract pitches, probably due to the relatively high content of oxygen groups. Moreover, more than half the pores were mesopores, making them potential candidates for applications not normally found for typical microporous coal-tar pitch fibers. 


\section{INTRODUCTION}

Pitch-based carbon fibers can be classified into one of two broad groups depending on the crystalline state of the fiber precursor. Those based on carbonaceous mesophase can develop carbon fibers of high strength and stiffness. Suitable starting materials include processed coal-tar pitch or petroleum pitch, and polymerized model compounds such as acenaphthylene or naphthalene. ${ }^{(1-6)}$ The key feature of mesophase is its liquid crystalline nature in which a highly ordered, yet deformable fluid is melt spun or extruded into filaments. The fiber-forming process tends to impart directional order of the mesophase molecules along the axis of the fiber. After stabilization and additional heat treatment, these fibers can be converted to filaments that are nearly graphitic.

However, the focus on the current project is the development of pitches for carbon fibers that are essentially non-mesophasic, i.e., isotropic. Carbon fibers derived from isotropic pitches, though not having the performance of carbon fibers based on mesophase, exhibit reasonable strength and stiffness and are more economical to manufacture. Several sources can be identified as precursors for isotropic carbon fibers such as low and hightemperature coal tars, petroleum pitches, residual oil-shale liquids, asphaltite, and coal extracts. ${ }^{(7-12)}$ These substances are comprised primarily of condensed three to five-ring aromatic molecules bonded to a variety of functional groups such as aliphatic side chains.

The bulk of pitch-based carbon fibers are conventionally derived from either the byproducts of metallurgical coking operations or petroleum refining. Another source of pitch that is attracting growing interest is based on solvent extraction of coal. ${ }^{(13)}$ The main motivation is that solvent extraction of coal can produce pitches that are highly 
tailorable in their reactivity, softening point temperature, viscosity, etc.. This is in contrast to other sources of pitch fibers that rely on industrial byproducts and thus are subjected to vagaries in quality and composition. Moreover, the yield of pitch obtained by solvent extraction of coal can be much greater than that from the processing of traditional pitches, as indicated in Table 1.

Table 1. Yield of isotropic pitches suitable for carbon fiber production

Coal-Tar Pitch

$10-20 \mathrm{lb} /$ ton coal
Petroleum Pitch

$0.1-0.5 \mathrm{gal} / \mathrm{barrel}$ crude
Coal Solvent Extract

$200-3001 b /$ ton coal

Figure 1 depicts the essential processing steps that are common to all carbon fiber production. The pitch precursor before spinning must be freed of all particulate matter as solids can lead to plugging of the spinneret and can produce defects in the filament.

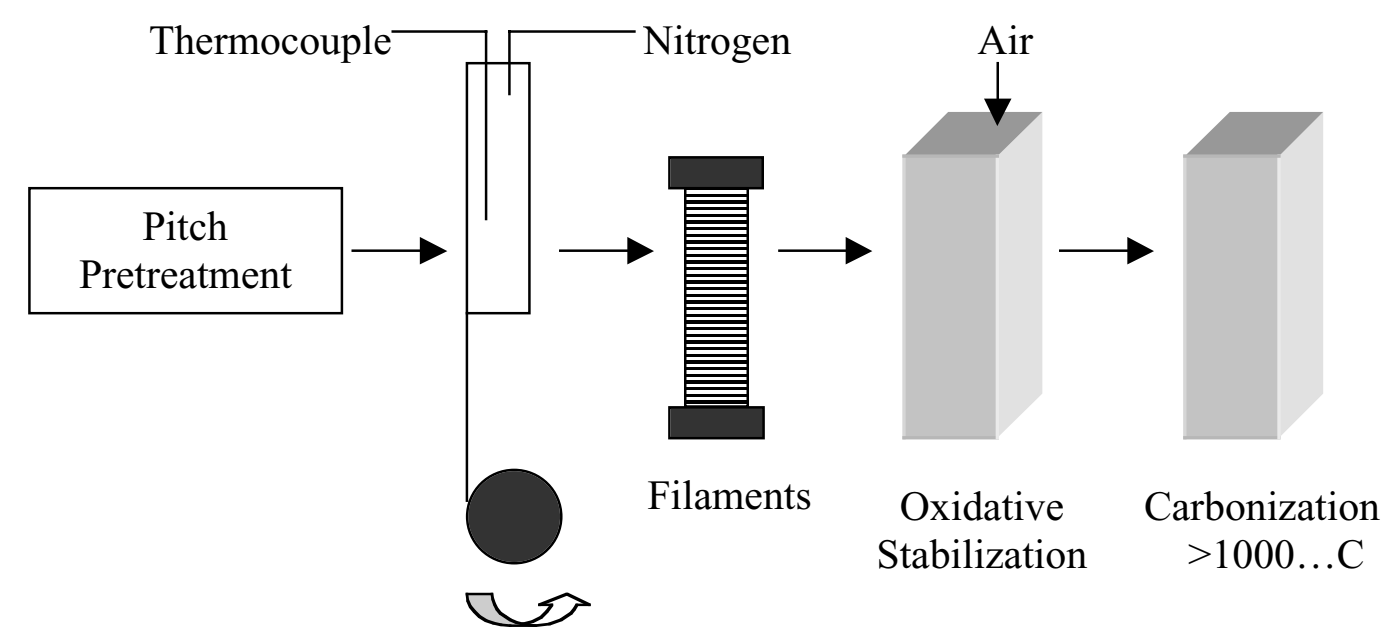

Melt Spinning

Figure 1. Processing steps in pitch fiber manufacture 
Normally, adjustments are made to the pitch softening point through heat soaking, solvent extraction, vacuum distillation, or by a combination of the three. The goal is to produce a pitch product with a relatively high and uniform molecular weight distribution. ${ }^{(14)}$ As the molecular weight of the pitch increases so does its coke yield, thermal stability, softening point, and viscosity.

The as-spun or green filaments are then rendered infusible by stabilization, usually by oxidation in air. Care must be exercised to initiate oxidative stabilization at temperatures below the glass transition temperature $\left(\mathrm{T}_{\mathrm{g}}\right)$ to prevent the filaments from melting and deforming in subsequent thermal processing. Figure 2 illustrates the relationship between the softening point of the pitch and the rate at which stabilization can occur. Though low softening point temperature facilitates the ease of spinning, oxidation of the fiber could require a prohibitively long period of time for stabilization.

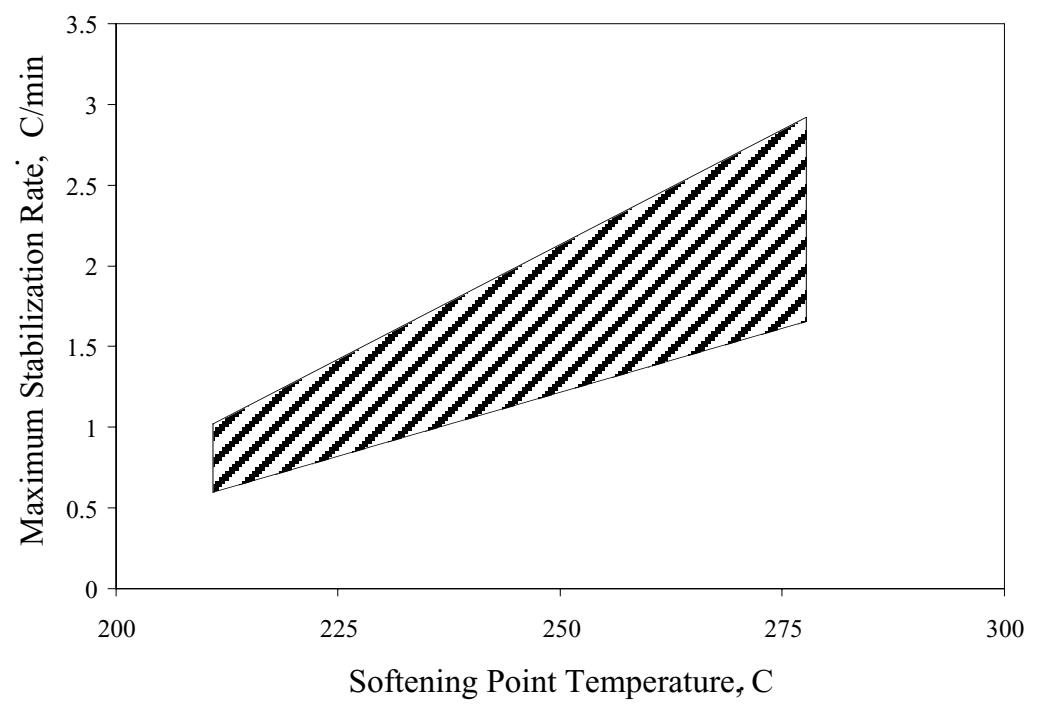

Figure 2. Relationship between stabilization rate and softening point 
After successful stabilization, the fibers are carbonized at about $1100 \ldots$ C. Heat treatment at this temperature converts the filaments to essentially pure carbon primarily through the elimination of heteroatoms and hydrogen. Higher carbonization temperatures provide no additional benefit in terms of strength as significant increased molecular ordering does not occur with isotropic pitch materials.

\section{SUMMARY OF YEAR 1}

A bituminous coal provided by Arch Coal, Inc. (PSOC 3001) was hydrogenated and the solid mineral matter and unconverted coal were separated from the pitch product by solvent extraction in N-methyl pyrrolidone (NMP). The Mettler softening point temperature for this raw pitch was between $100 \ldots \mathrm{C}$ and $130 \ldots \mathrm{C}$, a temperature too low for proper carbon-fiber spinning. This pitch material was then heat treated to increase its molecular weight and to remove volatile matter in such a way that a softening point temperature above $200 \ldots$ C was achieved. Some characteristics of the isotropic pitch thus produced are provided in Table 2.

Table 2. Properties of coal-derived fiber precursor developed in year 1

\begin{tabular}{|c|c|}
\hline Mettler Softening Point, ${ }^{\circ} \mathrm{C}$ & 212.9 \\
\hline Density by He Pycnometry, $\mathrm{g} / \mathrm{cm}^{3}$ & 1.306 \\
\hline Conradson Carbon, $\mathrm{wt} \%$ & 79.1 \\
\hline Quinoline Insolubles, $\mathrm{wt} \%$ & 3.7 \\
\hline Ash Content, $\mathrm{wt} \%$ & $<0.1$ \\
\hline
\end{tabular}

Pitches with softening point temperatures in the $250 \ldots \mathrm{C}$ range are usually preferred for spinning carbon fibers. The softening point temperature shown in Table 2 is considerably lower than this. Nevertheless this pitch spun without any difficulty and, more 
importantly, stabilized at rates up to $1 \ldots \mathrm{C} / \mathrm{min}$. The high rate suggests that the chemical composition makes the pitch more reactive to oxidation.

The stabilized fibers were carbonized in an inert atmosphere of nitrogen to $1100 \ldots \mathrm{C}$ at a rate of $20 \ldots \mathrm{C} / \mathrm{min}$ and held at this temperature for 1 hour. Figure 3 is an SEM micrograph of the resultant fiber. Note the lack of structure across the cross section (unlike mesophase-based fibers) and the smooth exterior surface typical of isotropic carbon fibers.

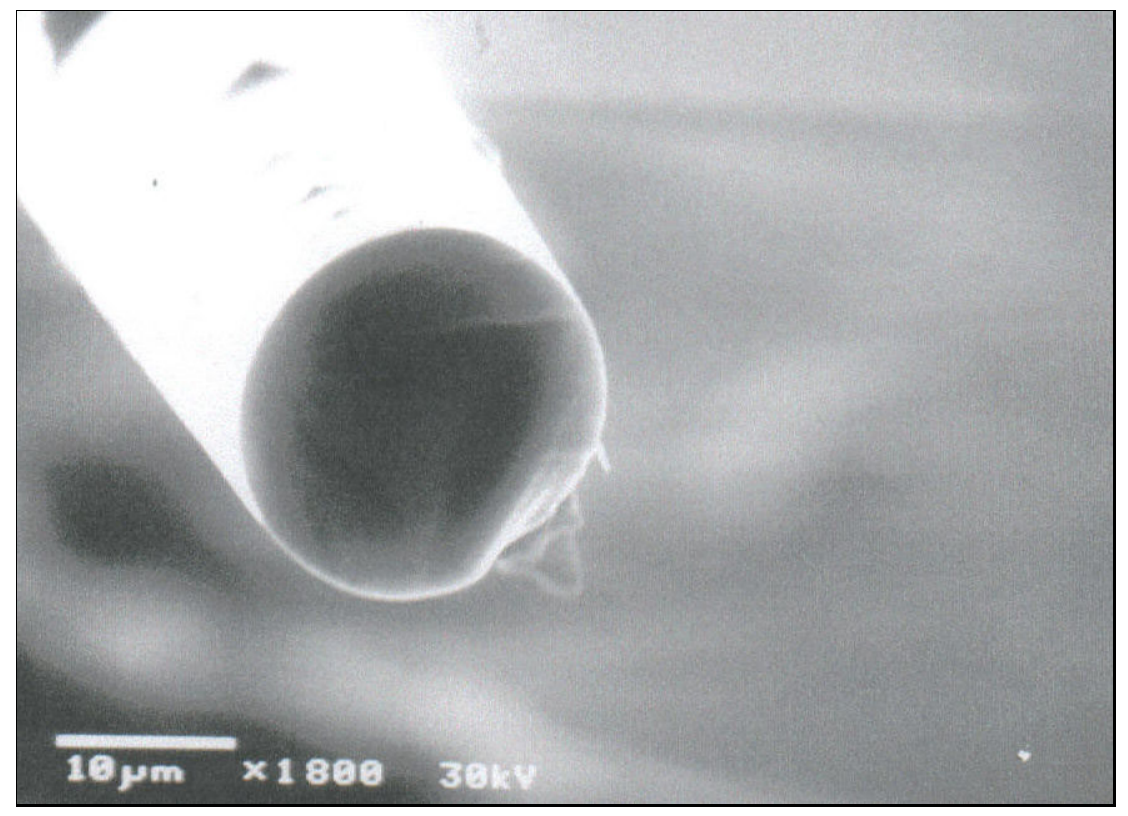

Figure 3. SEM of coal-derived carbon fiber

Single carbonized filaments had average diameters of about $12 \_\mathrm{m}$, an average electrical resistivity of $3.8 \mathrm{~m} \_-\mathrm{cm}$, and an average tensile strength of 1.36GPa. It should be noted that these characteristics for fibers derived from isotropic pitches are considered very good. 
The coal-derived fibers were also used to fabricate a carbon-carbon (C-C) composite with a conventional coal-tar pitch (CTP) for a binder. Fibers were placed in a small mold and wetted with a mixture of CTP and NMP. This method assures that the fibers are evenly distributed with the binder.

After evaporating the NMP from the composite, pressure was applied to the mold at $100 \mathrm{psi}$, while gradually heating to $200^{\circ} \mathrm{C}$, which is $50^{\circ} \mathrm{C}$ above the softening point of the pitch. At $200^{\circ} \mathrm{C}$, the pressure was increased to $200 \mathrm{psi}$ and maintained while the die cooled to room temperature.

The green composite was heated under nitrogen at $0.5^{\circ} \mathrm{C} / \mathrm{min}$ to $1100^{\circ} \mathrm{C}$ and held for one hour. Since the coal-tar pitch used has a coke yield of about $50-55 \%$, the pyrolyzed sample was reimpregnated with liquid coal-tar pitch and pyrolyzed again to $1100^{\circ} \mathrm{C}$. This procedure was repeated twice, representing a total of three pitch impregnations counting the initial impregnation.

The final density of the carbonized composite was $1.72 \mathrm{~g} / \mathrm{cm}^{3}$, which is considered comparable to the best state-of-the-art $\mathrm{C}$-C composites. The average strength was $150 \mathrm{MPa}$ in a three-point flexure test. An SEM of the fracture surface is shown in Figure 4. This image is representative of what a good C-C composite would look like. Thus this all-coal based C-C composite was at least as good as the best state-of-the-art C-C composites made from isotropic carbon fibers. 


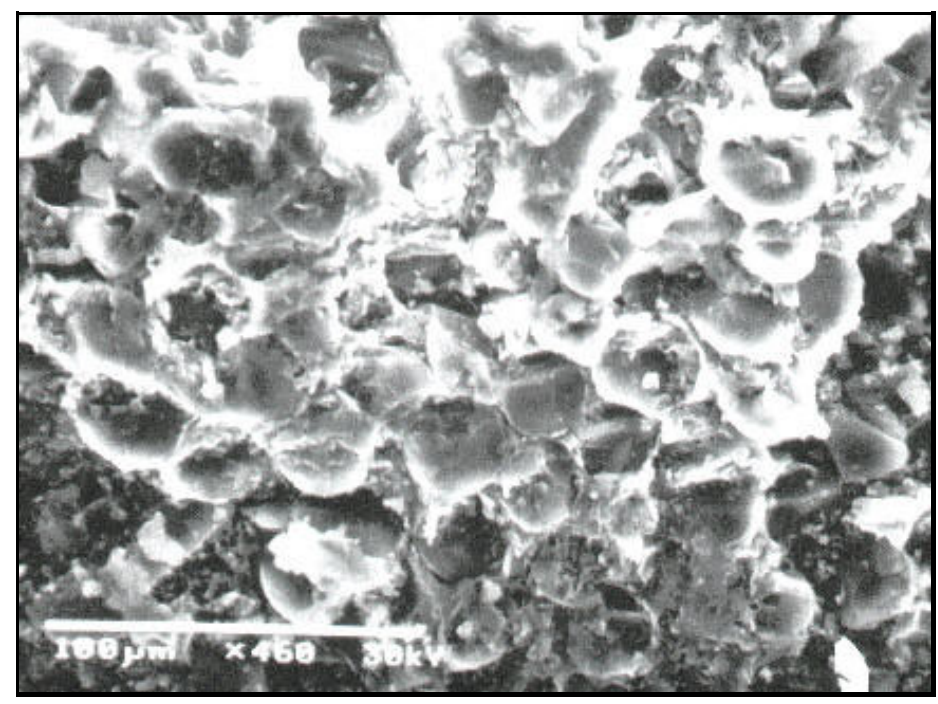

Figure 4. Fracture surface of the coal-derived C-C composite

\section{SUMMARY OF YEAR 2}

\section{Coal-derived pitch development}

Some characteristics of the bituminous coal used in year 1 and year 2 of this project are provided are in Table 3.

Table 3. Properties of Arch Coal (PSOC 3001)

\begin{tabular}{|c|c|c|c|c|}
\hline \multicolumn{2}{|c|}{$\begin{array}{c}\text { Moisture, wt } \% \text { as received } \\
1.79\end{array}$} & $\begin{array}{c}\text { Ash, wt \% dry } \\
7.36\end{array}$ & \multicolumn{2}{|c|}{$\begin{array}{l}\text { Volatile Matter, wt \% dry } \\
\qquad 31.57\end{array}$} \\
\hline $\begin{array}{c}\text { Carbon } \\
\text { wt \% dry } \\
80.31\end{array}$ & $\begin{array}{c}\text { Hydrogen } \\
\text { wt \% dry } \\
4.56 \\
\end{array}$ & $\begin{array}{c}\text { Nitrogen } \\
\text { wt } \% \text { dry } \\
1.41\end{array}$ & $\begin{array}{c}\text { Sulfur } \\
\text { wt } \% \text { dry } \\
0.71\end{array}$ & $\begin{array}{c}\text { Oxygen } \\
\text { by difference } \\
5.65\end{array}$ \\
\hline $\begin{array}{l}\text { Vitrinite } \\
\text { vol \% } \mathrm{mf} \\
\quad 57.2 \\
\end{array}$ & $\begin{array}{l}\text { Lip } \\
\text { vol } \\
\end{array}$ & & $\begin{array}{l}\text { Inertinite } \\
\text { Vol \% mf } \\
30.3\end{array}$ & $\begin{array}{c}\text { Mineral Matter } \\
\text { vol } \% \mathrm{mf} \\
4.2\end{array}$ \\
\hline
\end{tabular}

The coal was ground in a hammer mill to about 20 mesh (Tyler sieve) top size and then dried in a vacuum oven overnight at $100^{\circ} \mathrm{C}$ to remove excess moisture. The dried coal was then sealed in $4 \mathrm{~L}$ glass bottles and stored in a refrigerator until ready to use. 
An initial sample of coal-derived pitch was produced by placing $600 \mathrm{~g}$ of coal along with $1.5 \mathrm{~L}$ of tetralin into a 1 gal bolted-closure autoclave. The reactor was purged of air with hydrogen gas and then pressurized to 400psig with molecular hydrogen at room temperature. The reactor contents were stirred while heating and brought to $450^{\circ} \mathrm{C}$ for 2 hours. Following reaction, the reactor was cooled to room temperature and vented. The products were transferred to a $10 \mathrm{~L}$ flask and the tetralin removed by rotary evaporation. Three liters of NMP were added to the flask and agitated for 2 hours at $110^{\circ} \mathrm{C}$. Afterward, the mixture was transferred to $750 \mathrm{~mL}$ centrifuge bottles and centrifuged for 1 hour at 2000G to separate unconverted coal and other insoluble material. The supernatant liquid was decanted and placed in a rotary evaporator device to remove the NMP. Finally, the coal-derived pitch was vacuum dried at about $150^{\circ} \mathrm{C}$ overnight before weighing. Table 4 provides some of the pitch properties from the hydrogenation experiment.

Table 4. Product yield and pitch properties from hydrogenation of PSOC 3001

\begin{tabular}{cccc}
\hline Reaction Conditions & Pitch Yield $^{1}$ & Coke Yield $^{2}, \mathrm{wt} \%$ & Softening Point, ${ }^{\circ} \mathrm{C}$ \\
\hline $450^{\circ} \mathrm{C}$ & & \\
2 Hours & 51 & 48 & 83.0 \\
${ }^{\text {TYield }}=\frac{\text { Weight NMP Soluble } X 100}{\text { Weight Dry Coal }}$ & ${ }^{2} \mathrm{WVU}$ coke method & &
\end{tabular}

The coal-derived pitch was heat-treated further to raise its softening point from $83^{\circ} \mathrm{C}$ to a higher temperature more suitable for fiber spinning. The treatment was carefully controlled to minimize the formation of mesophase. Following this step, the pitch was dissolved in boiling NMP, the solution cooled, and then pressure filtered through a $0.2 \mu \mathrm{m}$ filter. The solvent was removed by rotary evaporation and the filtrate dried in a vacuum 
oven overnight above $170^{\circ} \mathrm{C}$ and about $10 \mathrm{mmHg}$. Characteristics of the resulting coalderived pitch are provided in Table 5.

Table 5. Properties of initial coal-derived isotropic pitch sample

\begin{tabular}{|c|c|c|c|c|}
\hline Sample ID & $\begin{array}{c}\text { Mettler Softening } \\
\text { Point, }{ }^{\circ} \mathrm{C}\end{array}$ & Coke Yield $^{1}, \mathrm{wt} \%$ & Density, $\mathrm{g} / \mathrm{cm}^{3}$ & Ash Content, wt $\%$ \\
\hline G024 & 230 & 82.0 & 1.304 & Nil \\
\hline
\end{tabular}

${ }^{1}$ WVU coke method

A larger sample of pitch was prepared using the procedure outline above. Several hydrogenation experiments were conducted in series until about $0.5 \mathrm{lb}$ of fiber precursor pitch had been produced. The characteristics of the larger-size sample are given in Table 6.

Table 6. Properties of larger size coal-derived isotropic pitch sample

\begin{tabular}{|c|c|c|c|c|}
\hline Sample ID & $\begin{array}{c}\text { Mettler Softening } \\
\text { Point, }{ }^{\circ} \mathrm{C}\end{array}$ & Coke Yield $^{1}, \mathrm{wt} \%$ & Density, $\mathrm{g} / \mathrm{cm}^{3}$ & Ash Content, $\mathrm{wt} \%$ \\
\hline G031 & 211 & 81.0 & 1.302 & Nil \\
\hline
\end{tabular}

${ }^{1}$ WVU coke method

A third sample of coal-derived pitch was prepared as well. The third pitch sample was designed for use as a matrix binder pitch. Matrix pitch is employed to hold the carbon filaments as a monolith in the C-C composite. Some properties of the matrix binder pitch are provided in Table 7.

Table 7. Properties of coal-derived matrix pitch

\begin{tabular}{|c|c|c|c|}
\hline Sample ID & $\begin{array}{c}\text { Mettler Softening Point, } \\
{ }^{\circ} \mathrm{C}\end{array}$ & Density, $\mathrm{g} / \mathrm{cm}^{3}$ & Ash Content, $\mathrm{wt} \%$ \\
\hline G039 & 230 & 1.302 & Nil \\
\hline
\end{tabular}




\section{FIBER SPINNING, PROCESSING, AND COMPOSITE TESTING}

\section{Spinning}

The pitch sample G024 was converted into filaments by melt spinning using the two different methods employed previously. ${ }^{(15)}$ Single hole spinning tests were carried out very successfully at a temperature of about $240 \ldots$... The second larger sample of pitch, G031, was also assessed by melt spinning through the single hole spinneret before transferring to the larger throughput centrifugal melt spinning (CMS) unit. The low softening temperatures of these pitches facilitated their conversion to filaments.

In the single-hole spinning tests the pitch was crushed to $-6 \mathrm{~mm}$ and transferred to the body of the spinneret where it was purged with nitrogen and heated to the required operating temperature. Once molten, the pitch was extruded through a $300 \mu \mathrm{m}$ diameter single-hole die using $80 \mathrm{psi}$ nitrogen overpressure. The extruded filament was attached to a $100 \mathrm{~mm}$ diameter take-up drum rotated at speeds of up to $1000 \mathrm{rpm}$, and thereby drawn down to yield green fibers with diameters in the range of 10 to $20 \mu \mathrm{m}$.

To process the larger quantities of fiber required for composite fabrication, the novel centrifugal melt spinning technique under development at the Center for Applied Energy Research (CAER) was used. This generates short non-uniform fibers (typically 5 to $10 \mathrm{~cm}$ in length) of more variable diameter in the form of a spun web or mat. The carbonized fibers derived from them are suitable for use in reinforcing applications or, if activated by further processing, as adsorbent materials in gas separation applications for example. The carbonized fiber can be used either as produced, chopped, or milled. 
Modifications were made to the CMS feed system to process the G031 pitch. These enabled the pitch to be successfully converted into filament.

\section{Stabilization and Carbonization}

The rate at which the fibers can be stabilized is related to the softening temperature of the pitch, its chemical composition and also to the diameter of the green fibers. The most practical and economic method of stabilization is by oxidation in air at a progressively increasing temperature to about $300^{\circ} \mathrm{C}$. To avoid fiber deformation and sticking, the cross-linking reactions must be initiated below the glass transition temperature, $T_{g}$. As oxidative cross linking reactions proceed, $\mathrm{T}_{\mathrm{g}}$ and the softening temperature both increase, and hence the reaction temperature can be raised until the fibers are rendered infusible and will not soften or melt as the temperature is raised further.

The softening points of these two pitches were below the preferred range, 230 to $260^{\circ} \mathrm{C}$, at which stabilization of the fibers can be achieved economically in an acceptable time scale. However, the softening temperature of the pitches processed in year ${ }^{\circ} 1$ of the project was similarly low and were converted into carbon filament without problems. This was attributed to the higher reactivity of these materials. Tests with the current materials showed similar behavior.

Tows of fiber removed from the wind-up drum were cut into convenient lengths and stabilized by heating in air to a programmed temperature profile in a controlled atmosphere furnace. The temperature of the furnace was rapidly raised to $120^{\circ} \mathrm{C}$, and 
then slowly increased at a rate of between 0.05 and $1{ }^{\circ} \mathrm{C} /$ minute to $310^{\circ} \mathrm{C}$. The furnace was held at this temperature for 60 minutes to ensure that complete stabilization of the fibers had been achieved before cooling to room temperature. Table 8 summarizes the stabilization conditions followed.

The small samples of stabilized fibers generated from the single hole spinneret were carbonized in an inert atmosphere by heating in a tubular reactor under a nitrogen flow of 1litre/minute. The samples were heated from room temperature to $1100^{\circ} \mathrm{C}$ at a rate of $20^{\circ} \mathrm{C} /$ minute and held at this temperature for 60 minutes. The reactor was then allowed to cool to room temperature under the flow of nitrogen. The larger samples of fiber produced in the CMS units were carbonized by heating in a silicon carbide container from which air was excluded.

Carbonization increases the strength and modulus of the fibers, but due to the lack of any ordered molecular structure in isotropic fibers there is usually little gain in strength or stiffness upon heat treatment to higher temperatures (e.g. graphitization temperature).

Table 8. Fiber Production Parameters

\begin{tabular}{|c|c|c|c|c|c|c|c|c|}
\hline \multirow[b]{2}{*}{ Sample } & \multirow{2}{*}{$\begin{array}{c}\text { Softening } \\
\text { Point } \\
{ }^{\circ} \mathrm{C}\end{array}$} & \multirow{2}{*}{$\begin{array}{l}\text { Spinning } \\
\text { Temp. } \\
{ }^{\circ} \mathrm{C}\end{array}$} & \multicolumn{2}{|c|}{ Stabilization } & \multicolumn{2}{|c|}{ Carbonization } & \multirow{2}{*}{$\begin{array}{c}\text { Linear } \\
\text { Shrinkage } \\
\%\end{array}$} & \multirow{2}{*}{$\begin{array}{c}\text { Carbon } \\
\text { Yield } \\
\%\end{array}$} \\
\hline & & & $\begin{array}{l}\text { Rate } \\
{ }^{\circ} \mathrm{C} / \text { min }\end{array}$ & $\begin{array}{c}\text { Temp. } \\
{ }^{\circ} \mathrm{C}\end{array}$ & $\begin{array}{l}\text { Rate } \\
{ }^{\circ} \mathrm{C} / \min \end{array}$ & $\begin{array}{c}\text { Temp. } \\
{ }^{\circ} \mathrm{C}\end{array}$ & & \\
\hline G024 & 230 & 240 & 0.05 & 310 & 20 & 1100 & 13 & 52 \\
\hline G031 & 210 & 235 & 1.0 & 310 & 20 & 1100 & $\mathrm{n} / \mathrm{m}$ & 82 \\
\hline
\end{tabular}


The larger sample of coal-derived isotropic pitch (G031) was successfully spun into continuous filaments. Samples of fibers were also made by a centrifugal melt spinning (CMS) technique. Both fiber types were stabilized in air and carbonized to $1100^{\circ} \mathrm{C}$.

\section{Composite fabrication and testing}

The coal-derived carbon fibers were used to produce a small C-C test coupon. Figure 5 shows the surface features of the fibers before they were introduced into the composite.
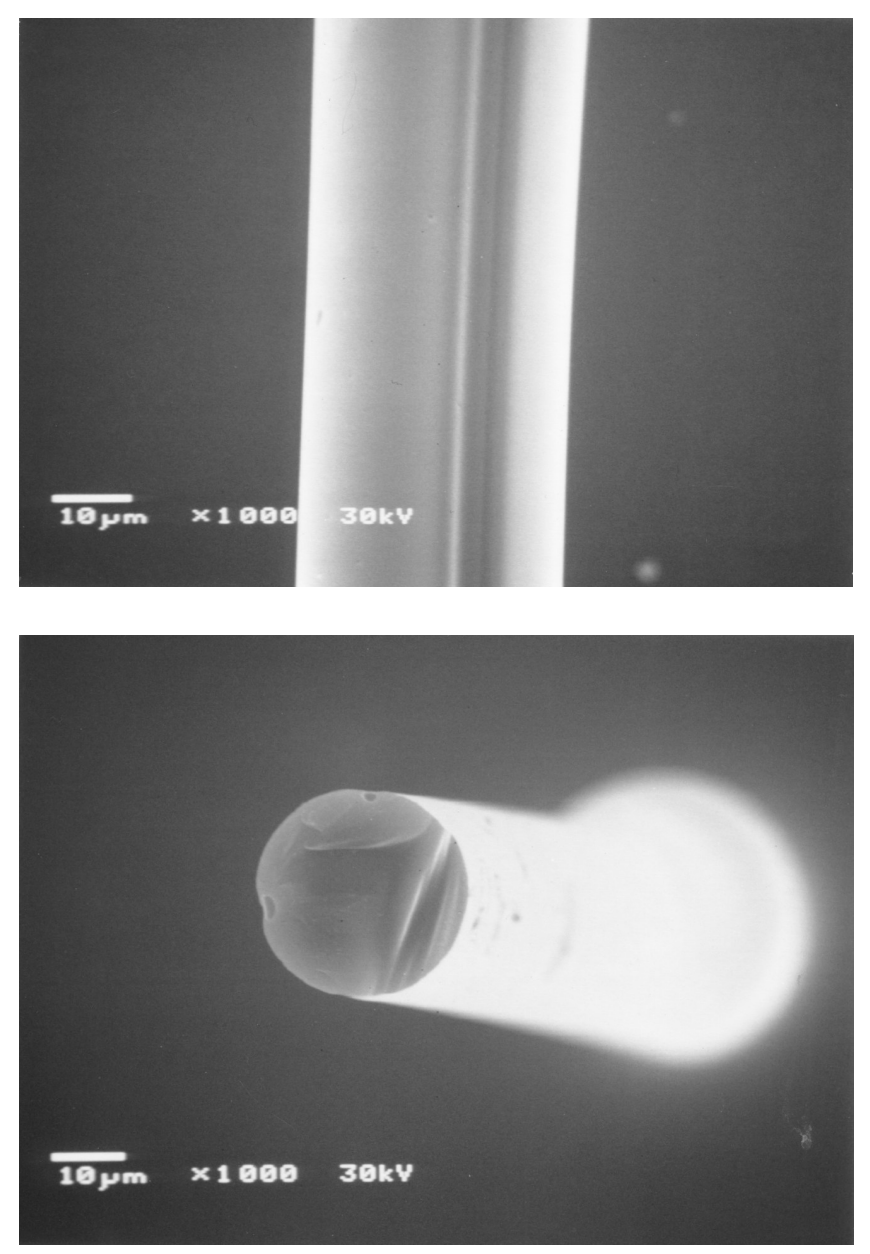

Figure 5. SEM of coal-derived carbon fibers 
The fibers were subjected to tensile-strength test on individual fibers with the results presented in Table 9. Note that the diameter of the fibers is somewhat larger than produced in the first year of the project. Nevertheless, the strength of this year s fibers is still considered very good.

Table 9. Characteristics of individual coal-derived carbon fibers

\begin{tabular}{|c|c|c|c|c|c|c|}
\hline Fiber No. & $\begin{array}{l}\text { Diameter } \\
\left(\_\mathrm{m}\right)\end{array}$ & $\begin{array}{l}\text { Peak } \\
\text { Strength } \\
\text { (g) }\end{array}$ & $\begin{array}{c}\text { Peak } \\
\text { Strength } \\
\left(\mathrm{lb} \times 10^{-2}\right)\end{array}$ & $\begin{array}{l}\text { Radius } \\
\left(\text { in } \times 10^{-4}\right)\end{array}$ & $\begin{array}{c}\text { Tensile } \\
\text { Strength } \\
\left(\mathrm{psi} \times 10^{4}\right)\end{array}$ & $\begin{array}{c}\text { Tensile } \\
\text { Strength } \\
\text { (MPa) }\end{array}$ \\
\hline 1 & 35.0 & 35 & 7.72 & 6.89 & 5.18 & 356.8 \\
\hline 2 & 28.0 & 44 & 9.64 & 5.51 & 10.1 & 696.1 \\
\hline 3 & 28.0 & 58 & 1.27 & 5.51 & 13.3 & 917.5 \\
\hline 4 & 36.0 & 29 & 6.42 & 7.09 & 4.07 & 280.4 \\
\hline 5 & 27.0 & 43 & 9.37 & 5.31 & 10.6 & 728.1 \\
\hline 6 & 24 & 41 & 9.06 & 4.72 & 12.9 & 891.1 \\
\hline 7 & 26.0 & 70 & 1.54 & 5.12 & 18.7 & 1291.3 \\
\hline 8 & 26.0 & 65 & 1.43 & 5.12 & 17.4 & 1200.8 \\
\hline 9 & 25.0 & 42 & 9.22 & 4.92 & 12.1 & 835.2 \\
\hline 10 & 24.0 & 41 & 9.08 & 4.72 & 13.0 & 893.3 \\
\hline Number & 10 & 10 & 10 & 10 & 10 & 10 \\
\hline Mean & 27.9 & 46.7 & 1.03 & 5.49 & 1.17 & 809.1 \\
\hline $\begin{array}{c}\text { Standard } \\
\text { Deviation }\end{array}$ & 4.0 & 12.5 & 0.027 & 0.000 & 4.389 & 302.6 \\
\hline
\end{tabular}

The fibers were placed in a closed die and coal-tar pitch added over the surface. The pitch was raised to above its melting point and pressure applied in the die at 200 psi. With pressure maintained, the temperature of the die was increased until coking of the binder pitch began at around $400_{i} \mathrm{C}$. After cooling, the partially coked composite was removed from the die and heat-treated to $1200_{i} \mathrm{C}$ in a nitrogen atmosphere. The composite was re-infiltrated with coal-tar pitch in a vacuum followed by an overpressure of nitrogen. The re-infiltrated sample was again heat treated to $1200_{i} \mathrm{C}$. 
The composite had a fiber volume of approximately $50 \%$ with a density of $1.78 \mathrm{~g} / \mathrm{cc}$, and flexure and compression strength of 60MPa. In Figure 6 is a SEM of the fracture surface of the composite. The composite properties are considered quite good based on the strength of the fiber when compared to commercial fiber C-C composites.

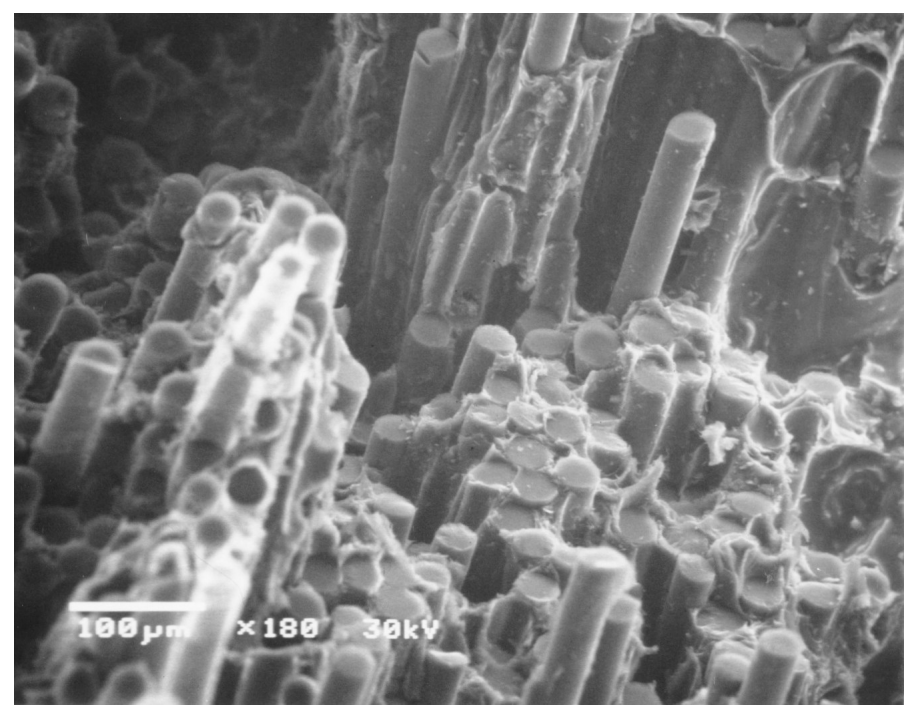

Figure 6. SEM of fraction surface of a coal-derived C-C composite

\section{Activation of Coal-Based Carbon Fibers}

Activated carbon fibers (ACF) are normally produced from petroleum pitch-based fibers by steam or $\mathrm{CO}_{2}$ activation at temperatures around $800-900^{\circ} \mathrm{C}$. High surface areas (up to $2000 \mathrm{~m}^{2} / \mathrm{g}$ compared to $1 \mathrm{~m}^{2} / \mathrm{g}$ before activation) are generated with a pore structure typified by a narrow distribution of micropores. Previous work has shown that ACFs produced from non-conventional pitch sources can possess substantially different properties that influence their adsorptive and catalytic properties. For example, ACFs synthesized from pitches with high heteroatom content, such as shale oil asphaltenes and 
certain coal liquefaction products, have been found to possess high mesopore volumes and to exhibit high catalytic activity for some reactions. ${ }^{(16-18)}$

For activation, the carbonized fibers were heated in steam for $0.25 \mathrm{hrs}$ at $800^{\circ} \mathrm{C}$ resulting in a carbon burn-off of 33\%. Surface areas were measured by nitrogen adsorption at $77^{\circ} \mathrm{K}$ using an OMNISORB $610 \mathrm{BET}$ analyzer. Pore size distributions and pore volumes were determined by the D-R method (micropores, pore entrance diameter $<^{\circ} 2 \mathrm{~nm}$ ) and the BJH method (mesopores, diameter 2 to $50 \mathrm{~nm})^{19}$.

The coal extract fibers could be activated at a rate of $2.2 \mathrm{wt} \% / \mathrm{min}$ (weight loss per minute) under standard steam activation conditions. Nitrogen adsorption measurements yield a surface area of $178 \mathrm{~m}^{2} / \mathrm{g}$ with a total pore volume of $0.396 \mathrm{ml} / \mathrm{g}$.

The source of the fiber precursor has a significant effect upon the rate of activation of the product carbonized fiber and can be correlated with the aromaticity of the pitches. ${ }^{(20)}$ Aliphatic pitches have the highest rate of activation, while the aromatic pitches activate more slowly. As such, the behavior of this extract pitch is different from that of a standard coal tar pitch, but similar in activation rate to other extract pitches. ${ }^{(20)}$ The oxygen content of the pitch can have a significant influence upon reaction kinetics in these types of activation tests. Generally, the samples with high concentrations of carbonyl and $\mathrm{C}-\mathrm{O}$ bonds exhibit the highest rates of activation.

Precursors with high heteroatom contents, while producing weaker carbonized fibers, may allow the formation of ACFs with quite different pore structures and surface 
chemistry. BET surface area, mesopore surface area and pore volumes of the fibers show that the pore volume is divide between micropores $(0.151 \mathrm{ml} / \mathrm{g})$ and mesopores $(0.245$ $\mathrm{ml} / \mathrm{g}$ ). The mesoporous nature of these fibers is likely due to the presence of nitrogen containing functional groups, and may make them suitable for applications not usually viable for primarily microporous coal tar pitch derived fibers.

\section{CONCLUSION}

Coal-derived pitches produced by hydrogenation, solvent extraction, and careful heat treatment were successfully spun into both continuous, single-filament fibers as well as the novel centrifugal melt-spun fiber mats. The isotropic fibers were made with little difficulty and had properties comparable to commercial fibers. Test C-C composites were fabricated from the fibers and again had very attractive properties. Finally the carbonized fibers were activated in steam to produce reasonable surface area at fairly high activation rates. The work demonstrates that coal-derived pitches are a viable and consistent source of fiber precursor capable of meeting or exceeding the performance of conventional petroleum-based fibers. 


\section{REFERENCES}

1) Singer, L. S., In Materially Speaking, 9(2), Materials Technology Center of Southern Illinois University at Carbondale, Carbondale, IL (1994).

2) Otani, S., Yamada, K., Koitabashi, T., and Yokoyama, A, Carbon 4, 425 (1966).

3) Edie, D. D. and Dunham, M. G., Carbon 27, 647 (1989).

4) Romey, I. and Hein, M., Fuel 60, 848 ((1981).

5) Donnet, J. B. and Bonsal, R. C., In Carbon Fibers, Lewin, M. et al. (eds), Marcel Dekker, New York (1984).

6) Edie, D. D., In Carbon Fibers Filaments and Composites, Figueiredo, J. L. et al. (eds), Kluwer Academic Publishers (1990).

7) El Akrami, H. A., Yardim, M. F., and Ekinci, E., Energy \& Fuels 13, 1030 (1999).

8) Fei, Y. Q., Derbyshire, F., and Robi, T., ACS Fuel Div. Preprints 39(1), 427 (1993).

9) Berkocvich, A. J., Lafferty, C. J., and Derbyshire, F. J., ACS Fuel Div. Preprints 45(2), 253 (2000).

10) Derbyshire, F. J., Andrews, R., Berkovich, A., Jacques, D., Jagtoyen, M., and Rantell, T., ACS Fuel Div. Preprints 45(4), 877 (2000).

11) Stansberry, P. G., Zondlo, J. W., Andrews, R., Rantell, T., and Withers, J., $26^{\text {th }}$ International Technical Conference on Coal Utilization and Fuel Systems, The Clearwater Conference, Clearwater, FL March 5-8, 2001.

12) Stansberry, P. G., Zondlo, J. W., and Stiller, A. H., The Great Lakes Carbon Conference, Sixth Carbon Conference, Houston, TX, September 26-28, 2000.

13) Stansberry, P. G., Zondlo, J. W., and Stiller, A. H., In Carbon Materials for Advanced Technologies, T. D. Burchell (ed), Pergamon Press, New York, NY, 205-34, 1999.

14) Edie, D. D., Proceedings of the Tenth Annual Pittsburgh Coal Conference, Pittsburgh, PA, September 20-24, 1993. 
15) Andrews, R., et al., Final Technical Report to the CPCPC, USDOE under contract DE-FC26-98FT40350, 1999.

16) Fei, Y Q, Derbyshire, F J, Jagtoyen, M and Mochida, I. Proceedings Eastern Oil Shale Symposium, Lexington, KY, Nov.16-19 1993; 38-45.

17) Kimber, G M, Vego, A, Rantell, T, Fowler, C and Derbyshire, F J. Proceedings Pittsburgh Coal Conference, Pittsburgh, PA, 1996; 553-558.

18) Derbyshire, F, Jagtoyen, M, Fei, Y Q and Kimber, G M. American Chemical Society, Fuel Division Preprints, 1994; 39 (1): 113-120.

19) Gregg, S J and Sing, K S. In Adsorption, surface area and porosity, $2^{\text {nd }}$ Ed. Academic Press, London, 1982

20) Derbyshire, F, Andrews, R, Jacques, D, Jagtoyen, M, Kimber, G and Rantell, T. Fuel 80, 345 (2001). 


\title{
ANTHRACITE FEEDSTOCKS FOR SPECIALTY GRAPHITE PRODUCTION
}

\author{
FINAL REPORT
}

Reporting Period Start Date: January 1, 2000

Reporting Period End Date: December 31, 2000

\author{
Report Prepared by \\ Bruce Conrad \\ Cornerstone Technologies \\ 126 S. Franklin Street \\ Wilkes-Barre, PA 18701
}

Report Issued

July 1, 2001

DOE Award Number DE-FC26-98FT40350

Other Contributors

The Pennsylvania State University

C211 Coal Utilization Laboratory

University Park, PA 16802 


\section{Disclaimer}

This report was prepared as an account of work sponsored by an agency of the United States Government. Neither the United States Government nor any agency thereof, nor any of their employees, makes any warranty, express or implied, or assumes any legal liability or responsibility for the accuracy, completeness, or usefulness of any information, apparatus, product, or process disclosed, or represents that its use would not infringe privately owned rights. Reference herein to any specific commercial product, process, or service by trade name, trademark, manufacturer, or otherwise does not necessarily constitute or imply its endorsement, recommendation, or favoring by the United States Government or any agency thereof. The views and opinions of authors expressed herein do not necessarily state or reflect those of the United States Government or any agency thereof. 


\begin{abstract}
Four Pennsylvania anthracites were selected from active mines and heat treated to various temperatures in an inert atmosphere in order to determine if the graphitizability of the geologically varied samples would be different. It was found that the graphitic crystal dimensions of the four anthracites, after having been heated to $2600^{\circ} \mathrm{C}$, were different, as measured by X-ray diffraction. It was believed that a possible reason for the differences in graphitizability could be attributed to differences in the inorganic constituents present in the coals, some of which may have a catalytic effect. The inorganic compositions of the raw and heat-treated samples were determined by computer controlled scanning electron microscopy (CCSEM). While the fate of the minerals was being determined through analysis of the CCSEM output, the most viable (in terms of being low ash and highly graphitizable) anthracite that could act as a filler in the production of specialty graphite was sent to Carbone of America. Carbone then produced an anthracite-based graphite by exactly the same procedure they use to produce petroleum-based graphites. The anthracite-based graphites were then tested against the petroleum-derived standards and were found to be in the "low-end" specialty graphite range.
\end{abstract}




\section{TABLE OF CONTENTS}

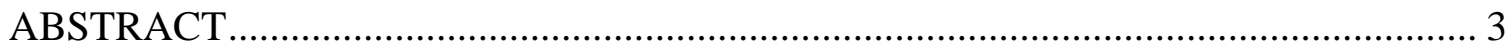

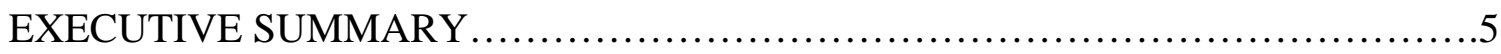

Chapter 1 . INTRODUCTION ............................................................................ 7

1.1 Background and Statement of Problem ........................................................... 7

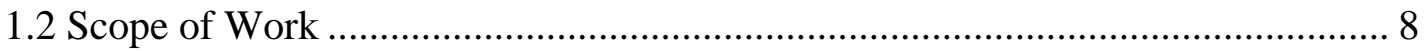

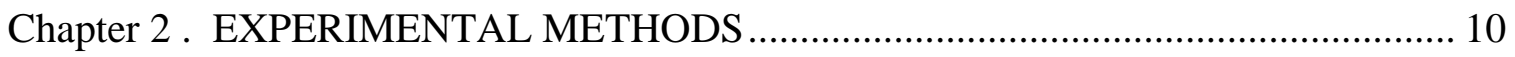

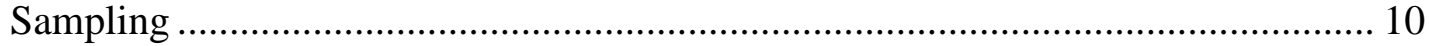

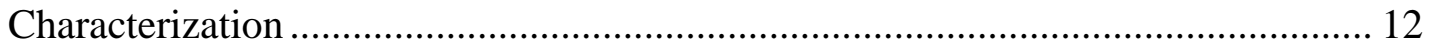

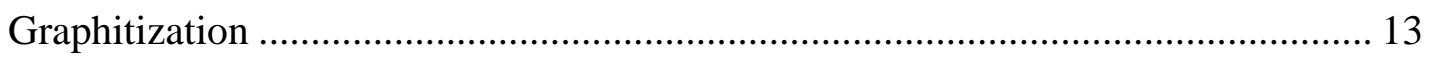

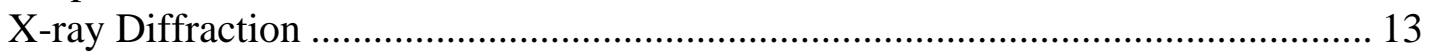

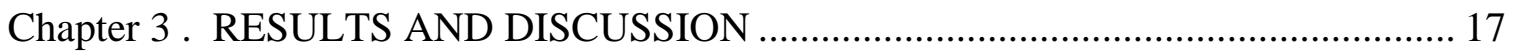

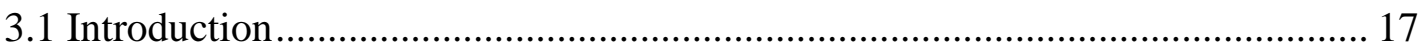

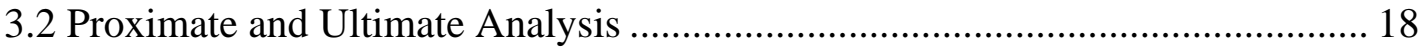

3.3 X-ray Diffraction Results of Raw and Heat Treated Samples .......................... 21

3.4 Computer-Controlled Scanning Electron Microscopy (CCSEM) ..................... 42

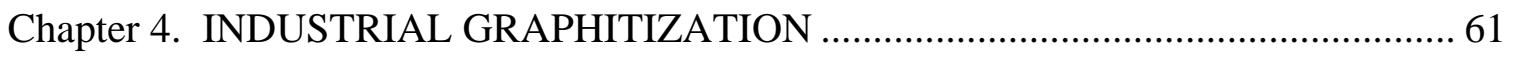

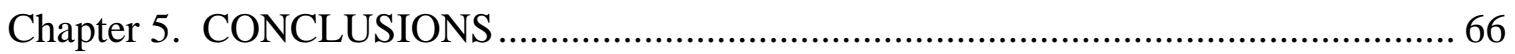

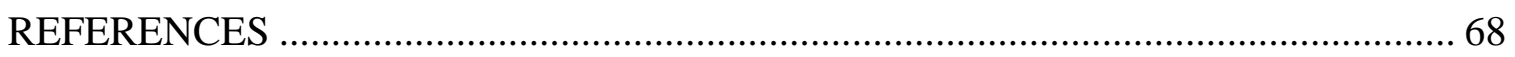

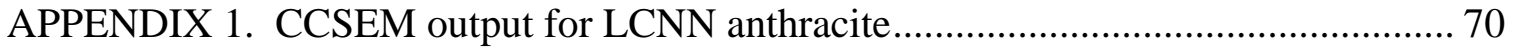




\section{EXECUTIVE SUMMARY}

Four anthracites were selected from active Pennsylvania mines based on presumed geological differences, such as mineral matter content and percentage of carbon. The LCNN and Jeddo samples came from the Mammoth vein of the Eastern Middle Seam, but from two geographically different locations, with the LCNN being further east. The UAE sample originated from the Lykens Valley \#2 vein, also of the Eastern Middle Seam, and the Summit sample came from the Tracey vein of the Southern Seam. The LCNN, Jeddo, and UAE sample all fall in the anthracite range according to ASTM rank classification, while the Summit anthracite is a semi-anthracite. The four anthracites were characterized and then heat treated to $2000^{\circ} \mathrm{C}, 2500^{\circ} \mathrm{C}$, and $2600^{\circ} \mathrm{C}$ and held at these temperatures for one hour. X-ray diffraction was performed on the raw and heat-treated samples in order to follow the structural changes that occurred during the heating regime. Crystalline natural graphite, the most graphitic material that exists, produces a characteristic X-ray diffraction peak with specific (hkl) lines at specific degrees. The sharpest, most intense, of these (hkl) lines is produced by the (002) peak. The (002) peak is used to determine the d-spacing, or distance between graphene layers, and the crystal height $\left(\mathrm{L}_{\mathrm{c}}\right)$, or number of parallel stacked graphene sheets. By comparing the (002) peaks of the heat-treated anthracites over various temperatures, a determination can be made of which anthracite best approached the X-ray diffraction pattern produced by natural graphite. It was found that in all the anthracites the most prominent increase, or jump, in graphitization occurred between $2500^{\circ} \mathrm{C}$ and $2600^{\circ} \mathrm{C}$, and that the LCNN and Summit samples had the highest discontinuous jump, thus producing the largest graphitic crystal dimensions.

It was believed that the reason for these two anthracites exhibiting the highest graphitization jump dealt with the composition of their inorganics. The Summit sample had $17 \%$ ash, while the LCNN anthracite had just over $6 \%$ ash, but they both produced roughly the same graphitic crystal parameters following heat treatment. Therefore the composition of the mineral matter, in terms of the elements present that may have a catalytic effect, was determined by CCSEM. The CCSEM output produces a wealth of data about the inorganics, and compares the data by several different methods, such as number of mineral particles, weight percent on a mineral or coal basis, and mineral area on a mineral or coal basis. Each of these comparisons is done for thirty-three different inorganic phases broken down into six size fractions, in microns. It was found that only the LCNN and Summit anthracites showed an increase in the relative weight percent of inorganics (on a mineral basis) of the largest size fraction of inorganic particles from 2500 to $2600^{\circ} \mathrm{C}$. This was confirmed by noting that the number of large particles (46400 microns) increased from 2500 to $2600^{\circ} \mathrm{C}$. This could only occur via the phase transition of inorganic particles in a smaller size fraction and their agglomeration into a larger particle upon cooling. The presence of hollow graphitic shells, catalyzed by the interaction of carbon with a liquid mineral, has been observed by other researchers. It is believed that the LCNN and Summit anthracites underwent catalytic graphitization because their inorganic constituents melted and traveled through the carbon matrix, 
absorbing cross-linking fragments in the process. The cross-links holding the crystallites in place were removed by this process, thus allowing the crystallites to align edge to edge and condense into larger graphitic crystals. The most likely inorganics responsible for this catalytic graphitization are titanium, calcium, or silica-bearing minerals because they are present in the $2600^{\circ} \mathrm{C}$ samples in higher concentrations than any other inorganic.

The LCNN sample was selected for industrial graphitization by Carbone because it produced less ash than the Summit anthracite, even though both were similar in their graphitizability. Carbone produced an anthracite-based graphite billet by combining the anthracite with a certain percentage of coal-tar pitch. The percentage of coal-tar pitch was monitored in order to determine the optimum anthracite to pitch ratio. The anthracite billets were tested against the standard sponge-coke billet and found to be in the "low end" specialty graphite range. This marks a drastic improvement from the tests that were performed over five years ago, in which the anthracite billet, in some cases, could not even hold its shape. 


\section{Chapter 1. INTRODUCTION}

\section{$\underline{1.1 \text { Background and Statement of Problem }}$}

Graphite is formed in nature and can be found in large deposits around the world, including Mexico, the United States, Brazil, Canada, and Sri Lanka. Natural graphite is highly aromatic, lustrous, soft, and is often used as a solid lubricant because it easily shears and flakes apart $[1,2]$. Graphite can also be produced artificially by heating some carbon materials to temperatures in the range of $2000-3000^{\circ} \mathrm{C}$, or by pressurizing the carbon as it is heated to a lower temperature. The vast majority of artificial graphites are produced from the combination of aromatic petroleum by-products, namely petroleum coke, and binders that allow the graphite to be shaped for a specific application. Natural graphite is not used as feedstock for synthetic graphite manufacture because it is more expensive than petroleum coke, and, because of its softness, forms a viscous, nonshapeable paste, when mixed with a binder. Petroleum coke is an acceptable feedstock for artificial graphite production for three reasons: (1) it undergoes structural changes during graphitization heat treatment temperatures of $3000^{\circ} \mathrm{C}$ that leave the final structure close to that of natural graphite; (2) when mixed with a binder, it produces a product that has certain properties that make it suitable for electrical conducting or thermal applications; and (3) it is less expensive than pure aromatic compounds, such as anthracene or naphthalene. Anthracite, like petroleum coke, is primarily carbon, and can have over $93 \%$ by weight carbon. Because of its high carbon content, it is conceivable 
that anthracite could also be used as a feedstock for artificial graphite production if it could also meet the three criteria listed above for petroleum coke.

\subsection{Scope of Work}

Anthracite is a high-carbon-content material that can be purchased for approximately $\$ 300-\$ 500$ per ton less than petroleum coke, and approximately $\$ 1100$ per ton less than natural graphite [3]. This fact would make anthracite an ideal feedstock for artificial graphite production if it would also undergo structural transitions during heat treatment that leave the heat-treated sample similar to natural graphite in structure. Therefore one component of this research is an analysis of the structural re-arrangements that anthracites undergo when heated to the typical laboratory-scale graphitization temperatures of $2000^{\circ} \mathrm{C}$ to $2800^{\circ} \mathrm{C}$ in an inert atmosphere. The hypothesis to be tested in this component is that some anthracites will better approach the structure of natural graphite as a result of differences in their innate inorganic constituents. The determination of how close in structure a heat treated anthracite is to the structure of natural graphite is made by a comparison of the X-ray diffraction data available on natural graphite and the X-ray diffraction output of the heat treated anthracite samples. In order to analyze the structural differences between anthracites that had been exposed to the same graphitization temperatures, four samples that had different levels of mineral matter content and weight percentages of carbon were obtained from active Pennsylvania mines. 
The second aspect of this research is the production of an artificial graphite suitable for industrial applications using anthracite as the feedstock instead of petroleum coke. The hypothesis to be tested in this component is that the anthracite that best approaches the structure of natural graphite following heat treatment will produce an artificial graphite most similar to a petroleum-based graphite, when mixed with a binder. The production of the anthracite-based artificial graphite was carried out by Carbone of America, an industrial synthetic graphite manufacturer located in St. Mary's Pennsylvania, and CPCPC member company. Carbone produces petroleum-based graphites as their standard product line; thus they have a wealth of information on the properties of their materials, which can be compared to the properties of the anthracitebased artificial graphite because both the petroleum- and anthracite-based product were produced in exactly the same manner. The determination of how suitable the anthracitebased synthetic graphite was for an industrial application was also made by Carbone, as they have more experience with matching properties of a material to a suitable application. 


\section{Chapter 2. EXPERIMENTAL METHODS}

\section{Sampling}

Anthracite samples for the study were selected from the field by sampling from four active anthracite mines based on mine longevity (with mining of same seam planned for, at minimum, five years), and geological variations such as amount of mineral matter present. The mines which met these criteria were Jeddo, UAE, Lehigh Coal and Navigation (LCNN), and Summit. Jeddo and LCNN mine the Mammoth vein of the Eastern Middle Seam in Pennsylvania while UAE mines the Lykens Valley \#2 vein. Summit mines a conglomeration of veins, but for this research run-of-mine, or unprocessed, anthracite was recovered from the Tracey vein. The Jeddo and LCNN samples were separated in heavy media into pea size and UAE was processed using a Diester table. Three 55-gallon drums of each mine's anthracite (twelve total barrels) were collected from the pea-sized pile of processed coal. This method could be referred to as a "grab" sample from the preparation plant, as opposed to a "channel" sample taken underground.

In order to ensure the homogeneity of the coal for analysis, a rigorous sampling procedure was followed, outlined by Glick and Davis of The Penn State Coal Sample Bank and Data Base [4]. First, all three barrels of a particular anthracite were dumped onto a clean surface. As specified by ASTM D346-90, the coal was shoveled on top of itself until the particles that were originally at the bottom of the pile had cycled from bottom to top and through the pile twice [5]. After this, the pile was coned and quartered, 
which is simply forcing a plus-sign-shaped system of boards through the pile, separating it into quarters. These quarters were each returned to a barrel, with the idea that each barrel would now have the same makeup as far as particle size and chemical composition. One of these barrels was coned and quartered again, taking opposite quarters (or half the barrel) and crushed down to $-1 / 4$ inch using a hammer mill. This quantity of $-1 / 4$ inch coal was put through a riffler three times. Next, one half of the $-1 / 4$ inch was saved in bags of approximately $10 \mathrm{lbs}$. each. The other half of $-1 / 4$ inch was put through the hammer mill again, this time with a -20 mesh screen in place. The quantity of -20 mesh was riffled again and broken down into aliquots of approximately $4 \mathrm{lbs}$. each.

After the above work was completed on all four samples, one bag of -20 mesh was separated into eight aliquots using a rotary splitter. Seven of these aliquots, weighing $250 \mathrm{~g}$ each, were sealed in foil laminate bags under an argon atmosphere; the remaining aliquot was further crushed to -60 mesh. This $250 \mathrm{~g}$ quantity of -60 mesh was also separated with a rotary splitter into sections weighing $35 \mathrm{~g}$ each. These -60 mesh aliquots were then sealed in foil laminate bags under argon. This sampling should ensure a good representation of the entire coal sample that was collected. The argon atmosphere will prevent any further oxidation so consistency of analytical results from one date of testing to another will not be a problem. Also, the small quantities sealed in each bag will further increase accuracy because they eliminate the problem of having to constantly open the bag, select the desired quantity of anthracite, and reseal the bag. This opening and closing will allow oxygen into the system, which can alter the coal structure by oxidation. 


\section{Characterization}

This suite of anthracites was characterized by proximate and ultimate analysis in accordance with ASTM D5142-90, ASTM D5373-93, and ASTM D3175-89a [6-8]. The instruments used were a $\mathrm{CHN}-600, \mathrm{SC}-132$ sulfur determinator, and MAC-400 proximate analyzer, both made by the Leco Corporation. For the CHN-600 between 0.03 and 0.07 grams of sample were weighed and placed in a tin crucible of cylindrical shape. The crucible was then crimped and folded over twice in order to promote smooth entry into the combustion chamber, where the sample is burned and the infrared spectra of the resulting $\mathrm{CO}_{2}$ and $\mathrm{H}_{2} \mathrm{O}$ are reduced to a weight percentage of elemental $\mathrm{C}$ and $\mathrm{H}$. The nitrogen is calculated via a thermal conductivity cell against a standard. Oxygen was calculated by difference.

The sulfur analyzer worked much on the same principle, except that instead of the IR spectra of $\mathrm{CO}_{2}$ and $\mathrm{H}_{2} \mathrm{O}$, the IR spectrum of $\mathrm{SO}_{2}$ is measured and reduced to a weight percentage. In this device, approximately 0.5 grams of sample is weighed and placed in a ceramic boat, which is then placed in a hot zone where all the sample is combusted.

Proximate analysis was determined using the MAC-400. This involved placing approximately 0.5 grams of anthracite in the crucibles provided and following the weight loss percentages as temperature is increased. The MAC-400 follows ASTM heating guidelines, which are $105^{\circ} \mathrm{C}$ for one hour to determine moisture, $950^{\circ} \mathrm{C}$ (no oxygen present) for seven minutes to determine volatile matter, and $750^{\circ} \mathrm{C}$ for two hours to determine ash. 


\section{Graphitization}

Following initial characterization, the samples were graphitized in a Centorr Vacuum Industry Series 45 furnace that operates in either a vacuum or argon atmosphere. The samples were weighed to $15 \mathrm{~g}$ and placed in graphite crucibles with lids, provided by POCO Graphite. These crucibles were then placed in the hot zone of the furnace $(6$ in $\mathrm{X}$ 9 in) and the top graphite plug and steel plate secured. The environment of the hot zone was purged by pulling a vacuum, and then backfilling with ultra-high purity argon three times. Following this purge, the samples were heated to $2000^{\circ} \mathrm{C}, 2500^{\circ} \mathrm{C}$, or $2600^{\circ} \mathrm{C}$ with a heating rate of $30^{\circ} \mathrm{C} / \mathrm{min}$ and hold at the maximum temperature for one hour (in argon). Following heat treatment, the anthracites were removed from the furnace for further characterization.

\section{$\underline{\text { X-ray Diffraction }}$}

X-ray diffraction data were acquired using a SCINTAG PAD-V X-ray diffraction unit that uses $\mathrm{Cu} \mathrm{K} \alpha$ radiation. The slit widths of this unit are $2^{\circ}$ for the primary beam, and $0.1^{\circ}$ for the diffracted beam. The PAD-V was set for continuous scanning at a rate of $2.5^{\circ} / \mathrm{min}$ from $5^{\circ}$ to $90^{\circ} 2 \theta$.

The anthracites were prepared for analysis in several different manners in order to check the effect of sample preparation on the X-ray diffraction pattern. First, the anthracites were taken directly from the graphitization furnace and mounted on a single crystal quartz slide from the Gem Dugout. The particle size of the anthracites was -60 mesh in this case, and the samples were mounted to the slide with petroleum jelly. The 
jelly was spread thinly over the surface of the slide and the anthracite powder was sprinkled over the top of this jelly layer. The idea behind this mounting process is to produce a random orientation of particles along the surface of the slide, approximately the same width everywhere. This method of sample preparation was repeated for -60 mesh anthracite samples that were heat-treated and then ground to pass a -100 mesh screen. The petroleum jelly must be used because the X-ray diffraction unit used for this research holds the quartz slide in a vertical position.

A second method of mounting the samples was drilling a $4 \mathrm{~mm}$ circular recess into the quartz slide and packing the powder into this constant volume. Again, -60 mesh and -100 mesh anthracites that had been heated to $2600^{\circ} \mathrm{C}$ were analyzed by this method.

The raw data curves were corrected for Compton scattering and smoothed by both Pierson VII and Box Car fitting software built into the SCINTAG operating system. Next, the peaks were found by the peak finder program also built into the SCINTAG software. The peak finder application uses a digital filter that contains two parameters the user must input. The two parameters are the ESD multiplier, and the ripple multiplier, which were set at seven and nine, respectively--the most stringent settings available for what curves will represent an identifiable peak. Once the peak finder application was performed, the properties of the identified peaks were exported to a viewable file where d-spacing, relative intensities (as percents), absolute intensities, and full width at half maximum (FWHM) were listed. The d-spacing, an important indicator of graphitic development, was instantaneously calculated from the (002) peak by the Bragg equation derived using simple geometry applied to the crystal configuration shown below. 


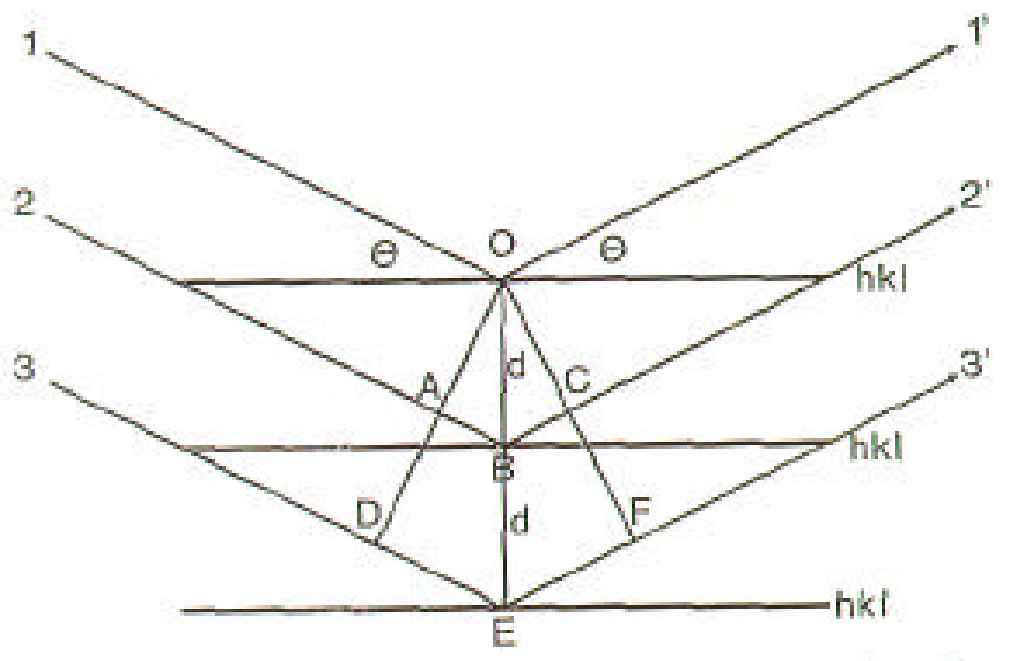

The Bragg equation is:

$$
\mathrm{n} \lambda=2 \mathrm{~d} \sin \theta
$$

where $\mathrm{n}=$ diffraction order, or 1 for the (002) peak

$\lambda=$ wavelength of $\mathrm{Cu} \mathrm{K} \alpha$ which is $1.54059 \AA$

$\mathrm{d}=$ interlayer spacing

$\theta=$ diffraction angle of $(002)$

The crystallite size, $\mathrm{L}_{\mathrm{c}}$, was also calculated from the (002) peak for all the samples using the Scherrer equation:

$$
\mathrm{L}_{\mathrm{c}}=\mathrm{K} \lambda /(\beta \cos \theta)
$$

where $\mathrm{L}_{\mathrm{c}}=$ crystalline height

$\mathrm{K}=$ Scherrer constant, taken as 0.9

$\beta=\mathrm{FWHM}$ in radians and:

$$
\beta^{2}=B^{2}-b^{2}
$$

and $\quad B=$ peak broadening of the (002) reflection of the sample 
$\mathrm{b}=$ peak broadening of crystal standard, quartz was used for this As seen in the Scherrer equation, a standard is used to correct for instrumental broadening. The standard was a highly crystalline material that should have little broadening due to its structure; thus any broadening can be attributed to the instrument. Quartz was used as the standard for this research. In the case of graphitized anthracite, broadening of the (002) peak is due more to small crystallite size than instrumental effects. The reason why small crystallite size causes broadening is the absence of planes capable of producing diffracted X-rays that will cancel out other rays that are very close to the Bragg angle. This is explained further in reference [9]. 


\section{Chapter 3. RESULTS AND DISCUSSION}

\subsection{Introduction}

Anthracite has been shown to behave as a graphitizing carbon when heated to temperatures in excess of $2500^{\circ} \mathrm{C}$, even though it acts as a non-graphitizing carbon at temperatures below $2500^{\circ} \mathrm{C}$ [10-12]. The structure of a graphitizing carbon is characterized by a lack of microporosity and cross-linking between graphene layers of neighboring crystallite regions, or basic structural units. A non-graphitizing carbon has a high microporosity and strong links between neighboring layers. Anthracite is able to behave as both a non-graphitizing and graphitizing carbon, depending on temperature, because of an anisotropic microporosity that aligns the basic structural units edge-toedge and enhances the probability of condensation. X-ray diffraction and transmission electron microscopy (TEM) data support this graphitization mechanism based on crystalline alignment, and have also been used to explain differences in graphitizability, in terms of crystallite parameters, between different anthracites. However, TEM images have also shown evidence of catalytic graphitization, via the formation of hollow graphitic shells, caused by the mineral matter present [13-16]. The relative importance of catalytic graphitization to the overall graphitizability of an anthracite is unknown, because the minerals or elements responsible for enhancing graphitization, and the mechanism by which it occurs, are also unknown. It is also conceivable that the minerals present are responsible for differences in graphitizability between different anthracites. The following sections summarize how the anthracites used for this study 
were characterized, with regard to their organic and inorganic structure, and explain why differences in graphitizability were observed.

\subsection{Proximate and Ultimate Analysis}

Ultimate analysis was performed on all four samples in order to determine the relative weight percentages of the major elements in the anthracites: carbon, hydrogen, nitrogen, and oxygen. Sulfur determination was also performed and is presented with the ultimate analysis results shown in Table 3.1. Proximate analysis results are presented in Table 3.2 and were recorded in order to determine the amount of mineral matter in the anthracite, or the amount of non-combustible material left after being heat in air to $950^{\circ} \mathrm{C}$.

Table 3.1. Ultimate analysis of anthracite samples*

\begin{tabular}{|c|c|c|c|c|c|c|}
\hline Anthracite & $\% \mathrm{C}$ & $\% \mathrm{H}$ & $\% \mathrm{~N}$ & $\% \mathrm{~S}$ & $\begin{array}{c}\% \mathrm{O} \text { (by } \\
\text { diff.) }\end{array}$ & $\mathrm{H} / \mathrm{C}$ \\
\hline LCNN & 95.8 & 1.5 & 1.2 & 0.5 & 1.0 & 0.19 \\
\hline Jeddo & 95.3 & 1.8 & 1.1 & 0.6 & 1.2 & 0.22 \\
\hline UAE & 94.2 & 2.2 & 1.0 & 0.5 & 2.1 & 0.29 \\
\hline Summit & 93.4 & 2.5 & 0.9 & 0.6 & 2.6 & 0.32 \\
\hline
\end{tabular}

*dry ash-free basis

Table 3.2. Proximate analysis of anthracite samples*

\begin{tabular}{|c|c|c|c|c|c|}
\hline Anthracite & \% Moisture & \% Volatiles & $\%$ Ash & Fixed Carbon & $\begin{array}{c}\text { Fixed Carbon } \\
(\mathrm{mmmf})\end{array}$ \\
\hline LCNN & 3.31 & 5.1 & 6.7 & 84.8 & 95.12 \\
\hline Jeddo & 4.7 & 5.9 & 8.0 & 81.4 & 94.28 \\
\hline UAE & 4.6 & 7.4 & 6.6 & 81.4 & 92.5 \\
\hline Summit & 2.6 & 11.0 & 17.6 & 68.8 & 88.1 \\
\hline
\end{tabular}

*all values are on an as received basis except for Fixed Carbon in last column that is on mmmf basis 
The LCNN and Jeddo samples have similar percentages of carbon, hydrogen, nitrogen, sulfur and oxygen. In fact, the greatest difference in any of the elements other than carbon is 0.3 weight percent, and in carbon it is less than one weight percent. This is not surprising, because both the Jeddo and LCNN anthracites came from the Mammoth vein of the Eastern Middle Field of Pennsylvania. One might be tempted to expect that they would behave the same under typical graphitization temperatures, due to their elemental similarities and origin from a common coal vein. However, phenanthrene and anthracene exhibit different levels of graphitizability and have the same number of carbons and hydrogens, but they differ in molecular shape and in location of relative carbon active sites. Presumably these differences in shape and location of carbons that are most likely to form bonds is responsible for their differences in graphitizability.

Again, the Summit and UAE anthracites have similar elemental compositions even though they do not come from the same vein of anthracite. The Summit anthracite was mined from the Tracey vein of the Southern Field, while the UAE came from the Lykens Valley \#2 vein of the Eastern Middle Seam. Based solely on their elemental compositions determined from ultimate analysis, one might expect the Summit and UAE samples to produce similar crystal development when exposed to graphitization temperatures. However, X-ray diffraction shows that similar elemental compositions are not an effective predictor of graphitizability, because the anthracites that would be expected to produce similar graphitic crystals following exposure to graphitization temperatures do not in fact behave this way. However, the ultimate analysis also provides the hydrogen-to-carbon ratio, which can be used to determine the size of a graphene layer. In most coals, the ratio of aromatic hydrogen to aromatic carbon will 
provide a basis by which to determine the number of condensed rings in a layer, and layer size. In anthracite, all the carbon is aromatic, therefore ratio of aromatic hydrogen to aromatic carbon reduces simply to the hydrogen-to-carbon ratio.

Proximate analysis data can be used to characterize the anthracites, but, as with ultimate analysis, cannot be used to make predictions about the graphitizability of the anthracites. Proximate analysis provides a good start towards understanding the role of inorganics during graphitization, in that it shows the amount of non-combustible material remaining after the coal was heated to $950^{\circ} \mathrm{C}$, which is correlated to the amount of mineral matter present in the raw coal. Oberlin [14-16] states that the formation of hollow graphitic shells of carbon occurs when the ash percentage of an anthracite is greater than $2 \%$. This would appear to be an over-simplification of the problem, because it makes no assumption about the relative weight percentages of minerals present, even though the minerals present in a coal vary from one geographic location to another. For example, if the inorganic portion of a $2 \%$ ash anthracite was comprised solely of quartz, would it develop hollow graphitic shells in exactly the same manner as a $2 \%$ ash anthracite whose inorganic constituent was solely pyrite? Also, if the inorganic portion of the anthracite, regardless of whether it was quartz or pyrite, contained this mineral in discrete particles separate from the coal matrix, would the graphitic shells develop just as well if the inorganic was finely disseminated throughout the coal matrix? Oberlin suggests that only the amount of mineral matter present, and not the relative concentrations of the minerals nor their interactive surface area with the organic matrix, is responsible for the formation of hollow graphitic shells. This seems counterintuitive because in most other catalytic systems the properties of the catalyst and interactive 
surface area are crucial factors affecting the catalysis reaction. To better understand the role of catalysis in graphitization, the relative weight percentages and types of minerals present must be determined because proximate analysis data can only be used predict how much mineral matter is present in the raw anthracites. The identification of mineral composition and translation of this information to weight percentages were accomplished by computer-controlled scanning electron microscopy (CCSEM). This work represents a novel approach to the study of catalytic graphitization in anthracites.

The ultimate and proximate analysis represent the starting points for characterization of the organic and inorganic constituents of the anthracites, respectively. The following sections of this chapter are therefore separated into a discussion of the organic structure and a discussion of the inorganic structure. The techniques used to characterize the organic portion are presented first, followed by those used to characterize the inorganics.

\subsection{X-ray Diffraction Results of Raw and Heat Treated Samples}

The four anthracite samples were heat treated to 2000,2500 , and $2600^{\circ} \mathrm{C}$ and held at highest temperature for one hour. The crystalline parameters of the raw and graphitized samples were then measured using X-ray diffraction. Figures 3.1 to 3.16 are the diffractograms for all the anthracite samples. In all the anthracites, the unheated samples show broad, diffuse peaks in the $2 \theta$ range where graphite exhibits the (002) and (004) peaks. In accordance with data presented by Franklin [10-12], these diffuse peaks continually sharpen and become more intense with increasing temperature. The sharpening of the (001) peaks is accompanied by the presence of (hk0) peaks, and broad (hkl) bands. The (hkl) bands, the presence of which is a requirement for any carbon to be 
considered graphitizing, are broad in all the anthracites, but they are still present. For comparison purposes, a petroleum needle coke, a carbon that is known to be highly graphitizable, was heat treated in exactly the same manner as the anthracites to the temperature of $2600^{\circ} \mathrm{C}$. Figure 3.17 shows a comparison the X-ray diffractogram of the graphitized needle coke and the LCNN anthracite, both heated to $2600^{\circ} \mathrm{C}$. It is apparent that the LCNN anthracite and needle coke have exactly the same number of peaks in the same position. Of these peaks, the weak, broad band at approximately $86^{\circ} 2 \theta$ must be the (112) peak in order for the needle coke and anthracite to exhibit the presence of an (hkl) band. The point of this comparison is to show that, in the conditions of the laboratory-scale furnace, the needle coke and anthracites develop the same number of peaks and both can be considered graphitizing carbons because of the (112) band common to graphite.

The anthracites show differences in the level of crystallinity achieved. The crystalline parameters $L_{c}$ and d-spacing for the four anthracites heat-treated at various temperatures are shown in Figures 3.18 and 3.19 , respectively. Based on Figures 3.18 and 3.19, the LCNN and Summit anthracites are the most graphitizable, because they produce the largest graphitic crystal. All of the anthracites tested are graphitizable because they exhibit a (hkl) peak, but the LCNN and Summit samples have the largest crystalline dimensions. The reason for these differences is discussed in the next section. 


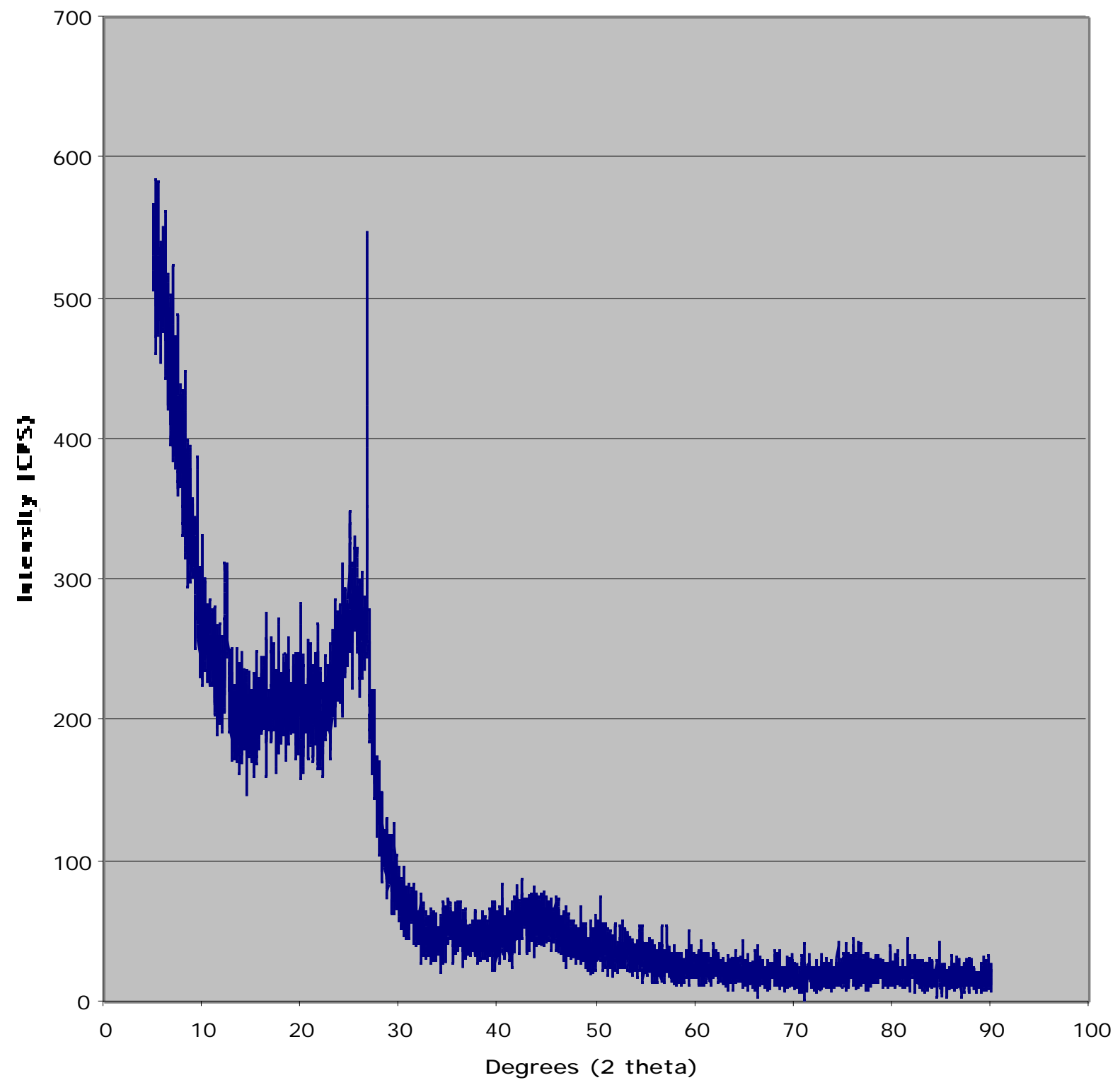

Figure 3.1 X-ray diffractogram of raw UAE anthracite 


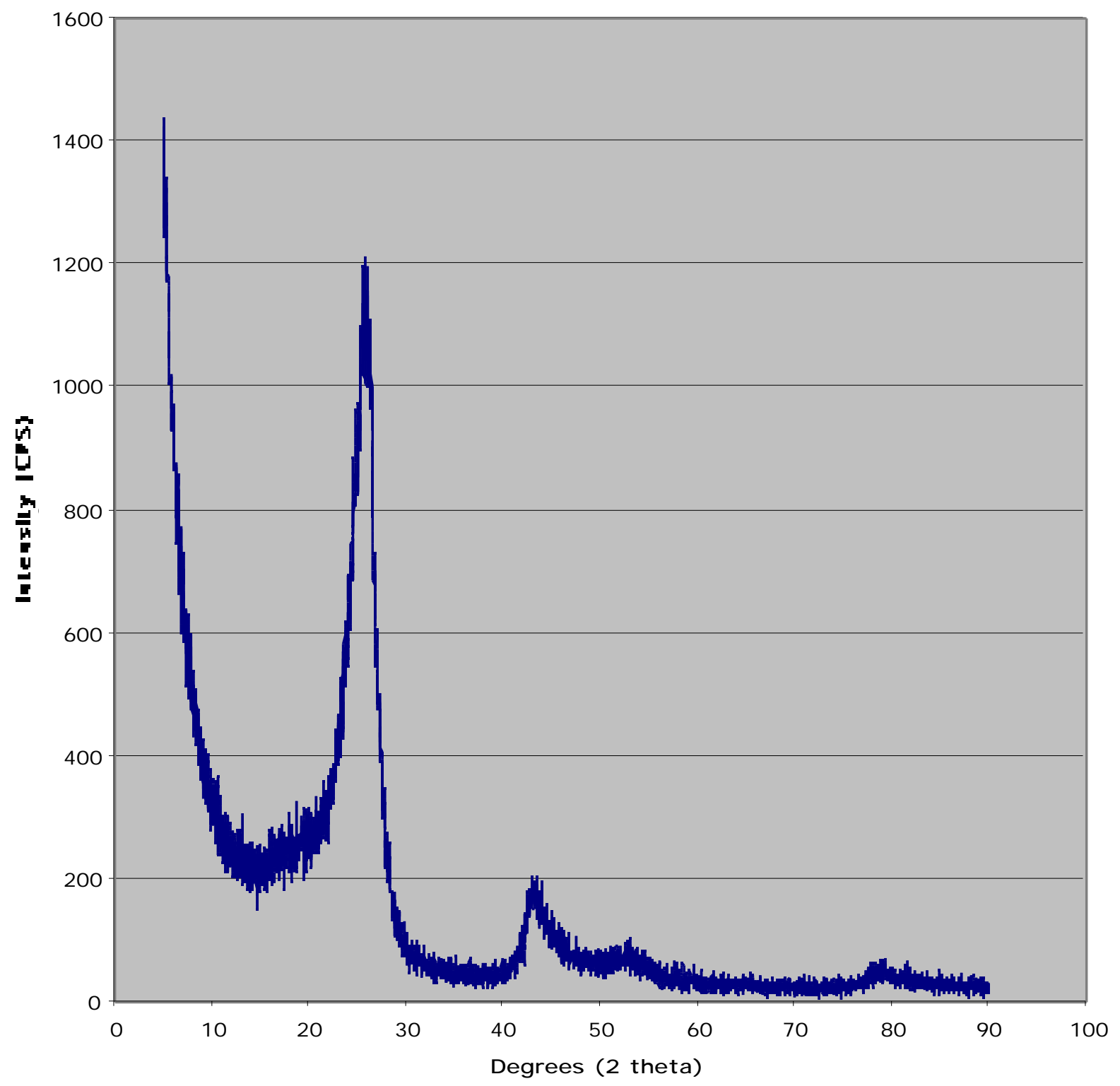

Figure 3.2 X-ray diffractogram of UAE anthracite heated to $2000^{\circ} \mathrm{C}$ 


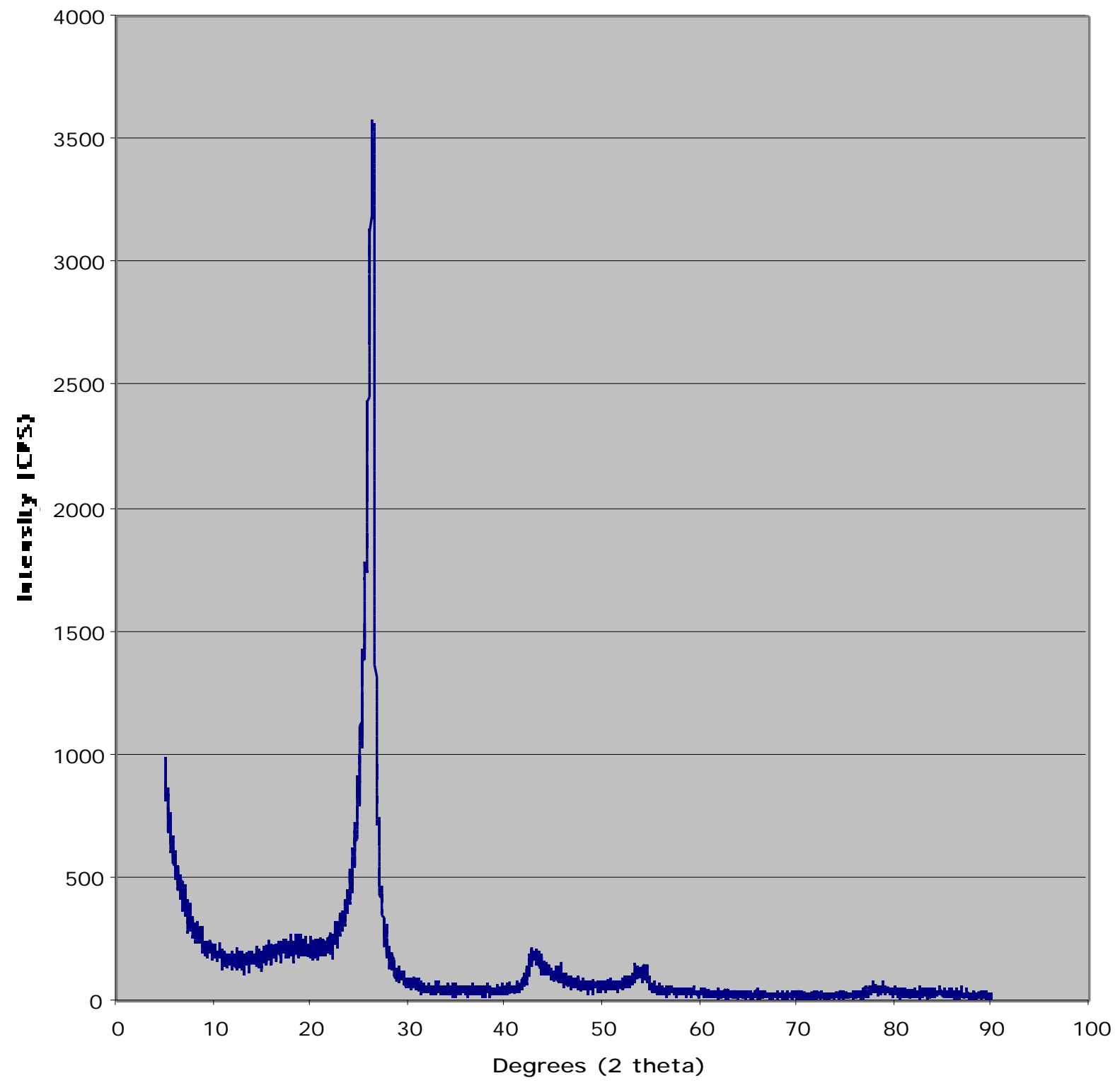

Figure 3.3 X-ray diffractogram of UAE anthracite heated to $2500^{\circ} \mathrm{C}$ 


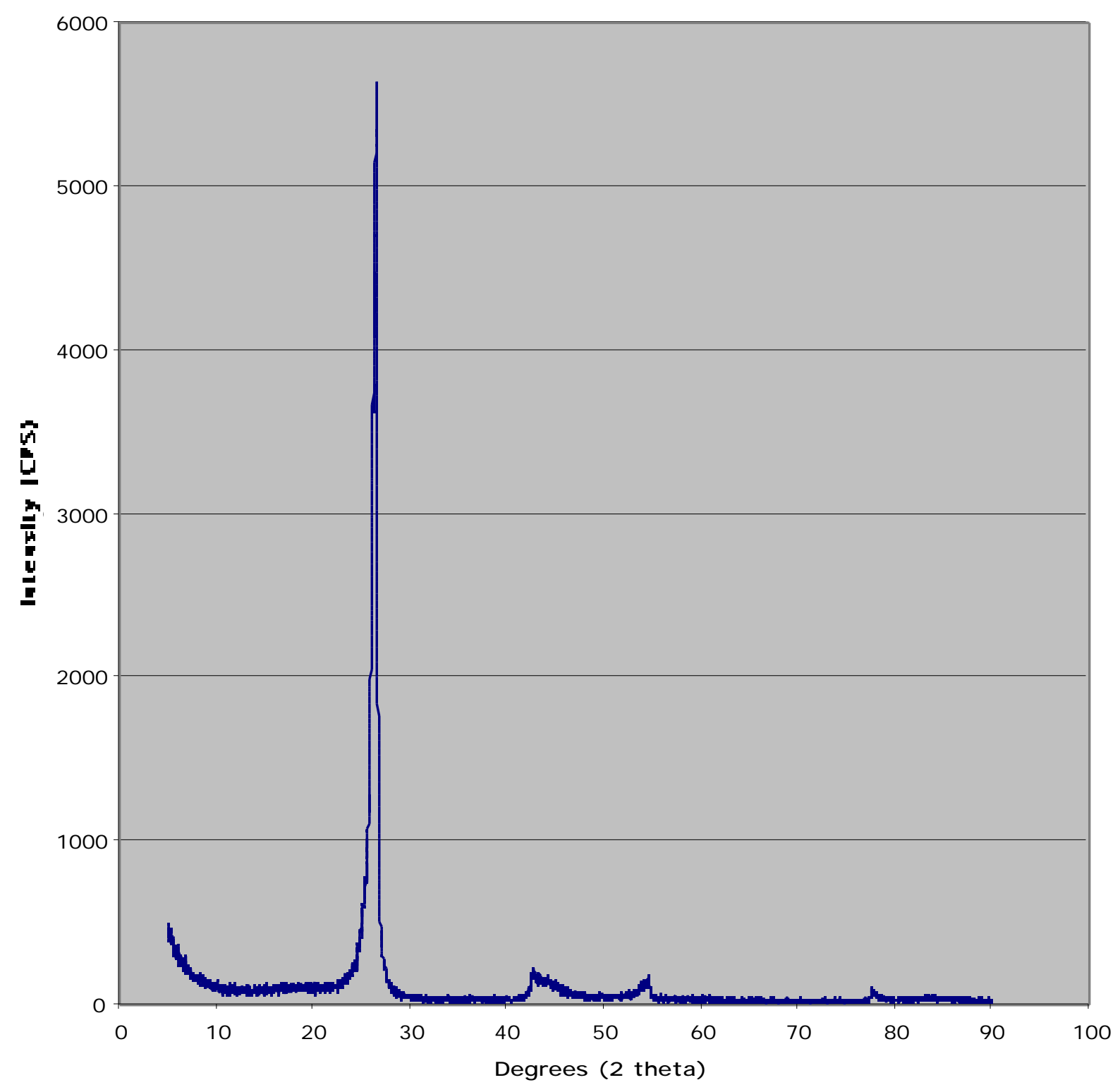

Figure 3.4 X-ray diffractogram of UAE anthracite heated to $2600^{\circ} \mathrm{C}$ 


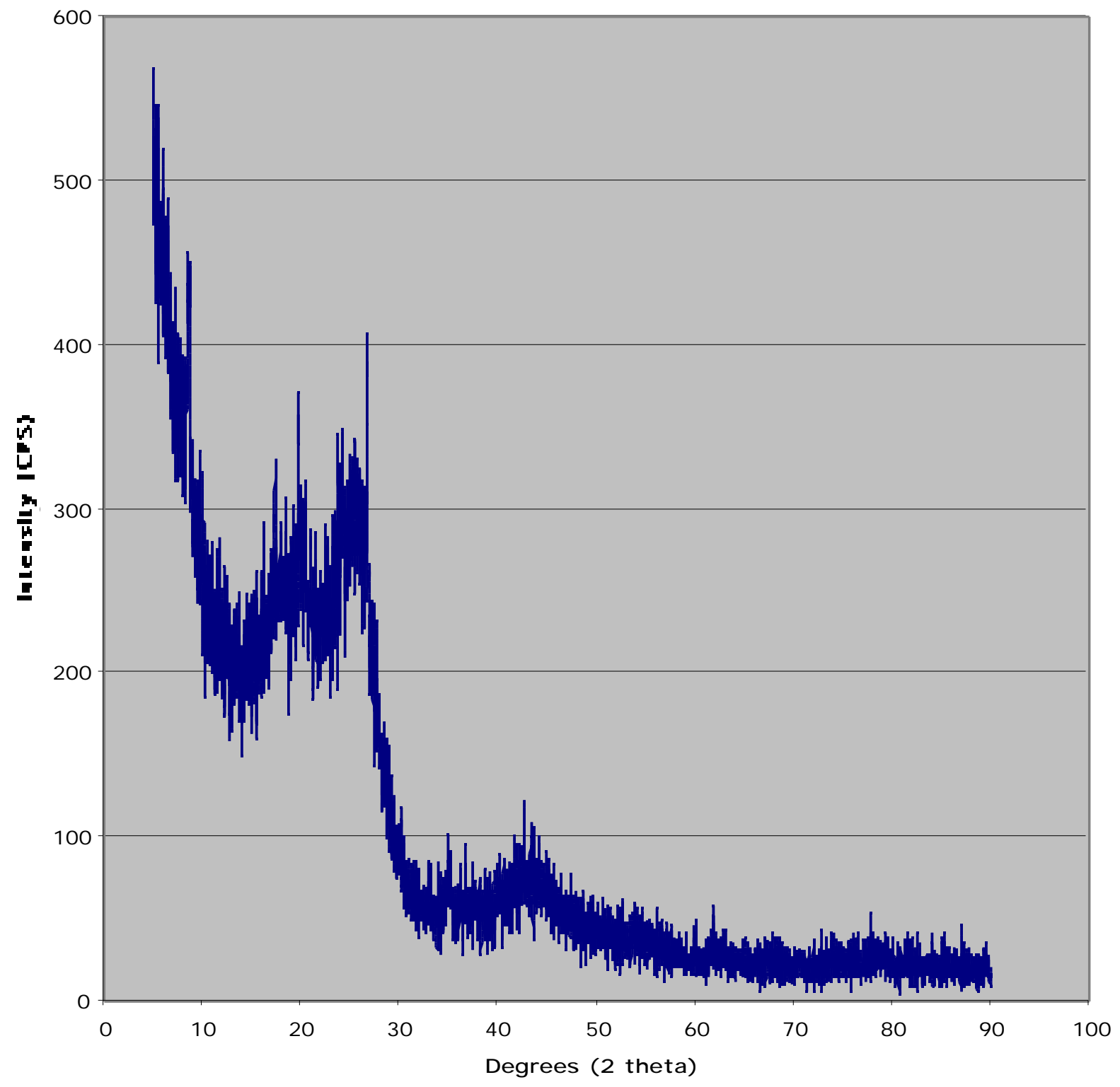

Figure 3.5 X-ray diffractogram of raw Jeddo anthracite 


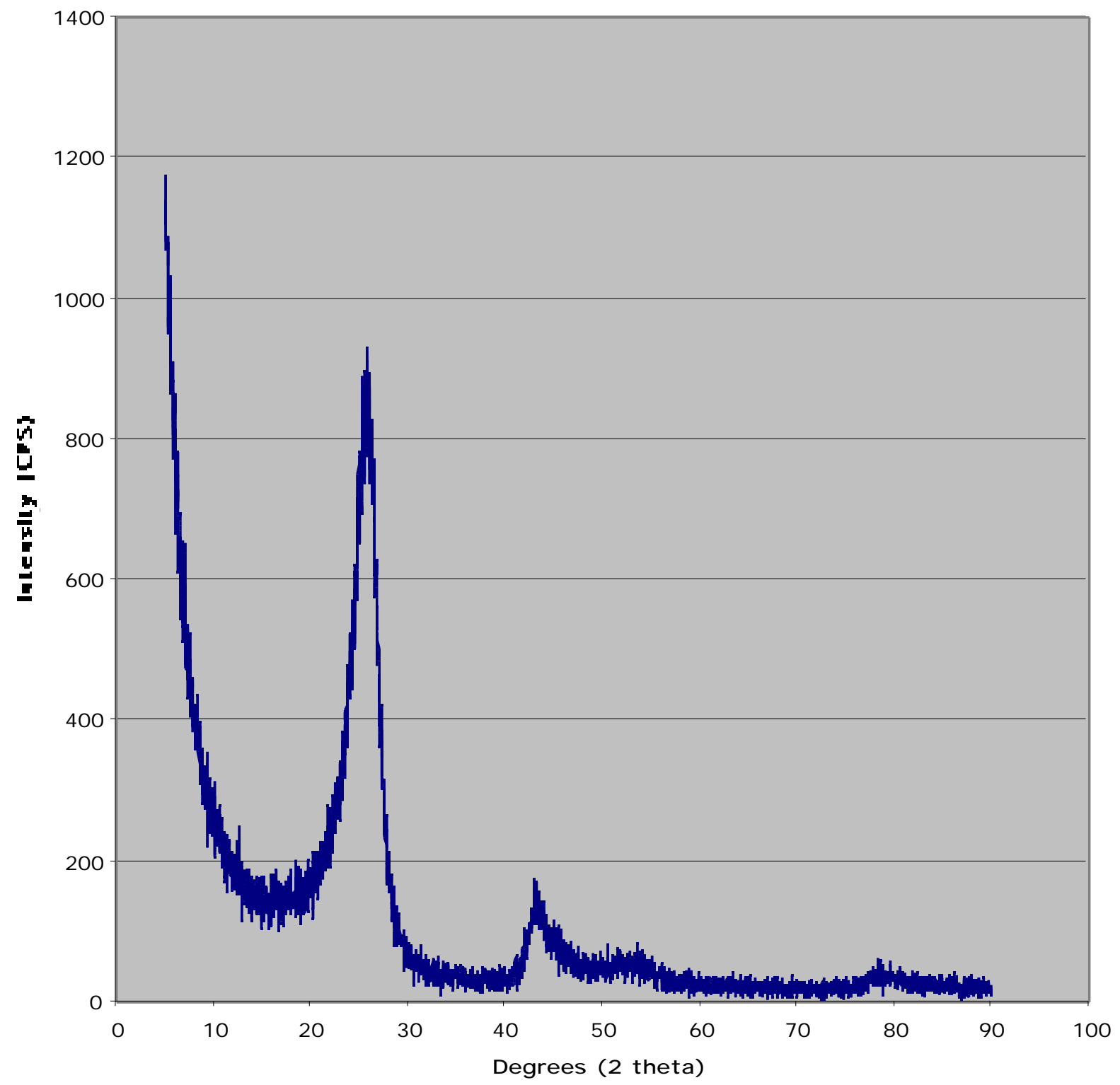

Figure 3.6 X-ray diffractogram of Jeddo anthracite heated to $2000^{\circ} \mathrm{C}$ 


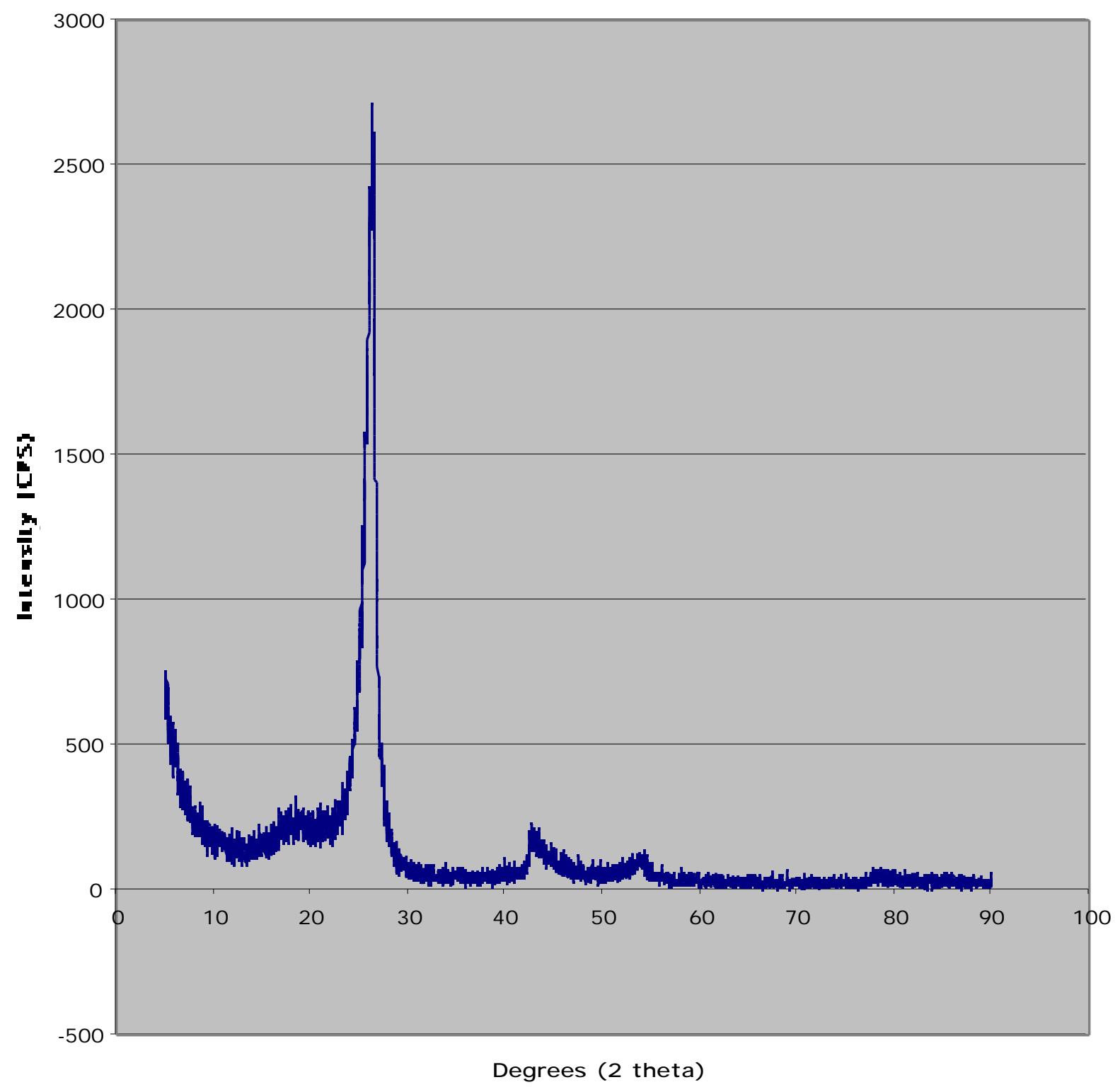

Figure 3.7 X-ray diffractogram of Jeddo anthracite heated to $2500^{\circ} \mathrm{C}$ 


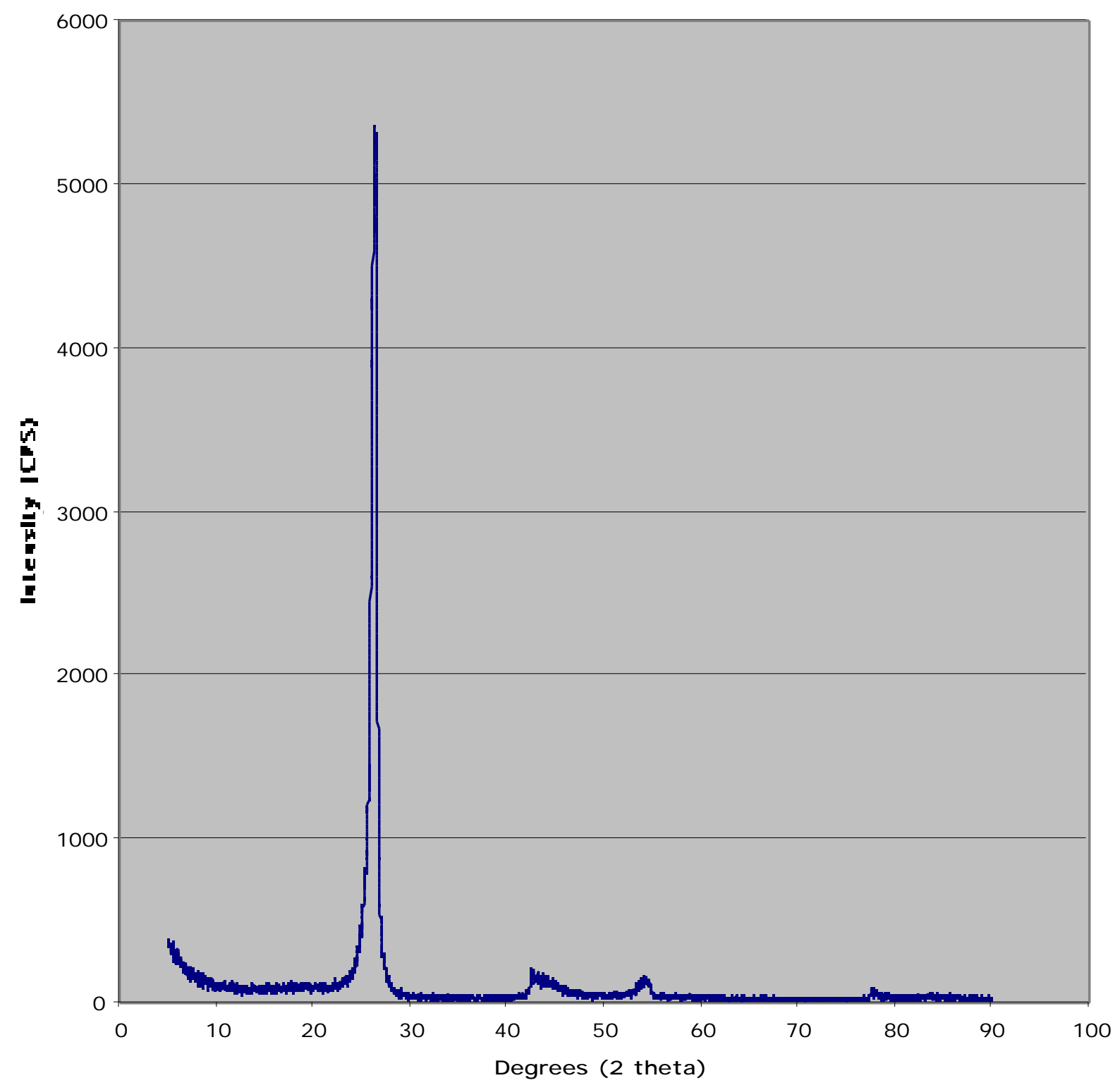

Figure 3.8 X-ray diffractogram of Jeddo anthracite heated to $2600^{\circ} \mathrm{C}$ 


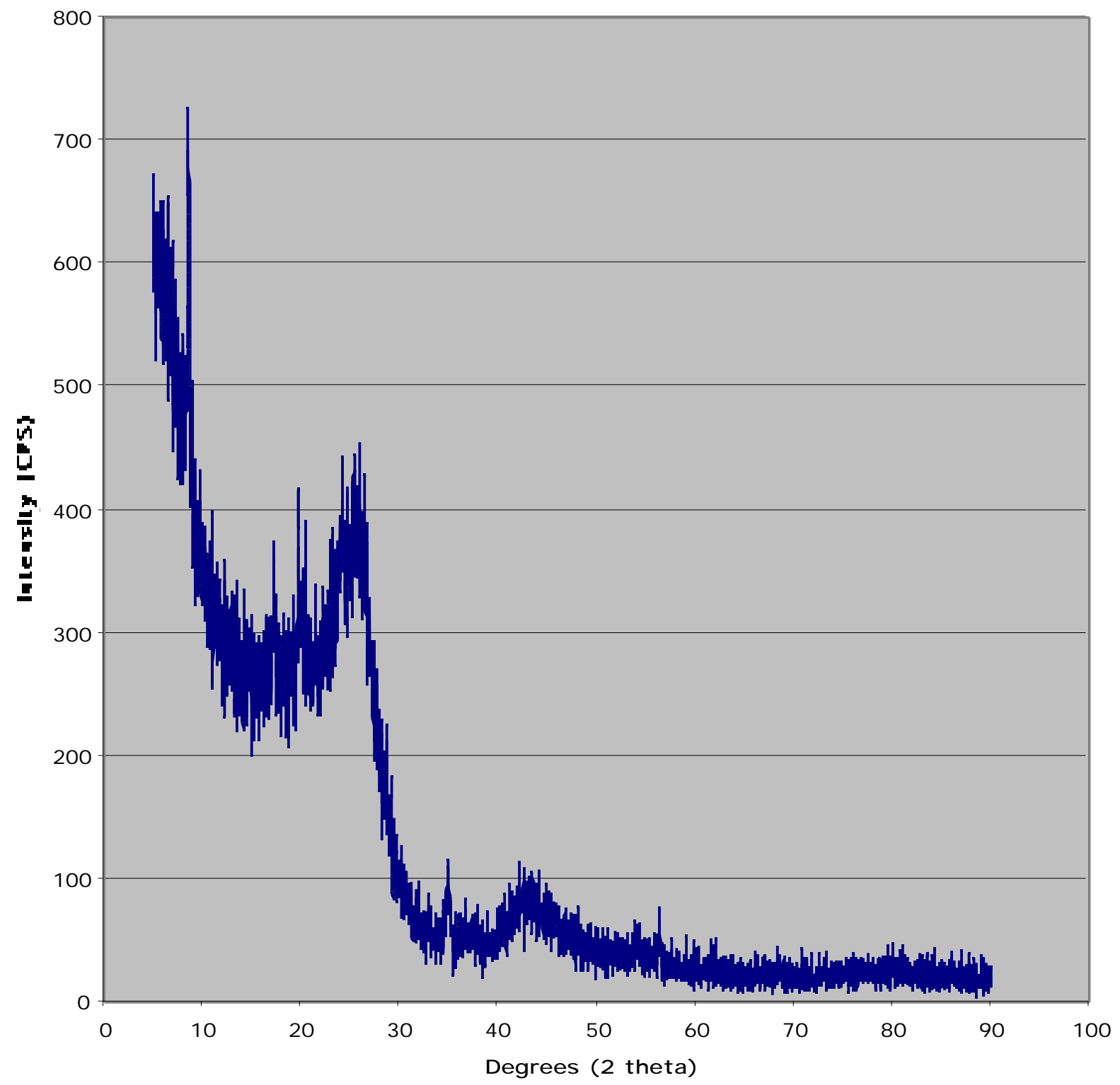

Figure 3.9 X-ray diffractogram of raw LCNN anthracite 


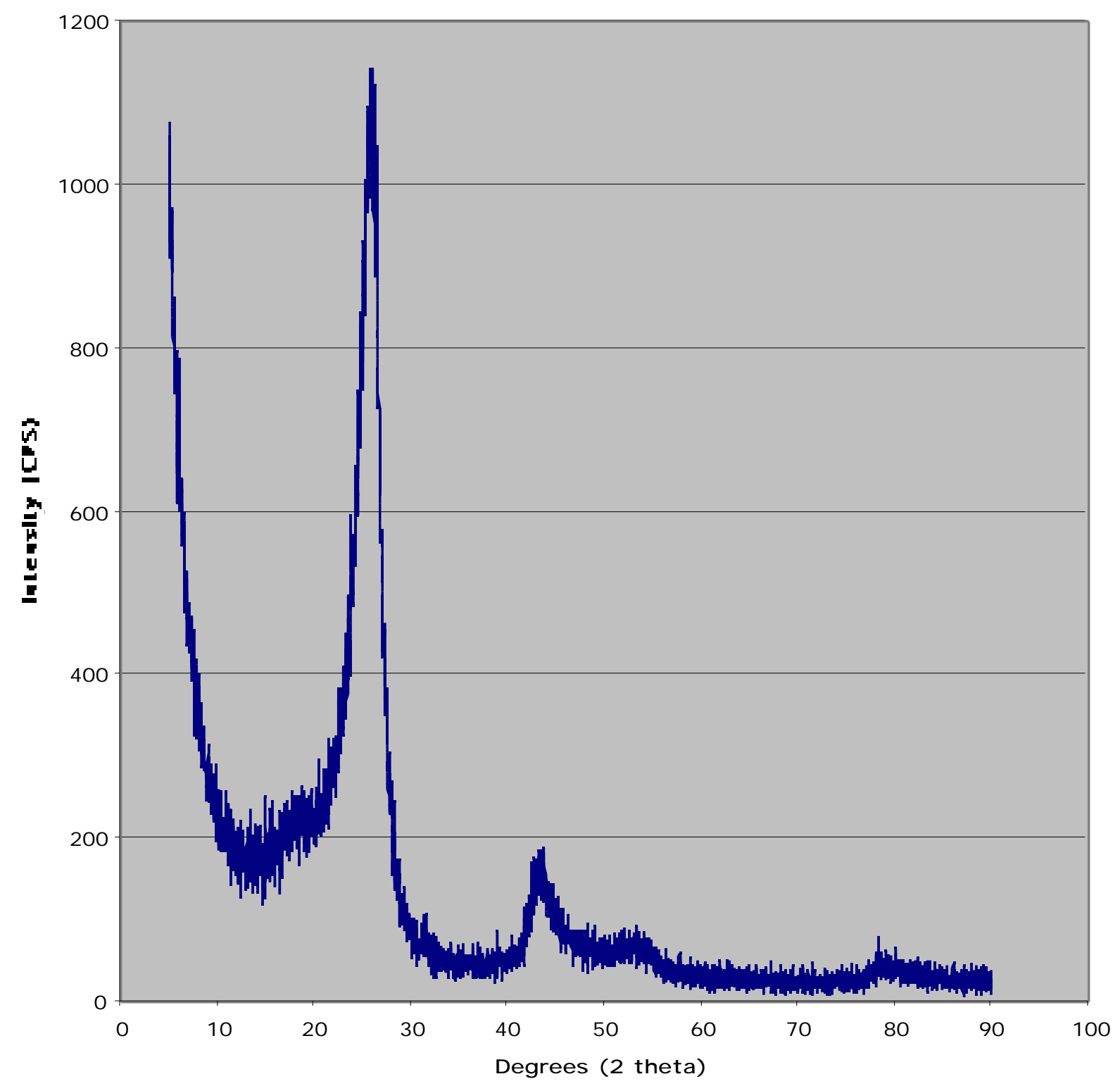

Figure 3.10 X-ray diffractogram of LCNN anthracite heated to $2000^{\circ} \mathrm{C}$ 


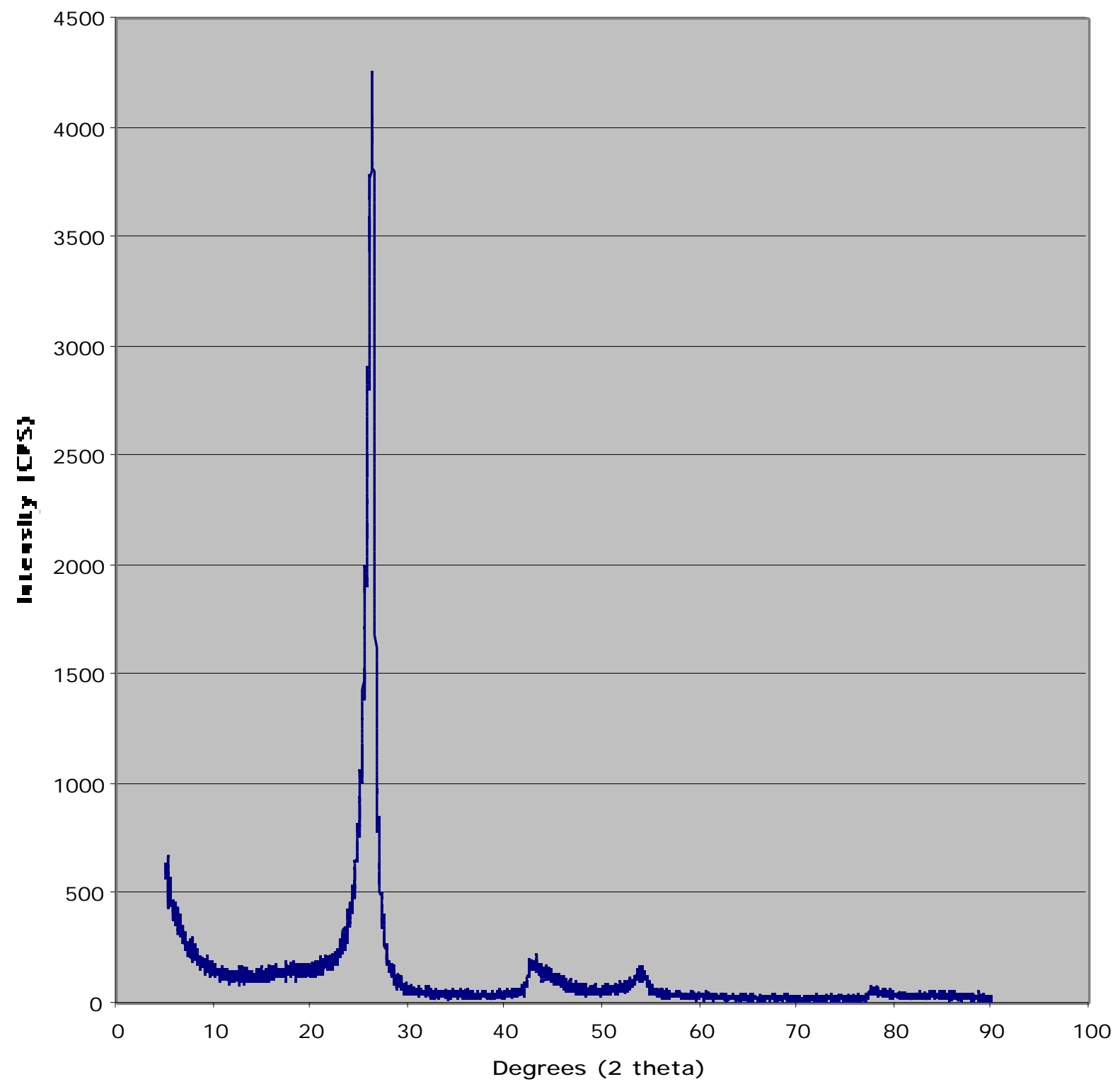

Figure 3.11 X-ray diffractogram of LCNN anthracite heated to $2500^{\circ} \mathrm{C}$ 


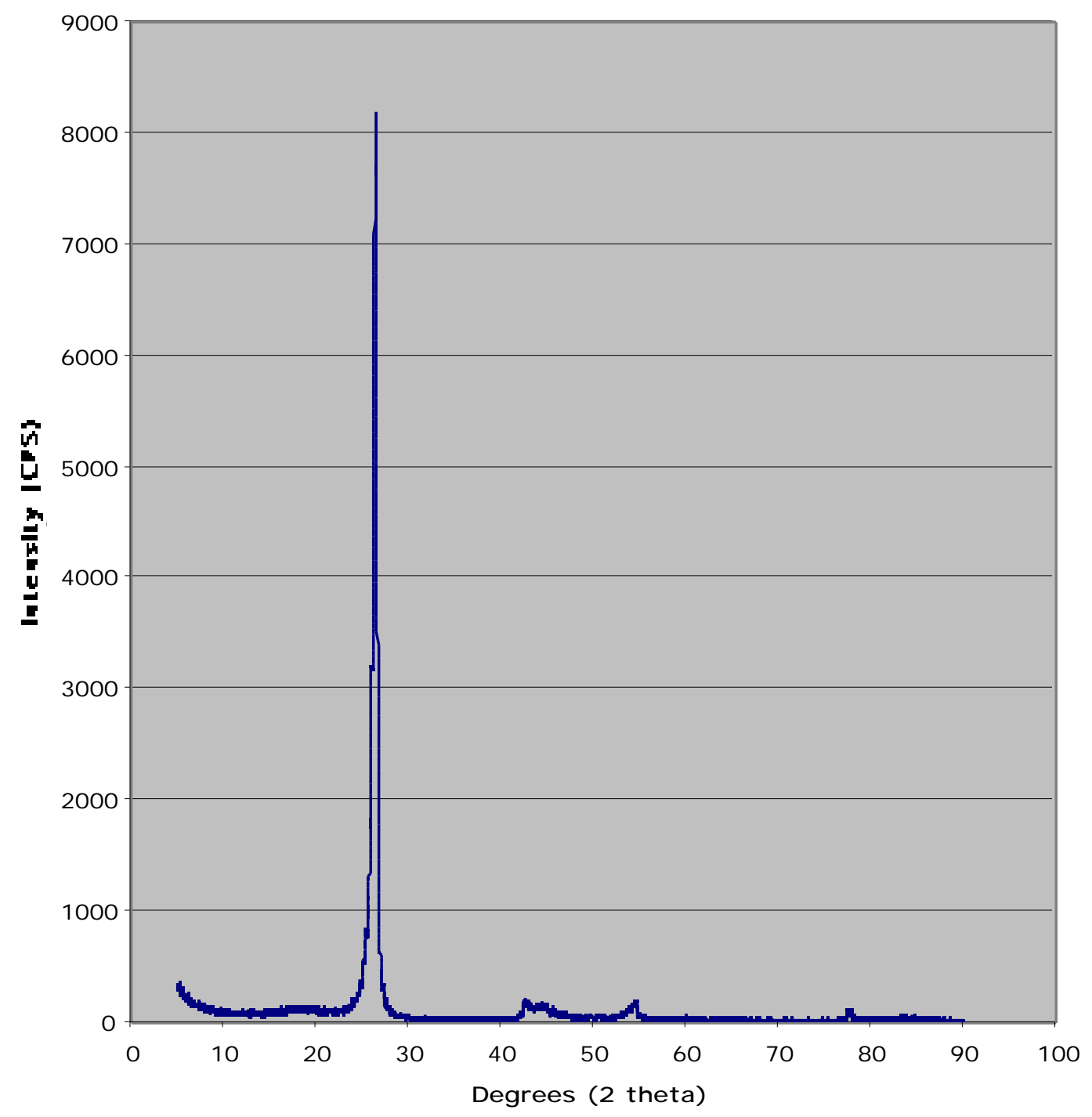

Figure 3.12 X-ray diffractogram of LCNN anthracite heated to $2600^{\circ} \mathrm{C}$ 


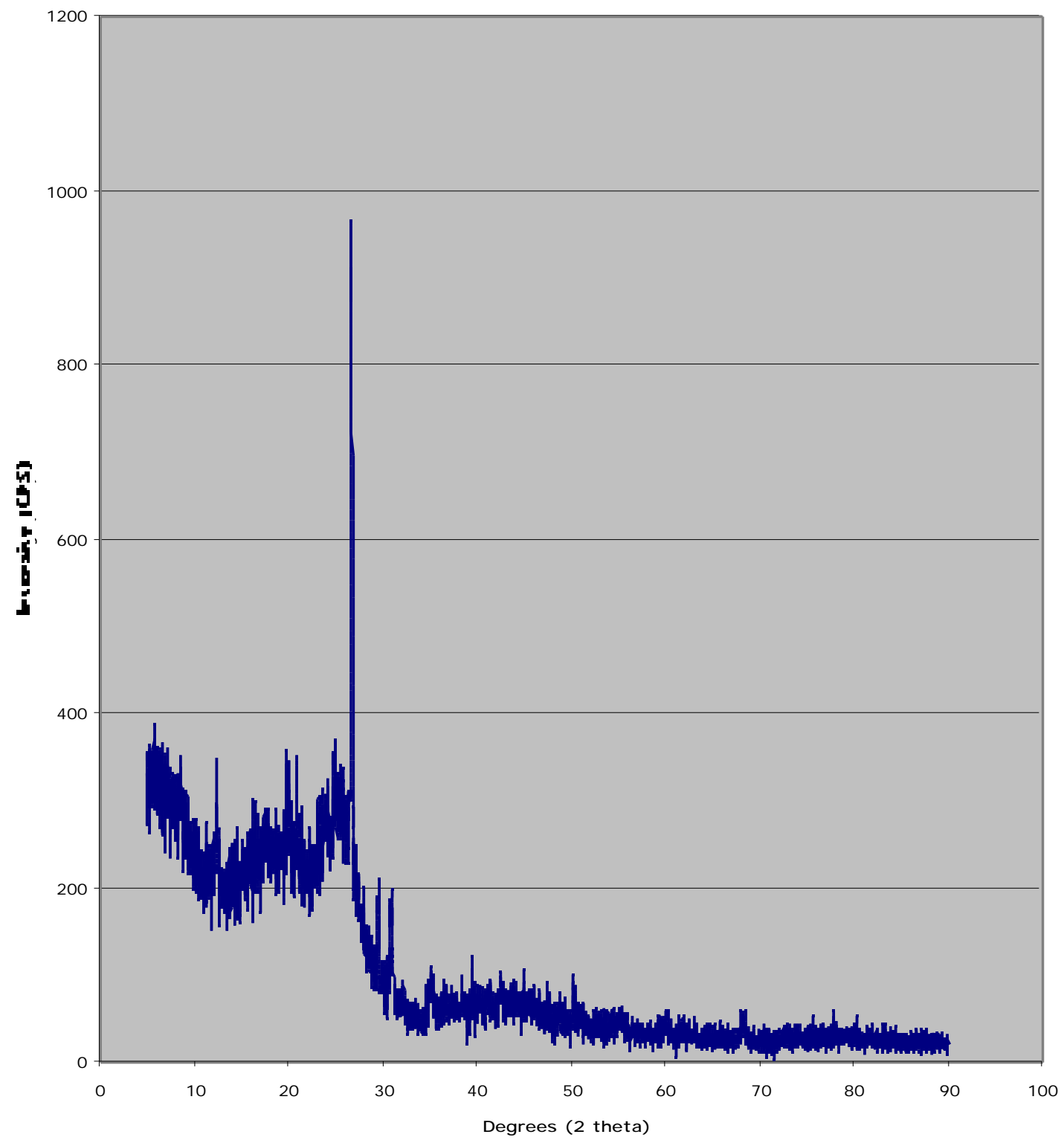

Figure 3.13 X-ray diffractogram of raw Summit anthracite 


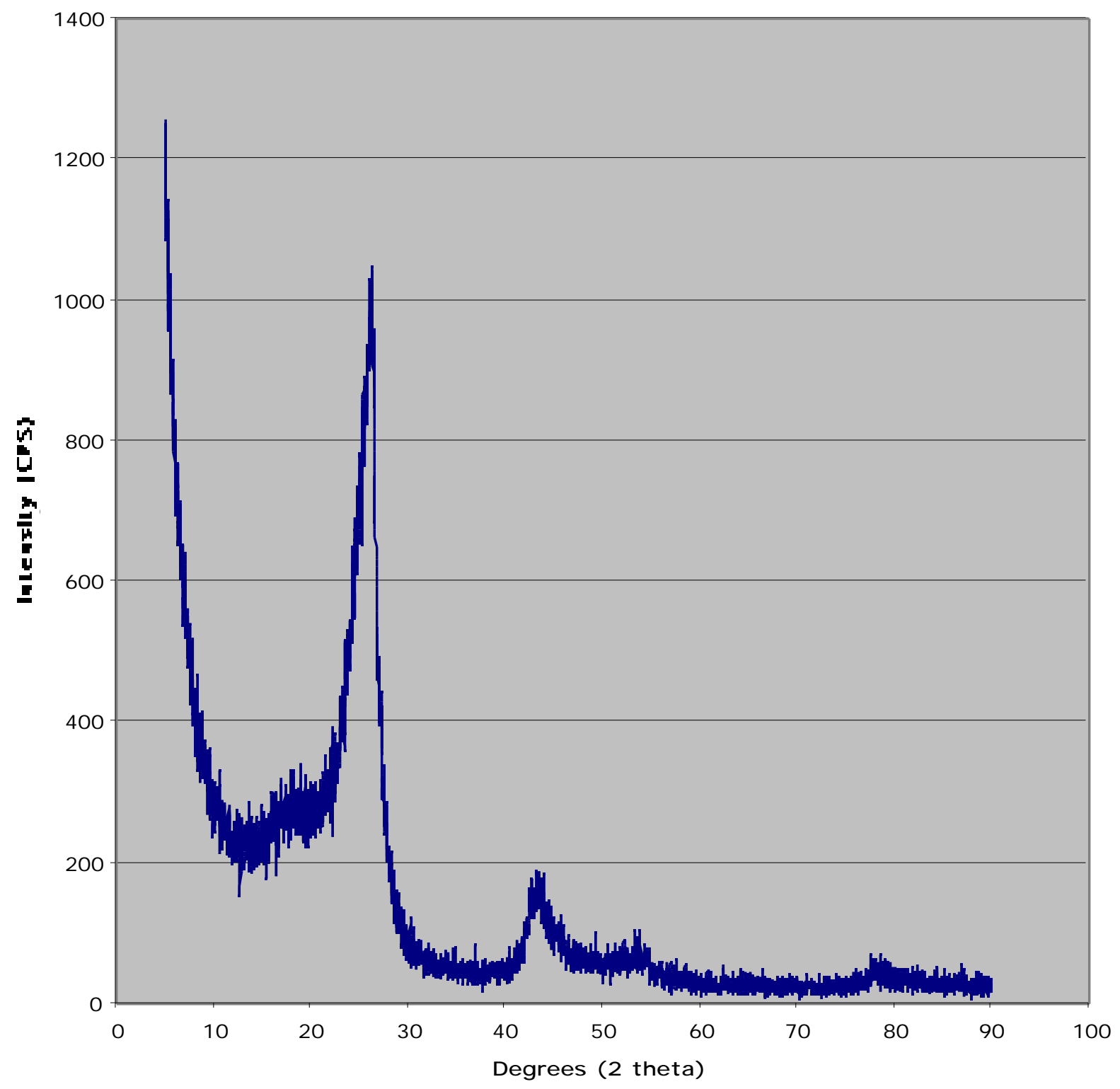

Figure 3.14 X-ray diffractogram of Summit anthracite heated to $2000^{\circ} \mathrm{C}$ 


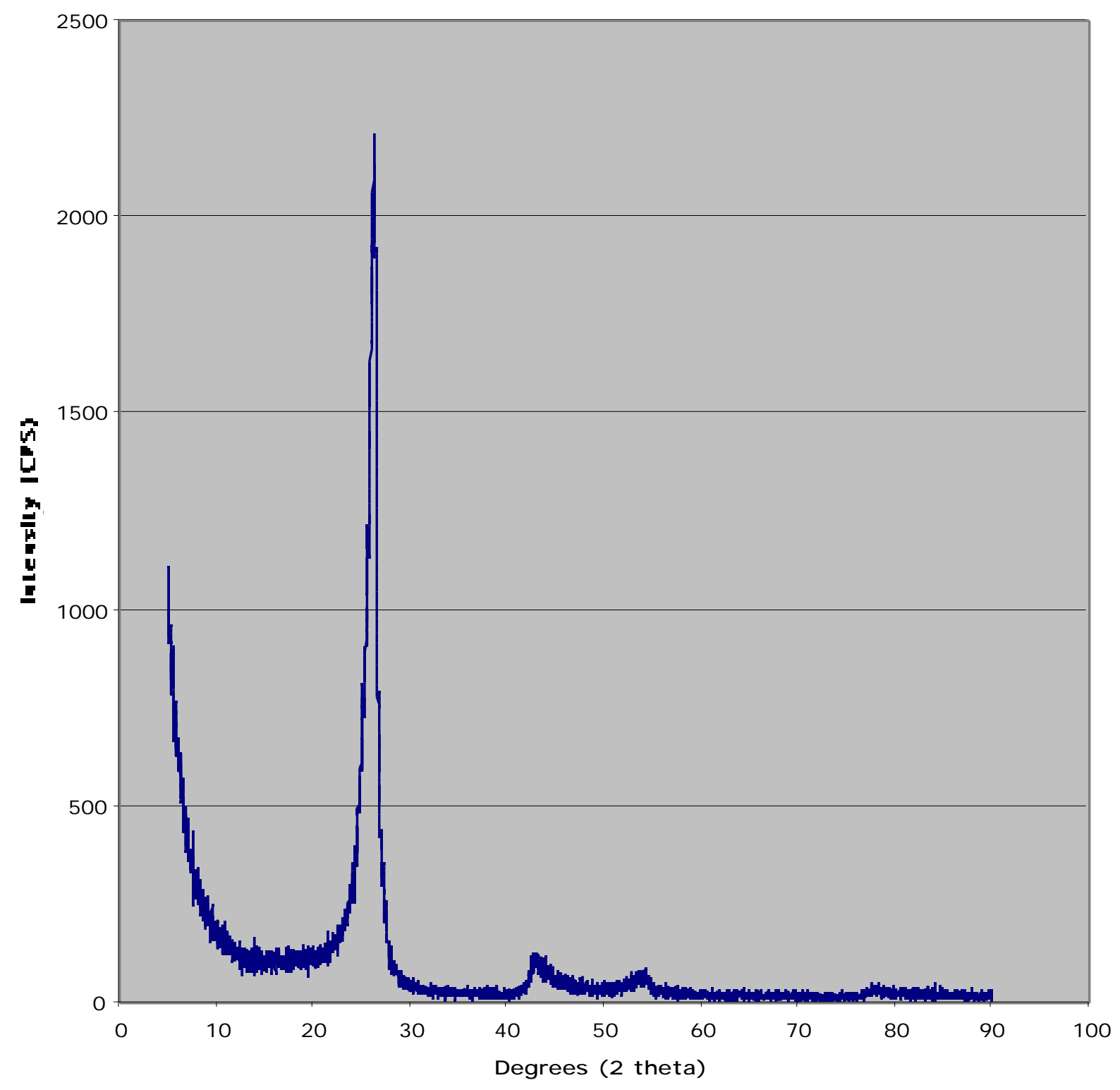

Figure 3.15 X-ray diffractogram of Summit anthracite heated to $2500^{\circ} \mathrm{C}$ 


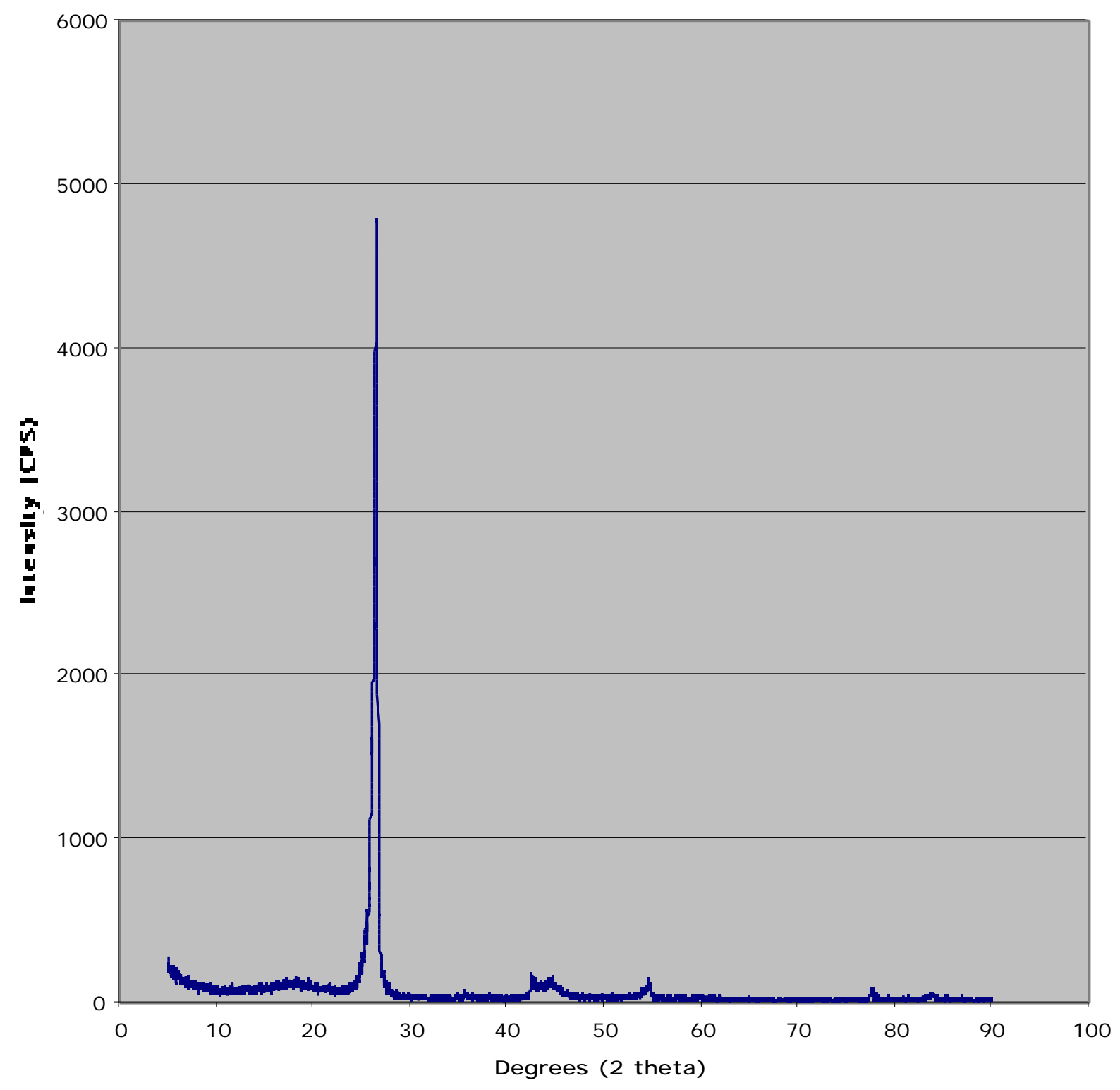

Figure 3.16 X-ray diffractogram of Summit anthracite heated to $2600^{\circ} \mathrm{C}$ 


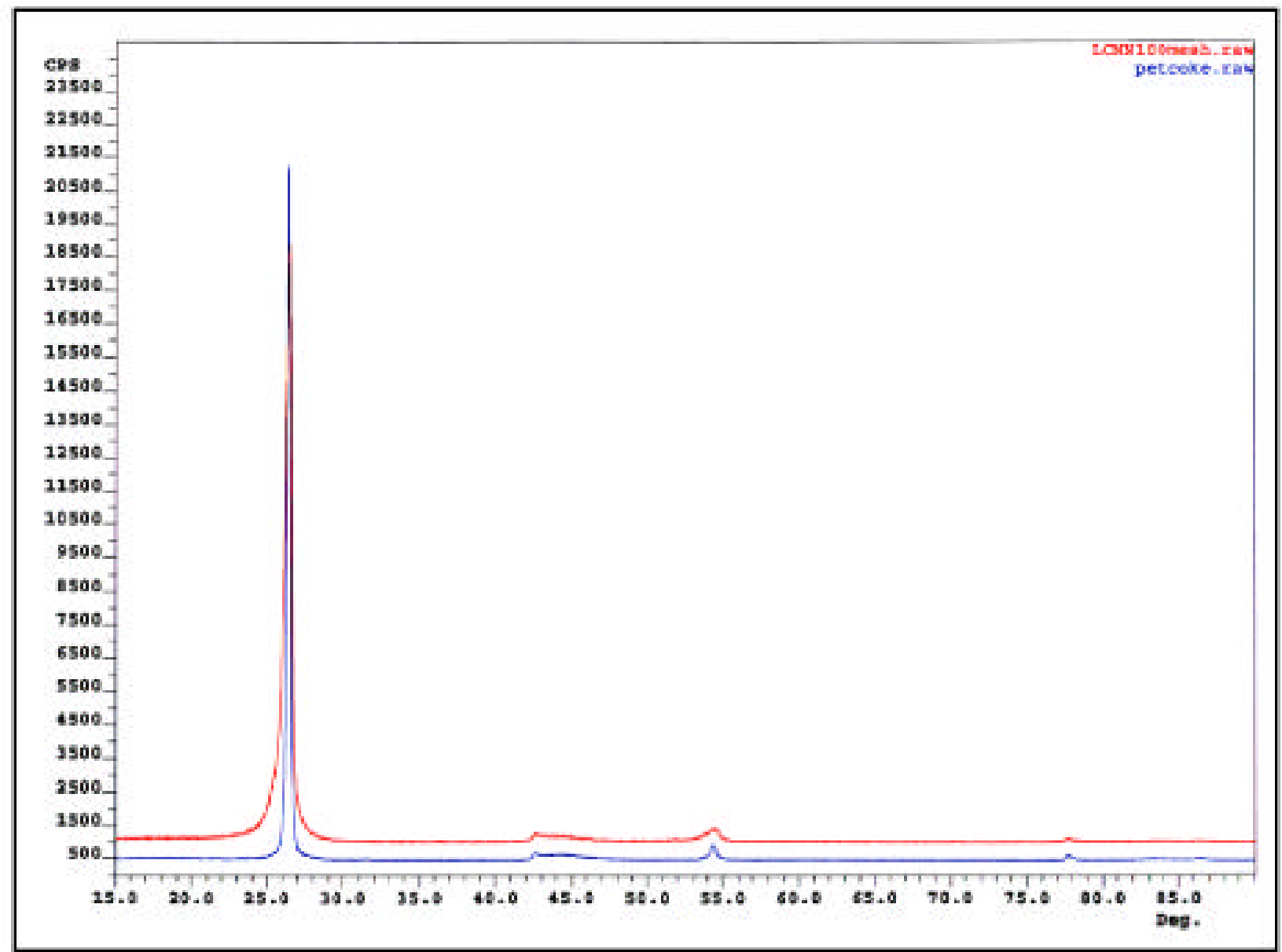

Figure 3.17 X-ray diffraction comparison between needle coke and LCNN anthracite 


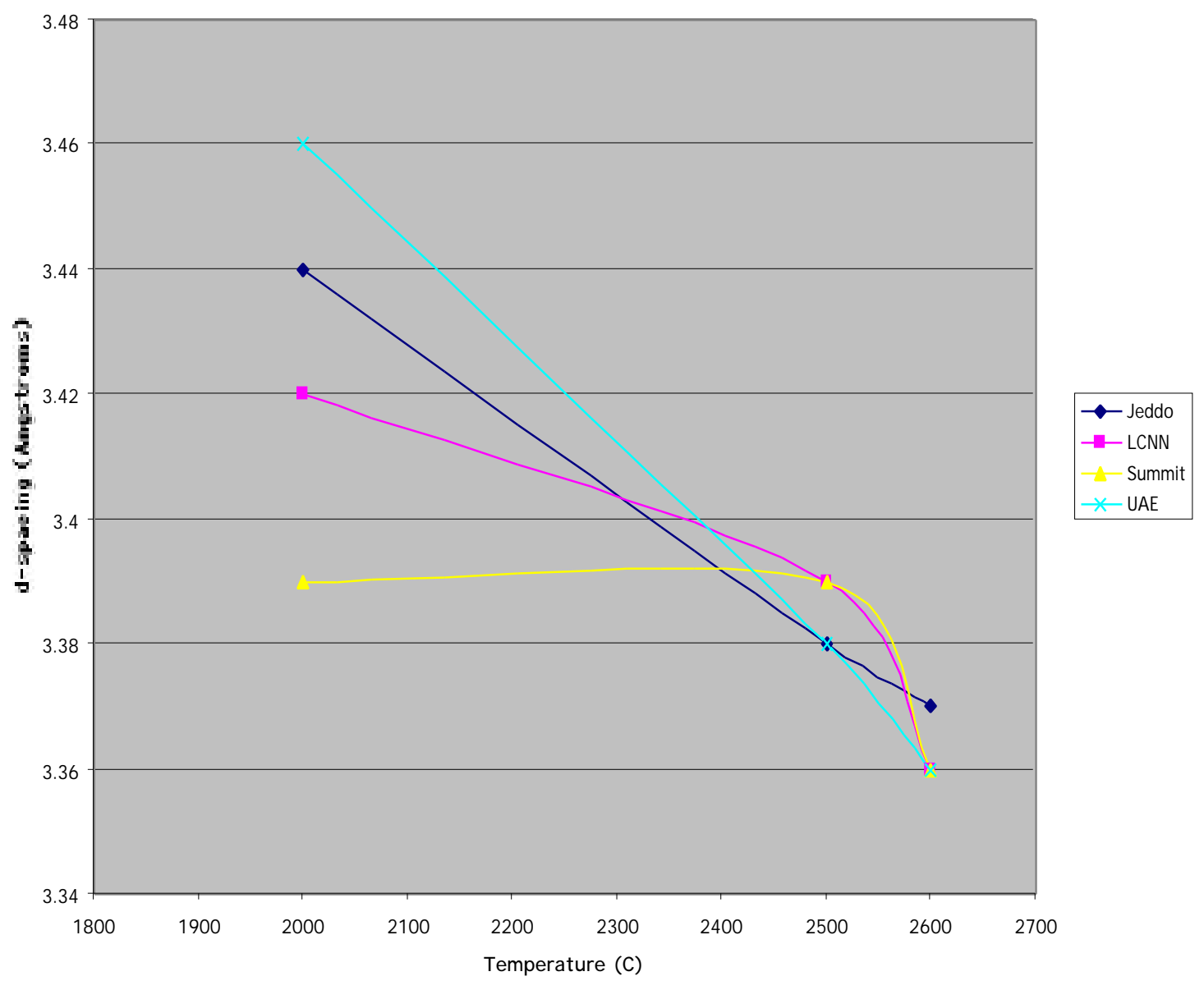

Figure 3.18 d-spacing changes with increasing temperature for the four anthracites 


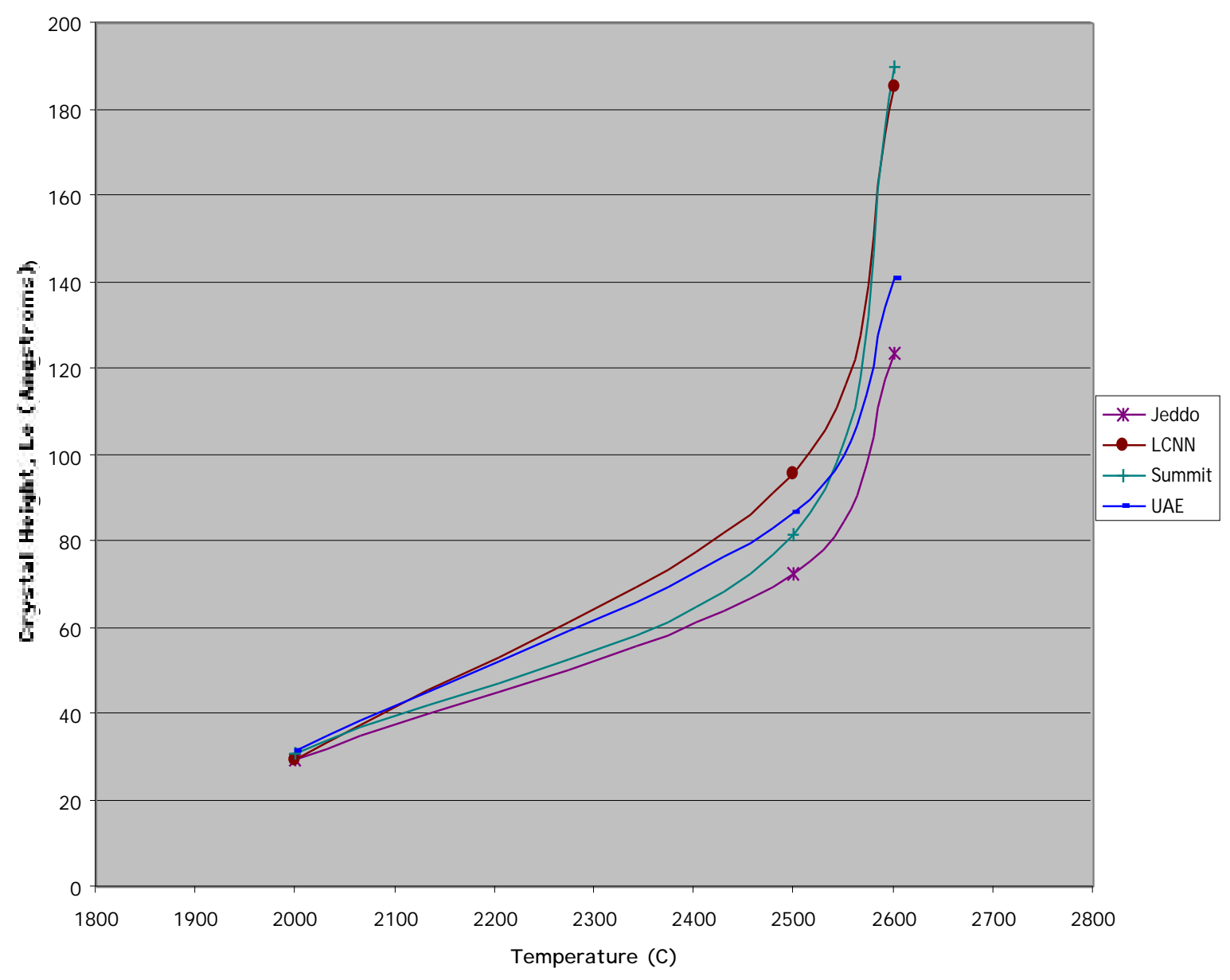

Figure 3.19 Crystal height changes with increasing temperature for the four anthracites 


\section{$\underline{3.4 \text { Computer-Controlled Scanning Electron Microscopy (CCSEM) }}$}

CCSEM provided a wealth of information on the inorganic elements present in the anthracites. In fact, all of the data combined for the raw and heat-treated anthracites totals over four hundred pages. Obviously, four hundred pages are too much data to present there, so the most relevant information must be extracted and shown in a concise manner. The inorganic phase data are presented in several different manners, such as relative mineral weight percent on a mineral basis, and number of particles of minerals in a certain size fraction. Since one of the hypotheses of this work is that the composition of the mineral matter present in coal, not simply its weight percent, is crucial for catalytic graphitization, the most relevant information from the CCSEM output is inorganic weight percent on a mineral basis, mineral area on a whole fuel or coal basis, and number of mineral particles in a certain size fraction. The mineral weight percent on a mineral basis is important because it provides the composition of the mineral matter in the anthracite. The mineral area on a coal basis is useful because it shows the interactive surface area between the inorganics and the carbon matrix. The higher the mineral area, the more likely a reaction between the inorganic and the carbon is to take place. Lastly, the number of mineral particles in a size fraction allows for the prediction of how the inorganics are dispersed throughout the coal. The mineral matter can be present as distinct particles separate from any coal particles, or finely disseminated throughout the carbon matrix. Typically, if a large number of small particles (less than 5 microns) are present, they can be assumed to be finely disseminated, whereas if large particles are present (between 46-400 microns), they are most likely present as discrete entities. Also, finely disseminated particles will have a larger surface 
area in contact with the carbon than will the large, extraneous particles, which would enhance the possibility of any catalytic reaction. Figures 3.20 to 3.31 show these three types of inorganic phase comparisons for the four anthracite samples. The figures are on a total number of mineral particle basis; individual inorganic phases are not shown. The CCSEM identifies thirty-three individual inorganic phases, which are listed in Appendix 1. These thirty-three minerals obviously make-up the total values shown in Figures 3.20 to 3.31.

Before making assumptions about what Figures 3.20 to 3.31 are showing, a brief explanation is provided. The "Size Fractions" $\mathrm{x}$-axis represents the width of the inorganic particle observed at its maximum, and these widths are broken down into the ranges shown. The $\mathrm{y}$-axis lists the graphitization temperatures that were used; thus all the same color columns are for a given temperature. Lastly, the z-axis shows the mineral comparison types.. Figures 3.20 to 3.23 show the relative weight percent of minerals, on a mineral basis, for the four anthracite samples. The UAE and Jeddo anthracite, Figures 3.20 and 3.21, definitely show a trend toward smaller particles with increasing temperature, in that the bulk of the mineral weight is contained in particles less than ten microns. For the UAE anthracite heated to $2600^{\circ} \mathrm{C}, 93.3 \%$ of the mineral weight is contained in particles less than ten microns, and for the 


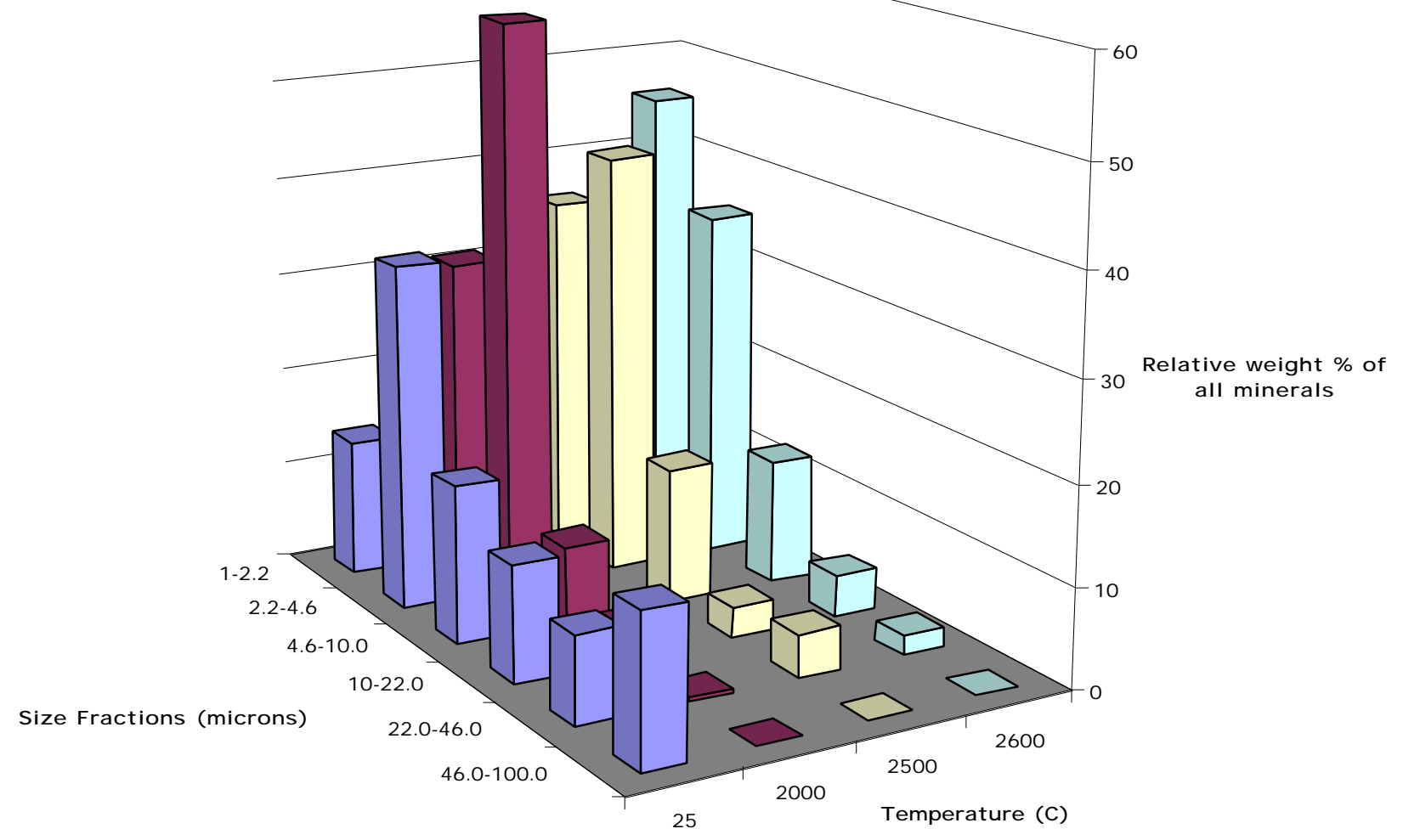

Figure 3.20 Relative weight \% of all inorganics in varying size fractions for UAE anthracite over all graphitization temperatures 


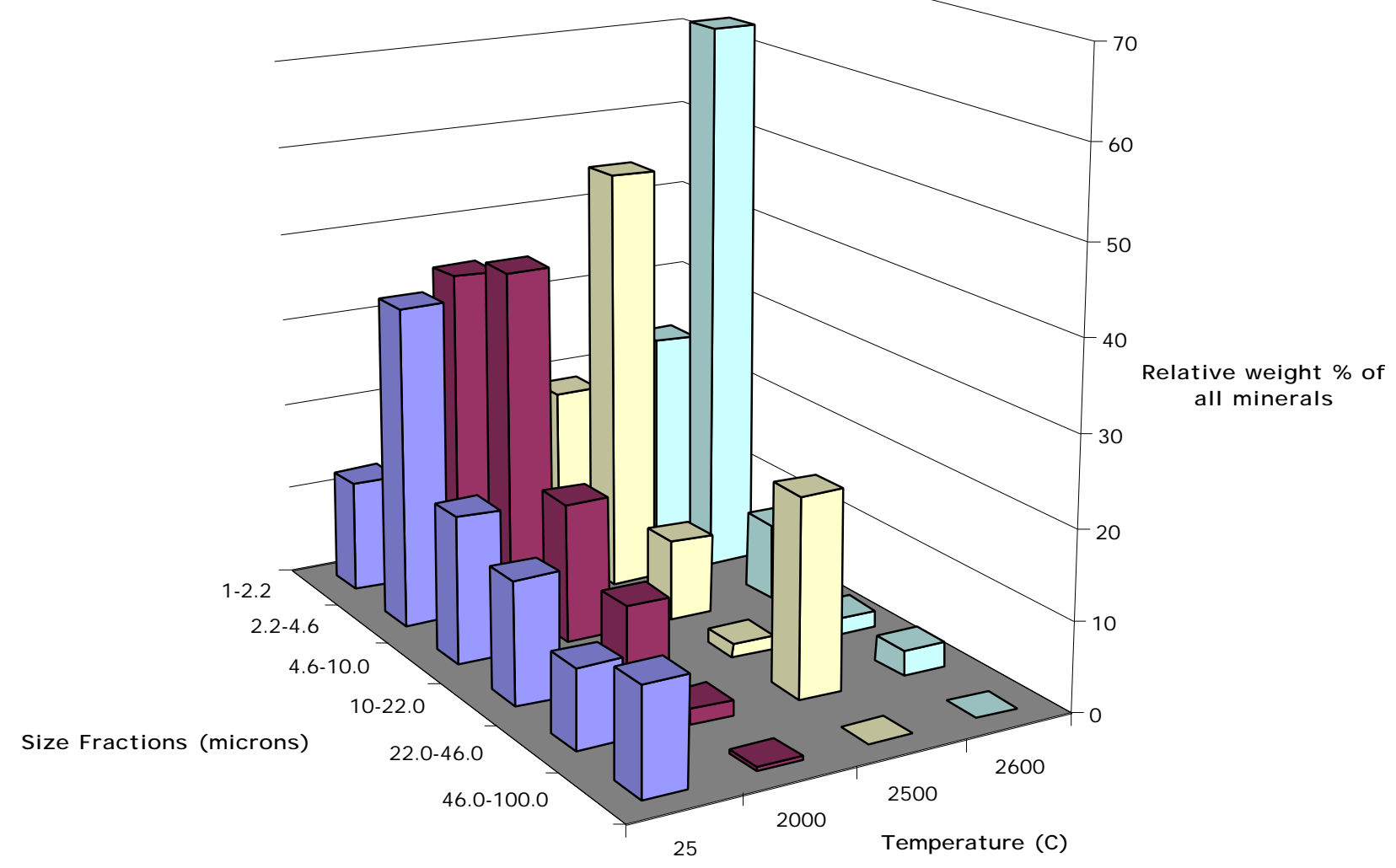

Figure 3.21 Relative weight $\%$ of all inorganics in varying size fractions for Jeddo anthracite over all graphitization temperatures 


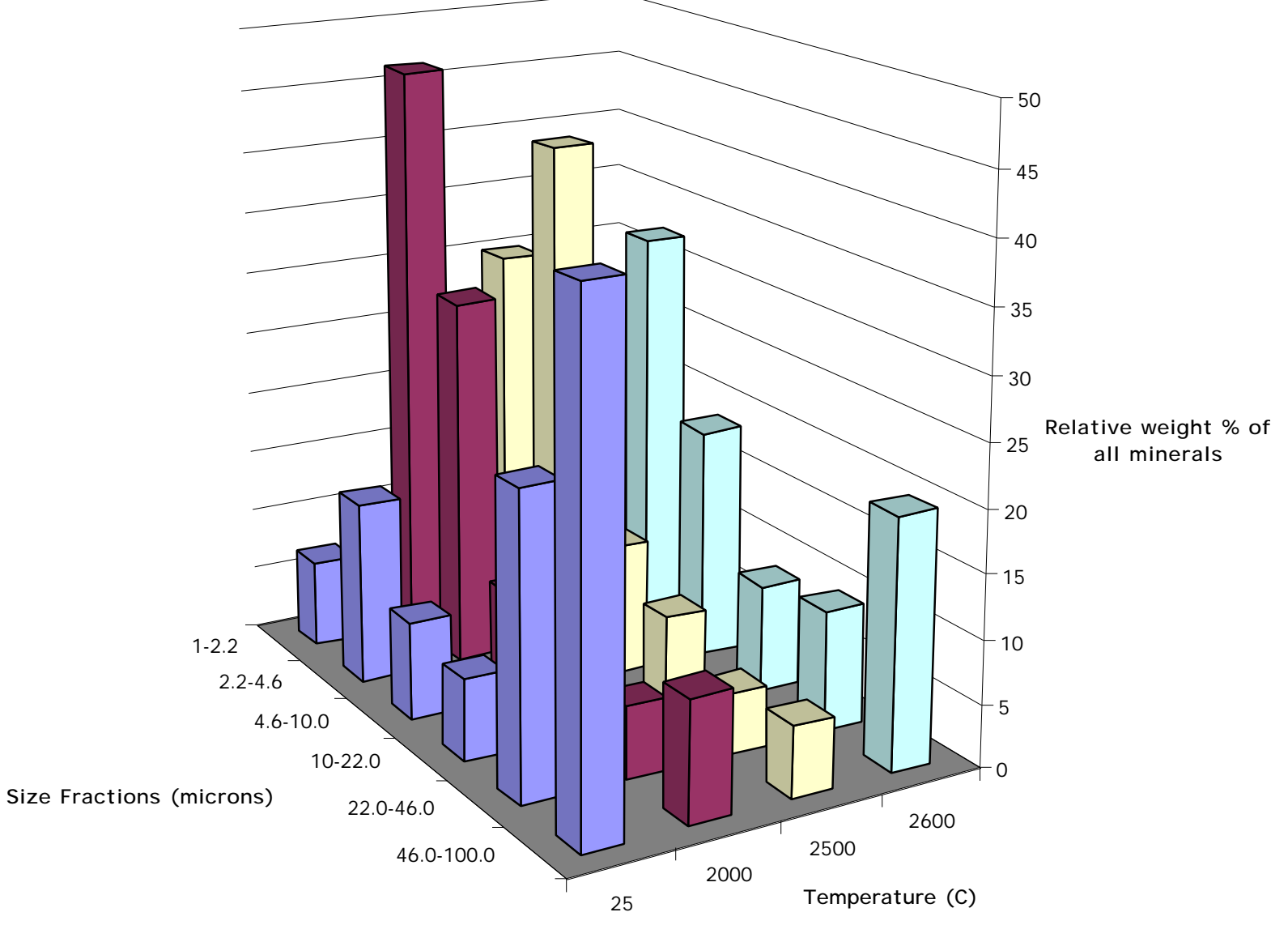

Figure 3.22 Relative weight $\%$ of all inorganics in varying size fractions for Summit anthracite over all graphitization temperatures 


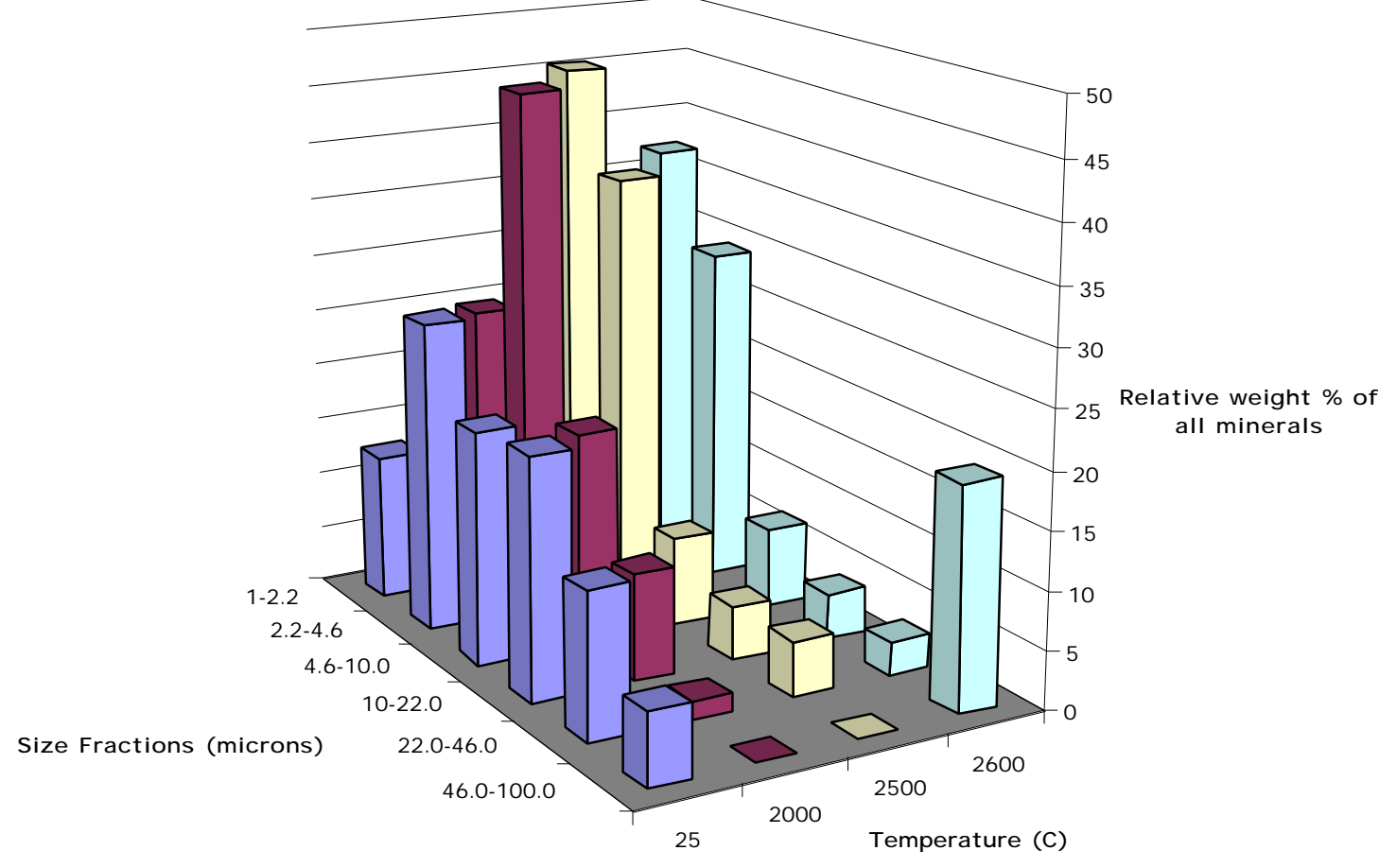

Figure 3.23 Relative weight \% of all inorganics in varying size fractions for LCNN anthracite over all graphitization temperatures 


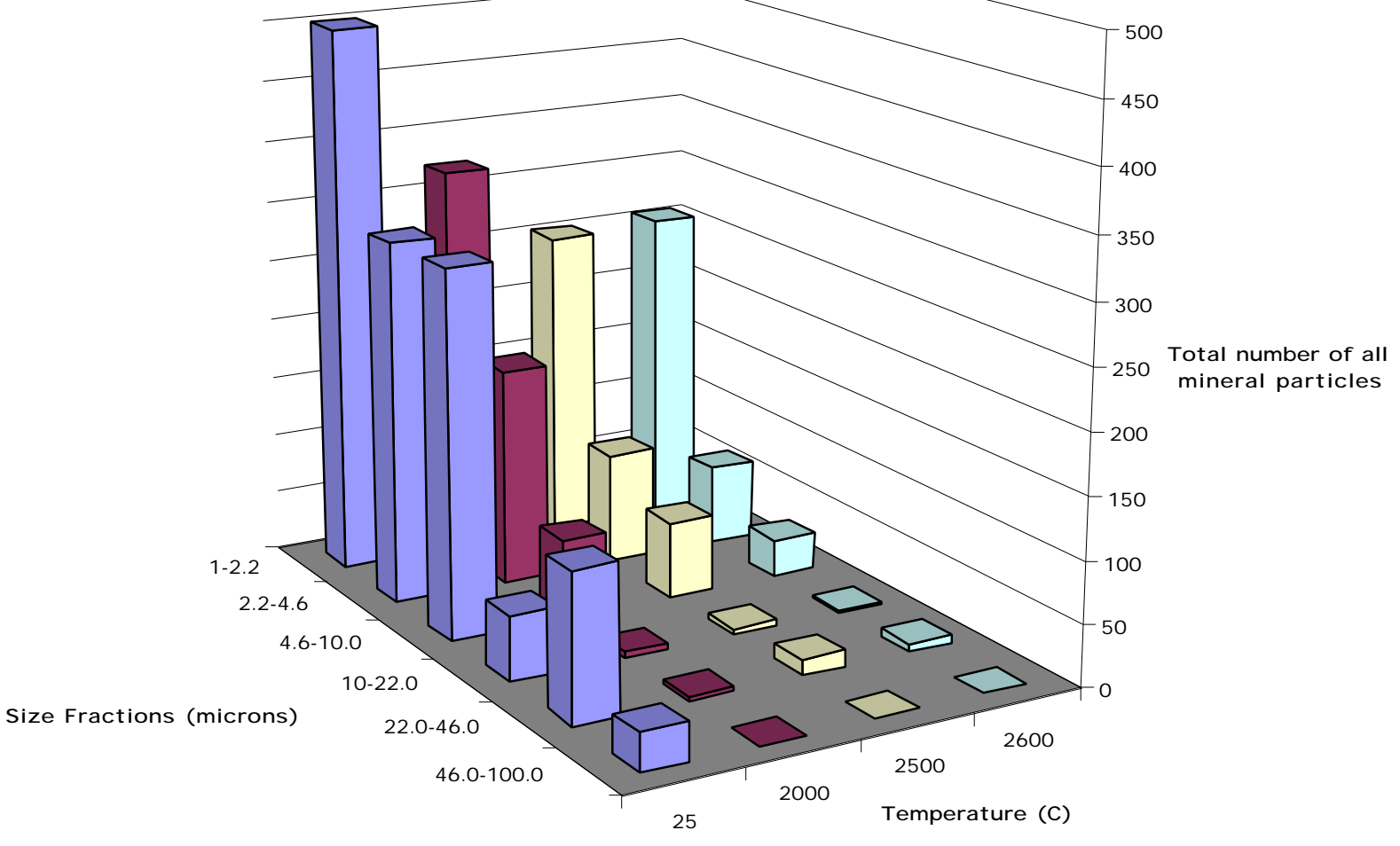

Figure 3.24 Total number of all inorganics in varying size fractions for UAE anthracite over all graphitization temperatures 


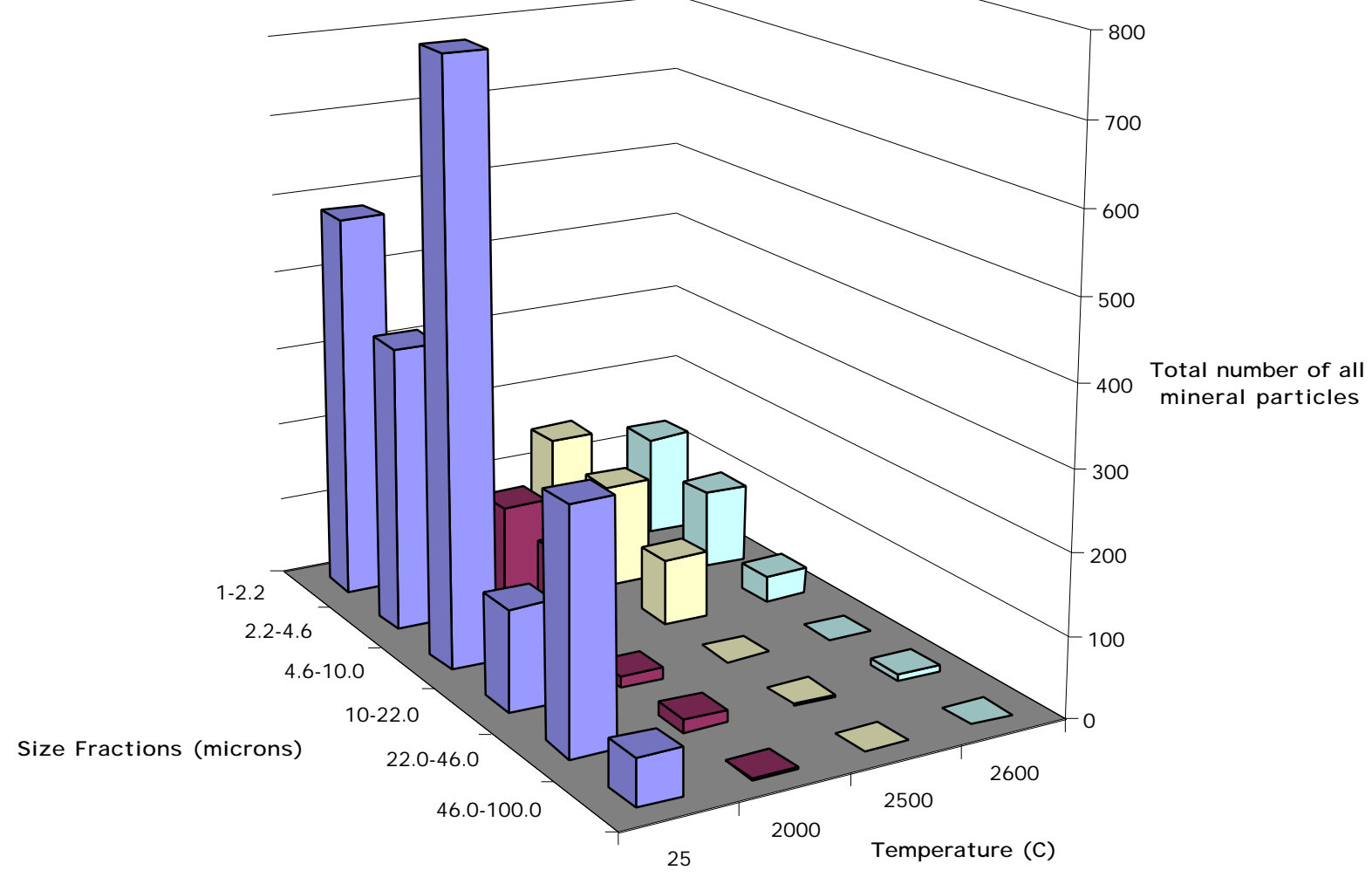

Figure 3.25 Total number of all inorganics in varying size fractions for Jeddo anthracite over all graphitization temperatures 


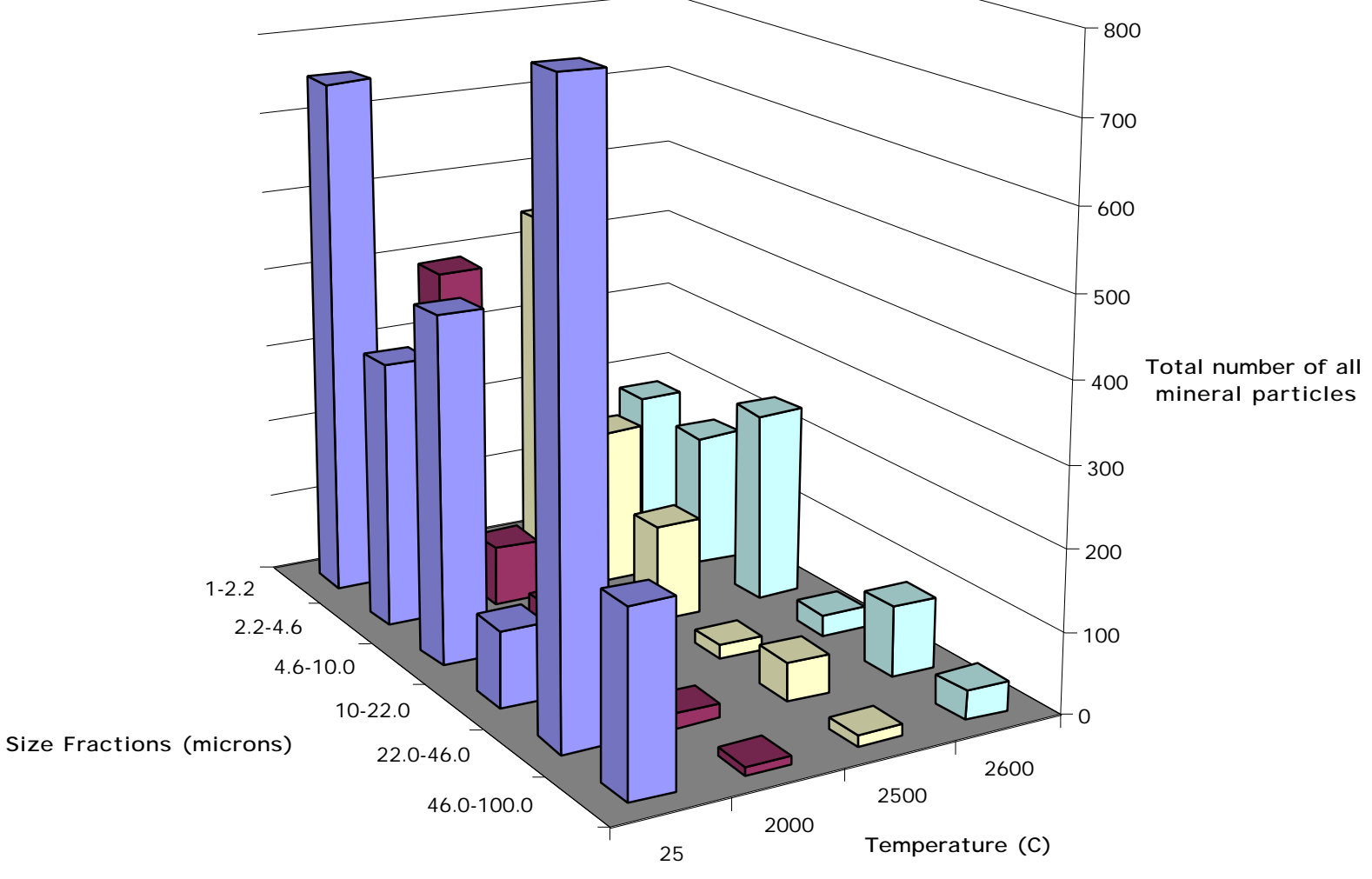

Figure 3.26 Total number of all inorganics in varying size fractions for Summit anthracite over all graphitization temperatures 


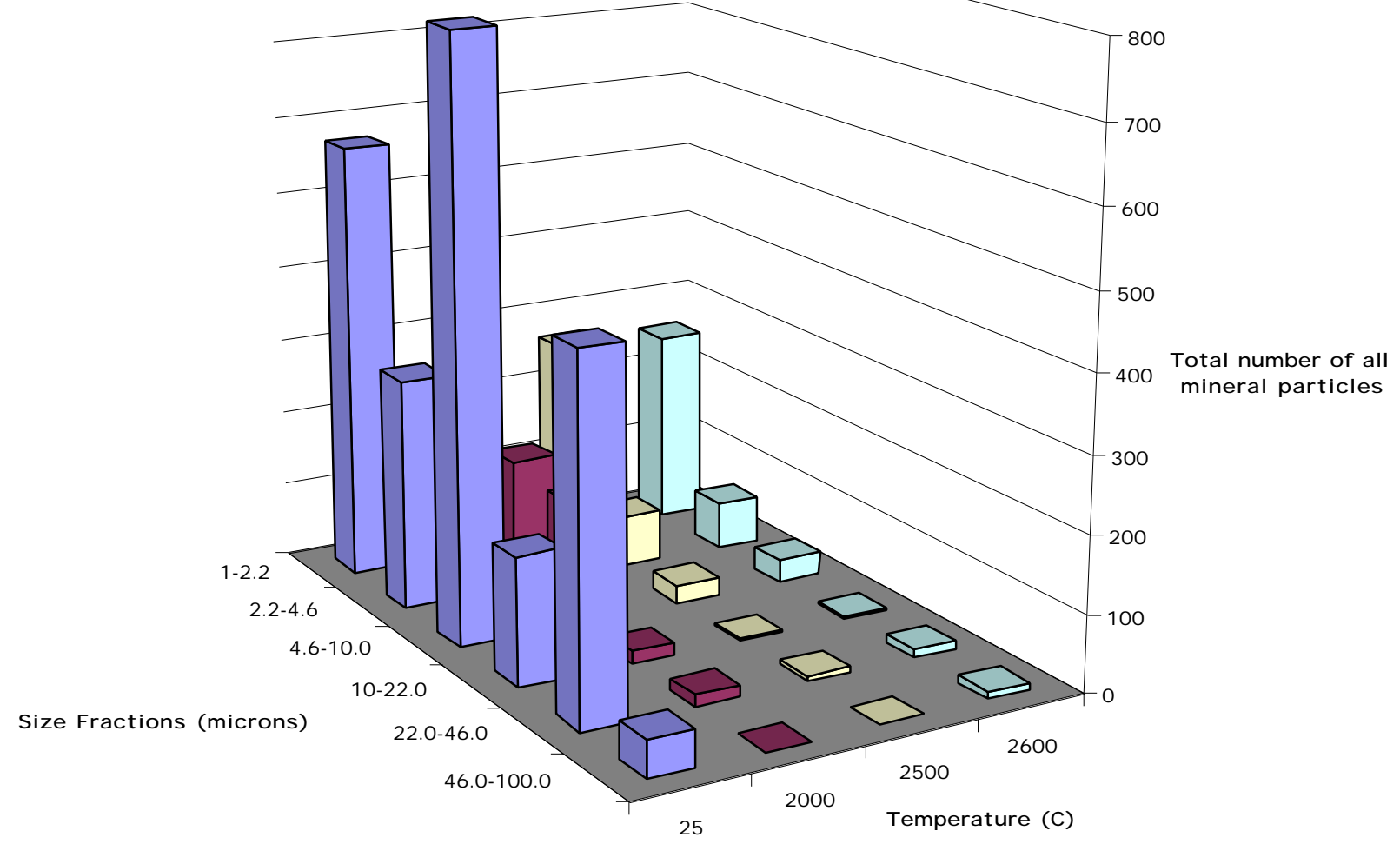

Figure 3.27 Total number of all inorganics in varying size fractions for LCNN anthracite over all graphitization temperatures 


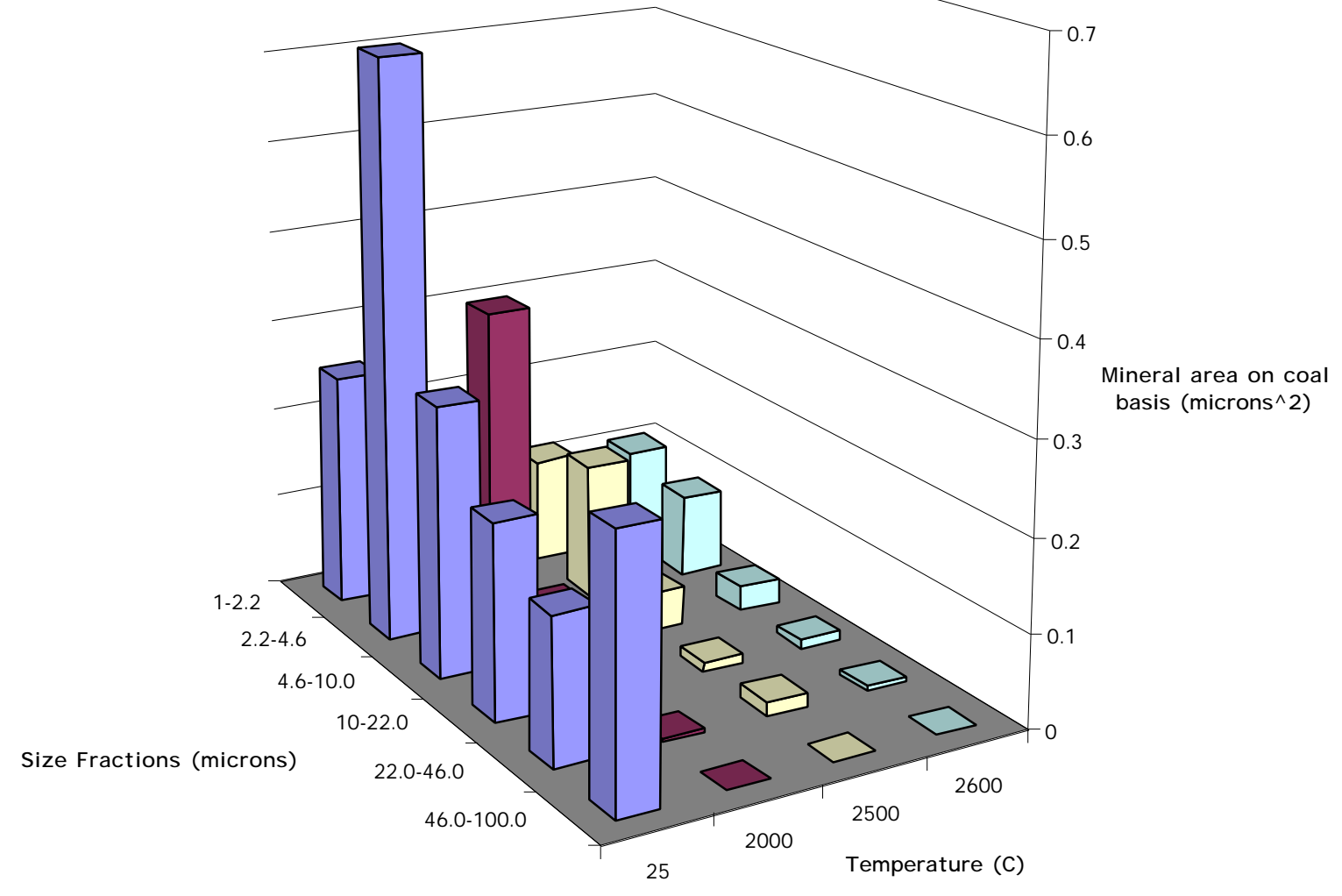

Figure 3.28 Inorganic area on a mineral basis of all inorganics in varying size fractions for UAE anthracite over all graphitization temperatures 


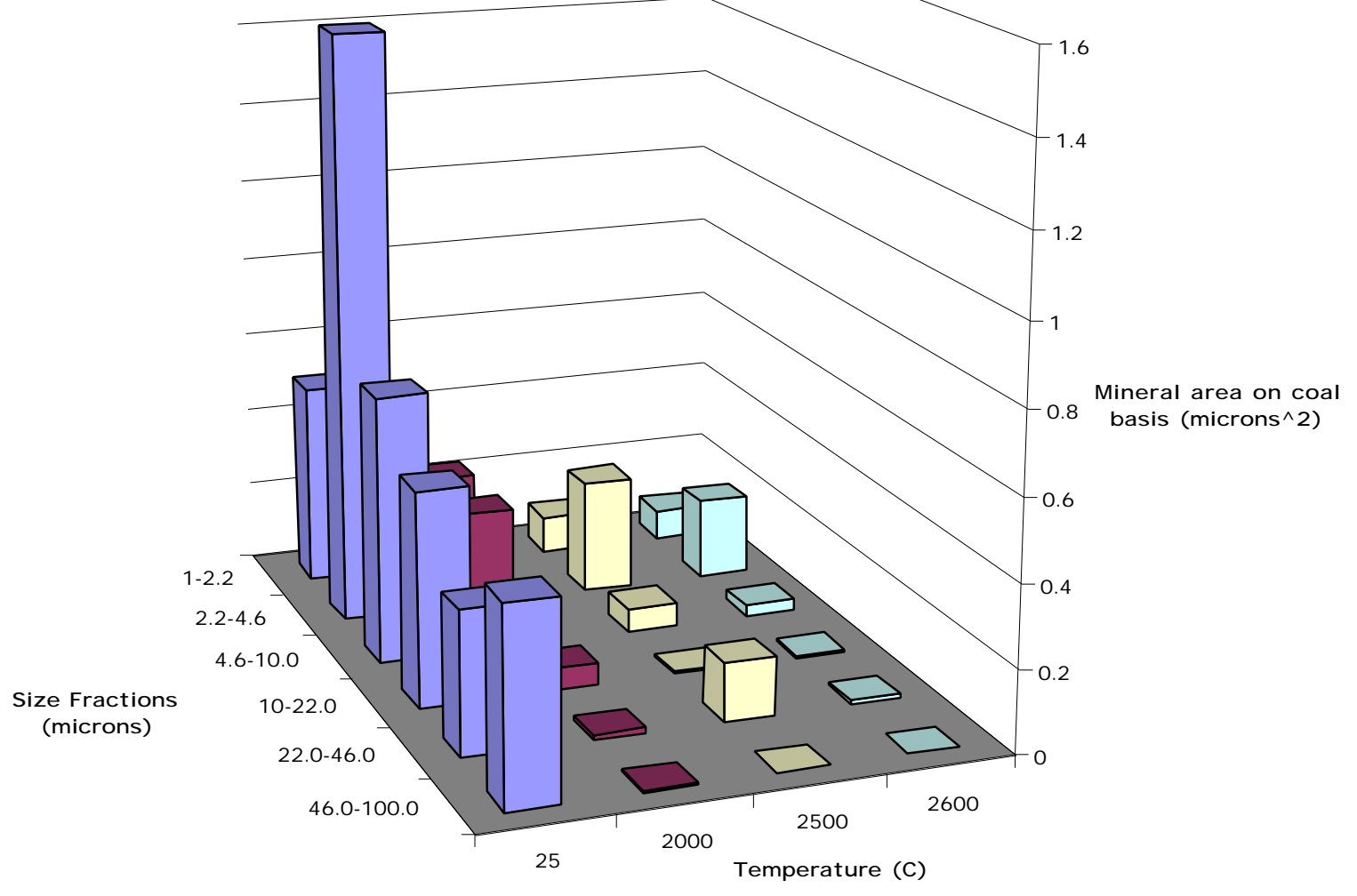

Figure 3.29 Inorganic area on a mineral basis of all inorganics in varying size fractions for Jeddo anthracite over all graphitization temperatures 


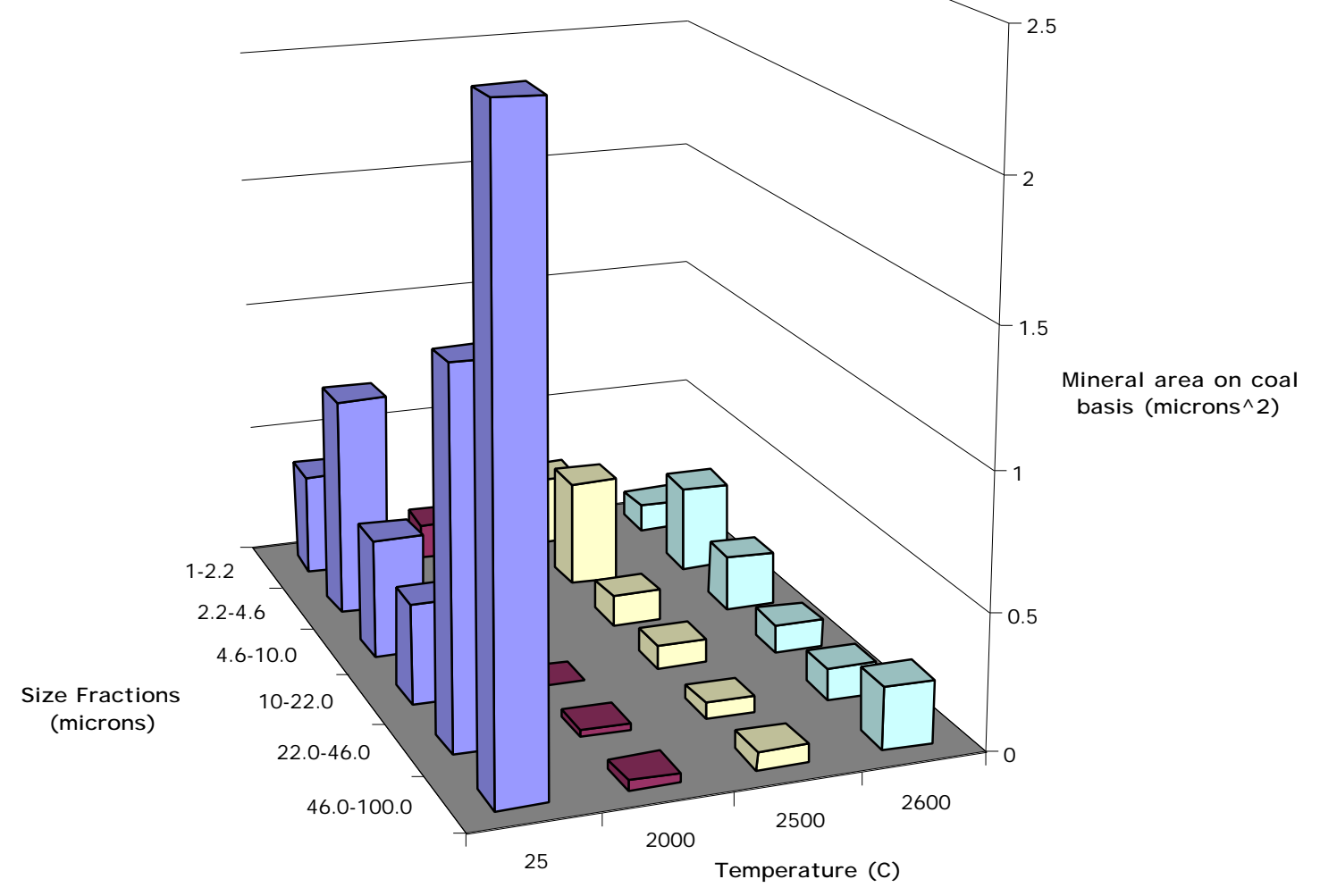

Figure 3.30 Inorganic area on a mineral basis of all inorganics in varying size fractions for Summit anthracite over all graphitization temperatures 


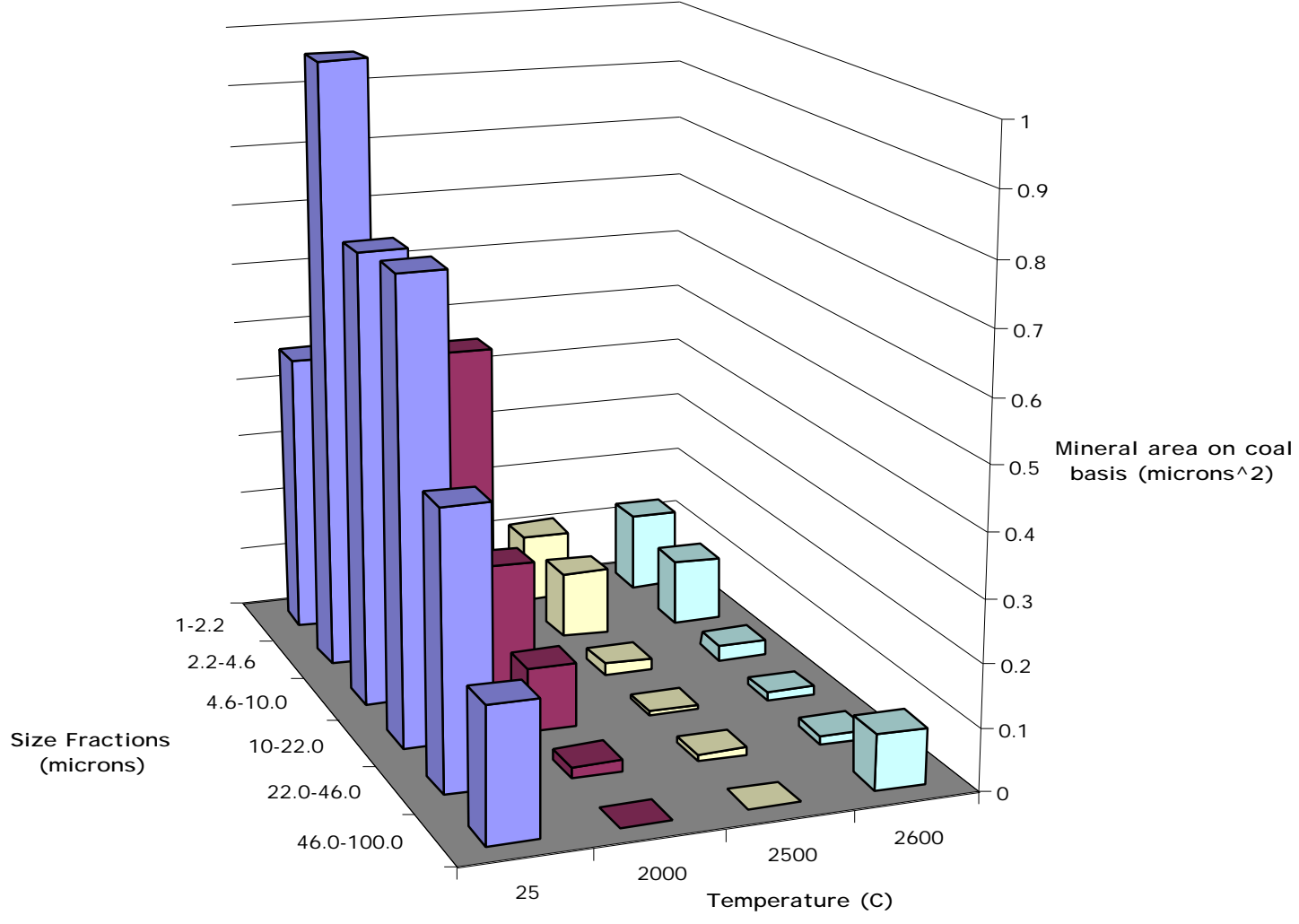

Figure 3.31 Inorganic area on a mineral basis of all inorganics in varying size fractions for LCNN anthracite over all graphitization temperatures 
$2600^{\circ} \mathrm{C}$ Jeddo sample, $94.6 \%$ exists in the same size range. In both the UAE and Jeddo anthracites, no mineral weight is seen in the 46 to 400 micron size fraction. Interestingly, in the Summit and LCNN samples, the weight percentage in the largest size range initially decreases (to zero in the case of $\mathrm{LCNN}$ ) and then increases from $2500^{\circ} \mathrm{C}$ to $2600^{\circ} \mathrm{C}$. Unlike the UAE and Jeddo samples, where over $90 \%$ of the weight distribution was contained in particles smaller than ten microns, the Summit and LCNN have 58.5\% and $69.2 \%$ in the same size range, respectively. In the largest size fraction, the Summit sample has $21.3 \%$ of its mineral weight, and the LCNN has $23.8 \%$. Graphitization in anthracite proceeds rapidly once a certain temperature has been reached. Figures 3.18 and 3.19, which show the d-spacing and $\mathrm{L}_{\mathrm{c}}$ changes for the anthracites, clearly illustrate that the graphitization jump for the Summit and LCNN samples is between $2500^{\circ} \mathrm{C}$ and $2600^{\circ} \mathrm{C}$. In Figures 3.26 and 3.27 , a reasonable explanation for the appearance of large particles after $2500^{\circ} \mathrm{C}$ is that a certain inorganic, or inorganics, underwent a phase transition, and then agglomerated into a larger particle upon cooling. It should be noted that Figures 3.20 to 3.23 represent the relative mineral weights in varying size fractions, so an alternative explanation may be that the large particles were always present, but the amount of smaller particles decreased, thus increasing the relative mineral weight of the large particles. This is not the case, though, as can be determined by examining Figures 3.26 and 3.27, which show how the number of particles contained in size ranges changes with temperature. All the samples show a decrease in the total number of inorganic particles, but the change in the distribution of particles is not the same for all the anthracites. The UAE and Jeddo sample both lose their largest particles at $2000^{\circ} \mathrm{C}$, and they do not re-appear at the higher temperatures. In fact, at $2600^{\circ} \mathrm{C}$, the UAE sample contains only $6.7 \%$ of its mineral weight in particles greater 
than ten microns, while the Jeddo sample has $5.4 \%$ mineral weight in this range. On the other hand, the Summit sample shows a decrease in the number of largest minerals from 25 to $2000^{\circ} \mathrm{C}$, but than an increase from 2500 to $2600^{\circ} \mathrm{C}$. The LCNN anthracite also follows this pattern, though the number of large inorganics actually decreases to zero at 2000 and $2500^{\circ} \mathrm{C}$, and then increases at $2600^{\circ} \mathrm{C}$. In both the Summit and LCNN anthracites at $2600^{\circ} \mathrm{C}$, the largest percentage of mineral particles is present in the less than ten micron size range, but the greatest mineral weight percent comes from the larger particles. So, Figures 3.26 and 3.27 clearly show that the reason for the increase in relative mineral weight percent of the large particles from 2500 to $2600^{\circ} \mathrm{C}$ is due to an increased number of large particles, and not a reduction in smaller particles.

The mineral areas of the four anthracites also support the observation that the UAE and Jeddo samples behave similarly, while Summit and LCNN are comparable to one another. In the raw UAE and Jeddo samples, Figures 3.28 and 3.29, the mineral area distribution is almost identical, even though the actual areas for the size fractions differ. With increasing temperature, the two coals show a trend toward the majority of their inorganic area being present in particles less than ten microns. At room temperature, the LCNN and Summit samples are different in that the majority of inorganic area for the Summit sample is contained in particles greater than 22 microns, while the LCNN anthracite has most of its inorganic area in particles less than 22 microns. Also, the un-heated Summit anthracite has a greater mineral area on an absolute scale, with a total of 5.769 microns $^{2}$, compared to 3.579 microns $^{2}$ for the LCNN sample. However, upon heat treatment to $2600^{\circ} \mathrm{C}$, the distribution of mineral area based on size fraction become 
more alike. Both show a bi-modal curve, in that the area is contained in the smallest and largest size fractions, but little is observed in the intermediate ranges.

The data shown in Figures 3.20 to 3.31 all point to the possibility that the minerals in the anthracites are undergoing transitions throughout the heating regime. In the case of the LCNN and Summit coals, this transition involves the increase in number, relative weight percent, and area of large particles from 2500 to $2600^{\circ} \mathrm{C}$. The only way the number of mineral particles could increase would be through the agglomeration of smaller particles. The columns in Figures 3.26 and 3.27 also support the probability of this occurring, because in all the samples the number of inorganics decreases with increasing temperature. Assuming the smaller particles melt or vaporize, they would be free to move throughout the carbon matrix. Evidence from the vaporgrown carbon fiber literature shows that carbon can translate through, or travel around the surface of, a liquid metal droplet [17]. Oberlin [14-16] has also witnessed the formation of graphitic shells in anthracite formed by the interaction of carbon with a liquid inorganic droplet. This being the case, the chance of inorganic droplets meeting and condensing into larger particles as they traverse the coal is not unreasonable. Franklin hypothesized that anthracite was readily graphitizable because once a certain temperature was reached the fragments holding the crystallites in place were absorbed into the crystallite itself, thus reducing porosity and increasing both $L_{c}$ and $L_{a}$. It has been shown that the rapid graphitization jump discussed by Franklin occurs after $2500^{\circ} \mathrm{C}$ in these four anthracites, with the jump being more pronounced in the LCNN and Summit samples. It has also been shown that this temperature range from 2500 to $2600^{\circ} \mathrm{C}$ is also accompanied by the reappearance of large inorganic particles in the LCNN and Summit anthracites. Therefore, it is conceivable that in this temperature range the absorbing of 
cross-links, suggested by Franklin, is accomplished by the catalytic graphitization of these fragments by either the inorganic liquid droplets or vapors traveling through the carbon matrix.

The appearance of large inorganic particles after heating beyond $2500^{\circ} \mathrm{C}$ provides evidence that a mineral decomposition, or transition, has taken place, which presumably catalyzes graphitization by attacking carbon or other fragments that link neighboring graphene layers. The next step in the work is that the inorganics that undergo this transition, and are responsible for the graphitization, must be determined. As stated in reference [17], the catalytic graphitization of carbon has been observed in the presence of both carbide and non-carbide forming metals. Other work predicts that the silica present in quartz dissociates from the oxygen and catalyzes graphitization [18]. In the graphite industry today, iron oxide is used to enhance graphitization, and anecdotal evidence claims that other elements, such as calcium and chlorine, can catalyze graphitization. Based on the information available in the literature, and gathered via conversations with graphite plant engineers, it appears that calcium, silica, and chlorine can behave as graphitization catalysts. Comparing this suite of possible catalysts with the inorganics present in at least five relative weight percent (on a mineral basis) in the $2600^{\circ} \mathrm{C}$ samples produces some interesting results. The reason for choosing five weight percent was that an initial scan of the data showed only a few inorganics were present in large concentrations, and that the remaining weight percents were scattered over the rest of the thirty-three minerals. Selecting a concentration of five relative weight percent as the initial criterion for reducing the entire suite of inorganics down to possible catalytic ones showed that three anthracites had exactly the same inorganics in this weight range. The LCNN, Jeddo, and UAE anthracites all had rutile, calcite, "Ca-rich," and "unknown" as their four most prominent inorganics. In fact, 
the LCNN anthracite had only 5.3 weight percent contained in inorganics other than these four, while the Jeddo and UAE had $8.4 \%$ and $6.3 \%$, respectively. The Summit sample's four most prominent inorganics were quartz, rutile, Fe-silicates, and "unknown;" the weight percentage not contained within these four was 4.9. The increased presence of unknown mineral phases in all the samples supports the idea of mobile inorganics traveling through the carbon matrix and agglomerating into distinct particles. The LCNN and Summit samples both showed the presence of large particles at $2600^{\circ} \mathrm{C}$ even though there were, or no, such particles at $2500^{\circ} \mathrm{C}$. The only way the particles could form is by the condensation of several inorganics. If a mineral were to melt, and then condense into a particle, whether large or small, after mixing with another inorganic, the resulting inorganic species would not adhere to any of the classification criteria used by CCSEM. This idea is supported by the fact that in the raw anthracites the weight percentage of unknown, or unclassified, inorganics ranges from $8.1 \%$ to $13.4 \%$, but in the anthracites heat treated to $2600^{\circ} \mathrm{C}$, this range of values increases to $16.5 \%$ to $44.5 \%$. The elements comprising the unknown mineral phases can be determined; but the label "unknown" is used because the inorganic particle does not fit into any of the other thirty-two classifications. In this case the unknown phases were found to contain predominantly titanium and silicon

Identifying the major inorganic components left in the anthracites after having been heated to $2600^{\circ} \mathrm{C}$ shows that the most likely catalytic elements are titanium, calcium, and silica. Particles containing these three elements decrease in number and appear as either unknown inorganics, or as larger particles. They are the major inorganic components remaining in the anthracites heat treated to $2600^{\circ} \mathrm{C}$. As stated earlier, reports from the literature and comments from graphite manufacturers support the possibility that they have a catalytic effect. 
Chapter 4. INDUSTRIAL GRAPHITIZATION 
The LCNN anthracite was selected for industrial graphitization because it produced less ash than the Summit anthracite, even though they exhibited similar graphitizabilities. The graphite industry desires a low ash feedstock because the presence of mineral matter is typically correlated to the formation of a mechanically weak product, due to the escape of volatiles associated with the mineral matter. Carbone of America performed the industrial graphitization by mixing anthracite with varying amounts of coal-tar pitch binder. The exact percentages used are confidential. A standard sponge-coke billet was also produced in order to compare with the properties of the anthracite billets. Figures 4.1, 4.2, and 4.3 show values of some selected properties critical to the graphite industry. The anthracite billets are shown in blue and labeled p19-p22, and p24-p27. The standard sponge coke billets are shown in red and labeled p18 and p23. Based on the criteria used by Carbone, which were not reported, the anthracite billets fall into the "low-end" specialty graphite category and could possibly be used for large-scale applications. A second batch of anthracite billets was made in order to determine if the "low end" classification could be elevated to normal specialty graphite. The upgrading procedure involved the same LCNN anthracite but combined with the coal-tar pitch by a different proprietary method. The second batch of billets showed improvements in all the properties tested, and may lead to a commercial product. 
Thermal Expansion of Billets in "a" Direction

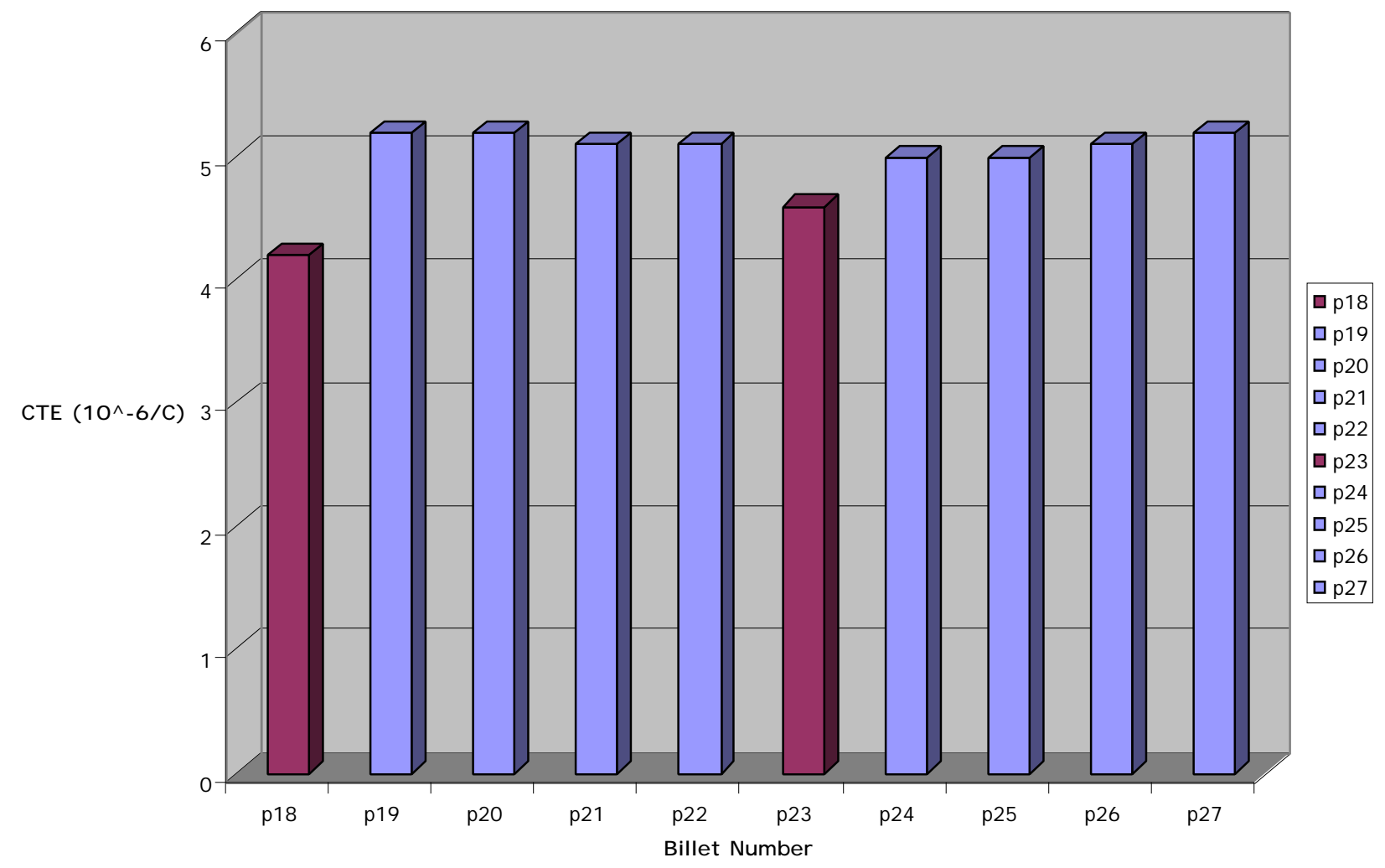

Figure 4.1 Thermal expansion of anthracite versus sponge coke billets 


\section{Ash Levels in Billets}

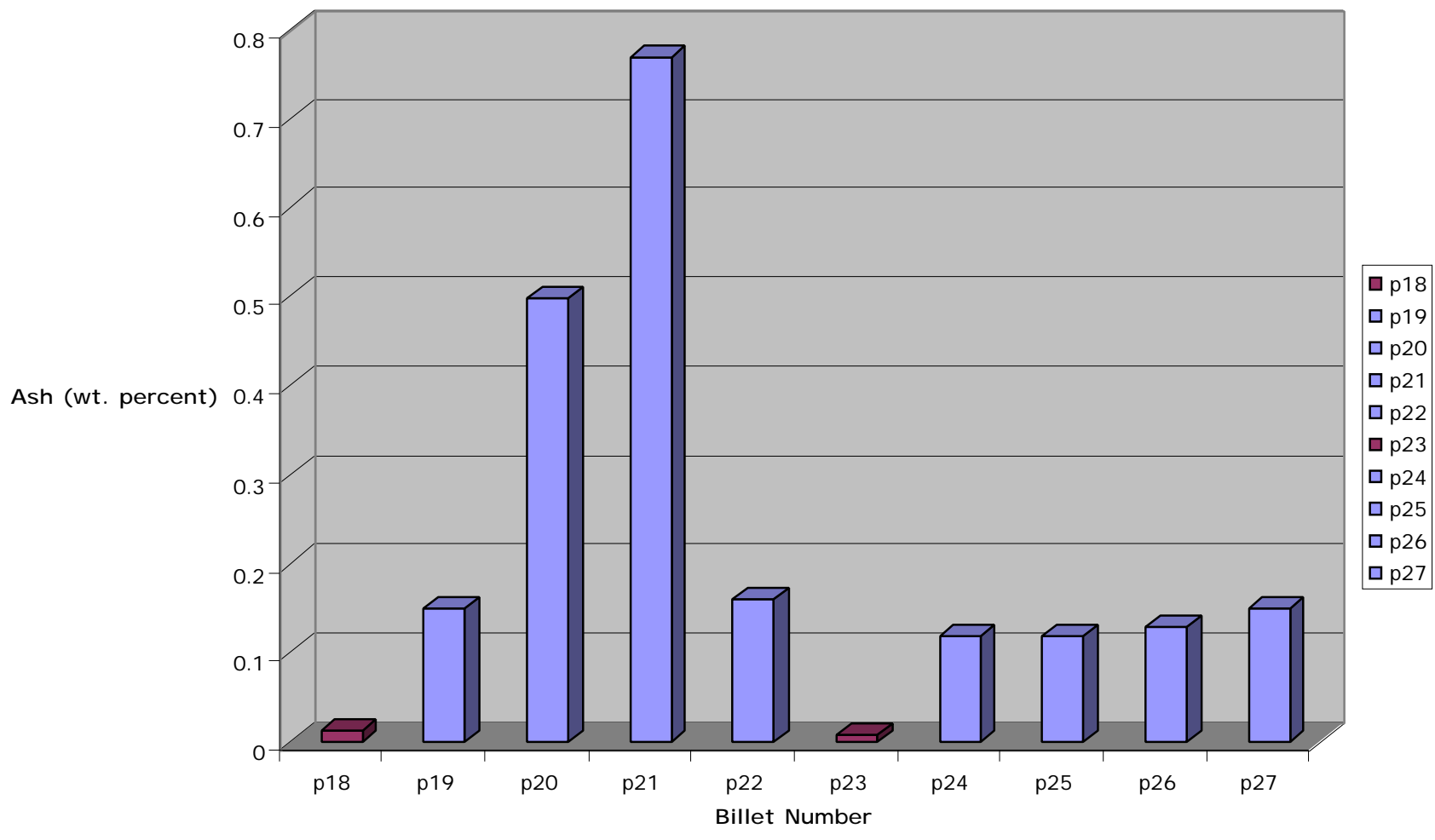

Figure 4.2 Ash levels in anthracite versus sponge coke billets 
Flexural Strength in "a" Direction

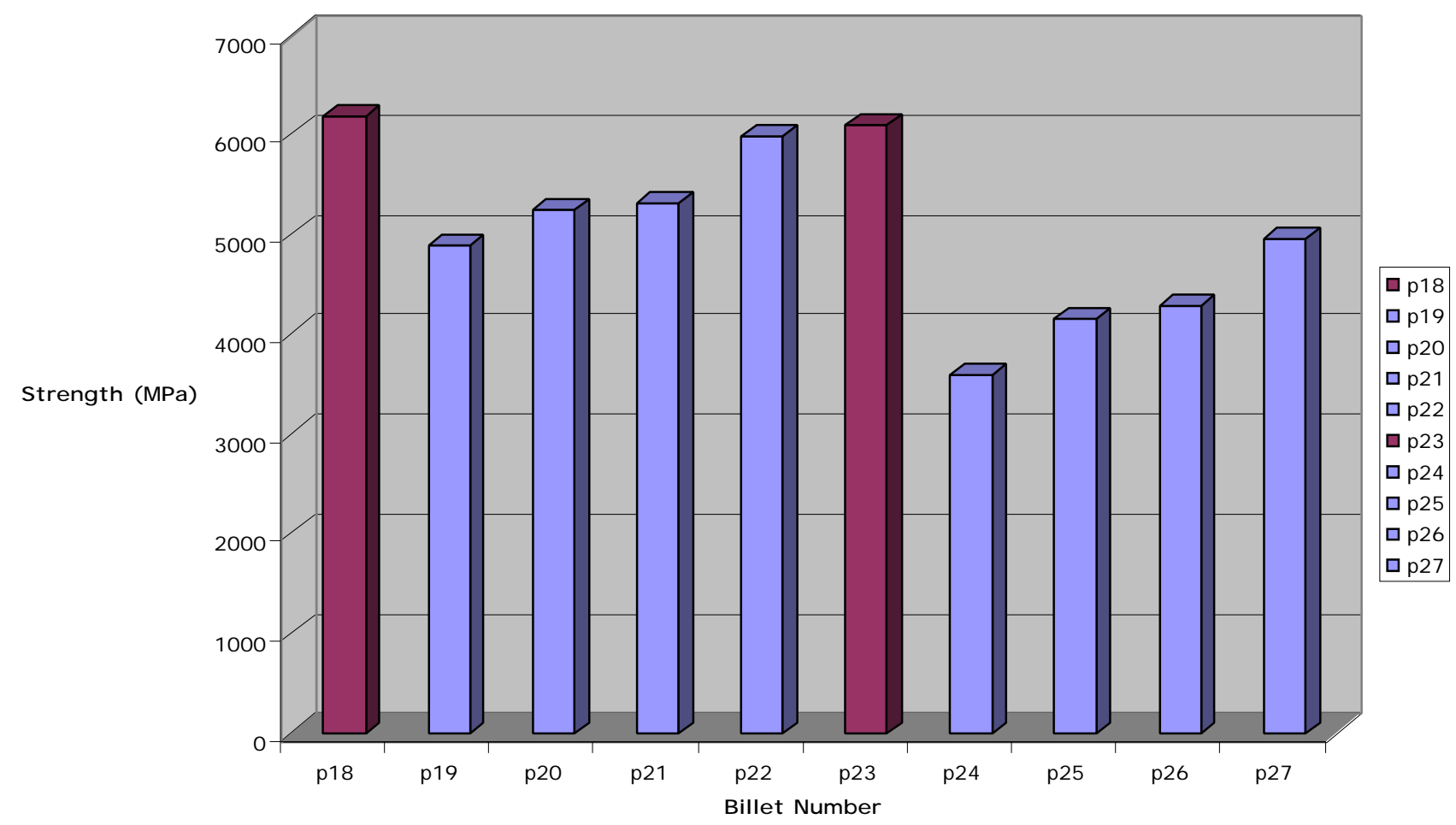

Figure 4.3 Flexural strength of anthracite versus sponge coke billet 


\section{Chapter 5. CONCLUSIONS}

The four anthracites selected for this project exhibited different levels of graphitizability, as measured by graphitic crystal development. The reason for these differences was due to the varied inorganic compositions of the anthracites, and the extent of catalytic graphitization that occurred due to the presence of certain inorganics. The LCNN and Summit samples were the best graphitizing anthracites, and also were the only two to show the presence of large inorganic particles in the $2600^{\circ} \mathrm{C}$ samples, even though there were fewer particles at lower temperatures. Presumably, the inorganic particles underwent a phase transition from 2500 to $2600^{\circ} \mathrm{C}$, and then agglomerated into both large and small, particles. This idea is also supported by the fact the percentage of "unknown" inorganics increased from the raw state to the $2600^{\circ} \mathrm{C}$ samples. If an inorganic particle were to melt and combine with other inorganic droplets, the resulting particle would not adhere to any of the classification systems used by the CCSEM. The percentage increase of unknowns is drastic especially for the LCNN anthracite, which originally had $8.1 \%$ at $25^{\circ} \mathrm{C}$, but $42 \%$ at $2600^{\circ} \mathrm{C}$. The mobile inorganics were able to travel through the carbon matrix of the coals and attack any non-graphitic carbon, or fragments linking crystallites together. Once these fragments had been removed, or absorbed into the graphene layer of a crystallite, the crystallites were then able to align edge to edge and condense into even large units. The most likely inorganics responsible for this catalytic graphitization were titanium, silica, and calcium because they were present in the highest concentration of the $2600^{\circ} \mathrm{C}$ samples. 
The LCNN anthracite was selected for industrial graphitization because it was highly graphitizable and produced less ash than the Summit sample. It was surmised that a highly graphitizable anthracite would make an adequate filler for the production of specialty graphite. Carbone of America produces specialty graphite and agreed to test anthracite based billets against their standard sponge coke billet. Based on their own internal criteria, the LCNN based billet fell into the "low end" specialty graphite category, better than any other coal-based product they had made before. A second round of testing showed that the properties of the anthracite billet improved to the point that addition of LCNN anthracite to their raw materials suite was a possibility. 


\section{REFERENCES}

1. Bain, G., The Graphite Deposits of Lousia, Quebec. Economic Geology, 1929. XXIV : p. 733-752.

2. Pallister, H. and J. Thoenen, Final, Flake-Graphite And Vanadium Investigation In Clay, Coosa, And Chilton Counties, Ala., . 1948, United States Department Of The Interior, Bureau Of Mines . p. 81.

3. Frank, J., personal communication, Chairman/CEO Centralia Coal Sales Company, . 1998 .

4. Glick, D. and A. Davis, Operation and composition of the Penn State Coal Sample Bank and Data Base. Org. Geochem., 1991. 17 (4): p. 421-430.

5. D346-90, A., Annual Book Of ASTM standards. Vol. 5.05 Coal and Coke. 1993.

6. D5142-90, A., Annual Book Of ASTM Standards. Vol. 5.05 Coal and Coke. 1993.

7. D5373-93, A., Annual Book Of ASTM Standards. Vol. 5.05 Coal and Coke. 1993.

8. D3175-89a, A., Annual Book Of ASTM Standards. Vol. 5.05 Coal and Coke. 1993.

9. Cullity, B.D. and S.R. Stock, Elements of X-ray Diffraction, third edition. 2001, New Jersey: Prentice Hall.

10. Franklin, R., The Interpretation of Diffuse X-ray Diagrams of Carbon. Acta Crystal, 1950.3 : p. 107-120.

11. Franklin, R., The Structure of Graphitic Carbons. Acta Crystal, 1951. 4 : p. 253260. 
12. Franklin, R.E., Crystallite growth in the graphitizing and non-graphitizing carbons. Proceedings of the Royal Society of London, Series A, 1951. 209 : p. 196-218.

13. Evans, E., J. Jenkins, and J. Thomas, Direct Electron Microscopic Studies Of Graphitic Regions In Heat-Treated Coals and Coal Extracts. Carbon, 1972. 10 : p. 637-642.

14. Oberlin, A. and G. Terriere, Graphitization Studies Of Anthracites By High Resolution Electron Microscopy. Carbon, 1975. 13 : p. 367-376.

15. Oberlin, A., Application Of Dark Field-Field Electron Microscopy To Carbon Study. Carbon, 1979.17 : p. 7.

16. Oberlin, A., Carbonization and Graphitization. Carbon, 1984. 22 (6): p. 521-541.

17. Baker, R.T.K., Catalytic Growth of Carbon Filaments. Carbon, 1989. 27 (3): p. $315-323$.

18. Brusset, H., La graphitization. Bulletin de la Societe Chimique de France, 1948. 16 : p. D49-52. 


\section{APPENDIX 1. CCSEM output for LCNN anthracite}

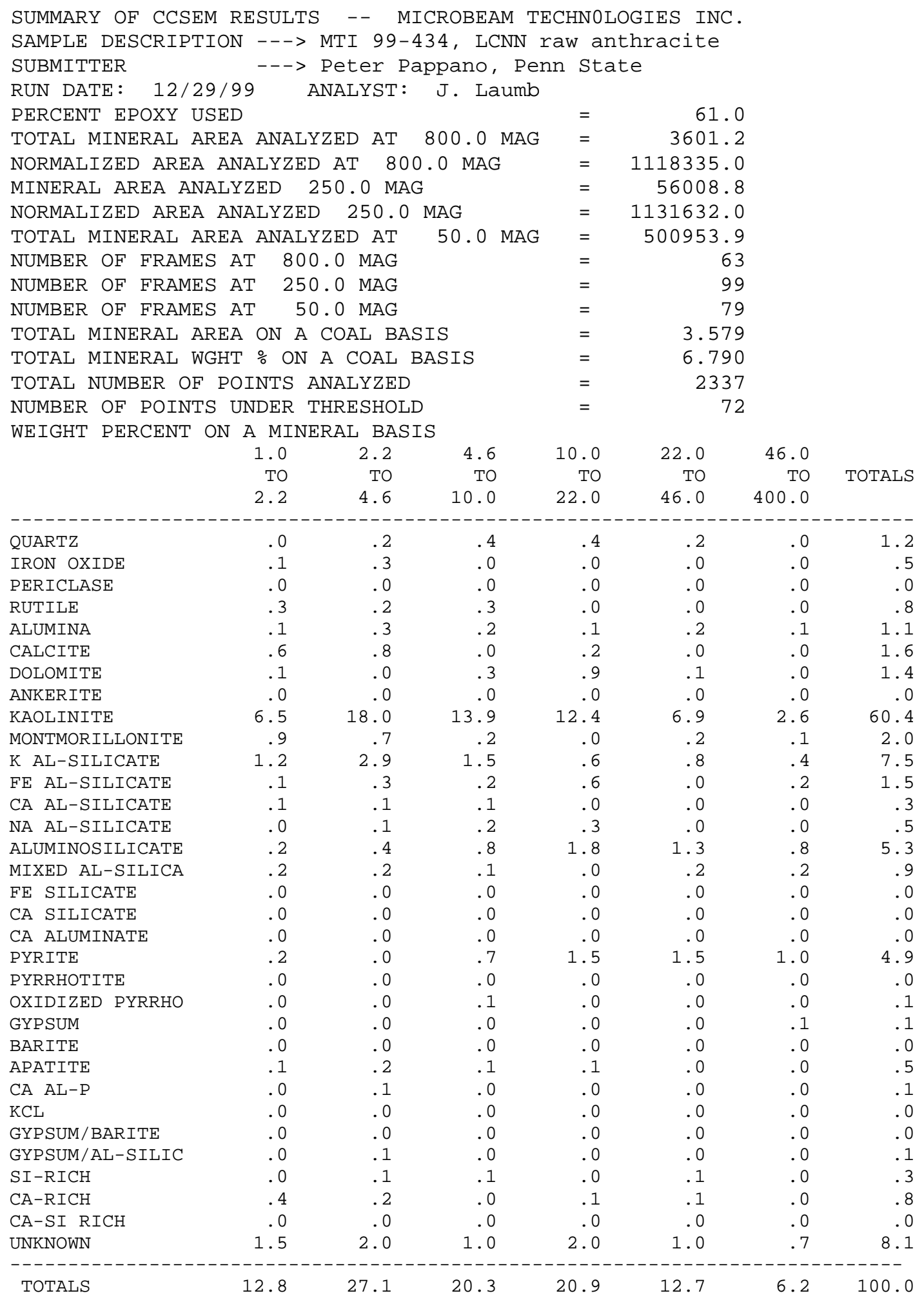


PAGE 1 MTI 99-434, LCNN raw anthracite

\begin{tabular}{|c|c|c|c|c|c|c|c|}
\hline A IN EACH SI & $\begin{array}{r}\text { RANGE } \\
1.0 \\
\text { TO } \\
2.2\end{array}$ & $\begin{array}{r}2.2 \\
\text { TO } \\
4.6\end{array}$ & $\begin{array}{r}4.6 \\
\text { TO } \\
10.0\end{array}$ & $\begin{array}{r}10.0 \\
\text { TO } \\
22.0\end{array}$ & $\begin{array}{r}22.0 \\
\text { TO } \\
46.0\end{array}$ & $\begin{array}{r}46.0 \\
\text { TO } \\
400.0\end{array}$ & TOTALS \\
\hline QUARTZ & 3.1 & 19.8 & 555.1 & 540.2 & 5158.3 & .0 & 6276.5 \\
\hline IRON OXIDE & 2.6 & 15.1 & 27.4 & .0 & 572.0 & .0 & 617.1 \\
\hline PERICLASE & .0 & .0 & .0 & .0 & .0 & .0 & .0 \\
\hline RUTILE & 13.0 & 12.1 & 200.9 & .0 & .0 & .0 & 226.1 \\
\hline ALUMINA & 5.2 & 21.0 & 184.9 & 103.9 & 4636.8 & 2521.3 & 7473.1 \\
\hline CALCITE & 48.0 & 67.3 & 60.0 & 216.8 & 868.5 & .0 & 1260.6 \\
\hline DOLOMITE & 5.0 & .0 & 398.8 & 1197.3 & 2660.1 & .0 & 4261.2 \\
\hline ANKERITE & .0 & .0 & 53.8 & .0 & .0 & .0 & 53.8 \\
\hline KAOLINITE & 601.2 & 656.8 & 19671.4 & 17484.7 & 197747.9 & 74100.3 & 311262.5 \\
\hline MONTMORILLONITE & 86.9 & 68.1 & 322.1 & .0 & 4601.0 & 2048.2 & 26.3 \\
\hline K AL-SILICATE & 117.0 & 272.0 & 2169.2 & 934.0 & 22702.4 & 10939.0 & 33.6 \\
\hline FE AL-SILICATE & 5.7 & 25.3 & 332.7 & 796.2 & 982.0 & 6209.7 & 1.7 \\
\hline CA AL-SILICATE & 12.1 & 4.8 & 190.5 & .0 & .0 & .0 & 7.4 \\
\hline NA AL-SILICATE & 1.9 & 6.6 & 251.0 & 364.0 & 811.7 & .0 & 35.1 \\
\hline ALUMINOSILICATE & 19.8 & 36.3 & 1068.3 & 2565.6 & 36938.7 & 23034.7 & 63.4 \\
\hline MIXED AL-SILICA & 19.5 & 19.8 & 119.4 & .0 & 4994.3 & 5986.8 & 11139.8 \\
\hline FE SILICATE & .0 & .0 & .0 & .0 & .0 & .0 & .0 \\
\hline CA SILICATE & 1.5 & .0 & .0 & .0 & .0 & .0 & 1.5 \\
\hline CA ALUMINATE & 3.0 & .0 & .0 & .0 & .0 & .0 & 3.0 \\
\hline PYRITE & 11.2 & .0 & 545.0 & 1085.2 & 22786.5 & 14900.8 & 39328.8 \\
\hline PYRRHOTITE & .0 & .0 & .0 & .0 & 725.5 & .0 & 725.5 \\
\hline OXIDIZED PYRRHO & 2.3 & .0 & 40.2 & .0 & .0 & .0 & 42.5 \\
\hline GYPSUM & 3.3 & .0 & .0 & .0 & 441.6 & 2744.2 & 3189.1 \\
\hline BARITE & .0 & .0 & .0 & .0 & .0 & .0 & .0 \\
\hline APATITE & 9.1 & 12.5 & 138.9 & 82.6 & .0 & .0 & 243.0 \\
\hline CA AL-P & .0 & 6.0 & .0 & .0 & .0 & .0 & 6.0 \\
\hline $\mathrm{KCL}$ & .0 & .0 & .0 & .0 & .0 & .0 & .0 \\
\hline GYPSUM/BARITE & .0 & .0 & .0 & .0 & .0 & .0 & .0 \\
\hline GYPSUM/AL-SILIC & .0 & 6.6 & .0 & .0 & .0 & .0 & 6.6 \\
\hline $\mathrm{SI}-\mathrm{RICH}$ & 3.1 & 9.7 & 71.4 & .0 & 2184.9 & .0 & 2269.1 \\
\hline $\mathrm{CA}-\mathrm{RICH}$ & 37.3 & 18.1 & 28.9 & 99.8 & 2634.9 & .0 & 2819.1 \\
\hline CA-SI RICH & .0 & .0 & .0 & .0 & .0 & .0 & .0 \\
\hline UNKNOWN & 135.3 & 176.2 & 1344.4 & 2763.9 & 27698.8 & 19323.1 & 51441.6 \\
\hline TOTALS & 1147.0 & 2454.2 & 27774.5 & 28234.3 & 339145.8 & 161808.1 & 560564.1 \\
\hline
\end{tabular}


PAGE 2 MTI 99-434, LCNN raw anthracite

\begin{tabular}{|c|c|c|c|c|c|c|c|}
\hline ORMALIZED AREA & $\begin{array}{r}\text { IN EACH } \\
1.0 \\
\text { TO } \\
2.2\end{array}$ & $\begin{array}{rr}\text { SIZE } & \text { RANGE } \\
2.2 \\
\text { TO } \\
4.6\end{array}$ & $\begin{array}{r}4.6 \\
\text { TO } \\
10.0\end{array}$ & $\begin{array}{r}10.0 \\
\text { TO } \\
22.0\end{array}$ & $\begin{array}{r}22.0 \\
\text { TO } \\
46.0\end{array}$ & $\begin{array}{r}46.0 \\
\text { TO } \\
400.0\end{array}$ & TOTALS \\
\hline QUARTZ & 972.0 & 6145.7 & 11216.5 & 14.1 & 5158.3 & .0 & 34406.7 \\
\hline IRON OXIDE & 798.1 & 4686.2 & 554.0 & .0 & 572.0 & .0 & 6610.3 \\
\hline PERICLASE & .0 & .0 & .0 & .0 & .0 & .0 & .0 \\
\hline RUTILE & 4043.3 & 3770.0 & 4059.9 & .0 & .0 & .0 & 11873.3 \\
\hline ALUMINA & 1621.1 & 6527.7 & 3735.6 & 2098.8 & 4636.8 & 2521.3 & 21141.3 \\
\hline CALCITE & 14893.9 & 20903.0 & 1211.9 & 4381.2 & 868.5 & .0 & 58.3 \\
\hline DOLOM & 1558.9 & .0 & 8057.4 & 24190.5 & 2660.1 & .0 & 66.9 \\
\hline $\mathrm{NK}$ & .0 & .0 & 1087.6 & .0 & .0 & .0 & 37.6 \\
\hline $\mathrm{AOI}$ & 186698.1 & 514509.1 & 397452.3 & 353270.0 & 197747.9 & 74100.31 & 8.0 \\
\hline LLONITE & 26999.0 & 21151.4 & 6507.3 & .0 & 4601.0 & 2048.2 & 6.9 \\
\hline K AL-SILICATE & 36318.5 & 84475.2 & 43827.7 & 18871.2 & 22702.4 & 10939.0 & 34.0 \\
\hline LICATE & 1776.3 & 7844.4 & 6722.9 & 16087.5 & 982.0 & 6209.7 & 2.8 \\
\hline CA AL-SILICATE & 3748.3 & 503.1 & 3849.6 & .0 & .0 & .0 & 0.9 \\
\hline A AL-SILICATE & 577.6 & 2049.6 & 5071.3 & 7353.8 & 811.7 & .0 & 64.1 \\
\hline ALUMINOSILICATE & 6148.8 & 11269.8 & 21584.9 & 51837.3 & 36938.7 & 23034.7 & 4.3 \\
\hline IIXED AL-SILICA & 6058.8 & 6151.9 & 2411.6 & .0 & 4994.3 & 5986.8 & 25603.4 \\
\hline $\mathrm{FE}$ & .0 & .0 & .0 & .0 & .0 & .0 & .0 \\
\hline CA SIL & 475.1 & .0 & .0 & .0 & .0 & .0 & 475.1 \\
\hline CA ALUM & 941.0 & .0 & .0 & .0 & .0 & .0 & 941.0 \\
\hline PYRITE & 3468.8 & .0 & 11012.5 & 21926.8 & 22786.5 & 14900.8 & 74095.4 \\
\hline PYRRHOTITE & .0 & .0 & .0 & .0 & 725.5 & .0 & 725.5 \\
\hline OXIDIZED PYRRHO & 698.7 & .0 & 812.2 & .0 & .0 & .0 & 1511.0 \\
\hline GYPSUM & 1015.5 & .0 & .0 & .0 & 441.6 & 2744.2 & 4201.3 \\
\hline BARITE & .0 & .0 & .0 & .0 & .0 & .0 & .0 \\
\hline APATITE & 2813.6 & 3885.0 & 2805.8 & 1668.9 & .0 & .0 & 73.2 \\
\hline $\mathrm{CA} \quad \mathrm{AL}-\mathrm{P}$ & .0 & 1875.7 & .0 & .0 & .0 & .0 & 1875.7 \\
\hline $\mathrm{KCL}$ & .0 & .0 & .0 & .0 & .0 & .0 & .0 \\
\hline GYPSUM/BARITE & .0 & .0 & .0 & .0 & .0 & .0 & .0 \\
\hline GYPSUM/AL-SILIC & .0 & 2043.4 & .0 & .0 & .0 & .0 & 2043.4 \\
\hline $\mathrm{SI}-\mathrm{RICH}$ & 975.1 & 2999.9 & 1442.8 & .0 & 2184.9 & .0 & 7602.7 \\
\hline $\mathrm{CA}-\mathrm{RICH}$ & 11592.7 & 5620.9 & 584.7 & 2017.2 & 2634.9 & .0 & 22450.5 \\
\hline $\mathrm{CA}-\mathrm{S}$ & .0 & .0 & .0 & .0 & .0 & .0 & .0 \\
\hline UNKNOWN & 42004.7 & 54724.7 & 27163.0 & 55843.1 & 27698.8 & 19323.1 & 226757.3 \\
\hline
\end{tabular}

TOTALS

$356198.1762136 .6 \quad 561171.5 \quad 570460.4 \quad 339145.8 \quad 161808.12750921 .0$ 


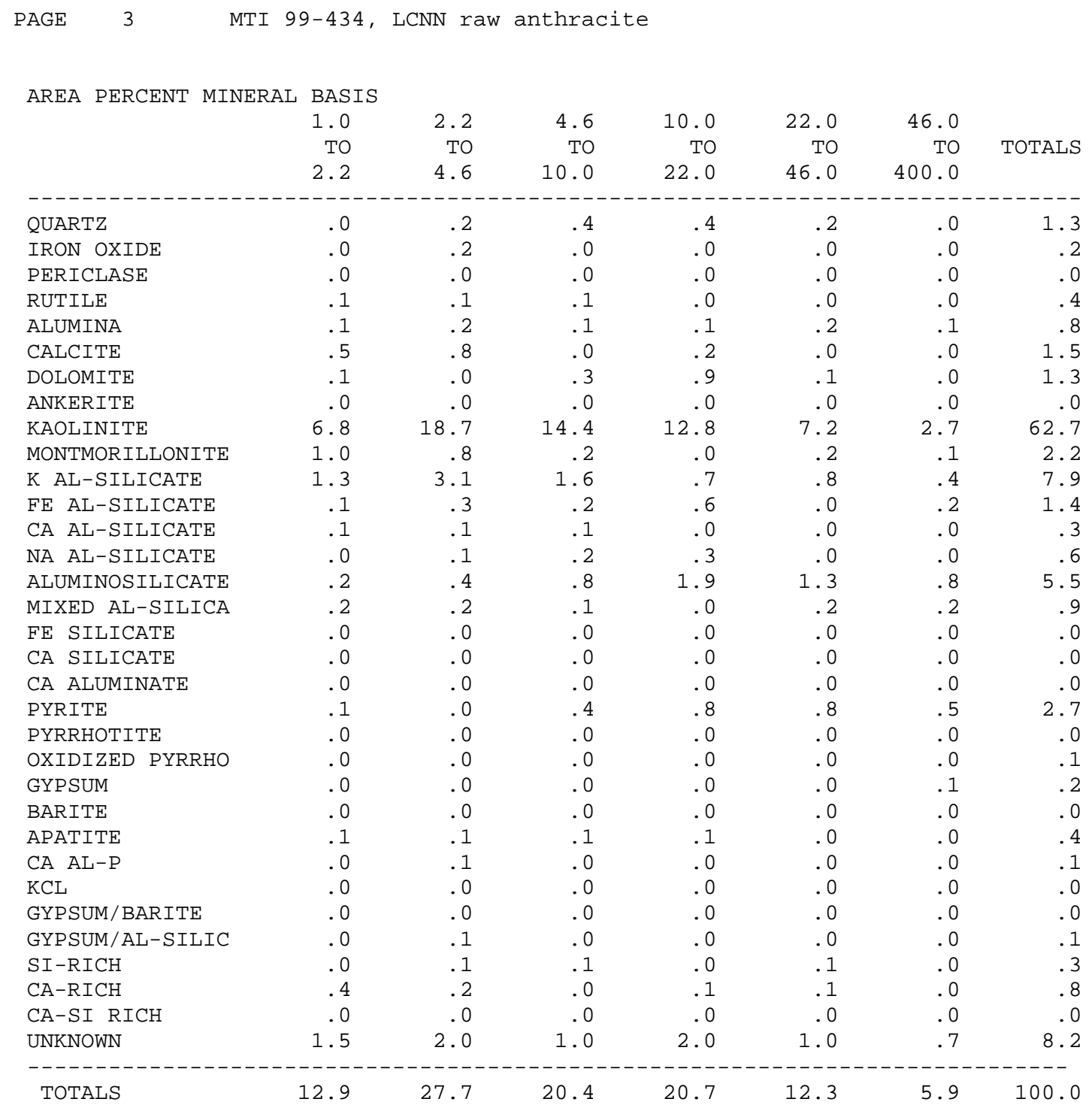


PAGE 4 MTI 99-434, LCNN raw anthracite

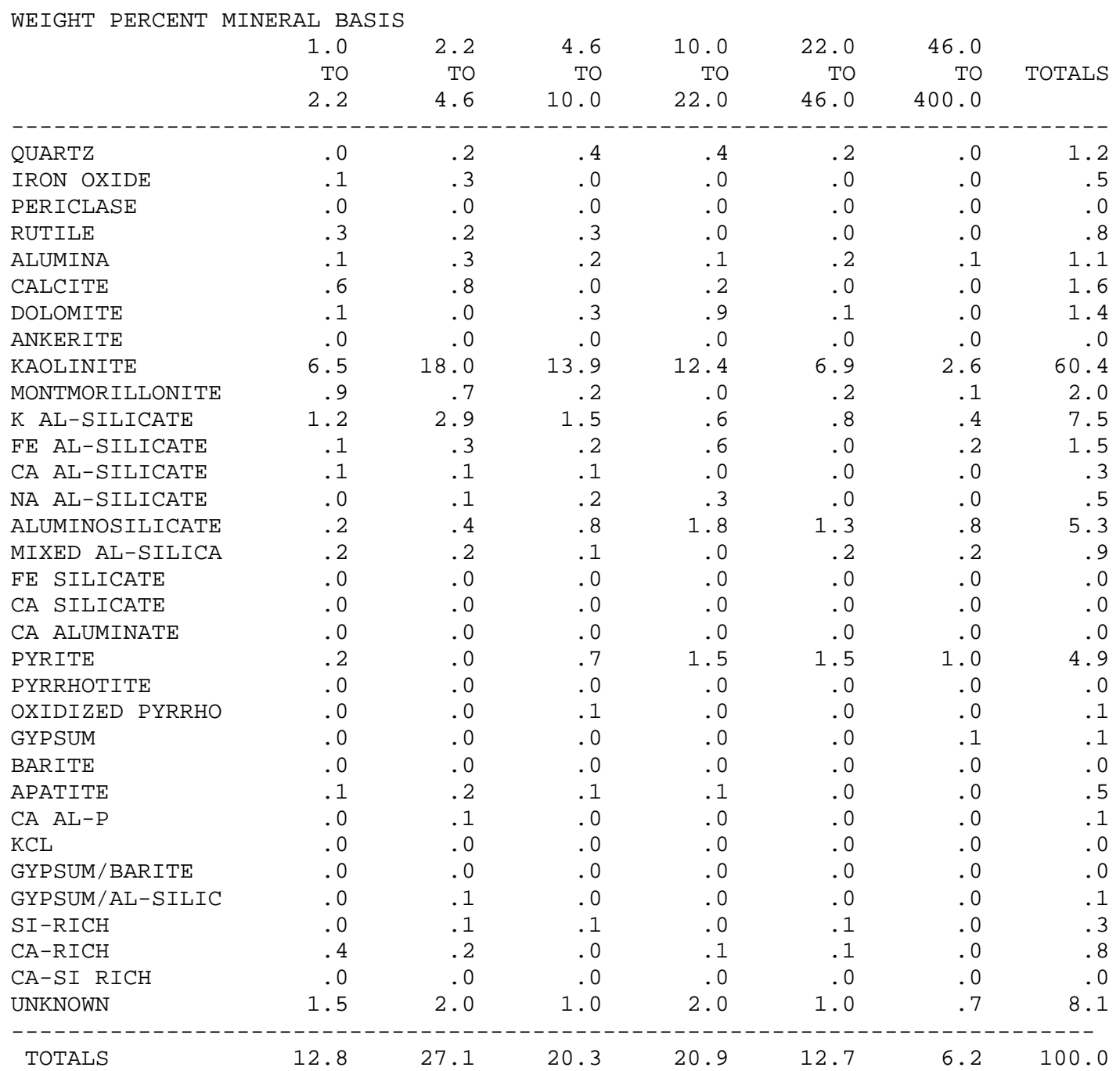




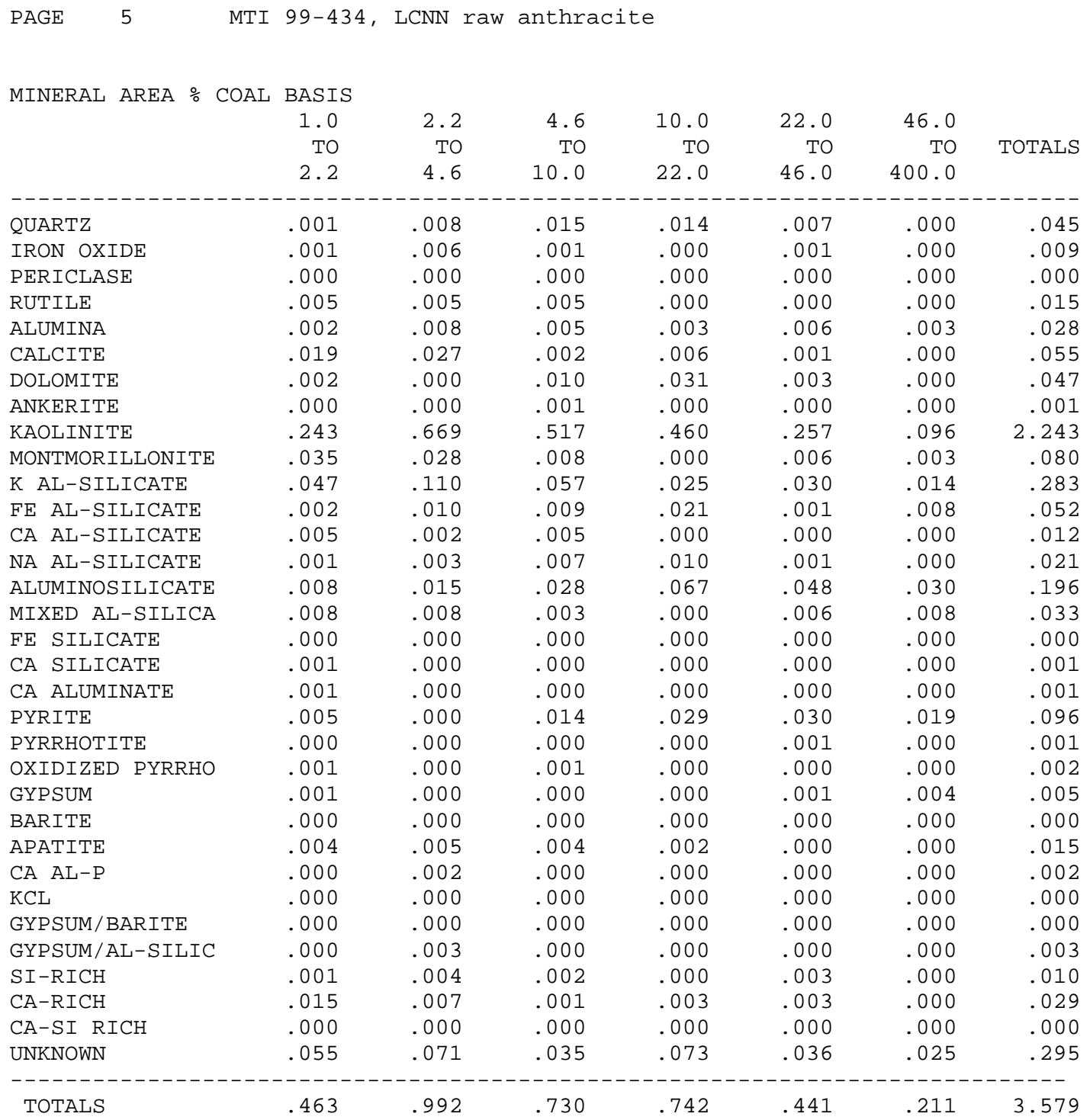


PAGE 6 MTI 99-434, LCNN raw anthracite

\begin{tabular}{|c|c|c|c|c|c|c|c|}
\hline & $\begin{array}{r}1.0 \\
\text { TO } \\
2.2\end{array}$ & $\begin{array}{r}2.2 \\
\text { TO } \\
4.6\end{array}$ & $\begin{array}{r}4.6 \\
\text { TO } \\
10.0\end{array}$ & $\begin{array}{r}10.0 \\
\text { TO } \\
22.0\end{array}$ & $\begin{array}{r}22.0 \\
\text { TO } \\
46.0\end{array}$ & $\begin{array}{r}46.0 \\
\text { TO } \\
400.0\end{array}$ & TOTALS \\
\hline QUARTZ & .002 & .015 & .027 & .026 & .012 & .000 & .082 \\
\hline IRON OXIDE & .004 & .022 & .003 & .000 & .003 & .000 & .031 \\
\hline PERICLASE & .000 & .000 & .000 & .000 & .000 & .000 & .000 \\
\hline RUTILE & .018 & .017 & .018 & .000 & .000 & .000 & .052 \\
\hline ALUMINA & .006 & .023 & .013 & .008 & .017 & .009 & .076 \\
\hline CALCITE & .037 & .053 & .003 & .011 & .002 & .000 & .106 \\
\hline DOLOMITE & .004 & .000 & .021 & .062 & .007 & .000 & .094 \\
\hline ANKERITE & .000 & .000 & .003 & .000 & .000 & .000 & .003 \\
\hline KAOLINITE & .444 & 1.225 & .946 & .841 & .471 & .176 & 4.104 \\
\hline MONTMORILLONITE & .061 & .048 & .015 & .000 & .010 & .005 & .138 \\
\hline K AL-SILICATE & .085 & .197 & .102 & .044 & .053 & .026 & .507 \\
\hline FE AL-SILICATE & .004 & .020 & .017 & .040 & .002 & .016 & .100 \\
\hline CA AL-SILICATE & .009 & .004 & .009 & .000 & .000 & .000 & .022 \\
\hline NA AL-SILICATE & .001 & .005 & .012 & .017 & .002 & .000 & .037 \\
\hline ALUMINOSILICATE & .015 & .027 & .051 & .123 & .088 & .055 & .359 \\
\hline MIXED AL-SILICA & .014 & .015 & .006 & .000 & .012 & .014 & .061 \\
\hline FE SILICATE & .000 & .000 & .000 & .000 & .000 & .000 & .000 \\
\hline CA SILICATE & .001 & .000 & .000 & .000 & .000 & .000 & .001 \\
\hline CA ALUMINATE & .002 & .000 & .000 & .000 & .000 & .000 & .002 \\
\hline PYRITE & .016 & .000 & .049 & .098 & .102 & .067 & .333 \\
\hline PYRRHOTITE & .000 & .000 & .000 & .000 & .003 & .000 & .003 \\
\hline OXIDIZED PYRRHO & .003 & .000 & .004 & .000 & .000 & .000 & .007 \\
\hline GYPSUM & .002 & .000 & .000 & .000 & .001 & .006 & .009 \\
\hline BARITE & .000 & .000 & .000 & .000 & .000 & .000 & .000 \\
\hline APATITE & .008 & .011 & .008 & .005 & .000 & .000 & .032 \\
\hline $\mathrm{CA} \quad \mathrm{AL}-\mathrm{P}$ & .000 & .005 & .000 & .000 & .000 & .000 & .005 \\
\hline $\mathrm{KCL}$ & .000 & .000 & .000 & .000 & .000 & .000 & .000 \\
\hline GYP SUM/BARITE & .000 & .000 & .000 & .000 & .000 & .000 & .000 \\
\hline GYPSUM/AL-SILIC & .000 & .005 & .000 & .000 & .000 & .000 & .005 \\
\hline SI-RICH & .002 & .007 & .003 & .000 & .005 & .000 & .018 \\
\hline $\mathrm{CA}-\mathrm{RICH}$ & .027 & .013 & .001 & .005 & .006 & .000 & .052 \\
\hline $\mathrm{CA}-\mathrm{SI} \mathrm{RICH}$ & .000 & .000 & .000 & .000 & .000 & .000 & .000 \\
\hline UNKNOWN & .102 & .133 & .066 & .135 & .067 & .047 & .550 \\
\hline TOTALS & .869 & 1.843 & 1.378 & 1.416 & .864 & .420 & 6.790 \\
\hline
\end{tabular}




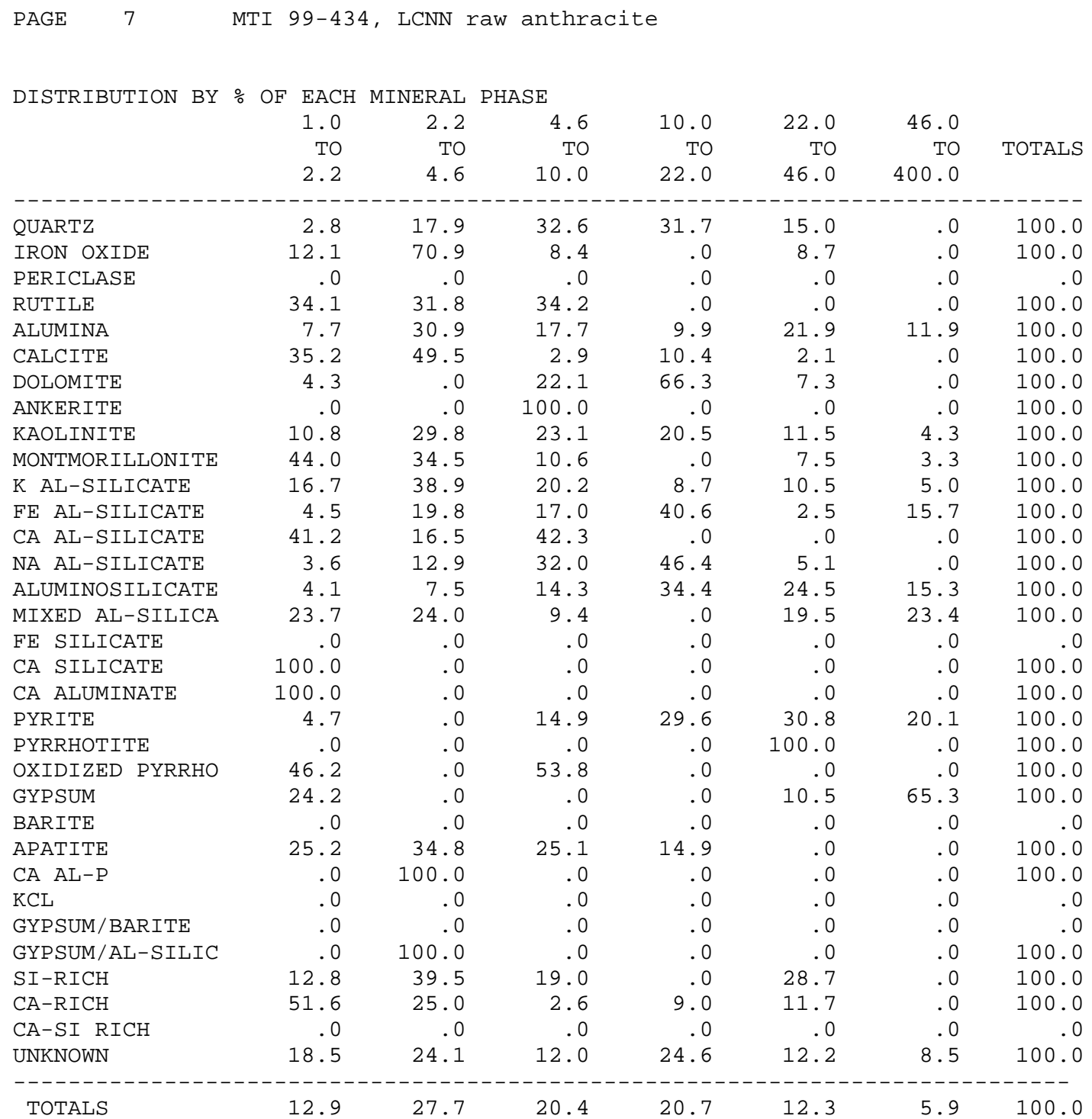




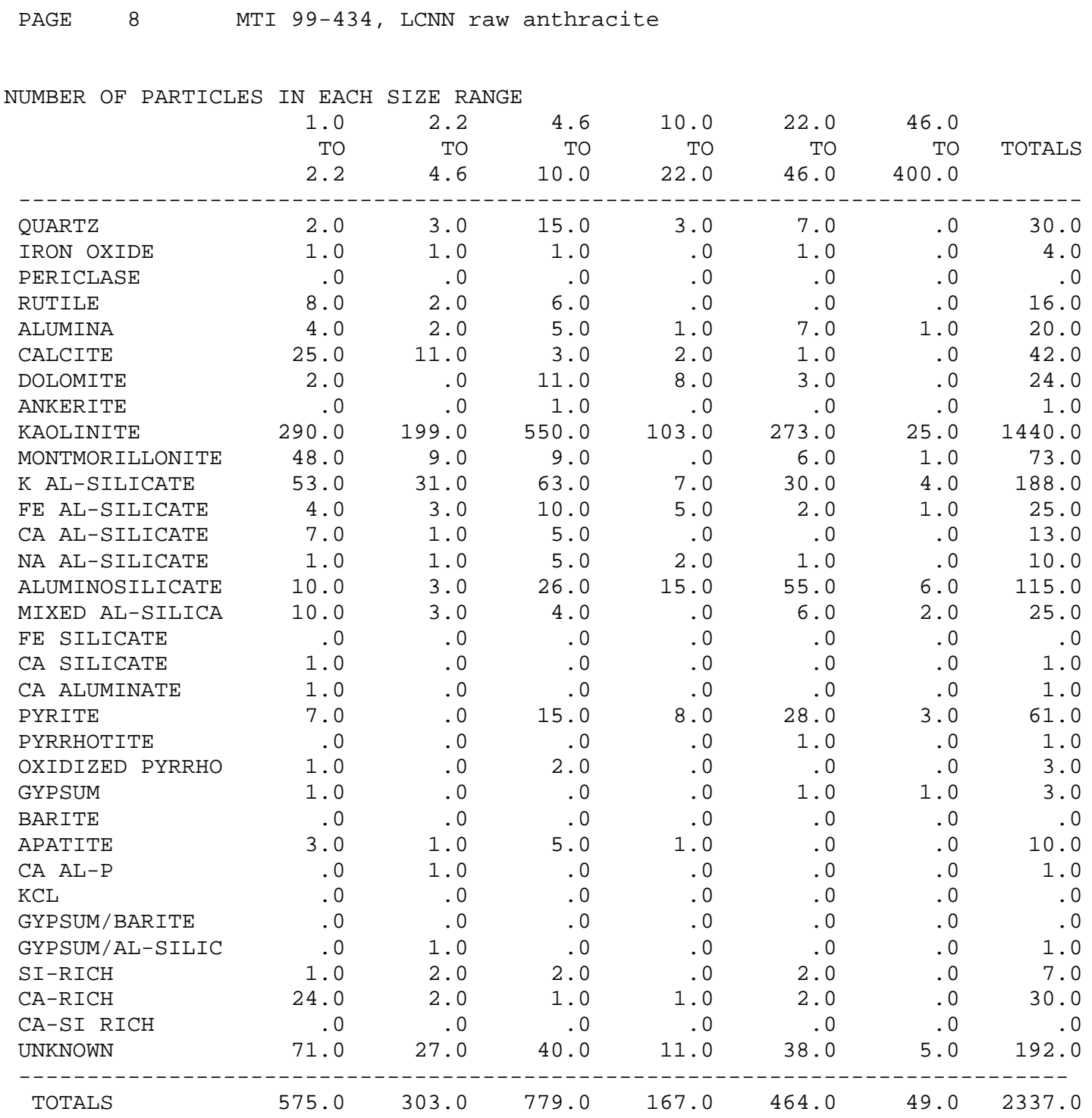




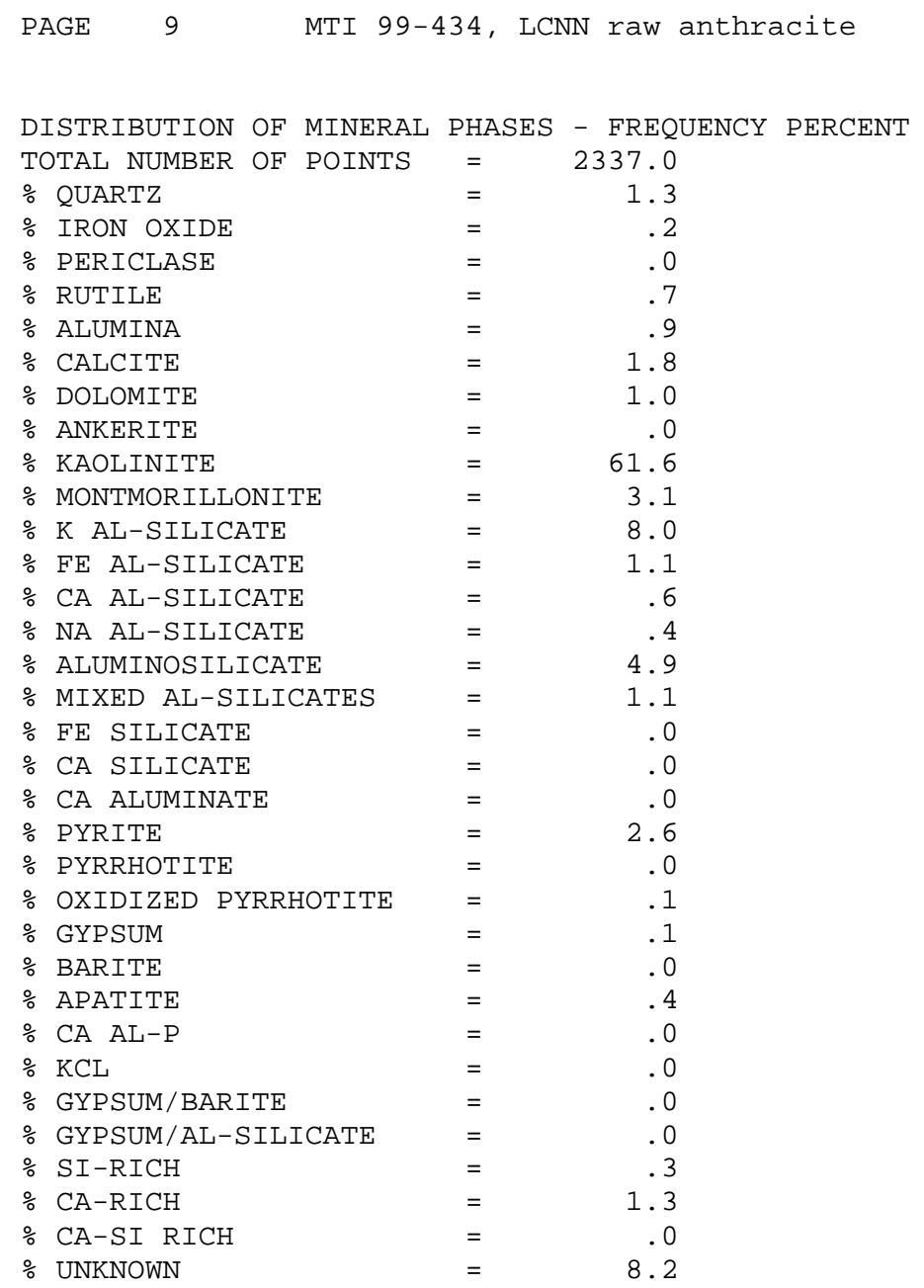




\title{
Technical Progress Report Submitted to
}

\author{
CONSORTIUM FOR PREMIUM CARBON PRODUCTS FROM COAL \\ The Pennsylvania State University \\ 407 Academic Activities Building \\ University Park, PA 16802-2398
}

\section{Comparison of Bituminous Coal Pyrolysis Tar and By-product Coke Oven Tar as Premium Feedstock for Carbon Black Production}

\section{Final Report}

Reporting Period Start Date: January 1, 2000

Reporting Period End Date: June 30, 2001

Principal Authors: Semih Eser and Richard Dutta

July 2001

DE-FC26-98FT40350

The Energy Institute 209 Academic Projects Building

University Park, PA 16802-2398 


\section{DISCLAIMER}

This report was prepared as an account of work sponsored by an agency of the United States Government. Neither the United States Government nor any agency thereof, nor any of their employees, makes any warranty, expressed or implied, or assumes any legal liability or responsibility for the accuracy, completeness, or usefulness of any information, apparatus, product, or process disclosed, or represents that its use would not infringe privately owned rights. Reference herein to any specific commercial product process, or service by trade name, trademark, manufacturer, or otherwise does not necessarily constitute or imply its endorsement, recommendation, or favoring by the United States Government or any agency thereof. The views and opinions of authors expressed herein do not necessarily state or reflect those of the United States Government or any agency thereof. 


\section{Summary}

This final report covers work done over the last year on analysis of coal tar, ethylene tar and decant oil samples used to produce carbon blacks. The report comprises three modified quarterly reports previously submitted to CPCPC and the latest quarterly data. The major objective of the research program was to determine the differences in chemical composition between coal pyrolysis tars, coke oven tars, and petroleum-derived feedstocks as alternative and potential for carbon black production. A total of 17 samples from the sponsor were analyzed by GC/MS and HPLC, and subsequently thermally stressed at $450 \mathrm{C}$ for 90 minutes to determine the types of carbonaceous solids produced. Several major results stand out as the important findings of the present study.

1. Gas Chromatography/Mass Spectrometry and High Pressure Liquid Chromatography are excellent analytical tools to determine the molecular composition and complexity of the samples.

2. Molecular complexity of the feedstock samples, especially in the high-molecular weight portion appears to be an important parameter that may relate to the undesired 'globular coke' during carbon black production.

3. Coke oven coal-tar distillates, and steam pyrolysis tars tend to be less complex and appear to have a lower tendency toward undesirable coke formation.

4. Upon thermal stressing, ethylene tars produce large pieces of pyrolytic carbons that appear to grow as concentric spheres. Decant oil samples produce anisotropic solids in relatively high yields. They appear to have been formed by liquid-phase carbonization via mesophase formation. Both ethylene tar and decant oil feedstocks appear to be more prone to producing undesirable coke than coal tar feedstocks. 
5. The differences in alkyl-substitution patterns of PAH's in coal tar- and petroleum-derived feedstocks are largely responsible for differences observed in coking tendency.

\section{First Quarterly Report}

The progress in this reporting period includes the selection and receipt of four samples from the sponsor followed by the analysis and testing of these samples. A summary of activities for each task is given below.

\section{Task 1. Selection of Coal Tar and Decant Oil Samples}

Samples of one commercial coal tar oil and three ethylene tars used for making different grades of carbon blacks were selected for analysis and testing and sent to PSU.

\section{Task 2. Analysis of Coal Tar and Decant Oil Samples}

The four feedstocks were quantitatively analyzed by GC/MS using a procedure modified after EPA Method $8270 b^{1}$ and used by Filley and Eser $^{2}$ to determine the composition of decant oils. High-Pressure Liquid Chromatogtaphy (HPLC) was used for a qualitative analysis of the samples. Analyses were performed on a Shimadzu QP-5000 gas chromatograph/mass spectrometer, and on a HPLC apparatus that consists of a Waters 600E system controller with a U6K syringe pump injector and a Waters 991 photodiode array detector.

The GC/MS spectra of the four samples are given Figures 1.1-4. The coal tar oil sample (\#1) has a distinctly different molecular composition from those of the ethylene tar samples (\#2-\#4). The principal differences include:

- Higher concentrations of PAH and higher aromaticity of coal tar oil compared to those of ethylene tar samples 
- Low concentrations of oxygen and nitrogen containing heterocyclic compounds in coal tar oil that are absent in ethylene tar

- Lower degree of substitution of aromatic ring systems in coal tar oil than those of the ethylene tar samples

\section{Task 3. Testing of Coal Tar/Decant Oil Samples for Coking Tendency}

Samples of the coal tar oil and three decant oils were tested for coking tendency in standard thermal treatment experiments carried out in tubing bomb reactors at $500^{\circ} \mathrm{C}$ for $3 \mathrm{~h}$. Optical textures of the semi-cokes produced from the four samples showed some differences. These differences were no yet quantified to compare the coking tendencies of the four commercial feedstock oil samples.

Task 4. Assessment of Relationships between Chemical Constitution of Feedstocks and Coking Tendency

The lower degree of alkyl substitution on the constituents of the coal tar oil sample is expected to result in lower coking tendency- or lower coking reactivity of this sample compared to the ethylene tar samples. The results from Task 3 , and possibly additional coking tests will be necessary to assess the relationships between the molecular composition of the feedstock samples and their coking tendency.

\section{References}

1. EPA Test Methods for Evaluating Solid Waste; Physical/Chemical Methods Method 8270b, Sept. 1994. Document \#SW-846.

2. Filley, R. M. and Eser, S. Energy Fuels 1997, 11, 623-630. 


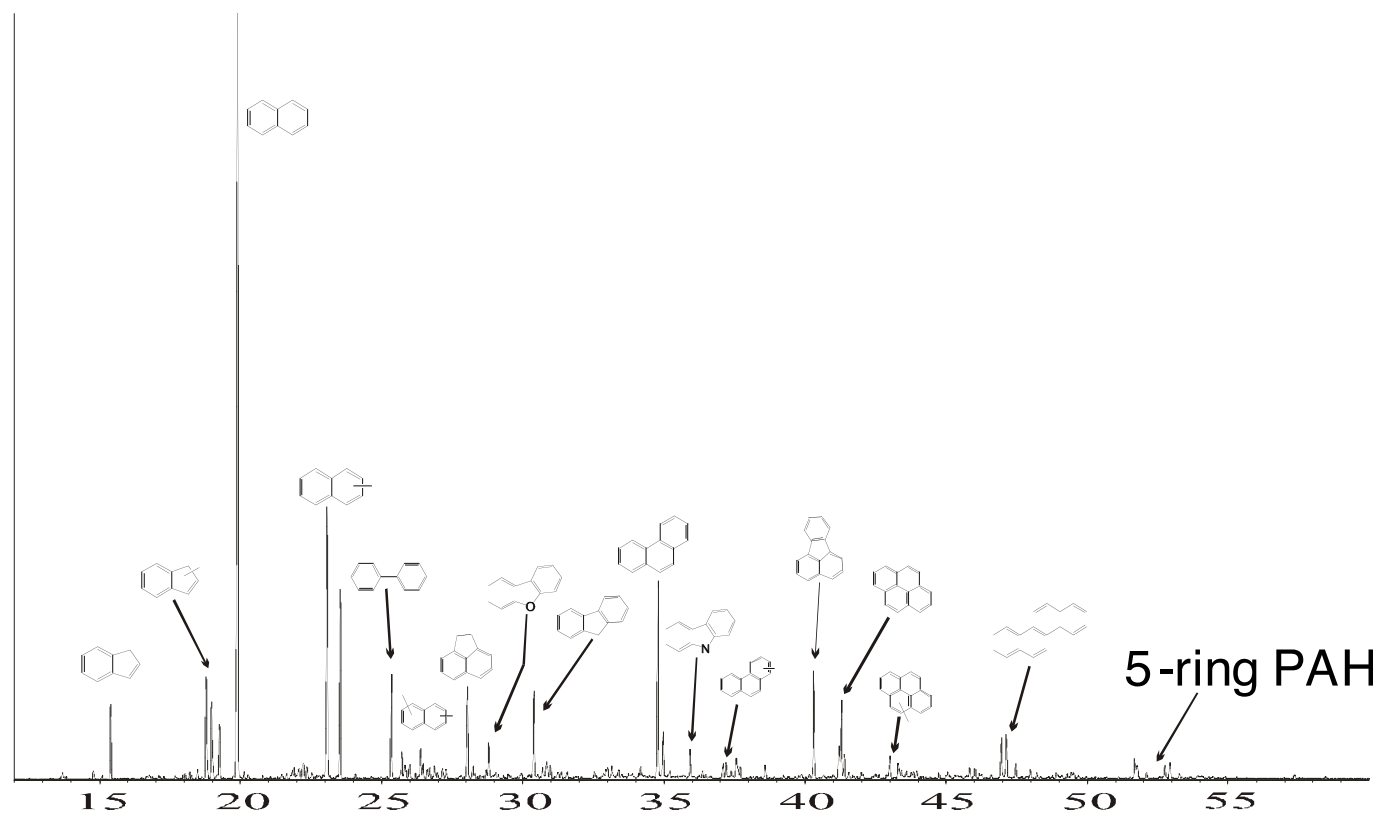

Figure 1. GC/MS Analysis of Feedstock \#1

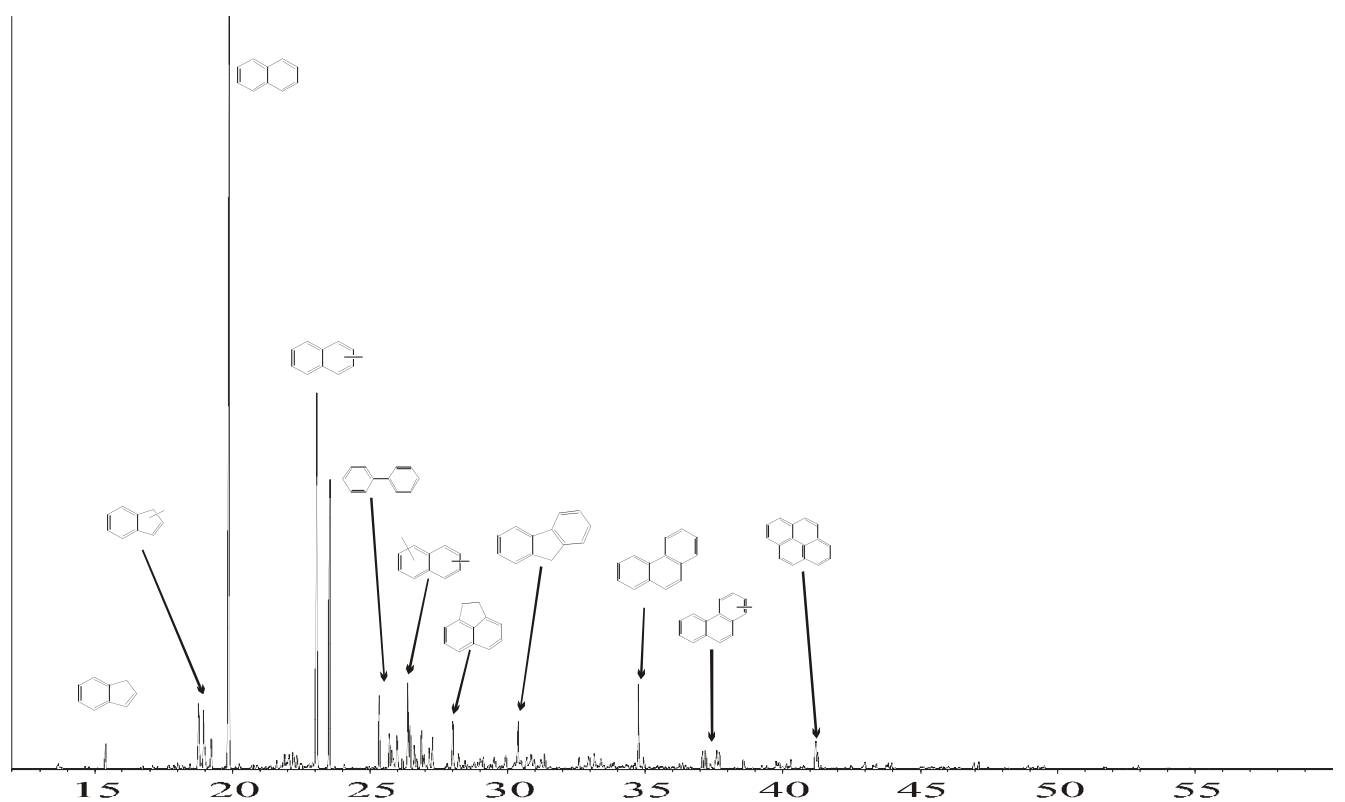

Figure 2. GC/MS Analysis of Feedstock \#2 


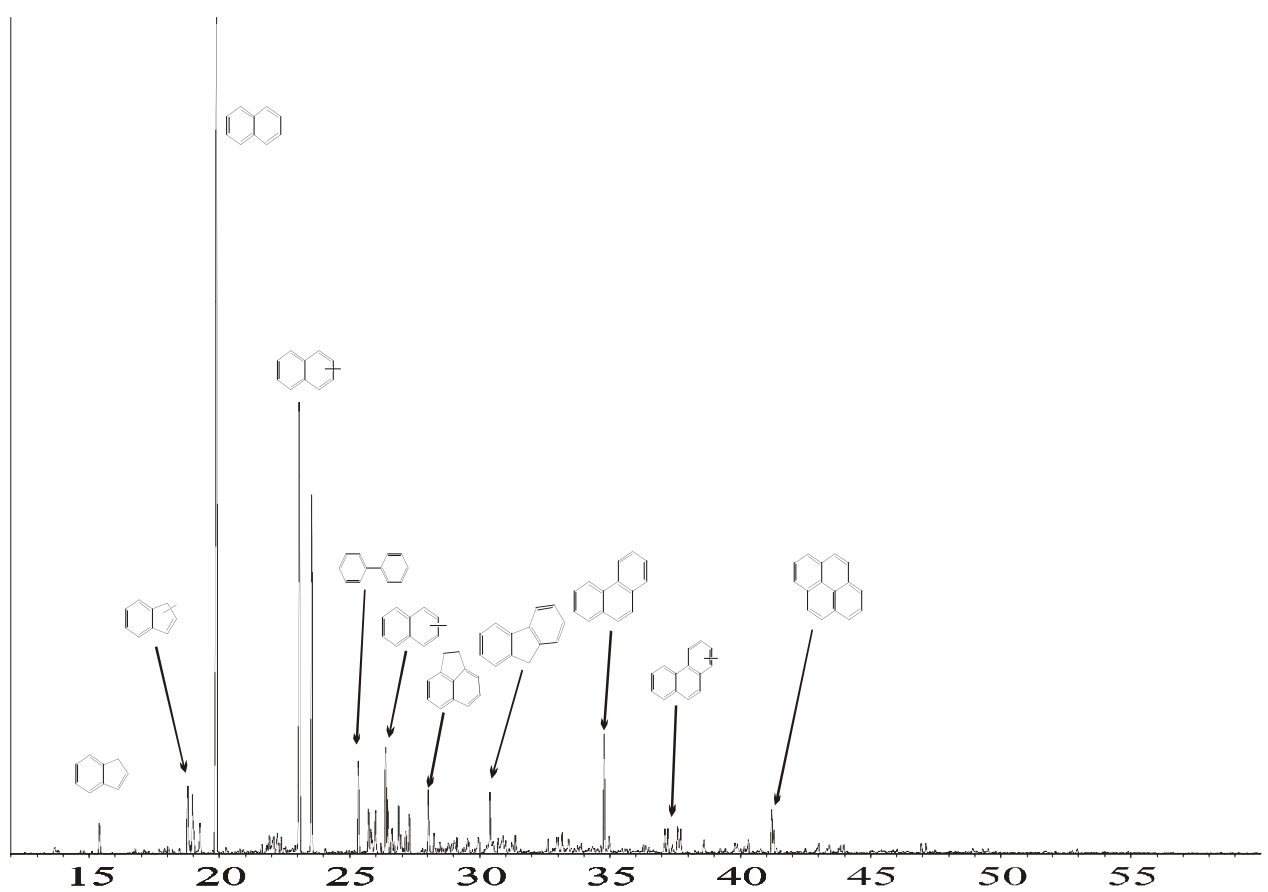

Figure 3. GC/MS Analysis of Feedstock \#3

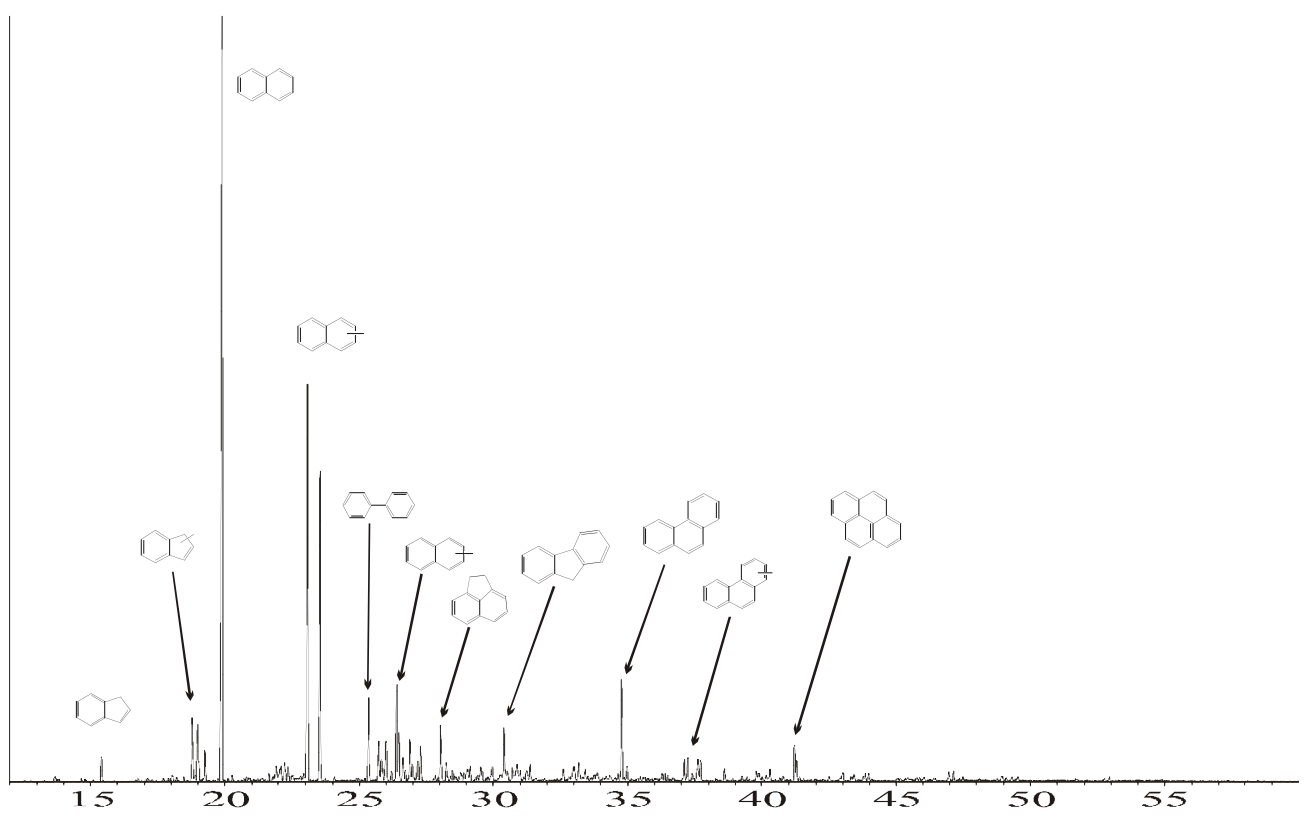

Figure 4. GC/MS Analysis of Feedstock \#4 

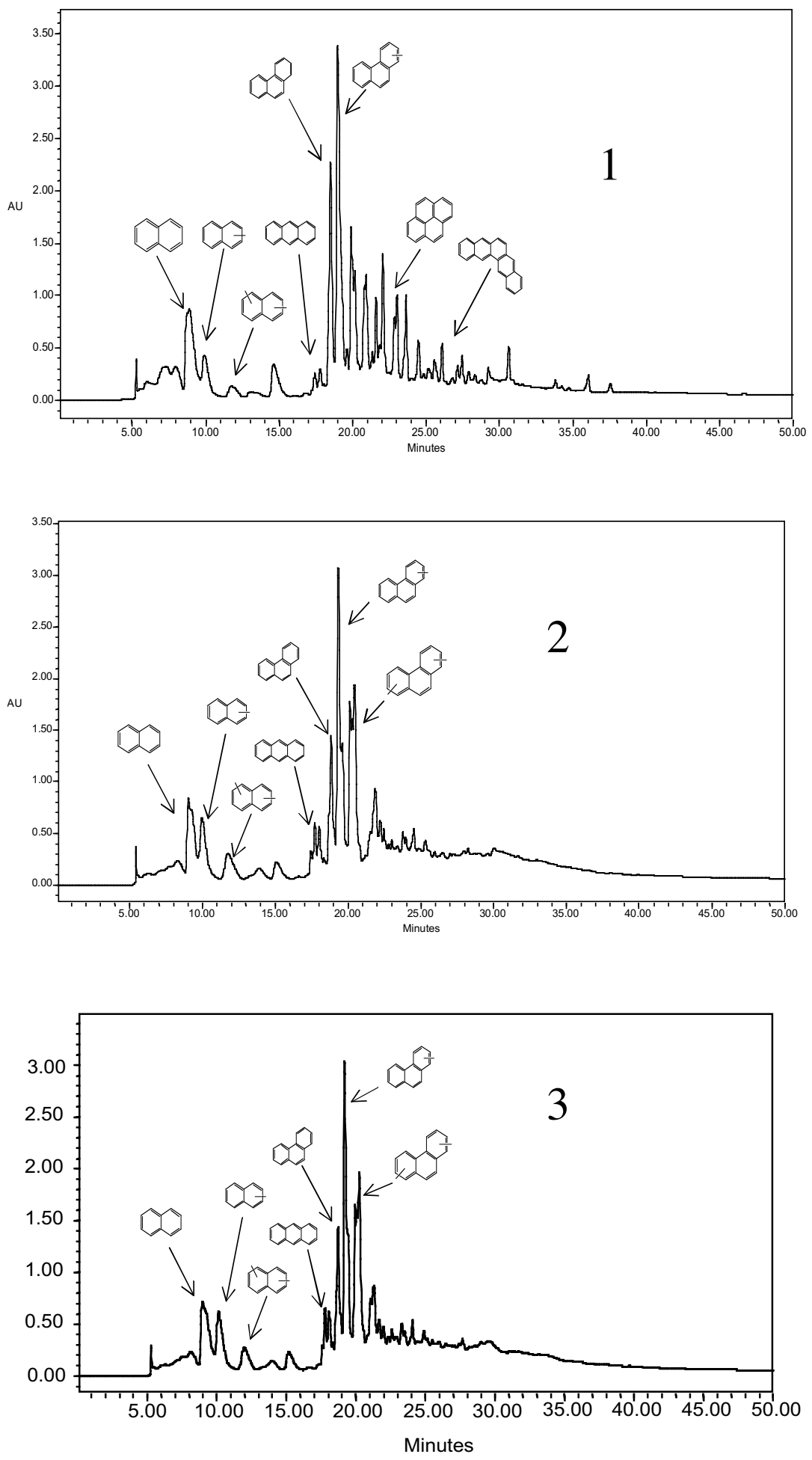

Figure 5. HPLC chromatograms of Samples \#1 (coal tar oil), \#2 (Ethylene tar), \#3 (Ethylene tar) 


\section{Second Quarterly Report}

In this reporting period, Amerikohl coal sample was pyrolyzed at temperatures $600-850{ }^{\circ} \mathrm{C}$ with and without flowing steam at different heating rates to produce seven different coal tar samples. In addition, a commercial coal tar oil sample received from the sponsor and a decant oil sample were analyzed using high pressure liquid chromatography.

\section{Task 1. Selection of Coal Tar and Decant Oil Samples}

A sample of a commercial coal tar oil was received and an FCC decant oil sample was selected for HPLC analysis.

\section{Task 2. Analysis of Coal Tar and Decant Oil Samples}

The coal tar oil received from Columbian Chemicals Company and an FCC decant oil sample (received from another source) were analyzed using an HPLC/PDAD system. The system consists of a Waters 600E system controller with a syringe pump and U6K injector, and a Waters 991 photodiode array detector (PDAD). A normal phase column (RingSep) was used with a gradient method using two solvents, hexane and dichloromethane for chromatographic separation.

Pyrolysis conditions and tar yields obtained from an Amerikohl sample are shown in Table 2.1.

\section{Task 3. Testing of Coal Tar/Decant Oil Samples for Coking Tendency}

No testing experiments were carried out in this reporting period.

Task 4. Assessment of Relationships between Chemical Constitution of Feedstocks and Coking Tendency

The large difference in molecular composition of these two feedstocks has ramifications in terms of their coking behavior under carbon black production conditions. The presence of larger and heavily substituted aromatic ring systems in DO would make 
it more thermally reactive and prone to coking reactions than $\mathrm{CTO}$, leading potentially to globular coke, or other kinds of undesired coke formation during carbon black production. It should be stressed that this particular DO sample was not received as a feedstock used for carbon black production, but most DO's have the principal characteristics of heavy alkyl substitution and polycondensed aromatic ring sizes of two to six rings.

Table 2.1. Pyrolysis conditions and product yields from an Amerikohl coal sample.

\begin{tabular}{|c|c|c|c|c|}
\hline Temp, ${ }^{\circ} \mathrm{C}$ & $\begin{array}{c}\text { Steam Flow } \\
\text { Rate, g/min }\end{array}$ & $\begin{array}{c}\text { Heating Rate, } \\
{ }^{\circ} \mathrm{C} / \mathrm{min}\end{array}$ & $\begin{array}{c}\text { Tar Yield, } \\
\% \text { wt, daf }\end{array}$ & $\begin{array}{c}\text { Char Yield, } \\
\% \text { wt, daf }\end{array}$ \\
\hline 600 & 3 & 10 & 15.8 & 69.3 \\
\hline 750 & 3 & 10 & 20.2 & 61.9 \\
\hline 800 & 3 & 10 & 8.8 & 61.9 \\
\hline 850 & 3 & 10 & 13.4 & 61.6 \\
\hline 700 & 0 & 10 & 14.4 & 69.2 \\
\hline 700 & 0 & 20 & 17.4 & 67.0 \\
\hline 800 & 0 & 10 & 11.8 & 67.0 \\
\hline
\end{tabular}




\section{Third Quarterly Report}

In this reporting period, eight samples were received from the sponsor. These samples were analyzed using GC/MS and HPLC and were subjected to thermal stressing tests to measure their "coking" tendency..

\section{Task 1. Selection of Coal Tar and Decant Oil Samples}

Samples received from the sponsor and studied in this period include a waste oil sample (\#5) coal tar distillates (samples \#6, \#7, \#8, and \#10), a decant oil (\#9), and ethylene tars (\#4, and \#16).

\section{Task 2. Analysis of Coal Tar and Decant Oil Samples}

Figure 3.1 and $3.1 \mathrm{~b}$ show the HPLC chromatograms for the seven feedstock samples. All coal tar distillates (\#6, \#7, \#8, \#10) gave well-resolved HPLC chromatograms, indicating a relatively low level of molecular complexity compared to the petroleum-derived feedstocks. Molecular complexity appears to increase in the order coal tar distillates, ethylene tar, and decant oil, respectively. Significant differences are also apparent in molecular composition among the coal tar distillates from visual comparison of the corresponding peak intensities in the HPLC chromatograms. These differences within the coal tar derived feedstocks are, however, relatively small compared to those between coal tar- and petroleum-derived feedstocks and those between ethylene tar and decant oil samples as seen in the chromatograms of Figure 3.1 and 3.1b. Sample \#5 is very different from all the other feedtocks, giving a very weak HPLC chromatogram either because of low aromaticity, or the presence of very large molecular constituents that are trapped in the HPLC column.

The unresolved hump seen in the HPLC chromatogram for the decant oil (\#9 in Figure 3.1b) clearly indicates the extreme complexity of its molecular composition because of high degrees of alkyl substitution on aromatic ring systems leading to a large number of isomers.

Figure 3.2 and 3.2b show the GC/MS total ion chromatograms of samples \#5-\#10, and \#16. The identification of PAH ring systems as labeled on the chromatograms is 
given in Table 3.1. As seen with the corresponding HPLC chromatograms, the coal tar distillates exhibit a much less complex molecular composition than those of the petroleum-derived feedstocks, as shown by a much better resolution of the individual peaks on the GC/MS TIC especially in the five-ring PAH region. Sample \#10 differed from the rest in the concentration of the individual components. The naphthalene fraction was more heavily substituted in sample \#10 than the other similar samples. Sample \#5 (a waste oil) was dominated by a compound that was likely to be a C4-cyclohexene (based on mass spectral analysis). The decant oil (or slurry oil) sample has, in turn, a more complex composition than that of the ethylene tar sample. Except for some coal tar distillates, GC/MS does not resolve the entire composition of the feedstock samples, but some compounds of interest are identified, e.g, two-five-ring PAH's, oxygen containing compounds, and substituted PAH's.

\section{Task 3. Testing of Coal Tar/Decant Oil Samples for Coking Tendency}

To test for coking tendency, samples of feedstocks $(3 \mathrm{~g})$ were heated to $450^{\circ} \mathrm{C}$ for 90 minute reaction times in $15 \mathrm{ml}$ tubing bomb reactors that had been purged three times with nitrogen. The feed was placed in small quartz tubes inside the stainless steel reactor so as to minimize wall effects. After the reaction, the reactor was quenched in cold water and the solid material was extracted by rinsing the quartz tube with methylene chloride. The solids produced were mounted in epoxy resin pellets, polished and observed with reflected polarized-light microscopy for signs of mesophase and pyrolytic carbon formation.

Substantial differences were observed in the optical textures of the solids (methylene chloride insolubles) produced by thermal stressing of the three kinds of feedstock samples. Figure 3.3a shows the laminar pyrolytic carbon layers on an isotropic pitch matrix produced upon stressing the coal tar distillate. In contrast, the ethylene tar sample produced large pieces of pyrolytic carbons that appear to have grown as concentric spheres (Figure 3.3b). As completely different from the coal tar- and ethylene tar-derived samples, decant oil sample produced anisotropic solids that have been formed by liquidphase carbonization via mesophase formation (Figure 3.3c). 
Task 4. Assessment of Relationships between Chemical Constitution of Feedstocks and Coking Tendency

Substantial differences were observed in the molecular composition of coal tar distillate, ethylene tar, and decant oil samples including differences in heavy end concentration, heterocyclic and substitution patterns on the constituent PAH's..

As evidenced by the striking differences observed in the optical textures of the solids produced by thermal stressing of the three kinds of feedstock samples, coal tar, ethylene tar, and decant oil samples my have very different tendencies toward undesired "coke" formation during carbon black production. In general, a more complex molecular composition in the feedstocks is considered to increase the "coking" tendency during carbon black production. In this respect, coal tar distillates appear to have the lowest tendency toward undesirable coke formation.

\section{References}

- Filley, R.M., Eser, S. Energy Fuels 1997, 11, 623-630 


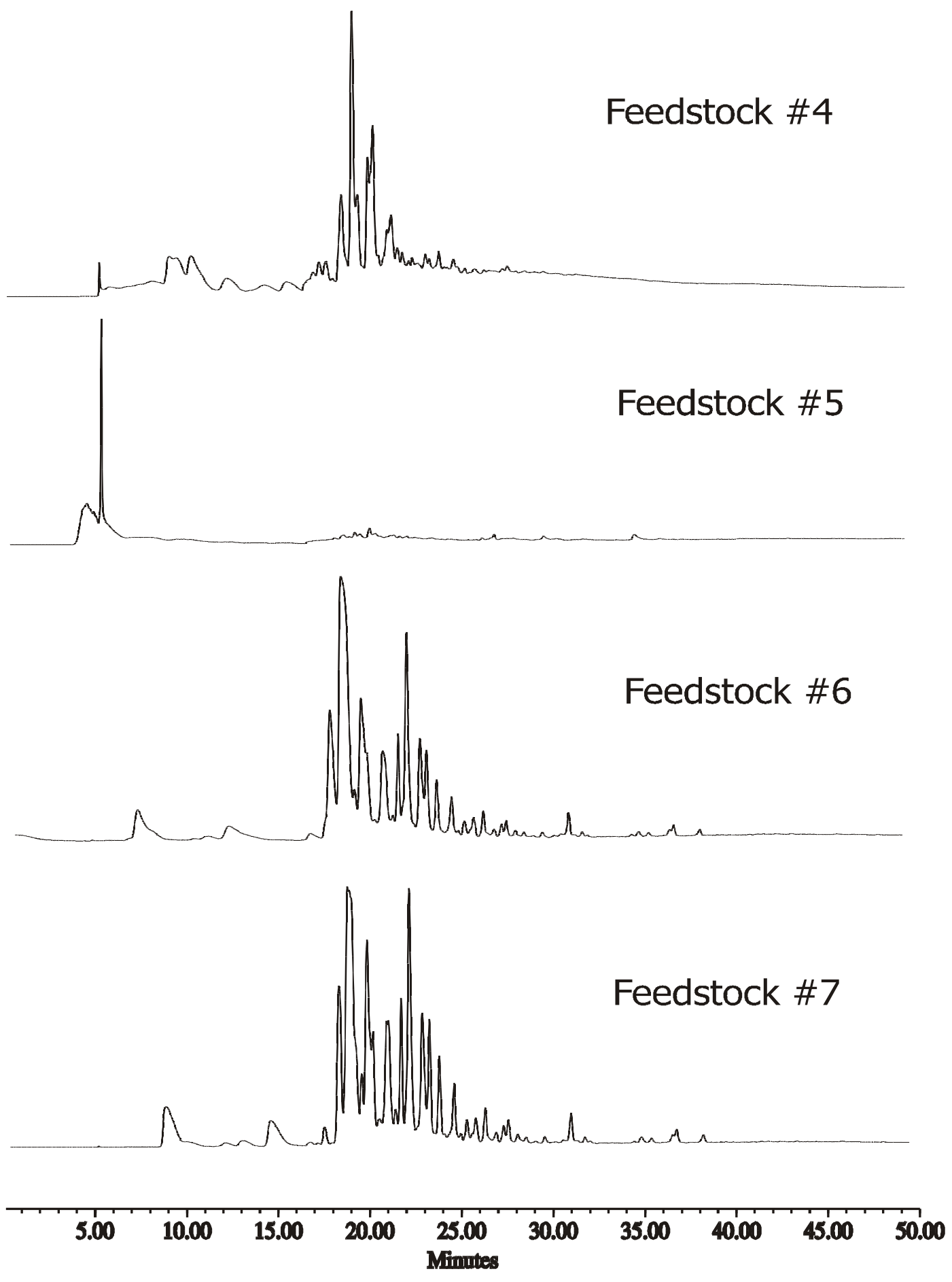

Figure 3.1. HPLC chromatograms of feeds \#4 - \#7 

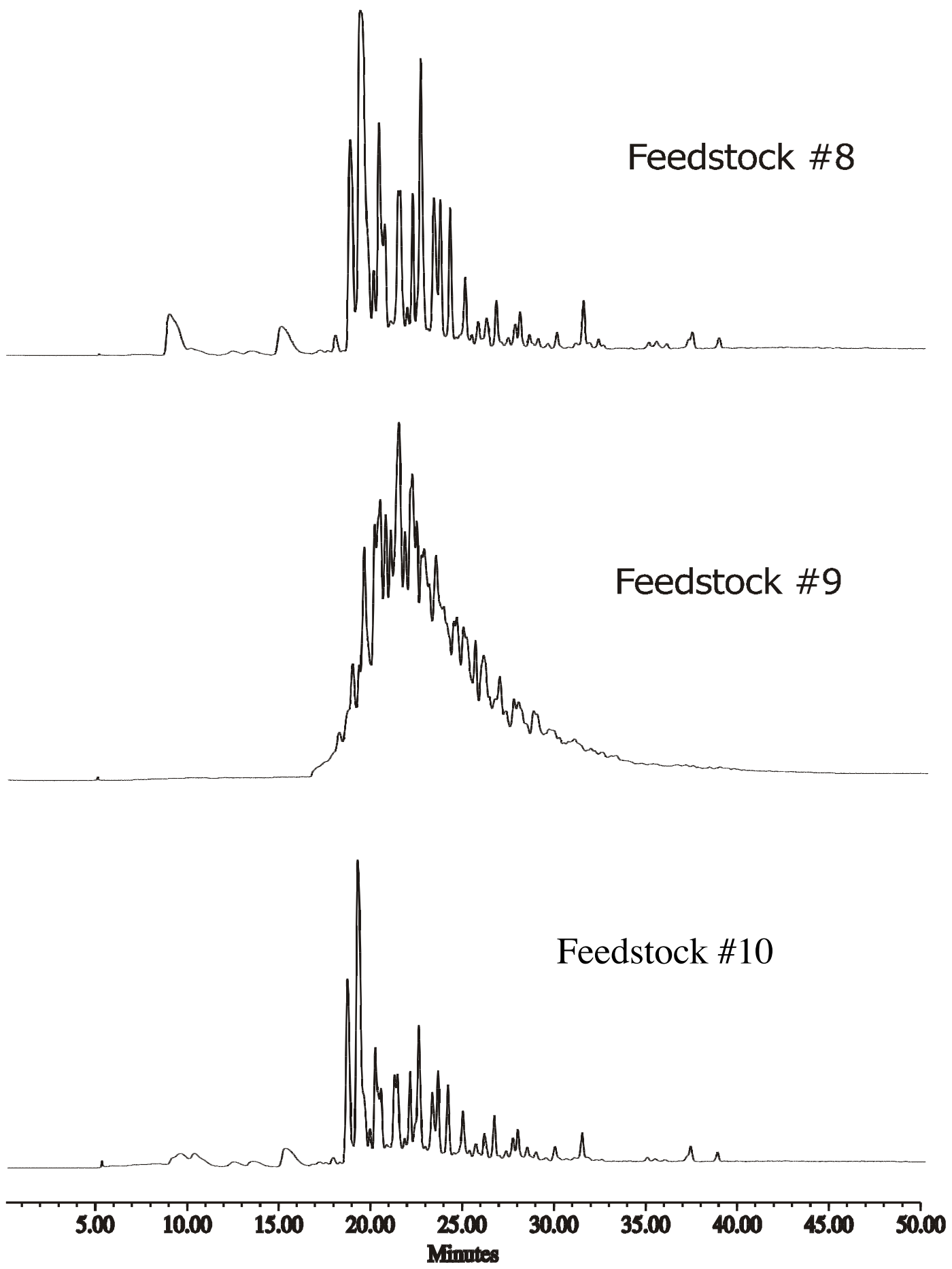

Figure 3.1b. HPLC chromatograms of Feedstock \#8-\#10 


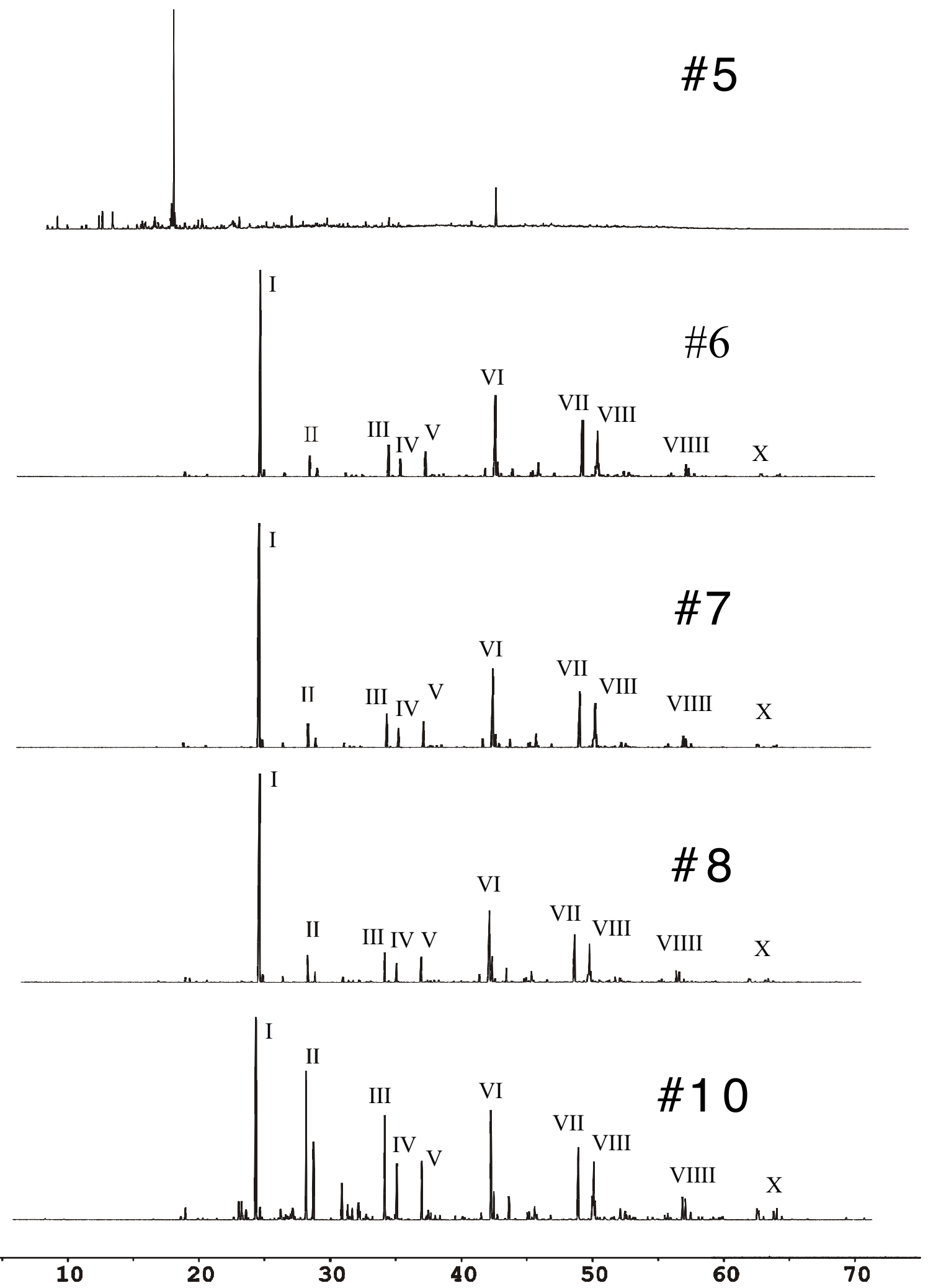

Figure 3.2. GC/MS analysis of feedstocks \#5, 6, 7, 8, 10 


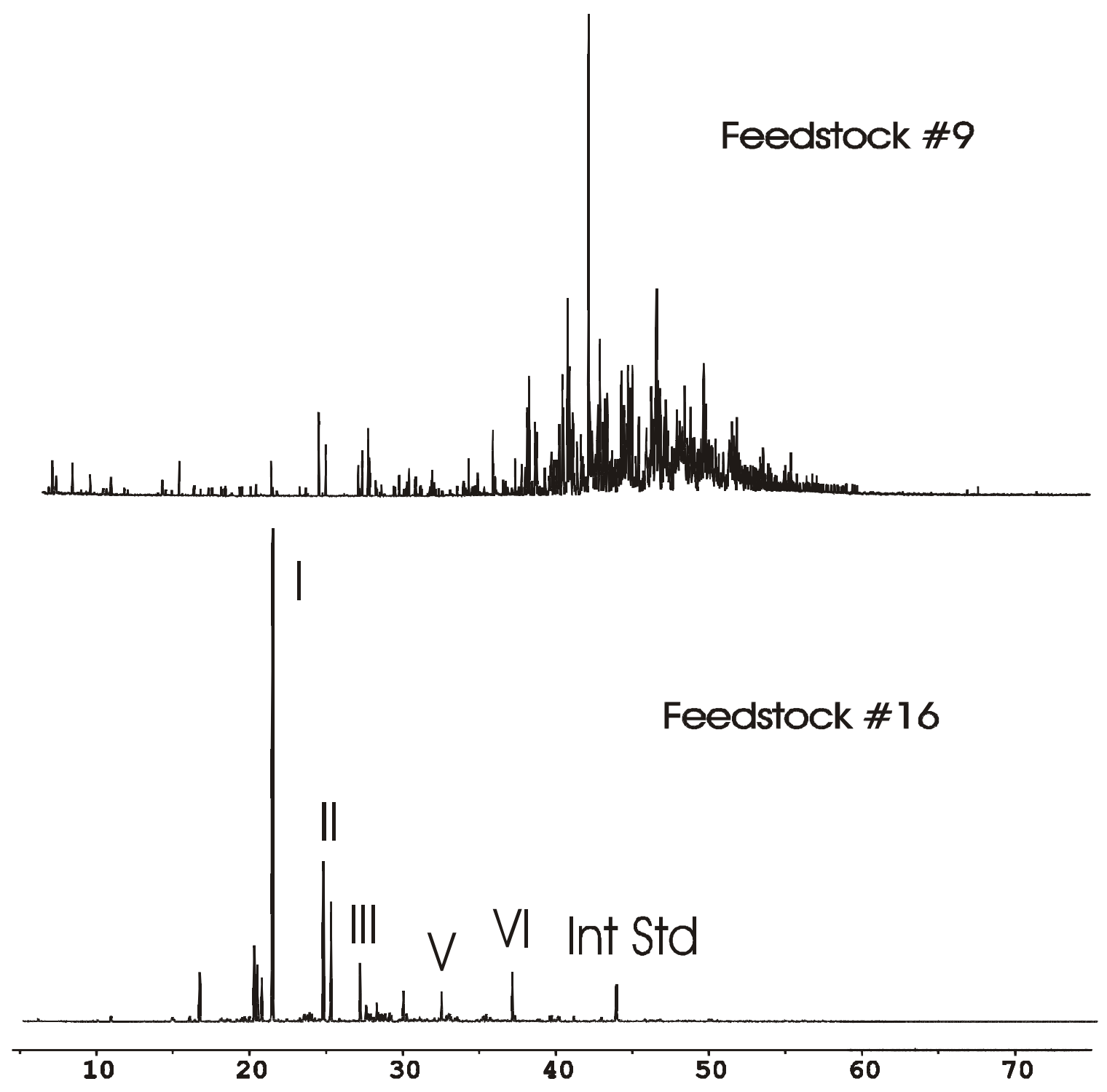

Figure 3.2b. GC/MS analysis of feedstocks \#9 and \#16 
Table 3.1. Chemical structure identification for Figure 3.2

Identification Chemical structure


Table 3.2. Molecular composition analysis of carbon black feedstocks (wt \%)

\begin{tabular}{|lccccccc|}
\hline & $\# 6$ & $\# 7$ & $\# 8$ & $\# 10$ & $\# 9$ & $\# 16$ & $\# 3$ \\
\hline & $w t \%$ & $w t \%$ & $w t \%$ & $w t \%$ & $w t \%$ & $w t \%$ & $w t \%$ \\
Naphthalene & 45.19 & 49.72 & 45.45 & 15.88 & $<.5$ & 9.89 & 7.98 \\
2-methylnaphthalene & 2.40 & 2.75 & 3.12 & 10.01 & $<.5$ & 2.73 & 3.68 \\
1-methylnaphthalene & 1.05 & 1.22 & 1.35 & 5.01 & $<.5$ & 1.98 & 2.81 \\
C2-naphthalene & 0.71 & 0.70 & 0.73 & 3.32 & $<.5$ & 1.97 & 2.67 \\
Dibenzofuran & 3.47 & 3.50 & 3.33 & 4.69 & $<.5$ & - & - \\
Acenapthene & 4.99 & 5.35 & 4.58 & 6.56 & $<.5$ & 1.22 & 0.17 \\
Fluorene & 3.88 & 3.93 & 3.85 & 4.32 & $<.5$ & 0.68 & 0.53 \\
Phenantharene & 19.73 & 18.72 & 15.87 & 9.13 & $<.5$ & 1.45 & 1.49 \\
Anthracene & 2.12 & 1.89 & 3.48 & 1.87 & $<.5$ & 0.16 & 0.2 \\
Biphenyl & - & - & - & - & $<.5$ & 1.00 & 0.83 \\
Pyrene & 7.71 & 7.50 & 5.86 & 3.83 & $<.5$ & 0.17 & 0.26 \\
Fluoranthene & 11.18 & 10.45 & 8.04 & 5.03 & $<.5$ & 0.12 & 0.13 \\
Benzanthracene & 0.78 & 0.85 & 0.66 & 0.73 & $<.5$ & 0.07 & 0.11 \\
Chrysene & 0.49 & 0.54 & 0.53 & 0.59 & $<.5$ & 0.07 & 0.1 \\
5-Ring (252) & 0.66 & 0.76 & 0.93 & 1.38 & $<.5$ & 0.09 & 0.22 \\
\hline not identified & - & - & 2.22 & 27.67 & $>90.00$ & 78.39 & 78.82 \\
\hline
\end{tabular}




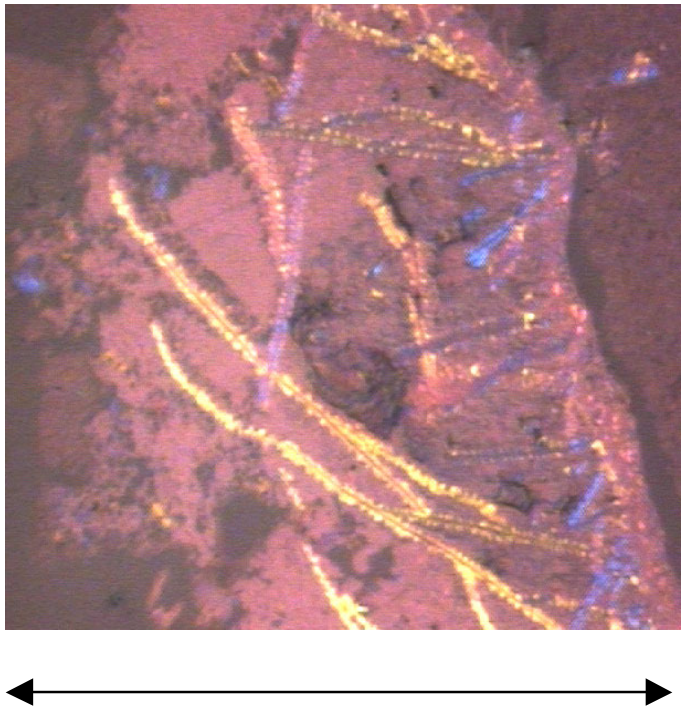

120 microns

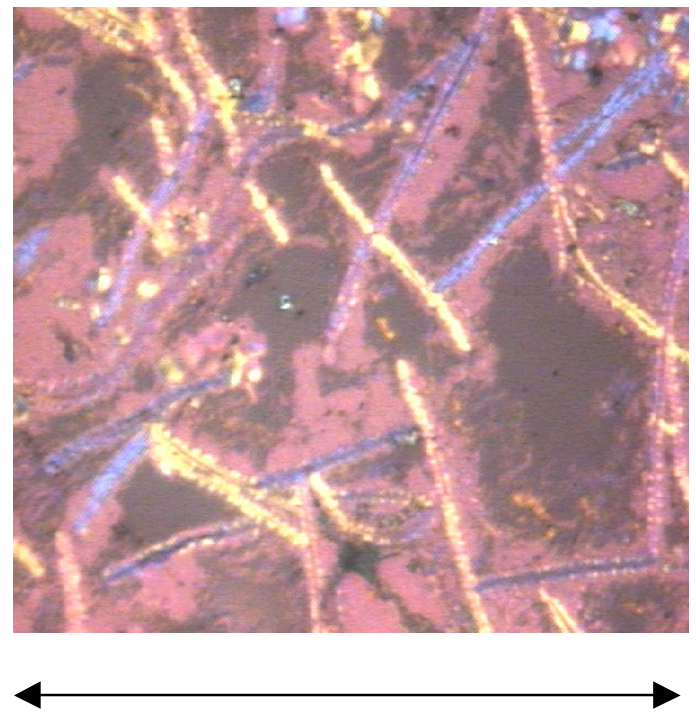

120 microns

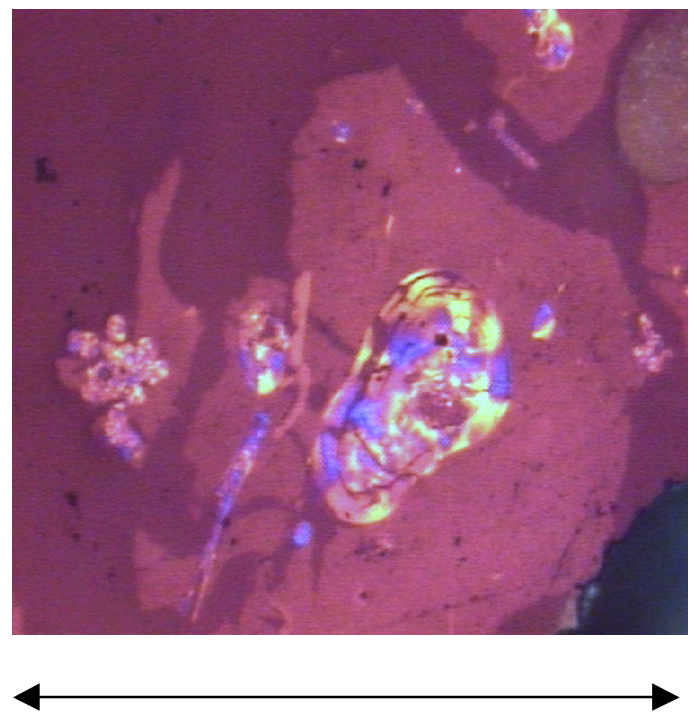

250 microns

Figure 3.3a. Polarized-light micrographs of solids produced by thermal stressing of a coal tar oil (Sample \#6). 

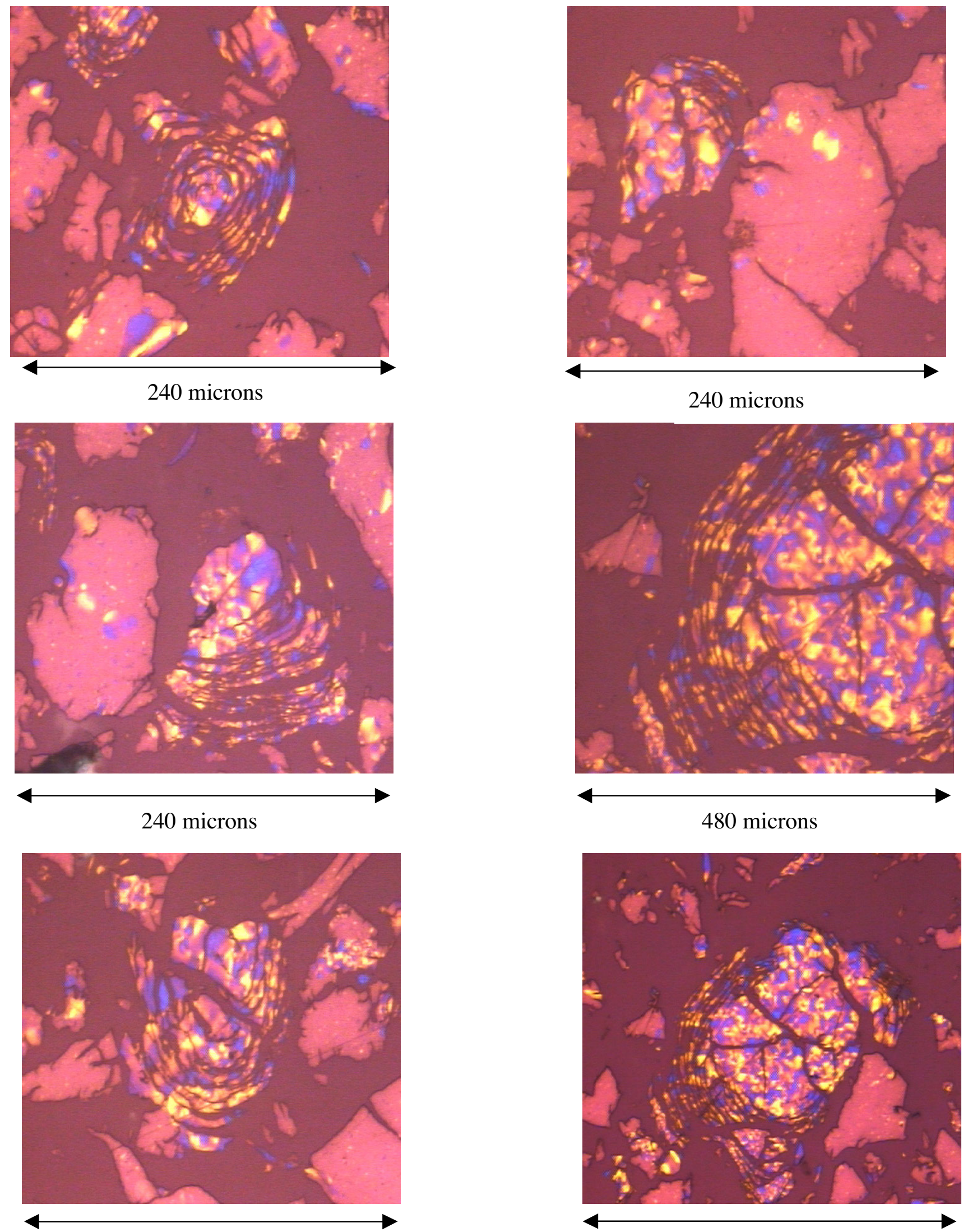

240 microns

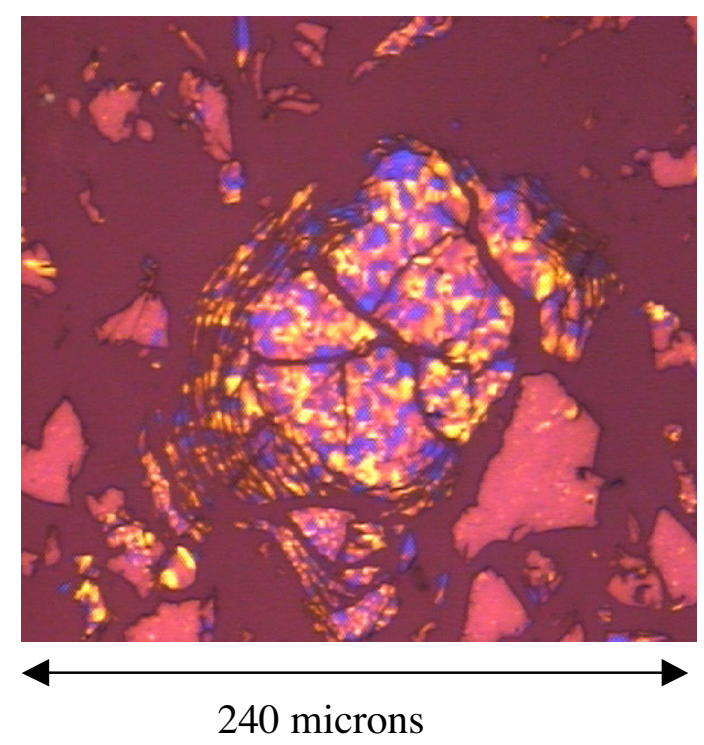

Figure 3.3a. Polarized-light micrographs of solids produced by thermal stressing of an Ethylene Tar (sample \#16) 

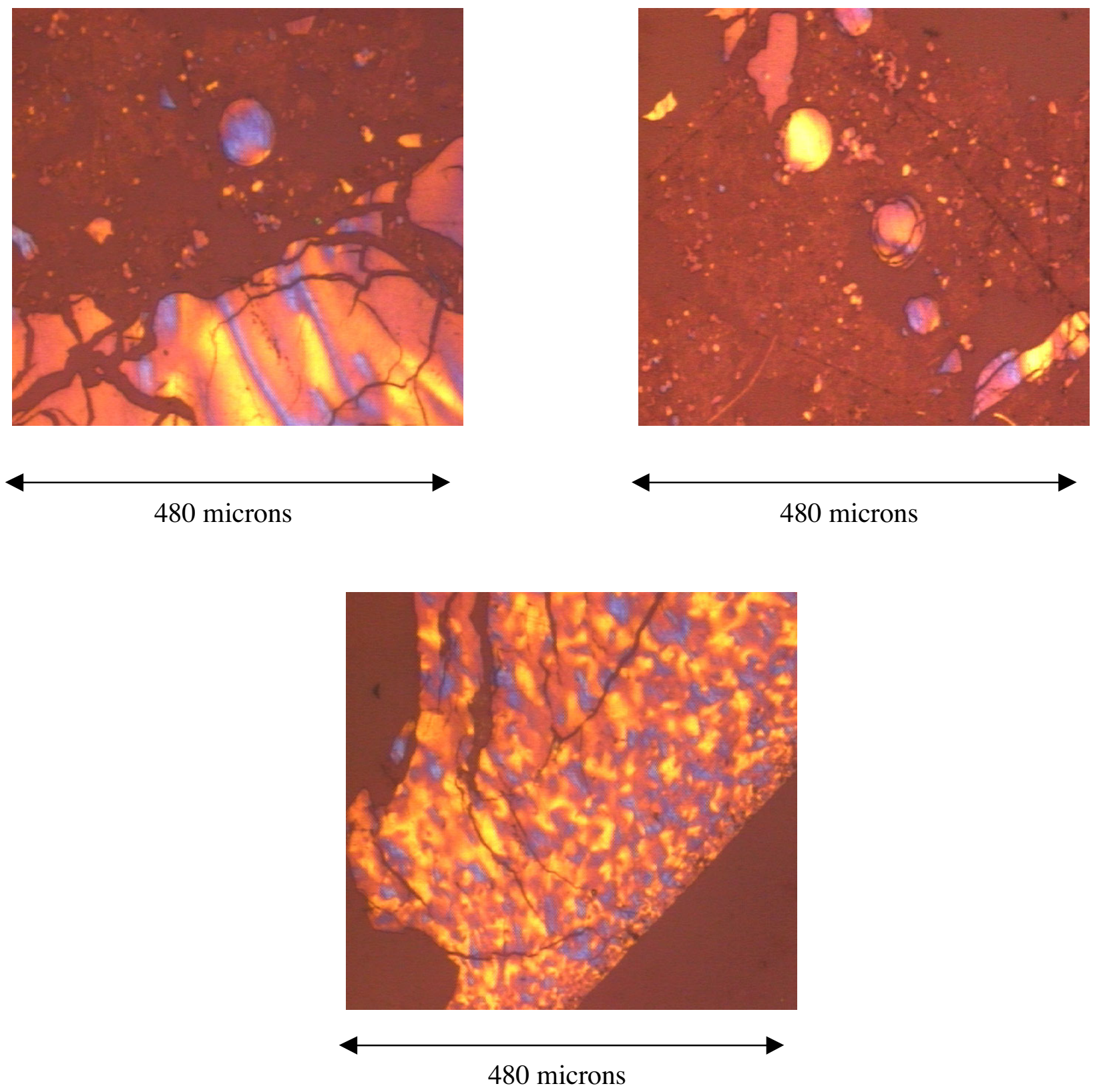

Figure 3.3a. Polarized-light micrographs of solids produced by thermal stressin decant oil (sample \#9). 


\section{Fourth Quarterly Report}

In this reporting period, six samples were received from the sponsor. These samples were analyzed using GC/MS and HPLC and were subjected to thermal stressing tests to measure their "coking" tendency. Yields of the solids produced are reported along with examples of optical analysis of the solids produced at 450C and 90 minutes stressing time.

\section{Task 1. Selection of Coal Tar and Decant Oil Samples}

Samples received from the sponsor and studied in this period include two decant oil samples (\#11 \& \#14), coal tar distillates (\#12,\#13, \& \#15), and one ethylene tar sample (\#17).

\section{Task 2. Analysis of Coal Tar and Decant Oil Samples}

Figure 4.1 and $4.1 \mathrm{~b}$ show the HPLC chromatograms for the six feedstock samples. As reported in the previous quarter, all coal tar distillates (\#12, \#13 \& \#15) gave well-resolved HPLC chromatograms, indicating a relatively low level of molecular complexity compared to the petroleum-derived feedstocks.

The unresolved hump seen in the HPLC chromatogram for the decant oil (\#11 and \#14) indicates the extreme complexity of its molecular composition because of high degrees of alkyl substitution on aromatic ring systems leading to a large number of isomers..

Sample \#17 contains some single ring compounds and indenes (see GC/MS data). The chromatogram is not as well resolved as the coal tar distillate samples, which indicates a higher level of complexity than the coal tar samples and the presence of some highly substituted PAH's.

Figure 4.2 shows the GC/MS chromatograms of the six samples. Quantitative analysis of the samples is shown in Figure 4.3. The data shows that among the coalderived samples, the molecular composition is similar, however the concentration of the individual compounds varies. The molecular complexity of the samples also show up using GC/MS by the fact that the coal and ethylene tar samples (\#12, 13, 15, and 17) show well resolved peaks, whereas the decant oil samples (\#11,\#14) show a broad hump of poorly resolved peaks. The GC/MS data together with the HPLC data give an overall 
qualititative pricture of the molecular composition of these samples, including molecular complexity and distribution of PAH's and substituted PAH's. Future and ongoing work is attempting to develop a more quantitative approach to measure the complexity and 'heaviness' of each feed and correlate it to coking tendency.

\section{Task 3. Testing of Coal Tar/Decant Oil Samples for Coking Tendency}

To test for coking tendency, samples of feedstocks $(3 \mathrm{~g})$ were heated to $450^{\circ} \mathrm{C}$ for 90 minute reaction times in $15 \mathrm{ml}$ tubing bomb reactors that had been purged three times with nitrogen. The feed was placed in small quartz tubes inside the stainless steel reactor so as to minimize wall effects. After the reaction, the reactor was quenched in cold water and the solid material was extracted by rinsing the quartz tube with methylene chloride. The solids produced were mounted in epoxy resin pellets, polished and observed with reflected polarized-light microscopy for signs of mesophase and pyrolytic carbon formation.

\section{Task 4. Assessment of Relationships between Chemical Constitution of Feedstocks and Coking Tendency}

Figure 4.4 shows the yield of solids generated from the six samples heated at $450 \mathrm{C}$ for 90 minutes. Samples \#11, 14, and 17 gave similar yields (12-13 wt\%). The coal derived samples gave less solid yield (0.5-3 wt\%). Samples \#13 and \#15 did not produce enough solids to pelletize in the resin.

The solids produced by thermal stressing of the three kinds of feedstock samples, coal tar, ethylene tar, and decant oil samples have very different tendencies toward undesired "coke" formation during carbon black production. In general, a more complex molecular composition in the feedstocks is considered to increase the "coking" tendency during carbon black production. In this respect, coal tar distillates appear to have the lowest tendency toward undesirable coke formation and this is reflected in the solid yield. In the previous report, sample \#16 produced large pieces of pyrolytic carbons that appear to have grown as concentric spheres. Sample \#17 also showed the same carbon structures under the microscope (see Fig 4.5). 

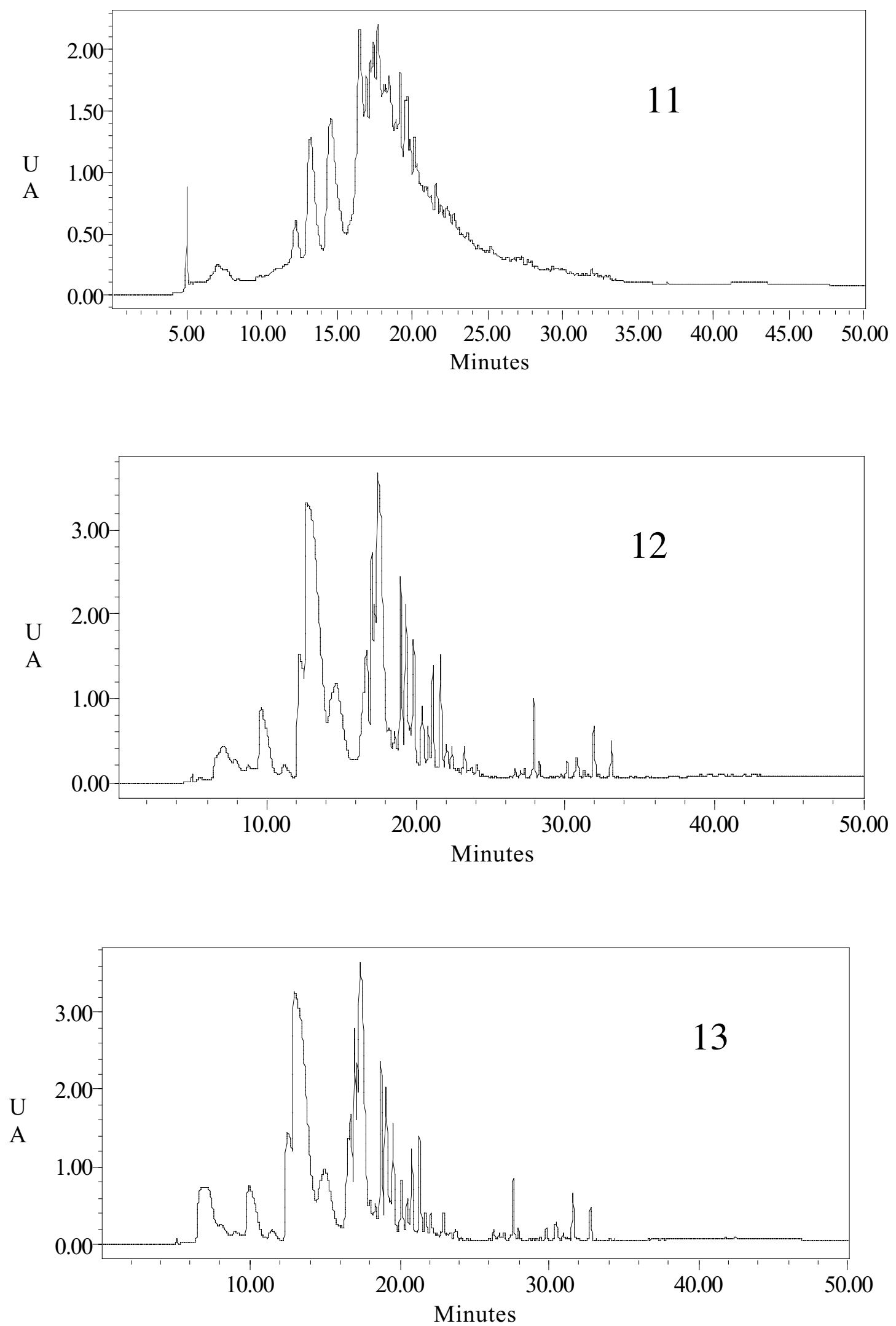

Figure 4.1a. HPLC chromatograms of samples $\# 11,12$, and \#13 

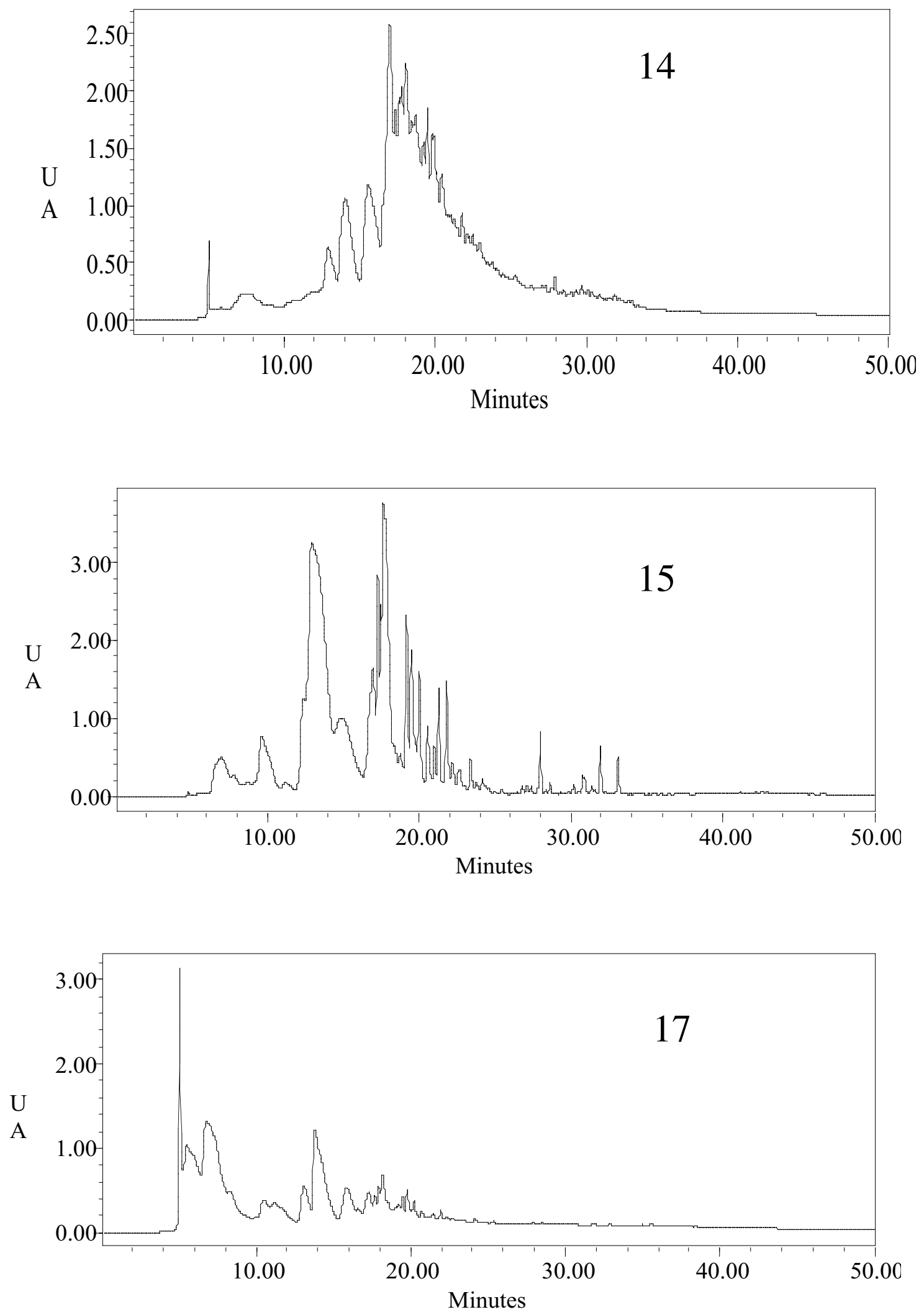

Figure 4.1b. HPLC chromatograms of samples \#14, \#15, and \#17 

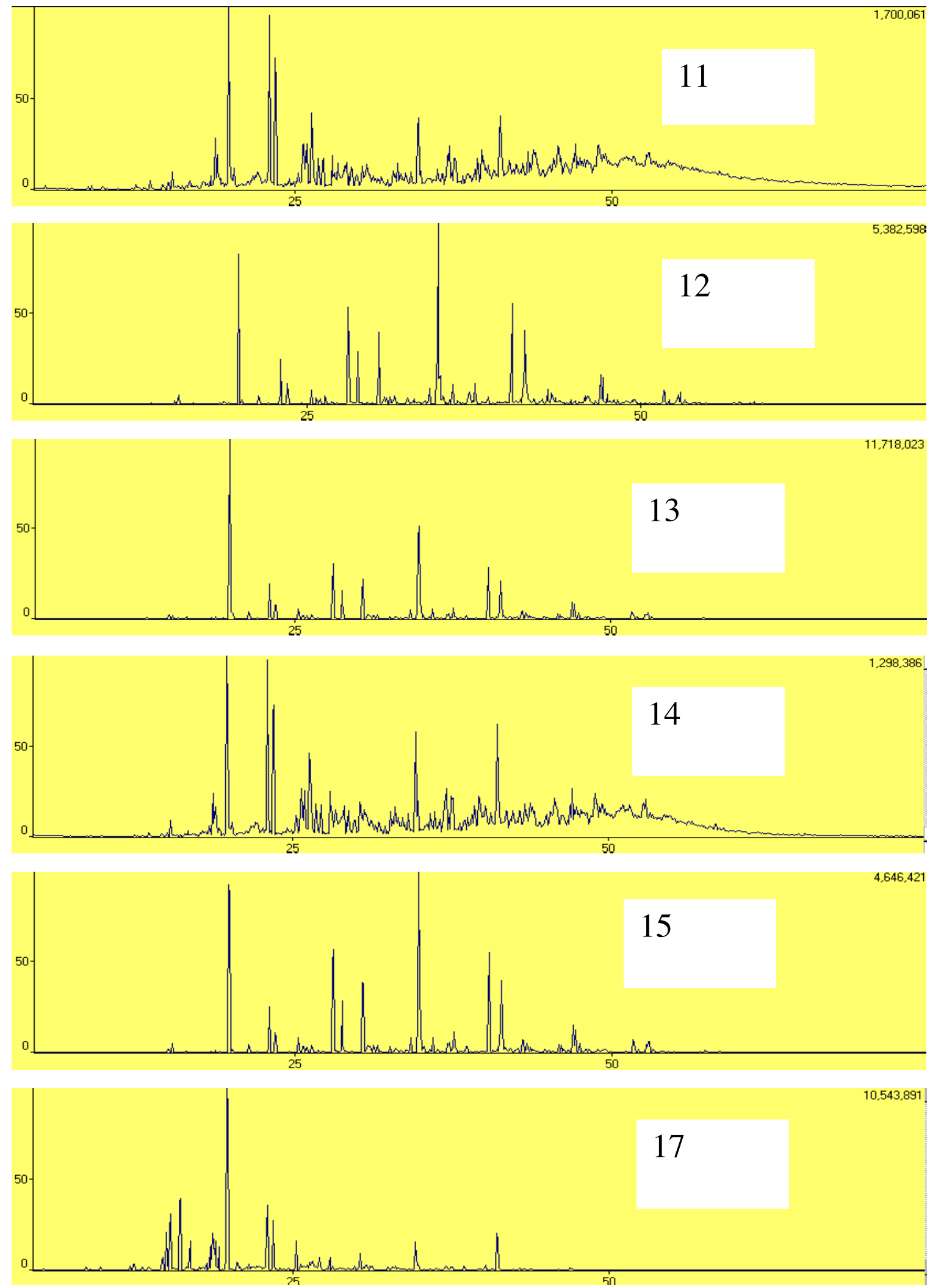

Figure 4.2. GC/MS Chromatograms of Samples \#11-17 


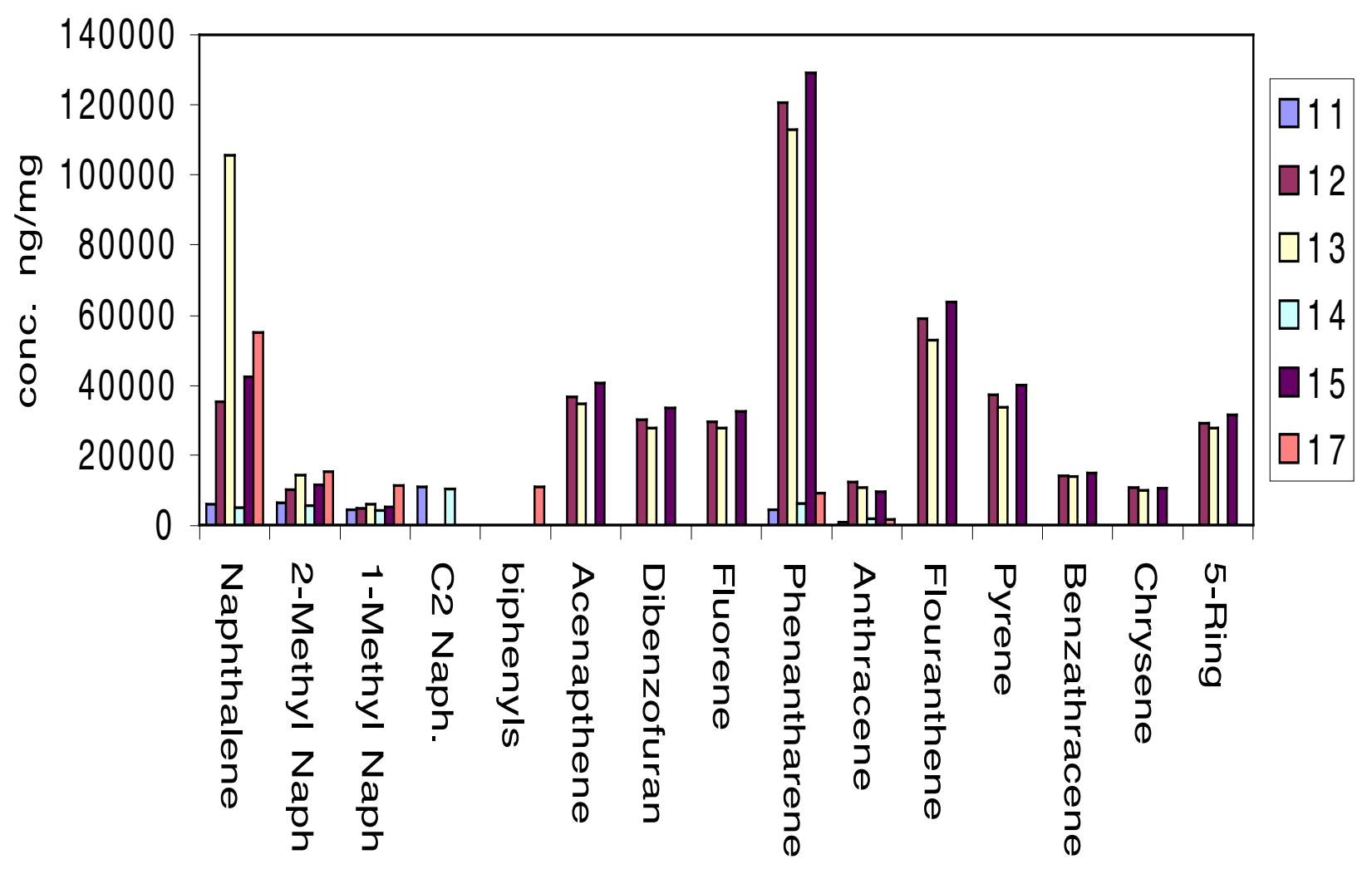

Figure 4.3. Molecualar composition of Samples \#11, 12, 13, 14, 15, 17 (From GC/MS)

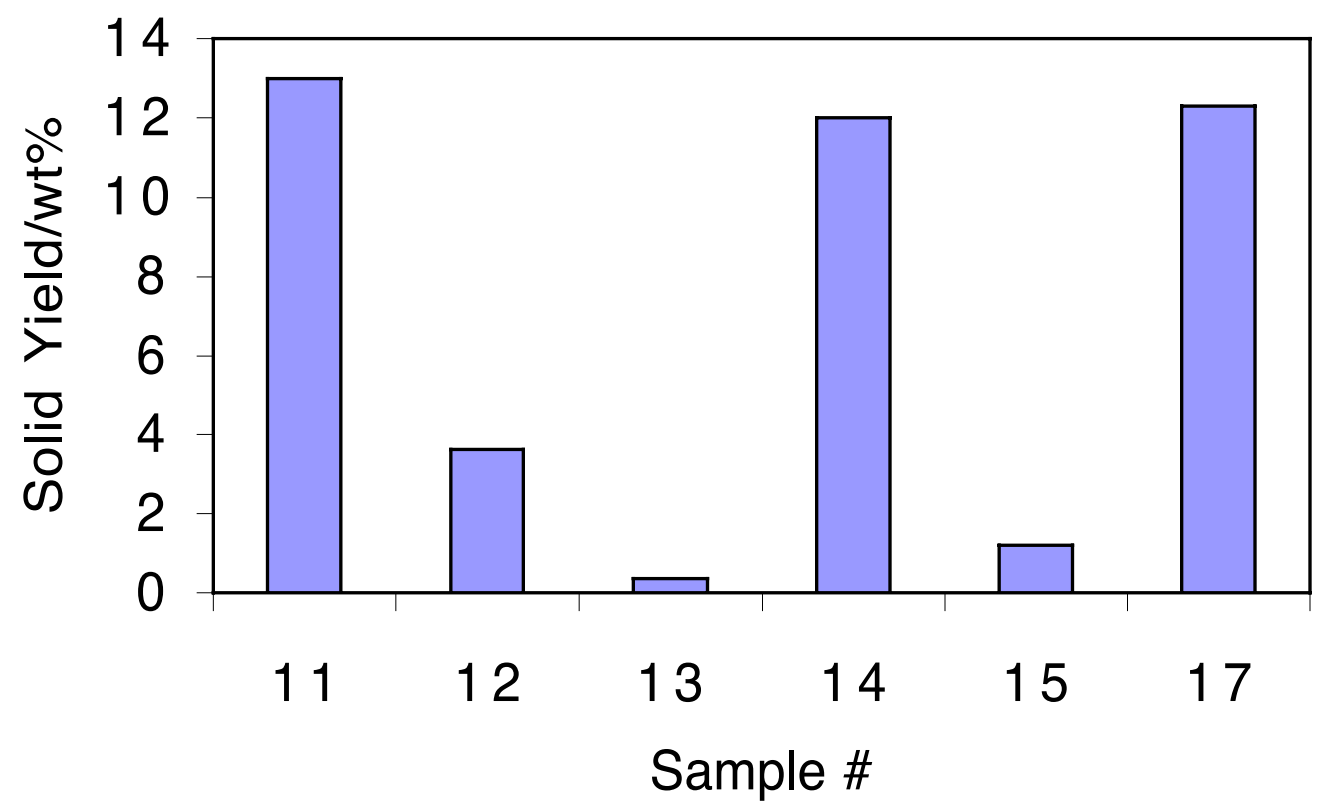

Figure 4.4. Yield of solids produced from samples \#11, 12, 13, 14, 15, 17 heated at $450 \mathrm{C}$ for $90 \mathrm{~min}$. 

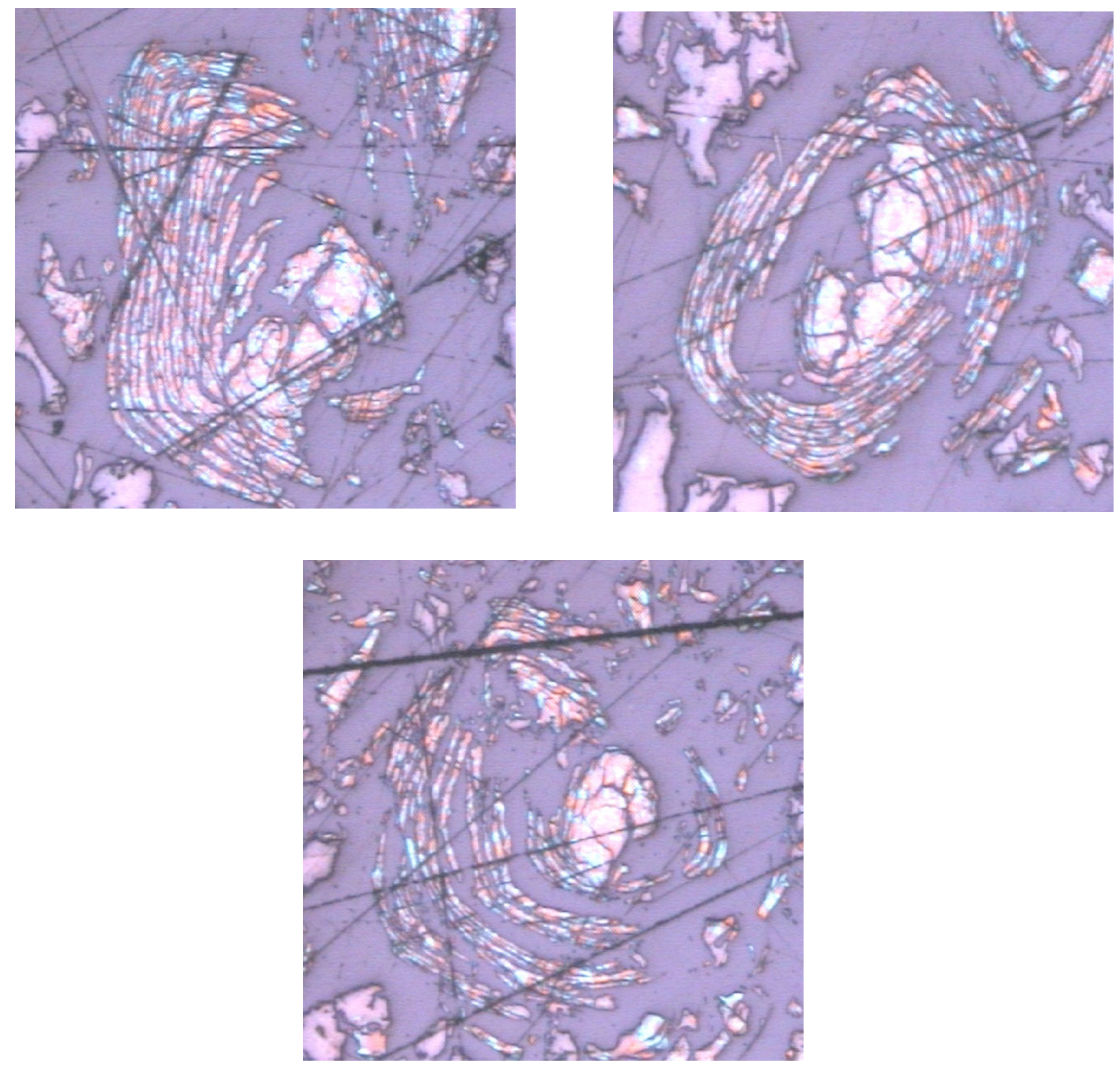

Figure 4.5 . Sample \#17 (Ethylene tar) solids produced at 450C and 90 minutes 

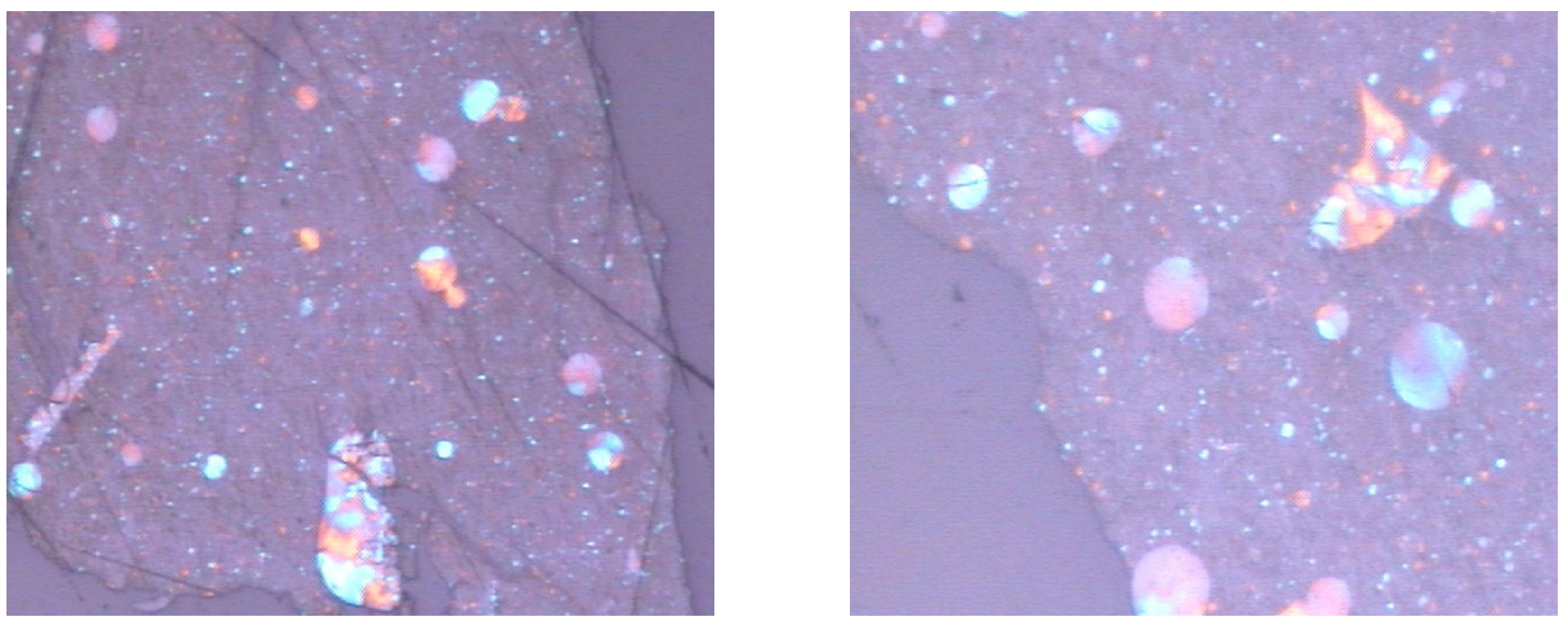

Figure 4.6. Sample \#14 (Decant Oil) solids produced at 450C and 90 minutes 

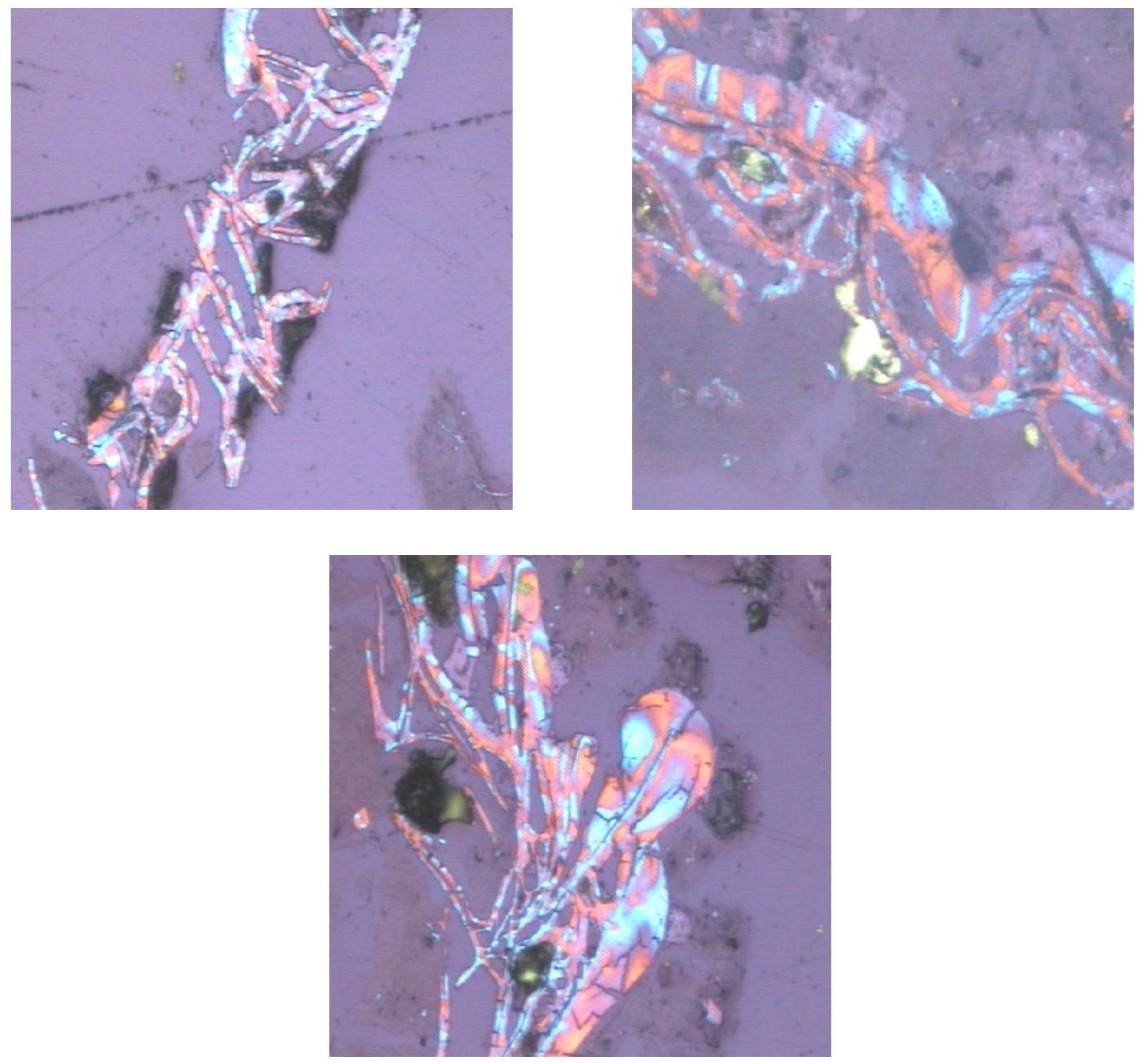

Figure 4.7. Sample \#12 (coal tar distillate) solids produced at 450C and 90 minutes 

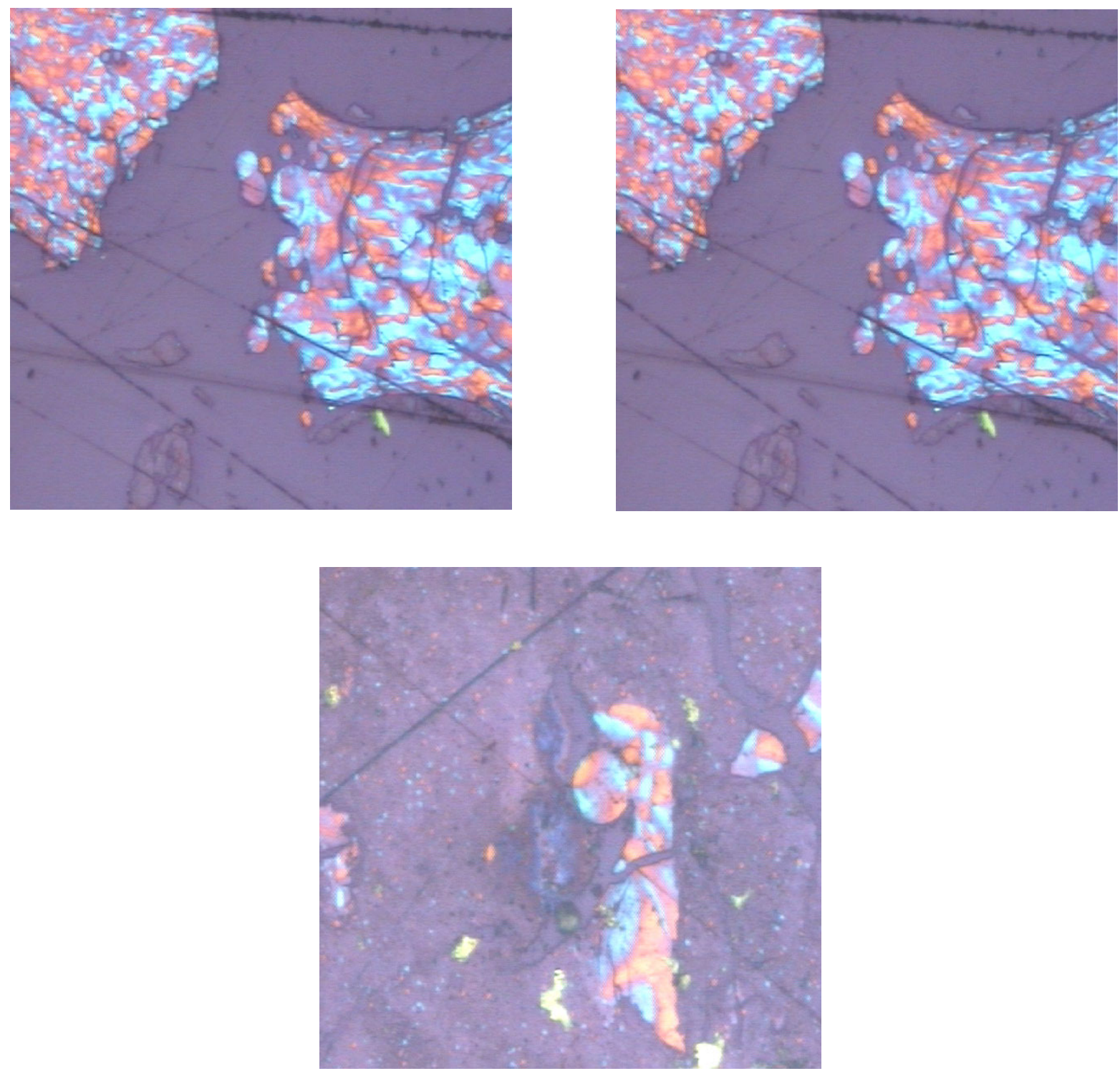

Figure 4.8. Sample \#11 (Decant Oil) solids produced at 450C and 90 minutes 


\title{
ANTHRACITES AS FEEDSTOCKS FOR BINDER PITCHES \\ OR CARBON FIBERS
}

\author{
FINAL REPORT \\ Reporting Period Start Date: January 1, 2000 \\ Report Prepared by \\ Bruce Conrad \\ Cornerstone Technologies \\ 126 S. Franklin Street \\ Wilkes-Barre, PA 18701
}

Reporting Period End Date: December 31, 2000

Report Issued

June 29, 2001

DOE Award Number DE-FC26-98FT40350

Other Contributors

The Pennsylvania State University

C211 Coal Utilization Laboratory

University Park, PA 16802 
Disclaimer:

This report was prepared as an account of work sponsored by an agency of the United States Government. Neither the United States Government nor any agency thereof, nor any of their employees, makes any warranty, express or implied, or assumes any legal liability or responsibility for the accuracy, completeness, or usefulness of any information, apparatus, product, or process disclosed, or represents that its use would not infringe privately owned rights. Reference herein to any specific commercial product, process, or service by trade name, trademark, manufacturer, or otherwise does not necessarily constitute or imply its endorsement, recommendation, or favoring by the United States Government or any agency thereof. The views and opinions of authors expressed herein do not necessarily state or reflect those of the United States Government or any agency thereof. 


\begin{abstract}
This report investigates the possibility of low-temperature hydrogenation of anthracite to produce a liquid product that would have potential applications in carbon materials technology as, e.g., binder pitches or precursors to carbon fibers. Reactions with $\approx 250 \mu \mathrm{m}$ (-60 mesh) LCNN anthracite, dihydroanthracene as a hydrogen donor, and molybdenum hexacarbonyl catalyst produce tetrahydrofuran-soluble products at $200^{\circ} \mathrm{C}$ and under $6.89 \mathrm{MPa}(1000 \mathrm{psi})$ hydrogen gas in a microautoclave reactor for 3 hours.

Major conclusions indicate that low-temperature hydrogenation of anthracite is possible. Optimization of conditions has to be accomplished depending on type of products desired. Data would then allow a decision to be made regarding a follow-on project to produce pilot-scale quantities of an anthracite-derived product for testing applications identified as a result of this project.
\end{abstract}




\section{TABLE OF CONTENTS}

Introduction $\quad 5$

$\begin{array}{ll}\text { Executive Summary } & 7\end{array}$

$\begin{array}{lr}\text { Experimental } & 8\end{array}$

$\begin{array}{ll}\text { Results and Discussion } & 10\end{array}$

$\begin{array}{ll}\text { Conclusions } & 13\end{array}$

$\begin{array}{lc}\text { References } & 14\end{array}$ 


\section{INTRODUCTION}

The hydro-treatment of aromatic structures to produce materials with fluid characteristics has been a quest for coal scientists for most of the 20th century. Different successful methods have been developed, including hydro-treatment of aromatic structures using hydrogen donors or the use of catalysts (Burgess, 1991; Dutta, 1996). One such example is the transformation of coal to liquids for the use as a thermally stable jet fuel, which was initiated and developed at Penn State (Burgess, 1994; Burgess and Schobert, 2000). Likewise, there is a major potential for hydro-treatment of highly aromatic structures, such as anthracite, over to viscous materials such as pitches. Taking into account the low volatile content of anthracite, the resultant fluid material could yield a binder pitch with superior coking yields, compared to those of current coal-tar-derived binder pitches that can lose up to 50 wt\% when heated (Andrésen et al., 1998a). Futhermore, there is a predicted reduced availability of coal tar pitch, especially in the US, due to the diminishing number of by-product coke-ovens, and therefore there is a clear need to produce pitches from alternative feedstocks or untraditional sources (Andrésen et al., 1999a). Both the structure and fluidity behavior of current coal tar binder pitches have been extensively characterized (Andrésen et al., 1998b; Andrésen et al., 1999b), making the basis for the synthesis of alternative binders. Due to its highly aromatic nature, low oxygen and other hetero-atom content and the possibility to achieve low ash levels, anthracite has been identified as an alternative feed-stock for the development of untraditional pitches. The key to successful use of anthracite for highperformance binder pitches may be the milling of the anthracite precursor to ultra-fine particles or powders, followed by tailored hydrogenation. Previous work has suggested that hydrogenation of anthracite is a feasible (Atria, 1995; Dutta, 1996). Accordingly, 
this work deals with the progress in anthracite hydrogenation, with the goal of producing an aromatic pitch from an hydrogenated anthracite. 


\section{EXECUTIVE SUMMARY}

The work presented here seeks to exploit various scattered observations made at Penn State that demonstrate the potential for producing liquid products from anthracites. Because of the expected highly aromatic nature of the resulting liquids, it is anticipated that they would have applications in carbon materials technology as, e.g., binder pitches or precursors to carbon fibers. The existing observations were made in the course of other projects and opportunities were not available at the time to follow up. Reactions of anthracites with hydrogen-donor molecules at $450-500^{\circ} \mathrm{C}$ transfer hydrogen to anthracite. The reaction occurs only at the particle surface, suggesting that if the anthracite could be ground to a fine enough particle size the reaction would proceed all the way through the particle, thus converting the anthracite completely. As seen in Figure 1., anthracite particles show evidence of hydrogenation at the edges. Therefore, by reducing the size of the anthracite particle to about $10 \mu \mathrm{m}$, hydrogenation will occur throughout the particle.

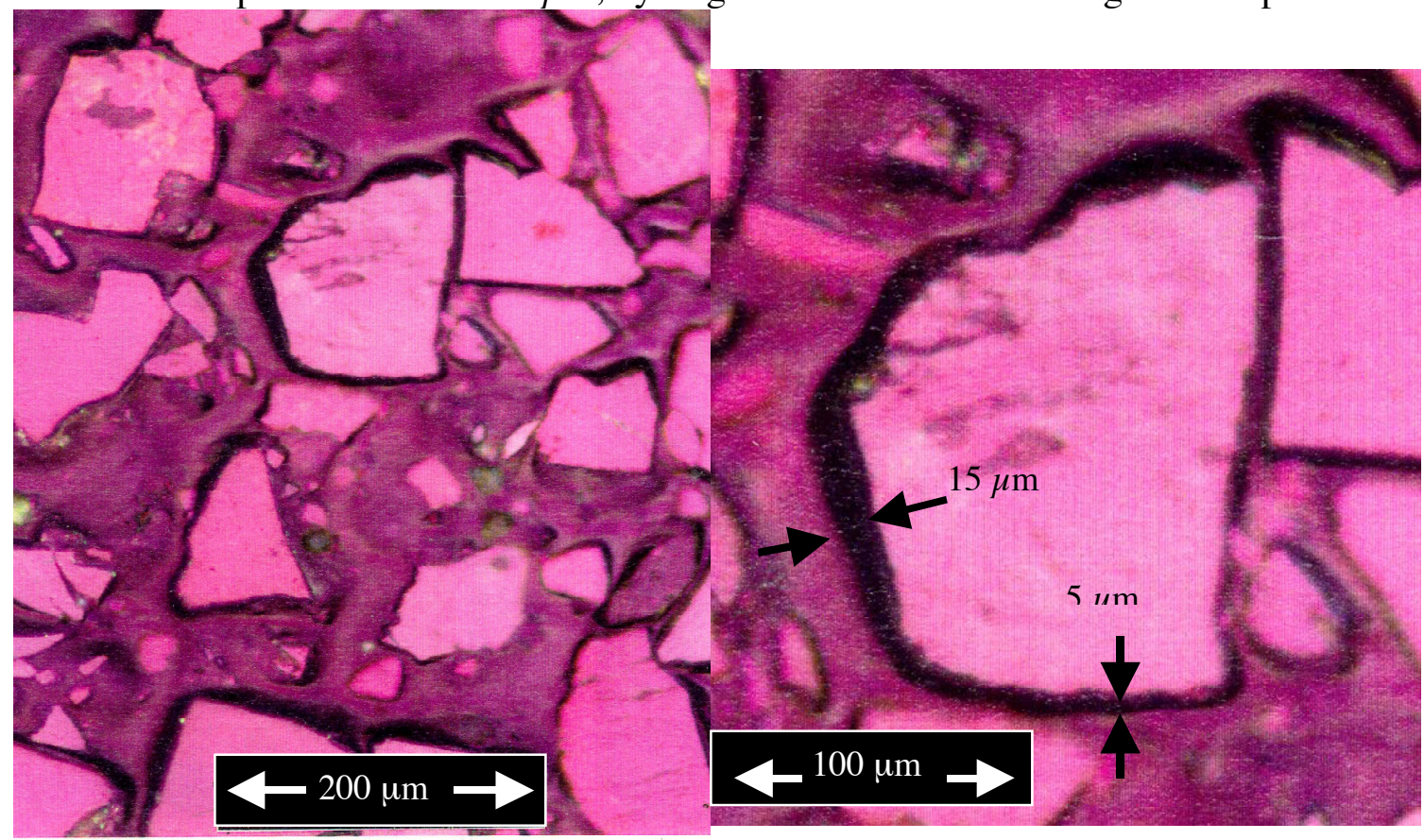

Figure 1. Optical micrograph of anthracite after hydrogenation.

Hydrogenation/dehydrogenation reactions of various aromatic molecules confirm that the larger the molecule, the lower the temperature that favors hydrogenation. Since anthracites consist of very large aromatic domains, this suggests that previous attempts to convert anthracites have been at too high a temperature. Thus low-temperature $\left(\approx 300^{\circ} \mathrm{C}\right)$ catalytic hydrogenation was proposed and tested. Results confirm that reaction with the coal takes place at low temperatures and under conventional pressures (6.89 $\mathrm{MPa}$ or 1000 psi). Yields and compositions of reaction products will be compared with existing commercial materials to determine future applications of these anthracite-derived substances in manufacture of premium carbon products. 


\section{EXPERIMENTAL}

The elemental and proximate analyses of the anthracites used, LCNN and Buck Mountain, are listed in Table 1. The letters ' $\mathrm{L}$ ' and ' $\mathrm{B}$ ' denote the coal used in that run, where ' $\mathrm{L}$ ' represents $\approx 250 \mu \mathrm{m}$ (-60 mesh) $\mathrm{LCNN}$ anthracite and 'B' represents $\approx 250 \mu \mathrm{m}$ Buck Mountain anthracite. The hydrogen donors used were dihydroanthracene (97\%, Aldrich), dihydrophenanthrene (94\%, Aldrich) and phenanthrene (98\%, Aldrich).

Table 1. Analyses of Buck Mountain and LCNN anthracites.

\begin{tabular}{|l|c|c|}
\hline \multicolumn{1}{|c|}{ Sample } & Buck Mountain & LCNN \\
\hline Proximate (as recieved) & 4.51 & 3.3 \\
\% Moisture & 6.52 & 6.7 \\
\% Ash & 3.49 & 4.5 \\
\% Volitile & 85.48 & 88.3 \\
\% Fixed Carbon & & \\
\hline Ultimate (dry) & 88.85 & 95.7 \\
\% Carbon & 1.29 & 1.5 \\
\% Hydrogen & 0.78 & 1.2 \\
\% Nitrogen & 0.49 & 0.5 \\
\% Total Sulfur & 1.76 & 1.0 \\
\% Oxygen (by diff.) & & \\
\hline
\end{tabular}

The anthracites and hydrogen donor mixtures were charged into stainless steel microautoclave reactors of nominal $20 \mathrm{ml}$ capacity in $3 \mathrm{~g}$ batches. The reactors were pressurized with 6.89 $\mathrm{MPa}$ (1000 psi) nitrogen or hydrogen gas and leak tested. Hydrogenation was conducted by immersing the reactors in a Techne FB-08 fluidised sandbath. The reactors were agitated at an average of 100 cycles/min to keep reactants well mixed. After reaction the reactors were quenched to room temperature by submersing them in water. Reaction products were Soxhlet-extracted with tetrahydrofuran (THF). The THF used was HPLC grade from J. T. Baker, and extraction was conducted for 24 hours.

The mixing ratios by weight of LCNN to hydrogen donor used for different isothermal runs are listed in Table 2. All runs with LCNN were carried out at 1000 psi $\mathrm{H}_{2}$ and at $300^{\circ} \mathrm{C}$. The catalyst used was molybdenum hexacarbonyl $\left(\mathrm{Mo}(\mathrm{CO})_{6}\right)$. Table 3 lists the conditions for the runs using Buck Mountain anthracite. These runs used a 
$75 / 25 \%$ ratio by weight of hydrogen donor to coal under nitrogen or hydrogen and the soaking times varied from 3 to 48 hours.

Table 2. Sample conditions of $\mathrm{LCNN}$ anthracite at $300^{\circ} \mathrm{C}$ for $3 \mathrm{~h}$ under $\mathrm{H} 2$.

\begin{tabular}{|l|l|l|l|}
\hline Run \# & Hydrogen Donor & Coal to H-donor ratio & Coal to Catalyst Ratio \\
\hline 2L & Dihydroanthracene & 1 to 1 & 10 to 1 \\
\hline 3L & Dihydroanthracene & 1 to 2 & 10 to 1 \\
\hline 4L & Dihydroanthracene & 1 to 1 & 2 to 1 \\
\hline 5L & None & 1 to 0 & 10 to 1 \\
\hline $7 \mathrm{~L}$ & Dihydrophenanthrene & 1 to 1 & 10 to 1 \\
\hline 15L & Dihydroanthracene & 1 to 1 & No Catalyst \\
\hline
\end{tabular}

Table 3. Sample conditions and heating profiles of Buck Mountain anthracite.

\begin{tabular}{|l|l|l|l|}
\hline Run \# & Catalyst & Gas & Heating Profile \\
\hline 9B & No catalyst & $\mathrm{N} 2$ & $200^{\circ} \mathrm{C}$ for $3 \mathrm{~h}$ \\
\hline 10B & No catalyst & $\mathrm{N} 2$ & $\begin{array}{l}200^{\circ} \mathrm{C} \text { for } 3 \text { hours; } 6^{\circ} \mathrm{C} / \mathrm{min} \text { to } \\
500^{\circ} \mathrm{C} ; 2 \mathrm{~h} \text { hold at } 500^{\circ} \mathrm{C}\end{array}$ \\
\hline 11B & No catalyst & $\mathrm{N} 2$ & $200^{\circ} \mathrm{C}$ for $48 \mathrm{~h}$ \\
\hline 12B & $\mathrm{Mo}(\mathrm{CO})_{6}$ & $\mathrm{H} 2$ & $200^{\circ} \mathrm{C}$ for $48 \mathrm{~h}$ \\
\hline
\end{tabular}




\section{RESULTS AND DISCUSSION}

The tetrahydrofuran (THF) solubility of the products can be used as the good indicator of the degree of hydrogenation of anthracites, and Table 4 lists the THF extraction values for the runs with the LCNN anthracite. These reactions used dihydroanthracene and dihydrophenanthrene as hydrogen donors and molybdenum hexacarbonyl $\left(\mathrm{Mo}(\mathrm{CO})_{6}\right)$ as a catalyst. $\mathrm{Mo}(\mathrm{CO})_{6}$ was used because it has been reported as a good coal liquefaction catalyst (Yamada, et al., 1985; Artok, et al., 1993) and has a relatively low melting point, $150^{\circ} \mathrm{C}$, suitable for this low-temperature reaction. Therefore, Table 4 also compares the use of different amounts of catalyst used in the reactions as well as different hydrogen donors. There is a difference of $3.9 \%$ between using a coal to hydrogen donor ratio of 1 to 1 and a ratio of 1 to 2 , as seen by comparing runs $2 \mathrm{~L}$ and $3 \mathrm{~L}$. However, since there is not an increase in THF solubles with an increase in hydrogen donor, it confirms that the THF-soluble product is not only unreacted hydrogen donor, but that some coal reaction has occurred. Another comparison, between runs $2 \mathrm{~L}$ and $4 \mathrm{~L}$, confirms that there is not a significant difference in THF-soluble yield between a 10 to 1 coal to catalyst ratio and a 2 to 1 ratio. Therefore, a 10 to 1 ratio was used throughout the remainder of the experiments where catalyst was added. Furthermore, dihydrophenanthrene seems to produce fewer THF solubles than dihydroanthracene, as shown by the comparison of run $2 \mathrm{~L}$ and $7 \mathrm{~L}$. Run $15 \mathrm{~L}$ demonstrates that the reaction produces negligible THF solubles when a catalyst is absent.

Table 4. Comparison of THF-soluble yields for different H-donors and catalyst ratios.

\begin{tabular}{|c|c|c|c|}
\hline Run \# & Hydrogen Donor & Coal to Catalyst Ratio & THF Solubles \\
\hline 2L & Dihydroanthracene & 10 to 1 & $41.5 \%$ \\
\hline 3L & Dihydroanthracene* & 10 to 1 & $37.6 \%$ \\
\hline 4L & Dihydroanthracene & 2 to 1 & $42.7 \%$ \\
\hline 5L & None & 10 to 1 & $33.1 \%$ \\
\hline 7L & Dihydrophenanthrene & 10 to 1 & $<1 \%$ \\
\hline 15L & Dihydroanthracene & No Catalyst & $<$ \\
\hline
\end{tabular}

*Run $3 \mathrm{~L}$ has a 1 to 2 ratio of coal to dihydroanthracene, whereas all other have 1 to 1 ratio. 
Table 5 compares the use of different heating profiles on the Buck Mountain anthracite. The results of this comparison show that more reaction occurs when reacted longer and at higher temperatures. Table 6 compares reactions over a 48-hour period under different conditions for Buck Mountain anthracite. Run 11B had no catalyst and was under nitrogen gas, whereas run $12 \mathrm{~B}$ had a 10 to 1 ratio by weight of coal to $\mathrm{Mo}(\mathrm{CO})_{6}$ and was under hydrogen gas. The results are inconsistent with the results from experiments performed above. It was expected that with the catalyst and under hydrogen gas, more coal would break apart and produce liquid products.

Table 5. Comparison of THF-soluble yields with heating profiles for Buck Mountain anthracite.

\begin{tabular}{|c|c|c|}
\hline Run \# & Heating Profile & THF Solubles \\
\hline $9 \mathrm{~B}$ & $200^{\circ} \mathrm{C}$ for $3 \mathrm{~h}$ & $8.4 \%$ \\
\hline $10 \mathrm{~B}$ & $200^{\circ} \mathrm{C}$ for 3 hours; $6^{\circ} \mathrm{C} / \mathrm{min}$ to & $30.1 \%$ \\
& $500^{\circ} \mathrm{C} ; 2 \mathrm{~h}$ hold at $500^{\circ} \mathrm{C}$ & \\
\hline
\end{tabular}

Table 6. Comparison of THF-soluble yields for different conditions for $48 \mathrm{~h}$.

\begin{tabular}{|c|c|c|}
\hline Run \# & Catalyst and Gas Used & THF Solubles \\
\hline 11B & No catalyst under N2 & $58.9 \%$ \\
\hline 12B & $\mathrm{Mo}(\mathrm{CO})_{6}$ under H2 & $10.6 \%$ \\
\hline
\end{tabular}

Further experimentation has been done to analyze the effect of coal particle size on hydrogenation reactions. The reactions in this set of data are using LCNN anthracite, dihydroanthracene as hydrogen donor, and molybdenum hexacarbonyl as catalyst under 1000 psi hydrogen and reacted at $300^{\circ} \mathrm{C}$. The reactant ratio reflects the amount of coal that is reacted with hydrogen donor and catalyst, respectively. Runs $17 \mathrm{~L}$ and $18 \mathrm{~L}$ represent the control group, where no hydrogen donor or catalyst was used. Runs 19L and $20 \mathrm{~L}$ represent a normal reaction using hydrogen donor and catalyst. This data is summarized briefly in Table 7 . 
Table 7. Comparison of THF-soluble yields for different particle sizes.

\begin{tabular}{|c|c|c|c|}
\hline Run \# & Reactant ratio* $^{*}$ & Particle Size $(\boldsymbol{\mu})$ & THF Solubles \\
\hline 17L & $10: 0: 0$ & 250 & $0.0 \%$ \\
\hline 18L & $10: 0: 0$ & 17 & $6.1 \%$ \\
\hline 19L & $10: 10: 1$ & 250 & $41.5 \%$ \\
\hline 20L & $10: 10: 1$ & 17 & $46.0 \%$ \\
\hline
\end{tabular}

*Reactant ratio represents the ratio of coal to hydrogen donor to catalyst, respectively.

Based on these results, a clear correlation can be made relating particle size to hydrogenation of anthracite. Coal having a particle size of $17 \mu$ produces more THF solubles than coal having a particle size of $250 \mu$ as expected from the theory presented above.

Coal pretreatment, or "radical quenching", was performed with samarium iodide on Pittsburgh \#8 bituminous coal to examine the effects of free radical interactions that may be holding the coal together. An established procedure was followed (Chen et al., 1998; Muntean et al. 1988). Effects are assumed to be more apparent in bituminous coal because of its known swelling ability. Results suggest that samarium iodide is a good radical quesnching agent. 


\section{CONCLUSIONS}

Several conclusions can be drawn from the results above. Dihydroanthracene works well as a hydrogen donor at a 1 to 1 ratio by weight of coal to hydrogen donor and $\mathrm{Mo}(\mathrm{CO})_{6}$ works well as a catalyst at a 10 to 1 ratio by weight of coal to catalyst for producing a THF-soluble product from $\approx 250 \mu \mathrm{m}(-60 \mathrm{mesh}) \mathrm{LCNN}$ anthracite at low temperatures. Also, there is evidence that extensive hydrogenation occurs on $\approx 250 \mu \mathrm{m}$ PSOC-1468 anthracite somewhere between $200^{\circ} \mathrm{C}$ and $500^{\circ} \mathrm{C}$.

More importantly, coal having a particle size of $17 \mu$ produces more THF solubles than coal having a particle size of $250 \mu$. This supports the theory presented above that smaller particle size coal will react more completely than larger particle sizes.

The results presented above confirm the theory that anthracite coal can be reacted at low temperatures to produce a THF-soluble liquid product. This coal-derived liquid will, conceptually, consist of large aromatic molecules. Such a liquid, having these properties, has potential to have applications in carbon materials technology as, e.g., binder pitches or precursors to carbon fibers.

When substantial analytical data are in hand it will be possible to conduct an assessment of the nature of the anthracite-derived products as they compare to current commercial products such as high-temperature coal tar pitches and feedstocks for carbon fiber production. That assessment constitutes a task that would be completed in the years following the current project. An entirely separate follow-on project could then be proposed to produce pilot-scale quantities of an anthracite-derived product for testing in targeted applications identified as a result of this present work. 


\section{REFERENCES}

J.M. Andrésen, C.A. Luengo, S.R. Moinelo, R. Garcia and C.E. Snape, Structural uniformity of toluene-insolubles from heat-treated coal tar pitch as determined by solid state ${ }^{13} \mathrm{C}$ NMR spectroscopy, Energy and Fuels, 12, 524-530, 1998a.

J.M. Andrésen, Y. Martín, S.R. Moinelo, M.M. Maroto-Valer and C.E. Snape, Solid state

${ }^{13} \mathrm{C}$ NMR and high temperature ${ }^{1} \mathrm{H}$ NMR determination of bulk structural properties for mesophase-containing semi-cokes prepared from coal tar pitch, Carbon, 36, 1043-1050, 1998b.

J.M. Andrésen, H.H. Schobert and F.J. Rusinko Jr., Structural characterization of coal tar pitches for the development of superior anode binders, International Conference on Coal Science, Taiyuan, China, 729-732, 1999a.

J.M. Andrésen, H.H. Schobert and F.J. Rusinko Jr., Correlation Between Structure and Fluidity of Coal Tar Pitch Fractions Studied By Ambient ${ }^{13} \mathrm{C}$ and High Temperature InSitu ${ }^{1} H$ Nuclear Magnetic Resonance, $16^{\text {th }}$ International Pittsburgh Coal Conference, Pittsburgh, USA, Paper 22-3.pdf (CD-ROM publication), 1999b.

L. Artok, A. Davis, G.D. Mitchell, and H.H. Schobert, Swelling pretreatment of coals for improved catalytic liquefaction. Energy and Fuels, 7, 67-77, 1993.

J.V. Atria, Novel approach to the production of graphite from anthracite, M.Sc. Thesis, The Pennsylvania State University, 1995.

C.E. Burgess, Direct coal liquefaction: A potential route to thermally stable jet fuel, Ph.D. Thesis, The Pennsylvania State University, 1994.

C.E. Burgess, Temperature-staged coal liquefaction of a subbituminous coal, using a hydrogen-donor-containing catalyst, M.Sc. Thesis, The Pennsylvania State University, 1991. 
C.E. Burgess and H.H. Schobert, Direct liquefaction for production of high yields of feedstocks for specialty chemicals or thermally stable jet fuels. Fuel Processing Technology, 64, 57-72, 2000.

C. Chen, J. Gao and Y. Yan, Role of Noncovalent Bonding in Swelling of Coal. Energy and Fuels, 12, 1328, 1998.

R.P. Dutta, Catalytic Hydrogenation-dehydrogenation of multicyclic compounds under fuel processing conditions, Ph.D. Thesis, The Pennsylvania State University, 1996.

J.V. Muntean, L.M. Stock and R.E. Botto, Improving the Reliability of Quantitative Solid-State C NMR Analysis of Coal. Energy and Fuels, 2, 1, 1988.

O. Yamada, T. Suzuki, J.H. Then, T. Ando and Y. Watanabe, Use of Various Metal Carbonyls as Catalyst Precursors for Coal Hydroliquefaction, Fuel Processing Technology, 11, 297, 1985. 


\title{
RECOVERY AND UTILIZATION OF CARBON FROM COAL-FIRED POWER PLANT FLY ASH
}

\author{
FINAL ANNUAL TECHNICAL PROGRESS REPORT
}

Reporting Period Start Date: January 1, 2000

Reporting Period End Date: June 30, 2001

Principal Authors: Dr. M. Mercedes Maroto-Valer

Dr. John M. Andrésen

Dr. Yinzhi Zhang

DOE Award number: DE-FC26-98FT40350

Submitting Organization: The Energy Institute

The Pennsylvania State University

405 Academic Activities Building

University Park, PA 16802-2398

Phone: (814) 8638265

Fax: (814) 8638892 


\section{Disclaimer}

This report was prepared as an account of work sponsored by an agency of the United States Government. Neither the United States Government nor any agency thereof, nor any of their employees, makes any warranty, express or implied, or assumes any legal liability or responsibility for the accuracy, completeness, or usefulness of any information, apparatus, product, or process disclosed, or represents that its use would not infringe privately owned rights. Reference herein to any specific commercial product, process or service by trade name, trademark, manufacturer, or otherwise does not necessarily constitute or imply its endorsement, recommendation, or favoring by the United States or any agency thereof. The views and

opinions of authors expressed herein do not necessarily state or reflect those of the United States or any agency thereof. 


\begin{abstract}
The concentration of unburned carbon present in fly ash has risen drastically over the last years, due to the implementation of increasingly stringent Clean Air Act Regulations regarding NOx emissions. The carbon-rich ash is either placed in holding ponds or landfilled and it is estimated that in 1997 around 6-8 million tons of unburned carbon were disposed due to the present lack of efficient routes for its utilization. However, the utilization of fly ash carbon can bring enormous economical and environmental benefits to the coal, utility and carbon industries. Accordingly, the overall objective of this research program is to develop routes for the recovery and utilization of carbon from coal-fired power plant fly ash. Seven collaborating organizations participated in this research program, including Reliant Energy, Carbon Plus, Prep Tech, Koppers Industries, Calgon Carbon, West Materials and The Pennsylvania State University.

This research program included the selection and characterization of a suite of coal-fired power plant fly ashes. During the present Phase II an industrial test was conducted on October 9-11, 2000 to implement the Carbon Plus technology at Shawville (Reliant Energy) power plant in Pennsylvania to precipitate selectively the unburned carbon. During the test it is estimated that Reliant used 4,300 tons of coal. The test successfully complied with DEP environmental requirements and it was shown that the carbon can be successfully concentrated in selected hoppers. The protocols developed during Phase I were used as baseline to establish optimum routes for the generation of activated carbon materials and carbon artifacts. The work reported here has also demonstrated the ability of unburned carbon from coal combustion by-products to generate activated carbons by steam activation. The surface area of the activated samples reached values up to $688 \mathrm{~m}^{2} / \mathrm{g}$, where high surface areas are characteristic for commercial activated carbons. For the carbon artifacts, the baking yields were very similar for all the carbon bodies investigated, around $90 \%$, as expected from the similar thermal history of petroleum coke and fly ash carbons. The densities of the green and baked carbon bodies produced with only petroleum coke were slightly higher than those of the carbon bodies prepared using fly ash carbon, probably due to the small particle size distribution of the formulations used.

The outcome of this research project can pave the way for the coal utilities to view unburned carbon as an asset instead of a liability and therefore preventing them from switching to natural gas and, hence, they will continue using coal as their main energy source. In addition, the carbon industries, such as those producing activated carbon and carbon artifacts, could then have cost-effective and novel precursors.
\end{abstract}

"Recovery and Utilization of Carbon from Coal-Fired Power Plant Fly Ash"; Page 3 


\section{Table of contents}

Page

1. INTRODUCTION

1.1. Rationale 6

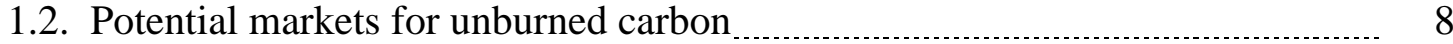

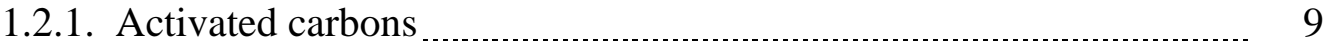

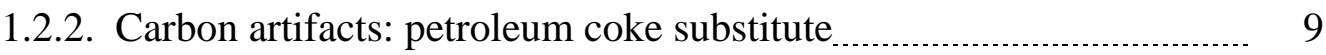

1.3. Program objectives and research design _..._................................. 10

1.3.1. Task 1: Suite selection and characterization $\quad 10$

1.3.2. Task 2: Beneficiation of fly ash carbon ………............................... 10

1.3.3. Task 3: Production of premium carbon products _................. 11

2. EXECUTIVE SUMMARY 13

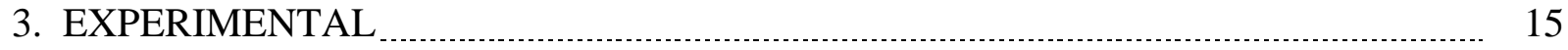

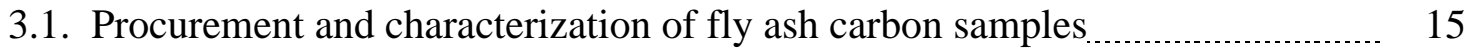

3.2. Beneficiation of fly ash carbon samples $\quad 15$

3.3. Production of activated carbons _.................................................. 16

3.4. Development of carbon artifacts 16

4. RESULTS AND DISCUSSION 17

4.1. Procurement and characterization of fly ash carbons _.............................. 17

4.1.1. Fly ash procurement _................................................................ 17

4.1.2. Loss-on-ignition (LOI) characterization _._._..... 17

4.2. Beneficiation of fly ash carbons _................................................. 18

4.2.1. Industrial scale testing _ 18

4.2.1.1. Industrial test preparation _....................................... 19

4.2.1.2. Implementing the technology _.... 19

4.2.1.3. Outcome of technology implementation test _................. 20

4.2.2. Laboratory scale beneficiation _............................................... 22 
4.3. Production of premium carbon products $\quad 23$

4.3.1. Production of activated carbons _........................................... 23

4.3.1.1. Steam activation: Effect of activation time _..................... 23

4.3.1.2. Steam activation: Pore volume distribution _........................ 24

4.3.2. Production of carbon artifacts _................................................. 25

4.3.2.1. Green carbon artifacts $\quad 26$

4.3.2.2. Baked carbon artifacts ...................................................... 27

5. CONCLUSIONS

6. PROJECT RELEVANCE TO THE COAL INDUSTRY _...................................... 31

7. REFERENCES 33 


\section{INTRODUCTION}

\subsection{Rationale}

The concentration of unburned carbon present in fly ash has risen drastically over the last years, due to the implementation of increasingly stringent Clean Air Act Regulations regarding NOx emissions (Maroto-Valer et al., 1998a; and 1999a). This has restricted the principal use of ash in the cement industry, since the carbon present in fly ash tends to adsorb the air-entrainment agents, which are added to the cement to prevent crack formation and propagation (Maroto-Valer et al., 1998b; 1999b; and 2001a). Consequently, the carbon-rich ash is either placed in holding ponds or landfilled and it is estimated that in 1997 around 6-8 million tons of unburned carbon were disposed (Maroto-Valer et al, 2000a). However, this landfill option results in rising costs for the utility companies in addition to the loss of revenue from ash sales. Moreover, the increasingly severe regulations on landfill and the limited access to new disposal sites with the subsequent rise in the cost of disposal, may demand the utility industry to begin offsetting coal combustion with natural gas, or require additional coal cleaning to remove the ash prior to combustion, or simply start utilizing the carbon in fly ash. The first two alternatives could compromise the coal industry, since the utilities could potentially reduce the NOx emissions and the ash disposal problem by using gas instead of coal as fuel, or require additional coal cleaning, which would increase the cost of the coal as fuel and reduce its competitive advantage (MarotoValer et al., 1998a; and 1999a). Consequently, the third alternative, concerning the use of fly ash carbon, will beneficiate both the coal and utility industries, and accordingly, environmental and cost-effective strategies need to be established for the use of these carbonaceous products from coal combustion. The authors have previously conducted extensive studies on the characterization of unburned carbon and showed that its properties are similar to those of conventional precursors for the production of premium carbon materials (Maroto-Valer et al., 1999b; 1999c; and 2001a).

During Phase I of this project, two routes for the utilization of fly ash carbon as precursor for the generation of premium carbon products were developed (Maroto-Valer et al., 2000a). The first route focused on the use of fly ash carbons as precursors for activated carbons. The present global consumption of activated carbons is estimated to rise around $7 \%$ annually, due to 
the ubiquitous use of activated carbons as adsorbent materials in a broad range of increasing environmental applications. Furthermore, fly ash carbons were readily converted into activated carbons, since they have already gone through a devolatilization process while in the combustor and, therefore, only required to be activated. Phase I showed that after steam activation at $850^{\circ} \mathrm{C}$, the fly ash carbons generated activated carbons with surface areas up to $\sim 450 \mathrm{~m}^{2} / \mathrm{g}$ with high solid yields (Maroto-Valer et al., 2000a). The second route concentrated on the utilization of fly ash carbons as replacement for calcined petroleum coke for the production of carbon artifacts. Currently, calcined petroleum coke is the dominant precursor for carbon artifacts and around 6 million tons of calcined petroleum coke, worth around \$1,200 million, are sold annually in US for the manufacture of carbon artifacts. During Phase I of this project, fly ash carbon from coal combustion proved to be very strong competitor, since fly ash carbons have similar H/C atomic ratios and thermal history to that of calcined petroleum coke (Andrésen et al., 1999; and 2000). For instance, Phase I proved that the helium density of carbon artifacts prepared with fly ash carbon is superior to that of conventional carbon artifacts prepared with petroleum coke, due to a synergistic effect between the fly ash carbon and the coal tar binder pitch used (Maroto-Valer et al., 2000a). An additional direct benefit of using fly ash carbon for carbon artifacts is the elimination of the heavy metal impurities, such as $\mathrm{Ni}$ and $\mathrm{V}$, as well as substantially lowering the sulfur content, that are present in petroleum coke and are known to mar the carbon products used in the aluminum and steel industries. The above two routes for the utilization of fly ash carbon identified in Phase I have clearly indicated that the added value generated from the fly ash carbon utilization would bring additional revenues to the coal-fired power plants and prevent them from offsetting coal combustion with natural gas, or from demanding additional coal cleaning. For instance, the average price for a ton of activated carbon ranges from $\$ 500$ up to $\$ 4000$, which implies a potential 25-200 fold increase compared to the price of the ash $(<\$ 20 /$ ton $)$. For the case of carbon artifacts, the calcined petroleum coke used for their manufacture usually costs $\sim$ 200-250 / ton.

The challenging issue during Phase I of this project was to meet the ash purity requirement for the utilization of fly ash carbon as precursor for carbon materials. For instance, to serve as a precursor in the production of activated materials, fly ash carbons must compete against wood precursors, that present very low ash contents $(<5 \%)$. However, since fly ash carbons consist primarily of carbon with extremely low hydrogen content (below $0.2 \%$ ) they 
present much higher solid yields upon activation than conventional raw materials, such as wood, where the solid yields after activation can be as low as $10 \%$. The ash requirement becomes even more stringent for the case of carbon artifacts, where typical commercial cokes contain less than $1 \%$ ash, preferably in the 100-300 ppm range. Therefore, it must be acknowledged that for fly ash carbon to compete effectively with conventional carbon materials precursors, it must be readily and cost-effectively separated from the ash. During Phase I, a company with a commercially available separation technology, Carbon Plus, was identified and it has became a collaborating organization in the present proposal. Their turnkey carbon recovery technology, which is currently used at First Energy's Niles, Ohio power plant can provide a concentrated stream of carbon fly ash (ash content 20\%) and the minimal costs involved can be easily recovered by the revenues from the sales of the carbon concentrates. In addition, preliminary studies conducted during Phase I have shown that ash levels of fly ash carbons can be reduced to $<3 \%$ by standard acid digestion methods (Maroto-Valer et al., 2000a). In addition, an industrial scale test was conducted on October 9-11, 2000 to implement the Carbon Plus technology at Shawville (Reliant Energy) power plant in Pennsylvania. We believe that this was the only industrial test conducted during year 2000 under the auspices of any CPCPC project.

\subsection{Potential markets for unburned carbon}

The utilization of unburned carbon can bring enormous economical and environmental benefits to both the coal and utility industry. Although several technologies have been successfully developed to separate the unburned carbon from the fly ash, only a few power plants have installed a beneficiation process on their sites. This is due to the low value of the resultant separated materials, since a ton of fly ash is generally sold for as little as \$10-20, and the unburned carbon is simply disposed or rerouted to the combustor. However, the economics of this process can be greatly enhanced if both separated materials can be used as precursors for high-value products. In fact, this is the case for the unburned carbon, which can be used as an excellent precursor for the generation of premium carbon products, like activated carbons and carbon artifacts. Therefore, the added value generated from the unburned carbon utilization would clearly offset the cost of the separation process. For instance, the average price for a ton of activated carbon ranges from $\$ 500$ up to $\$ 4000$, which implies a potential 25-200 fold increase compared to the price of the ash $(<\$ 20 /$ ton $)$. For the case of carbon artifacts, the calcined petroleum coke used for their manufacture usually costs $~ \$ 220-250$ / ton. 


\subsubsection{Activated carbons}

The present global consumption of activated carbons is over 350,000 tons and it is estimated to rise around 7\% annually. The main reason for this expanding market is the ubiquitous use of activated carbons as adsorbent materials in a broad range of increasing household, medical, industrial, military and scientific applications. These range from gas-phase adsorption in household air conditioning equipment and industrial emissions control, to liquidphase adsorption for water treatment and even gold recovery. Due to the expanding market for activated carbons, especially in applications related to environmental protection, new precursors are being sought. However, for these new precursors to compete effectively with conventional raw materials, such as wood, they must be inexpensive, have a low mineral matter content and be easily converted into activated carbons. The unburned carbon in the fly ash furnishes satisfactorily all these conditions, since it can (i) be easily obtained from the utility industries as a by-product; (ii) beneficiated from the fly ash by commercially available techniques; and (iii) it has already gone through a devolatilization process while in the combustor and, therefore, only requires to be activated (Maroto-Valer et al., 1998a; and 1999d).

\subsubsection{Carbon artifacts: petroleum coke substitute}

Currently, 6 million tons of calcined petroleum coke, worth around \$1,200 million, are sold annually in US for the manufacture of carbon artifacts. Even though calcined petroleum coke is the dominant precursor for carbon artifacts, the unburned carbon from coal combustion is a potential competitor, as described here. The unburned carbon has been treated at temperatures well above $1200-1300^{\circ} \mathrm{C}$, and can be regarded as calcined coke. For instance, the $\mathrm{H} / \mathrm{C}$ atomic ratios of the unburned carbon are below 0.02 and they are comparable with commercial precursors for carbon artifact production, where the typical $\mathrm{H} / \mathrm{C}$ atomic ratios are around 0.01 (Maroto-Valer et al., 2001a). The challenging issue in this task will be to meet the purity requirement, since typical commercial cokes contain less than $1 \%$ ash, preferably in the 100-300 ppm range. Sink/float methods using a high-density liquid media can effectively enrich the carbon content, by reducing the ash to around 10-20\% (Alonso et al., 1999). Other methods, such as acid digestions, can further reduce this value. Previous work conducted on the removal of mineral matter from coal, has shown that ash levels as low as 100-200 ppm are readily achieved by acid digestion (Maroto-Valer et al., 1998c). Therefore, the unburned carbon from 
coal combustion could be a strong competitor to petroleum coke for the production of carbon artifacts.

\subsection{Program objectives and research design}

The overall objective of this research program is to develop and commercialize routes for the recovery and utilization of carbon from coal-fired power plant fly ash. This research program included the following tasks:

\subsubsection{Task 1: Suite selection and characterization}

A suite of coal-fired power plant fly ashes were selected and characterized at The Pennsylvania State University. The samples were selected from the sample bank of Carbon Plus and included high-carbon fly ashes from coal-fired power plants, where the separation technology of Carbon Plus has been successfully installed. In addition, samples from a coalfired power plant operated by Reliant Energy and where Carbon Plus conducted an evaluation of the installation of their separation process were also included in the suite. This coal-fired power plant was the Pennsylvania utility located at Shawville, where during Phase I of this project, a detailed study of a series of fly ash hoppers of Unit \#4 revealed the presence of fly ash carbons with an ash content $<50 \%$ (Maroto-Valer et al., 2000a). The characterization studies included thermogravimetric profiles and particle size distribution studies, as well as proximate analyses. Furthermore, the properties of these high-carbon fly ash samples towards their use as precursors for carbon products were also investigated.

\subsubsection{Task 2: Beneficiation of fly ash carbon}

In addition to the above industrial scale test, a laboratory scale beneficiation was also conducted. As previously described, the challenging issue in the utilization of carbon from fly ash is to meet the ash purity requirement of precursors for carbon materials. The separation method of Carbon Plus provided samples with carbon content $\sim 80 \%$, that were further beneficiated using several protocols, including acid digestion and oil agglomeration. Preliminary studies conducted during Phase I of this project have shown that ash levels can be reduced to < $3 \%$ by standard acid digestion methods, and this protocol was further explored and optimized

"Recovery and Utilization of Carbon from Coal-Fired Power Plant Fly Ash"; Page 10 
during Phase II at The Pennsylvania State University (Maroto-Valer et al., 2000a). The ultimate goal of this Task is to facilitate a process, that can reduce the inorganic content of fly ash carbons to levels acceptable for the manufacture of carbon products, while still being an economically sustainable beneficiation process.

\subsubsection{Task 3: Production of premium carbon products}

The high-purity carbon samples obtained from the above enrichment process were used to produce premium carbon products at The Pennsylvania State University. Samples derived from the beneficiation step developed in Task 2 were used in Task 3. Based on the protocols successfully developed in Phase I of this project, a parametric study was conducted for the production of (3a) activated carbons and (3b) carbon artifacts.

Task 3a. Production of activated carbons The activation of the fly ash carbon was carried out in an activation furnace that was designed and used by the proposers to activate carbon from coal-fired power plant ashes (Maroto-Valer et al., 2000a). During Phase I, the proposers demonstrated that a one-step process, that includes simultaneous carbonization and activation, can be employed successfully for these materials. This is due to the nature of the fly ash carbon, that has already gone through a devolatilization step while in the combustor, and therefore, only requires to be activated. The preliminary processes identified during Phase I were optimized to design a superior route for the generation of activated carbon materials from carbon in fly ash. The properties of the activated carbons were systematically characterized at The Pennsylvania State University, including a detailed description of the porous structure (micropores or $<2 \mathrm{~nm}$ in width, mesopores or $2-50 \mathrm{~nm}$ in width, and macroporous or $>50 \mathrm{~nm}$ in width) using conventional adsorption techniques, like $\mathrm{N}_{2}$ adsorption isotherms at $77 \mathrm{~K}$.

Task 3b. Production of carbon artifacts The production of carbon artifacts was conducted by mixing the high-purity fly ash carbon concentrates with suitable binder pitches. During Phase I, the proposers demonstrated for the first time that carbon from fly ash could be used as an excellent substitute for calcined petroleum coke in the production of carbon artifacts. A protocol was developed to prepare, mix and pelletize fly ash carbon with calcined petroleum coke and binder pitch (Maroto-Valer et al., 2000a; and Andrésen et al., 1999). During Phase II, the above protocol was optimized with the ultimate goal of maximizing the concentration of the 
fly ash carbon in the mixtures, while producing carbon artifacts with superior properties. In Task 3, different proportions of fly ash carbon and pitches were mixed and pelletized under various temperatures and pressures. Identification of suitable binder pitches, which performed well with fly ash carbons, was also conducted. 


\section{EXECUTIVE SUMMARY}

The concentration of unburned carbon present in fly ash has risen drastically over the last years, due to the implementation of increasingly stringent Clean Air Act Regulations regarding NOx emissions. The carbon-rich ash is either placed in holding ponds or landfilled and it is estimated that in 1997 around 6-8 million tons of unburned carbon were disposed due to the present lack of efficient routes for its utilization. However, the increasingly severe regulations on landfill and the limited access to new disposal sites with the subsequent rise in the cost of disposal, may demand the utility industry to begin offsetting coal combustion with natural gas, or require additional coal cleaning to remove the ash prior to combustion, or simply start utilizing the unburned carbon. Therefore, the utilization of fly ash carbon can bring enormous economical and environmental benefits to the coal, utility and carbon industries. Accordingly, the overall objective of this research program is to develop routes for the recovery and utilization of carbon from coal-fired power plant fly ash. Seven collaborating organizations participated in this research program, including Reliant Energy, Carbon Plus, Prep Tech, Koppers Industries, Calgon Carbon, West Materials and The Pennsylvania State University.

This research program firstly included the selection and characterization of a suite of coal-fired power plant fly ashes. The suite included high-carbon fly ashes from coal-fired power plants, and the procurement was carried out by Reliant Energy and Carbon Plus. The characterization of this suite included thermogravimetric profiles, particle size distribution, and proximate analyses. During Phase II of this research program, an industrial scale test was performed in a coal-fired plant to precipitate selectively the fly ash carbons. The fly ash carbon samples were then used as precursor for activated carbons and substitute for petroleum coke in the production of carbon artifacts. The protocols developed during Phase I were used as baseline to optimize the routes for the generation of activated carbon materials and carbon artifacts.

During the present Phase II an industrial test was conducted on October 9-11, 2000 to implement the Carbon Plus technology at Shawville (Reliant Energy) power plant in Pennsylvania to precipitate selectively the unburned carbon. This is the only industrial test conducted in 2000 under the auspices of any CPCPC project, as far as we are aware. Shawville station (Bradford Township, PA) with a net capacity of 624MW has been retrofitted with lowNOx burners, and uses primarily Lower, Middle and Upper Kittanning and Lower and Upper Freeport seam coals. The four units of the power plant consume over 5,000 tons of coal/day. This power plant also produces 200,000 tons of fly ash/year and 34,000 tons of unburned carbon/year. The test was conducted in Unit \#4 with a capacity of $180 \mathrm{MW}$, and during the test it is estimated that Reliant used 4,300 tons of coal. The outcome of the industrial technology test was mainly monitored by two parameters: LOI (loss-on-ignition) that is basically the carbon content and particle size distribution. The test successfully complied with DEP environmental requirements and it was shown that the carbon can be successfully concentrated in selected hoppers. In addition, a laboratory scale beneficiation process was also conducted to reduce the ash contents $<1 \%$ by using chemical digestion methods.

The work reported here has also demonstrated the ability of unburned carbon from coal combustion by-products to generate activated carbons by steam activation. The inherent porosity of the parent unburned carbon samples with surface areas between $30-40 \mathrm{~m}^{2} / \mathrm{g}$, is mainly due to the presence of meso- and macropores. The samples activated with steam presented surface

"Recovery and Utilization of Carbon from Coal-Fired Power Plant Fly Ash"; Page 13 
areas significantly higher than the parent samples $\left(40 \mathrm{~m}^{2} / \mathrm{g}\right.$ vs. $\left.688 \mathrm{~m}^{2} / \mathrm{g}\right)$. The solid yields decreased as the steam activation time increased, and the samples activated for the longest period of time presented the highest surface areas. However, as the activation time increased, the developing rate of micropore volume also decreased. Therefore, the activation process can tailor the inherent mesoporosity of these materials into the desired porosity for a specific application.

For the use of unburned carbon as a substitute of calcined petroleum coke for the production of carbon artifacts, the greatest challenge identified was the overall removal of minerals, which was achievable using a laboratory chemical cleaning method, where ash levels were reduced $<1 \%$, and sulfur content $<0.5 \%$. For the carbon artifacts, the baking yields were very similar for all the carbon bodies investigated, around $90 \%$, as expected from the similar thermal history of petroleum coke and fly ash carbons. The densities of the green and baked carbon bodies produced with only petroleum coke were slightly higher than those of the carbon bodies prepared using fly ash carbon, probably due to the small particle size distribution of the formulations used.

Finally, the long-term benefits of this research program can be summarized as follows: (i) the coal industry will continue being the main provider to the utility industry, where currently around 1 billion tons of coal are sold annually; (ii) the carbon industries, such as those producing activated carbon and carbon artifacts, will have cost-effective and novel precursors; and (iii) this program prevents pollution at its source by simultaneously reducing NOx emissions and byproduct waste streams, including unburned carbon and ash, and will therefore have a vast benign environmental impact. 


\section{EXPERIMENTAL}

\subsection{Procurement and characterization of fly ash carbon samples}

Reliant Energy conducted the procurement of the fly ash samples in the Shawville station Unit \#4 (Bradford Township, PA) with a net capacity of 180 MW. This unit has been retrofitted with a low-NOx burner, and uses primarily Lower, Middle and Upper Kittanning and Lower and Upper Freeport seam coals (1,500 tpd). The sampling procedure was conducted all along the electrostatic precipitator of each train at each of the three units. The procedure used was to put the systems on hand and "pull" on each hopper in turn until plant personnel was sure that the hoppers were empty. Once all the hoppers on that boiler were certified as empty, they then went back, shut down the ash transport system and then got a hand sample (5 gallons) from each hopper in turn, thus assuring that the ash in the sample was "fresh ash".

The loss-on-ignition (LOI) contents of the fly ashes assembled were determined according to the ASTM C113 procedure. These analyses were conducted in duplicates. For fly ashes commonly derived from Eastern U.S. coals, the LOI value essentially equates to carbon content.

\subsection{Beneficiation of fly ash carbons}

An industrial scale test for fly ash carbon beneficiation was conducted on October 9-11, 2000 to implement the Carbon Plus technology at Shawville (Reliant Energy) power plant in Pennsylvania, in which 4,300 tons of coal were utilized and it is estimated that 470 tons of fly ash and 80 tons of unburned carbon were generated. This is the only industrial test conducted during 2000 under the auspices of any СРCPC project, as far as we are aware. In addition, prior to the manufacture of the carbon artifacts, a series of preliminary enrichments were conducted on the fly ashes with the highest LOI values to reduce their ash levels. These steps included an oilwater agglomeration separation, that was similar to that reported for ash reduction in coal fines (Alonso et al., 1999), followed by acid digestion. After the oil-water agglomeration, the sample was washed with acetone to remove the residual oil and dried at $105^{\circ} \mathrm{C}$ for 1 hour. An acid digestion step was then conducted by following conventional $\mathrm{HCl} / \mathrm{HF}$ treatments (Bishop et al.,

"Recovery and Utilization of Carbon from Coal-Fired Power Plant Fly Ash"; Page 15 
1958) to further reduce the ash concentrations. The resultant pure unburned carbon samples presented a LOI value of $\sim 99 \%$.

\subsection{Production of activated carbons}

The activation of the samples was carried out in an activation furnace, that consists of a stainless steel tube reactor inside a vertical tube furnace. Typically $\sim 3 \mathrm{~g}$ of sample was held isothermally at $850^{\circ} \mathrm{C}$ for periods of 60 or 120 minutes in flowing steam (Maroto-Valer et al., 2000a). The porosity of the samples was characterized conducting $\mathrm{N}_{2}$ adsorption isotherms at 77K using a Quantachrome adsorption apparatus, Autosorb-1 Model ASIT. The BET surface areas were calculated using the adsorption points at the relative pressures $\left(\mathrm{P} / \mathrm{P}_{0}\right) 0.1-0.25$. The values reported were corrected to a mineral-free basis using the $6 \mathrm{~m}^{2} / \mathrm{g}$ surface area measured for a high content ash sample and the TGA-derived inorganic contents for the respective density fractions (Maroto-Valer et al., 1999c). The total pore volume, $\mathrm{V}_{\text {тот }}$, was calculated from the amount of vapor adsorbed at the relative pressure of 0.95 . The mesopore (pores 2-50 nm in width) and micropore (pores $<2 \mathrm{~nm}$ in width) size distribution were calculated using the BJH (Barrett-Joyner-Halenda) and H-K (Horvath-Kawazoe) equations, respectively, and the micropore volumes were derived from the $\alpha_{\mathrm{s}}$ method using a non-porous carbon black sample as standard (Gregg et al., 1991). The mesopore volume was then calculated from the difference between the $\mathrm{V}_{\text {тот }}$ and the micropore volume.

\subsection{Development of carbon artifacts}

The green carbon pellets were produced from mixtures with different formulations of fly ash carbon, petroleum coke (sponge or needle) and a coal tar binder pitch. The mixtures were heated to $\sim 130^{\circ} \mathrm{C}$ and pressed into pellets, as previously described (Andrésen et al., 1999; Andrésen et al., 2000; Maroto-Valer et al., 2000a). The green carbon bodies were then baked in a horizontal tube furnace (maximum temperature $1000^{\circ} \mathrm{C}$ ), using Argon to carry the volatiles out of the tube and preventing them from condensing inside the furnace. The baking program consisted of three segments as follows: (1) $25-500^{\circ} \mathrm{C}$ at $1{ }^{\circ} \mathrm{C} / \mathrm{min}$; (2) $150-500^{\circ} \mathrm{C}$ at $0.5^{\circ} \mathrm{C} / \mathrm{min}$; and (3) $500-800^{\circ} \mathrm{C}$ at $1{ }^{\circ} \mathrm{C} / \mathrm{min}$, providing an overall length of around 24 hours for a completed baking cycle. The absolute densities of the green and baked pellets were measured by using a Quantachrome MVP-1 Multi Pycnometer with helium as density medium.

"Recovery and Utilization of Carbon from Coal-Fired Power Plant Fly Ash"; Page 16 


\section{RESULTS AND DISCUSSION}

\subsection{Procurement and characterization of fly ash carbons}

\section{$\underline{4.1 .1 . ~ F l y ~ a s h ~ p r o c u r e m e n t ~}$}

A total of 8 samples of fly ash containing unburned carbon were collected from Shawville station unit \#4 (Bradford Township, PA), that is operated by GPU/Reliant Energy. This unit has a net capacity of $180 \mathrm{MW}$, that has been retrofitted with a low-NOx burner, and uses primarily Lower, Middle and Upper Kittanning and Lower and Upper Freeport seam coals (1,500 tpd). Samples were collected from the Economizer hopper and the Research-Cottrell Precipitator hoppers \#5-8 and \#10-12 (Maroto-Valer et al., 2000b). The Economizer hopper is the first precipitator in the hot-side and is located in front of the Research-Cottrell precipitators, then in the gas flow direction are the hoppers \#10-12, which are on the first row of the ResearchCottrell precipitators, while hoppers \#5-8 are in the second row (see Figure 1). Furthermore, this sampling at Shaville unit \#4 compliments the one performed during Phase I of this project, where samples from the Buell precipitators (hoppers 13-21) were collected. The procedure used was to put the systems on hand and "pull" on each hopper in turn until plant personnel was sure that the hoppers were empty. Once all the hoppers on that boiler were certified as empty, they then went back, shut down the ash transport system and then got a hand sample (5 gallons) from each hopper in turn, thus assuring that the ash in the sample was "fresh ash".

\subsubsection{Loss-on-ignition (LOI) characterization}

The loss-on-ignition (LOI) of all the 8 fly ash samples was determined according to the ASTM C311 procedure, as described during Phase I, and all the analyses were conducted in duplicates. Figure 1 shows the LOI of all fly ash samples with their configuration and the gas flow direction is also indicated. Despite the dark color of the samples collected and the relatively large particle size, that are indicatives of cool-side hoppers or high carbon content fly ashes (Andrésen et al., 1999), the LOI values of all the samples investigated during this current reporting period were below $7 \%$.

"Recovery and Utilization of Carbon from Coal-Fired Power Plant Fly Ash"; Page 17 


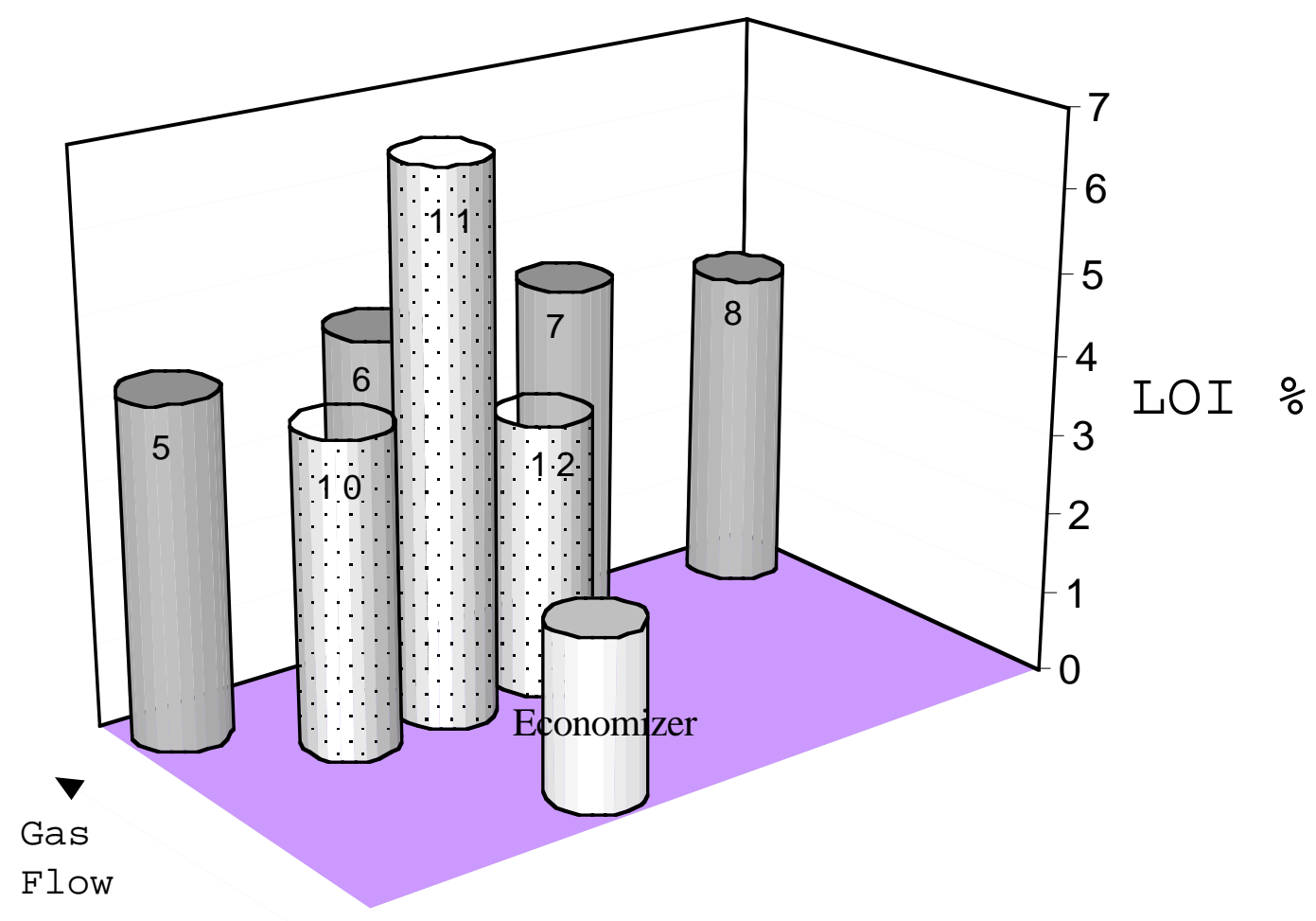

Figure 1. Variation in LOI of the fly ashes collected from Shawville Unit \#4, where the gas flow direction is indicated.

\subsection{Beneficiation of fly ash carbons}

This section covers the outcome of an industrial test that was conducted in a power plant to precipitate selectively the fly ash and also the results of a laboratory scale beneficiation process to beneficiate the fly ash carbons to ash contents $<1 \%$.

\subsubsection{Industrial scale testing}

This section summarizes an industrial scale test that was conducted on October 9-11, 2000 to implement the Carbon Plus technology at Shawville (Reliant Energy) power plant in Pennsylvania. This is the only industrial test conducted in 2000 under the auspices of any CPCPC project, as far as we are aware. 


\subsubsection{Industrial test preparation}

Shawville station (Bradford Township, PA) has a net capacity of 624MW, and it has been retrofitted with low-NOx burners. The four units of the power plant consume over 5,000 tons of coal/day. This power plant also produces 200,000 tons of fly ash/year and 34,000 tons of unburned carbon/year. The test was conducted in Unit \#4 with a capacity of $180 \mathrm{MW}$. Preliminary data collected during the project has provided evidence that the unburned carbon and ash can be precipitated selectively in the different hoppers of the Shaville power plant, producing a high value carbon feedstock and a high value ash stream (Maroto-Valer et al, 2000a; and 2000d).

Prior to conducting the test it was required to apply for a Department of Environmental Protection (DEP) permit. This application was conducted in collaboration with the plant personnel at Shawville and the environmental personnel of Reliant Energy at Johnstown (Pennsylvania), who filed the application. The chronological history of this process is outlined below:

- February 21, 2000: Meeting at Niles power plant: Need to require a PA-DEP permit

- April 19, 2000: Meeting at Shawville power plant: Draft PA-DEP permit.

- May 25, 2000: Permit submitted to Northcentral Regional Office.

- July 27, 2000: Meeting at Shawville power plant: Additional information required by PADEP.

- September 13, 2000:Written approval received.

- September 26, 2000: Meeting at Shawville power plant: Plan for the industrial test.

- October 9-11, 2000: Industrial test conducted: Results reported here.

\subsubsection{Implementing the technology: Complying with DEP permit}

The test was conducted on October 9-11,2000. During all the testing period the plant was operated close to full load by plant personnel, using around 4,300 tons of coal for the test. The implementation of the technology was conducted stepwise as illustrated in Figure 2 and by the end of the test on Wednesday the technology was 97\% installed. In addition and following the requirements issued under the DEP granted permit, the opacity (a quick measurement of the amount of particles emitted in the stack) was not allowed to surpass the $15 \%$ level at any given 
time during the test. This threshold value is represented by the horizontal line in Figure 2. The DEP permit also demanded to halt the test if this value was surpassed. Indeed, during all the test the opacity levels stayed well below the threshold value, as shown in Figure 2. The spikes present in the graph were also observed under routinely operating conditions. There was also a DEP personnel on-site during the test conducted on Tuesday, who was very satisfied by the compliance of the environmental regulations during the testing. Therefore, the test fulfilled successfully the DEP requirements and there was no impact of the implementation of the new technology on the opacity levels. Furthermore, there were no changes in the NOx and SOx emission levels.

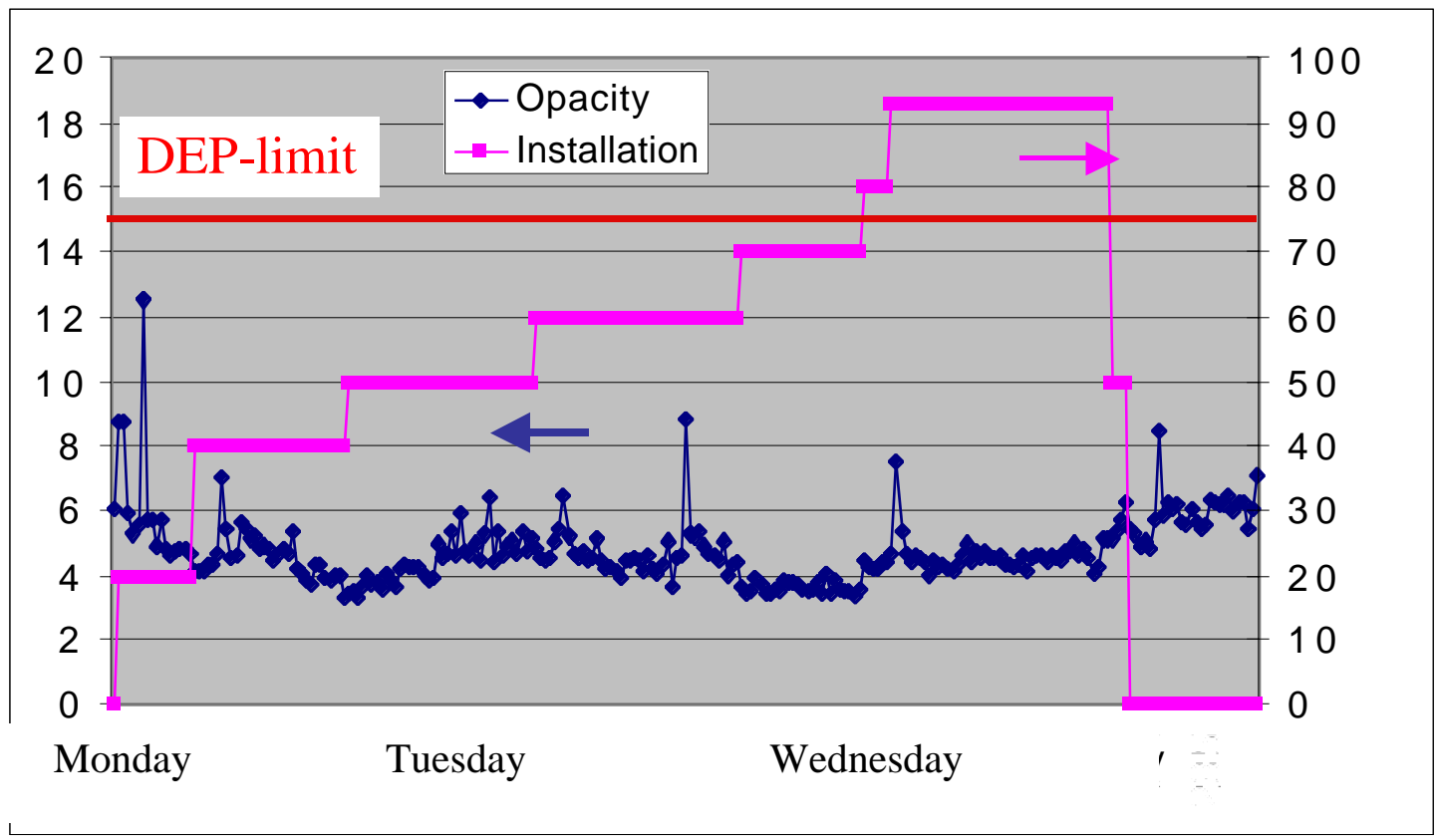

Figure 2. Implementing the separation technology: Complying with DEP permit

\subsubsection{Outcome of technology implementation test}

The outcome of the technology test was mainly monitored by two parameters: (i) LOI (loss-on-ignition) that is basically the carbon content; and (ii) particle size distribution, as described below. The test successfully complied with DEP environmental requirements, and it was shown that the carbon can be successfully concentrated in selected hoppers.

Variations in LOI during test implementation. Figure 3 shows the variation in LOI before and after installation of the technology for the train of hoppers 5-1-13-18. As expected, 
the LOI values increased for the hot-side bins 1-5 and decreased for the cool-side bins 13-18, indicating that the carbon can be successfully concentrated in selected bins.

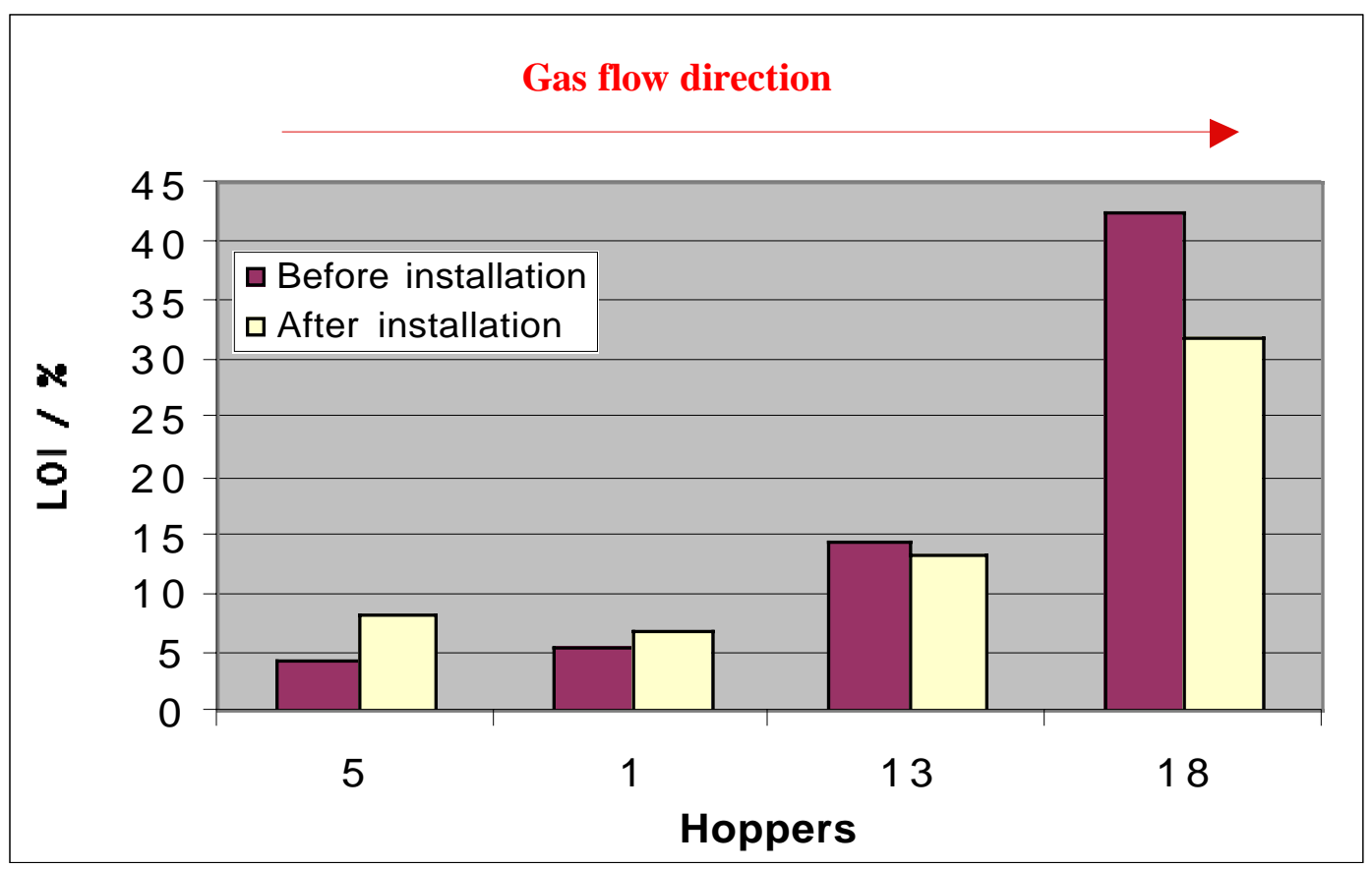

Figure 3. Loss-on-ignition (LOI) for the hoppers investigated.

Variations in particle size distribution during test implementation. Figures 4 and 5 show the particle size distribution for the hoppers 5 and 6 before installation, $5 b$ and $6 \mathrm{~b}$, and after installation, 6a and 6b, respectively.

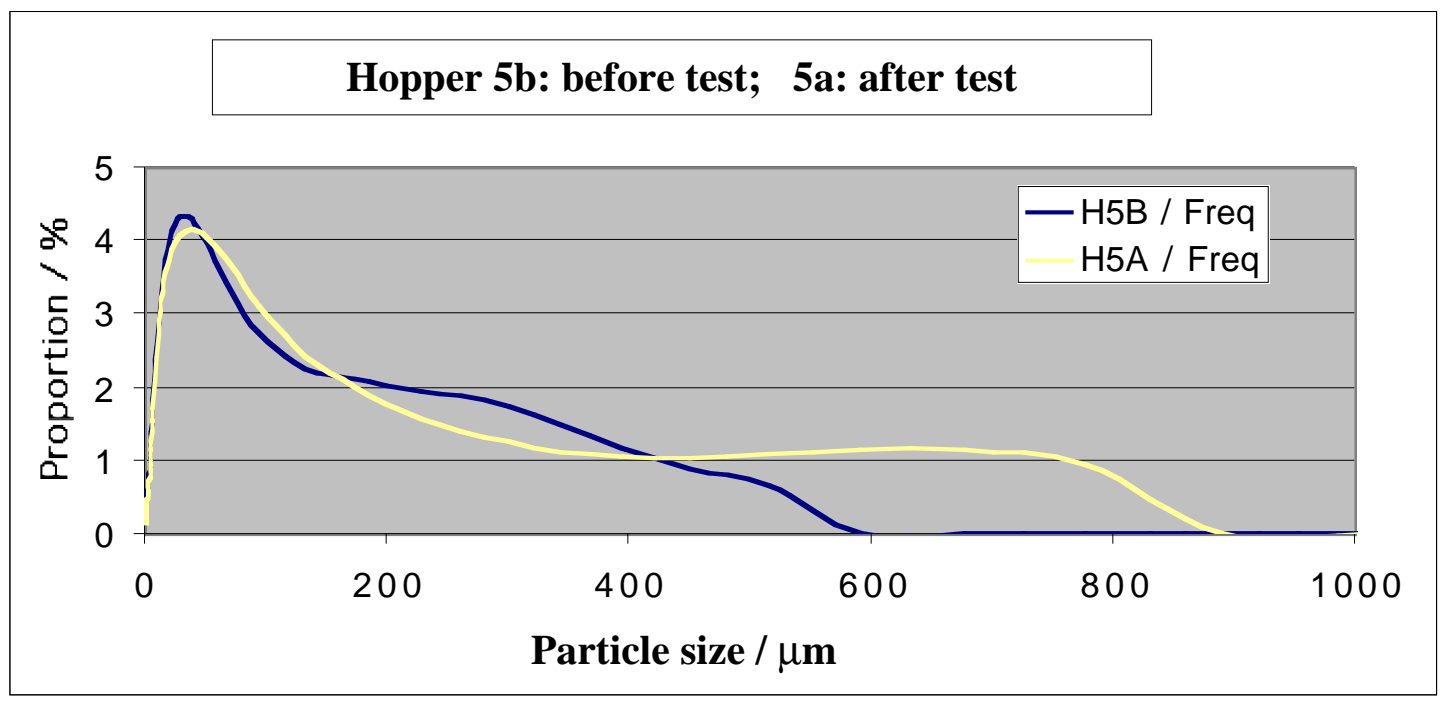

Figure 4. Particle size distribution for hopper 5. 
For both hoppers, the technology installation results in a larger size particle distribution, that is consistent with their higher LOI (Figure 3), since carbon particles present larger sizes than their ash counterparts (Maroto-Valer et al., 2000a).

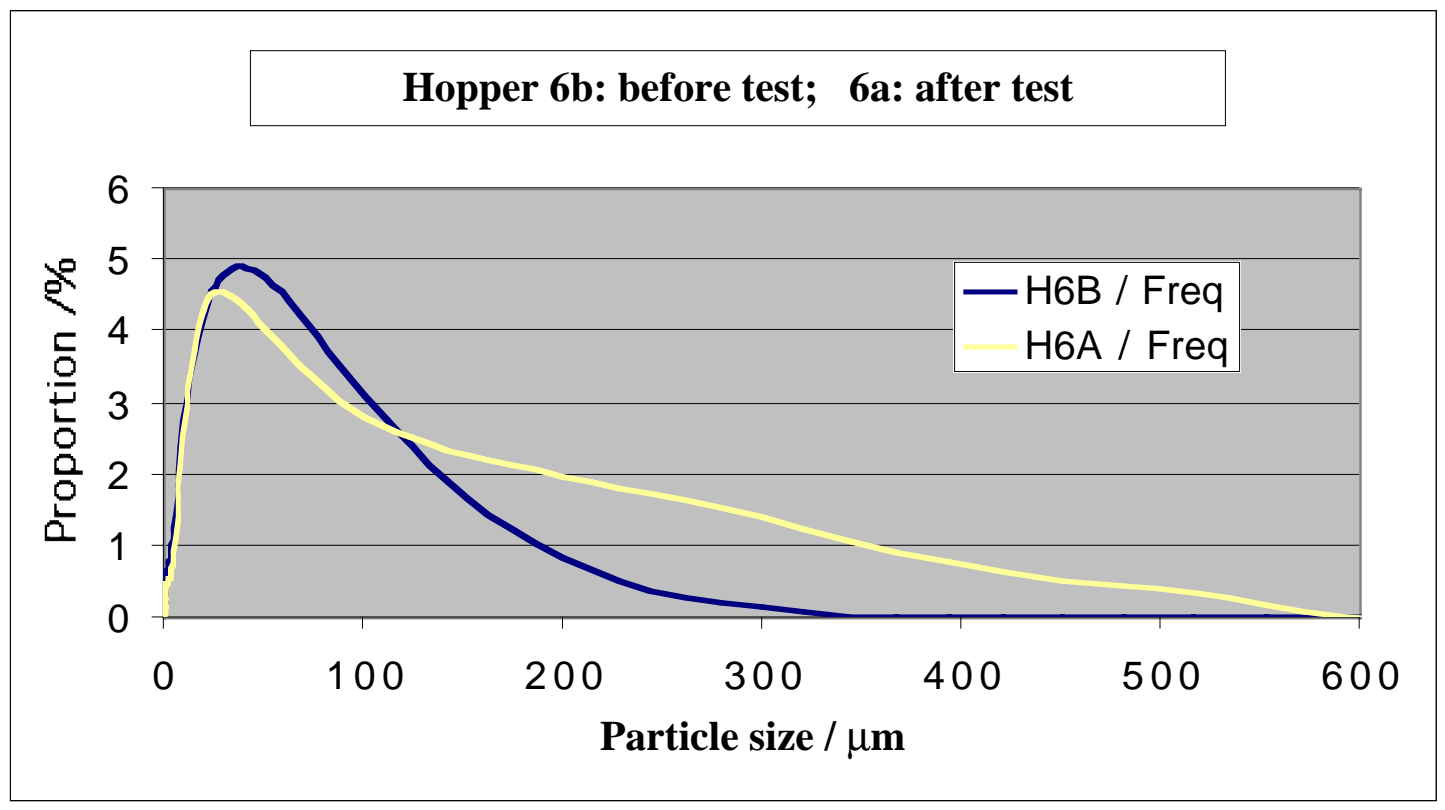

Figure 5. Particle size distribution for hopper 6.

\subsubsection{Laboratory scale beneficiation}

As previously described in the program proposal, the challenging issue in the utilization of carbon from fly ash is to meet the ash purity requirement of precursors for carbon materials (Maroto-Valer et al., 1998a; 1999a). The separation method of Carbon Plus provides samples with carbon content $\sim 85 \%$, that were further beneficiated using acid digestion methods. During this reporting period, the original fly ashes were enriched using the chemical protocol developed during Phase I of this program (Maroto-Valer et al., 2000a) to produce unburned carbon concentrates with ash content $<0.5 \%$. The ultimate goal of this Task is to facilitate a process, that can reduce the inorganic content of fly ash carbons to levels acceptable for the manufacture of carbon products, while still being an economically sustainable beneficiation process. 


\subsection{Production of premium carbon products}

The high-purity carbon samples obtained from the above enrichment process were used to produce premium carbon products following the two routes successfully developed in Phase I of this project and that include the production of activated carbons and carbon artifacts.

\subsubsection{Production of activated carbons}

The activation of the fly ash carbons was carried out in an activation furnace that was designed and used by the proposers to activate carbon from coal-fired power plant ashes. During Phase I, the proposers have demonstrated that a one-step process, that includes simultaneous carbonization and activation, can be employed successfully for these materials (Maroto-Valer et al., 2000a). This is due to the nature of the fly ash carbon, that has already gone through a devolatilization step while in the combustor, and therefore, only requires to be activated. During the present reporting Phase II, the preliminary processes identified during Phase I were optimized to design a superior route for the generation of activated carbon materials from carbon in fly ash (Maroto-Valer et al., 2000c). This process involves physical activation with steam of the fly ash carbons at temperatures around $850^{\circ} \mathrm{C}$ for periods of 1 or 2 hours. The properties of the activated carbons were characterized using conventional $\mathrm{N}_{2}$ adsorption isotherms at $77 \mathrm{~K}$.

\subsubsection{Steam activation: Effect of activation time.}

Table 1 presents the solid yields and BET surface areas for the parent unburned carbon samples and their steam activated counterparts.

Table 1: Solid yields and surface areas of the parent samples and their steam activated counterparts at $850^{\circ} \mathrm{C}$.

\begin{tabular}{l|c|c|c}
\hline Sample & Activation time / min & Solid yield / wt $\%$ & Surface area $/ \mathrm{m}^{2} / \mathrm{g}$ \\
\hline A & -- & -- & 40 \\
B & -- & -- & 38 \\
\hline A & 60 & 73 & 332 \\
B & 60 & 55 & 443 \\
\hline A & 120 & 38 & 540 \\
B & 120 & 29 & 688 \\
\hline
\end{tabular}


The raw unburned carbon samples have low surface area $\left(\sim 40 \mathrm{~m}^{2} / \mathrm{g}\right)$. In contrast, the surface area of the activated samples are greatly increased compared to the parent samples and reached values up to $688 \mathrm{~m}^{2} / \mathrm{g}$, where high surface areas are characteristic for commercial activated carbons. As expected, the solid yield decreases as the activation time increases, while the samples activated for the longest time (120 minutes) present higher surface areas than their counterparts activated for only 60 minutes (540 and $688 \mathrm{~m}^{2} / \mathrm{g}$ vs. 332 and $443 \mathrm{~m}^{2} / \mathrm{g}$, respectively). Despite the low particle size of the unburned carbon samples, the solid yields are relatively high, since the unburned carbon has undergone devolatilization in the combustor. This makes unburned carbon an attractive precursor for the production of activated carbons, since they present much higher solid yields than conventional precursors, such as wood. Sample A presents higher solid yields than B (38\% vs. $29 \%$, respectively), due to its larger particle size (200 $\mu \mathrm{m}$ vs. $45 \mu \mathrm{m})$. Previous studies have shown that the particle size of the precursor strongly affects the solid yields of the resultant activated samples, with higher yields for bigger particle size fractions (Maroto-Valer et al., 2000e).

\subsubsection{Steam activation: Pore volume distribution.}

Figure 6 compares the meso- and micropore volume of the two precursors, and their steam activated samples, determined using the $\alpha_{\mathrm{s}}$ method. Pore size distribution studies were conducted and showed that the pore volume of the parent samples is mainly due to mesopores, with the mesopore volume accounting for $74 \%$ and $67 \%$ of the total pore volume for sample A and $\mathrm{B}$, respectively. However, the steam activation process increases the pore volume of the samples, and promotes the development of micropores, with the micropore volume now accounting for $78 \%$ and $75 \%$ of the total for the sample A and B activated for 60 minutes, respectively. However, as the activation time increases, there is a decrease in the rate of micropore volume development, with the micropore volume accounting for $63 \%$ and $72 \%$ of the total for the sample A and B activated with steam for 120 minutes, respectively. Present studies conducted at our laboratories are focusing on developing activated carbons with high surface areas and narrow microporosity, that are preferred for commercial adsorbent materials. 


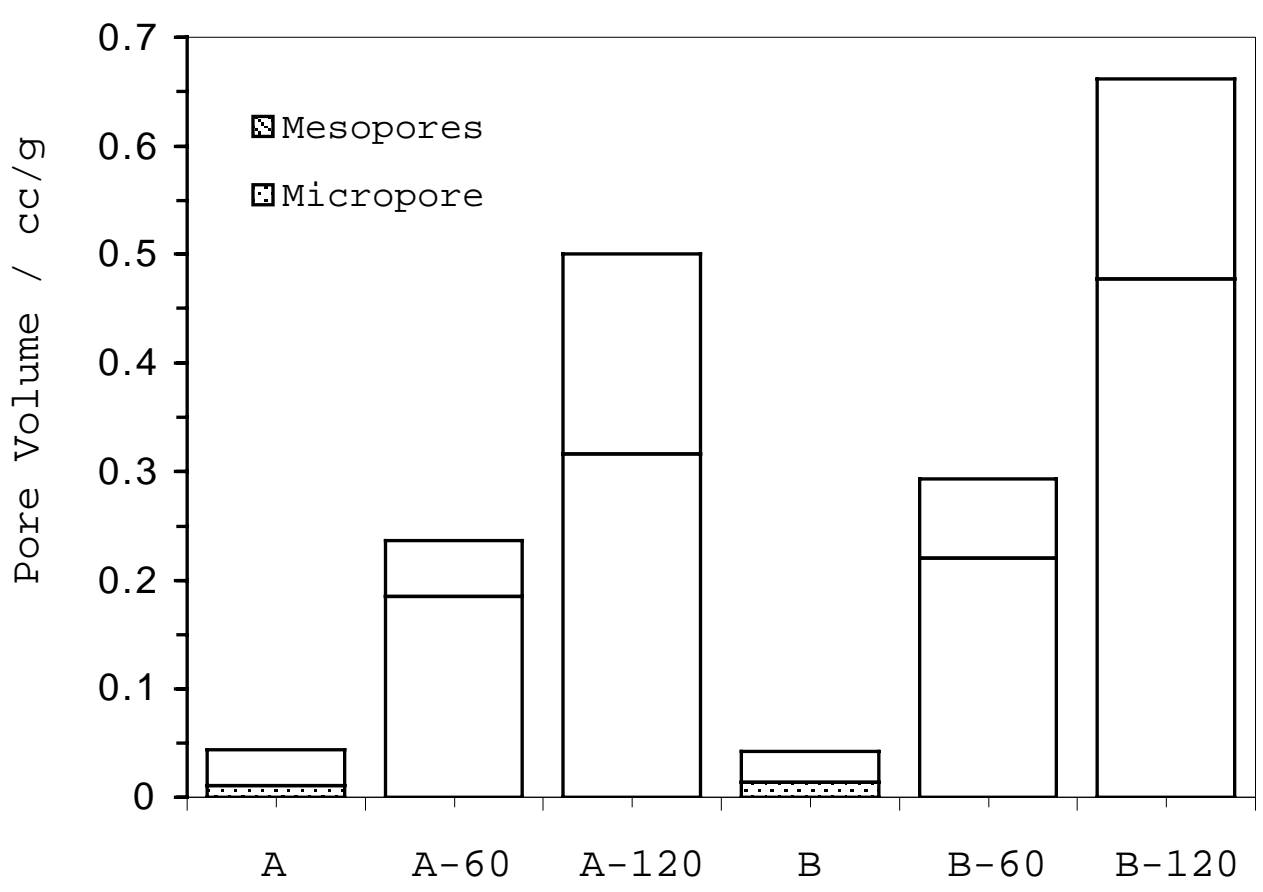

Figure 6. Distribution of the micro- and mesopore volume of the two precursors, A and B, and their activated counterparts with steam.

\subsubsection{Production of carbon artifacts}

Table 2 lists the formulation of the carbon bodies produced using fly ash carbon as a replacement for the petroleum coke fraction.

Table 2. Formulations of the carbon bodies prepared

\begin{tabular}{c|c|c|c|c}
\hline $\begin{array}{c}\text { Carbon } \\
\text { Body }\end{array}$ & $\begin{array}{c}\text { Fine } \\
\text { Coke }\end{array}$ & $\begin{array}{c}\text { Formulation /\% } \\
\text { Fly Ash Carbon }\end{array}$ & $\begin{array}{c}\text { Intermediate } \\
\text { Coke }\end{array}$ & Pitch \\
\hline CB-A & $40(\mathrm{Sp})$ & 0 & $40(\mathrm{Sp})$ & 20 \\
CB-B & $20(\mathrm{Sp})$ & 20 & $40(\mathrm{Sp})$ & 20 \\
CB-C & $10(\mathrm{Sp})$ & 30 & $40(\mathrm{Sp})$ & 20 \\
\hline CB-D & $40(\mathrm{Ne})$ & 0 & $40(\mathrm{Ne})$ & 20 \\
CB-E & $20(\mathrm{Ne})$ & 20 & $40(\mathrm{Ne})$ & 20 \\
CB-F & $10(\mathrm{Ne})$ & 30 & $40(\mathrm{Ne})$ & 20 \\
CB-G & 0 & 35 & $35(\mathrm{UC})$ & 30 \\
\hline
\end{tabular}

$\mathrm{Sp}=$ Calcined Sponge Coke; $\mathrm{Ne}=$ Calcined Needle Coke; UC = unburned carbon 
The conventional production of carbon artifacts involves a filler, such as calcined petroleum coke, a binder, such as coal tar pitch, and a series of additives to enhance their properties. In the preparation of conventional carbon materials, the petroleum coke is used as filler and it is normally separated into at least three different particle size fractions: fine $(<200$ mesh); intermediate; and coarse (>20 mesh), to obtain improved packing densities. Due to the nature of the combustion process, most fly ash carbons are milled to at least the size of the fine fraction, which is used for the production of carbon materials. Hence, this study concentrated on the production of carbon pellets, where the fine fraction of petroleum coke was replaced by unburned carbon. For the purposes of comparison, a pellet was produced only using fly ash carbon (CB-G).

\subsubsection{Green carbon artifacts}

Table 3 lists the apparent and helium densities of the green carbon pellets produced with fly ash carbon, conventional calcined petroleum coke (either sponge or needle) and coal tar binder pitch prior to baking (green).

Table 3. Apparent and helium densities for the green carbon bodies investigated.

\begin{tabular}{c|c|c}
\hline $\begin{array}{c}\text { Carbon } \\
\text { Body }\end{array}$ & \multicolumn{2}{|c}{ Density / g/cc } \\
& Apparent & Helium \\
\hline CB-A & 1.570 & 1.791 \\
CB-B & 1.532 & 1.796 \\
CB-C & 1.523 & 1.777 \\
\hline CB-D & 1.653 & 1.791 \\
CB-E & 1.541 & 1.781 \\
CB-F & 1.511 & 1.755 \\
\hline CB-G & 1.551 & 1.603 \\
\hline
\end{tabular}

The densities (apparent and helium) of the green carbon bodies prepared using sponge coke or needle coke (A and D, respectively) are very similar. When half of the fine fraction of petroleum coke was replaced by fly ash carbon (i.e. $20 \%$ of the total), for green carbon bodies B and E, the helium densities were similar to those of the green bodies prepared only using 
petroleum coke (A and D). However, the replacement of 3/4 of the fine coke fraction by fly ash carbon (i.e. $30 \%$ of the total), for green carbon bodies $\mathrm{C}$ and $\mathrm{F}$, resulted in lower helium and apparent densities. This could be due to a non-optimized mixing of the different components in the mixture. Furthermore, the pitch content may not be enough to wet all the fly ash carbon, that is known to have larger surface areas than conventional petroleum coke, $30-40 \mathrm{~m}^{2} / \mathrm{g} \mathrm{vs} .1-5 \mathrm{~m}^{2} / \mathrm{g}$, respectively (Maroto-Valer et al., 2001a).

\subsubsection{Baked carbon artifacts}

Table 4 lists the baking yields and densities (apparent and helium) of the carbon bodies after baking.

Table 4. Baking yields and densities (apparent and helium) of the baked carbon bodies

\begin{tabular}{c|c|c|c}
\hline $\begin{array}{c}\text { Carbon } \\
\text { Body }\end{array}$ & Baking & \multicolumn{2}{|c}{ Density / g/cc } \\
\hline YB-A & 90.2 & Apparent & Helium \\
CB-B & 90.6 & 1.306 & 1.976 \\
CB-C & 90.2 & 1.276 & 1.895 \\
CB-D & 90.4 & 1.290 & 1.893 \\
CB-E & 90.5 & 1.284 & 1.986 \\
CB-F & 91.0 & 1.262 & 1.959 \\
CB-G & 86.8 & 1.178 & 1.952 \\
\hline
\end{tabular}

The baking yields are very similar for all the carbon bodies investigated, around $90 \%$, as expected from the similar thermal history of petroleum coke and fly ash carbons (Maroto-Valer et al., 1999b). The lower yield for the carbon body prepared using only fly ash carbon (Table 3 ) is lower than for the other bodies, $86.8 \%$ vs $90 \%$, due to its higher pitch content compared to that of the other bodies investigated (30\% vs 20\%). As expected, the densities of the baked carbon bodies are higher than their green counterparts. The densities of the green and baked carbon bodies produced with only petroleum coke, either sponge (CB-A) or needle (CBD), are higher than those of the carbon bodies where fly ash carbon was used. This could 
presumably be related to the lower density of the unburned carbon compared to that of calcined petroleum coke (Maroto-Valer et al., 2000c; and 2001b). However, recent optical microscopy studies have indicated that the mixing of the different ingredients used in the production of the carbon bodies was not optimized. 


\section{CONCLUSIONS}

The present work has developed routes for the use of fly ash carbon as a high value product, including the beneficiation of fly ash carbon, the production of activated carbons and carbon artifacts.

During the present Phase II an industrial test was conducted on October 9-11, 2000 to implement the Carbon Plus technology at Shawville (Reliant Energy) power plant in Pennsylvania to precipitate selectively the unburned carbon. This is the only industrial test conducted in 2000 under the auspices of any CPCPC project, as far as we are aware. Shawville station (Bradford Township, PA), with a net capacity of 624MW, has been retrofitted with lowNOx burners. The four units of the power plant consume over 5,000 tons of coal/day. This power plant also produces 200,000 tons of fly ash/year and 34,000 tons of unburned carbon/year. The test was conducted in Unit \#4 with a capacity of 180MW, and used 4,300 tons of coal during the testing. The outcome of the industrial technology test was mainly monitored by two parameters: LOI (loss-on-ignition) that is basically the carbon content and particle size distribution. The test successfully complied with DEP environmental requirements and it was shown that the carbon can be successfully concentrated in selected hoppers. In addition, a laboratory scale beneficiation process was also conducted to reduce the ash contents $<1 \%$ by using chemical digestion methods.

The work reported here has also demonstrated the ability of unburned carbon from coal combustion by-products to generate activated carbons by steam activation with high surface areas. The inherent porosity of the parent unburned carbon samples with surface areas between $30-40 \mathrm{~m}^{2} / \mathrm{g}$, is mainly due to the presence of meso- and macropores. The samples activated with steam present surface areas significantly higher than the parent samples $\left(40 \mathrm{~m}^{2} / \mathrm{g} v \mathrm{vs} .688 \mathrm{~m}^{2} / \mathrm{g}\right)$. The solid yields decrease as the steam activation time increases, and the samples activated for the longest period of time present the highest surface areas. However, as the activation time increases, the developing rate of micropore volume decreases. Therefore, the activation process can tailor the inherent mesoporosity of these materials into the desired porosity for a specific application. 
For the use of unburned carbon as a substitute of calcined petroleum coke for the production of carbon artifacts, the greatest challenge identified was the overall removal of minerals, which was achievable using a laboratory chemical cleaning method, where ash levels were reduced $<1 \%$. For the carbon artifacts, the baking yields are very similar for all the carbon bodies investigated, around 90\%, as expected from the similar thermal history of petroleum coke and fly ash carbons. The densities of the green and baked carbon bodies produced with only petroleum coke are slightly higher than those of the carbon bodies prepared using fly ash carbon, probably due to the small particle size distribution of the formulations used.

Finally, it is anticipated that the revenues obtained from the sale of the unburned carbon as precursor for premium carbon products (activated carbons or carbon artifacts) could offset the cost of separation and/or beneficiation processes. 


\section{PROJECT RELEVANCE TO THE COAL INDUSTRY}

The rise in unburned carbon concentration in coal combustion fly ashes may lead to the demand for the coal utility industry to begin offsetting coal with natural gas, or require additional coal cleaning to remove the ash prior to combustion. Both alternatives would clearly compromise the coal industry. Hence, the implication of this research program is to turn unburned carbon containing fly ash from a liability into an asset for the coal industry.

The U.S. energy industry requires a green chemistry and engineering solution that can guarantee a long-term source of energy by simultaneously reducing emissions and byproduct waste streams. This can be achieved by installing low- $\mathrm{NO}_{\mathrm{x}}$ burners, which have been proven to efficiently reduce $\mathrm{NO}_{\mathrm{x}}$ emissions, coupled with strategies to manage the associated increase of byproduct streams, as illustrated in Figure 7.

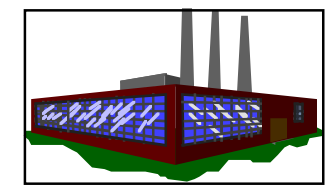

Green Chemistry and Engineering Solution for the Energy Industry

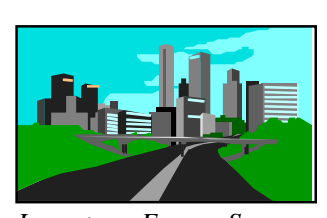

Long-term Energy Source Affordable energy Use of resources Elimination of landfill
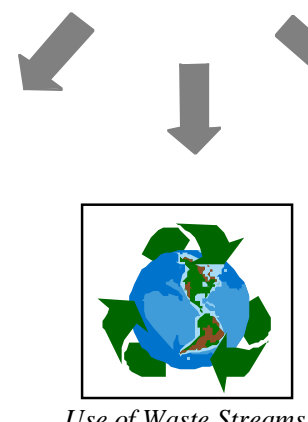

Production of activated carbons Manufacture of carbon artifacts Cement extender

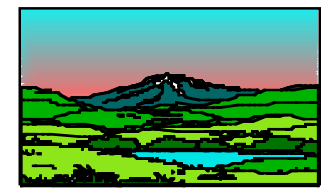

Pollution Prevention Reduction of $\mathrm{NO}_{\mathrm{x}}$ and $\mathrm{CO}_{2}$ Clean water resources Mercury capture

Figure 7. Representation of a green chemistry and engineering solution designed for the U.S. energy industry.

Accordingly, the recovery and recycling of energy byproducts can bring enormous economical and environmental benefits to the U.S. energy industry and to society at large. However, the implementation of Clean Air Act Regulations is potentially detrimental to the marketability of ash, in the sense that more unburned carbon is present in the ash, with the 
subsequent rise in waste streams to follow. Several technologies have been successfully developed to recover and separate the unburned carbon from the ash. These technologies can be divided into wet (froth flotation) and dry (triboelectrostatic) processes, and they can give inorganic ash concentrates with purities that meet the requirement for the cement industry, as well as carbon concentrates with purities of $85 \%$ and above. However, only a few power plants have installed a beneficiation process on their sites. One of the main reasons for this is the low value of the resultant separation products, since one ton of "clean" fly ash is generally sold for as little as $\$ 10$, and the unburned carbon concentrated stream is simply rerouted to the combustor. However, the economics of this process can be significantly enhanced if both separated materials can be used as precursors for high-value products. Accordingly, this research program has developed novel routes for the commercial use of unburned carbon present in fly ash as a precursor for premium carbon materials: (i) production of activated carbons; and (ii) substitute for petroleum coke in the manufacture of carbon artifacts. Furthermore, during Phase II of this program, that was conducted during the calendar year 2000, the protocols developed during Phase I were used as baseline to establish optimum routes for the generation of activated carbon materials and carbon artifacts.

The outcome of this research project can pave the way for the coal utilities to get profits from the revenue of the sale of the unburned carbon to the carbon industries, and by not incurring additional costs of disposal. This will prevent the utility industries from switching to natural gas and, therefore, they will continue using coal as their main energy source. In addition, this research program has a broad application in industry and its technical adequacy is also reflected by the large number of diverse industries that are presently collaborating in Phase II of this program.

To conclude, the benefits of this research program can be summarized as follows: (i) the coal industry will continue being the main provider to the utility industry, where currently over 900 million tons of coal are sold annually; (ii) the carbon industries, such as those producing activated carbon and carbon artifacts, will have cost-effective and novel precursors; and (iii) this program prevents pollution at its source by simultaneously reducing NOx emissions and byproduct waste streams, including unburned carbon and ash, and will therefore have a vast benign environmental impact.

"Recovery and Utilization of Carbon from Coal-Fired Power Plant Fly Ash"; Page 32 


\section{REFERENCES}

Alonso, M., Valdes, A.F., Martinez-Tarazona, R. M., and Garcia, A.B., 1999, Fuel, 78, 753.

Andrésen, J.M., Maroto-Valer, M.M., Andrésen C.A., and Battista, J., 1999, Assessing the potential of unburned carbon as a filler for carbon artifacts, 1999 International Ash Utilization Symposium, 534-540.

Andrésen, J.M., Maroto-Valer, M.M., Andrésen C.A., and Schobert, H. H., 2000, Fly ash carbon as a filler for carbon bodies, Eurocarbon 2000, Vol. 1, 361-362.

Bishop, M. and Ward, D.L., 1958, Fuel, 37, 191.

Gregg, S. J., Sing, K. S. W., 1991, Adsorption, Surface Area and Porosity; Academic Press: New York.

Maroto-Valer, M.M., Battista, J.J. and Andrésen, J.M., CPCPC Proposal "Development Of HighValue Products From Carbon In Fly Ash“, 1998a and references therein.

Maroto-Valer, M. M., Taulbee, D.N. and Hower, J.C. 1998b, Prepr. Am. Chem. Soc., Div. Fuel Chem., Vol 4, 1014.

Maroto-Valer, M.M., Taulbee, D. N., Andrésen, J.M., Hower, J.C., and Snape, C.E., 1998c, Fuel, $77,805$.

Maroto-Valer, M.M., Andrésen, J.M., Morrison, J.L., 1999a, CPCPC Proposal "Recovery and utilization of carbon from coal-fired power plant fly ash" and references therein.

Maroto-Valer, M.M., Taulbee, D. N., and Hower, J.C, 1999b, Energy \& Fuels, 13, 947-953.

Maroto-Valer, M.M., Taulbee, D. N., Schobert, H.H., and Hower, J.C., 1999c, Characterization of differing forms of unburned carbon present in fly ash, International ash utilization symposium, 188-194.

Maroto-Valer, M.M., Taulbee, D. N., Schobert, H.H., 1999d, Assessing condensed aromatic coal materials as precursors for high-value carbon products, Prepr. Am. Chem. Soc. Div. Fuel Chem., 44(1), 101-105.

Maroto-Valer, M.M., Battista, J.J. and Andrésen, J.M., 2000a, CPCPC Final Technical Progress Report "Development Of High-Value Products From Carbon In Fly Ash".

Maroto-Valer, M.M., Andrésen, J.M., and Zhang, Y., 2000b, CPCPC First Technical Progress Report "Recovery and utilization of carbon from coal-fired power plant fly ash".

Maroto-Valer, M.M., Andrésen, J.M., and Zhang, Y., 2000c, CPCPC Second Technical Progress Report "Recovery and utilization of carbon from coal-fired power plant fly ash". 
Maroto-Valer, M.M., Andrésen, J.M., and Zhang, Y., 2000d, CPCPC Third Technical Progress Report "Recovery and utilization of carbon from coal-fired power plant fly ash".

Maroto-Valer, M. M., Andrésen, J.M., and H. H. Schobert, 2000e, Understanding the interrelationship between structure and porosity for a series of activated anthracites, Eurocarbon, Volume 1, 115.

Maroto-Valer, M.M., Taulbee, D. N., and Hower, J.C, 2001a, Characterization of differing forms of unburned carbon present in fly ash, Fuel, 80, 795-800.

Maroto-Valer, M.M., Zhang, Y., Andrésen, J. M., and Morrison, J. L., 2001b, Preparation and characterization of carbon bodies prepared with cokes derived from coal combustion, 2001 Carbon Conference, In Press. 


\title{
Low Cost Carbon Fibers from Coal-Based Precursors $2^{\text {nd }}$ Year
}

Final Report for 2000

\author{
James C. Withers
}

June 2001

Contract \#1656-MERC-DOE-40350

\section{Materials \& Electrochemical Research (MER) Corporation 7960 S. Kolb Road, Tucson, AZ 85706 Phone (520) 574-1980 Fax (520) 574-1983 \\ Web: www.mercorp.com E-Mail: jcwithers@mercorp.com}

\begin{abstract}
This report was prepared as an account of work sponsored by an agency of the United States Government. Neither the United States Government nor any agency thereof, or any of their employees, makes any warranty, expressed or implied, or assumes any legal liability or responsibility for the accuracy, completeness, or usefulness of any information, apparatus, product, or process disclosed, or represents that its use would not infringe privately owned rights. Reference herein to any specific commercial product, process, or service by trade, trademark, manufacturer, or otherwise does not necessarily constitute or imply its endorsement, recommendation, or favoring by the United States Government or any agency thereof. The views and opinions of authors expressed herein do not necessarily state or reflect those of the United States Government or any agency thereof.
\end{abstract}




\section{DISCLAIMER}

This report was prepared as an account of work sponsored by an agency of the United States Government. Neither the United States Government nor any agency thereof, nor any of their employees, makes any warranty, expressed or implied, or assumes any legal liability or responsibility for the accuracy, completeness, or usefulness of any information, apparatus, product, or process disclosed, or represents that its use would not infringe privately owned rights. Reference herein to any specific commercial product process, or service by trade name, trademark, manufacturer, or otherwise does not necessarily constitute or imply its endorsement, recommendation, or favoring by the United States Government or any agency thereof. The views and opinions of authors expressed herein do not necessarily state or reflect those of the United States Government or any agency thereof. 


\begin{abstract}
It was demonstrated a filtered coal tar pitch (CTP) could be thermally processed with an oxidant additive to produce a suitable precursor for spinning pitch fibers. The thermal processing and the oxidant additive eliminated the requirement for stabilization/oxidation before pyrolysis/carbonization to produce an isotropic carbon fiber. Heat treatment to $1200^{\circ} \mathrm{C}$ produced an isotropic CTP based carbon fiber, which had strength greater than petroleum based pitch fibers, and equivalent to petroleum based polyacrylonitrile (PAN) carbon fibers. The low cost processing from CTP provides the potential for these carbon fibers meeting the low cost requirement of the transportation/automotive industry as well as a plethora of other applications.
\end{abstract}




\section{INTRODUCTION}

During the proceeding contract period of calendar 1999, it was demonstrated that a filtered coal tar pitch (CTP) could be pretreated by thermal processing in air, solvent extraction and further thermal treating could be utilized to spin fibers which could be pyrolized without oxidation/stabilization and without fiber fusion. The fiber strengths were in the $1.3 \mathrm{GPa}$ range. During this second year, CTP processing was refined to produce carbon fibers with strengths equivalent to commercial carbon fibers produced from polyacrylonitrile (PAN) and superior to petroleum pitch base fiber.

\section{BACKGROUND}

Currently no carbon fibers are known to be produced from a coal tar pitch processor. Primarily, carbon fibers are produced from polyacrylonitrile (PAN) with some specialty niche carbon fibers produced from petroleum pitch. The PAN is produced from petroleum feed stock making all fibers from petroleum, which in a large part is import dependant leading to a tenuous supply as well as expensive with prices always rising. Because of variability in crude quality and particularly impurities, the cost of purification continues to accelerate.

In addition to the cost of the petroleum base feed for producing carbon fibers, another major cost in carbon fibers production is the stabilization/oxidation of the thermoplastic to prevent melting/fusion of the fibers during the pyrolysis step to produce carbon. A major cost in the carbon fiber production is the cost of heat treating/pyrolysis of the green spun fiber into carbon, and the higher the temperature required to achieve good mechanical properties in the fiber, the more costly of that step.

These combined costs of petroleum base feed, purification treatment required to produce a suitable carbon fiber processor, the cost of stabilization/oxidation and the cost of high temperature heat treatment has combined to limit the cost of continuous carbon fiber to around $\$ 10 / \mathrm{lb}$. An alternative of discontinuous fiber production may reduce the cost some but not to the entry cost requirement of under $\$ 5 / \mathrm{lb}$. requirement for utilization in the transportation/automotive industry. The automotive industry has lowered the bar to $\$ 3.50 / \mathrm{lb}$. for large-scale utilization, which is an unlikely reality for a petroleum base feed.

Desirable features of CTP is that it is a totally domestic supply and offers the potential as a more economical feed than petroleum base. CTP is a byproduct of producing coke or derived directly from coal, and can be projected to cost only a fraction of petroleum feed. Further in the first year, the CPCPC program identified low cost simplified CTP processing to produce a suitable precursor for fiber spinning. The precursor including an oxidant which permitted eliminating the stabilization/oxidation step and direct pyrolysis/heat treatment without fusion of the carbon fibers. Further, high strengths were obtained with heating to only $1200^{\circ} \mathrm{C}$, as well as 
microwave heating. Conventional heating to only $1200^{\circ} \mathrm{C}$, is the most economical and efficient form of heating which is accomplished with iron based resistance heating elements.

Combining the features of domestic source, low cost processing to produce a suitable precursor for fiber spinning including oxidation additives that eliminate post spinning stabilization/oxidation, and achieving mechanical properties equivalent to state-of-the-art commercial fibers, from CTP, provides an opportunity to produce carbon fibers from CTP at a sufficiently low cost for large scale utilization in the transportation/automotive industry, as well as a plethora of additional applications.

\section{RESULTS OF WORK DURING YEAR 2000}

During this annual repeating period, a considerable amount of the effort was devoted to refining the CTP preparation to eliminate the requirement for stabilization/oxidation and to produce fibers with improved strength over the average of $1.3 \mathrm{GPa}$ achieved in the first year of 1999.

The stabilization/oxidation step consists of slowly oxidizing the spun fiber to the point of preventing melting or fusion between fibers when they are heated to pyrolize the pitch into carbon. This step is controlled by the diffusion of oxygen into the green spun fiber which is limited by the diffusivity if oxygen at the maximum temperature before fusion between fibers. Obviously the higher the softing point of the pitch used to spin fibers, the higher the temperature and the greater diffusion rate of oxygen. Typically, this step required days to even weeks, which accounts for its high cost contribution to fiber cost. In this program, an oxidant was added to the pitch precursor along with oxidation of the pitch in it's preparation was utilized which provided sufficient internal oxidation to permit fiber heating without a long duration stabilization/oxidation step and without fusion. It was, however, found if too much oxidant was added to the pitch, the final fibers had random pits as shown in Figure 1.

The strength of these fibers as would be expected, was low at 0.08 to $1.56 \mathrm{GPa}$. However, with proper CTP preparation which includes ratio of oxidant added and the oxidation thermal treatments performed, it was possible to produce a green spun fiber which could be directly pyrolized without a slow stabilization/oxidation step that produced good highe strength fibers. An example of the fibers produced is shown in Figure 2 and 3. 


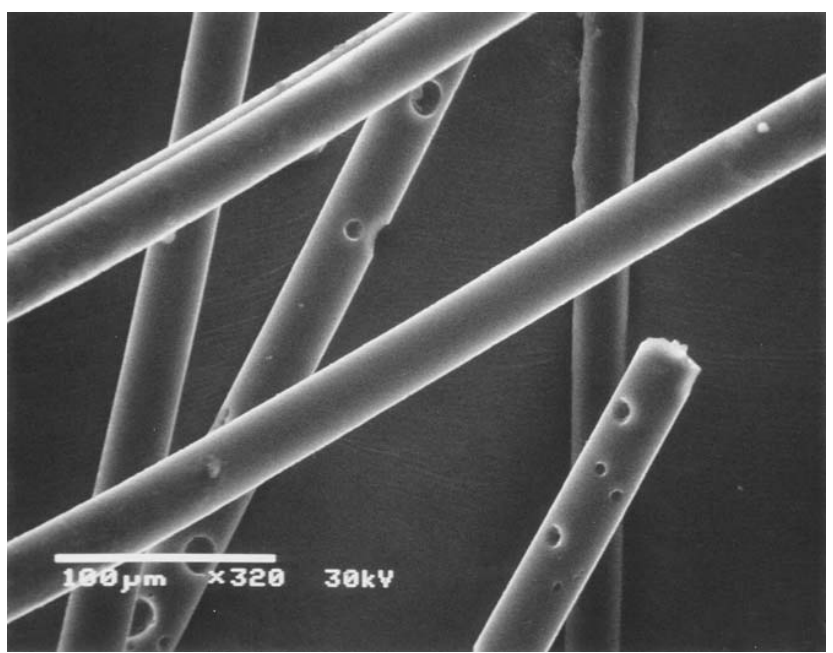

Figure 1

Example of porosity/holes in a pyrolized/carbonized fiber when excessive oxidant is added in the coal-tar pitch precursor preparation.

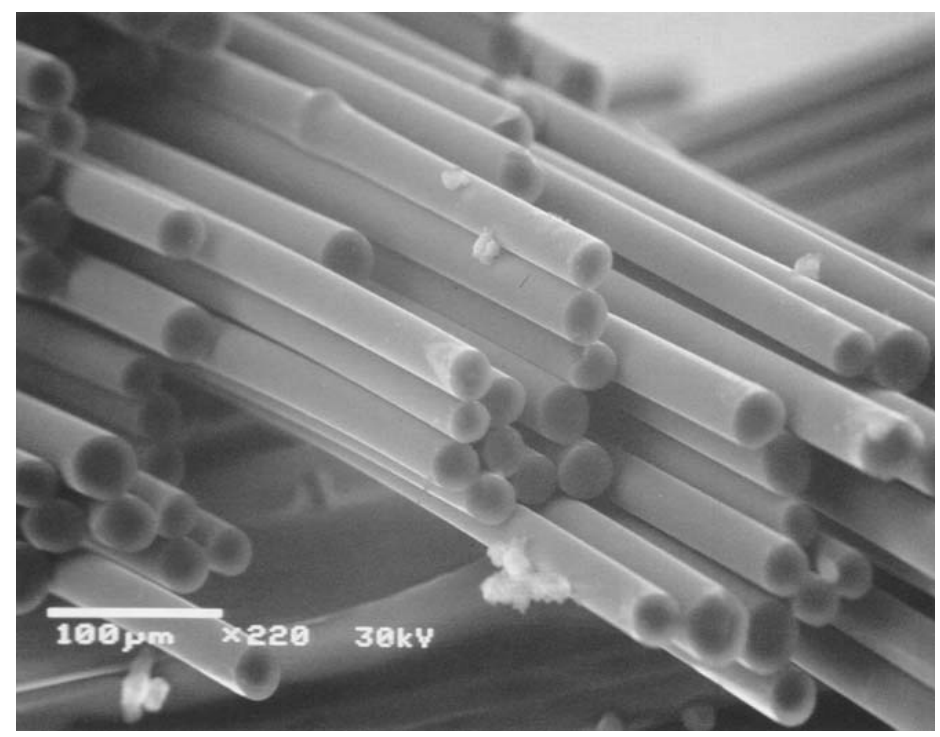

Figure 2

Fibers spun from prepared coal-tar pitch and pyrolized/ carbonized without stabilization. 


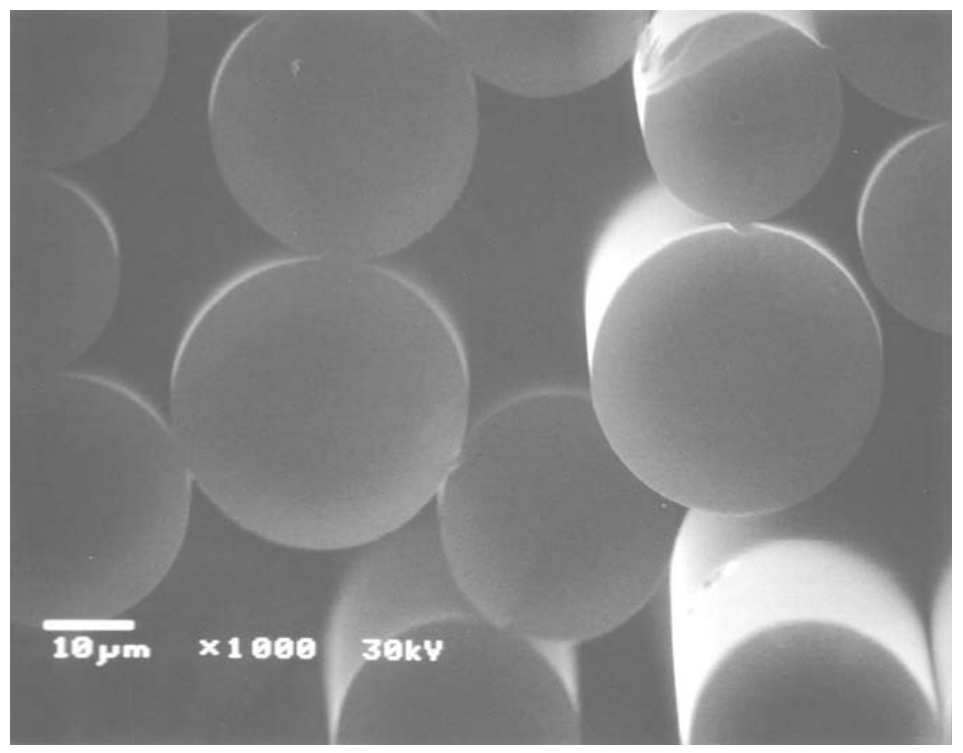

Figure 3

Fibers spun from a pre-treated coal tar pitch and directly pyrolized/carbonized without the necessity of stabilization after spinning.

Cursory examination was conducted to relate the strength of the fibers versus heat treatment temperatures. Pyrolysis to $1100^{\circ}$ produced strengths in the range of $2-3.2 \mathrm{GPa}$ achieving reasonable strengths below heat treatments temperatures of $1200^{\circ} \mathrm{C}$ works to a considerable cost saving for producing carbon fiber. Heat treatments to higher temperatures of $1800^{\circ} \mathrm{C}$ is much more expensive than $1200^{\circ} \mathrm{C}$. After achieving the above results with a single hole spinerette system, a nineteen- (19) hole spinerette was utilized to simulate spinning a fiber tow. The small tows of 19 fibers were spun to establish their properties versus a single fiber. It was found that properties of individual fibers from the 19 tow were substantially the same as single spun fibers. The 19-hole spinerette was damaged in one of the many disassemblyassembly cycles of spinning batches and was replaced with a 25-hole spinerette. A photograph of a 25-tow spinning is shown in Figures 4 and 5. 


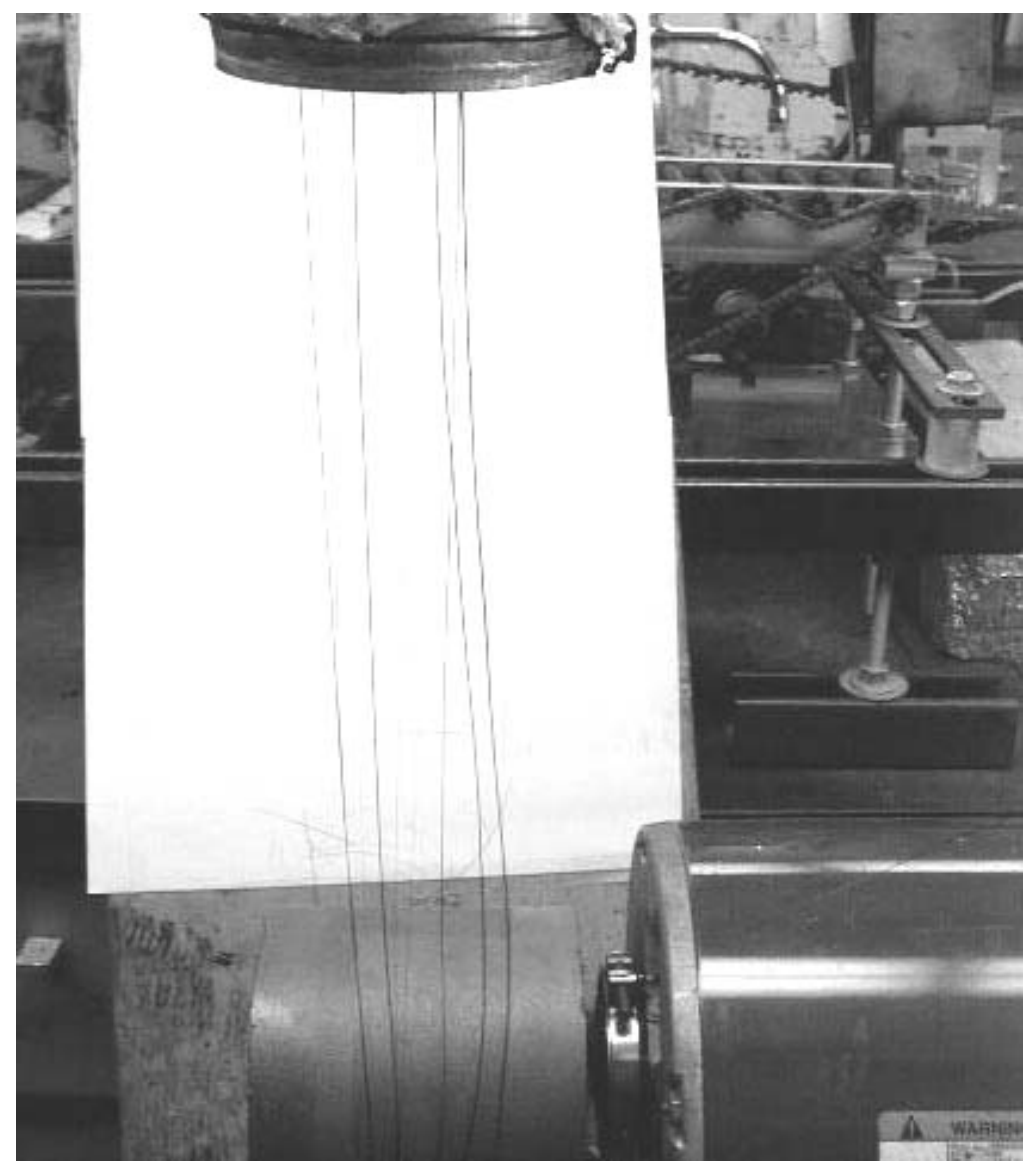

Figure 4

A 25-hole spinerette head showing larger fibers for photographic purposes (if fibers are 10-15 $\mu$ diameter they don't show up in the photograph). 


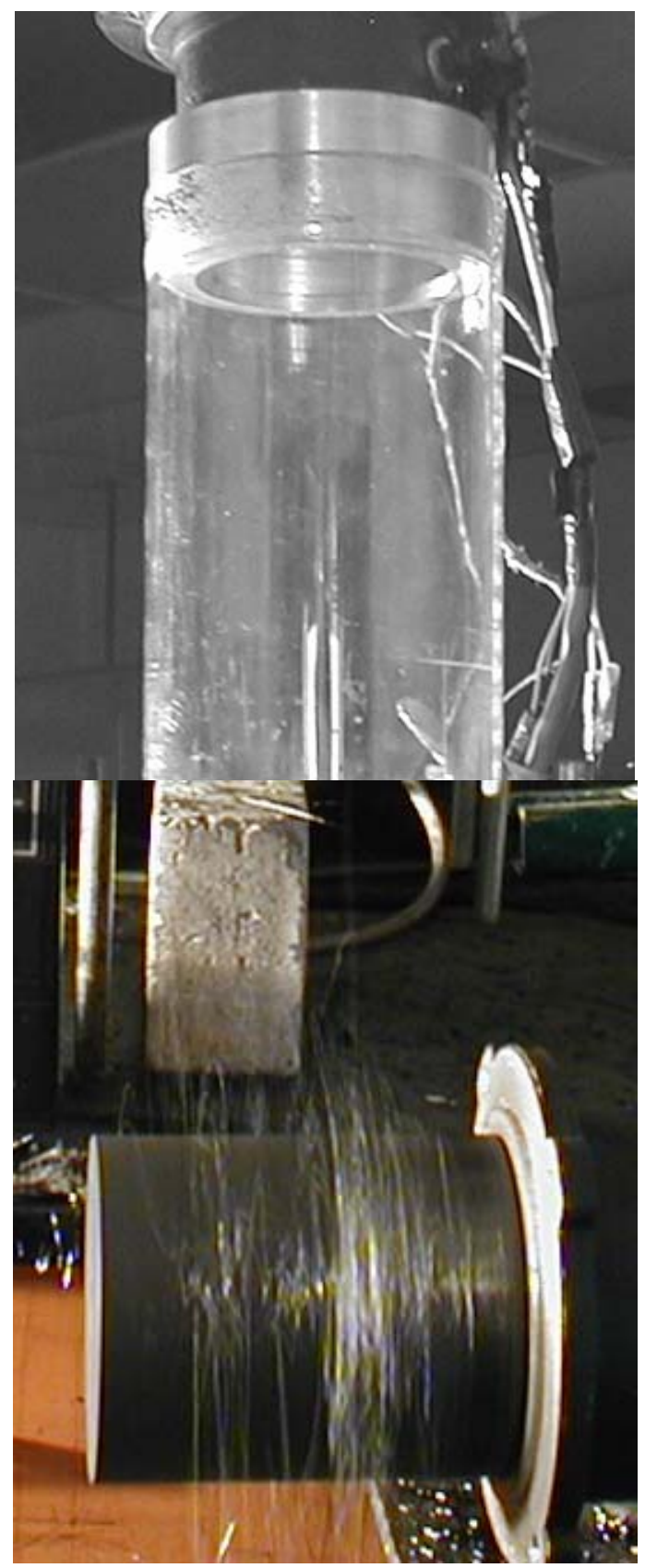

Figure 5

Spinning head showing protection tube with 25 fibers being simultaneously spun. The take-up spool is below showing green spun fiber being wound onto the spool.

In order to further consider lowering the cost of producing carbon fibers, microwave heating of the spun fibers was cursory investigated. Twenty-five tow fibers were microwave heated in a standard 750-watt kitchen microwave to nearly red heat. In addition, the 25 -fiber tow was passed through a microwave set-up used to heat a substrate for diamond deposition. These 
fibers were also raised to low red heat. In neither case did the fibers fuse. Microwave heating has the potential to achieve a higher production rate of heating fibers and the temperature is not limited to $1200^{\circ} \mathrm{C}$ or some other value improsed by economics or fiber properties. Tuning the microwave frequency for optimum heating rate and temperature will provide optimized cost/performance.

The 25 tow fibers were again heat treated in a nitrogen atmosphere to establish the effect of temperature on mechanical properties. In this investigation, the results are shown in Table 1, along with the comparative strength of petroleum pitch fibers and the most common commercial carbon fiber, T300 produced from PAN.

Table 1

\section{Properties of Carbon Fibers Prepared} From Coal Tar Pitch Precursor

\begin{tabular}{|c|c|c|c|c|}
\hline \multirow{2}{*}{$\begin{array}{c}\text { Fiber } \\
\text { Pyrolysis } \\
\text { Temp }{ }^{\circ} \mathrm{C}\end{array}$} & \multicolumn{2}{|c|}{$\begin{array}{l}\text { Fiber Tensile } \\
\text { Strength, GPa }\end{array}$} & \multicolumn{2}{|c|}{$\begin{array}{l}\text { Commercial Fiber } \\
\text { Strength, GPa }\end{array}$} \\
\hline & Isotropic & Anisotropic & $\begin{array}{l}\text { Petroleum } \\
\text { Pitch }\end{array}$ & $\begin{array}{l}\text { Polyacrylonitrile } \\
\text { (PAN) T300 }\end{array}$ \\
\hline 600 & 1.8 & -- & -- & -- \\
\hline 1000 & 2.3 & -- & -- & -- \\
\hline 1200 & 3.8 & 2.5 & $=$ & -- \\
\hline 1800 & 4.2 & -- & -- & -- \\
\hline & & & $2-3$ & 3.5 \\
\hline
\end{tabular}

The CTP treatment described above results in substantially an isotropic pitch structure, which produces an isotropic carbon fiber. An isotropic carbon fiber has many advantages including similar thermal expansion in the longitudinal and transverse directions - resulting in isotropic components and a lower modulus, which can also provide greater strain to failure. However, anisotropic fibers, which are all commercial fibers, and particularly those derived from petroleum pitch, provide specialty properties such as high thermal conductivity and very high modules, (i.e.: $1200 \mathrm{WmK}$ and $827 \mathrm{GPa}(120 \mathrm{MSi}$ ). In some market areas, it would be desirable to produce low cost anisotropic fibers from CTP. Therefore, a minimal effort was conducted to produce mesophase from CTP. The isotropic prepared pitch was heated additional times in air and inert atmosphere, while stirring to polymerize a mesophase. At temperatures of $420^{\circ} \mathrm{C}$, it was possible to produce about $80 \%$ mesophase in the CTP. It is possible to separate the mesophase with solvent extractions by known techniques to produce a 100\% mesophase fraction. However, this was not done. Fibers were spun from the $80 \%$ mesophase CTP, which are shown in Figure 6. 


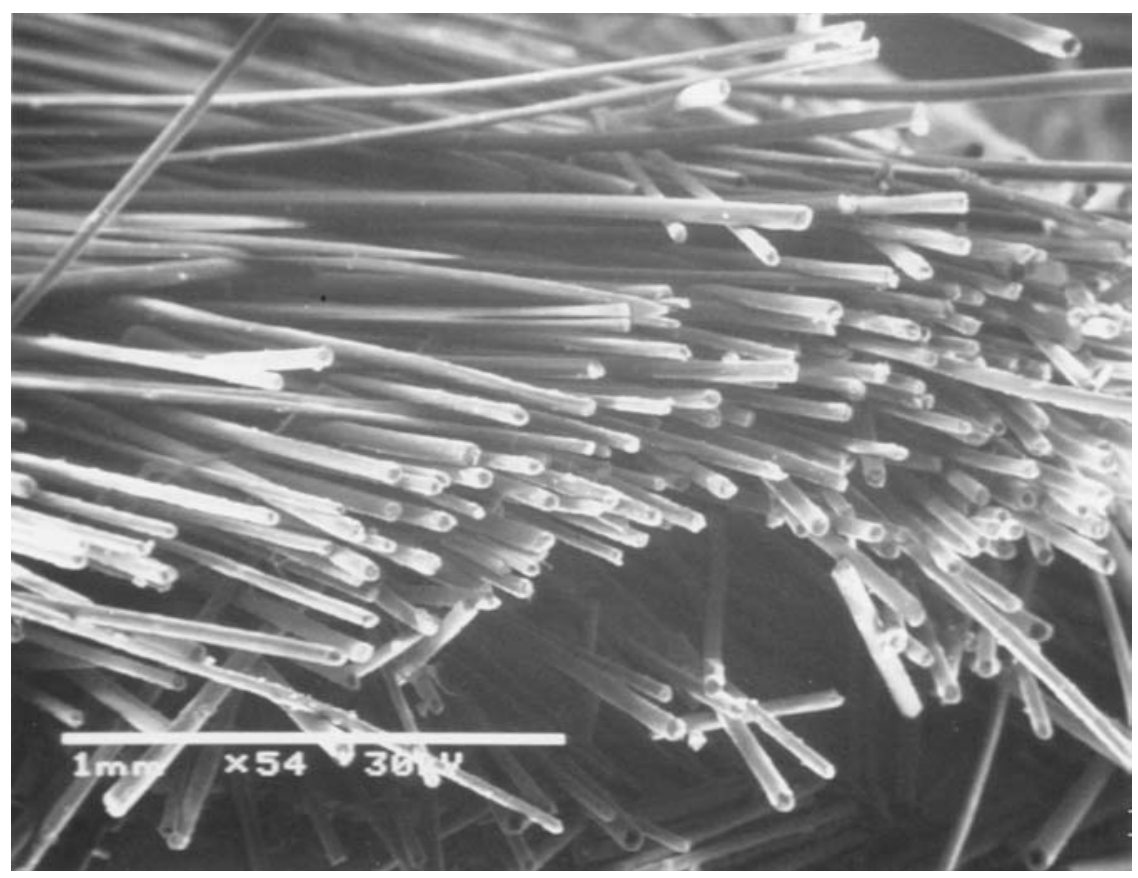

Figure 6

Carbon fibers spun from mesophase coal-tar pitch (after heat treatment to $1100^{\circ} \mathrm{C}$ )

It was noted some fibers were hollow after pyrolysis as shown in Figure 7. The mesophase fiber strength after pyrolysis to $1100^{\circ}$ was in the $1.5-2.5 \mathrm{GPa}$ range. Undoubtedly, further optimization could yield higher strength that was achieved with further investigations using isotropic pitch. This cursory investigation did demonstrate it was feasible to produce a mesophase from CTP and produce anisotropic fibers that could meet the markets for high thermal conductivity and high modulus. 


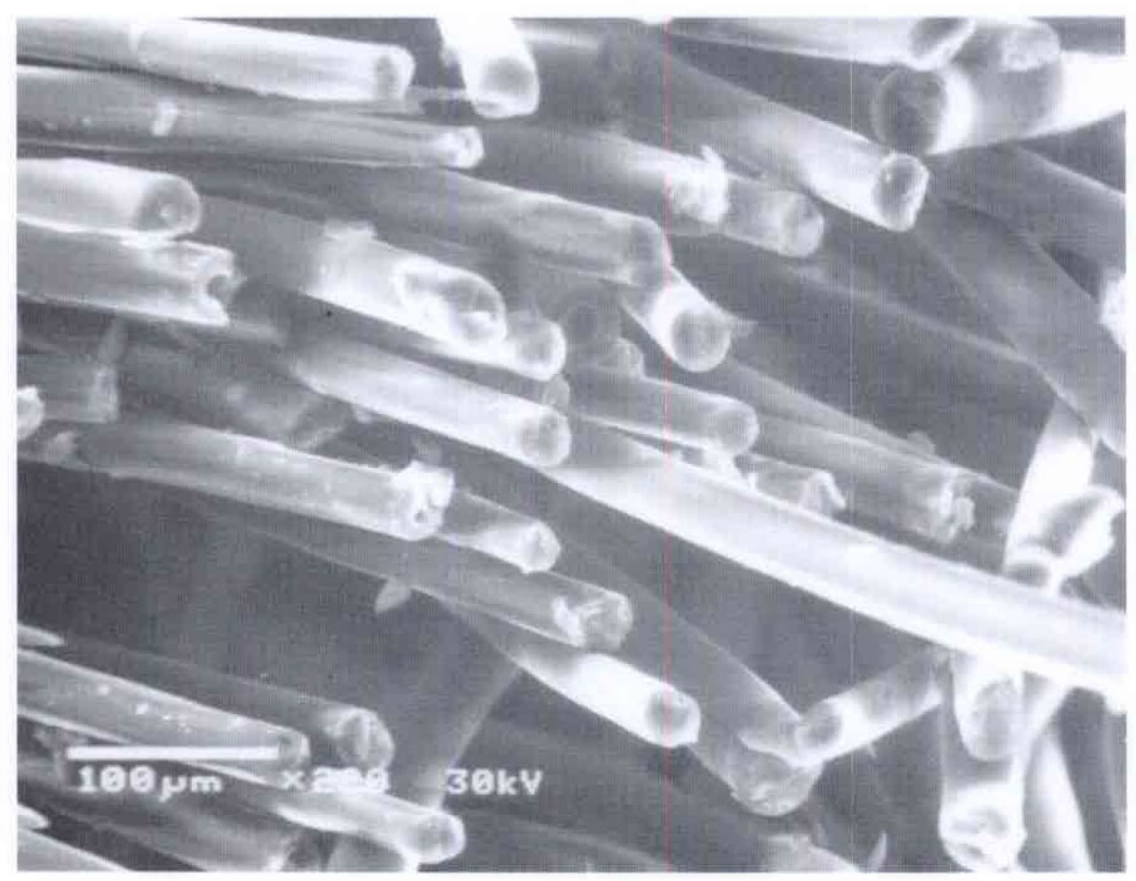

Figure 7

Hollow carbon fibers produced from mesophase derived from CTP.

\section{CONCLUSION}

It has been demonstrated during the year 2000, work that commercial source filtered coal tar pitch can be treated using solvent extraction and thermal processing with the addition of an oxidant to form a low cost precursor for spinning fiber. The spun fiber with the internal oxidant can be directly pyrolized/carbonized without the necessity of stabilization/oxidization to prevent the fibers from fusing. It was demonstrated that carbonized fibers heat treatment to $1200^{\circ} \mathrm{C}$ were isotropic and produced strengths greater that commercial petroleum pitch based fibers and equivalent to the most used commercial fiber T300 produced from PAN. The $1200^{\circ} \mathrm{C}$ heat treatment is the most economical form of processing compared to commercial fibers heat treated to $1400-1800^{\circ} \mathrm{C}$, which is much more costly. It was also demonstrated the microwave heating could be used to heat treat the green spun CTP fibers.

The low cost domestic source CTP and the low cost processing demonstrated here, along with high strength fiber, suggest CTP based fibers potentially can meet the low cost requirement for utilization in the transportation/automotive industry, as well as a plethora of other applications, including fuel cell and battery electrodes, aerospace composites, sports applications, etc. 


\title{
CHARACTERIZATION OF COAL-DERIVED MERCURY SORBENTS
}

\author{
Final Report
}

Prepared by:

Dr. Steven A. Benson

Dr. Edwin S. Olson

Grant E. Dunham

Jason D. Laumb

June 2001

DOE Award Number

DE-FC26-98FT40350

Issued by:

Energy \& Environmental Research Center

University of North Dakota

15 North 23rd Street

PO Box 9018

Grand Forks, ND 58202-9018

2001-EERC-01-05 


\section{DISCLAIMER}

This report was prepared as an account of work sponsored by an agency of the United States Government. Neither the United States Government nor any agency thereof, nor any of their employees, makes any warranty, express or implied, or assumes any legal liability or responsibility for the accuracy, completeness, or usefulness of any information, apparatus, product, or process disclosed, or represents that its use would not infringe privately owned rights. Reference herein to any specific commercial product, process, or service by trade name, trademark, manufacturer, or otherwise does not necessarily constitute or imply its endorsement, recommendation, or favoring by the United States Government or any agency thereof. The views and opinions of authors expressed herein do not necessarily state or reflect those of the United States Government or any agency thereof. 


\section{TABLE OF CONTENTS}

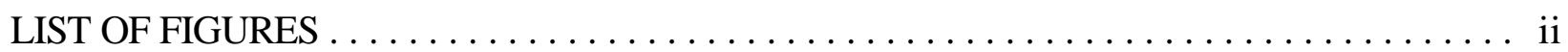

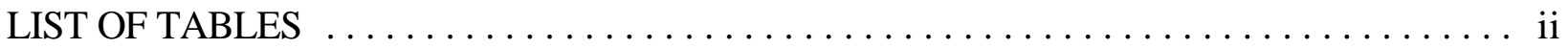

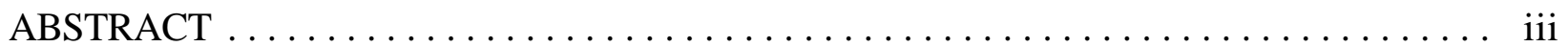

EXECUTIVE SUMMARY $\ldots \ldots \ldots \ldots \ldots \ldots \ldots \ldots \ldots \ldots \ldots \ldots \ldots \ldots$

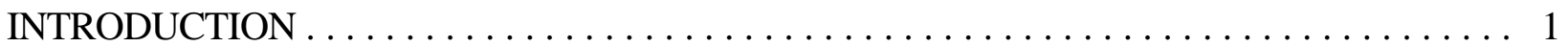

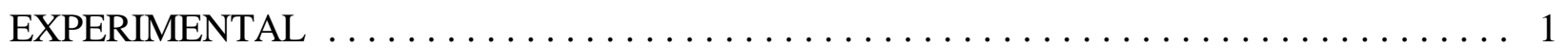

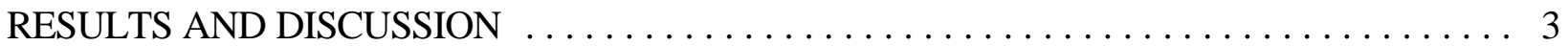

Preparation of Loaded Sorbent Samples ........................... 3

X-ray Absorption Fine Structure Analysis $\ldots \ldots \ldots \ldots \ldots \ldots \ldots \ldots \ldots \ldots \ldots$

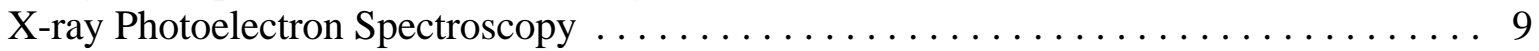

Fourier Transform Infrared Spectroscopy . . . . . . . . . . . . . . . . . . . . . 11

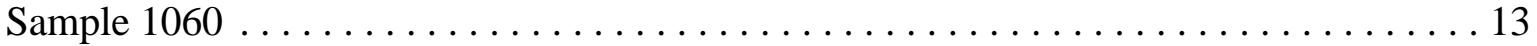

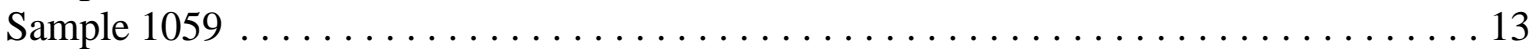

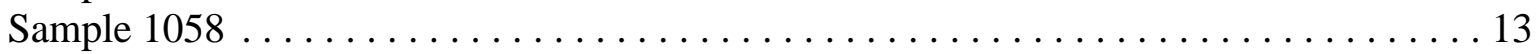

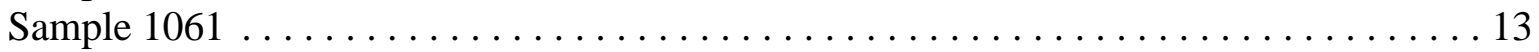

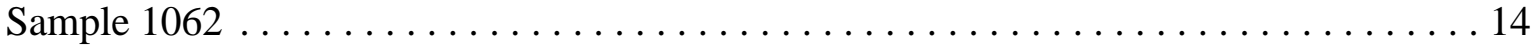

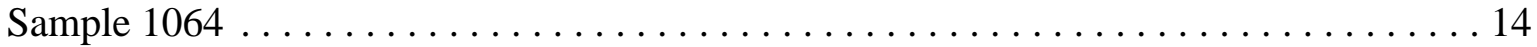

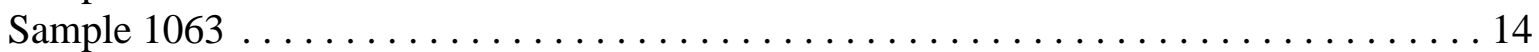

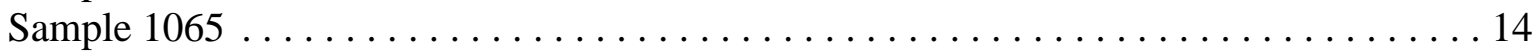

Mechanisms for Acidic Gas Sorption on Carbon ......................... 14

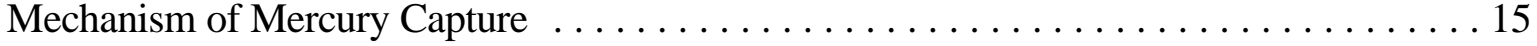

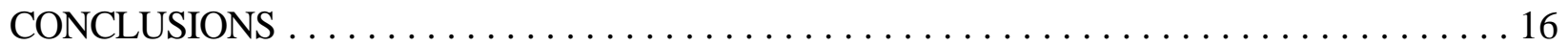

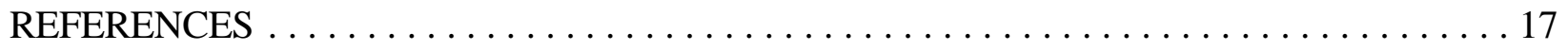

BREAKTHROUGH CURVES FOR THE FIRST EIGHT TESTS $\ldots \ldots \ldots \ldots \ldots$ Appendix A

BREAKTHROUGH CURVES FOR THE SECOND EIGHT TESTS .......... Appendix B 


\section{LIST OF FIGURES}

1 Schematic of EERC Mercury Laboratory $\ldots \ldots \ldots \ldots \ldots \ldots \ldots \ldots \ldots \ldots \ldots$

2 Mercury XANES for Tests $1050-1057 \ldots \ldots \ldots \ldots \ldots \ldots \ldots \ldots$

3 Derivative of mercury XANES for Tests 1052 and $1054 \ldots \ldots \ldots \ldots \ldots$

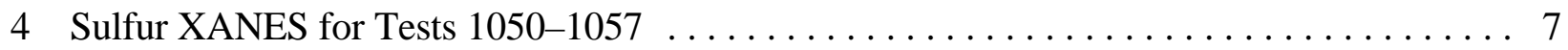

5 Low-energy sulfur XANES for Tests $1050-1057 \ldots \ldots \ldots \ldots \ldots \ldots \ldots$

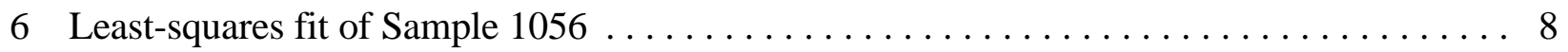

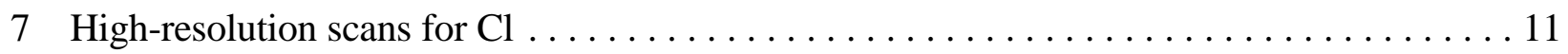

8 Overlays of high-resolution scan for $\mathrm{C}, \mathrm{S}, \mathrm{Cl}, \mathrm{Hg}, \mathrm{N}$, and $\mathrm{Fe} \ldots \ldots \ldots \ldots \ldots \ldots \ldots$

\section{LIST OF TABLES}

1 Composition of the Baseline Flue Gas $\ldots \ldots \ldots \ldots \ldots \ldots \ldots \ldots \ldots \ldots \ldots \ldots \ldots \ldots$

2 Actual Test Matrix Used for Exposing the Sorbents to Flue Gas and Elemental Mercury Test Matrix for Current Project $\ldots \ldots \ldots \ldots \ldots \ldots \ldots \ldots$

3 Numerical Values Determined from $\mathrm{Hg}$ XANES Spectra $\ldots \ldots \ldots \ldots \ldots \ldots \ldots \ldots$

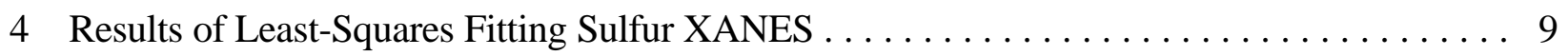

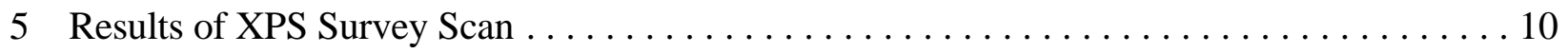

6 A Quantitative Result of Fitting High-Resolution Scans for Chlorine,

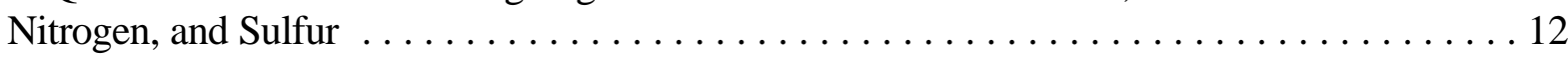




\title{
CHARACTERIZATION OF COAL-DERIVED MERCURY SORBENTS
}

\begin{abstract}
During coal combustion, mercury completely volatilizes and can remain in the vapor phase throughout the combustion and environmental control system. Mercury is partitioned into elemental, oxidized, and particulate phases in the flue gas stream. Air pollution control devices such as scrubbers can remove the oxidized and particulate-bound mercury. Elemental mercury cannot be effectively removed by current control technologies. One proposed technology involves injecting a powdered carbon-based sorbent upstream of the air pollution control device to capture mercury. Previous work has identified lignite-derived activated carbon (Norit LAC) as a possible sorption material for mercury in a flue gas atmosphere. This project is focused on determining the chemical changes taking place on two activated carbon (AC) surfaces that influence mercury sorption and desorption. The carbons tested included the Norit lignite activated carbon (LAC) and an activated carbon derived from high-sodium lignite made at the Energy \& Environmental Research Center. The effect of $\mathrm{SO}_{2}, \mathrm{NO}_{2}, \mathrm{HCl}$, and $\mathrm{H}_{2} \mathrm{O}$ on the carbon's ability to sorb mercury was evaluated for both activated carbons. The sorbents were tested for their ability to sorb and retain $\mathrm{Hg}^{0}$ in a simulated baseline flue gas matrix containing varying mixtures of $\mathrm{SO}_{2}, \mathrm{NO}_{2}, \mathrm{HCl}$, and $\mathrm{H}_{2} \mathrm{O}$. The breakthrough of $\mathrm{Hg}$ was determined for each sorbent under varying flue gas compositions. The exposed sorbents were characterized using x-ray absorption fine structure (XAFS), x-ray photoelectron spectroscopy (XPS), and diffuse reflectance Fourier transform infrared spectroscopy (FT-IR).
\end{abstract}

Previous work has demonstrated the potential for the sorption of mercury by activated carbon sorbents. Recent results from a full-factorial test matrix, with $\mathrm{NO}_{2}, \mathrm{SO}_{2}, \mathrm{HCl}$, and $\mathrm{NO}$ concentrations as the independent variables, identified a major interaction between $\mathrm{NO}_{2}, \mathrm{SO}_{2}$, and the sorbent's capacity to capture mercury. In addition, the absence of water and $\mathrm{HCl}$ improved the sorbent's ability to capture mercury in laboratory tests. As observed in previous tests, an $\mathrm{SO}_{2}-\mathrm{NO}_{2}$ interaction results in early breakthrough of mercury species. XAFS analysis provided information on the sulfur and mercury species in the sorbent. Sulfur was found to be in the sulfate form along with minor amounts of thiophene and elemental sulfur. The form of mercury was found to be either with chlorine or sulfur. Variations in the forms were observed when exposed to varying combinations of acid gases.

The surface of the exposed sorbents were characterized by XPS analysis. The chemistry of sulfur, chlorine, oxygen, nitrogen, silicon, iron, and carbon was determined. Several differences in sorbent chemistry have been observed between the Norit LAC and the EERC AC. The EERC AC was higher in sodium, calcium, magnesium, and barium. The differences in $\mathrm{S}, \mathrm{N}$, and $\mathrm{Cl}$ levels are likely due to the atmosphere to which the sorbent was exposed. XPS analysis for mercury was unsuccessful because of spectral interferences with silicon. 
Detailed, high-resolution XPS scans were completed for $\mathrm{S}, \mathrm{Cl}, \mathrm{N}$, and Fe. The detailed scan shows the specific chemistry of each desired element. The largest differences observed are with the chlorine, sulfur, and nitrogen chemistries as a result of changing atmospheres. The detailed scan revealed that most of the sulfur was bound as sulfate and chlorine was present as chloride and organic chlorine. Chlorine seems to be very important for the sorption of mercury. When $\mathrm{HCl}$ was absent from flue gas, breakthrough occurred faster. Chlorine also disappears from the carbon surface when breakthrough occurs.

Several sorption events occur during the exposure of carbon sorbents to flue gas components. Part of the $\mathrm{Hg}$ binding mechanism involves the oxidation of $\mathrm{SO}_{2}$. When $\mathrm{NO}_{2}$ is omitted from the flue gas, less sulfate was accumulated. The effect of $\mathrm{H}_{2} \mathrm{O}$ also indicates that the oxidation mechanism involves water, likely in the formation of the sulfite intermediate. $\mathrm{HCl}$ did not appear to have an effect on the sulfate formation reaction in the case of either carbon. One argument is that the volatility of $\mathrm{HCl}$ is much greater than the $\mathrm{H}_{2} \mathrm{SO}_{4}$. $\mathrm{HCl}$ may compete effectively with $\mathrm{SO}_{2}$ for the active sites, but as time progresses, the formation of sulfate changes the relative volatility of the acids. Protons would then transfer to chloride, and $\mathrm{HCl}$ escapes in the gas phase. Tests at lower temperatures would elucidate this question. 


\section{CHARACTERIZATION OF COAL-DERIVED MERCURY SORBENTS}

\section{EXECUTIVE SUMMARY}

Two activated carbons, high-calcium Norit LAC and high-sodium carbon made at the EERC, were evaluate to determine their ability to sorb mercury and to determine the surface chemistry of the reacted sorbent particles after exposure to flue gas components. The activated carbons were placed in a fixed bed and subjected to a simulated flue gas atmosphere with mixture levels of $\mathrm{SO}_{2}$, $\mathrm{NO}_{2}, \mathrm{HCl}, \mathrm{Hg}^{0}$, and $\mathrm{H}_{2} \mathrm{O}$. The testing procedure is not meant to mimic the injection of AC into a flue gas stream but simply to gain information about the sorbent's capacity and surface chemistry.

Under simulated flue gas conditions deficient in $\mathrm{HCl}$, the $\mathrm{AC}$ made at the EERC exhibited the ability to capture mercury for a longer period of time without breakthrough than did the Norit LAC. Thus it improved the capacity for $\mathrm{Hg}$ sorption. The absence of water and $\mathrm{HCl}$ also improved the EERC sorbent's capacity to capture mercury. As seen in previous tests, an $\mathrm{SO}_{2}-\mathrm{NO}_{2}$ interaction exists that results in the desorption of oxidized mercury captured in the sorbent.

The carbons were characterized by x-ray absorption fine structure (XAFS) to determine the speciation of chlorine, sulfur, and mercury. Most of the sulfur present was of the sulfate form. Sulfur was also present in the elemental and sulfide forms. XAFS also indicated $\mathrm{Hg}$ was bound as a chloride or a sulfide/sulfate. The bond energies of these two compounds are too close to differentiate between them.

XPS analysis was used to determine the form and abundance of $\mathrm{Cl}, \mathrm{S}$, and $\mathrm{N}$ on the surface of the ACs. A survey scan revealed the presence of C, N, O, Na, Mg, Al, Si, P, S, Cl, Ca, and Fe on the ACs. More detailed high-resolution scans indicated predominantly sulfate sulfur and organic chlorine and chloride. Nitrogen was present as an ammonium salt and a nitride. Analysis of an unexposed sample indicated no $\mathrm{Cl}$ and mostly sulfate sulfur. The analysis of unexposed sample also indicated sulfur absorbed from the flue gas is sulfate.

FT-IR (Fourier transform infrared spectroscopy) analysis was completed on the eight exposed samples. The FT-IR analysis could only indicate the presence of sulfate and possibly nitrate. Using the FT-IR technique gleaned no different information. Future related projects will not include this analysis.

Chlorine seems to be very important in the $\mathrm{Hg}$ sorption process. When $\mathrm{HCl}$ is not in the flue gas, breakthrough of $\mathrm{Hg}$ occurs earlier. After breakthrough, $\mathrm{Cl}$ disappears from the AC. A future study will have several tests involving a sorbent deficient in silicon. The absence of silicon will allow for XPS (x-ray photoelectron spectroscopy) analysis of the $\mathrm{Hg}$ on the sorbent.

Several sorption events occur during the exposure of carbon sorbents to flue gas components. Part of the $\mathrm{Hg}$ binding mechanism involves the oxidation of $\mathrm{SO}_{2}$. When $\mathrm{NO}_{2}$ is omitted from the flue gas, less sulfate was accumulated. The effect of $\mathrm{H}_{2} \mathrm{O}$ also indicates that the oxidation mechanism involves water, likely in the formation of the sulfite intermediate. $\mathrm{HCl}$ did not appear to have an effect on the sulfate formation reaction in the case of either carbon. One argument is that the volatility of $\mathrm{HCl}$ is much greater than the $\mathrm{H}_{2} \mathrm{SO}_{4}$. $\mathrm{HCl}$ may compete effectively with $\mathrm{SO}_{2}$ for the active sites, but as time progresses, the formation of sulfate changes the relative 
volatility of the acids. Protons would then transfer to chloride, and $\mathrm{HCl}$ escapes in the gas phase. 


\section{CHARACTERIZATION OF COAL-DERIVED MERCURY SORBENTS}

\section{INTRODUCTION}

The control of mercury emissions has become a priority of the U.S. Environmental Protection Agency (EPA). When coal is combusted, mercury associated with the fuel vaporizes and cannot be effectively captured by current control technologies. With the exception of some particle-bound and oxidized mercury removed by scrubbers, a portion of the mercury contained in the coal is typically released to the atmosphere. Injecting a sorbent upstream of the air pollution control device is likely the most cost-effective and promising control strategy. However, the sorbent must have the ability to capture all forms of gas-phase mercury and convert mercury to a stable form that cannot be removed by wet-ash-handling procedures.

Previous work has demonstrated the potential for the sorption of mercury by activated carbon sorbents. Recent results from a full-factorial test matrix, with $\mathrm{NO}_{2}, \mathrm{SO}_{2}, \mathrm{HCl}$, and $\mathrm{NO}$ concentrations as the independent variables, identified a major interaction between $\mathrm{NO}_{2}, \mathrm{SO}_{2}$, and the sorbent's capacity to capture mercury. The same study also indicated the conversion of elemental mercury $\left(\mathrm{Hg}^{0}\right)$ to oxidized mercury $\left(\mathrm{Hg}^{2+}\right)$ across a fixed bed of carbon and that the sorption process is not mass transfer limited (Miller et al., 1999).

The goal of this project was to further understand the effect of flue gas composition on a sorbent's ability to capture mercury and to determine how mercury is bound on the particle surface. Two activated carbons were tested. One carbon is a high-calcium Norit LAC (lignite-derived activated carbon) and the other is derived from a high-sodium North Dakota lignite made at the Energy \& Environmental Research Center (EERC).

\section{EXPERIMENTAL}

Sorbents were exposed to flue gas components and gas-phase mercury during breakthrough tests using the bench-scale test system. A schematic diagram of the mercury lab setup is shown in Figure 1. Carbon-based sorbents were preloaded on a quartz filter and exposed to a simulated flue gas. A Semtech 2000 mercury analyzer was used to continuously measure the elemental mercury $\left(\mathrm{Hg}^{0}\right)$ at the outlet. In order to speciate between elemental and oxidized forms of mercury, a conversion unit was installed before the analyzer.

The fixed-bed tests are not intended to simulate the conditions where a sorbent is injected continuously upstream of a particulate control device, but they provide a good indication of sorbent effectiveness, provided the exposure conditions are similar. Sorbents will be exposed to simulated flue gas compositions in the bench-scale system. 


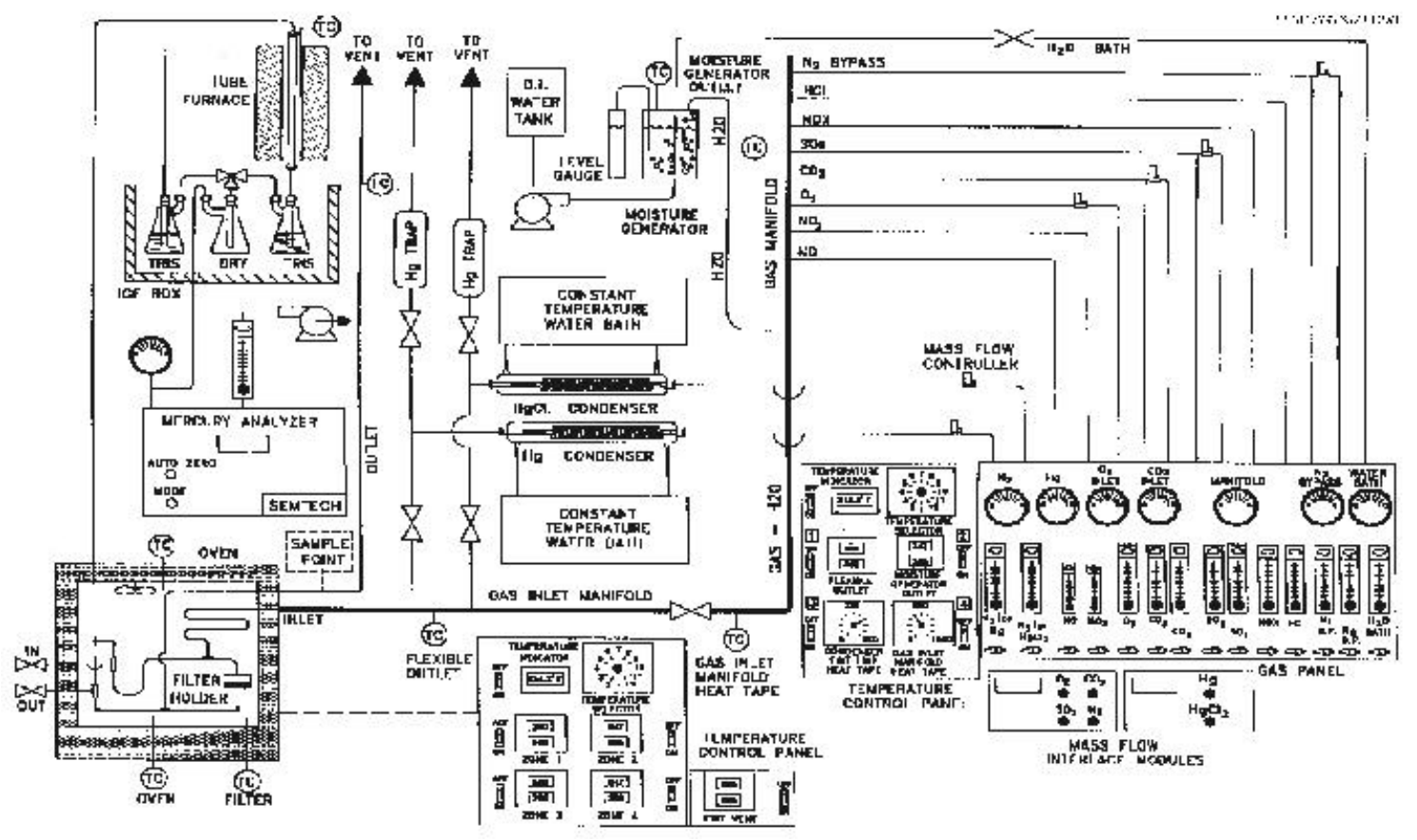

Figure 1. Schematic of EERC Mercury Laboratory.

Approximately 500-1000 mg of activated carbon was placed in a fixed bed and subjected to a simulated flue gas environment for various times (2-14 hours). The shorter tests were conducted to help differentiate between the species on the carbon surface before and after breakthrough. Table 1 contains the baseline flue gas composition. The test matrix for this project is shown in Table 2. All tests used the baseline gas composition previously presented in Table 1 with the adjustments in gas components noted in Table 2. All of the simulated flue gas tests had an elemental mercury injection concentration of $15 \mu \mathrm{g} / \mathrm{m}^{3}$, which is similar to the range observed in coal-fired boilers.

TABLE 1

Composition of the Baseline Flue Gas

\begin{tabular}{lc}
\hline Component & Concentration, mass percent \\
\hline $\mathrm{O}_{2}$ & $6 \%$ \\
$\mathrm{CO}_{2}$ & $12 \%$ \\
$\mathrm{~N}_{2}$ & Balance \\
$\mathrm{H}_{2} \mathrm{O}$ & $8 \%$ \\
\hline
\end{tabular}




\section{TABLE 2}

Actual Test Matrix Used for Exposing the Sorbents to Flue Gas and Elemental Mercury Test Matrix for Current Project

\begin{tabular}{|c|c|c|c|c|c|c|c|}
\hline $\begin{array}{l}\text { Test } \\
\text { No. }\end{array}$ & Carbon & $\begin{array}{l}\mathrm{SO}_{2} \\
\mathbf{p p m}\end{array}$ & $\begin{array}{r}\mathrm{NO}_{2} \\
\text { ppm }\end{array}$ & HCl, ppm & $\begin{array}{c}\mathbf{H}_{2} \mathbf{O} \\
\%\end{array}$ & Breakthrough & $\begin{array}{c}\text { Run Time, } \\
\text { hr }\end{array}$ \\
\hline 1050 & Norit & 1600 & 2 & 50 & 8 & Partial after & 7.5 \\
\hline 1060 & & & & & & After & 8.0 \\
\hline 1051 & Norit & 0 & 20 & 50 & 8 & No BT & 4.5 \\
\hline 1058 & & & & & & No BT & 4.0 \\
\hline 1052 & Norit & 1600 & 20 & 0 & 8 & No BT & 3.2 \\
\hline 1062 & & & & & & Partial after & 2.3 \\
\hline 1053 & Norit & 1600 & 0 & 50 & 8 & No BT & 4.3 \\
\hline 1061 & & & & & & No BT & 4.5 \\
\hline 1054 & Norit & 1600 & 20 & 50 & 0 & No BT & 14.4 \\
\hline 1064 & & & & & & No BT & 2.0 \\
\hline 1055 & Norit & 1600 & 20 & 50 & 8 & Before & 2.0 \\
\hline 1059 & & & & & & Before & 2.5 \\
\hline 1056 & EERC & 1600 & 20 & 50 & 8 & No BT & 3.0 \\
\hline 1063 & & & & & & After & 7.0 \\
\hline 1057 & EERC & 1600 & 20 & 0 & 8 & No BT & 7.5 \\
\hline 1065 & & & & & & No BT & 2.0 \\
\hline
\end{tabular}

\section{RESULTS AND DISCUSSION}

\section{Preparation of Loaded Sorbent Samples}

Mercury breakthrough curves were produced for each test conducted, and the exposed sample was submitted for analysis using XAFS, XPS, and FT-IR. Two sets of samples were produced for analysis. The results of the first set of tests are shown in Appendix A and the second set is included in Appendix B.

Test 1060 conducted with $500 \mathrm{mg}$ of Norit LAC sorbent in the baseline gas plus all acid gases $\left(\mathrm{SO}_{2}, \mathrm{NO}, \mathrm{NO}_{2}, \mathrm{HCl}\right)$ is a typical breakthrough curve for a carbon sorbent in the full gas component conditions as shown in Figure B-6. The breakthrough time inflection was at $7 \mathrm{hr}$ as compared with $1 \mathrm{hr}$ for the normal $100 \mathrm{mg}$ beds for the Norit LAC. The dip at the beginning can possibly be attributed to bed settling.

Test 1050 shows abnormal initial breakthrough to $30 \%$ as shown in Figure A-1. This is likely due to a leakage problem resulting from bed fracture. A further indication of a problem in this test is that the inlet concentration is $40 \%$ of what it should be.

Figure A-6 shows the curve for Test 1055 with $500 \mathrm{mg}$ of Norit LAC under full flue gas conditions, stopped at about $2 \mathrm{hr}$ just prior to breakthrough. The repeat Test 1059 shown in Figure B-2 also shows little breakthrough. The curve is similar to the early part of 1060 and 
appears to be a normal observation. These two samples represent sorbents loaded under prebreakthrough full flue gas conditions

Test 1058 shown in Figure B-1 was conducted with $500 \mathrm{mg}$ of Norit LAC in the baseline gas with $\mathrm{NO}, \mathrm{NO}_{2}$, and $\mathrm{HCl}$ but without the $\mathrm{SO}_{2}$ component. No breakthrough was experienced as expected, but the run time was shorter than the $7 \mathrm{hr}$ in Test 1060. Test 1051 shown in Figure A-2 shows clear indication of instability. This is probably in the detection system rather than the bed. Thus these two samples represent sorbents loaded in the oxidizing acid gases $\left(\mathrm{NO}, \mathrm{NO}_{2}, \mathrm{HCl}\right)$ without the $\mathrm{SO}_{2}$.

Test 1052 was conducted with $1000 \mathrm{mg}$ of the Norit LAC under baseline plus $\mathrm{SO}_{2}, \mathrm{NO}$, $\mathrm{NO}_{2}$, but in the absence of $\mathrm{HCl}$ as shown in Figure A-3. After a small initial loss, the $\mathrm{Hg}$ in the effluent from the bed decreased and then slowly increased over several hours. The repeat test, Test 1062 with $500 \mathrm{mg}$ of Norit LAC sorbent, showed a similar behavior as illustrated Figure B-3, but the increase occurred more rapidly as expected for the smaller sorbent mass.

Test 1053 was conducted with $500 \mathrm{mg}$ of Norit LAC sorbent in baseline gas plus $\mathrm{SO}_{2}$, NO, $\mathrm{HCl}$, but without $\mathrm{NO}_{2}$. Very little breakthrough was observed after $4 \mathrm{hr}$ as shown Figure A-4. Test 1061 with $500 \mathrm{mg}$ of Norit LAC sorbent in the same conditions also showed little breakthrough in $4 \mathrm{hr}$, shown in Figure B-4.

Test 1054 was conducted with $500 \mathrm{mg}$ of Norit LAC sorbent in baseline gas without $\mathrm{H}_{2} \mathrm{O}$ plus $\mathrm{SO}_{2}, \mathrm{NO}, \mathrm{NO}_{2}$, and $\mathrm{HCl}$ for $14 \mathrm{hr}$, shown in Figure A-5. Test 1064 was similar but for $2 \mathrm{hr}$, shown in Figure B-5. Neither test showed any breakthrough of mercury.

The EERC sorbent $(500 \mathrm{mg}$ ) was loaded under full flue gas conditions for 3 hours in Test 1056. Figure A-7 for Test 1056 showed no breakthrough. The repeat test, Test 1063, was performed for $8 \mathrm{hr}$, and breakthrough occurred at about $4.2 \mathrm{hr}$, as shown in Figure B-7. These two samples will represent loading in full flue gas conditions before and after breakthrough, respectively.

The EERC sorbent (500 mg) was exposed to baseline plus $\mathrm{SO}_{2}, \mathrm{NO}$, and $\mathrm{NO}_{2}$ but without $\mathrm{HCl}$ in Test 1057. No breakthrough was observed for $7.5 \mathrm{hr}$, as shown in Figure A-8. The repeat test, Test 1065, was conducted for 2 hr. Again, no breakthrough was observed, as shown in Figure $\mathrm{B}-8$. These samples both represent loading under acidic gas conditions without $\mathrm{HCl}$, but different concentrations of surface species are expected. These results clearly indicate that the EERC carbon has a much higher capacity for $\mathrm{Hg}$ sorption than the Norit LAC under conditions when $\mathrm{HCl}$ is not present in the flue gas.

\section{X-Ray Absorption Fine Structure Analysis}

XAFS analysis was completed on the samples generated from the first set of eight breakthrough tests. XAFS analysis provides a means of determining the sulfur form and mercury forms. Figure 2 illustrates the X-ray absorption near-edge structure (XANES) spectrum for mercury (derived from XAFS). Figure 3 has the derivative of the XANES curves for the samples having the best (1054) and worst (1052) quality data. The double-peak structure is characteristic of mercury. 


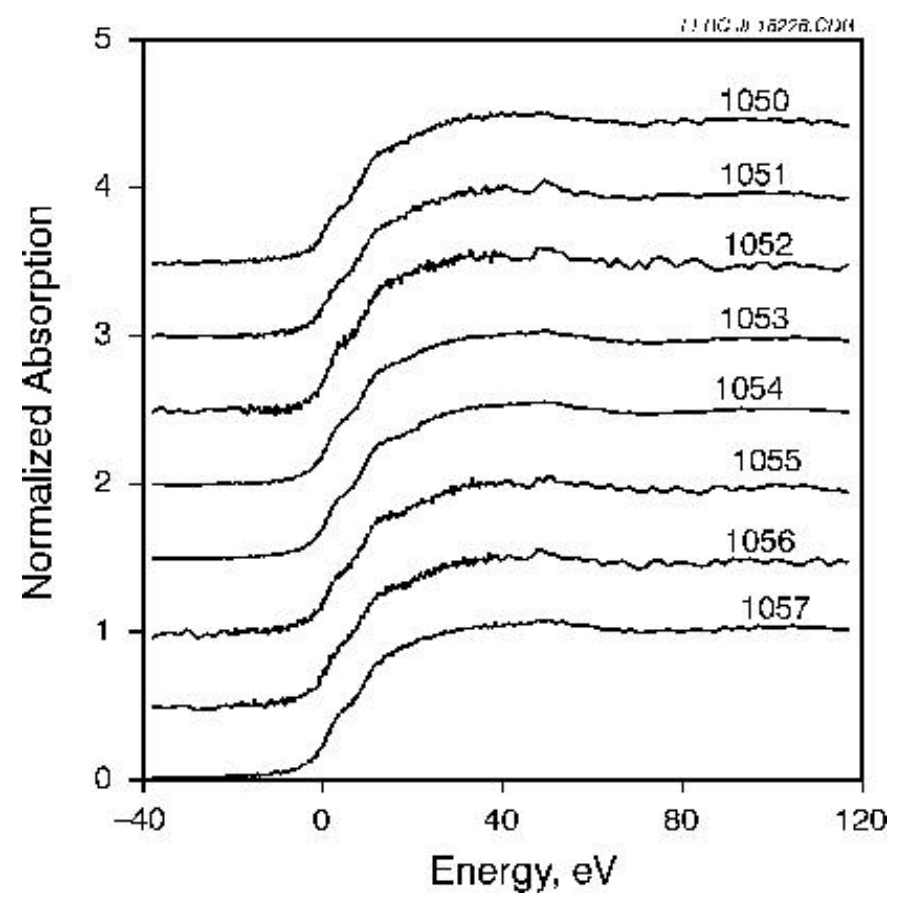

Figure 2. Mercury XANES for Tests 1050-1057.

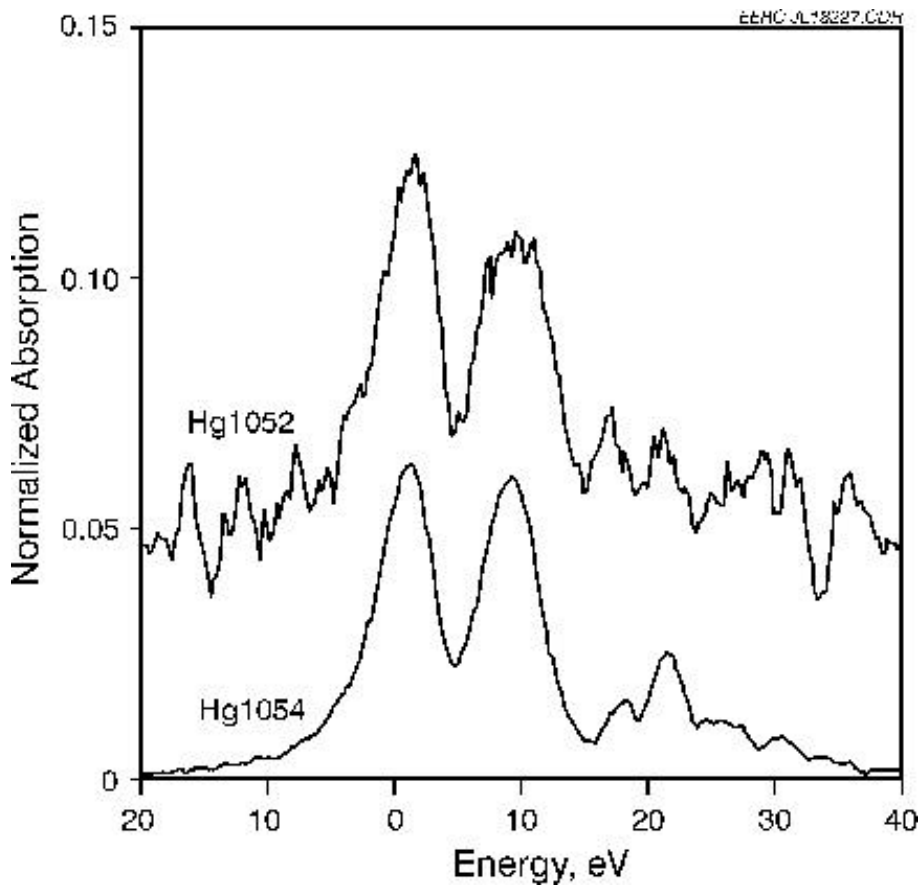

Figure 3. Derivative of mercury XANES for Tests 1052 and 1054. 
Several numbers can be calculated from the XANES spectra, including the following:

- IPD - Inflection point difference, defined as the separation in $\mathrm{eV}$ of the double peak in the differential XANES spectrum; it is a measure of the ionic nature of the $\mathrm{Hg}$ bonding to the atoms in the nearest neighbor coordination shell.

- HR - Peak height (ht) ratio, height (low-energy peak)/height (high-energy peak).

- Edge step - the normalization factor for the XANES spectra, defined as the difference in average absorption above and below the edge in the raw XAFS spectrum; the value of this parameter roughly reflects the mercury content of the sample.

- I0 - The magnitude of the absorption just before the onset of the edge.

- Step/I0 - The ratio of the last two parameters, probably a slightly better XAFS measure of the concentration of mercury in the sample (again, this is only a rough approximation).

- Radial structure function (RSF) - The position in $\AA$ of the major peak in the RSF spectrum; this value reflects the average $\mathrm{Hg}$ nearest neighbor coordination shell bond distance.

- RSF height - The magnitude of the major peak in the RSF spectrum, which reflects both the coordination number and atomic number of the atoms in the coordination shell.

Table 3 contains the numerical values as determined by XAFS for Tests 1050-1057. Several RSF numbers could not be determined because of poor-quality signal. Variations of the edge-step and step/I0 parameters indicate varying levels of mercury in the sample. This is not surprising since the tests were conducted for different amounts of time. The worst data came from Test $1052(3 \mathrm{hr})$ and the best data from Test $1054(14 \mathrm{hr})$. The IPD indicates the ligand atoms that surround the mercury atoms and is one of the most important values listed. The values vary from 7.5 to $8.2 \mathrm{eV}$. These values are consistent with those of chlorine $(8.4 \pm 0.2 \mathrm{eV})$ and sulfur $(7.5 \pm$ $0.2 \mathrm{eV})$. The RSF height for the three best-quality spectra $(1053,1054$, and 1057) also is indicative of sulfur and chlorine ligands. This indicates that $\mathrm{Hg}$ is associated with $\mathrm{Cl}$ or $\mathrm{S}$ on the surface. No distinction can be obtained between these ligands, as indicated in previous work (Huggins and others, 1998).

Sulfur XANES was obtained. No attempt has been made to calculate RSFs from the EXAFS. The sulfur XANES are shown in Figure 4. The low-energy portion of the curve is displayed in Figure 5. The spectra are similar in shape and are dominated by the sulfate peak around $10 \mathrm{eV}$. However, there are differences in the low-energy region $(1-9 \mathrm{eV})$.

All of the sulfur XANES spectra have been least squares-fitted between $\nabla$ and $16 \mathrm{eV}$. Figure 6 is a sample output of this type of fitting. The individual peaks represent different sulfur forms, and the area under the curve can be converted to sulfur percent. Table 4 contains the 


\section{TABLE 3}

Numerical Values Determined from Hg XANES Spectra

\begin{tabular}{|c|c|c|c|c|c|c|c|c|}
\hline $\begin{array}{l}\text { Sample } \\
\text { Description }\end{array}$ & Time, hr & IPD & HR & Edge-Step & IO & Step/I0 & RSF & RSF ht \\
\hline 1050, Norit, Full & 11 & 7.9 & 0.96 & 0.19 & 0.52 & 0.37 & 1.82 & 310 \\
\hline $\begin{array}{l}\text { 1051, Norit, } \\
\quad \nabla \mathrm{SO}_{2}\end{array}$ & 4.5 & 8.0 & 0.92 & 0.13 & 0.58 & 0.22 & - & - \\
\hline $\begin{array}{l}\text { 1052, Norit, } \\
\quad \nabla \mathrm{HCl}\end{array}$ & 3.5 & 8.0 & 0.92 & 0.13 & 0.58 & 0.22 & - & - \\
\hline $\begin{array}{l}\text { 1053, Norit, } \\
\text { } \mathrm{NO}_{2}\end{array}$ & 4.2 & 7.7 & 1.09 & 0.27 & 0.46 & 0.59 & 1.96 & 365 \\
\hline $\begin{array}{l}\text { 1054, Norit, } \\
\quad \nabla \mathrm{H}_{2} \mathrm{O}\end{array}$ & 14 & 8.0 & 1.04 & 0.44 & 0.30 & 1.47 & 1.90 & 350 \\
\hline 1055, Norit, Full & 2 & 7.5 & 1.05 & 0.12 & 0.60 & 0.20 & - & - \\
\hline 1056, EERC, Full & 3 & 8.2 & 1.10 & 0.14 & 0.58 & 0.24 & - & - \\
\hline $\begin{array}{l}\text { 1057, EERC, } \\
\quad \mathbf{H C l}\end{array}$ & 7.5 & 8.2 & 1.06 & 0.30 & 0.42 & 0.71 & 2.00 & 390 \\
\hline
\end{tabular}

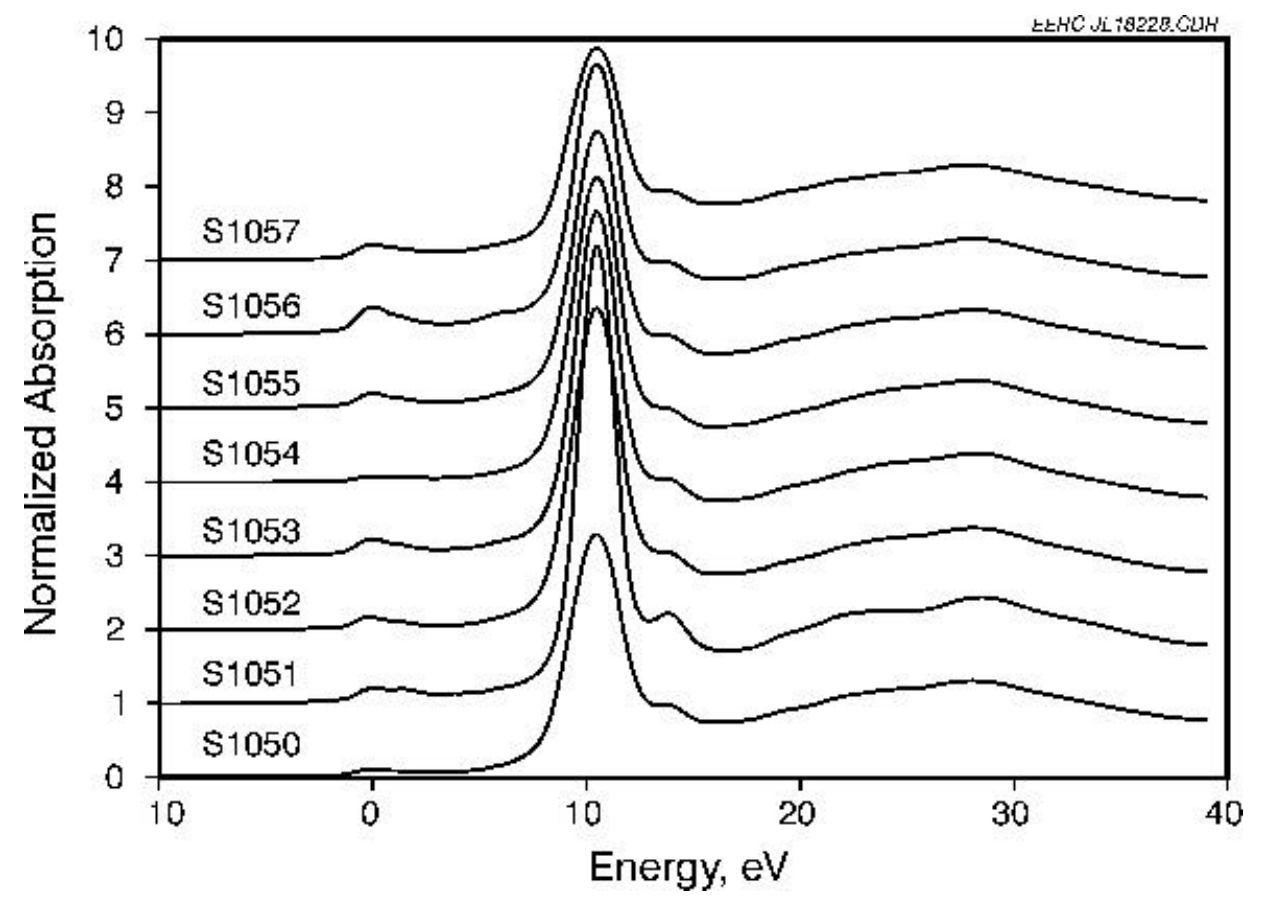

Figure 4. Sulfur XANES for Tests 1050-1057. 


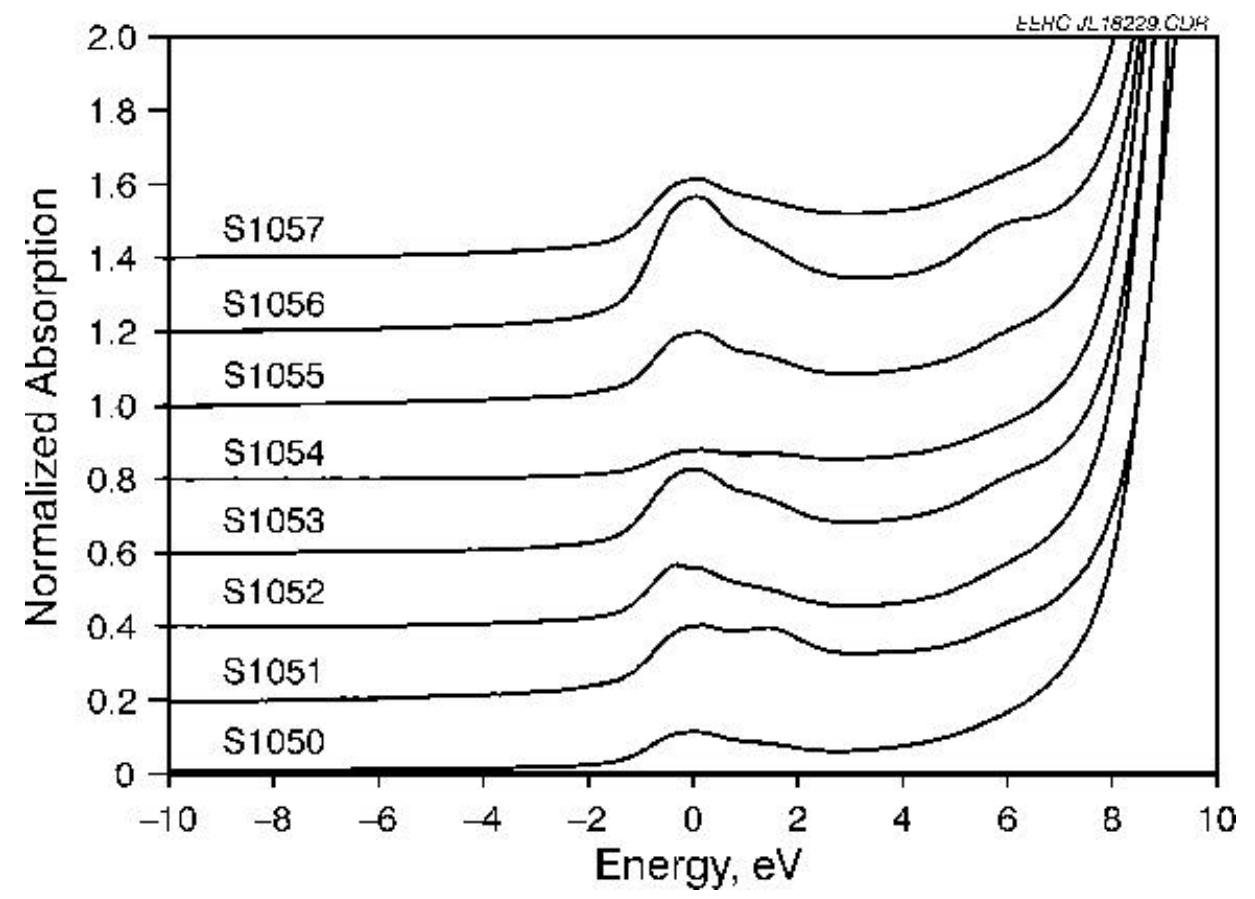

Figure 5. Low-energy sulfur XANES for Tests 1050-1057.

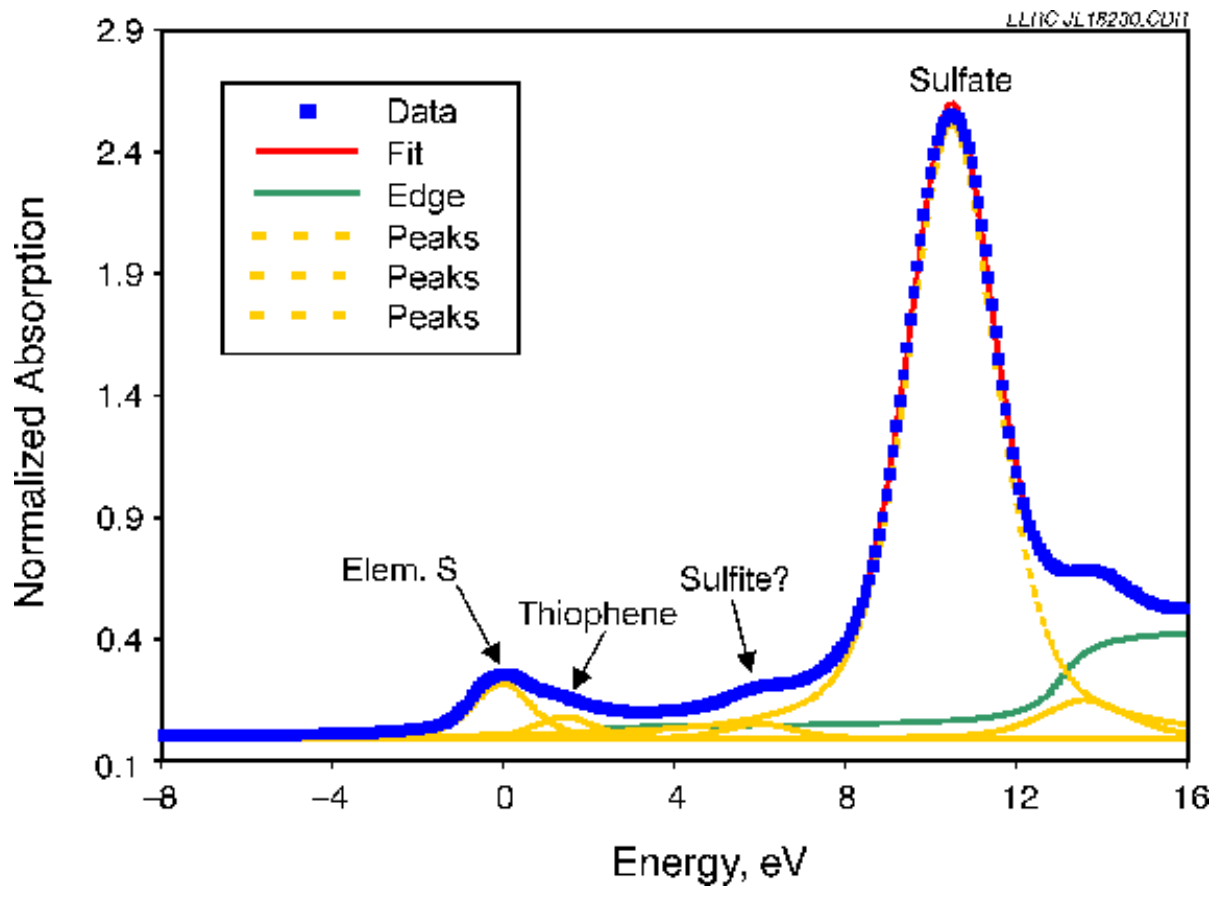

Figure 6. Least-squares fit of Sample 1056. 
TABLE 4

Results of Least-Squares Fitting Sulfur XANES

\begin{tabular}{|c|c|c|c|c|c|c|}
\hline Sample & Time, hr & $\begin{array}{c}\text { Elem. } \\
\text { S }\end{array}$ & Thiophene & Sulfite (?) & Bisulfate (?) & Sulfate \\
\hline 1050, Norit, Full & 11 & 3 & 1 & & 3 & 93 \\
\hline 1051 , Norit, $\vee \mathrm{SO}_{2}$ & 4.5 & 4 & 3 & & & 93 \\
\hline 1052, Norit, $\mathbf{v} \mathrm{HCl}$ & 3.5 & 5 & 1 & & & 94 \\
\hline 1053 , Norit, $\cdot \mathrm{NO}_{2}$ & 4.2 & 6 & 2 & & & 92 \\
\hline 1054 , Norit, $\mathbf{v}_{2} \mathrm{O}$ & 14 & 2.5 & 1 & & & 96.5 \\
\hline 1055, Norit, Full & 2 & 5.5 & 2 & 0.5 & & 92 \\
\hline 1056, EERC, Full & 3 & 11 & 4 & 1 & & 84 \\
\hline 1057, EERC, $\vee \mathrm{HCl}$ & 7.5 & 7.5 & 2.5 & Trace & & 90 \\
\hline
\end{tabular}

results of fitting all of the sulfur XANES. Sulfate was the predominant form of sulfur. Traces of thiophene, sulfite, and bisulfite were also detected. The thiophene sulfur represents the sum of sulfur originally present in the carbon structure. The highest level of sulfate and lowest sulfide was found for Sample 1054, which was the Norit LAC exposed for $14 \mathrm{hr}$ to conditions lacking $\mathrm{H}_{2} \mathrm{O}$.

\section{X-ray Photoelectron Spectroscopy}

XPS, also known as electron spectroscopy for chemical analysis (ESCA), involves irradiating a sample with a monoenergetic $\mathrm{x}$-ray beam that causes photoelectrons to be emitted from the sample. The photoelectrons are emitted from the first 30-50 angstroms of the sample surface. An energy analyzer is used to determine the binding energy of the emitted electrons. From the binding energy and intensity of the photoelectron peak, the elemental identity, chemical state, and quantity of an element is determined. The XPS was equipped with a cold stage to minimize volatilization when exposed to a high vacuum.

Samples from the full test matrix as well as one unexposed Norit LAC were submitted for XPS analysis at Physical Electronics in Eden Prairie, Minnesota. The chemistry of sulfur, chlorine, oxygen, nitrogen, silicon, iron, and carbon was determined. Table 5 shows the results of a survey scan which gives atomic percent $(>0.1 \%)$ of the most concentrated elements. Several differences in sorbent chemistry have been observed between the Norit LAC and the EERC AC. The EERC AC was higher in sodium, calcium, magnesium, and barium. Analysis of an unexposed Norit LAC sample shows lower concentrations of $\mathrm{S}, \mathrm{Cl}$, and $\mathrm{O}$. These differences in elemental levels of $\mathrm{N}, \mathrm{S}$, and $\mathrm{Cl}$ are likely due to the atmosphere to which the sorbent was 


\section{TABLE 5}

Results of XPS Survey Scan, atomic percent

\begin{tabular}{ccccccccccccc}
\hline Run & $\mathbf{C}$ & $\mathbf{N}$ & $\mathbf{O}$ & $\mathbf{N a}$ & $\mathbf{M g}$ & $\mathbf{A l}$ & $\mathbf{S i}$ & $\mathbf{P}$ & $\mathbf{S}$ & $\mathbf{C l}$ & $\mathbf{C a}$ & $\mathbf{F e}$ \\
\hline LAC & 85.10 & 0.40 & 10.70 & ND & 0.20 & 0.70 & 1.00 & ND & 0.40 & ND & 1.10 & 0.10 \\
1058 & 82.16 & 0.22 & 11.10 & 0.11 & 0.40 & 0.62 & 1.36 & 0.14 & 0.48 & 2.01 & 1.26 & 0.13 \\
1059 & 76.16 & 0.30 & 17.30 & 0.10 & 0.46 & 0.45 & 1.14 & 0.02 & 2.43 & 0.19 & 1.37 & 0.09 \\
1060 & 66.73 & 0.21 & 25.72 & 0.11 & 0.19 & 0.51 & 1.22 & 0.06 & 3.95 & 0.00 & 1.18 & 0.13 \\
1061 & 79.32 & 0.35 & 14.31 & 0.05 & 0.52 & 0.57 & 1.22 & 0.06 & 1.79 & 0.26 & 1.44 & 0.12 \\
1062 & 77.14 & 0.22 & 16.74 & 0.17 & 0.32 & 0.48 & 1.11 & 0.07 & 2.32 & 0.00 & 1.31 & 0.12 \\
1063 & 48.85 & 0.12 & 35.61 & 2.79 & 1.16 & 0.90 & 1.02 & 0.23 & 6.44 & 0.00 & 2.65 & 0.19 \\
1064 & 78.45 & 0.24 & 15.03 & 0.04 & 0.65 & 0.52 & 1.17 & 0.06 & 1.81 & 0.61 & 1.33 & 0.10 \\
1065 & 62.74 & 0.23 & 24.94 & 2.21 & 1.32 & 0.53 & 1.12 & 0.21 & 4.06 & 0.00 & 2.55 & 0.02 \\
\hline
\end{tabular}

*Not determined.

exposed, rather than the minerals associated with the AC. Detection of mercury was unsuccessful because of spectral interferences with silicon.

More detailed, high-resolution scans for selected elements were also completed. The detailed scan shows the specific chemistry of each desired element. The largest differences observed are with the chlorine, sulfur, and nitrogen chemistries.

Figure 7 contains all eight detailed scans showing the energies corresponding to chlorine. Figure 7 will also serve as a legend for the rest of the scans. The net absorption of $\mathrm{Cl}$ and $\mathrm{S}$ was dependent on both exposure time and flue gas constituents. In tests where $\mathrm{SO}_{2}$ was excluded from the flue gas (1058), $\mathrm{Cl}$ absorption was the highest. When $\mathrm{SO}_{2}$ was included in the gas components (1059 - full flue gas composition), the concentration of $\mathrm{Cl}$ was much lower in the sample by a factor of 10, although the contact time was one-half of that in Sample 1058. The concentration of $\mathrm{Cl}$ further dropped to 0 in Sample 1060 where the test was extended to $7.5 \mathrm{hr}$ (after breakthrough). These data indicate that the $\mathrm{Cl}$ and sulfate (or possibly other sulfur species derived from $\mathrm{SO}_{2}$ ) compete at carbon sites that bond these species, with sulfate displacing $\mathrm{Cl}$ with continued exposure to the flue gas. The nature of this bonding has yet to be determined. When $\mathrm{HCl}$ was excluded (1062), no $\mathrm{Cl}$ was detected in the sample.

The presence or absence of $\mathrm{NO}_{2}$ seemed to have little influence on the absorption of $\mathrm{Cl}$. The absence of water (1064) increased the capture of $\mathrm{Cl}$ compound with full flue gas conditions (1059). This may be related to the role of water in the formation of sulfate. The EERC ACs did not capture $\mathrm{Cl}(1063,1065)$, possibly because of the high $\mathrm{Na}$ content and, therefore, increased S absorption.

The flue gas constituents also affected the absorption of S. Sample 1060 with the longest exposure to full flue gas conditions $(7.5 \mathrm{hr}) \mathrm{had}$ a much higher sulfate concentration than sample 1059 that was exposed for $2 \mathrm{hr}$. Omission of $\mathrm{SO}_{2}$ (1058) gave a low sulfate concentration as expected. The small value probably results from formation of iron sulfate from the iron sulfides present. 


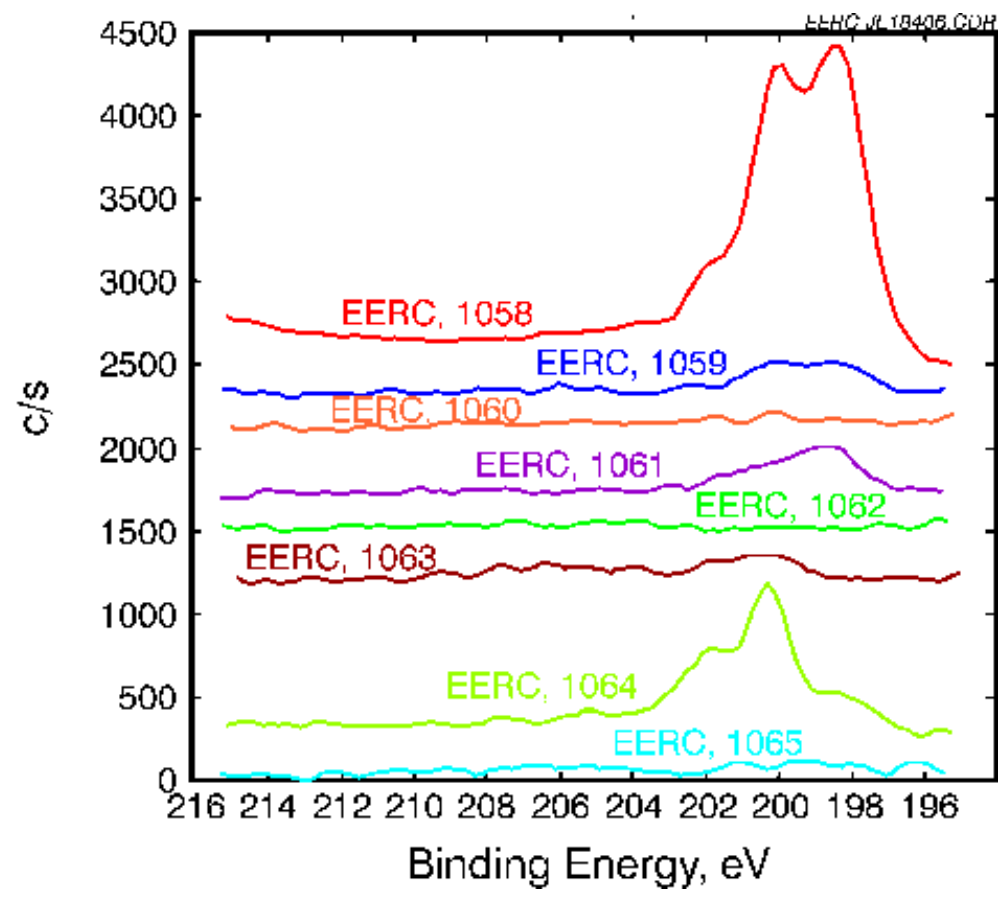

Figure 7. High-resolution scans for $\mathrm{Cl}$, also serving as a legend for the following figures.

The absence of $\mathrm{NO}_{2}$ in the gas composition (1061) results in somewhat lower sulfate concentrations. This can be explained by the role of $\mathrm{NO}_{2}$ in oxidation of $\mathrm{SO}_{2}$ to form sulfate. The absence of water (1064) has a similar lowering effect on sulfate concentration. Again, the role of water in sulfate formation explains these data. The presence or absence of $\mathrm{HCl}$ in the flue gas had no effect on the amount of $\mathrm{S}$ in the sorbent

Figure 8 contains overlays of high-resolution scans for $\mathrm{C}, \mathrm{S}, \mathrm{Cl}, \mathrm{Hg}, \mathrm{N}$, and $\mathrm{Fe}$. The carbon present was graphitic in nature and did not vary between samples. The sulfur was sulfate, sulfide, or thiophene. The amount of sulfate sulfur was lower in the unexposed sample, indicating that sulfur added to the exposed sorbents is the sulfate form. Chlorine was present only in the exposed samples as chloride or organic chlorine and varied between several of the tests. That bound chlorine in the samples appears to be of more than one form is of significant interest, but an adequate explanation for this unprecedented finding and a model for the nature of this bonding require further investigation. Some of the chlorine is chloride, but the remaining chlorine is covalently bound to carbon, hydrogen, or some other element (nitrogen, oxygen) or complexed with a metal.

Nitrogen was found as a nitride and an ammonium salt. Iron sulfide and sulfate were also identified. Quantitative results of the detailed scans are found in Table 6.

\section{Fourier Transform Infrared Spectroscopy}

Samples were analyzed by diffuse reflectance FT-IR. Peaks resulting from addition of components of the gas phase or other changes caused by flue gas interactions were very small, in fact, smaller than the differences between one activated carbon and another. Thus the original 

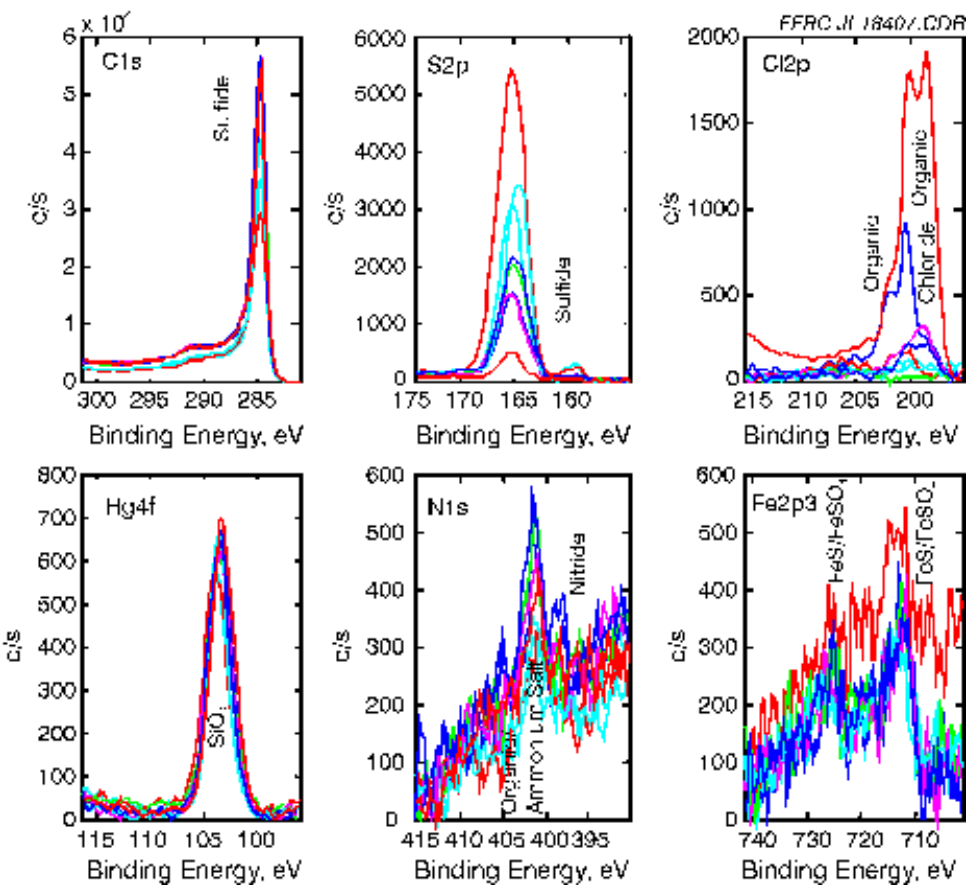

Figure 8. Overlays of high-resolution scan for C, S, Cl, Hg, N, and Fe.

Table 6

A Quantitative Result of Fitting High-Resolution Scans for Chlorine, Nitrogen, and Sulfur

\begin{tabular}{|c|c|c|c|c|c|c|}
\hline Sample & Sulfate & Sulfide & $\begin{array}{l}\text { Organic } \\
\text { Chlorine }\end{array}$ & Chloride & $\begin{array}{c}\text { Ammonium } \\
\text { Salt }\end{array}$ & Nitride \\
\hline Norit, unreacted & 83.00 & 17.00 & $\mathrm{ND}^{*}$ & ND & 100.00 & ND \\
\hline 1058 , Norit, $\nabla \mathrm{SO}_{2}$ & 100.00 & 0.00 & 76.80 & 23.19 & 93.65 & 6.35 \\
\hline 1059, Norit, Full & 98.79 & 1.21 & 72.39 & 27.61 & 74.95 & 25.05 \\
\hline 1060, Norit, Full & 99.68 & 0.32 & ND & ND & 93.94 & 6.06 \\
\hline 1061, Norit, $\nabla \mathrm{NO}_{2}$ & 98.29 & 1.71 & 66.67 & 33.34 & 94.94 & 5.06 \\
\hline 1062, Norit, $\mathbf{v H C l}$ & 97.92 & 2.08 & ND & ND & 75.05 & 24.95 \\
\hline 1063, EERC, Full & 97.92 & 2.08 & ND & ND & 75.05 & 24.95 \\
\hline 1064 , Norit, $>\mathrm{H}_{2} \mathrm{O}$ & 97.73 & 2.27 & 22.24 & 77.76 & 92.44 & 7.56 \\
\hline $\begin{array}{l}\text { 1065, EERC, } \\
\quad \nabla \mathrm{H}_{2} \mathrm{O}\end{array}$ & 95.09 & 4.91 & ND & ND & 72.17 & 27.83 \\
\hline
\end{tabular}

*Not detected. 
sorbent was subtracted as a reference blank from the spectrum of the spent sorbent to observe the changes in spectral bands. Even with this technique, the difference spectra are very noisy and generally much less informative than the XPS spectra. The best of these data can only confirm the presence of sulfate on the sorbent.

\section{Sample 1060}

This sample was generated during mercury sorption on the Norit LAC in a full gas composition, obtained after breakthrough (7.5-hr run time).

The spectrum of this sample exhibits the broad band at $1160 \mathrm{~cm}^{-1}$ attributed to sulfate. Unfortunately, there is a large background peak at about $1100 \mathrm{~cm}^{-1}$ that is subtracted but makes any peak of this wave number difficult to see. The distinction between forms with different numbers of cations or protons on the oxygen (one or two) could not be made. Sulfite is unlikely to be present in significant amounts, owing to the lack of 900 and $675 \mathrm{~cm}^{-1}$ bands expected for a metal-oxygen bonded sulfite or $650 \mathrm{~cm}^{-1}$ expected for the metal-sulfur bonded sulfite. However, the presence of a pyramidal metal- $\mathrm{SO}_{2}$ complex cannot be ruled out, since it would exhibit peaks at 1190 and 1050 $\mathrm{cm}^{-1}$. There is also a very weak broad peak at about $1380 \mathrm{~cm}^{-1}$ that could be attributed to nitrite. The nitrate band expected at 1420 may be lost in the noise.

\section{Sample 1059}

This sample was generated during mercury sorption on the Norit LAC in a full gas composition obtained before breakthrough (2-hr run time).

The spectrum of this sample exhibits the broad sulfate band at $1124 \mathrm{~cm}^{-1}$, but it is weak (0.004 KM units). This may be due to the shorter contact time. The spectrum does show the weak higher wave number bands at $1370 \mathrm{~cm}^{-1}$, attributed to the nitrite band. Again, the nitrate band may be lost in the noise.

\section{Sample 1058}

This sample was generated during mercury sorption on the Norit LAC in a gas composition lacking $\mathrm{SO}_{2}$, obtained after $4 \mathrm{hr}$.

The spectrum showed a negative band centered at $1114 \mathrm{~cm}^{-1}$. This is consistent with the lack of $\mathrm{SO}_{2}$ in the gas composition that results in no sulfate being formed. A weak broad peak was also observed centered at about $1331 \mathrm{~cm}^{-1}$. This is attributed to nitrite or nitrate, but no distinction can be made, owing to the low intensity of the band.

\section{Sample 1061}

This sample was generated during mercury sorption on the Norit LAC in a gas composition lacking $\mathrm{NO}_{2}$, obtained after $4.5 \mathrm{hr}$. 
The spectrum showed the broad band centered at $1187 \mathrm{~cm}^{-1}$, consistent with the sulfate bands. The peak is a little less intense than that in the 1058 sample. As discussed above, sulfite bands are missing, although a metal- $\mathrm{SO}_{2}$ peak is possible. No peak is present at $1300-1400 \mathrm{~cm}^{-1}$ that would correspond to the nitrite or nitrate band.

\section{Sample 1062}

This sample was generated during mercury sorption on the Norit LAC in a gas composition lacking $\mathrm{HCl}$, obtained after $2 \mathrm{hr}$.

The difference spectrum showed a negative peak around $1100 \mathrm{~cm}^{-1}$.

\section{Sample 1064}

This sample was generated during mercury sorption on the Norit LAC in a gas composition lacking $\mathrm{H}_{2} \mathrm{O}$, obtained after $2 \mathrm{hr}$.

The spectrum was basically identical to the original LAC; thus the difference spectrum was not informative. A negative peak was seen for the $1100 \mathrm{~cm}^{-1}$ band in the difference spectrum.

\section{Sample 1063}

This sample was generated during mercury sorption on the EERC AC in a full gas composition.

The spectrum shows a large peak at $1167 \mathrm{~cm}^{-1}$, corresponding to sulfate. A weaker peak at $1313 \mathrm{~cm}^{-1}$ may be the nitrite.

\section{Sample 1065}

This sample was generated during mercury sorption on the EERC AC in a gas composition lacking $\mathrm{HCl}$.

The spectrum shows a large peak at $1192 \mathrm{~cm}^{-1}$, corresponding to sulfate. A weaker peak at $1319 \mathrm{~cm}^{-1}$ may be the nitrite.

\section{Mechanisms for Acidic Gas Sorption on Carbon}

Several sorption events occur during the exposure of carbon sorbents to flue gas components. Most of these will occur independently of the mercury sorption, but some of these may be related to or affect the capture of mercury, and understanding the nature of these interactions of flue gas components with the carbon sorbent is essential to developing an understanding of how mercury is captured and how flue gas components affect the mercury capture mechanism. 
The data discussed above clearly indicate that the majority of sulfur species in the exposed sorbents are sulfate. So part of the binding mechanisms that occur involve oxidation of $\mathrm{SO}_{2}$ to sulfate. The electron sink for the reaction could be either $\mathrm{O}_{2}, \mathrm{NO}$, or $\mathrm{NO}_{2}$, but $\mathrm{NO}_{2}$ is by far the most reactive. Omission of $\mathrm{NO}_{2}$ from the gas components clearly had a significant negative effect on sulfate accumulation. The effect of water shows that the oxidation mechanism on the sorbent involves $\mathrm{H}_{2} \mathrm{O}$, probably in the formation of the sulfite intermediate, as it does in the formation of sulfate in wet scrubbing.

There did not appear to an effect for $\mathrm{HCl}$ on the sulfate formation reaction in the case of the Norit LAC carbon. There was a significant difference in the sulfate accumulated in the two tests with the EERC carbon. But Test 1063 (with $\mathrm{HCl}$ ) ran more than three times longer than test 1065 (no $\mathrm{HCl}$ ), which would explain why the sulfate was higher in Sample 1063. So it unlikely that there was a effect for $\mathrm{HCl}$ on sulfate accumulation for this carbon.

The data also clearly indicate a competition between chlorine and sulfate or other sulfur species derived from $\mathrm{SO}_{2}$ for the binding sites on the sorbent. A major problem in explaining the nature of this competition is that we do not yet understand whether chemical or physical processes are dominating this competitive phenomenon. Another problem is that there appear to be two forms of chlorine, covalent and ionic (chloride), involved in binding to the carbon sorbents. Nevertheless, we can offer some ideas about some of the factors that may be involved in determining the competitive binding of chlorine and sulfate.

One argument is that the volatility of $\mathrm{HCl}$ is much greater than $\mathrm{H}_{2} \mathrm{SO}_{4}$. Initially, the $\mathrm{HCl}$ competes effectively with $\mathrm{SO}_{2}$ at basic carbon binding sites since the volatilities are similar. Later, as sulfate is formed from $\mathrm{SO}_{2}$ over the course of the experiments, the equilibrium is driven by the greater volatility of $\mathrm{HCl}$, so protons transfer to chloride and $\mathrm{HCl}$ escapes to the gas phase. Further work at lower temperatures may help elucidate this question. Both chloride and bisulfate are relatively weak bases, so it is less likely that the relative basicity is an important factor in the competition.

If chlorine is bound covalently to the carbon surface, it could be displaced by a sulfate group. But since we do not know the atom to which chlorine is bound, it is difficult to offer arguments based on hard-soft base character. In the end, it may be that it does not matter and the equilibrium is still driven by the greater volatility of the $\mathrm{HCl}$.

\section{Mechanism of Mercury Capture}

XANES data for the various loaded sorbents indicate that the mercury IPD values are consistent with that of a mercury(II) chloride or sulfide. That the mercury on the sorbent is oxidized is consistent with all the previous testing of sorbents for $\mathrm{Hg}$ capture at above ambient conditions (Olson et al., 2000). However, neither of the two suggested $\mathrm{Hg}$ (II) forms provides a very satisfactory model for the mercury binding. Two of the tests did not involve any kind of chlorine species that could have formed a chloride salt. Mercuric chloride is also highly volatile

at the temperatures involved in testing and would be expected to have desorbed from the sorbent. It is unlikely that the $\mathrm{SO}_{2}$ could have reduced to sulfide in the strongly oxidizing conditions in 
the acid flue gas; in fact, the evidence is plentiful that most of the sulfur is oxidized to sulfate. The activated carbons do not contain any elemental sulfur as a result of the severe conditions of the activation process, although some thiophenic sulfur may survive the activation process. However, thiophenic sulfur does not strongly bind $\mathrm{Hg}$ (II).

XANES data are available for only a very few standard mercury salts. Thus some compounds such as $\mathrm{HgO}$ can be ruled out. But some of the other nonvolatile types of $\mathrm{Hg}$ (II) compounds cannot be eliminated on the basis of the XANES data. These would include the very large number of basic $\mathrm{Hg}$ salts where combinations of oxygen, nitrogen, partially oxidized sulfur, and other atoms covalently bind mercury in a polymeric matrix.

The current model for explaining the capture of $\mathrm{Hg}$ (II) formed in the initial oxidation step describes the sorption of the $\mathrm{Hg}$ (II) at a basic site on the carbon to form a nonvolatile salt (Miller et al., 2000). This occurs until the basic sites are exhausted (by reaction with $\mathrm{SO}_{2}$, sulfate, or $\mathrm{HCl}$ ). At this time, the $\mathrm{Hg}(\mathrm{II})$, which continues to form, reacts with nitrate (from $\mathrm{NO}_{2}$ ) or with $\mathrm{HCl}$ to form volatile salts such as the nitrate hydrate or chloride, and breakthrough of oxidized mercury appears. In addition, the release of oxidized mercury from the basic binding sites on the sorbent occurs, resulting from the conversion of these nonvolatile basic salts, in which the $\mathrm{Hg}$ (II) is initially captured, into volatile $\mathrm{Hg}$ (II) salts.

The current project supports the hypothesis that acid gases $\left(\mathrm{SO}_{2}\right.$ and $\left.\mathrm{HCl}\right)$ and their oxidation products (sulfate) bind with basic sites on the carbon. These results show that there is competition for these basic sites, and that at breakthrough, the sites must be saturated with sulfate, since no more $\mathrm{Cl}$ can bind. Thus the $\mathrm{Hg}$ (II) is also unable to bind to the stabilizing basic sites at this time and is released as volatile $\mathrm{Hg}(\mathrm{II})$ forms.

\section{CONCLUSIONS}

A significant difference was observed between the Norit LAC and the EERC AC with respect to $\mathrm{Hg}$ sorption capacity. The EERC AC showed little to no breakthrough in flue gas conditions with the absence of $\mathrm{HCl}$, in initial testing. In contrast, the Norit carbon showed a gradual decrease in $\mathrm{Hg}$ sorption from the start in the absence of $\mathrm{HCl}$. The test was not long enough to see complete breakthrough. However, in the presence of $\mathrm{HCl}$, the behavior was somewhat similar. The EERC carbon gave no breakthrough until $4.5 \mathrm{hr}$, whereas the Norit gave a more gradual breakthrough. The EERC AC also has more ability to capture $\mathrm{SO}_{2}$ in the flue gas, but no $\mathrm{Cl}$ was captured. Most of the Norit samples performed as expected. The tests performed to date indicate a potential for the use of an AC as a sorbent that could be injected into a combustion atmosphere.

XAFS analysis indicated most of the sulfur species present are of the sulfate form. Traces of sulfite, thiophene, and bisulfite were also detected. Analysis of the mercury XANES suggests ligand atoms surrounding mercury atoms are predominantly chlorine or sulfur, rather than oxygen. 
XPS analysis was used to determine the fate of $\mathrm{Cl}, \mathrm{S}$, and $\mathrm{N}$ on the surface of the ACs. A survey scan revealed the presence of $\mathrm{C}, \mathrm{N}, \mathrm{O}, \mathrm{Na}, \mathrm{Mg}, \mathrm{Al}, \mathrm{Si}, \mathrm{P}, \mathrm{S}, \mathrm{Cl}, \mathrm{Ca}$, and $\mathrm{Fe}$ on the ACs. More detailed high-resolution scans indicated predominantly sulfate sulfur and organic chlorine and chloride. Nitrogen was present as an ammonium salt. Analysis of an unexposed sample indicated no $\mathrm{Cl}$ and mostly sulfate sulfur. The analysis of unexposed sample also indicated sulfur absorbed from the flue gas is also sulfate.

FT-IR analysis was completed on the eight exposed samples. The FT-IR analysis could only indicate the presence of sulfate and possibly nitrate. The FT-IR technique added no detailed information. Future related projects will not include this analysis.

Several sorption events occur during the exposure of carbon sorbents to flue gas components. Part of the $\mathrm{Hg}$ binding mechanism involves the oxidation of $\mathrm{SO}_{2}$. When $\mathrm{NO}_{2}$ is omitted from the flue gas, less sulfate was accumulated. The effect of $\mathrm{H}_{2} \mathrm{O}$ also indicates that the oxidation mechanism involves water, likely in the formation of the sulfite intermediate. $\mathrm{HCl}$ did not appear to have an effect on the sulfate formation reaction in the case of either carbon. One argument is that the volatility of $\mathrm{HCl}$ is much greater than the $\mathrm{H}_{2} \mathrm{SO}_{4}$. $\mathrm{HCl}$ may compete effectively with $\mathrm{SO}_{2}$ for the active sites, but as time progresses, the formation of sulfate changes the relative volatility of the acids. Protons would then transfer to chloride, and $\mathrm{HCl}$ escapes in the gas phase. Tests at lower temperatures would elucidate this question.

\section{REFERENCES}

Huggins, F.E.; Huffman, G.P.; Dunham, G.E.; Senior, C.L. Energy \& Fuels 1998, 13, 114-121.

Miller, S.J.; Dunham, G.E.; Olson, E.S.; Brown, T.D. Flue Gas Effects on a Carbon-Based Mercury Sorbent. In Air Quality: Mercury, Trace Elements, and Particulate Matter, Special Issue of Fuel Process. Technol. 2000, 65-66, 343-363.

Miller, S.J.; Dunham, G.E.; Olson, E.S.; Brown D.T. Fuel Processing Technology 1999, 65-66, 343-363.

Olson, E.S.; Miller, S.J.; Sharma, R.K.; Dunham, G.E. and Benson, S.A. Journal of Hazardous Materials 2000, 74, 61-79. 


\section{APPENDIX A}

\section{BREAKTHROUGH CURVES FOR THE FIRST EIGHT TESTS}




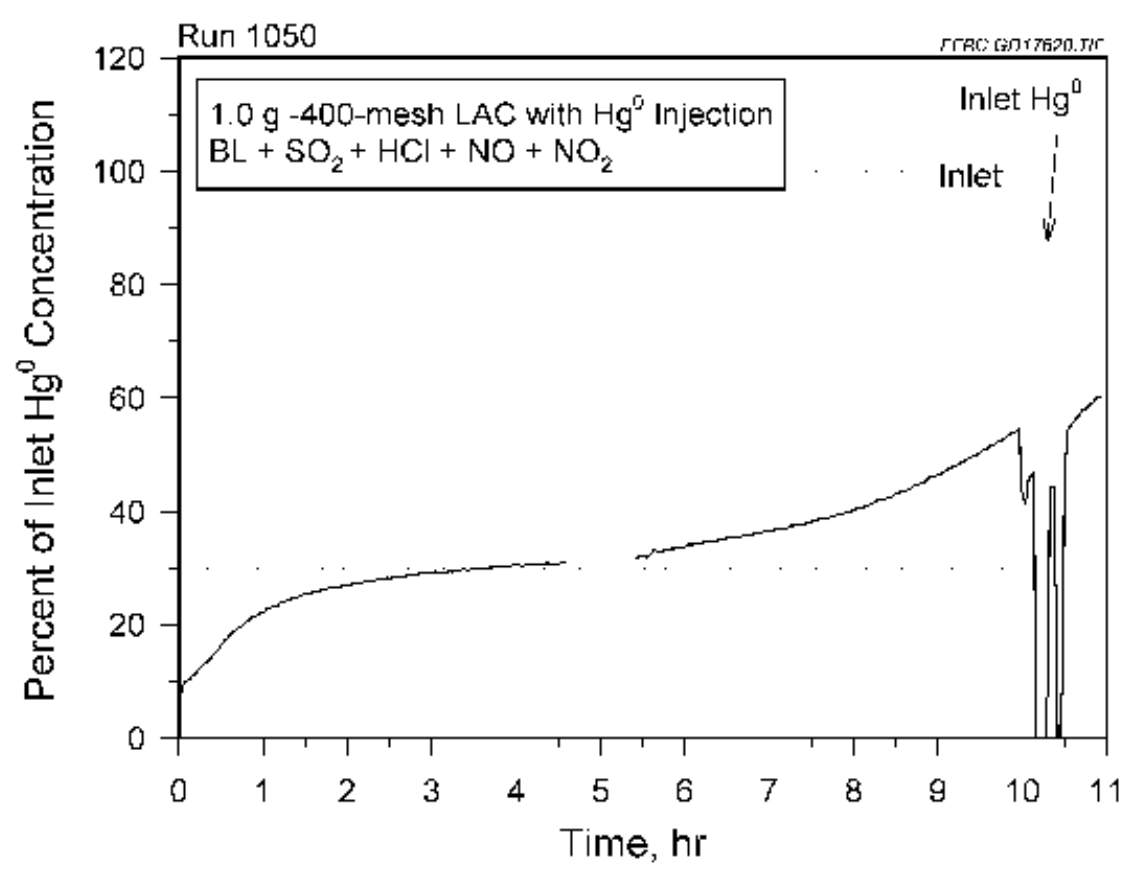

Figure A-1. Breakthrough curve for Test 1050 Norit LAC with full gas composition.

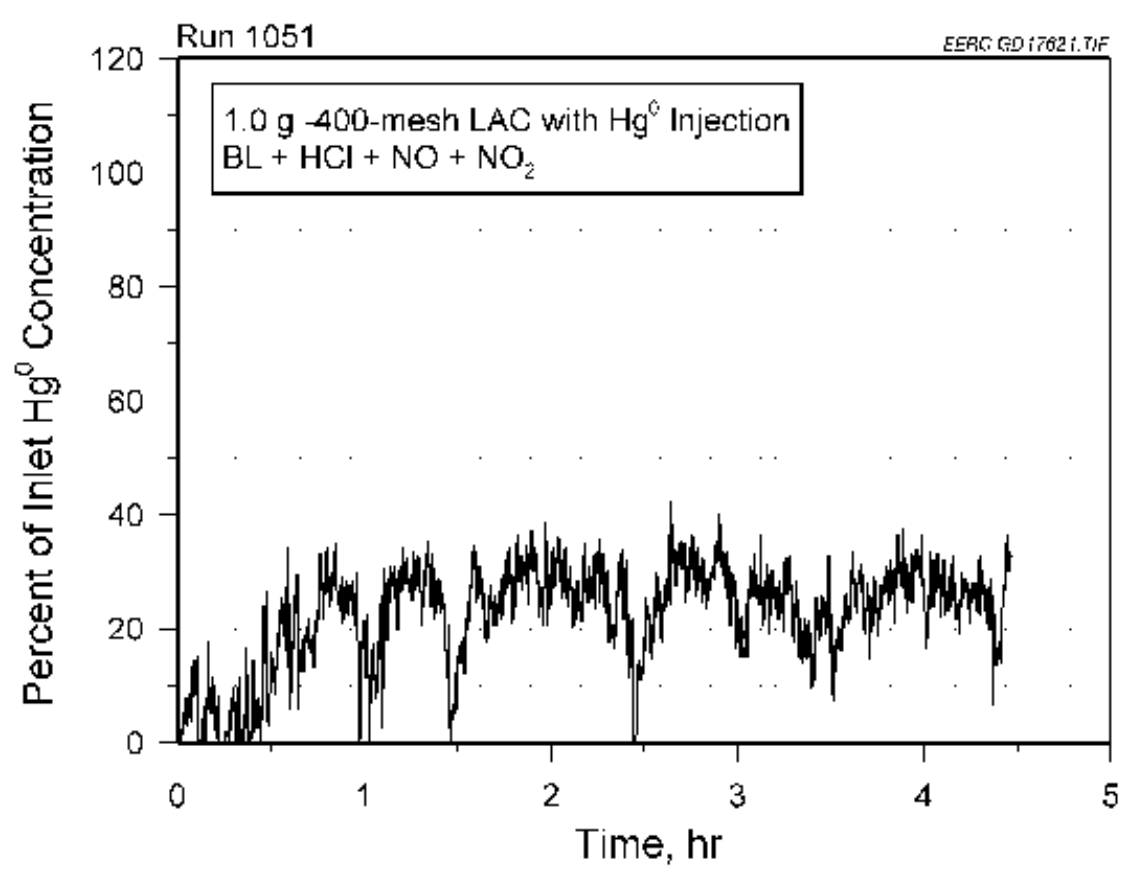

Figure A-2. Breakthrough curve for Test 1051 Norit LAC without $\mathrm{SO}_{2}$. 


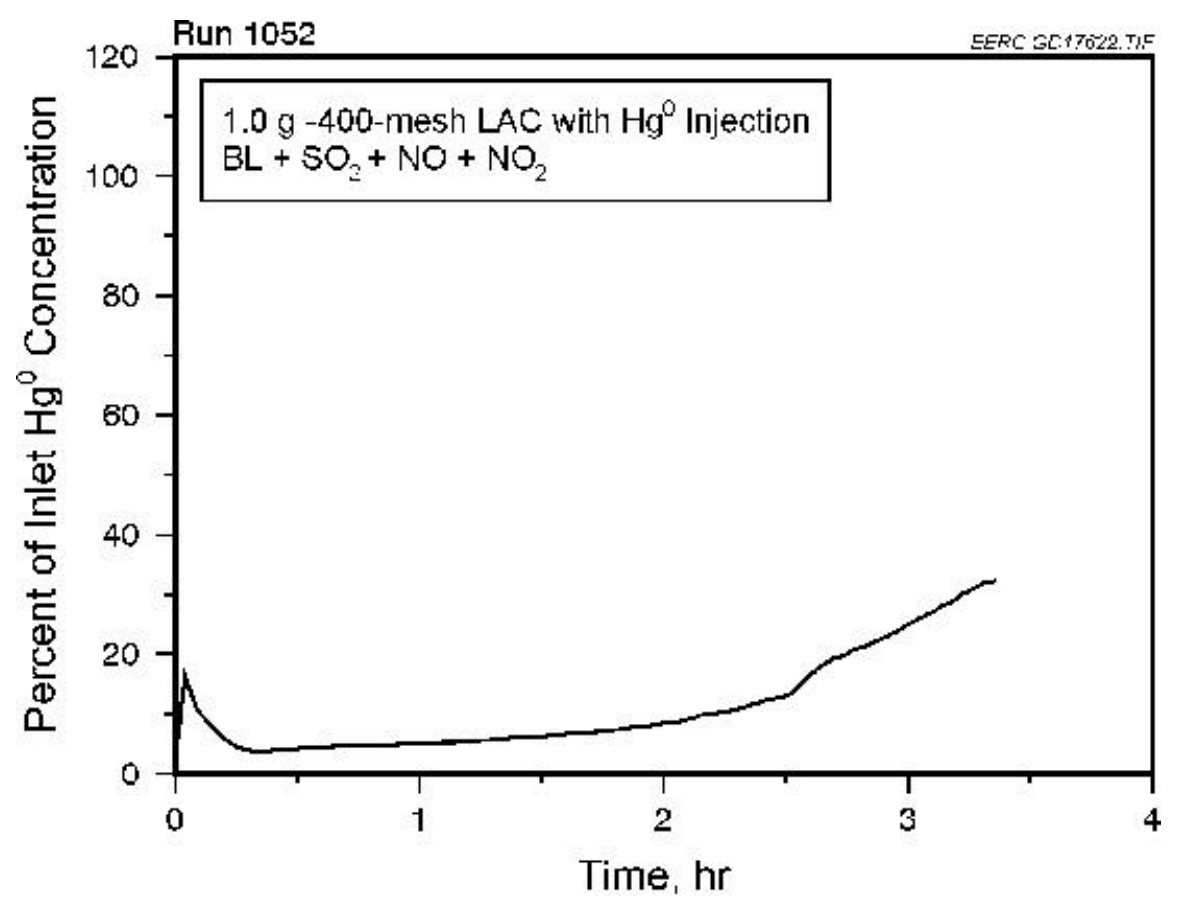

Figure A-3. Breakthrough curve for Test 1052 Norit LAC without HCl.

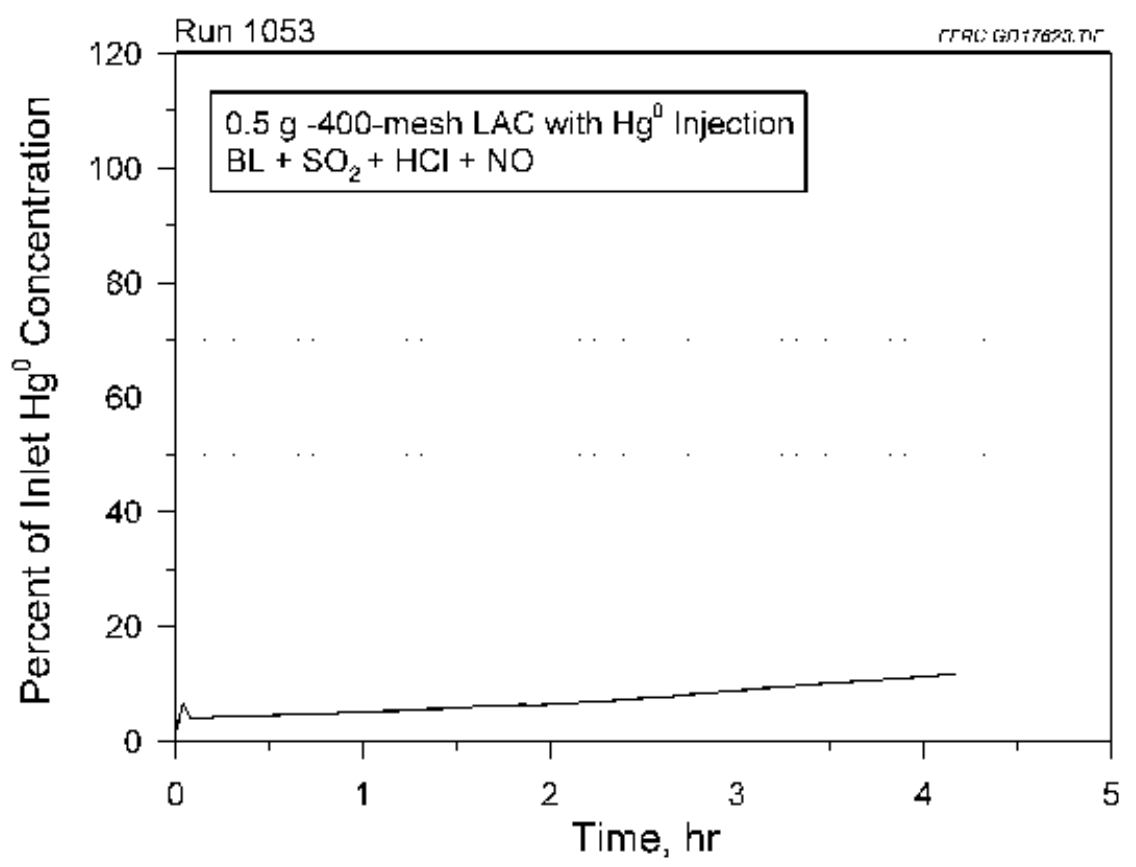

Figure A-4. Breakthrough curve for Test 1053 Norit LAC without $\mathrm{NO}_{2}$. 


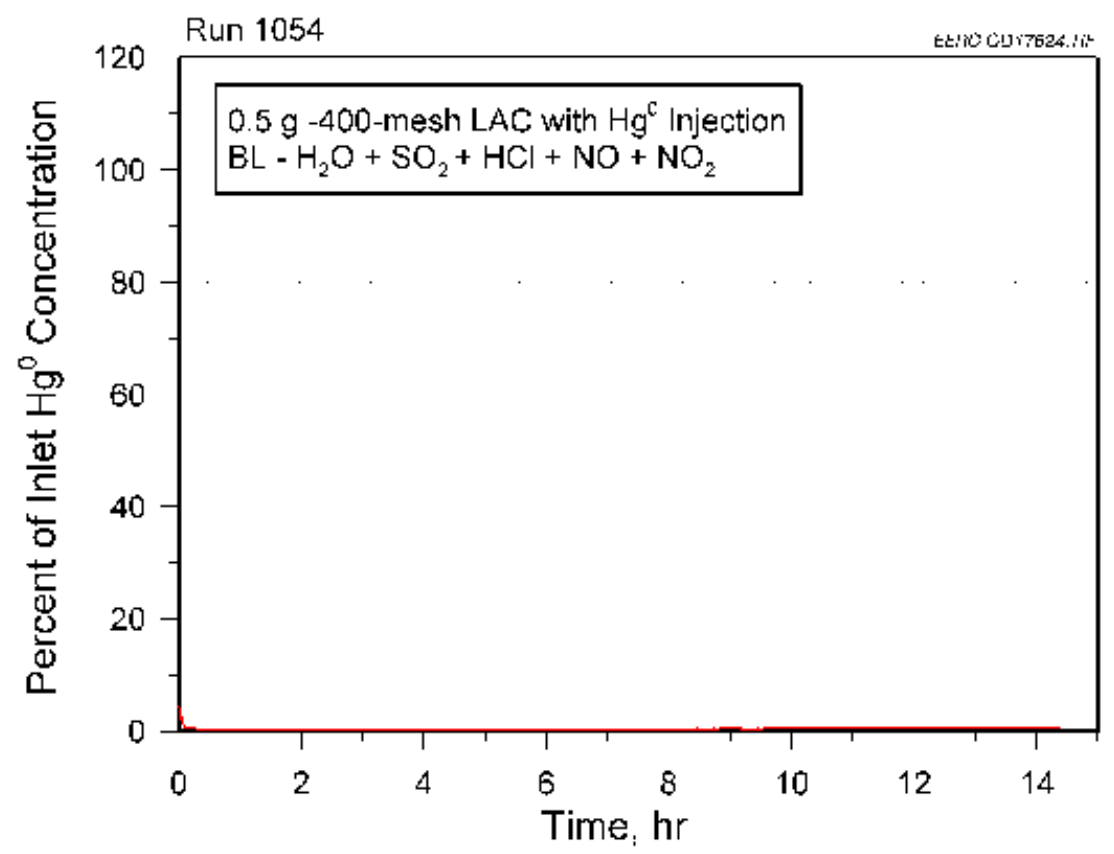

Figure A-5. Breakthrough curve for Test 1054 Norit LAC without $\mathrm{H}_{2} \mathrm{O}$.

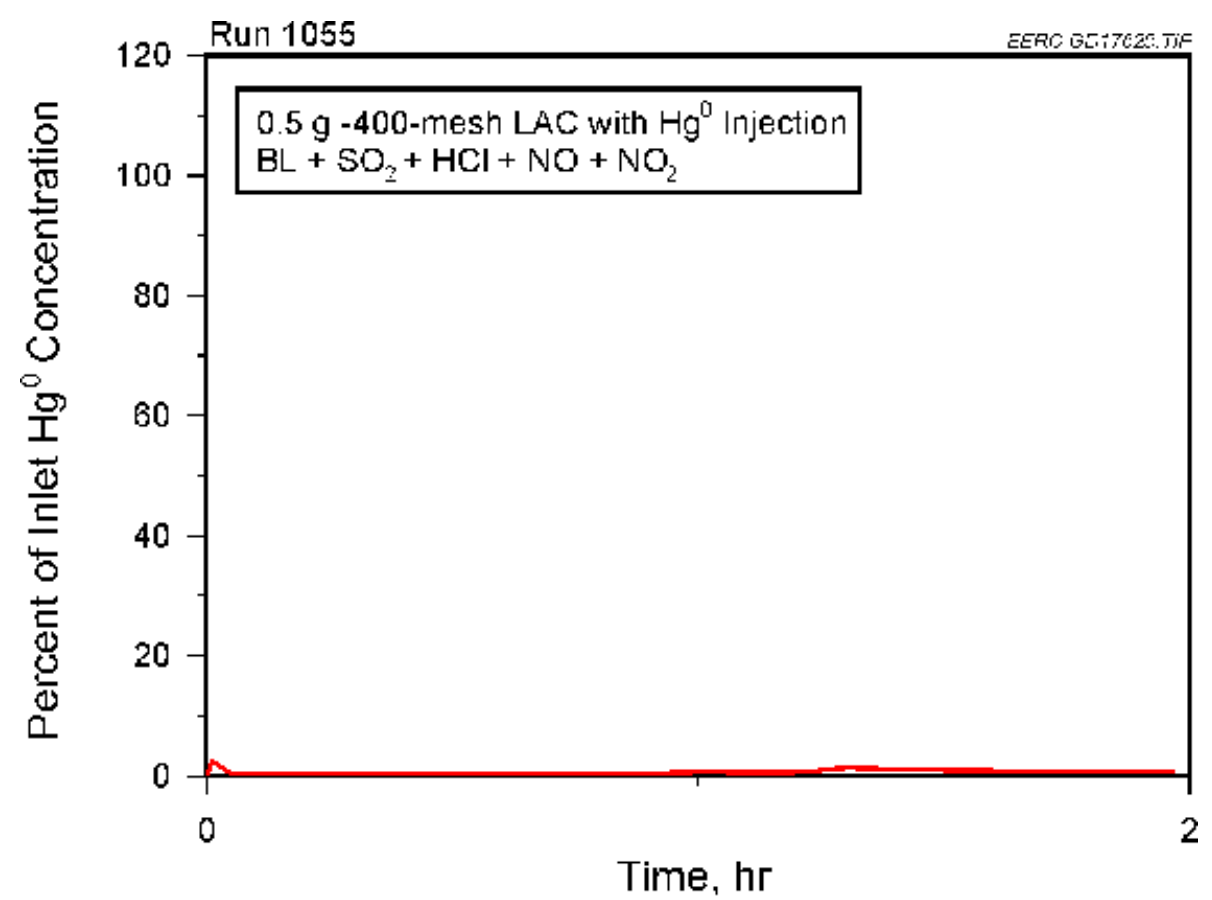

Figure A-6. Breakthrough curve for Test 1055 Norit LAC full gas, before breakthrough. 


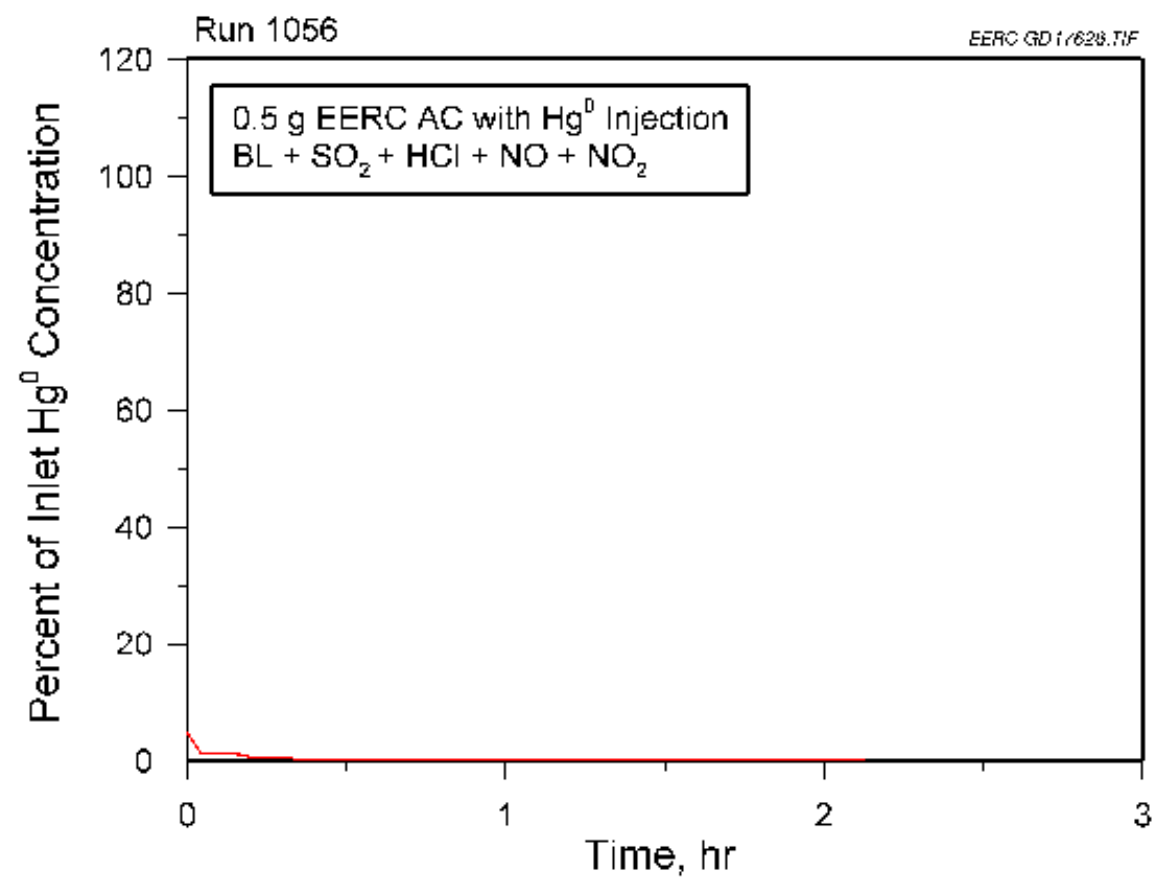

Figure A-7. Breakthrough curve for Test 1056 EERC AC with full gas matrix.

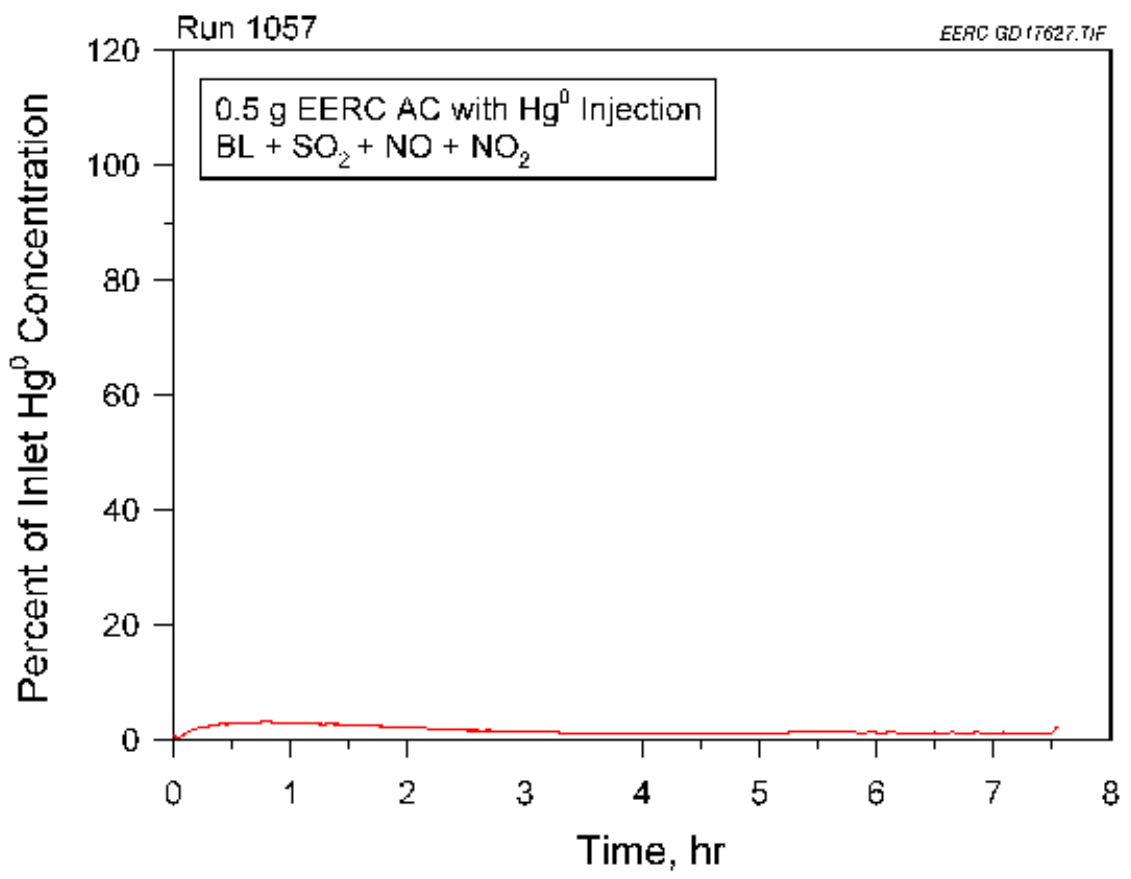

Figure A-8. Breakthrough curve for Test 1057 EERC AC without HCl. 


\section{APPENDIX B}

\section{BREAKTHROUGH CURVES FOR THE SECOND EIGHT TESTS}




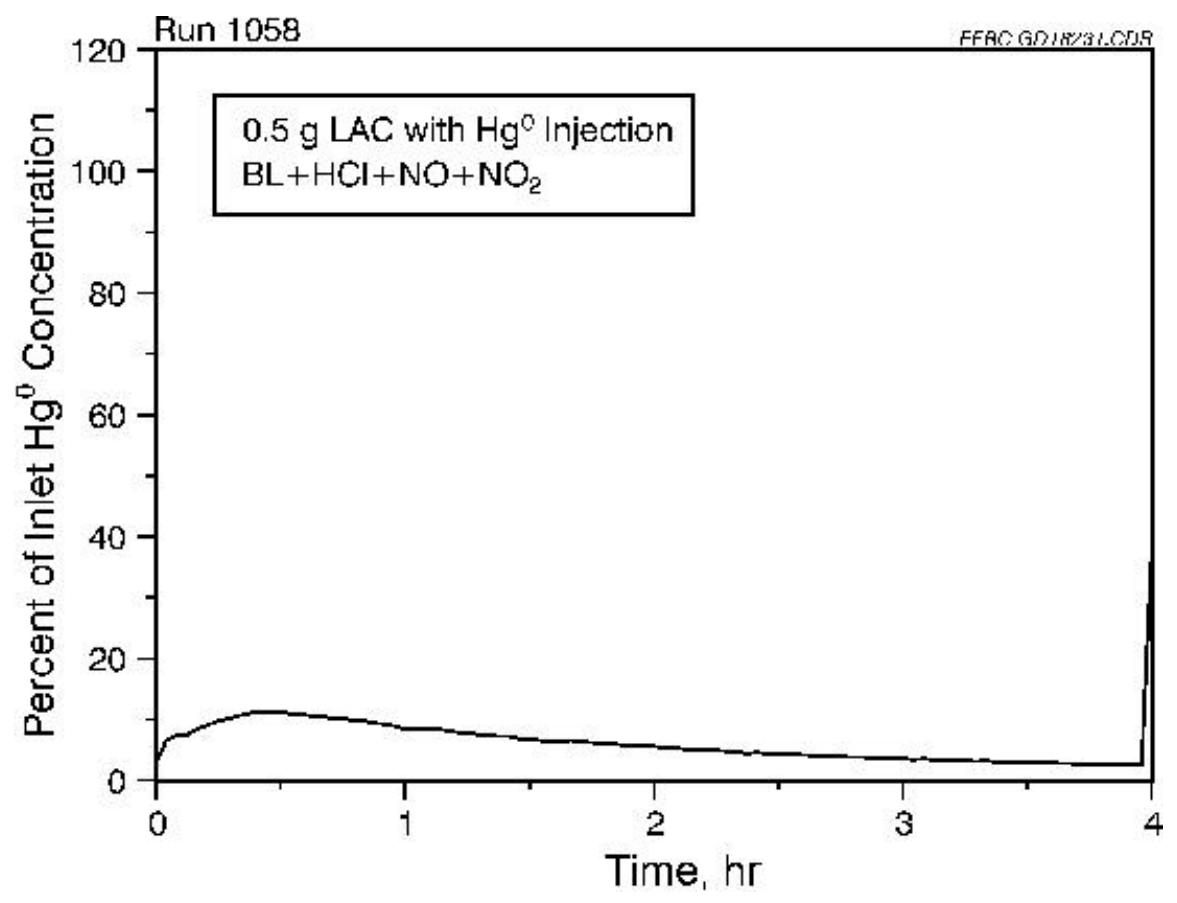

Figure B-1. Breakthrough curve for Test 1058.

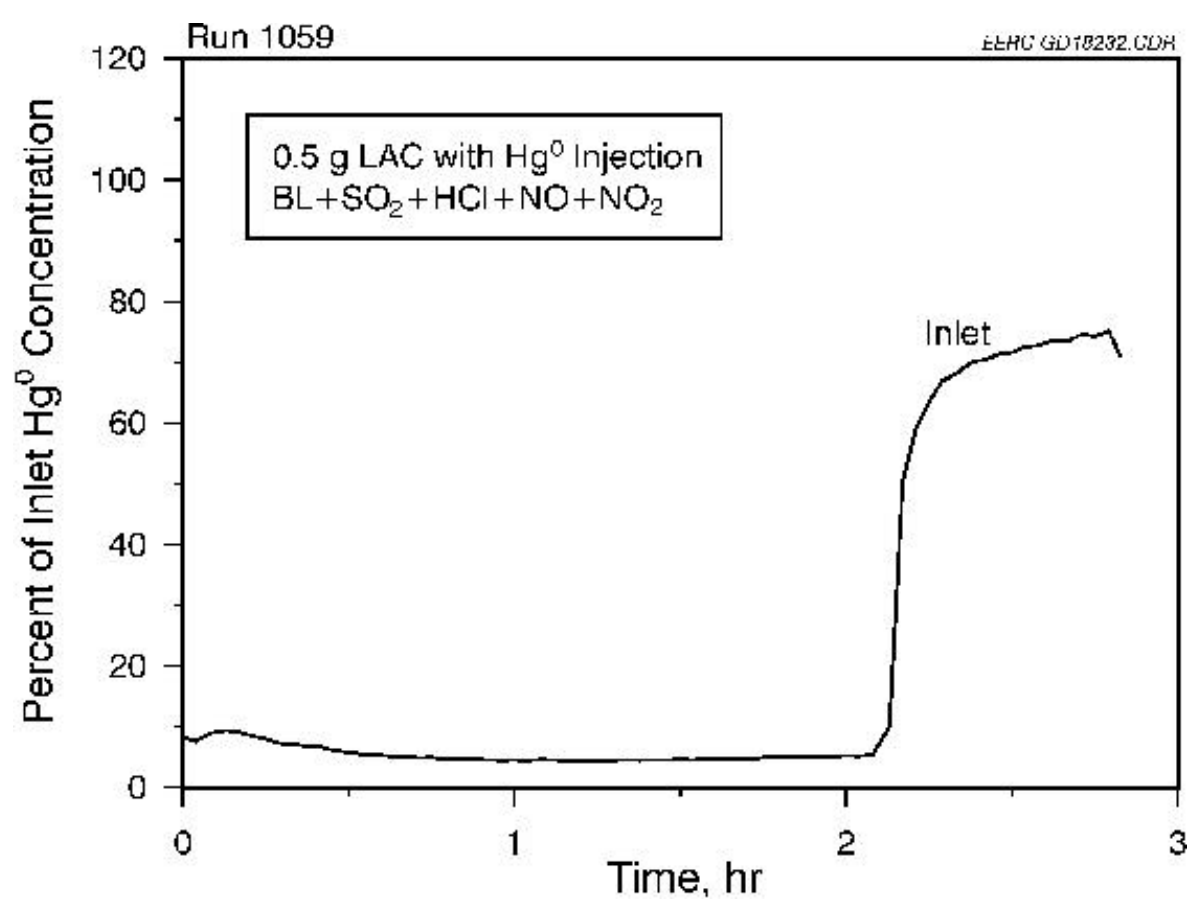

Figure B-2. Breakthrough curve for Test 1059.

B-1 


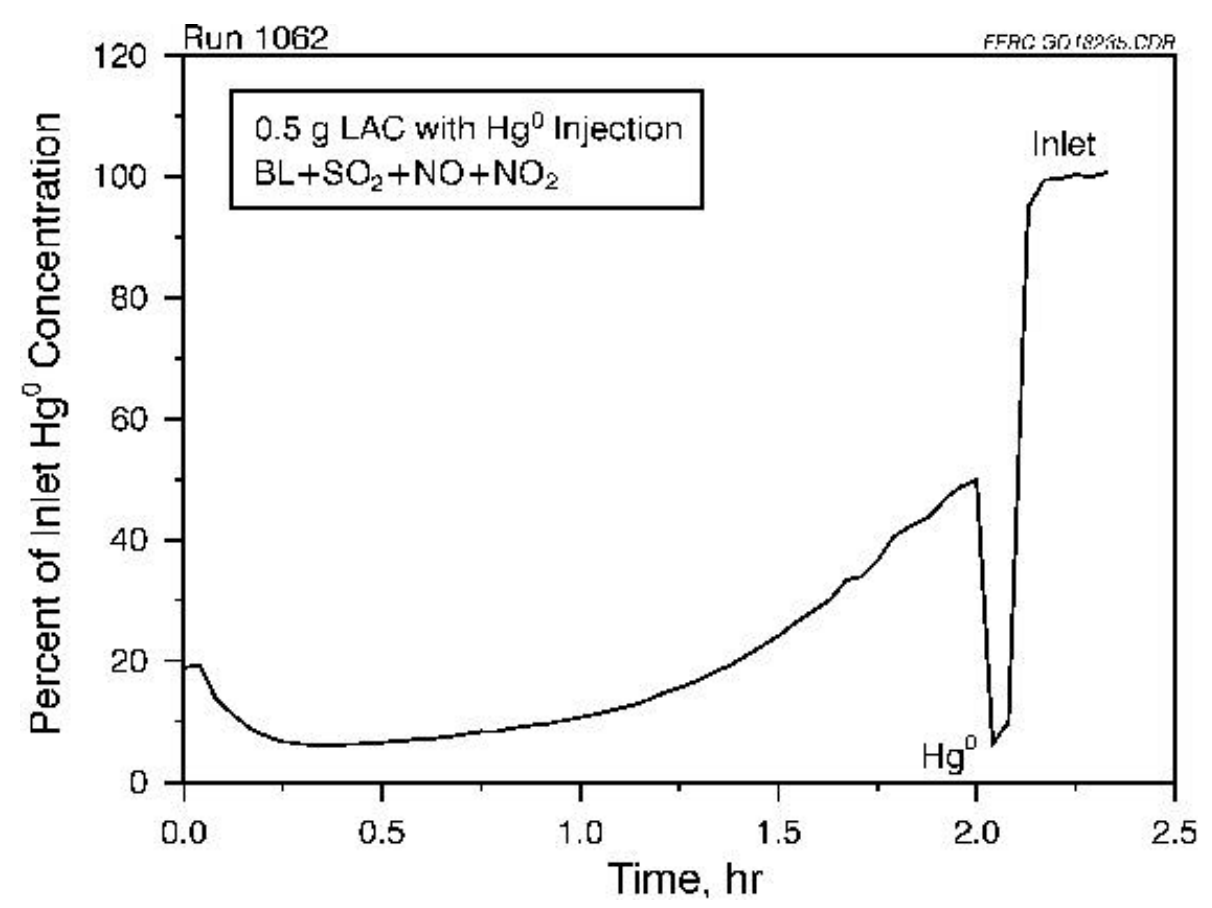

Figure B-3. Breakthrough curve for Test 1062.

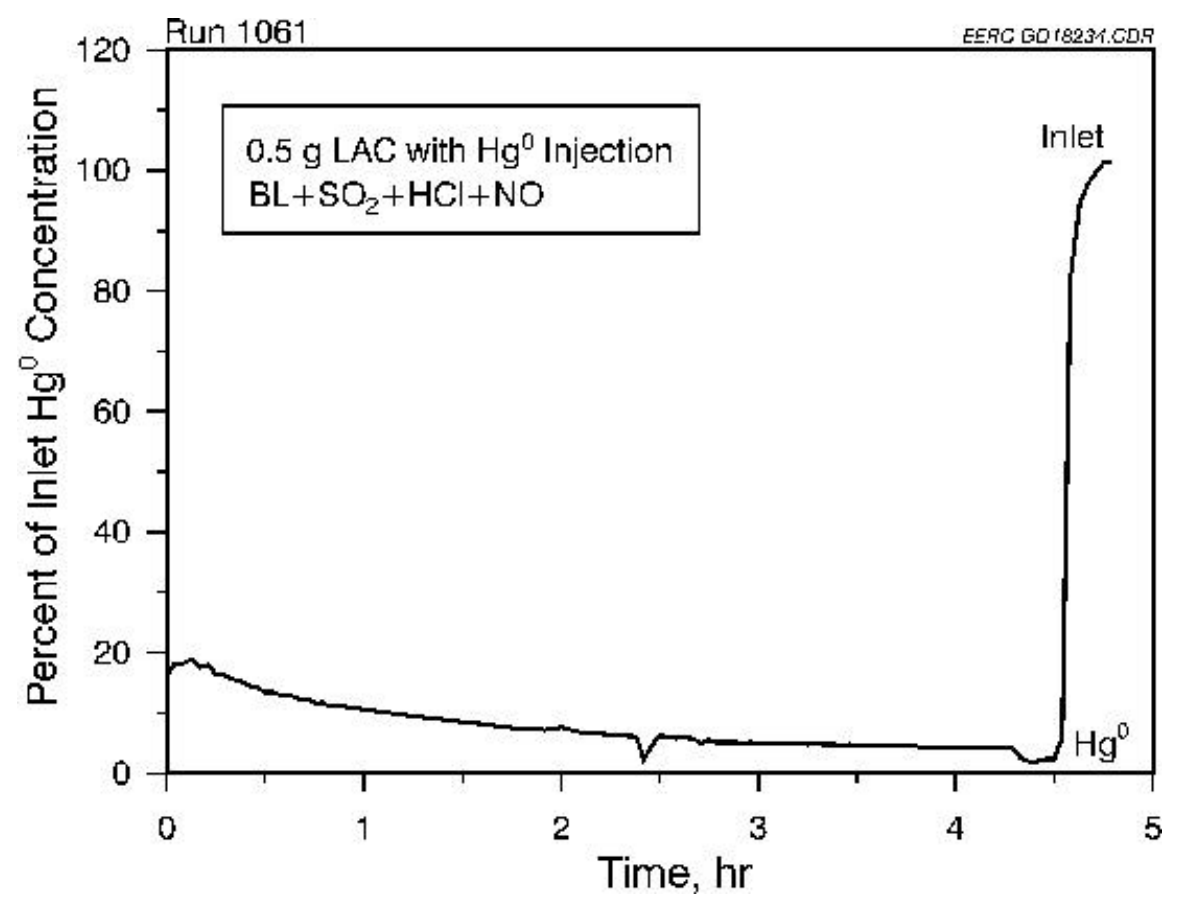

Figure B-4. Breakthrough curve for Test 1061. 


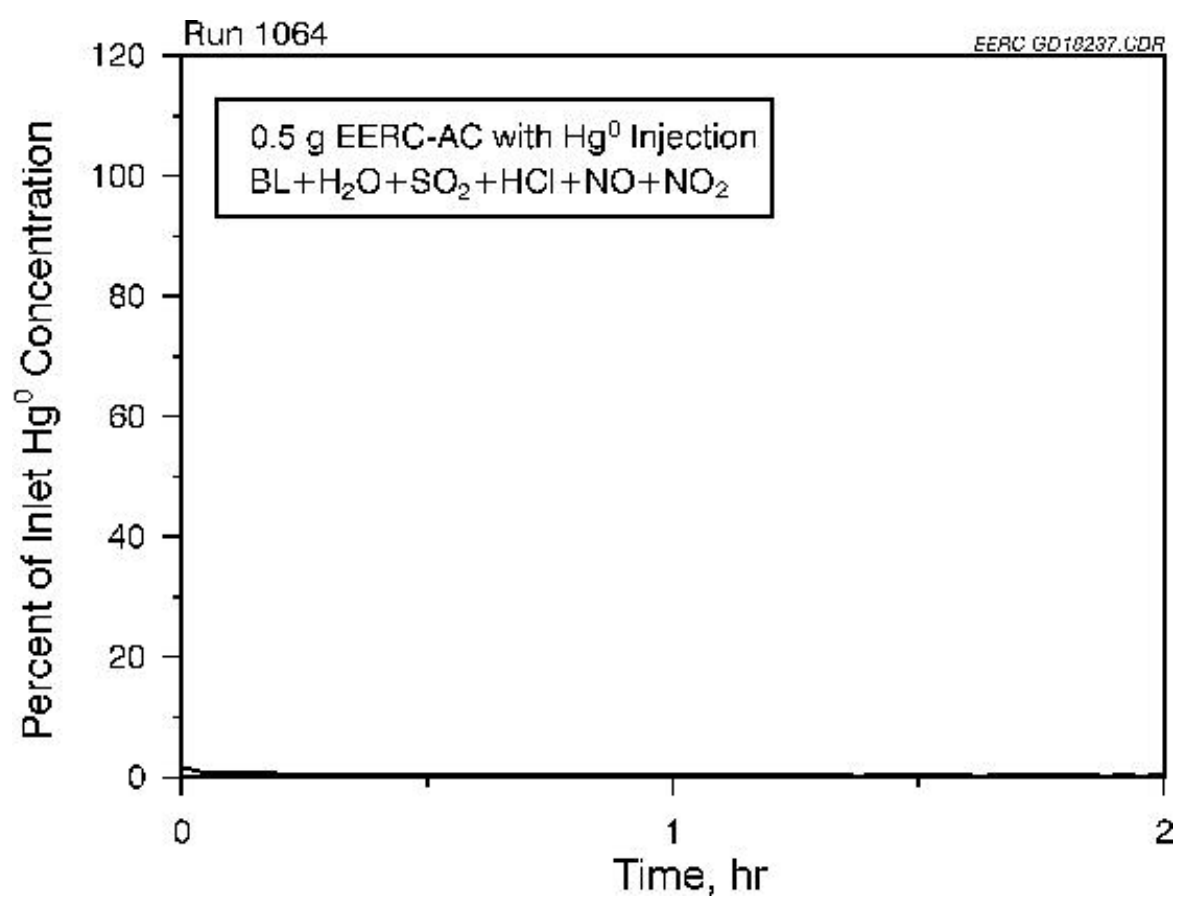

Figure B-5. Breakthrough curve for Test 1064.

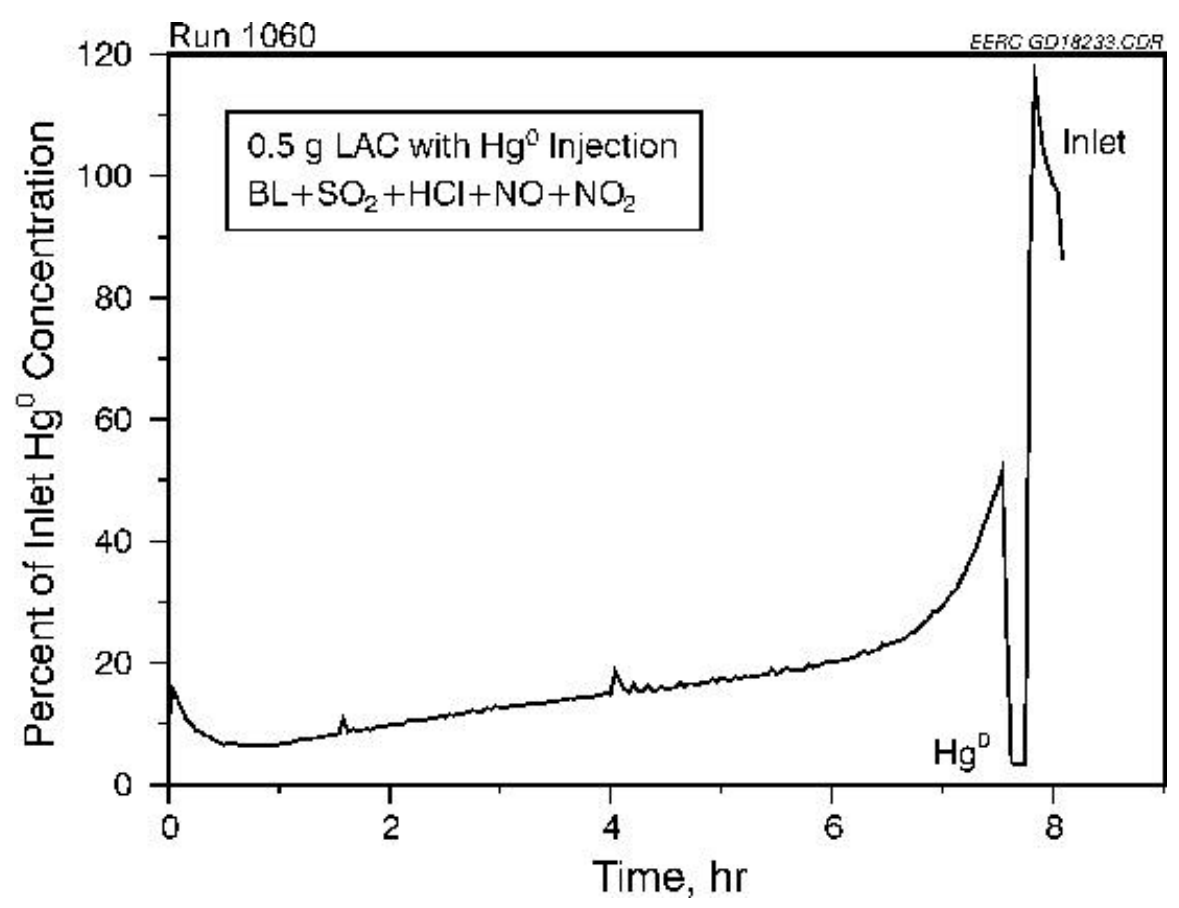

Figure B-6. Breakthrough curve for Test 1060. 


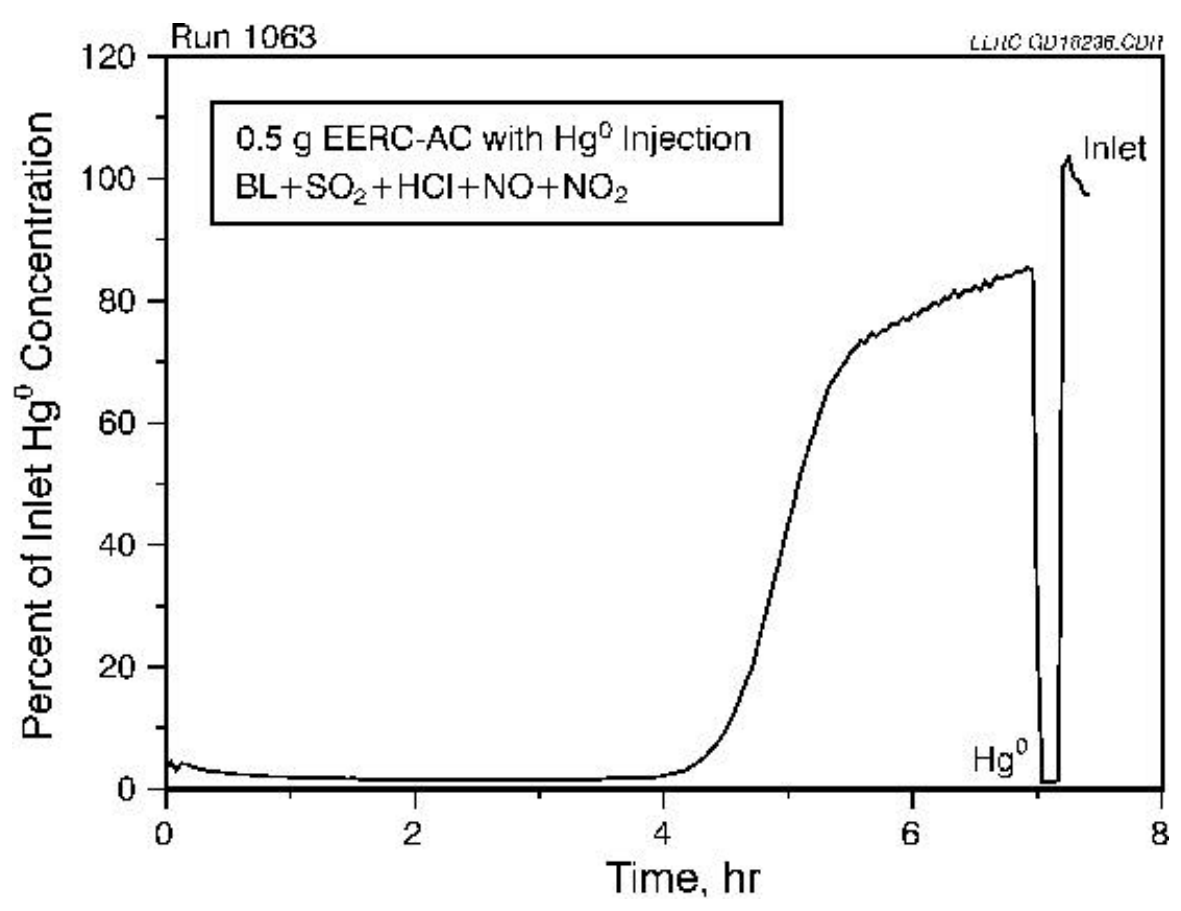

Figure B-7. Breakthrough curve for Test 1063.

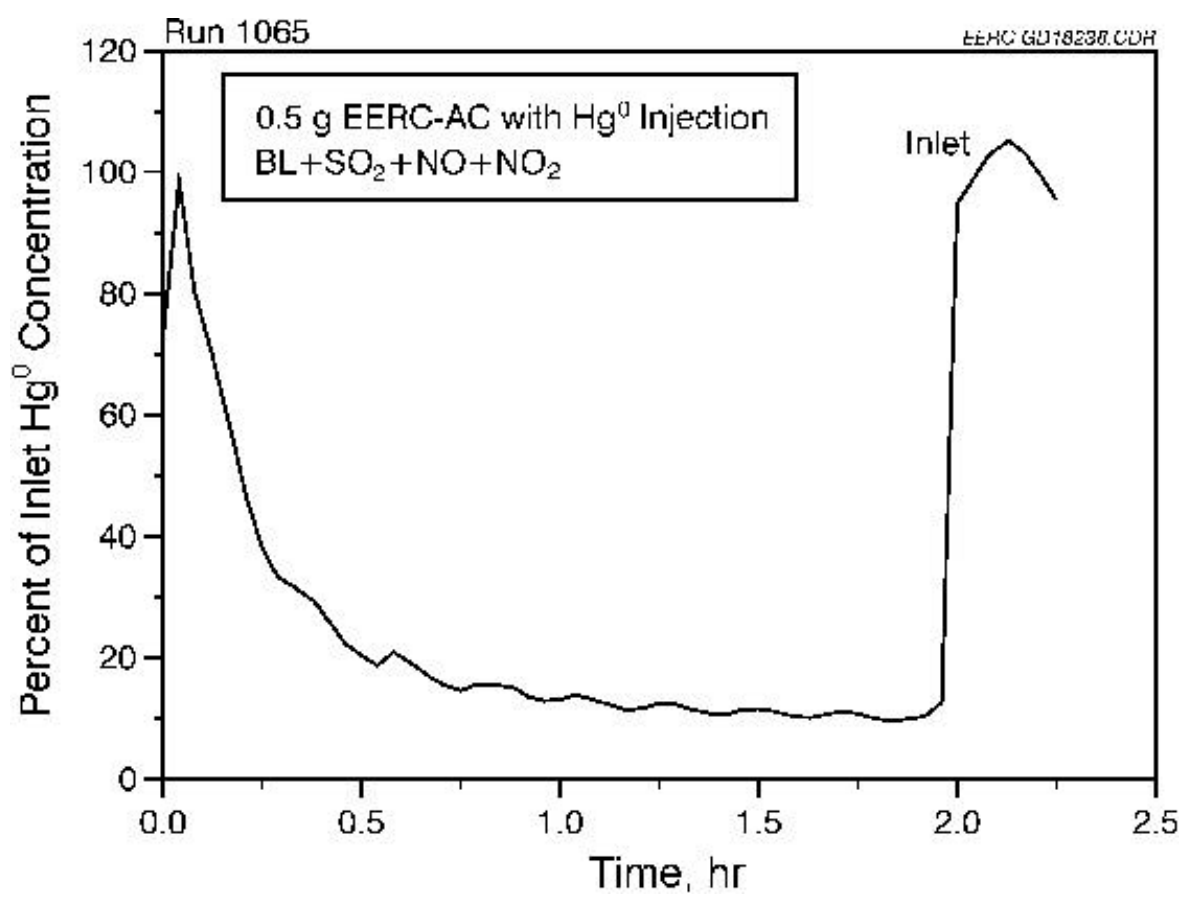

Figure B-8. Breakthrough curve for Test 1065. 


\title{
Solvent Extracted Coal Tar Pitch for Nanofiber Production FINAL REPORT
}

\section{Consortium for Premium Carbon Products from Coal \\ The Pennsylvania State University \\ 407 Academic Activities Building \\ University Park PA 16802-2308}

\author{
BY \\ Elliot B. Kennel, ASI \\ Applied Sciences, Inc. \\ and \\ John W. Zondlo, PhD \\ Peter G. Stansberry, $\mathrm{PhD}$ \\ Alfred H. Stiller, $\mathrm{PhD}$ \\ Dept. of Chemical Engineering \\ West Virginia University
}




\section{DISCLAIMER}

This report was prepared as an account of work sponsored by an agency of the United States Government. Neither the United States Government nor any agency thereof, nor any of their employees, makes any warranty, expressed or implied, or assumes any legal liability or responsibility for the accuracy, completeness, or usefulness of any information, apparatus, product, or process disclosed, or represents that its use would not infringe privately owned rights. Reference herein to any specific commercial product process, or service by trade name, trademark, manufacturer, or otherwise does not necessarily constitute or imply its endorsement, recommendation, or favoring by the United States Government or any agency thereof. The views and opinions of authors expressed herein do not necessarily state or reflect those of the United States Government or any agency thereof. 


\section{TABLE OF CONTENTS}

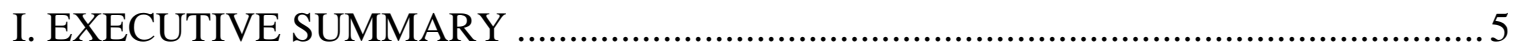

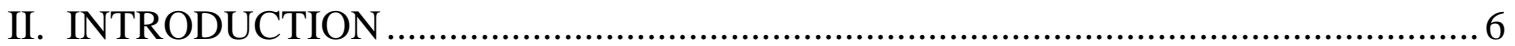

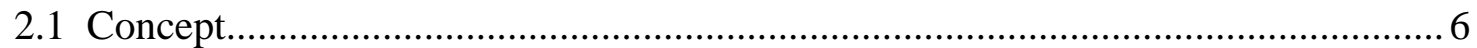

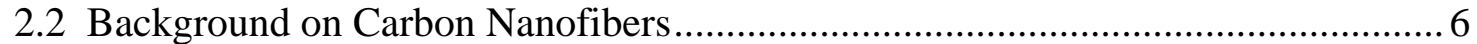

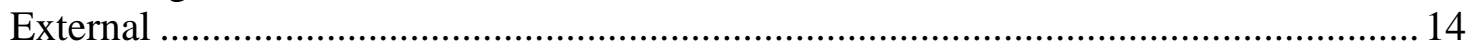

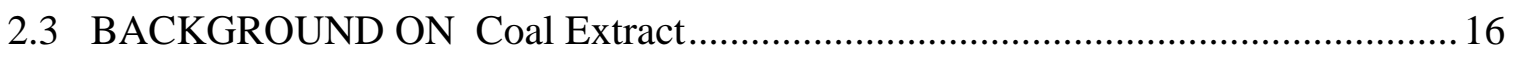

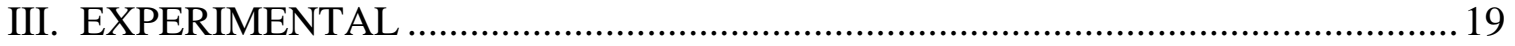




\section{LIST OF FIGURES}

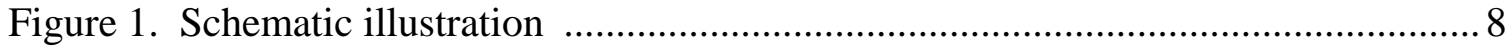

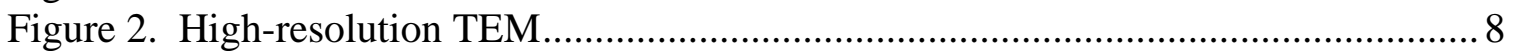

Figure 3. Low-resolution TEM showing iron catalyst particle and hollow fiber............... 9

Figure 4. SEM of Pyrograf-III Carbon Fiber ……………...........................................

Figure 5. Schematic of the carbon nanofiber synthesis reactor system .......................... 10

Figure 6. Schematic of the carbon nanofiber synthesis reactor system using coal pitch. 11

Figure 7. ASI Nanofiber Facility, with Pump and Pump Controller Installed.................. 11

Figure 8. Coal-derived nanofibers were successfully produced ..................................... 12

Figure 9. Higher Magnification reveals ................................................................... 12

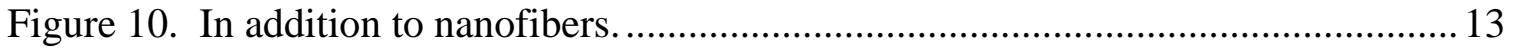

Figure 11. Tensile strength of polypropylene carbon nanofiber ..................................... 14

Figure 12. Modulus and strength of polypropylene filled.............................................. 15

Figure 13. Block Flow Diagram of Coal Extraction Unit ............................................... 17

Figure 14. Process Flow Diagram for Production of Coal-Based Carbon Pitch.............. 18

Figure 15. Desired flow profile.................................................................................2 20

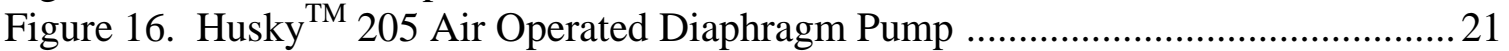

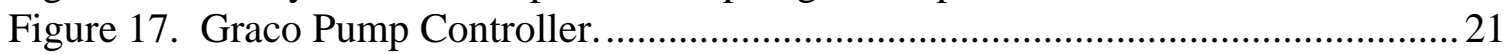




\section{LIST OF TABLES}

Table 1. Properties of PYROGRAF ${ }^{\mathrm{TM}}$-I Fibers ......................................................... 16

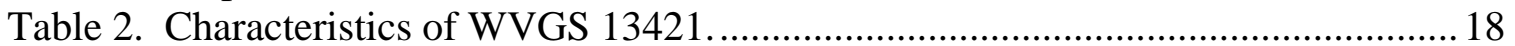

Table 3. Composition of NMP-Soluble Coal Extract wt \% .......................................... 19

Table 4. Nanofibers Production from Solvent-Extracted Coal Pitch ..............................22 


\section{EXECUTIVE SUMMARY}

This project demonstrated that carbon nanofibers can be produced using solvent extracted coal pitch redissolved in n-methyl pyrrolidone. 


\section{INTRODUCTION}

\subsection{Concept}

The purpose of this project is to develop a production capability for carbon nanofibers using solvent extracted coal pitch. At present, carbon nanofibers are created from the gas phase using natural gas with expensive hydrogen sulfide addition. The use of coal derived products eliminates the expense of sulfur addition because sulfur is already present in the coal naturally in the appropriate range of concentrations required for nanofiber production ( 0.5 to 4.0 percent). In addition, because the nanofibers scavenge sulfur very effectively, the exhaust from the furnace can be clean. In several cases, the exhaust gas was measured at less than 100 ppm sulfur.

Carbon nanofibers are a very attractive value-added product which is useful for many applications including reinforcement of plastic, synthetic rubber and other polymers; electromagnetic shielding; stealth and low observables; battery electrodes and so on.

The present state of the art is to use natural gas to produce nanofibers. This requires the addition of hydrogen sulfide as a catalyst. As shown below, the catalyst is the most expensive item in the protocol, not the source of the hydrocarbons.

However, if West Virginia coal extract is used, it is not necessary to use hydrogen sulfide at all. This has been shown conclusively in experiments performed at ASI facilities in August 1999. Thus, the motivation for using coal pitch extract is not so much because of its value as a source of hydrocarbons, although that is important, but mainly because it is a very inexpensive source of sulfur catalyst. The sulfur present in coal is actually the most valuable ingredient in this sense.

Using solvent extraction, an organic pitch like extract can be produced from coal. The inorganic or ash-forming material is separated out. The extracted coal pitch can be injected in liquid form, either by heating it or mixing it with solvent, resulting in a very economical means of producing nanofibers.

\subsection{Background on Carbon Nanofibers}

The so-called Fullerene or C60 "buckyball" molecule led to the 1996 Nobel Prize for Robert F. Curl, Harold W. Kroto and Richard E. Smalley. The realization that geometrically complex and intricate carbon allotropes are possible led to the realization that other structures are possible, including single-walled nanotubes, multi-walled nanotubes and nanofibers.

There are three main distinct nano-morphologies which are discussed in this report.

a. A single-walled nanotube (SWNT) consists of a single layer of carbon atoms.

b. In addition, multi-walled nanotubes (MWNT) which consist of a finite number of atomic layers. Often these MWNT consist of a specific integral number of layers; for example, the eight-layer tube being common. ${ }^{1}$ 
c. Carbon nanofibers are grown using metal catalyst particles and are essentially similar to MWNT, with additional carbon layers deposited pyrolytically. Such nanofibers are typically 50-200 $\mathrm{nm}$ in diameter. Such materials are made by Applied Sciences Inc. The graphene lattice is actually wrapped into a conic section, rather than a cylindrical form as shown in Figure 1. Thus, the surface of the nanofiber contains edge planes, an important consideration for chemical bonding.

d. The term carbon nanostructure is a more general term which encompasses C60 derivatives, SWNT, MWNT and carbon nanofibers.

This terminology is not completely standard within the scientific community, and the terms MWNT and "carbon nanofiber" are sometimes used interchangeably. Nevertheless, this terminology will be used throughout this report.

Bonding to polymer matrix materials requires functionalization of the surface of the nanomaterial. This is extremely difficult for structures such as multi-walled nanotubes, and especially single-walled nanotubes, which are sp2 bonded and thus are not normally available to participate in chemical reactions. Thus, SWNT composites tend to have good bonding at the tips of the SWNT, but not along the length. This means that the incredible properties of the nanotube do not translate to exceptional properties for composites at the macroscopic level, and in fact they are often worse because of the difficulty of bonding to the graphene surface (i.e., analogous to the surface of planar graphite).

Functional groups have been successfully attached to the lattice mainly at defect sites. Yet such discontinuities can cause a weak point in the lattice, thus partially defeating the original intended purpose. ${ }^{2}$

Other groups have apparently observed functional groups on pristine nanotubes, but there is still some question whether the functional groups are in fact attached to the graphene lattice or whether instead they may be attached to carbon impurities or other defect sites.

The unique structure of the carbon nanofiber, depicted below offers a different alternative. Instead of a truly tubular lattice structure, the nanofiber consists of nested conic sections (referred to as a "Dixie Cup" configuration). Therefore the surface of the structure does contain edge planes, which act as bonding sites. 


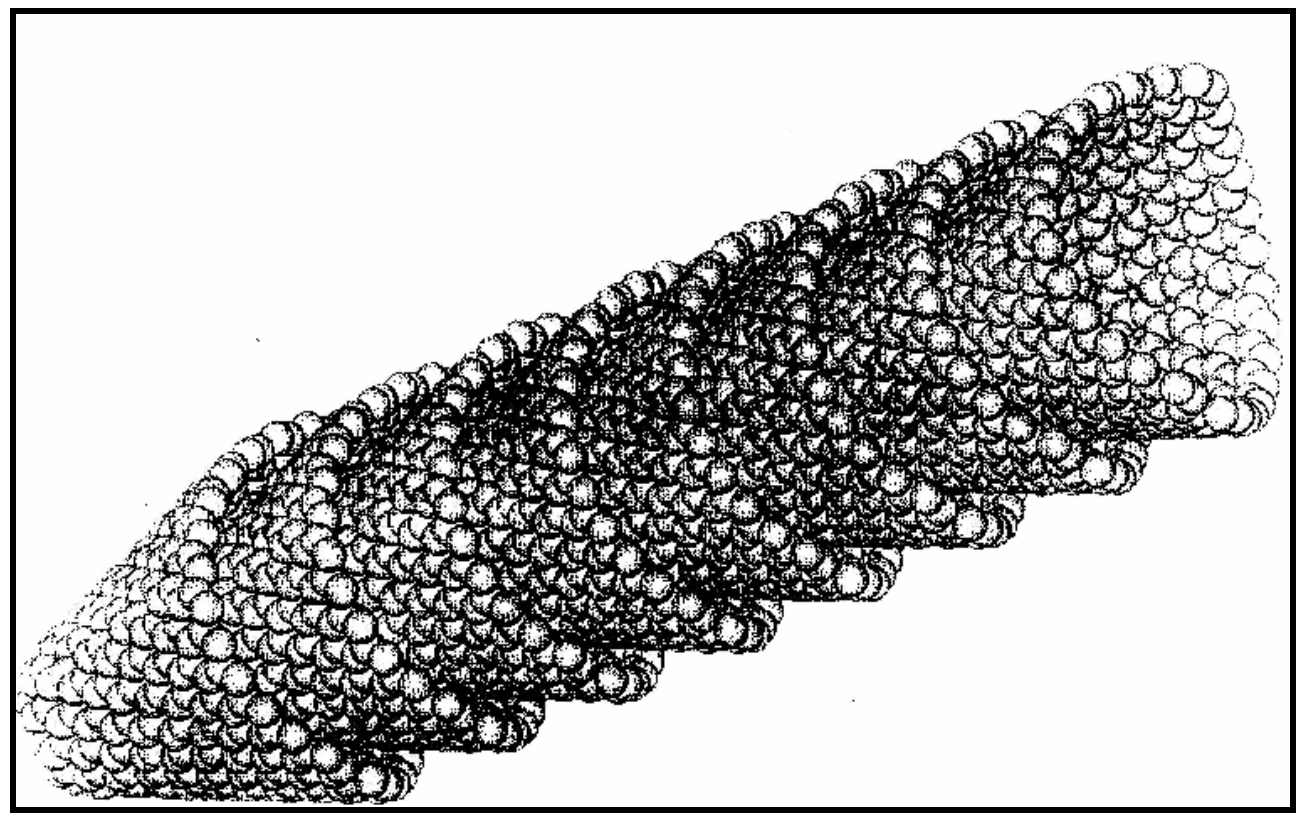

Figure 1. Schematic illustration based on models by Rodriguez and further elaborated by M. Endo at Shinsho University, Tohoku Japan, of the ASI carbon nanofiber. ${ }^{3,4,5}$ It consists of stacked conic sections of graphite lattice (courtesy M. Endo). This is also referred to as a "herringbone" structure in the literature.

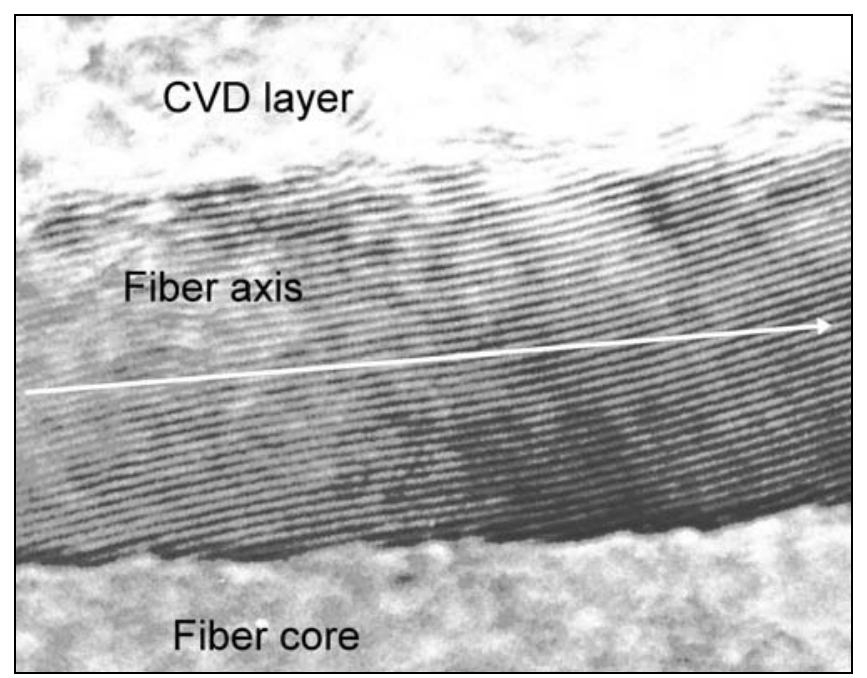

Figure 2. High-resolution TEM reveals that the graphene planes are in fact at an angle with respect to the nanofiber core, confirming that the true form of each graphene plane is a conic section. 


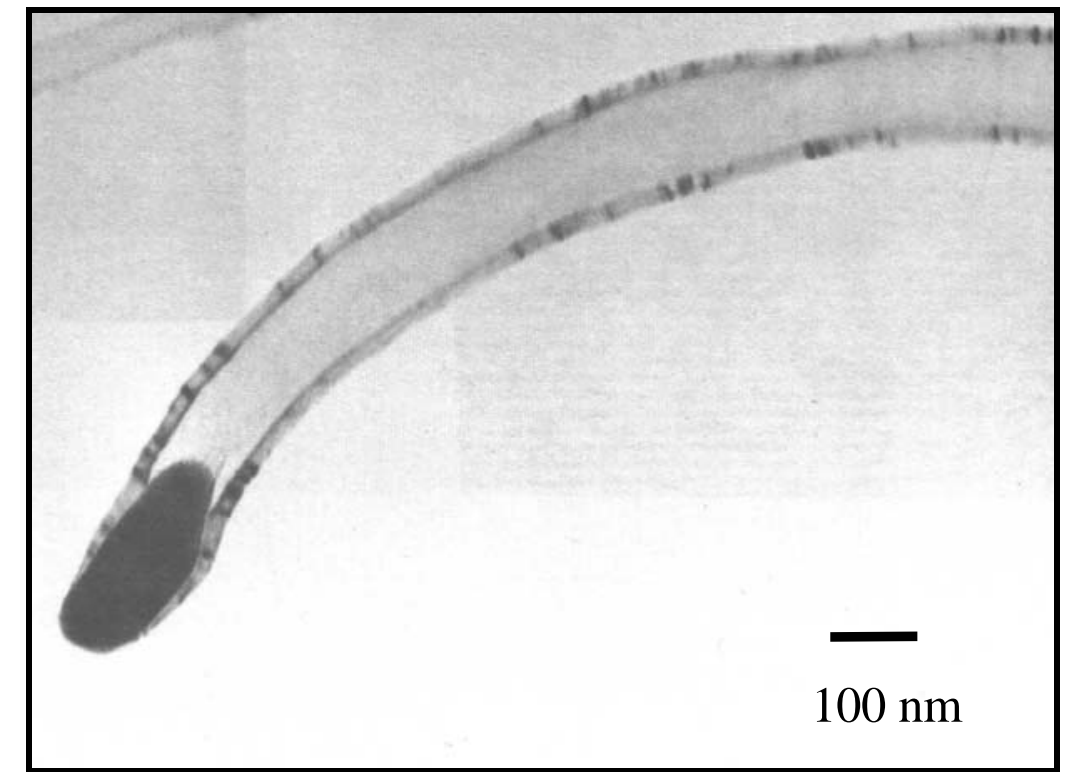

Figure 3. Low-resolution TEM showing iron catalyst particle and hollow fiber.

The fiber that was produced in the early years of development consisted of a hollow core (see Figure 4) with a graphitic sheath. A CVD carbon overcoat on top of the graphitic portion completed the fiber structure. The CVD portion of the fiber consisted of turbostratic carbon and, as such, had only short range structure. X-ray analysis showed that the graphitic portion had what can best be described as a nested cone structure. The graphitic planes were oriented at an angle to the fiber axis, roughly $20^{\circ}$ off-axis .

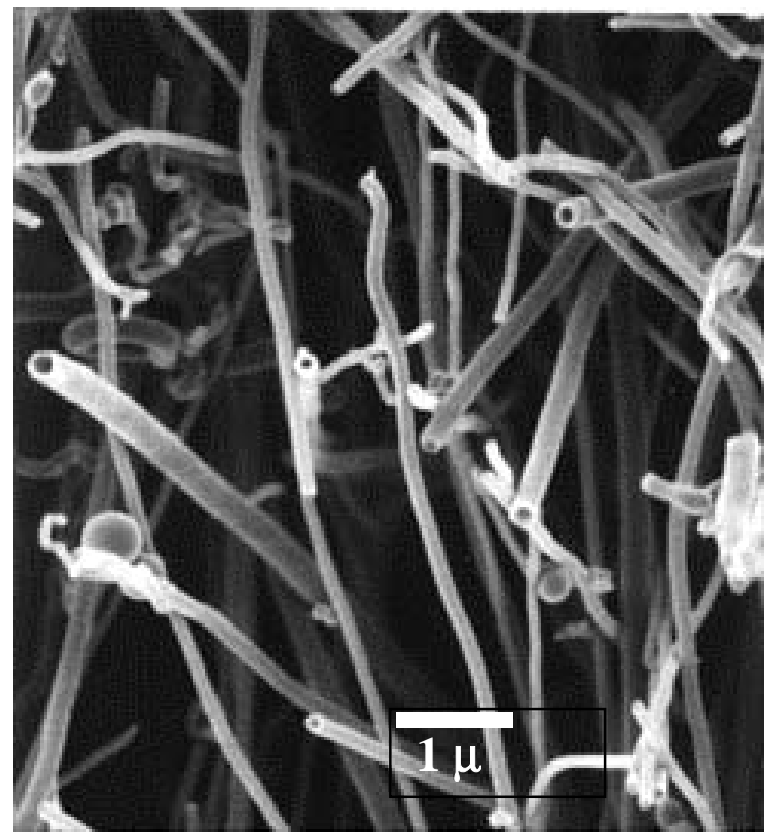

Figure 4. SEM of Pyrograf-III Carbon Fiber 
Contemporary efforts aimed at understanding the formation and growth of nanofibers have been lead by Oberlin, Endo, and Koyama, ${ }^{7}$ Baker, ${ }^{8}$ and Tibbetts, ${ }^{9}$ with notable contributions by many others. The large body of investigation performed over the past thirty years has been primarily devoted to understanding growth mechanisms, and determining the remarkable physical properties of fibers produced from various similar gas phase techniques. Research has been fueled by the perceived potential not only for marked improvement in the physical properties of composites, but also for the production of graphitic reinforcements in a wide range of forms at low cost. Excellent reviews by Rodriguez, ${ }^{10}$ Dresselhaus et al., ${ }^{11}$ Bartholomew, ${ }^{12}$ Baker, ${ }^{13}$ and Trimm ${ }^{14}$ of research performed on nanofibers reflect this activity.

Carbon nanofibers of the Pyrograf-III type produced by ASI can be very inexpensive since it is grown using economical coal or natural gas as a feed material, and because the fiber is produced in a simple, one-stage process. ${ }^{15}$ Figure 4 illustrates the basic method. Gas phase reactants are introduced into a heated furnace, where the decomposition of the gaseous compounds generate the species required for nucleation and growth of nanoscale carbon fibers with highly graphitic structure. Because of properties such as near-metallic electrical conductivity and excellent strength and modulus, these fibers are useful for a number of applications such as reinforcement of thermoplastics, rubbers, polyurethanes and even concrete. Very large markets can exist if the cost continues to decrease. Since the basic materials are similar to those used to produce carbon black, the ultimate cost can approach that of carbon black as an asymptote.

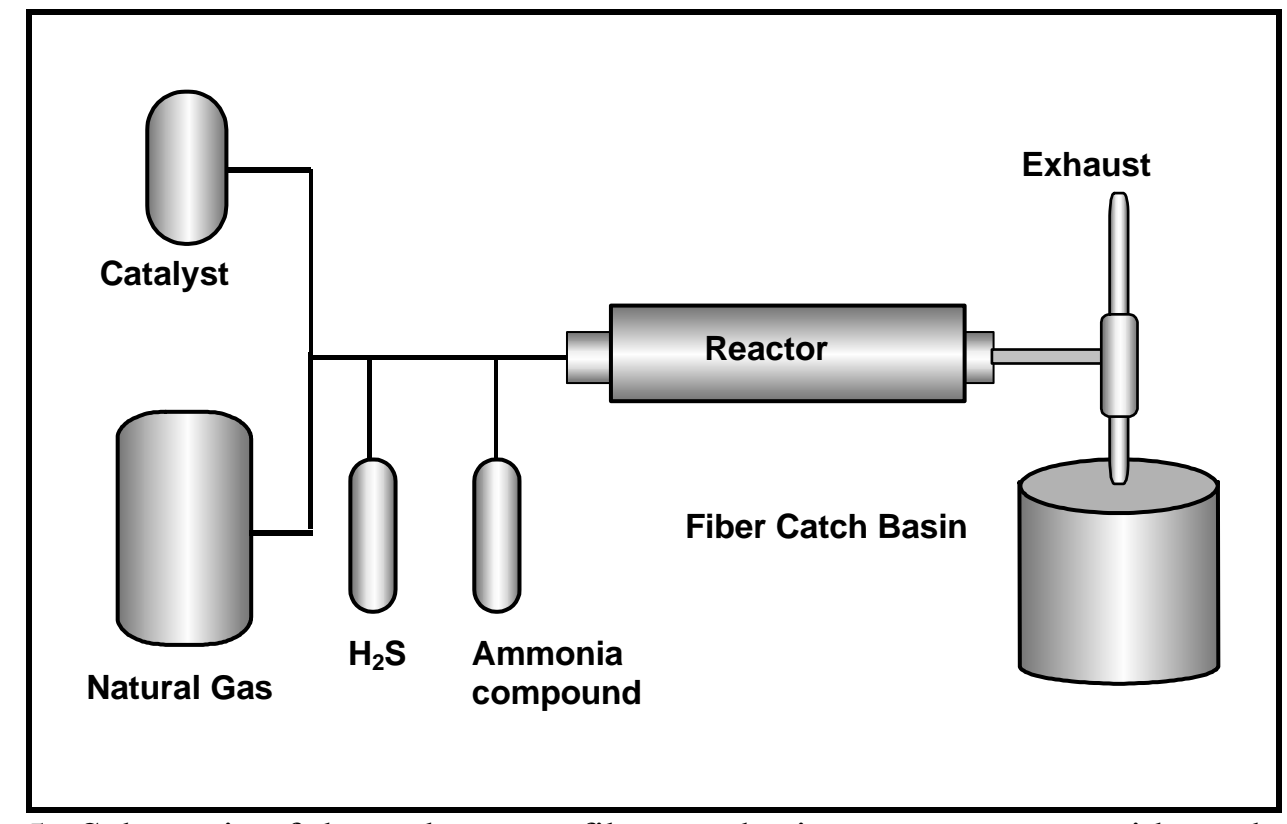

Figure 5. Schematic of the carbon nanofiber synthesis reactor system, without the use of coal. 


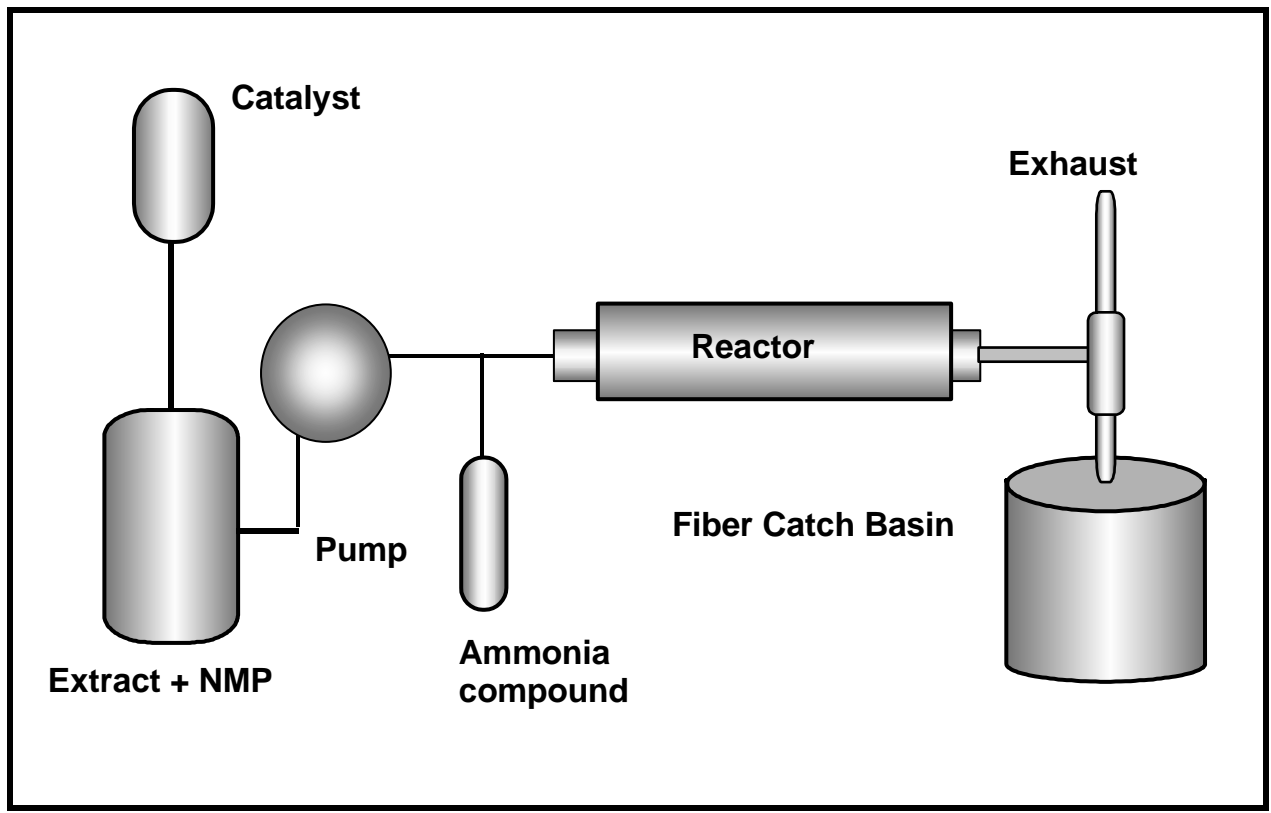

Figure 6. Schematic of the carbon nanofiber synthesis reactor system using coal pitch.

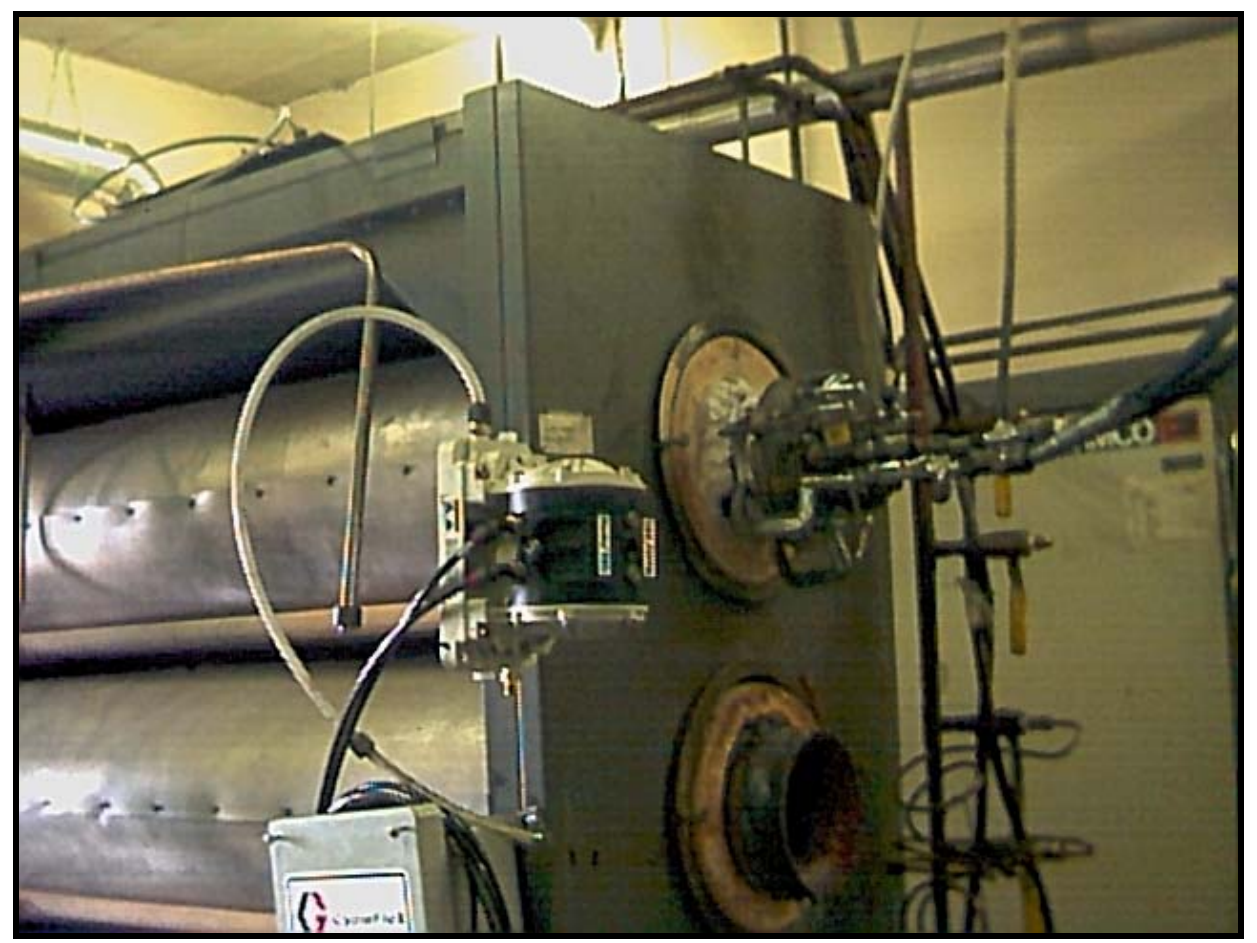

Figure 7. ASI Nanofiber Facility, with Pump and Pump Controller Installed. 


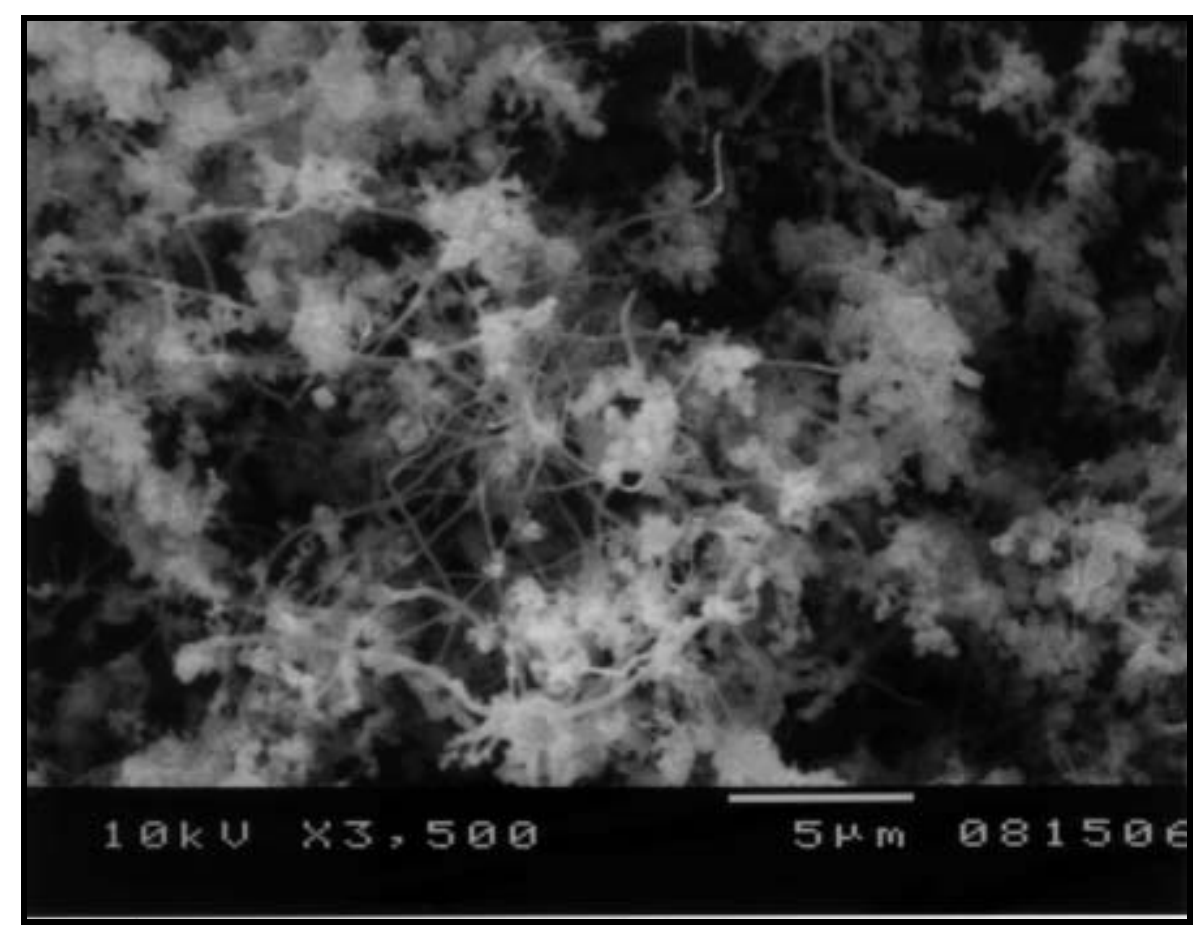

Figure 8. Coal-derived nanofibers were successfully produced during this reporting period. The light colored particles are likely disordered carbon.

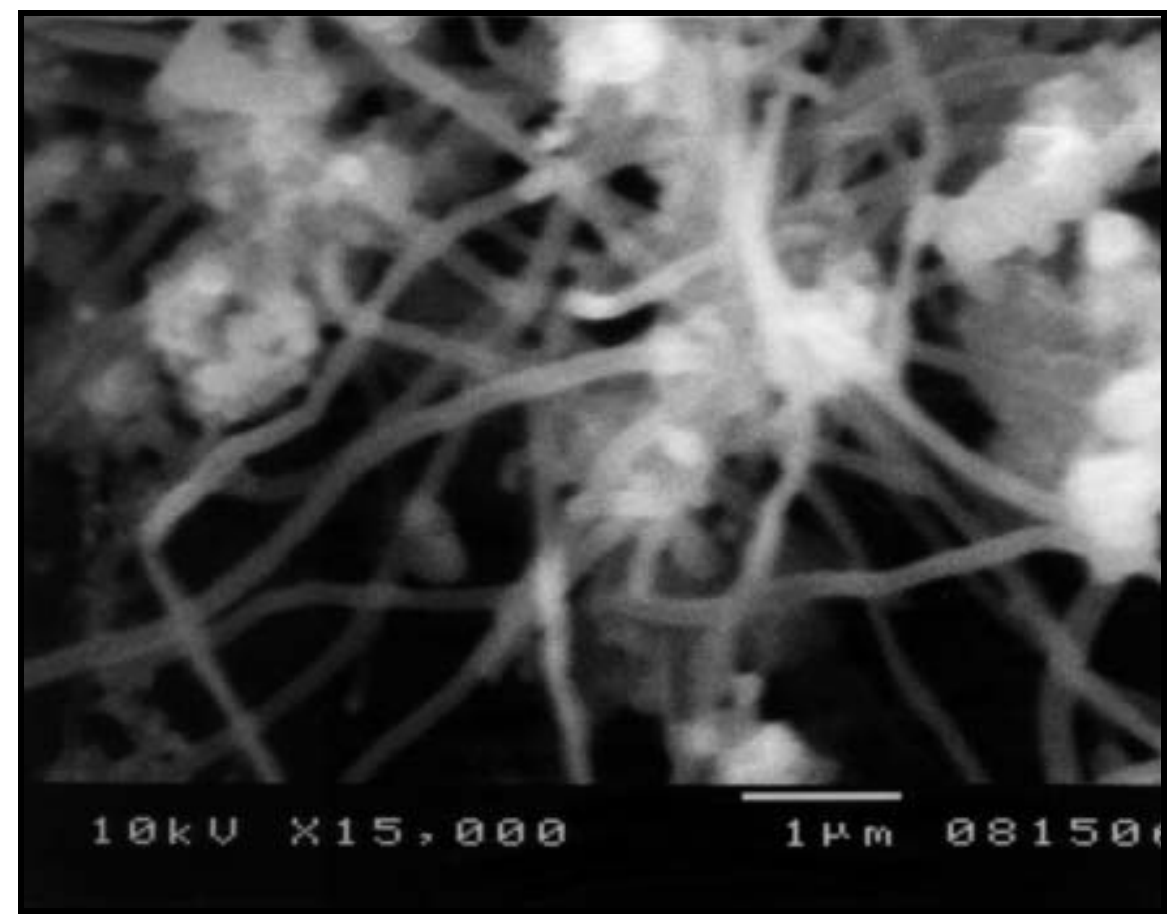

Figure 9. Higher Magnification reveals that many of the nanofibers are rather uniform; about $100-200 \mathrm{~nm}$ in diameter. 


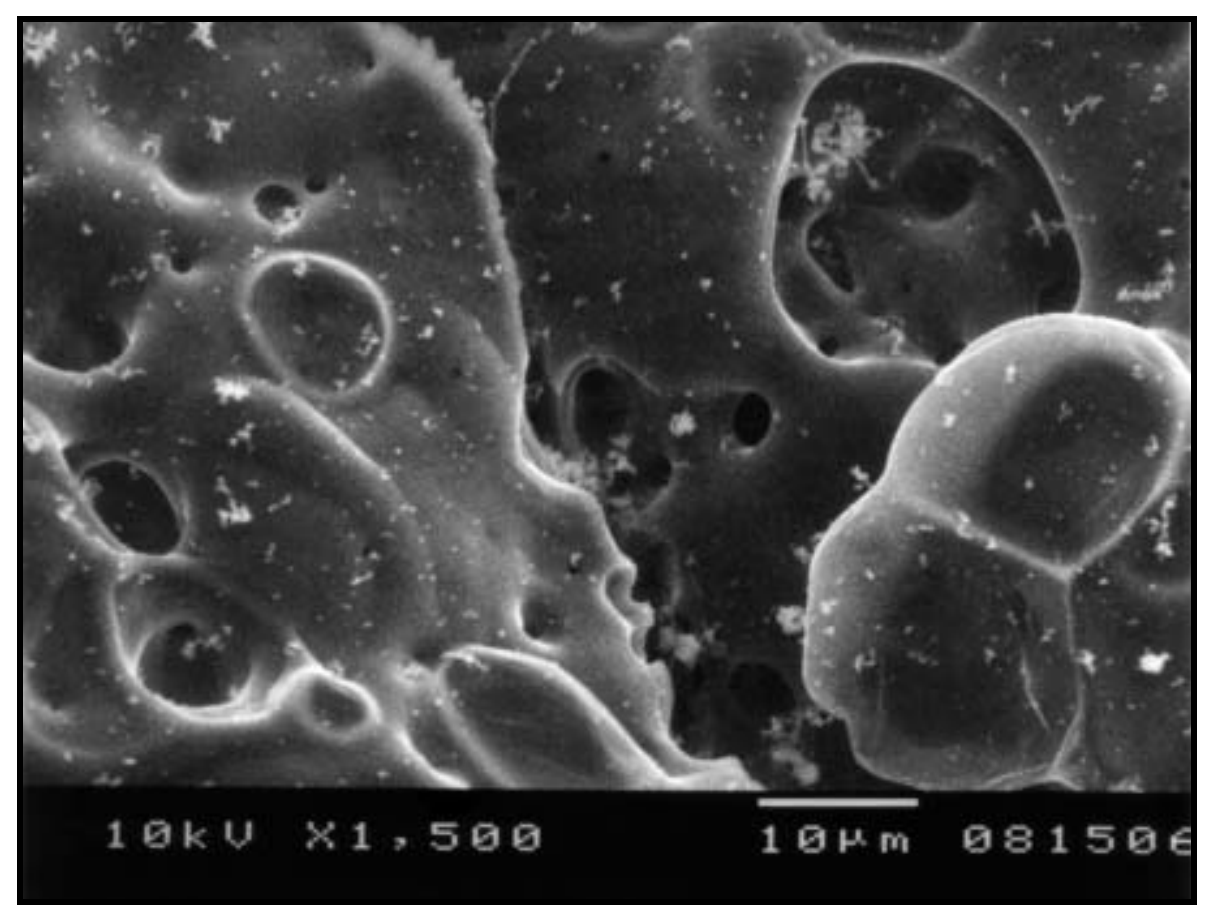

Figure 10. In addition to nanofibers, particles were created from the coal-derived pitch. These particles resemble the carbon foam which was developed by West Virginia University.

Previous work had shown that PP was readily reinforced by the type of carbon nanofiber typically produced using the process patented by Applied Sciences, Inc. A considerable amount of information was available concerning the effect of fiber surface energy, surface area and surface functional groups on tensile strength of these composites. In general this data showed that a maximum in tensile strength existed with respect to surface energy and area within the limits of the range of values studied. This relationship is shown in Figure 6. 

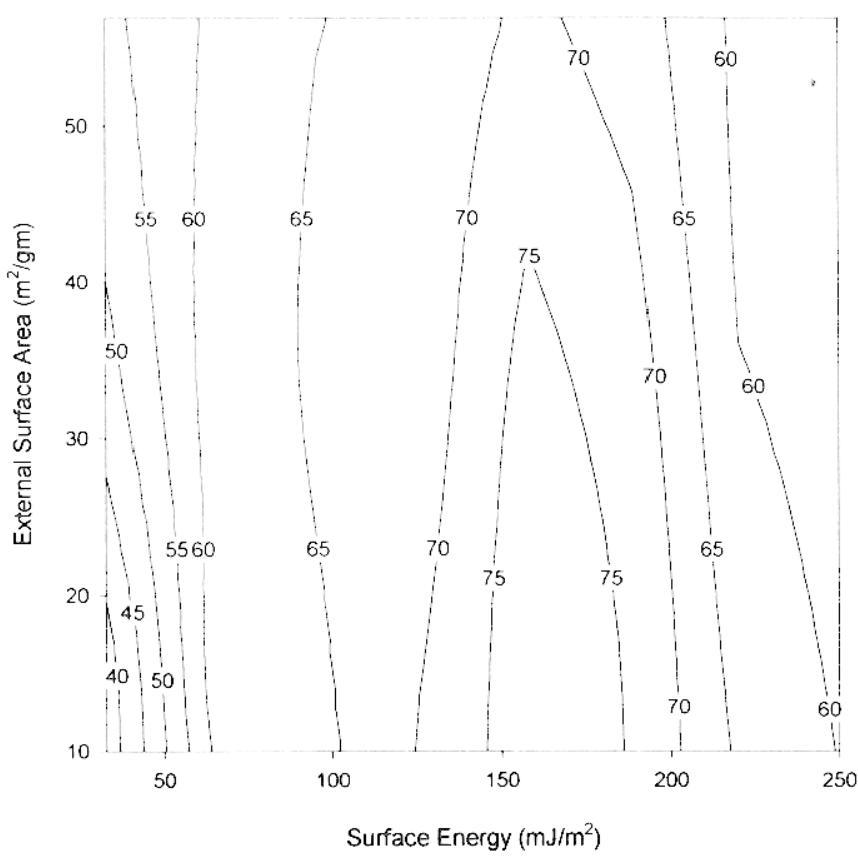

Figure 11. Tensile strength of polypropylene carbon nanofiber( $15 \mathrm{vol} \%$ fiber) composite as a function of fiber surface energy and surface area.

Figure 6 compares the "before" and "after" values of tensile strength which have been observed for as-grown and oxidized nanofiber. The higher surface energy of the oxidized fiber is believed to enhance wetting and dispersion of the fibers into the matrix, and the higher surface area, resulting in part from creation of surface macro-porosity, is believed to enable physical interlocking of the polypropylene matrix with the fiber. The improvement in tensile strength is remarkable considering that the fiber architecture is essentially an isotropic orientation, but the tensile strength is much less than values anticipated from a carbon fiber reinforcement where adequate adhesion permits optimum load transfer among reinforcements.

Table 1: Range of Pyrograf ${ }^{T M}$-IIII Nanofiber Surface Properties

\begin{tabular}{|c|c|c|c|}
\hline \multirow{2}{*}{$\begin{array}{c}\text { Process } \\
\text { Desigmation }\end{array}$} & \multicolumn{2}{|c|}{$\begin{array}{c}\text { Surface area, } \\
\mathbf{m}^{2} / \mathbf{g m}\end{array}$} & $\begin{array}{c}\text { Surface energy, } \\
\mathbf{m J} / \mathbf{m}^{2}\end{array}$ \\
\cline { 2 - 3 } & Total & Extermal & \\
\hline PR-18 & 15 & 10 & 33 \\
\hline PR-1 & 14 & 10 & 48 \\
\hline PR-1A & 34 & 16 & 57 \\
\hline PR-1A & 123 & 46 & 79 \\
\hline PR-11-2 & 83 & 28 & 106 \\
\hline PR-11-5 & 26 & 15 & 156 \\
\hline PR-11-7 & 91 & 53 & 248 \\
\hline PR-11-0 & 191 & 57 & 470 \\
\hline
\end{tabular}




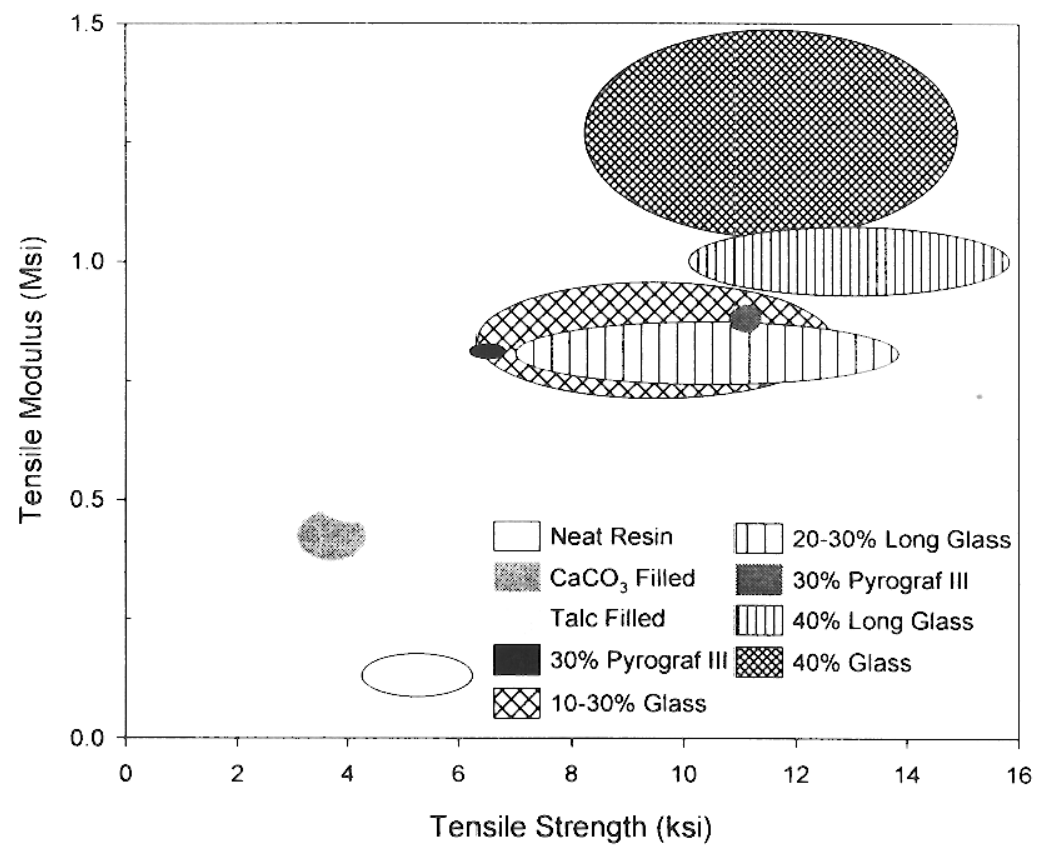

Figure 12. Modulus and strength of polypropylene filled with various reinforcement agents. The difference between the red circle and the black oval shows the improvement obtained so far by the development of nanofiber surface treatment techniques.

Low surface energy fibers are obtained directly from the fiber production process. Their low surface energy is due to the presence of a small layer of polyaromatic hydrocarbons (PAHs) that condense on the fiber surface during production. The intermediate surface energy fibers, i.e. surface energies of $100-150 \mathrm{~mJ} / \mathrm{m}^{2}$, are obtained by removal of the PAH layer exposing the underlying fiber surface. High surface energy and surface area fibers were obtained by mild oxidation at elevated temperatures.

In general introduction of oxygen based functionality (as much as 4.6 atom\% oxygen) through mild oxidation of fiber did not enhance the fiber-PP adhesion. Nearly the same tensile strengths were obtained as found with fibers which had been heated to the same temperatures in inert atmospheres. This process removed the PAHs and left a fiber surface that was inherently produced in the process.

A limited amount of work on the corresponding nylon 66 composites showed mainly degradation of tensile strength values with increasing fiber loading. This was true regardless of surface energy or surface area, at least within the limits of the few tests performed. The most promising data was found with a fiber oxidized in air. This fiber had a 4.6 atom\% level of surface oxygen. It appeared to consist of about an equal amount of carboxylic and phenolic groups based on XPS analysis. This data lead to the study of the effect of surface functionality on interfacial bonding that is reported herein. 


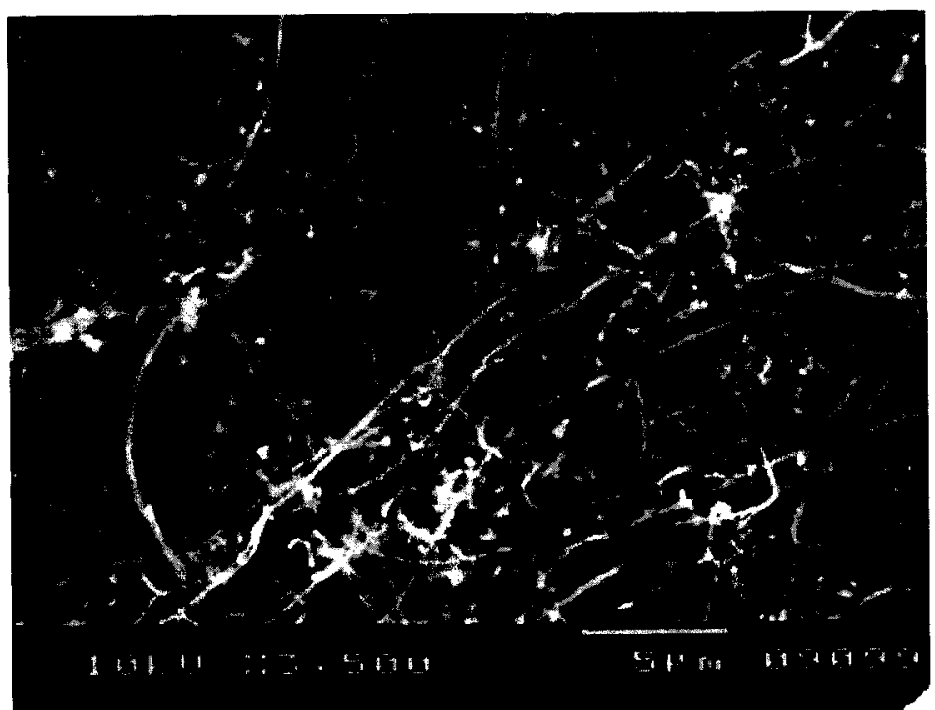

Figure 3. Scanning Electron Micrograph of coal-derived carbon nanofibers made from West Virginia University solvent-extracted coal pitch.

Table I. Properties of PYROGRAF ${ }^{\mathrm{TM}}$-I Fibers (PYROGRAF ${ }^{\mathrm{TM}}$-III Carbon Nanofibers are believed to be similar).

Property

Tensile Strength

Tensile Modulus

Ultimate Strain

Density

C.T.E.

Electrical Resist.

Thermal Conduct.

\section{As Grown}

2.7

400

1.5

1.8

1000

20
Heat Treated

600

0.5

2.1

$-1.0$

55

1950

$\frac{\text { Units }}{\mathrm{GPa}}$
$\mathrm{GPa}$
$\%$
$\mathrm{~g} / \mathrm{cm}^{3}$
$\mathrm{ppm} /{ }^{\circ} \mathrm{C}$
$\mu \Omega-\mathrm{cm}$
$\mathrm{W} / \mathrm{m}-\mathrm{K}$

\subsection{Background on Coal Extract}

In experiments done at WVU, coal has been solvent-extracted using $\mathrm{N}$-methyl pyrrolidone to produce quinoline insoluble-free pitches. A pilot scale coal extraction unit was constructed by the Chemical Engineering Department at West Virginia University in order to produce large quantities of N-methyl pyrrolidone (NMP) soluble coal extracts for testing by other researchers. A block flow diagram of the system is provided in the figure below. 


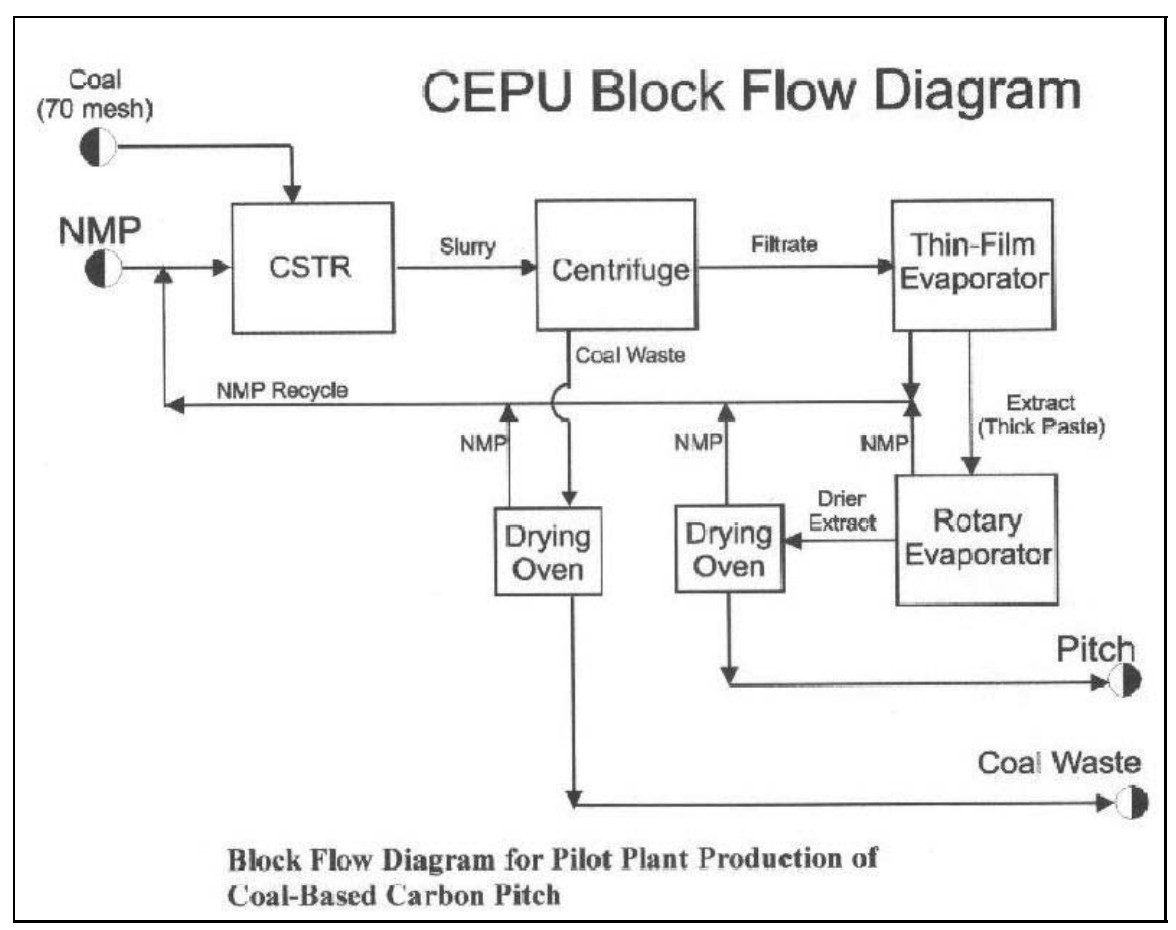

Figure 13. Block Flow Diagram of Coal Extraction Unit

The system consists of a 25 gal continuous-stirred-tank reactor (CSTR), centrifuge, thinfilm and rotary evaporators, and vacuum ovens. A bituminous coal was supplied by the West Virginia Geological Survey (WVGS) and is designated WVGS 13421. A detailed process flow diagram is provided below. 


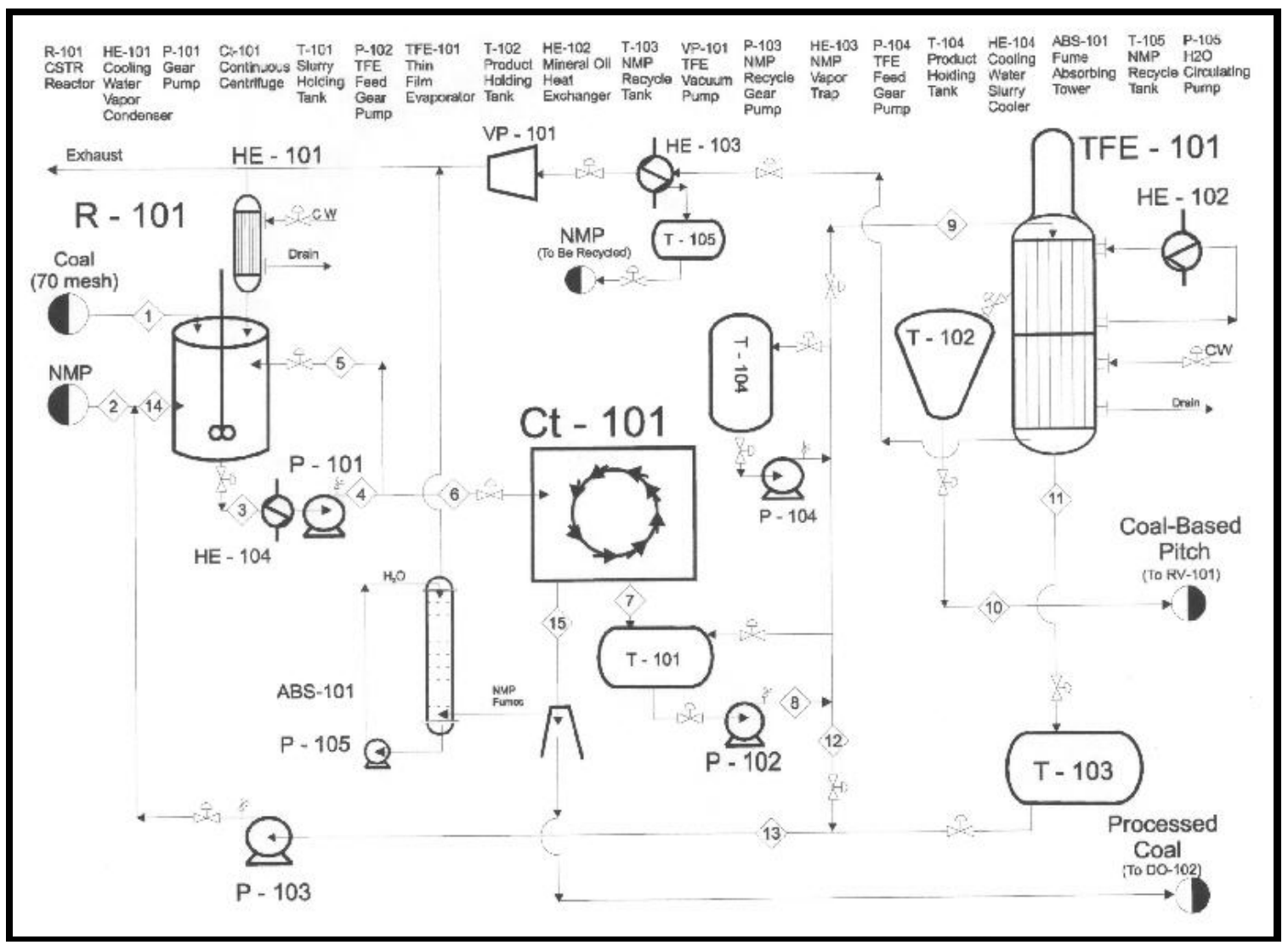

Figure 14. Process Flow Diagram for Production of Coal-Based Carbon Pitch

Some of the characteristics of the bituminous coal used are presented in the table below. The coal was ground in a hammer mill to pass through a 60 mesh sieve (Tyler 60 mesh sieve) and dried in a vacuum oven overnight at about $110{ }^{\circ} \mathrm{C}$ to remove moisture. The ground coal was stored in sealed glass jars under refrigerated conditions until ready for use.

Table 2. Characteristics of WVGS 13421.

\begin{tabular}{|l|r|}
\hline Moisture, wt\% as received & 0.98 \\
\hline Ash, wt \% dry & 3.19 \\
\hline Volatile Matter, wt \% dry & 27.96 \\
\hline Carbon, wt \% dry & 81.59 \\
\hline Hydrogen, wt \% dry & 4.56 \\
\hline Nitrogen, wt \% dry & 1.10 \\
\hline Sulfur, wt \% dry & 0.73 \\
\hline Oxygen, by difference & 4.82 \\
\hline Vitrinite, vol \% mf & 63.3 \\
\hline Liptinite, vol \% mf & 5.7 \\
\hline Inertinite, vol \% mf & 30.0 \\
\hline
\end{tabular}


The coal extract was prepared by first placing $100 \mathrm{~kg}$ of NMP along with $10 \mathrm{~kg}$ of coal into the CSTR and bringing the solution to the normal boiling point of the solvent $\left(202^{\circ} \mathrm{C}\right)$ for about one hour. A pump transferred the slurry to a centrifuge to remove unextracted coal and mineral matter from the soluble portion by centrifugation at $2200 \mathrm{G}$. A transfer line conveyed the extract solution to a thin-film evaporator to remove about $70 \%$ of the NMP at a rate of about $0.5 \mathrm{~L} / \mathrm{min}$. With a $70 \%$ reduction in solvent, the product leaves the thin-film evaporator as a thick paste. The majority of the remaining NMP was removed from the thickened extract in a modified rotary evaporation unit. The rotary evaporator takes the remaining $30 \%$ of initial NMP and reduces it down to about $5 \%$. The product leaving the rotary evaporator is semi-solid. The rotary evaporation step was then followed by a vacuum drying step to remove the remainder of the NMP. In each step, NMP is collected and recycled back to the reactor for another run.

Ideally, the pilot plant can produce up to $35 \mathrm{~kg}$ of coal extract in a week under the supervision of two technicians. This is compared to the $0.6 \mathrm{~kg}$ of extract per week that was previously produced using conventional laboratory equipment. The new facility allows the production of significant quantities of material to be produced in a timely manner.

This coal generated about $35 \mathrm{wt} \%$ NMP-soluble material. The elemental composition and high-temperature content for the extract are shown in the table below.

Table 3. Composition of NMP-Soluble Coal Extract wt\%

\begin{tabular}{|c|c|c|c|c|c|}
\hline $\mathrm{C}$ & $\mathrm{H}$ & $\mathrm{N}$ & $\mathrm{S}$ & $\mathrm{O}^{*}$ & Ash \\
\hline 84.24 & 5.47 & 2.08 & 0.77 & 7.44 & 0.19 \\
\hline
\end{tabular}

oxygen by difference

\section{EXPERIMENTAL}

Initial tests were successfully carried out by hand. First, a suspension of partially dissolved coal pitch was formed with a solvent (such as methanol). The approximate ratio is $2 \mathrm{ml}$ per gram of pitch. To this mixture, an iron-containing organometallic catalyst is added. A syringe was filled with about 30 to $60 \mathrm{cc}$. The syringe is immediately connected to the reactor via a Swagelok ${ }^{\circledR}$ fitting on the endcap. The entire contents of the syringe (containing dissolved coal pitch as well as iron catalyst) is squirted into the furnace in about one second, with sufficient force that the liquid mixture immediately reaches the hot zone of the furnace where it is vaporized.

This method is effective, but cumbersome and labor intensive. A more practical automatic system was proposed which would replace the human operator with a pump. Several different pumps were considered for this application. Syringe pumps, which can accurately meter out the requisite amount of fluid, typically do not expel the fluid in as short a time as one second. This has implications for the reaction. In the hand-operated case, most of the fluid is immediately driven into the hot zone of the furnace (>1000 C) where it is essentially flash evaporated. For a slower delivery time, however, the nanofibers are not formed.

The reason for the failure to grow nanofibers in slow feed rate situations is probably due to the rate of heating. Iron catalyst condensed and grows from the 
organometallic hydrogen compounds present in the reactor. If they grow too large too quickly, they can not catalyze nanofiber growth. Conversely, if they grow too slowly, the pyrolyzing carbon can entomb the catalyst particles in pyrolytic carbon, also terminating the reaction.

Thus slower feed rates upset the kinetics of nanofiber growth.

The use of an automotive fuel injector was attempted, but was not very effective because it became clogged after only a few cycles of operation.

Flow Rate (1/min)

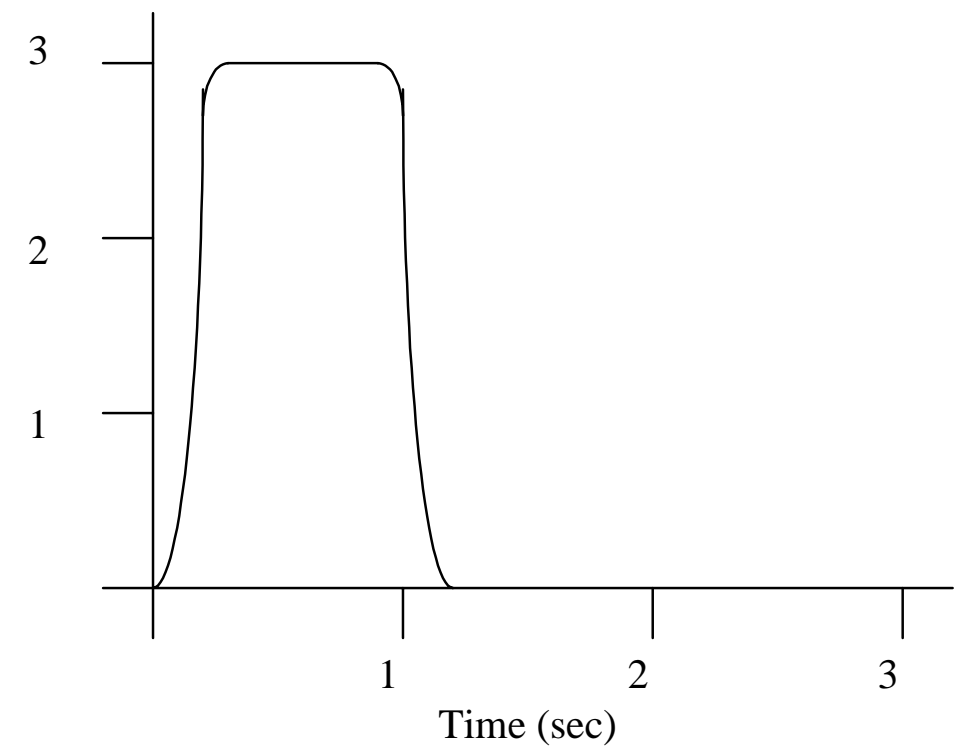

Figure 15. Desired flow profile.

An air operated diaphragm pump proved to be satisfactory. The pump chosen was a Husky ${ }^{\mathrm{TM}} 205$ air-operated diaphragm pump, which has a maximum flow rate of 19 liters/min, which is six times higher than the required rate. The pump was controlled using a Graco CycleFlow ${ }^{\mathrm{TM}}$ II Pneumatic Controller, which permits accurate cycle control, and rapid startup and shut down. 


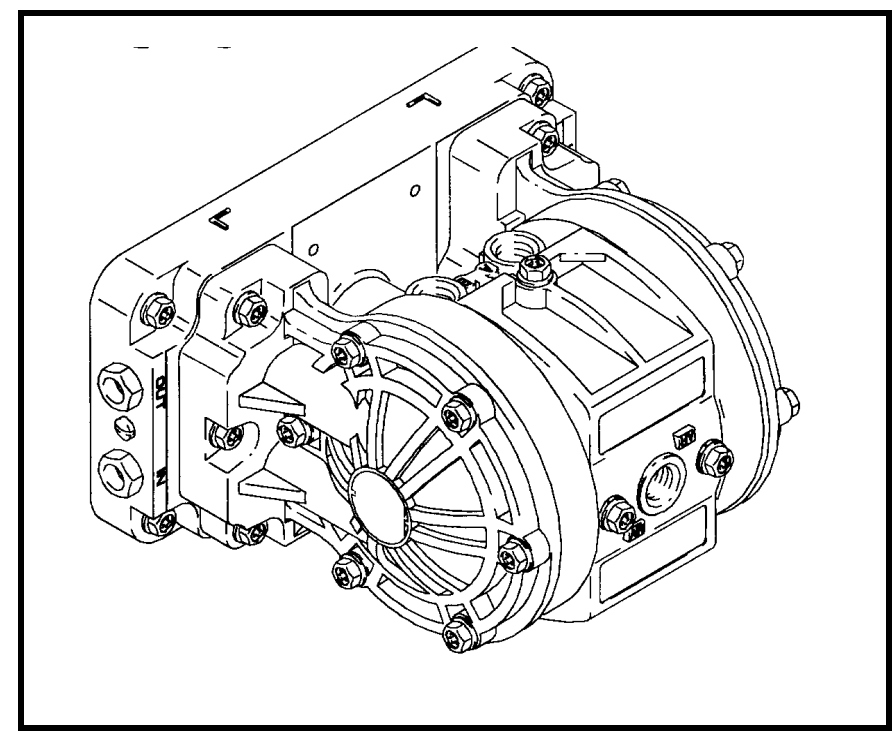

Figure 16. Husky ${ }^{\mathrm{TM}} 205$ Air Operated Diaphragm Pump (courtesy Graco).

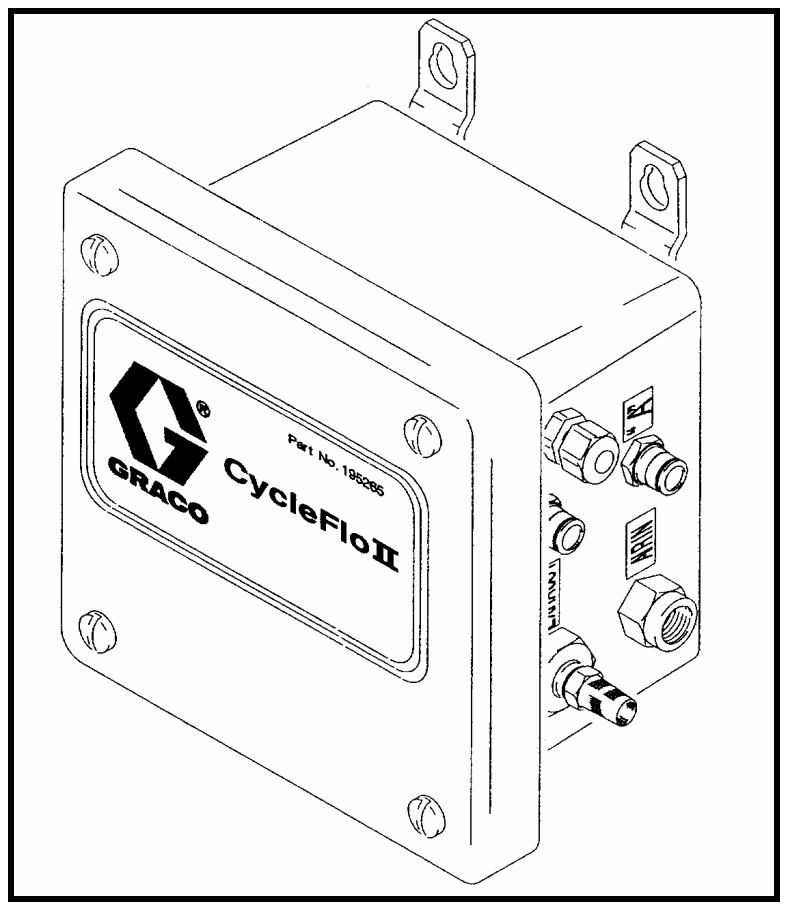

Figure 17. Graco Pump Controller.

Because of the relative expense of NMP, as well as the alternatives were sought to NMP for carrying the coal pitch to the reactor. The most obvious method would be to melt the pitch so that it can be pumped as a liquid. The difficulty with this solution is that the injection port builds up carbon as the pitch devolatilizes. This can still be accomplished if the tube is exposed to air between runs in order to oxidize the tube.

Another alternative is to re-dissolve the solvent in NMP and to inject the solution into the furnace. This was ultimately the most successful procedure. Substitutes for NMP such as methanol and quinoline were trialed with modest success. 
a. Using heat to melt the pitch with no solvent.

b. Using a substitute solvent such as methanol or quinoline.

In the near term, this cost is acceptable, although in the long run it will probably be advantageous to reduce the cost of solvent for the process.

The production rates were established by flowing 2 liters of coal extract in NMP at ambient temperature, with an approximate concentration was $0.5 \mathrm{~kg}$ of extract per liter of NMP. The resultant nanomaterial mass was 156 grams. with an apparent density of $0.13 \mathrm{~g} / \mathrm{cc}$.

Assuming an average flow rate of 1 liter per hour, the yield (product out divided by carbon input) was about $18 \%$, and the production rate was about $80 \mathrm{~g} / \mathrm{hr}$.

Full production runs (i.e., of about a week's duration) were not attempted owing to the shortage of solvent extracted coal pitch, which is in high demand for several projects in addition to this one. In addition, the buildup of coal residue in the research reactor tube (requiring frequent shutdowns for burning out the tube in an air atmosphere) prohibited continuous operation for more than several hours.

Using 2 liters of NMP per kg of coal pitch, and converting $18 \%$ of the carbon in the coal to nanofibers results in 11 liters per $\mathrm{kg}$ of carbon nanofiber produced. Assuming a cost of $\$ 1.70$ per gallon of NMP (source: BASF), the solvent cost is about $\$ 8.60$ per pound of nanofibers produced, not including catalyst cost. This does not include the cost of the coal pitch itself, or the other catalysts.

This cost is potentially acceptable for niche-market-scale production, though large scale production economics will require that the solvent cost be reduced eventually, either by finding ways to reduce the amount of solvent consumed, to increase the carbon efficiency or by finding a less expensive substitute feedstock.

Table 4. Nanofibers Production from Solvent-Extracted Coal Pitch

\begin{tabular}{|l|l|}
\hline Figure of Merit & Quantity \\
\hline Production Rate & $80 \mathrm{~g} / \mathrm{hr}$ \\
\hline $\begin{array}{l}\text { Carbon conversion efficiency (product weight } \\
\text { divided by mass of carbon in the coal feedstock). }\end{array}$ & 0.18 \\
\hline Average flow rate & 0.02 liter/minute \\
\hline Pulsed flow rate & 19 liters $/$ minute \\
\hline Soot content & Not measured \\
\hline Average nanofiber diameter & $\sim 150 \mathrm{~nm}$ \\
\hline Apparent density & $0.13 \mathrm{~g} / \mathrm{cm}^{3}$ \\
\hline NMP cost @ \$1.70 per gallon & $\sim \$ 8.60$ \\
\hline & \\
\hline
\end{tabular}




\section{DISCUSSION}

Technical feasibility has been proven for the creation of value-added nanofibers using solvent-extracted coal pitch as a feedstock material, as well as a source of sulfur catalyst. This is especially promising because nanomaterial synthesis was very reproducible.

Little attempt was made to optimize the concentration of catalyst or to optimize the ratio of sulfur to metal for this process. Moreover, no attempt was made to improve production efficiency and production rate by varying the reactor temperature. Such steps would very likely improve the production statistics greatly.

Because of the relative expense of sulfur catalyst, it is likely that, in one form or another, coal-derived feedstocks will continue to be of interest to large scale nanomaterial production processes.

Other methods, such as coal gasification, have also been tried by ASI as well as other research groups, with considerable success.

Ultimately, the use of solvent-extracted coal will depend upon the success it has in transitioning to commercially viable quantities, and reduced cost. 


\section{REFERENCES}

1 Young-Kyun Kwon et al., "Morphology and Stability of Growing Multi-Wall Carbon Nanotubes” Phys. Rev. Lett. 79, 2065 (1997).

2 Y. Chen et al., "Chemical attachment of organic functional groups to single-walled carbon nanotube material,” J. Mater. Res. (1998) Vol. 13, No. 9, 2423-2431.

3 N. M. Rodriquez, J. Mater. Res. 8 (1993) 3233.

4. M. Endo, unpublished analysis.

5. E. V. Barrera, "Current Process in Nanotube Composite Characterization." NanoSpace 2001 - The Fourth Annual International Conference on Integrated Nano/Microtechnology for Space and Biomedical Applications, March 12th, 2001

6. Lozano, K. and E. Barrera (2001). "Nanofiber-reinforced thermoplastic composites. I. Thermoanalytical and mechanical analyses." Journal of Applied Polymer Science 79: 125-133.

7. A. Oberlin, M. Endo, and T. Koyama, J. of Crystal Growth, 32335 (1976).

8. R. T. K. Baker, CARBON 27, No. 3, pp. 315-323, 1989

9. G. G. Tibbetts, J. Crystal Growth 66, 632 (1984).

10. N.M. Rodriquez, J. Mater. Res. 8 (1993) 3233

11. M. S. Dresselhaus, G. Dresselhaus, K. Sugihara, I. L. Spain, H. A. Goldberg, Graphite Fibers and Filaments Springer-Verlag: New York, 1988

12. C. H. Bartholomew, Catal. Rev. Sci. Eng. 24, 67 (1982)

13. R. T. K. Baker, "Chemistry and Physics of Carbon," 14 Marcel Dekker, New York, 1978

14. D. L. Trimm, Catal. Rev. Sci. Eng. 16, p. 155, 1977

15. G. G. Tibbetts, R. L. Alig, D. W. Gorkiewicz, "Production and Properties of VaporGrown Filaments and Fibres", International Conference on Carbon, Essen/Germany, 2226 June (1992). 


\title{
Coal-Derived Cokes for the Production of Anodes For the Aluminum Industry
}

\author{
FINAL REPORT \\ Reporting Period Start Date: January 1, 2000 \\ Reporting Period End Date: June 30, 2001 \\ Report Prepared by \\ Peter G. Stansberry \\ \& \\ John W. Zondlo \\ Department of Chemical Engineering \\ College of Engineering and Mineral Resources \\ P. O. Box 6102 \\ West Virginia University \\ Morgantown, WV 26506-6102 \\ Report Issued \\ June 2001
}

DOE Award Number DE-FC26-98FT40350

Other Contributor

Bernard Racunas

Aluminum Company of America

100 Technical Drive

Alcoa Center, PA 15069-0001 


\section{DISCLAIMER}

This report was prepared as an account of work sponsored by an agency of the United States Government. Neither the United States Government nor any agency thereof, nor any of their employees, makes any warranty, expressed or implied, or assumes any legal liability or responsibility for the accuracy, completeness, or usefulness of any information, apparatus, product, or process disclosed, or represents that its use would not infringe privately owned rights. Reference herein to any specific commercial product process, or service by trade name, trademark, manufacturer, or otherwise does not necessarily constitute or imply its endorsement, recommendation, or favoring by the United States Government or any agency thereof. The views and opinions of authors expressed herein do not necessarily state or reflect those of the United States Government or any agency thereof. 


\begin{abstract}
Arch coal (PSOC 3001) obtained from a CPCPC member company was subjected to a combination of prehydrogenation and solvent extraction in the solvent N-methyl pyrrolidone in an attempt to produce a coal-derived alternative to petroleum coke for carbon anodes. Extracts from raw coal, hydrogenated coal, and a blend of the two were then coked and calcined under conditions normally encountered in industrial practice. The salient physical and chemical properties of the calcined coal-derived coke were then compared to typical petroleum cokes. It was found that the weight loss upon calcination, the HGI values, the apparent green-coke density, and the ash values for the coal-based coke were in the range of or better than those of the petroleum coke. In addition, the content of critical elements such as nickel, vanadium, and sulfur were as much as an order-of-magnitude lower in the coal-derived material. This fact, coupled with the enhanced long-range order of the coal-derived structure, indicates that coal may not only be a potential source of anode coke but may, in fact, yield a coke with excellent performance and lower environmental impact.
\end{abstract}




\section{TABLE OF CONTENTS}

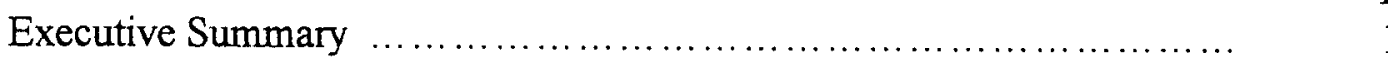

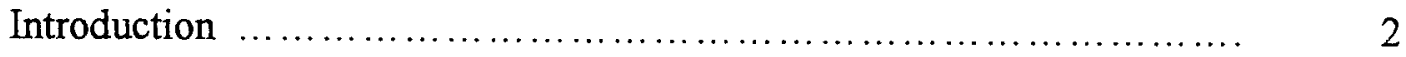

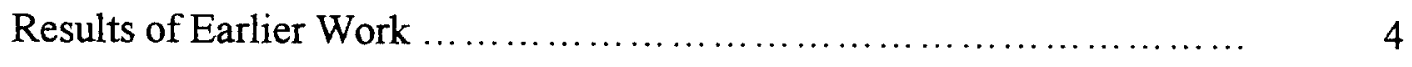

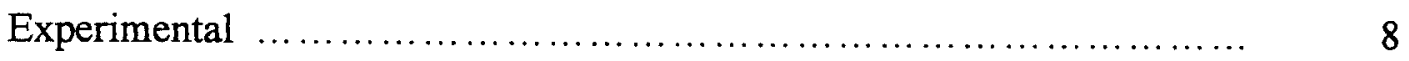

Development of Coal-Derived Coke Precursors $\ldots \ldots \ldots \ldots \ldots \ldots \ldots . \ldots$

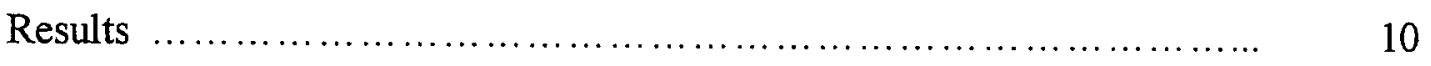

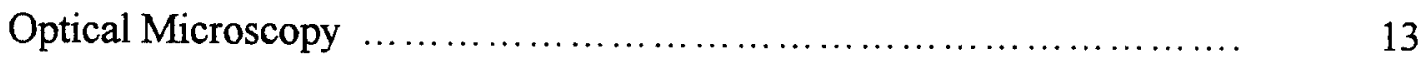

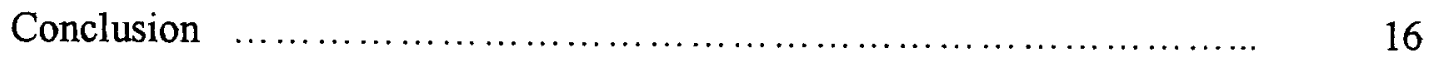

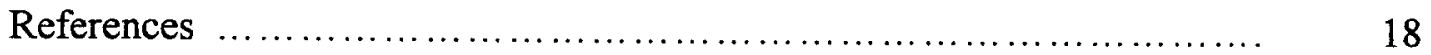




\section{LIST OF TABLES}

1 Aluminum Smelting-Grade-Calcined Petroleum Coke

Target Values

Page

4

2 Comparison of WVU Calcined Coke with Commercial

Petroleum Anode Coke

3 Properties of Arch Coal (PSOC 3001) ........................ 8

4 Product Yield and Pitch Properties from Hydrogenation of PSOC 3001

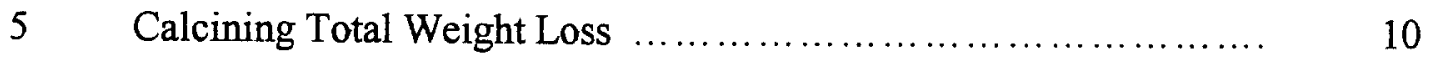

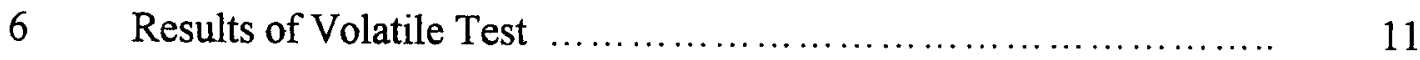

$7 \quad$ Hardgrove Index Values of Calcined Cokes $\ldots \ldots \ldots \ldots \ldots \ldots \ldots \ldots \ldots \ldots \ldots$

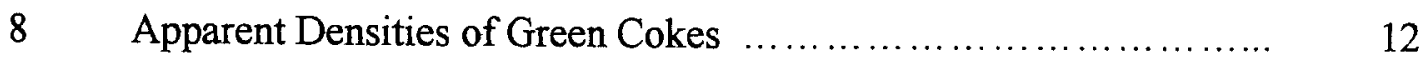

9 ICP Analysis of Calcined Coke from Coal-Derived Precursors ...... 12

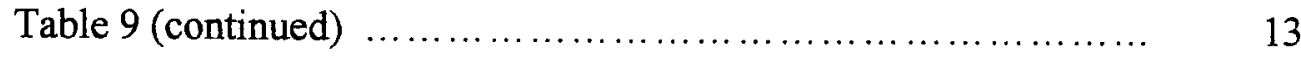

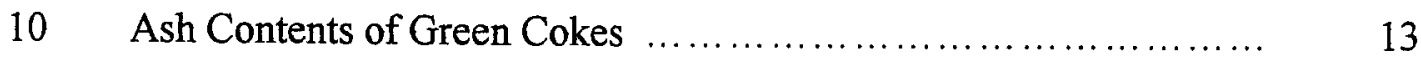




\section{LIST OF FIGURES}

1 Photomicrographs of Calcined Cokes Taken Under Polarized

Page

Light with a Phase-Sensitive Plate

2 Photomicrographs of Carbon Anode

3 Photomicrographs of Coal-Derived Green Cokes

4 Photomicrograph of Green Coke From Raw Coal Extract

16 


\section{EXECUTIVE SUMMARY}

Currently, aluminum metal is derived from alumina by means of an electrochemical reaction employing carbon as the anode. During the operation carbon is sacrificially converted to carbon dioxide. Hence large quantities of anode material are required each year. The bulk of the anode $(85 \%)$ is comprised of calcined coke and recycled anode butt material all of which is held together with coal-tar binder pitch. The coke, primarily derived from petroleum resid, is becoming increasingly concentrated in undesirable impurities such as sulfur, vanadium, and nickel. Hence an alternate supply of cleaner coke is sought.

Through a process developed at West Virginia University, coal has been treated by a combination of prehydrogenation and solvent extraction to produce a pitch, which upon coking has attractive and improved properties. In the present project, Arch coal (PSOC 3001) obtained from a CPCPC member was hydrotreated at 400...C for 2 hours and followed by solvent extraction in N-methyl pyrrolidone (NMP). The hydrotreatment is employed to adjust the characteristics of the final coke and the solvent extraction removes most of the inherent mineral matter from the coal. Following coking and calcination, the various coal-derived cokes were compared to conventional petroleum coke. It was found that the weight loss upon calcination, the HGI values, the density, and the ash content of the coal-derived coke were all similar to those of the petroleum cokes. Moreover, elemental analysis has confirmed substantially lower content of nickel, vanadium, and sulfur in the coal-derived cokes. This fact should have a significant effect on both anode performance and environmental issues. Finally, the optical texture of the 
coal-derived coke shows longer-range structure and anisotropic character, again indicating the desirability of the coal-derived coke.

\section{INTRODUCTION}

Two types of carbon anodes are use for the production of aluminum metal by molten salt electrolysis. In the self-baking method (Soderberg technology) a blend of calcined petroleum coke and coal-tar pitch is added to a casing and the anode formed continuously as it is consumed during the electrolytic reaction. The Soderberg process requires up to $35 \mathrm{wt} \%$ binder pitch and high operating temperatures to perform properly. ${ }^{(1)}$ Newer cells use carbon anodes that are prebaked. Prebaked anodes are normally manufactured from a blend of calcined petroleum coke, recycled anode material (butts), and coal-tar pitch. The blend is sufficiently mixed together at a temperature high enough for the binder to wet and plasticize all the paste particles. Forming of the final shape will take place at a controlled lower temperature. It is important for the binder to harden upon cooling of the shaped article for handling and packing in the subsequent baking step. Baking is accomplished in gas or oil-fired furnaces after carefully positioning the green anode in a packing material that will both provide an even distribution of heat and protection from oxidation as well as physical support during baking. The temperature of the furnace is monitored closely such that the desired heating curve is maintained. Baking is complete when an internal furnace temperature of about $1100^{\circ} \mathrm{C}$ is attained. Baking cycles often require nearly a month to complete before the finished product can be unpacked and inspected. Finally, the baked anode is cleaned and fitted with an electrical conductor before it is brought into service. 
Ideally the anode carbon is oxidized to carbon dioxide in the electrochemical reaction at a rate of $0.334 \mathrm{~kg}$ per $\mathrm{kg}$ of aluminum, though the actual consumption rate ranges from 0.400 to $0.500 \mathrm{~kg}$ per $\mathrm{kg}$ of aluminum. Because the carbon anode is a necessary reactant in aluminum production, a large quantity of calcined coke and coal-tar pitch is used in the United States. Currently, approximately 2,000,000 tons of calcined petroleum coke and 746,000 tons of coal-tar pitch are utilized domestically in the rendering of aluminum.

The major component in prebaked carbon anodes is the calcined coke filler $(80-90 \mathrm{wt} \%)$, which is derived predominantly by the delayed coking of petroleum residuals. This process produces a variety or grades of coke in which the quality suitable for carbon anode manufacture is but a fraction of the total coke currently produced. Delayed coking is a petroleum refining process to upgrade or dispose of otherwise low-profit byproducts into gas, distillates, and coke by severe thermal decomposition. ${ }^{(2-6)}$ The material harvested directly out of the delayed coker is still considered green and must be further heat treated in a rotary calciner or rotating hearth calciner to about $1300^{\circ} \mathrm{C}$ before it can be used in other carbon products. At this temperature residual volatile matter is removed and the density of the coke is increased.

It is not untrue to say that petroleum refiners do not operate delayed cokers to make coke but rather operate to maximize the slate of more profitable, lighter hydrocarbons. As such, the materials fed to the delayed coker are the bottom-of-barrel leftovers of previous petroleum processing and contain essentially all of the metals, ash, sulfur, and other undesirable elements. More importantly, rising levels of impurities in the delayed coker feedstocks become concentrated in the coke and can have deleterious effects in aluminum 
production. For example, metals such as vanadium and nickel can catalyze the oxidation reaction of carbon in the anode to carbon dioxide and hence lead to higher than normal carbon consumption in the cell. In addition, sour crudes are becoming increasingly prevalent resulting in higher amounts of sulfur in the petroleum coke. Excess sulfur can lead to puffing of the coke or the emission of sulfur-containing pollutants from the electrolysis cell. In Table 1 typical specifications are listed for smelting-grade-anode coke.

Table 1 Aluminum smelting-grade-calcined petroleum coke target values

\begin{tabular}{|c|c|}
\hline Item & Specification, wt $\%$ \\
\hline Sulfur & $3.0 \mathrm{max}$ \\
\hline Silicon & $0.02 \mathrm{max}$ \\
\hline Iron & $0.03 \mathrm{max}$ \\
\hline Nickel & $0.04 \mathrm{max}$ \\
\hline Vanadium & $0.045 \mathrm{max}$ \\
\hline Ash & $0.5 \mathrm{max}$ \\
\hline Volatile Matter & $0.5 \mathrm{max}$ \\
\hline Moisture & $0.5 \mathrm{max}$ \\
\hline
\end{tabular}

For all of the above reasons, an alternate source of anode coke is required to augment or replace the declining supply of quality petroleum coke. With its huge domestic reserves, coal could represent a possible solution to this problem in the United States. The focus of the present work explores conversion of coal to anode coke. The results of this project are timely as one of the main concerns of the CPCPC membership is the need for a secure supply of domestic coke free of metals and low in sulfur.

\section{RESULTS OF EARLIER WORK}

At least two conditions must be met in order to use coal as a feedstock for anode coke. First, the levels of ash-forming inorganic material and sulfur containing species have to 
be lowered to acceptable concentrations. Second, the coke must exhibit a high degree of structural order. Work at West Virginia University has shown that the dipolar, aprotic solvent N-methyl pyrrolidone (NMP) can solubilize appreciable quantities of the organic matter in coal while the inorganic material is not solubilized. ${ }^{(7,8)}$ Hence a simple solids separation step such as filtration or centrifugation is all that is required to effect recovery of clean coal from contaminants. After removal and recovery of the NMP, the extract contains very low ash and sulfur. The extract from the raw coal will produce a highly isotropic coke after carbonization.

Hydrogenation of the coal prior to solvent extraction will produce a pitch-like material with properties very different than those of the raw coal extract. The hydrogenated coal will have a definite softening point temperature, greater solubility in solvents such as toluene and NMP, and will make anisotropic cokes after carbonization.

A wide variety of laboratory tests is available to the aluminum producers to measure and predict with confidence the performance of cokes used in carbon anodes. ${ }^{(9)}$ Of course, judgments can best be made with anodes used in full-size commercial cells; a situation not always practical. Nevertheless, certain standardized tests on pilot anodes, and the cokes and binders that are employed, can be utilized to give reasonable estimations as to the likelihood of success. Some of these methods of evaluation include microstructural imaging, density determination, grindability study, chemical analyses, and so forth. Some results of an earlier study involving coal-derived cokes developed at WVU are presented below. ${ }^{(10)}$ 
In Figure 1, A through $\mathrm{C}$, are photomicrographs of calcined cokes of a commercial petroleum coke, coke from a mildly hydrogenated coal, and coke from a severely hydrogenated coal, respectively. All three cokes have an anisotropic microstructure typical of anode-grade coke. Note the development of long-range molecular ordering and the appropriate level of porosity. Some porosity is desirable to permit mechanical anchoring and bridging with the coal-tar binder pitch, but excessive voids could require unusually large amounts of binder.
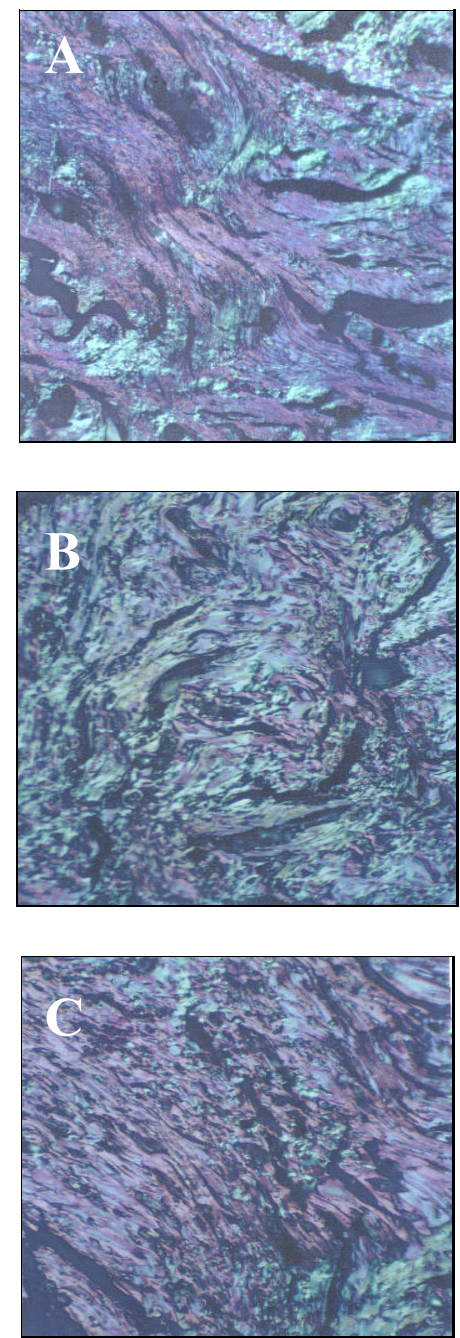

Figure 1 Photomicrographs of calcined cokes taken under polarized light with a phase-sensitive plate, 200X. A, petroleum coke; B, mildly hydrogenated coal; $\mathrm{C}$, severely hydrogenated coal. 
In Table 2 is a comparison of the calcined coke from the severely hydrogenated coal and a commercial petroleum coke. The real density value and crystallite height measurement for the WVU coke are within the range suitable for carbon anodes. Most notable is the $0.32 \mathrm{wt} \%$ sulfur content of the WVU coke, which is about a factor of ten lower than the petroleum counterpart. Moreover, the nickel and vanadium content for the WVU coke are very low. Typical specifications call for no more than $0.045 \mathrm{wt} \%$ vanadium and 0.04 $\mathrm{wt} \%$ nickel. These early results were very encouraging and thus formed the impetus for expanding the work in the current project.

As stated previously, prehydrogenation and solvent extraction of coal using the solvent $\mathrm{N}$-methyl pyrrolidone (NMP) is an effective technique for substantially reducing the ash content of coal. By selection of processing conditions in the prehydrogenation step, cokes with wide ranges of anisotropy have been produced. Another method to control anisotropy entails blending hydrogenated coal extracts with raw-coal extracts in NMP. ${ }^{(11)}$ By varying the proportions of hydrogenated and unhydrogenated coal extracts, cokes with targeted characteristics can be made. Thus, the objective of this research is to develop coal-based pitches for conversion into cokes for testing. The anode coke precursors are made by hydrogenating coal and blending with unhydrogenated coal extract.

Table 2 Comparison of WVU Calcined Coke with Commercial Petroleum Anode Coke

\begin{tabular}{|l|c|c|}
\hline \multicolumn{1}{|c|}{ Property } & WVU Coke & Commercial Coke \\
\hline Crystallite Height, & 28 & 30 \\
\hline Sulfur, $\mathrm{wt}^{\circ} \%$ & 0.32 & $2-4$ \\
\hline $\mathrm{Ni}, \mathrm{wt} \%$ & 0.0038 & 0.04 \\
\hline $\mathrm{V}, \mathrm{wt} \%$ & 0.0002 & 0.045 \\
\hline Real Density, $\mathrm{g} / \mathrm{cm}^{3}$ & 2.06 & 2.08 \\
\hline
\end{tabular}




\section{EXPERIMENTAL}

\section{Development of Coal-Derived Coke Precursors}

The Pennsylvania State University CPCPC members supplied about $18 \mathrm{~kg}$ of a bituminous coal from Arch Coal, Incorporated. Some characteristics of the coal provided are shown in Table 3.

Table 3 Properties of Arch Coal (PSOC 3001).

\begin{tabular}{ccccc} 
Moisture, wt \% as received & Ash, wt \% dry & \multicolumn{2}{c}{ Volatile Matter, wt \% dry } \\
1.79 & & 7.36 & & 31.57 \\
\hline & & & & \\
Carbon & Hydrogen & Nitrogen & Sulfur & Oxygen \\
wt \% dry & wt \% dry & wt $\%$ dry & wt \% dry & by difference \\
80.31 & 4.56 & 1.41 & 0.71 & 5.65 \\
\hline & & & & \\
Vitrinite & Liptinite & & Inertinite & Mineral Matter \\
vol \% mf & vol $\% \mathrm{mf}$ & Vol $\% \mathrm{mf}$ & vol \% mf \\
57.2 & 8.3 & & 30.3 & 4.2 \\
\hline
\end{tabular}

The coal was ground in a hammer mill to about 20 mesh (Tyler sieve) top size and then dried in a vacuum oven overnight at about $100^{\circ} \mathrm{C}$ to remove excess moisture. The dried coal was then sealed in $4 \mathrm{~L}$ glass bottles and stored in a refrigerator until ready to use.

Coal-derived pitches were produced in batches by placing $600 \mathrm{~g}$ of coal along with $1.5 \mathrm{~L}$ of tetralin into a 1 gal bolted-closure autoclave. The reactor was purged of air with hydrogen gas and then pressurized to 400psig with molecular hydrogen at room temperature. The reactor contents were stirred while heating and brought to $400^{\circ} \mathrm{C}$ for 2 hours. Following reaction, the reactor was cooled to room temperature and vented. The products were washed out with NMP and collected in a 10L flask. The unreacted tetralin and NMP were then removed by rotary evaporation. Three liters of NMP were added back to the flask and agitated for 2 hours at $110^{\circ} \mathrm{C}$. Afterward, the mixture was 
transferred to $750 \mathrm{~mL}$ centrifuge bottles and centrifuged for 1 hour at 2000 times the force of gravity $(2000 \mathrm{G})$ to separate unconverted coal and other insoluble material. The supernatant liquid was decanted and placed in a rotary evaporator device to remove the NMP. Finally, the coal-derived pitch was vacuum dried at about $150^{\circ} \mathrm{C}$ overnight before weighing. Additional hydrogenations were conducted until several hundred grams of material were made. Table 4 provides some of the nominal characteristics of the coalderived pitch precursor.

Table 4 Product Yield and Pitch Properties from Hydrogenation of PSOC 3001.

\begin{tabular}{cccc}
\hline Reaction Conditions & Pitch Yield $^{1}$ & Coke Yield $^{2}, \mathrm{wt} \%$ & Softening Point, ${ }^{\circ} \mathrm{C}$ \\
\hline $400^{\circ} \mathrm{C}$ & 58 & 131.3 \\
2 Hours & 66 & 58 & \\
${ }^{\top}$ Yield $=\frac{\text { Weight NMP Soluble X }}{\text { Weight Dry Coal }}$ & ${ }^{2} \mathrm{WVU}$ coke method & &
\end{tabular}

Raw coal extracts were prepared by mixing 1 part coal with 10 parts by weight NMP in a 1-L flask and refluxing for 1 hour at the normal boiling point of NMP $202^{\circ} \mathrm{C}$. The solution was filtered hot using conventional filtration glassware to separate the insoluble matter from the filtrate. The NMP was removed from the extract by rotary evaporation and the extract dried in a vacuum oven over night at about $170^{\circ} \mathrm{C}$ to constant weight. The yield of soluble extract was found to be $27.7 \mathrm{wt} \%$ based on the initial weight of dry coal. This process was repeated until several hundred grams of raw coal extract were obtained.

Blends were prepared by dissolving the hydrogenated and raw coal extract in a 75:25 proportion by weight in boiling NMP. The NMP was removed from the blend by rotary evaporation and the blend dried in a vacuum oven at $170^{\circ} \mathrm{C}$ overnight. 
The coal-derived precursors were coked under controlled conditions up to $600^{\circ} \mathrm{C}$. Enough sample was prepared such that Alcoa would have sufficient material for testing. Also, several pounds of a commercial green and calcined petroleum coke were obtained. The petroleum cokes were compared to the WVU cokes to determine similarities or differences in properties.

\section{RESULTS}

\section{Characterization of WVU and Commercial Cokes}

Samples of the green cokes were calcined to $1250{ }^{\circ} \mathrm{C}$ in a covered crucible under argon at a rate of $10{ }^{\circ} \mathrm{C} / \mathrm{hr}$ to $600{ }^{\circ} \mathrm{C}$, then $25{ }^{\circ} \mathrm{C} / \mathrm{hr}$ to $1250{ }^{\circ} \mathrm{C}$ and then held at this temperature for 10 hours. The test provides an indication of volatile matter content but more importantly an indication of coke shrinkage. The results are shown in Table 5 where it can be seen that the coal-derived cokes undergo significantly less weight change than do the petroleum-based materials.

Table 5 Calcining total weight loss results

\begin{tabular}{|l|c|}
\hline \multicolumn{1}{|c|}{ Sample Type } & Weight Loss, $\mathrm{wt} \%$ \\
\hline Coal-Based Green Coke & 8.50 \\
\hline Green Coke from Hydrogenated Coal & 7.24 \\
\hline Green Coke from Coal Blend & 7.24 \\
\hline Petroleum Coke A & 9.40 \\
\hline Petroleum Coke B & 9.80 \\
\hline Petroleum Coke C & 11.00 \\
\hline Petroleum Coke D & 10.00 \\
\hline
\end{tabular}

Volatile tests were conducted by rapidly heating $3 \mathrm{~g}$ of green coke in a $10 \mathrm{~mL}$ quartz crucible in a $950^{\circ} \mathrm{C}$ furnace for 8.5 minutes ( 6 minutes plus 2.5 minutes recovery time) while under an inert atmosphere. The results of the weight changes are shown in Table 6 . 
In general, probably because of the lower final temperature, the weight loss is less than that compared to the calcining weight loss determination.

Table 6 Results of volatile tests

\begin{tabular}{|l|c|}
\hline \multicolumn{1}{|c|}{ Sample Type } & Weight Loss, $\mathrm{wt} \%$ \\
\hline Coal-Based Green Coke & 7.0 \\
\hline Green Coke from Hydrogenated Coal & 7.0 \\
\hline Green Coke from Coal Blend & 8.0 \\
\hline Petroleum Coke A & 9.0 \\
\hline Petroleum Coke B & 9.0 \\
\hline Petroleum Coke C & 11.0 \\
\hline Petroleum Coke D & 8.7 \\
\hline
\end{tabular}

Hardgrove index values (HGI) indicate the relative hardness of coke and thus provide information on grindability and propensity for dust generation. Fifty grams of calcined coke of $-14 /+28$ mesh are tumbled in a proscribed manner and the amount, which passes through a 200-mesh sieve, is determined. The results are shown in Table 7 . Note that the lower the HGI the more resistant the coke is to making fines. The coal-derived cokes are comparable to the petroleum cokes though the HGI value for the $75 \%$ hydrogenated coal extract $-25 \%$ raw coal extract blend, in particular, is somewhat higher.

Table 7 Hardgrove index (HGI) values of calcined cokes

\begin{tabular}{|l|c|}
\hline \multicolumn{1}{|c|}{ Sample Type } & HGI, grams \\
\hline Coal-Based Coke & 36 \\
\hline Coke from Hydrogenated Coal & 34 \\
\hline Coke from Coal Blend & 42 \\
\hline Petroleum Coke A & 30 \\
\hline Petroleum Coke B & 34 \\
\hline Petroleum Coke C & 30 \\
\hline Petroleum Coke D & 27 \\
\hline
\end{tabular}


Apparent density of the green cokes was determined by use of a mercury pycnometer and the measurements tabulated in Table 8. Densities for both the coal-derived and petroleum cokes ranged from 1.75 to about $1.90 \mathrm{~g} / \mathrm{cm}^{3}$.

Table 8 Apparent densities of green cokes

\begin{tabular}{|l|l|}
\hline \multicolumn{1}{|c|}{ Sample Type } & $\mathrm{g} / \mathrm{cm}^{3}$ \\
\hline Coal-Based Green Coke & 1.815 \\
\hline Green Coke from Hydrogenated Coal & 1.881 \\
\hline Green Coke from Coal Blend & 1.772 \\
\hline Petroleum Coke A & 1.865 \\
\hline Petroleum Coke B & 1.755 \\
\hline Petroleum Coke C & 1.750 \\
\hline Petroleum Coke D & 1.899 \\
\hline
\end{tabular}

Elemental determination by inductively coupled plasma (ICP) methods on the coalderived calcined cokes is provided in Table 9. The silicon and iron contents of the coalderived cokes are slightly higher than that demanded by the typical specifications for petroleum cokes, but much more importantly the sulfur, nickel, and vanadium contents for the coal-based materials are dramatically lower. These elements are particularly troublesome because of contributions to environmental pollution or enhancement of anode air burn.

Table 9 ICP analysis of calcined coke from coal-derived precursors

\begin{tabular}{|l|c|c|c|c|}
\hline \multicolumn{1}{|c|}{ Sample ID } & $\begin{array}{c}\text { Coal-Based } \\
\text { Coke }\end{array}$ & $\begin{array}{c}\text { Hydrogenated } \\
\text { Coal Coke }\end{array}$ & $\begin{array}{c}\text { Coal-Based } \\
\text { Blend Coke }\end{array}$ & $\begin{array}{c}\text { Target } \\
\text { Specification }\end{array}$ \\
\hline Sulfur & $\mathrm{wt} \%$ & $\mathrm{wt} \%$ & $\mathrm{wt} \%$ & $\mathrm{wt} \%$ \\
\hline Silicon & $<0.02$ & $<0.02$ & $<0.02$ & 3.0 \\
\hline Iron & 0.04 & 0.1 & 0.06 & 0.02 \\
\hline Nickel & 0.072 & 0.02 & 0.079 & 0.03 \\
\hline Vanadium & $<0.01$ & $<0.01$ & 0.012 & 0.04 \\
\hline Aluminum & $<0.02$ & $<0.02$ & $<0.02$ & 0.045 \\
\hline Sodium & 0.027 & 0.032 & 0.23 & -- \\
\hline Calcium & $<0.05$ & $<0.05$ & $<0.05$ & -- \\
\hline
\end{tabular}


Table 9 (continued)

\begin{tabular}{|l|c|c|c|c|}
\hline \multicolumn{1}{|c|}{ Sample ID } & $\begin{array}{c}\text { Coal-Based } \\
\text { Coke }\end{array}$ & $\begin{array}{c}\text { Hydrogenated } \\
\text { Coal Coke }\end{array}$ & $\begin{array}{c}\text { Coal-Based } \\
\text { Blend Coke }\end{array}$ & $\begin{array}{c}\text { Target } \\
\text { Specification }\end{array}$ \\
\hline \multicolumn{5}{|l|}{} \\
$\mathrm{wt} \%$ & $\mathrm{wt} \%$ & $\mathrm{wt} \%$ & $\mathrm{wt} \%$ \\
\hline Magnesium & $<0.01$ & 0.013 & $<0.01$ & -- \\
\hline Potassium & $<0.05$ & 0.05 & $<0.05$ & -- \\
\hline Lead & $<0.05$ & $<0.05$ & $<0.05$ & -- \\
\hline Phosphorus & $<0.02$ & $<0.02$ & $<0.02$ & -- \\
\hline
\end{tabular}

Ashing tests on the green cokes were accomplished by heating $5 \mathrm{~g}(-200 \mathrm{mesh})$ in air to $950^{\circ} \mathrm{C}$ for 16 hours, the results are shown in Table 10 . The amount of high-temperature ash in the coal-derived cokes compare favorably with the petroleum cokes.

Table 10 Ash contents of green cokes

\begin{tabular}{|l|c|}
\hline \multicolumn{1}{|c|}{ Sample Type } & Ash Content, $\mathrm{wt} \%$ \\
\hline Coal-Based Green Coke & 0.4 \\
\hline Green Coke from Hydrogenated Coal & 0.6 \\
\hline Green Coke from Coal Blend & 0.4 \\
\hline Petroleum Coke A & 0.6 \\
\hline Petroleum Coke B & 1.4 \\
\hline Petroleum Coke C & 0.4 \\
\hline Petroleum Coke D & 0.2 \\
\hline
\end{tabular}

\section{Optical Microscopy}

A sample of a carbon anode used in a commercial aluminum smelter was embedded in epoxy resin and hand polished following conventional techniques. Observations of optically active surface structures were made with a Zeiss Axioskop polarized-light microscope equipped with a $35 \mathrm{~mm}$ camera and automated film exposure system. Figure 2 shows several features common to most carbon anodes. 

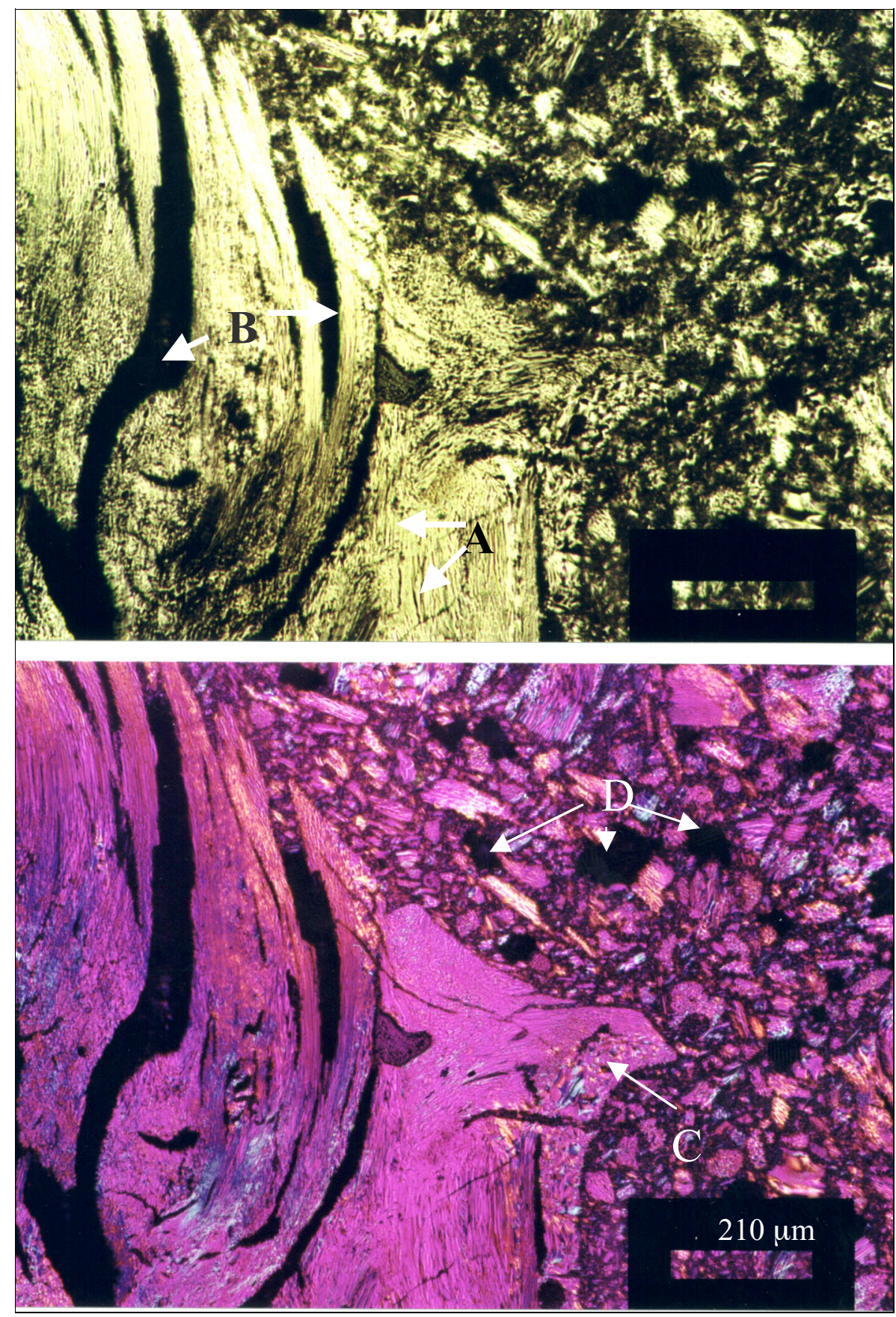

Figure 2. Photomicrographs of carbon anode. Top: polarized light; Bottom: polarized light, tinted plate. A, calcined petroleum coke; B, shrinkage cracks; C, pitch binder coke; D, voids.

As can be seen, carbon anodes are a complex aggregate of many coke types including large pieces clearly visible to the naked eye to particles on the order of microns, all held 
together by bridges produced by the carbonization of the binder pitch. Coke microstructures can range from highly anisotropic to nearly isotropic in appearance. Note the striations in the petroleum sponge coke (A), an indication of long-range order
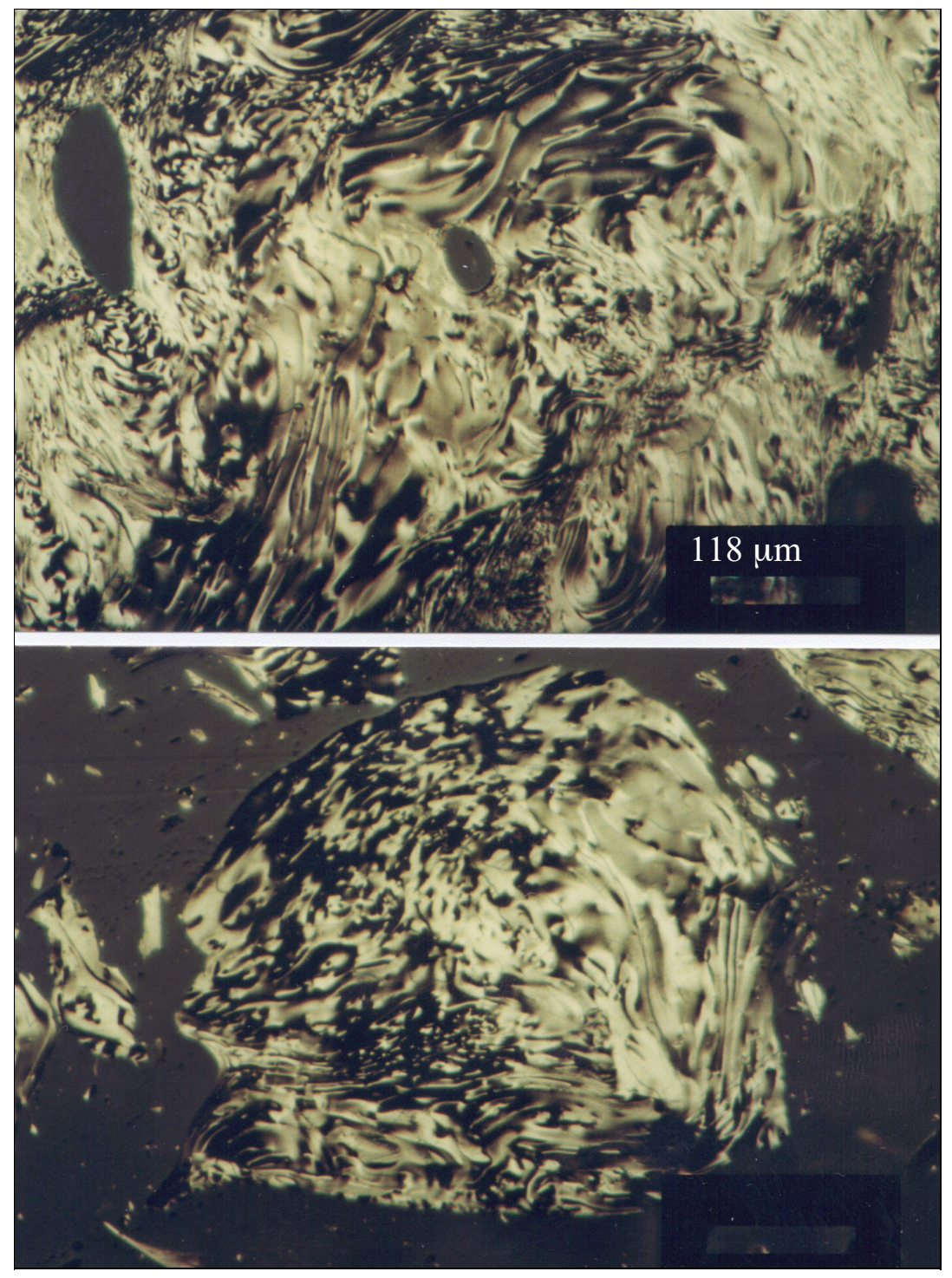

Figure 3. Photomicrographs of coal-derived green cokes. Top, hydrogenated coal extract; Bottom, blend of 75:25 hydrogenated coal extract and raw coal extract.

Figure 3 show the optical texture of green cokes developed by the hydrogenated coal extract and the blend with raw coal extract. The appearances seem quite similar although 
the properties of their calcined cokes were different. These cokes indicate considerable long-range order of carbon molecules. By contrast, Figure 4 is a photomicrograph of the green coke from raw coal extract. Note the very limited development and restricted growth of planar aromatic structures. The properties of this coke would be expected to be highly isotropic.

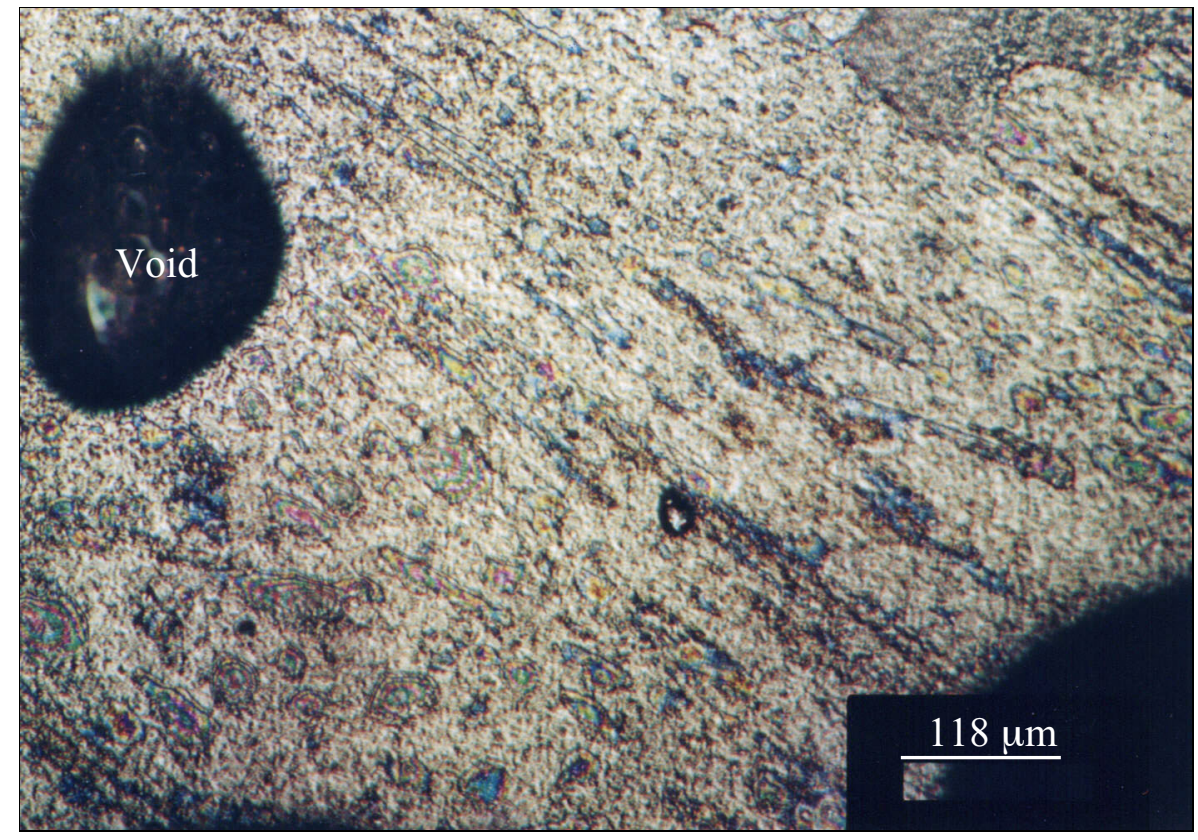

Figure 4. Photomicrograph of green coke from raw coal extract.

\section{CONCLUSION}

By a combined treatment of hydrogenation and solvent extraction, coal-derived coke has been shown to be a very promising alternative to conventional petroleum coke for use in carbon anodes for the aluminum industry. When comparing both physical and chemical properties, the coal-derived cokes are acceptable in almost every case. Moreover the optical properties (i.e., the propensity to form long-range order during coking and 
calcination) of the coal-derived cokes indicate structures that are of the nature desired for high quality anodes for the aluminum industry. 


\section{REFERENCES}

1) Newman, J. W. and Newman, K. L., In Introduction to Carbon Technologies; Marsh, H., Heintz , E. A., and Rodriguez-Reinoso, F., Eds; University of Alicante: Spain, 1997; pp. 269-328.

2) Rodriguez, J., Tierney, J. W., and Wender, I. Fuel 73, 1863 (1994).

3) Gary, J. H. and Handwerk, G. E., In Petroleum Refining, Technology and Economics; Marcel Dekker, Inc.: New York, NY; 1977, Chapter 5.

4) Marsh, H., Calvert, C., and Bacha, J. J. Mater. Sci. 20, 289 (1985).

5) Ellis, P. J. and Bacha, J. D. Light Metals, 477 (1996).

6) Adams, H., In Introduction to Carbon Technologies; Marsh, H, Heintz, E. A., and Rodriguez-Reinoso, F., Eds; University of Alicante: Spain, 1997; pp. 491-518.

7) Renganathan, K., Zondlo, J. W., Mintz, E. A., Kneisl, P., and Stiller, A. H. Fuel Proc. Tech.18, 273 (1988).

8) Stansberry, P. G., Zondlo, J. W., and Stiller, A. H., In Carbon Materials for Advanced Technologies; T. D. Burchell, Ed.; Pergamon Press: New York, NY, 1999; Chapter 10.

9) Heintz, E. A. Carbon 34, 699 (1996).

10) Belitskus, D. L., Production of Aluminum Reduction Electrodes from SolventExtracted Coal-Derived Carbon Feedstocks, Final Technical Report submitted to United States Department of Energy under contract DE-AC05-960R22464, September 20, 1996.

11) Zondlo, J. W., Stiller, A. H., Stansberry, P. G., "Method of Producing High Quality, High Purity, Isotropic Graphite from Coal, U S. Patent No. 5,705,139, January 6, 1998. 


\section{Understanding Microstructural Development in}

\section{Coal-Derived Foams during Thermal Processing}

Final Technical Report

Period of March 2000 through June 2001

Submitted: 19 January 2001

Submitted to: Dr. Frank Rusinko

Consortium for Premium Carbon

Products from Coal (CPCPC)

The Pennsylvania State University

407 Academic Activities Building

University Park, PA 16802-2308

Submitted by: Touchstone Research Laboratory, Ltd.

The Millennium Centre

Triadelphia, WV 26059

Signed:

Date:

Darren K. Rogers 


\section{DISCLAIMER}

This report was prepared as an account of work sponsored by an agency of the United States Government. Neither the United States Government nor any agency thereof, nor any of their employees, makes any warranty, expressed or implied, or assumes any legal liability or responsibility for the accuracy, completeness, or usefulness of any information, apparatus, product, or process disclosed, or represents that its use would not infringe privately owned rights. Reference herein to any specific commercial product process, or service by trade name, trademark, manufacturer, or otherwise does not necessarily constitute or imply its endorsement, recommendation, or favoring by the United States Government or any agency thereof. The views and opinions of authors expressed herein do not necessarily state or reflect those of the United States Government or any agency thereof. 


\subsection{INTRODUCTION}

This effort between Touchstone Research Laboratory, Ltd. (TRL) and West Virginia University (WVU) was aimed at studying the feasibility of producing high-performance carbon foams for a variety of low-cost bituminous coal precursors and establishing systematic means for determining processing conditions for any given feedstock. The ability to select candidate precursors based on readily-available material data and further screen potential precursors using simple laboratory tests would be a major advantage in (1) rapid material selection and project economic analysis, and (2) optimizing a foam for a specific application through precursor selection. Further, understanding how feedstock and foaming process conditions selections influence subsequent processing is a must for product design and robust process control.

\subsection{OVERVIEW OF CARBon FoAM TeChNOLOGY}

CFOAM $^{\mathrm{TM}}$ is produced simply by a controlled coking process. Extracts produced from bituminous coals of low volatile content, such as those found in the eastern U.S., are attractive and inexpensive - precursors for carbon foam. After the coal extract is foamed in an autoclave, the material can be heat-treated to further dictate its mechanical, thermal, and physical properties. "Green" foams still contain an appreciable quantity of organic matter (e.g., small aliphatic groups) and are flammable. When calcined at $1000-1200^{\circ} \mathrm{C}$ under inert gas to remove these materials, such foams resist ignition, have high compressive strength, impact resistance, and low thermal conductivity. Heat treating at higher temperatures, such as above $1700^{\circ} \mathrm{C}$ increases graphitic ordering and results in increases in electrical conductivity, thermal conductivity, and elastic modulus. Thus, foam properties can be designed through (1) precursor selection, (2) foaming process conditions, and (3) heat treatment conditions.

Carbon foams produced by these processes can be machined by conventional methods and require no special tooling or conditions. They may be impregnated with polymers by traditional resin transfer means or with metals by pressure casting. Thus, the finishing operations and forms in which carbon foams may be used are almost limitless. Graded foams, or foams having designed density gradients through their thickness, have recently been developed. This technique may allow the foam to be further tailored to meet localized property requirements.

\subsection{Advantages OF THE CFOAM ${ }^{\mathrm{TM}}$ MATERIAL}

Unique properties of the carbon foam material include:

1. Precursors: coals are inexpensive and readily available.

2. Manufacturing of the foam can be readily scaled up by (1) continuous extrusion of constant cross-section parts, or (2) net-shape batch production of special shapes. Required manufacturing equipment is commercially available; projected finished material cost is less than $\$ 30.00$ per pound).

3. Fire resistance: once carbonized at $>1000^{\circ} \mathrm{C}$, the foam does not contain a sufficient volatile material with which to support combustion. Figure 1 illustrates its resistance to combustion and heat protection when exposed to a $3000^{\circ} \mathrm{F}$ acetylene flame. 
4. Low bulk thermal conductivity: less than $1.0 \mathrm{~W} / \mathrm{m} / \mathrm{K}$, but potential for heat exchange application by convection (gas flowing across high surface area graphitic ligaments if the foam is converted to graphite through heat treatment at temperatures above $1700^{\circ} \mathrm{C}$ ).

5. It will not give off noxious or hazardous fumes when heated.

6. Its properties can be readily engineered to meet different requirements. By varying the processing conditions, the density, compressive strength, and ability to absorb energy can be tailored to meet specific requirements. Materials with densities from $10 \mathrm{lbs} / \mathrm{ft}^{3}$ to $>80 \mathrm{lbs} / \mathrm{ft}^{3}$ have been produced. Compressive strengths of over 3000 psi have been achieved for highdensity foams.

7. Integration with other materials: examples include impregnation with phenolic or other resins, lamination with glass-reinforced vinyl ester facesheets (shown in Figure 2), and lamination with a phenolic-resin skin. Attaching fiber-reinforced polymer or metallic facesheets allows joining to other components by more conventional methods, protects the foam from localized damage or abrasive wear, and transfers loads uniformly to the foam.

8. Machinability: easily cut, milled, turned, etc. with conventional equipment and tooling.

9. Formability: foam assumes shape of mold in batch operation, and may be continuously formed.

10. Joining: using a coke fusion process, in which "green" coke is heated to form strong bonds between components; this feature enables foams with different mechanical, thermal or electrical conductivity properties to be joined to produce a highly tailorable, anisotropic, sandwich material, as well as allows repair to damaged structures.

11. Impact absorption: carbon foam performs better than conventional polyurethane foams that are currently used extensively for impact absorption in aircraft.

12. Additional improvements: additives such as chopped fibers, nanofibers or nanotubes, and crushed calcined cokes can add significantly to the strength and tailorability of the foams; unidirectional expansion of the foam and the orientation of fibers within the matrix enable the production of anisotropic foams with directional properties.

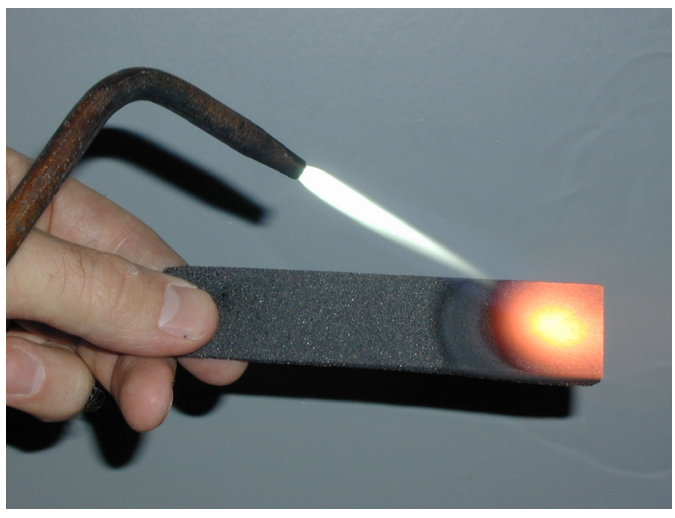

Figure 1. Carbon foam, exposed to a $3000^{\circ} \mathrm{F}$ acetylene flame, doesn't burn and provides excellent insulating properties

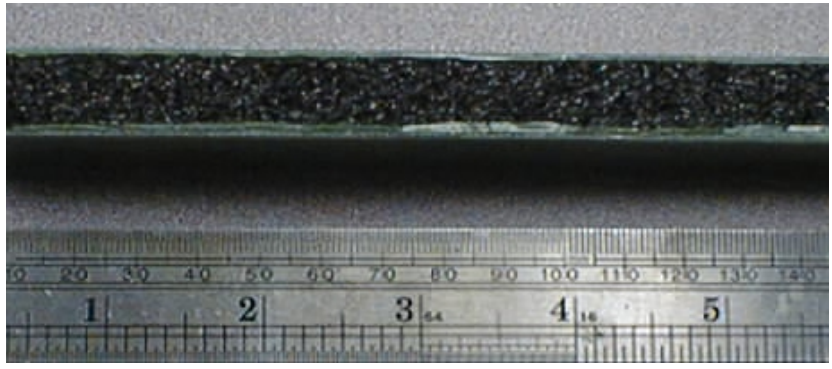

Figure 2. Carbon foam core laminated with glass-reinforced vinyl ester sheet

A summary of the properties of two standard carbon foam grades is presented in Table 1. It is important to realize that carbon foam density can be varied from around $10 \mathrm{lbs} / \mathrm{ft}^{3}$ to over 60 $\mathrm{lbs} / \mathrm{ft}^{3}$ and, even for a given density, quite different cell sizes and connectivity is possible. In 
addition, these foams may be heat treated, or "graphitized" at elevated temperatures to produce stiffer foams. Thus, the properties of coal-based carbon foams are quite tailorable, and the envelope of possible properties has only partially been explored.

\section{Table 1. Demonstrated properties of CFOAM ${ }^{T M}$}

\begin{tabular}{|c|c|c|c|c|}
\hline \multirow[b]{2}{*}{ Property } & & \multicolumn{2}{|c|}{ Touchstone CFOAM } & \multirow[b]{2}{*}{ Notes } \\
\hline & & LD Grades & HD Grades & \\
\hline Density & (Ibs/cubic foot) & 10 to 20 & 20 to 50 & \\
\hline $\begin{array}{l}\text { Compressive strength } \\
\text { Compressive Modulus }\end{array}$ & $\begin{array}{l}\text { (psi) } \\
\text { (ksi) }\end{array}$ & $\begin{array}{l}200 \text { to } 2000 \\
\text { approx. } 20\end{array}$ & $\begin{array}{c}2000 \text { to } 3000 \\
\text { approx. } 80\end{array}$ & \\
\hline $\begin{array}{l}\text { Tensile Strength } \\
\text { Tensile Modulus }\end{array}$ & $\begin{array}{l}\text { (psi) } \\
\text { (psi) }\end{array}$ & $\begin{array}{l}100 \text { to } 400 \\
\text { approx. } 20\end{array}$ & $\begin{array}{c}400 \text { to } 1000 \\
\text { approx. } 80\end{array}$ & \\
\hline Shear Strength & (psi) & approx. 300 & approx. 400 & \\
\hline Impact Strength & (ft-lbs/square inch) & 0.30 to 0.35 & 0.35 to 0.40 & \\
\hline Coefficient of Thermal Expansion & (ppm/deg. C) & \multicolumn{2}{|c|}{0.6 to 1.0 or 5.5 to 6.3} & $\begin{array}{l}\text { depends upon precursor } \\
\text { and heat treatment }\end{array}$ \\
\hline Thermal Conductivity & @ 25C & N/A & 0.30 & \\
\hline$(\mathrm{W} / \mathrm{mK})$ & @ 100C & N/A & 0.35 & \\
\hline & @ 200C & N/A & 0.45 & \\
\hline & @ 300C & N/A & 0.53 & \\
\hline Electrical Resistivity & ohm-cm & \multicolumn{2}{|c|}{0.01 to $10,000,000$} & $\begin{array}{l}\text { depends strongly upon post- } \\
\text { foaming heat treatment }\end{array}$ \\
\hline Fire Resistance & (critical heat flux, kW/sq. meter) & $>100$ & $>100$ & passes ASTM E1354 \\
\hline Noise Reduction & (absorption coefficient) & 0.1 & 0.4 & tested by ASTM 1050 \\
\hline
\end{tabular}

\subsubsection{Graded FoAm Structures}

Functionally-graded foams further expand the possibilities for these materials and can be readily produced by modifications of the foaming process, as illustrated in Figures 3 and 4 . In Figure 3, the density of the foam is graded, and this might be useful to offer higher density at panel surfaces for bearing load support or impact/abrasion resistance, or to provide greater durability at attachment points, while maintaining an overall low component density. The graded structure of Figure 4 is one of cell size, which might be useful for heat exchange or selective fluid flow direction. 

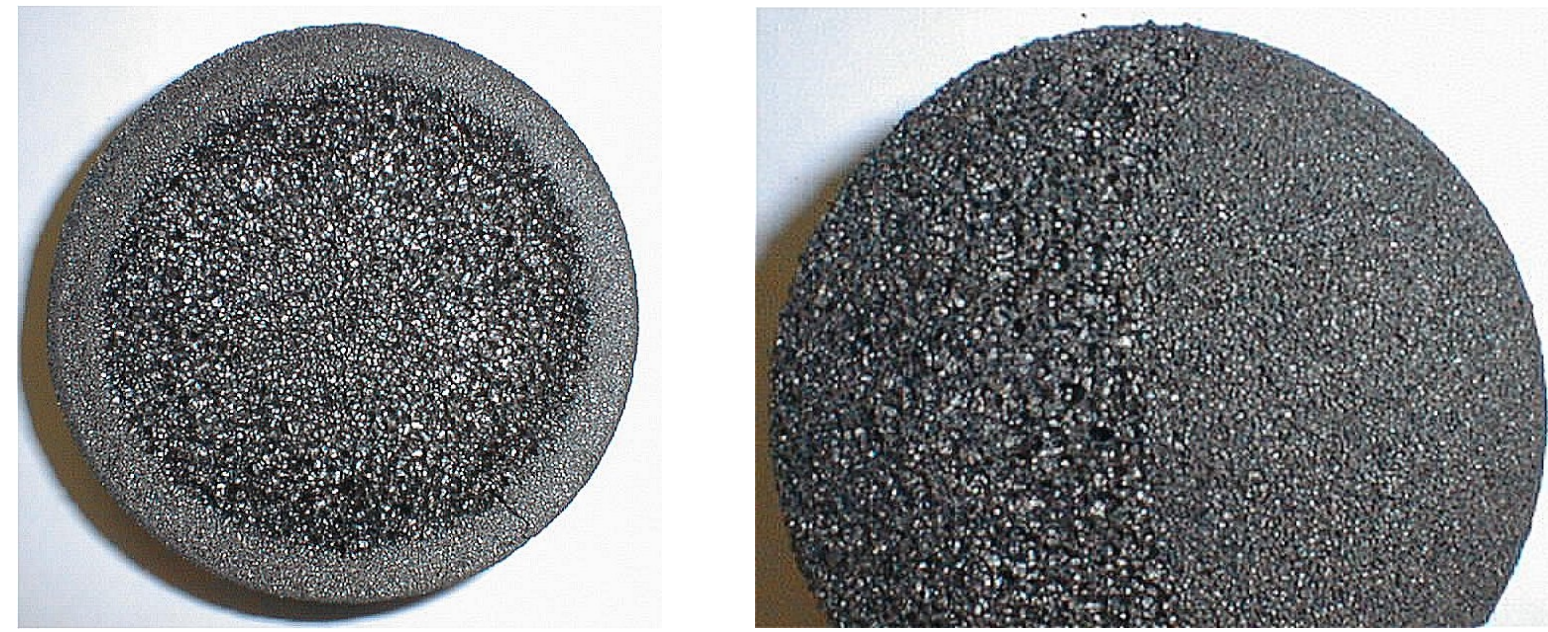

Figures 3 and 4. Carbon foams, showing radial (left) and linear (right) grading.

\subsection{Potential Applications for Coal-Based Carbon Foams}

Carbon foams made from coal are being considered for a number of aerospace, military, and commercial applications. Some examples of these are presented in Table 2. Touchstone currently is working under the following Department of Defense, NASA, and Department of Energy programs, in addition to this CPCPC-sponsored effort, to develop coal-based carbon foams for many of these applications.

1. "Manufacturing of Designed Carbon Foams for Naval Structures," a Phase II continuation of Department of Defense Phase I SBIR under Navy Topic OSD 98-043, entitled "High Temperature Multifunctional Foam Core Material for Lightweight Composite Structures;" Darren Rogers, principal investigator; started in March 2000. Client: NSWC; Dr. Roger Crane.

2. "A Lightweight, Structural Foam with Fire, Thermal, Noise and Impact Protection," a Phase II continuation of NASA Phase I SBIR under Subtopic 99.04.01, "General Aviation System Technologies;" began January 2001. Client: NASA Langley Research Center; William Freeman.

3. "Reducing the Cost of Naval Vessels Through Use of Inexpensive, Lightweight Structural Foams," Navy Phase I SBIR under Topic N00-091, "Shipbuilding Affordability;” began May 2000 ; Client: Office of Naval Research, John Carney.

4. "Advancing Carbon Foams for Aerospace and Commercial Applications, " Air Force PRDA00-04-MLKN; began August 2000; Client: Air Force Research Laboratory, Dr. Ajit Roy

5. "Tailorable, Inexpensive Carbon Foam Electrodes for High-Efficiency Fuel Cell and Electrochemical Applications" Department of Energy SBIR Topic 06-22; began October 2000; Client: Department of Energy. 
Table 2. Potential Applications for Coal-Based Carbon Foams

\begin{tabular}{|c|c|}
\hline Potential Markets & Potential Applications of Carbon Foam \\
\hline $\begin{array}{l}\text { Aerospace: aircraft, } \\
\text { spacecraft and satellites }\end{array}$ & $\begin{array}{l}\text { - } \quad \text { thermal protection systems (TPS) } \\
\text { - } \quad \text { firewall insulation } \\
\text { - } \quad \text { passenger compartment noise reduction } \\
\text { - } \quad \text { energed laminate interior panels and structural components } \\
\end{array}$ \\
\hline Navy & $\begin{array}{l}\text { - } \text { corrosion- and fire-resistant walls, floors \& ventilation ducts } \\
\text { - jet blast deflectors } \\
\text { - radar-selective material for composite masts }\end{array}$ \\
\hline $\begin{array}{l}\text { Other Defense } \\
\text { Applications }\end{array}$ & $\begin{array}{ll} & \text { fire and ballistic protection for personnel vehicles and structures } \\
\text { - } & \text { thermal / noise insulation \& ballistic protection for engines / compressors } \\
\text { - lightweight body armor (attached to Kevlar } & \text { Tace sheets) } \\
\end{array}$ \\
\hline $\begin{array}{l}\text { Automotive / } \\
\text { Transportation }\end{array}$ & $\begin{array}{l}\text { - energy-absorbing bumpers and side panels } \\
\text { - thermal, fire and noise insulation } \\
\text { - heat exchangers }\end{array}$ \\
\hline Construction Materials & $\begin{array}{l}\text { - thermal insulation for metal buildings } \\
\text { - lightweight, modular emergency structures } \\
\text { - drywall replacement }\end{array}$ \\
\hline
\end{tabular}

\subsection{OBJECTIVES OF THIS EFFORT}

The objectives, or deliverables, of this effort include

- a procedure by which candidate carbon foam precursors might be selected,

- a "foamability" test pertinent to coals and coal extracts,

- demonstration of the capability to produce foams of different density and morphology from several commonly-available bituminous coals,

- a database of chemical, structural, and morphological data for these foams, illustrating the changes that occur in cellular carbons during thermal processing,

- predictive models relating feedstock and "green" foam attributes to behavior during thermal processing, and

- demonstration carbon foam articles made from several coal-derived materials.

The effort has been divided into nine tasks, including

Task 1. Procurement of Raw Materials,

Task 2. Development of a "Foamability" Test,

Task 3. Production of Foams,

Task 4. Characterization of "Green" Foams,

Task 5. Calcining,

Task 6. Graphitization,

Task 7. Characterization of Foam Structure and Morphology,

Task 8. Modeling, and

Task 9. Reporting.

A summary of the work completed under each task is presented in the following sections. 


\section{TASK 1.0 Procurement OF CoAl Feedstocks}

Multiple bituminous coals and coal extracts were considered under this effort. In preliminary laboratory experimentation, conducted between August, 1999, and December, 1999, Touchstone had demonstrated that carbon foams could be produced from untreated coals, such as Lower Powellton and 610. Touchstone asked Dr. Peter Stansberry of West Virginia University to guide identification of a cross-section of bituminous coals for examination. Dr. Stansberry provided the broad ranges specified in Table 3 .

Table 3. Broad classifications of coals considered during this study

\begin{tabular}{|c|c|c|c|c|}
\hline Family & ASTM Rank & Volatile Matter & $\begin{array}{c}\text { Free-Swelling } \\
\text { Index }\end{array}$ & $\begin{array}{c}\text { Gray-King } \\
\text { Group }\end{array}$ \\
\hline 1 & LV bituminous & 14 to 20 & 3 to $>4$ & G to G8 \\
\hline 2 & MV bituminous & 23 to 30 & 2 to 4 & E to G2 \\
\hline 3 & HV-A bituminous & $>30$ & any value & any value \\
\hline
\end{tabular}

This description was provided to the Pinson Coal Company of Huntington, WV. Matt Pinson provided the following coals in 10 to 20 pound lots. The only exceptions were POW, or Lower Powellton, coal and n-methyl pyrollidone (NMP) extracted Lower Powellton coal samples provided by West Virginia University, the latter in an approximately 10-pound sample.

Table 4. Descriptions of coals included in this study

ID Seam Comments

the following material was provided by West Virginia University

POW: Lower Powellton Powellton Country

the following materials were provided by Pinson Coal Company

603 Stockton-Lewiston Mingo County Washed Stoker

610 Elkhorn Pike County Stoker

701 Pocahontas 3\&4 McDowell County Pond Fines

710 Coalburg Lincoln-Mingo Counties

715 Coalburg Mingo County

720 Coalburg Wayne County

725 Coalburg Wayne County

729 Coalburg Wayne County

731 Beckley McDowell County

734 Fire Creek "C" Split McDowell County

735 Pocahontas \#3 McDowell County

800 Sewell McDowell County

801: Sewell Wyoming County

Raw Strip

High-Volatile

Strip and Deep Washed Stockpile

Raw, Deep Mine High-Volatile

Washed, Deep Mine High-Volatile

Washed, Deep Mine High-Volatile

Raw, Deep Mine $\quad$ Low-Volatile

Raw Strip Low-Volatile

Raw, Deep Mine Low-Volatile

Stoker Low-Volatile

Surface Mine Outcrop Low-Volatile 
The as-received coals were subjected to a series of tests at Tradet Laboratory in Triadelphia, WV. Tests, for which the results are summarized in Table 5, included

- constituent analysis,

- ultimate analysis,

- free-swell index (in accordance with ASTM D720), and

- Gieseler plasticity (in accordance with ASTM D2639).

For these tests, the coals were dried and ground to -60 mesh. Touchstone also characterized the true (solid) density of these powders using a Micromeritics AccuPyc 1330 helium pycnometer. These data are presented in Table 6 and illustrate the exceptionally high densities of certain materials (e.g., 720), which is largely due to high ash content that also contributed to the poor foaming potential of these materials. 
Table 5. Summary of coal analytical data

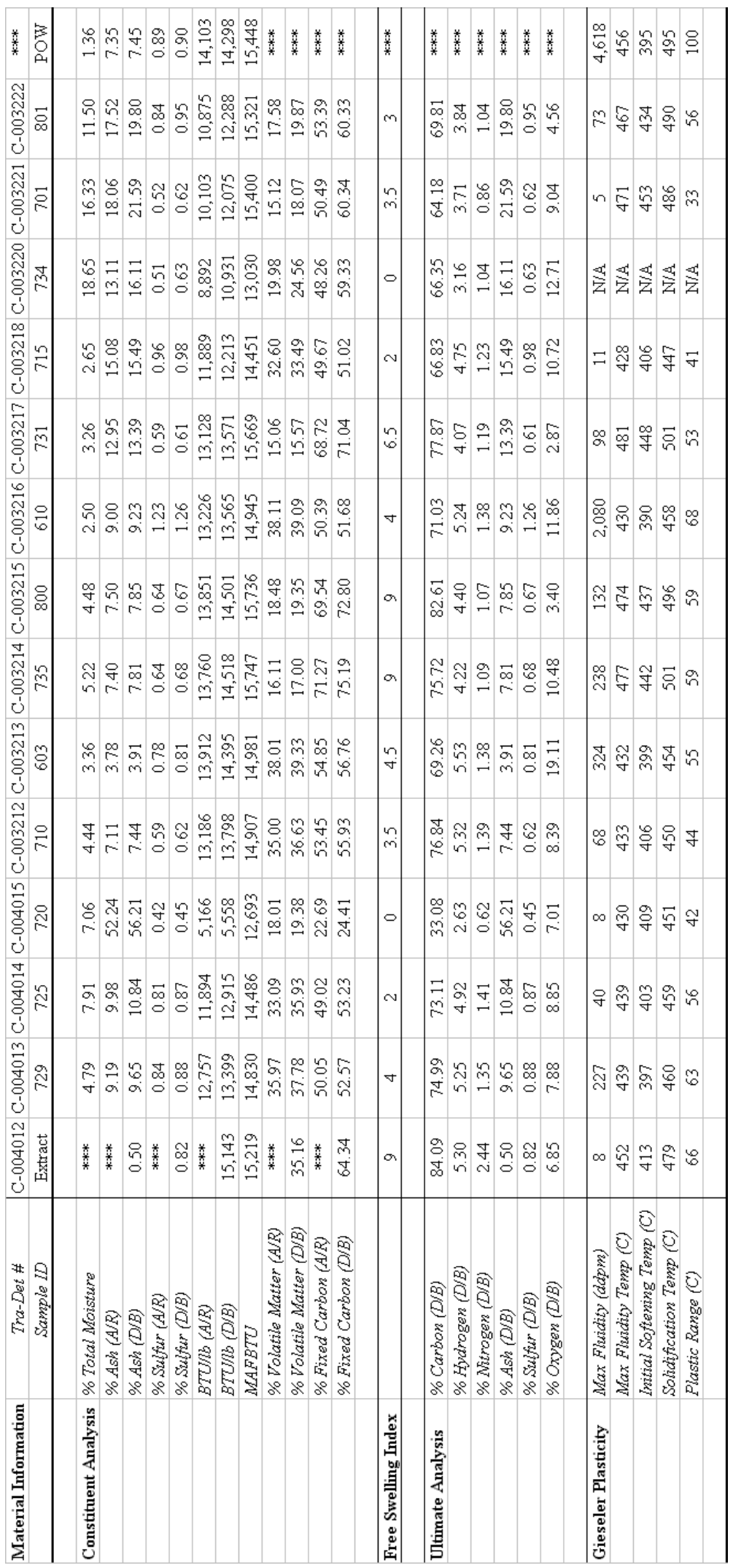


Table 6. True, or solid, densities of coals as determined by helium pycnometry

\begin{tabular}{cc}
\hline Coal & Density $(\mathrm{g} / \mathrm{cc})$ \\
\hline & \\
729 & 1.3511 \\
725 & 1.3732 \\
720 & 1.8355 \\
710 & 1.3466 \\
603 & 1.3209 \\
735 & 1.4083 \\
800 & 1.4032 \\
610 & 1.3693 \\
731 & 1.4537 \\
715 & 1.4360 \\
734 & 1.5515 \\
701 & 1.5268 \\
801 & 1.4988 \\
POW & 1.3581 \\
1060 & 1.3464 \\
Extract & 1.2833 \\
& \\
\hline
\end{tabular}

\section{TASK 2.0 DeVelopment OF A "FoAmability" TeST}

Optimizing the foaming conditions for a given precursor can be quite a complicated task requiring sound characterization of material properties of the precursor and detailed characteristics of its thermal behavior. A test was developed to examine (1) the foaming behavior of different raw materials quickly and efficiently, and (2) the influence of temperature and pressure on the foaming process. The experimental setup is shown on Figure 5. A small sample of a candidate precursor material was processed using certain (arbitrary) thermal cycle under isobaric conditions.

Characterization of foaming behavior of different materials was carried out through direct foaming experiments, in which coal powder samples were subjected to thermal cycling at different conditions. Another approach, based on monitoring of temperature changes inside the reactor, was verified for one particular system.

In the standard foaming test, the foam reactor - after preliminary equilibration at intermediate temperature - was heated to a final temperature at a constant heating rate, with heating conditions controlled by temperature of the wall of the reactor. The experimental Parr Instruments reactor was equipped with additional thermocouple positioned just above the powdered sample. It was expected that the signal from this thermocouple would allow identification of the events occurring during foaming. Because of geometrical limitations of the head of the reactor, the 
monitoring thermocouple had to be placed in the radial position 2 inch from the center and, thus, the size of the sample was increased to 5 inches in diameter. The aluminum mold containing 200 $\mathrm{g}$ of selected grade of 900 coal (POW) was positioned that way that the distance of the bottom of thermowell from the surface of the powder was $10 \mathrm{~mm}$.

Figure 5 shows temperature variations recorded for coal foaming experiment and reference run (empty reactor in the same configuration) during thermal cycle $475^{\circ} \mathrm{C}$ at $500 \mathrm{psi}$. Because of differences in the thermal mass of the system when loaded versus empty, the reference curve is shifted towards higher temperatures although the general character of both curves is quite similar. Closer inspection of the system response can be based on variations (calculated from temperature-time relationship) of actual heating rate measured inside the mold. The comparison of both experiments expressed that way is illustrated on Figure 6 (only high temperature region above $350^{\circ} \mathrm{C}$ - is displayed). Initially increasing heating rate reflects ramping the wall temperature, and decaying part of the curve (decreasing rate) corresponds to soaking stage with constant wall temperature. As can be seen the adjustment of internal temperature to wall conditions is in the case of empty reactor smooth and monotonous (variations are mostly the result of controller characteristics). In the case of coal sample two events occur changing the internal rate of heating, one relatively weaker at $390^{\circ} \mathrm{C}$ and second stronger at ca. $430^{\circ} \mathrm{C}$. The first transition is related to low temperature sintering of the powder (powder-to-"solid" transition without actual foaming of the sample) changing heat transfer conditions between walls of the mold and gas above the sample. The deflection occurring at higher temperature (above $430^{\circ} \mathrm{C}$ ) reflects direct contact of foamed material with temperature sensor. Such interpretation was later confirmed through separate foaming experiments conducted at different final temperatures. Thus, it seems that monitoring of internal temperature of the foaming reactor (after improving and modifying sensor insertion) has a potential as a process identification tool and relatively quick way to estimate / (verify) foaming characteristics of tested material. 


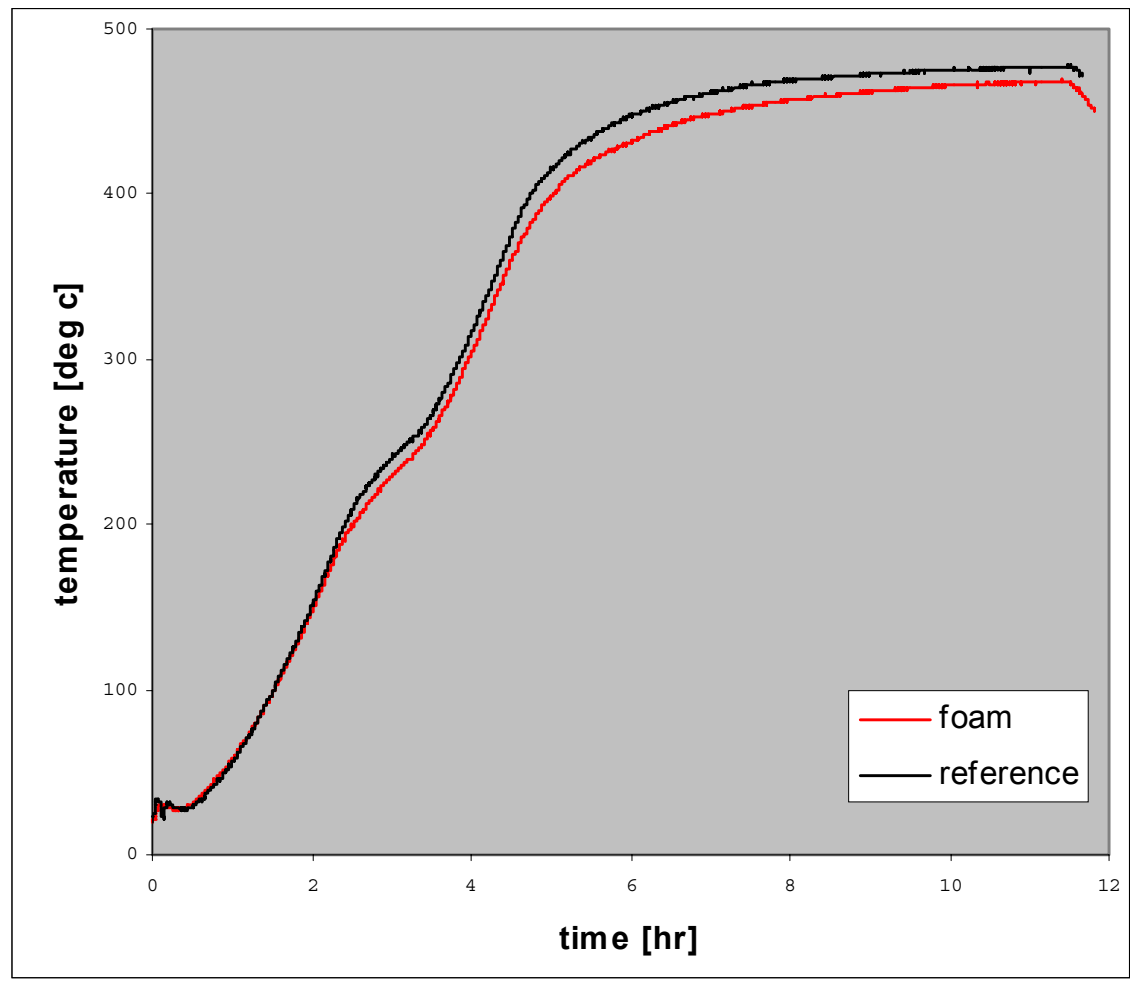

Figure 5. Temperature versus time plot for "foamability" test

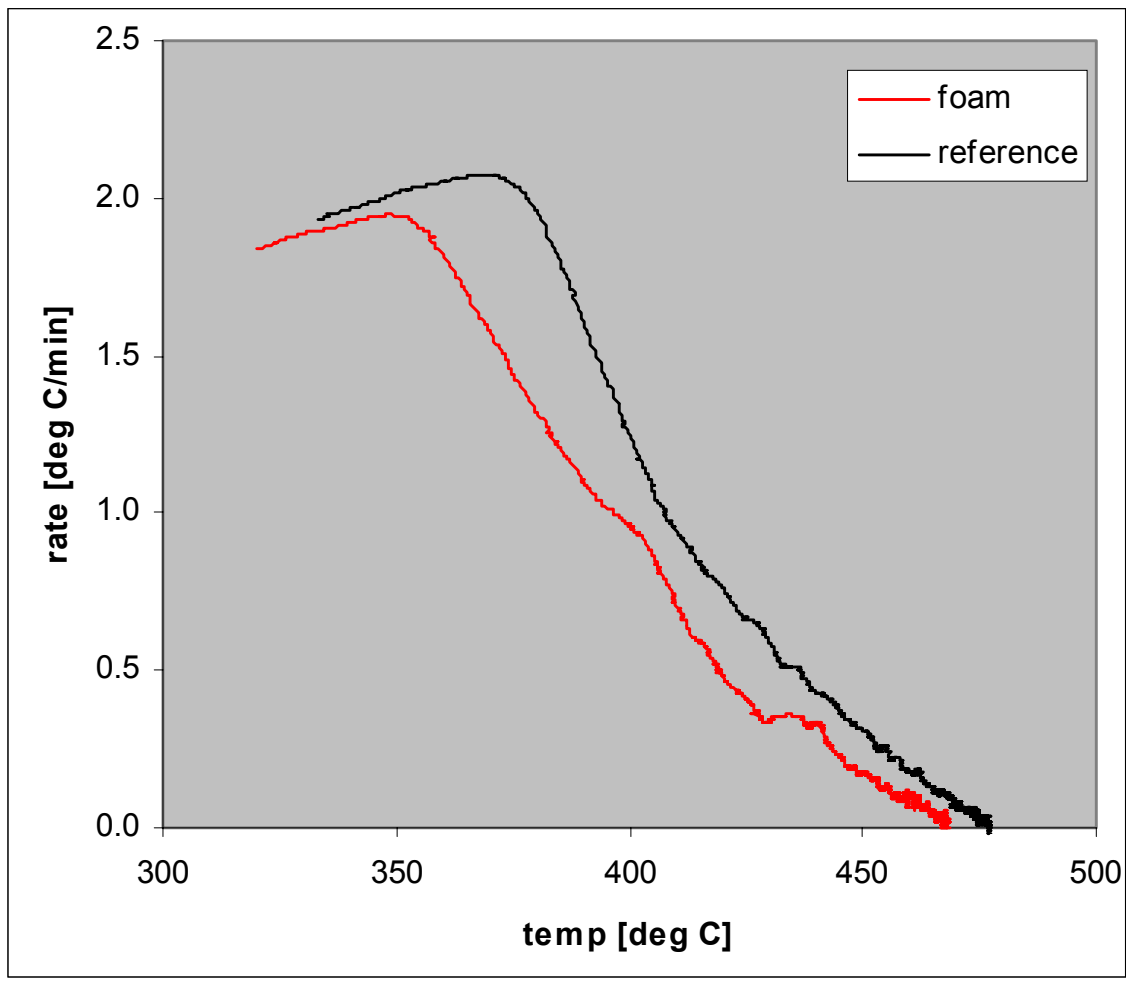

Figure 6. Temperature derivative (rate) plot versus temperature for "foamability" test 


\section{TASK 3.0 Production OF FoAMS}

Carbon foam test articles were fabricated by foaming (thermally decomposing under controlled temperature and pressure conditions to produce a cellular material of uniform density) and calcining (heat treating in an inert atmosphere to remove aliphatic material from the carbon structure) bituminous coal powders. Foaming took place in reactors manufactured by Parr Instruments (Moline, IL) at temperatures between 425 and $550^{\circ} \mathrm{C}$ and nitrogen pressures between 0 (ambient) and 500 psi. Two identical Model 4570 high pressure reactors, with $600^{\circ} \mathrm{C}$ temperature and 3000 psi pressure service capabilities, were used in this study. A photo of these 1.5 gallon, 5.5-inch internal diameter units is presented in Figure 7.

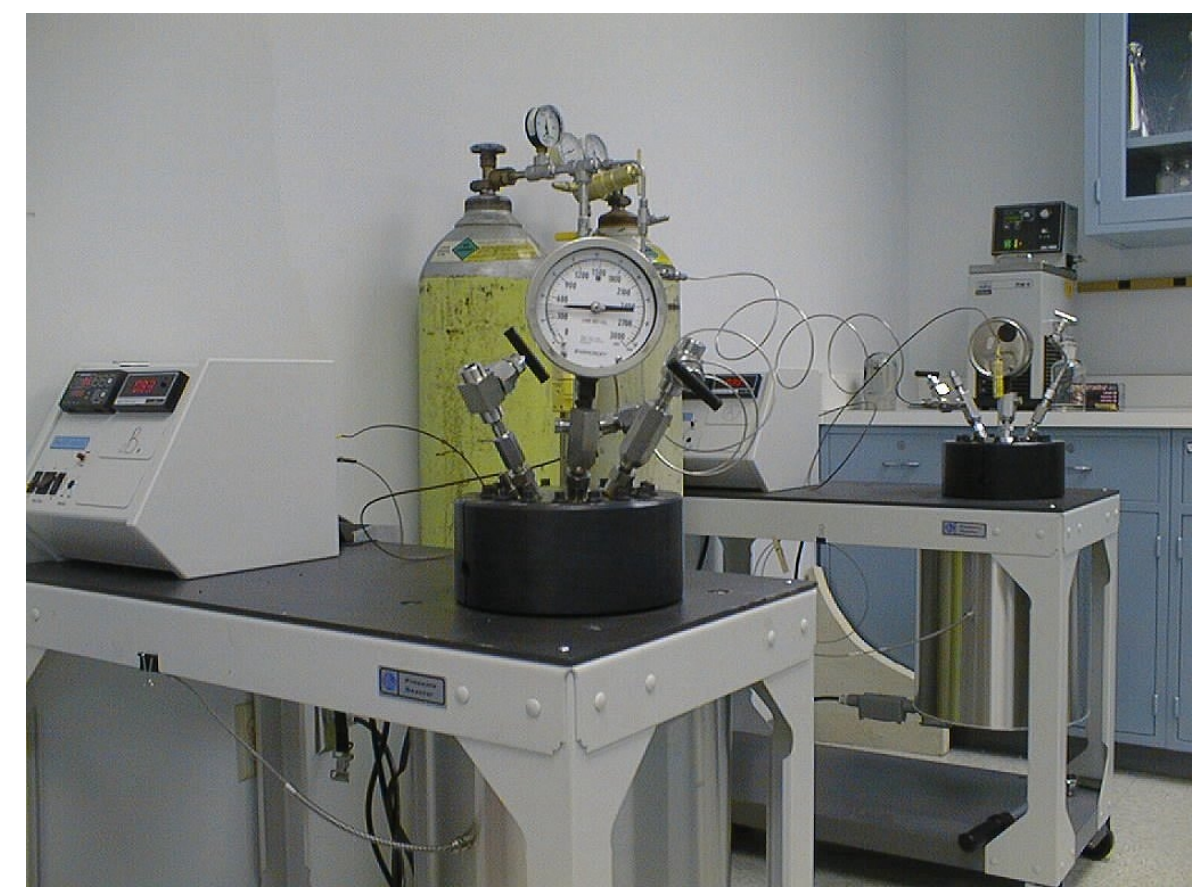

Figure 7. Parr Instruments high pressure reactors

For the initial screening experiments of many coals, ceramic (glazed whiteware) cylindrical containers of nominally 2.1-inch internal diameter and 4.0-inch height were used. Three such containers could be placed in the bottom of the pressure vessels simultaneously so that the temperature/pressure conditions could be explored in a minimum number of reactor operations.

In this screening study, approximately 25.0 grams of coal powder of -60 mesh particle size was loaded into the ceramic containers and tapped to promote good particle packing. Later, after selection of candidate high-performance foam precursors, larger test articles were produced by loading approximately 200 grams of coal into stainless steel or aluminum containers of up to 5.0inch diameter. In all cases, the masses of the container and coal was determined to 0.005 gram precision using an Ohaus electronic balance. The containers were loaded into bottom the pressure vessels and covered with slotted, circular disks of flexible graphite foil. As the foaming process proceeded, these disks prevented oil or tar decomposition products from vaporizing, condensing on the cooler head of the reactor, and dripping back into the ceramic containers. The 


\section{CPCPC Final Technical Report}

January 2001

vessel was sealed with sixteen (16) set screws that forced the vessel flanges together and onto a flexible graphite gasket. The heating and pressurization profile selected for carbon foam production was as follows:

- Load reactor with container(s) filled with -60 mesh coal powder,

- Seal reactor by tightening sixteen (16) set screws in star pattern to $30 \mathrm{ft}-\mathrm{lbs}$ in four cycles (one at $10 \mathrm{ft}-\mathrm{lbs}$, one at $20 \mathrm{ft}-\mathrm{lbs}$, and two at $30 \mathrm{ft}-\mathrm{lbs}$ ) using a torque wrench,

- pressurize system to at least 100 psi nitrogen,

- vent reactor to 0 psi,

- pressurize reactor and ballast tanks to the desired operating pressure for the experiment ( 0 to $500 \mathrm{psi}$,

- seal-off gas supply tanks, retaining connection between reactor and ballast tanks to moderate pressure excursions during operation,

- start heating profile, which includes five steps

- heat at $2.5^{\circ} \mathrm{C}$ per minute from ambient temperature to $325^{\circ} \mathrm{C}$,

- soak at $325^{\circ} \mathrm{C}$ for one hour,

- heat at $2.0^{\circ} \mathrm{C}$ per minute from $325^{\circ} \mathrm{C}$ to the ultimate temperature (between 450 and $\left.550^{\circ} \mathrm{C}\right)$,

- soak at the ultimate temperature for seven hours, and

- cool from the ultimate temperature to $25^{\circ} \mathrm{C}$ at an uncontrolled rate,

- vent the reactor when temperature was between 50 and $100^{\circ} \mathrm{C}$, and

- loosen bolts by reversing the tensioning procedure at $30+\mathrm{ft}-1 \mathrm{bs}$ torque and remove the containers.

Examples of the resulting 2.1-inch diameter screening study "pucks," and a 5.0-inch diameter disk from follow-up studies are shown, respectively, in Figures 8 and 9.

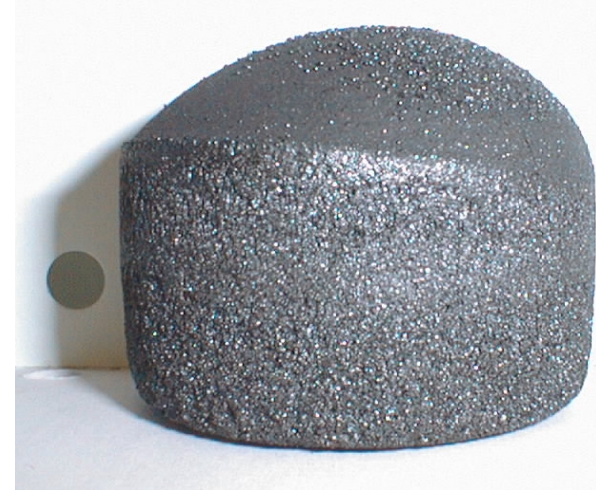

Figure 8. Screening study test article

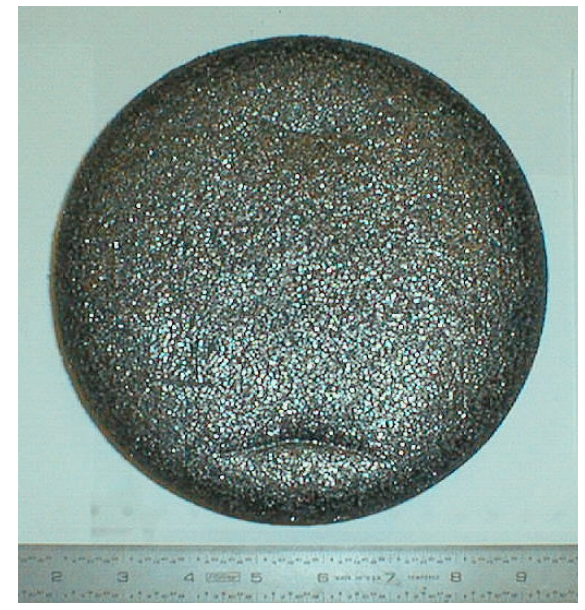

Figure 9. Follow-up study test article

Screening test articles were produced, where possible, for all sixteen (16) different precursors at foaming process temperatures of $425,450,475,500,525$, and $550^{\circ} \mathrm{C}$. The foaming process consists of two sub-processes, (1) sintering of coal particles (also known as agglomeration) to form a consolidated mass, and (2) devolatilization, or removal of volatile materials. 
In the case of some precursors (e.g., 720), the coal neither sintered nor foamed, so the result was a non-agglomerated powder mass. Mass losses for these trials were still recorded but, of course, the material was not heat treated or characterized further. This was typically observed at the lower foaming temperatures (e.g., 425 or $450^{\circ} \mathrm{C}$ ) and only for a few of the candidate precursors. If a precursor showed no foaming potential at $450^{\circ} \mathrm{C}$, it was not considered at $425^{\circ} \mathrm{C}$. Similarly, only precursors that had not produced adequate foams at 500 and $525^{\circ} \mathrm{C}$ were considered at $550^{\circ} \mathrm{C}$, the top (safe) service temperature of the Parr Instruments laboratory-scale reactors. Table 7 presents the mass losses of these precursors as functions of foaming process temperature at a constant vessel pressure of 500 psi. The same data are illustrated graphically in Figure 10.

Table 7. Mass losses of coal precursors at foaming temperatures between 425 and $525 C$ and at 550 psi pressure

\begin{tabular}{c|rrrrrr}
\cline { 2 - 7 } Precursor & \multicolumn{5}{|c}{ Foaming Process Temperature (C), 500 psi pressure } \\
\hline & 425 & 450 & \multicolumn{1}{c}{475} & 500 & 525 & 550 \\
729 & $16.02 \%$ & $17.47 \%$ & $18.86 \%$ & $20.39 \%$ & $20.43 \%$ & $20.46 \%$ \\
725 & $12.31 \%$ & $16.36 \%$ & $17.41 \%$ & $18.36 \%$ & $16.68 \%$ & $20.55 \%$ \\
720 & & $6.98 \%$ & $8.02 \%$ & & $7.63 \%$ & $9.01 \%$ \\
710 & & $17.52 \%$ & $18.86 \%$ & $16.91 \%$ & $19.21 \%$ & \\
603 & $16.48 \%$ & $17.59 \%$ & $19.83 \%$ & $20.79 \%$ & $20.51 \%$ & \\
735 & $2.62 \%$ & $3.34 \%$ & $6.43 \%$ & $6.59 \%$ & $6.91 \%$ & $7.22 \%$ \\
800 & & $3.94 \%$ & $8.66 \%$ & $8.02 \%$ & $6.75 \%$ & $10.16 \%$ \\
610 & $16.43 \%$ & $17.12 \%$ & $18.61 \%$ & $19.33 \%$ & $19.94 \%$ & \\
731 & & $3.37 \%$ & $5.67 \%$ & $5.40 \%$ & $6.66 \%$ & $8.15 \%$ \\
715 & & $13.82 \%$ & $16.08 \%$ & $16.55 \%$ & $16.45 \%$ & \\
734 & & $15.21 \%$ & $17.58 \%$ & $15.11 \%$ & $18.17 \%$ & \\
701 & & $3.04 \%$ & $4.66 \%$ & $4.79 \%$ & $4.99 \%$ & \\
801 & & $5.51 \%$ & $7.21 \%$ & $8.40 \%$ & $8.50 \%$ & \\
900 & & $10.53 \%$ & $12.29 \%$ & $13.90 \%$ & $12.32 \%$ & \\
1060 & & $18.89 \%$ & $19.55 \%$ & $21.19 \%$ & $21.56 \%$ & \\
& & & & & \\
\hline Average & $10.50 \%$ & $11.38 \%$ & $13.31 \%$ & $13.98 \%$ & $13.78 \%$ & $12.59 \%$ \\
Minimum & $-0.88 \%$ & $3.04 \%$ & $4.66 \%$ & $4.79 \%$ & $4.99 \%$ & $7.22 \%$ \\
Maximum & $16.48 \%$ & $18.89 \%$ & $19.83 \%$ & $21.19 \%$ & $21.56 \%$ & $20.55 \%$ \\
& & & & & \\
\hline
\end{tabular}


Effects of Foaming Temperature on Mass Loss

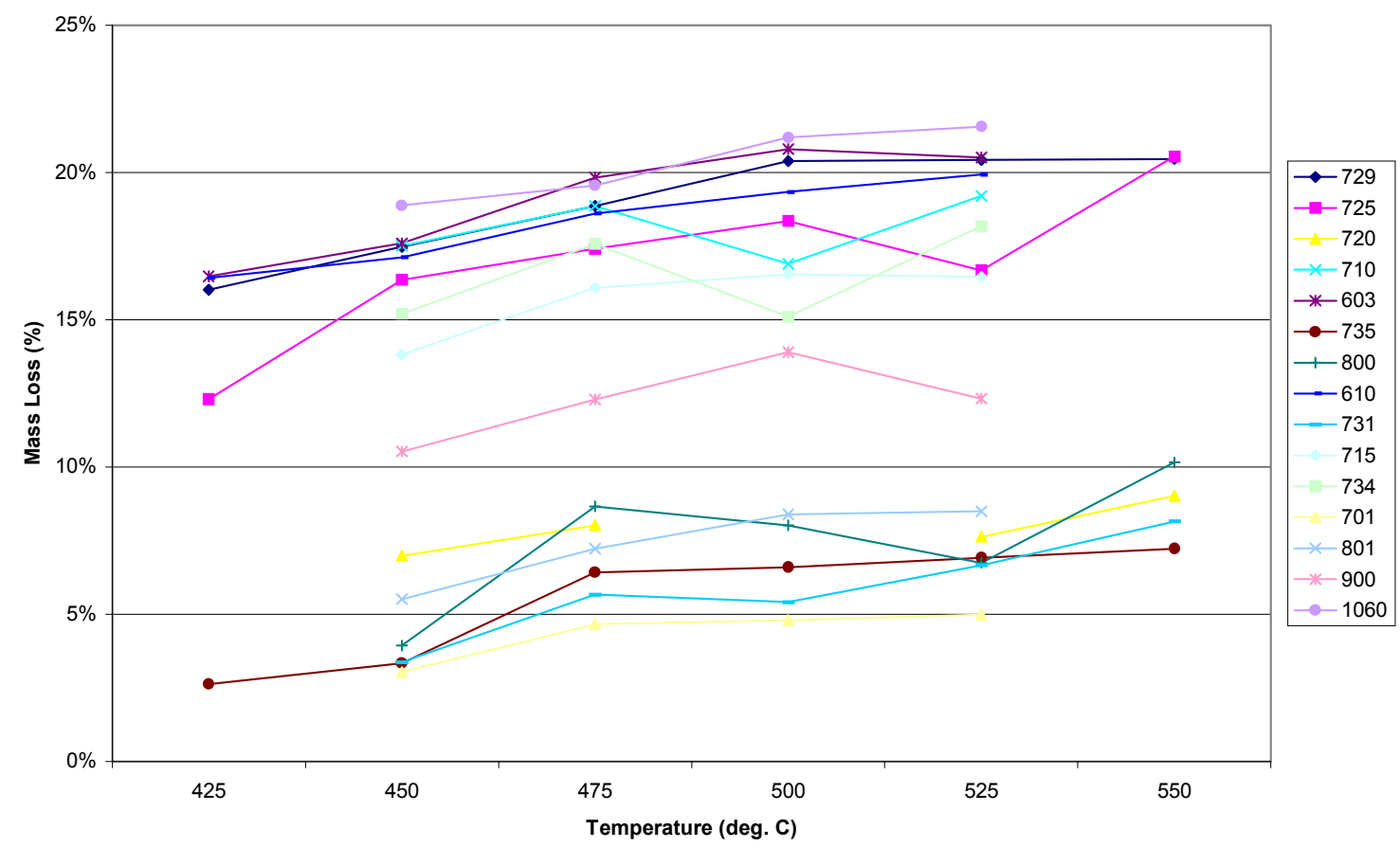

Figure 10. Mass loss with processing temperature for different precursors (at 500 psi)

Some precursors, especially (1) those forming superior foams over then entire process temperature range (e.g. 603, 610, 729, and POW), and (2) those having little foaming potential at 500 psi over this temperature range, were processed at lower pressures. Table 8 shows a partially-completed table of foaming mass losses with various temperature and pressure combinations. Table 9 shows the bulk densities of foams produced from all coals considered during this study at 500 psi foaming pressure and over a range of foaming temperatures, after calcining to $1050^{\circ} \mathrm{C}$ to equalize the completeness of mass loss. As low density is one of the prime "selling points" for carbon foams, a few precursors were selected at this point for further study, simply based upon (1) ease of raw material handling and mold loading, (2) ease of foaming, and (3) low foam bulk density. The calcined foam bulk density data are also graphically presented in Figure 11. Most foams are also intended for sale/use at the calcined stage, where their compressive strength is near peak and their thermal insulation and fire protection performance is maximized. For this reason, calcined foam compressive strength was also used to select promising coals for further study. Table 10 presents compressive strengths of the same calcined foams. 
Table 8. Mass losses of coals foamed at their "optimum" temperature and at different reactor pressures

\begin{tabular}{|c|c|c|c|c|c|c|c|}
\hline \multirow[b]{2}{*}{ Precursor } & \multirow{2}{*}{$\begin{array}{c}\text { Foaming } \\
\text { Temperature }(C)\end{array}$} & \multicolumn{6}{|c|}{ Foaming Pressure (psi) } \\
\hline & & 0 & 100 & 200 & 300 & 400 & 500 \\
\hline 729 & & & $18.98 \%$ & $18.07 \%$ & & & $18.86 \%$ \\
\hline 725 & N/A & & & & & & \\
\hline 720 & N/A & & & & & & \\
\hline 710 & N/A & & & & & & \\
\hline 603 & 475 & & $25.19 \%$ & $25.20 \%$ & $25.33 \%$ & & $24.66 \%$ \\
\hline 735 & & $5.92 \%$ & & & & & \\
\hline 800 & 500 & $8.54 \%$ & & & & & $5.80 \%$ \\
\hline 610 & 475 & & $24.12 \%$ & $25.42 \%$ & $25.51 \%$ & & $25.15 \%$ \\
\hline 731 & 500 & $5.88 \%$ & & & & & $4.79 \%$ \\
\hline 715 & N/A & & & & & & \\
\hline 734 & N/A & & & & & & \\
\hline 701 & N/A & & & & & & \\
\hline 801 & N/A & & & & & & \\
\hline 900 & N/A & & & & & & \\
\hline 1060 & N/A & & & & & & \\
\hline
\end{tabular}

Table 9. Foam bulk densities after foaming at 500 psi over a range of temperatures; foams selected for further study are shown in red

\begin{tabular}{c|cccccc}
\cline { 2 - 7 } & \multicolumn{6}{c}{ Foam Bulk Density at 500 psi pressure } \\
Precursor & 425 & 450 & 475 & 500 & 525 & 550 \\
\hline & & & & & & \\
729 & $\mathbf{0 . 6 8 7}$ & $\mathbf{0 . 5 3 1}$ & $\mathbf{0 . 5 1 2}$ & $\mathbf{0 . 4 8 9}$ & $\mathbf{0 . 4 8 3}$ & $\mathbf{0 . 4 5 5}$ \\
725 & 1.224 & 0.817 & 0.758 & 0.597 & 0.581 & 0.556 \\
720 & & & & & & \\
710 & & 0.668 & 0.526 & 0.472 & 0.449 & \\
$\mathbf{6 0 3}$ & $\mathbf{0 . 6 4 8}$ & $\mathbf{0 . 5 1 5}$ & $\mathbf{0 . 4 3 7}$ & $\mathbf{0 . 4 0 5}$ & $\mathbf{0 . 3 9 3}$ & \\
735 & & 1.373 & 0.588 & 0.573 & 0.551 & 0.526 \\
$\mathbf{8 0 0}$ & $\mathbf{1 . 1 1 3}$ & $\mathbf{1 . 2 9 0}$ & $\mathbf{0 . 5 4 8}$ & $\mathbf{0 . 5 0 5}$ & $\mathbf{0 . 4 7 1}$ & $\mathbf{0 . 4 7 1}$ \\
$\mathbf{6 1 0}$ & $\mathbf{0 . 5 5 2}$ & $\mathbf{0 . 4 5 7}$ & $\mathbf{0 . 4 0 8}$ & $\mathbf{0 . 3 5 3}$ & $\mathbf{0 . 3 4 4}$ & \\
731 & & 1.136 & 1.221 & 0.749 & 0.631 & 0.613 \\
715 & & 1.085 & 1.149 & 1.089 & 1.049 & \\
734 & & & & & & \\
701 & & & & & & \\
801 & & & & 0.985 & 1.029 & \\
$\mathbf{9 0 0}$ & & $\mathbf{0 . 6 6 1}$ & $\mathbf{0 . 5 6 3}$ & $\mathbf{0 . 4 9 7}$ & $\mathbf{0 . 4 7 4}$ & \\
$\mathbf{1 0 6 0}$ & & $\mathbf{0 . 4 6 2}$ & $\mathbf{0 . 4 1 3}$ & $\mathbf{0 . 3 9 2}$ & $\mathbf{0 . 3 6 8}$ & \\
& & & & & & \\
\hline Average & 0.845 & 0.818 & 0.648 & 0.592 & 0.568 & 0.524 \\
Minimum & 0.552 & 0.457 & 0.408 & 0.353 & 0.344 & 0.455 \\
Maximum & 1.224 & 1.373 & 1.221 & 1.089 & 1.049 & 0.613 \\
\hline
\end{tabular}


Calcined Foam Bulk Density

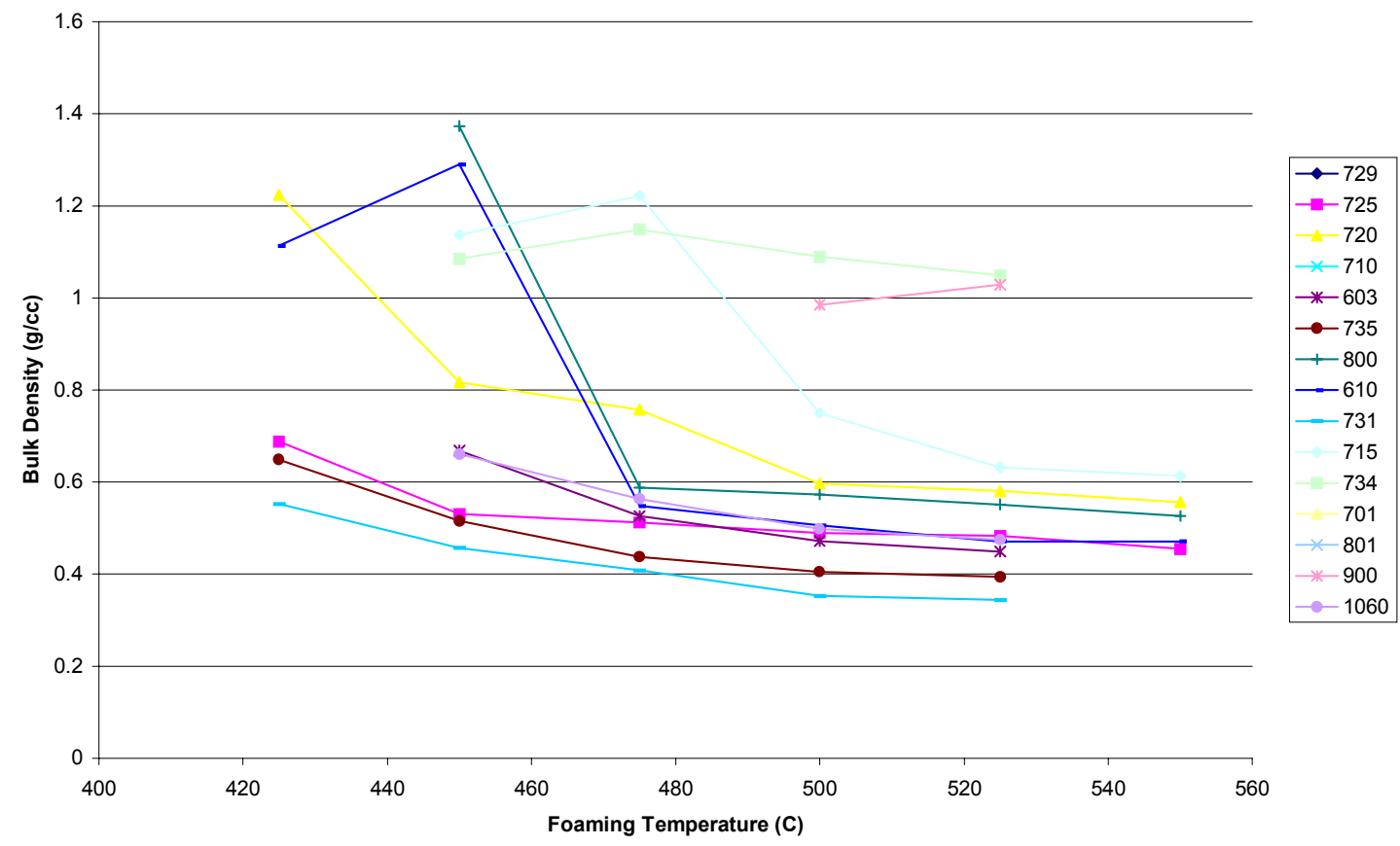

Figure 11. Bulk densities of foams, after calcining, produced from different precursors and at different foaming temperatures

Table 10. Compressive strengths of calciend foams

\begin{tabular}{|c|c|c|c|c|c|c|}
\hline \multirow[b]{2}{*}{ Precursor } & \multicolumn{6}{|c|}{ Calcined Foam Strength at 500 psi pressure } \\
\hline & 425 & 450 & 475 & 500 & 525 & 550 \\
\hline 729 & 3318 & 2058 & 1828 & 1512 & 1472 & 1001 \\
\hline 725 & 3821 & 2880 & 3009 & 2750 & 2804 & 2536 \\
\hline 720 & & & & & & \\
\hline 710 & & 3013 & 1320 & 2027 & 1603 & \\
\hline 603 & 2361 & 2999 & 1800 & 1458 & 1269 & \\
\hline 735 & & 3595 & 4145 & 3816 & 3200 & 2447 \\
\hline 800 & 1138 & 4960 & 4142 & 3228 & 2381 & 2431 \\
\hline 610 & 2169 & 1349 & 886 & 632 & 679 & \\
\hline 731 & & 1448 & 7464 & 3762 & 4682 & 4182 \\
\hline 715 & & 1292 & 3758 & 4502 & 4522 & \\
\hline 734 & & & & & & \\
\hline 701 & & & & & & \\
\hline 801 & & & & 190 & 399 & \\
\hline 900 & & 4623 & 2881 & 2393 & 2071 & \\
\hline 1060 & & 2022 & 1340 & 1169 & 1136 & \\
\hline Average & 2561 & 2749 & 2961 & 2287 & 2185 & 2519 \\
\hline Minimum & 1138 & 1292 & 886 & 190 & 399 & 1001 \\
\hline Maximum & 3821 & 4960 & 7464 & 4502 & 4682 & 4182 \\
\hline
\end{tabular}




\section{TASK 4.0 CHARACTERIZATION OF "GREEN" FOAMS, AND TASK 5.0 CALCINING}

"Green," or as-foamed, samples were characterized by (1) helium pycnometry, (2) mercury porosimetry, (3) compressive strength, and (4) microscopy. The methods employed and data collected will be described in the following sections.

\section{Compressive Strength/Modulus}

Compression tests were conducted by test method ASTM C365. Touchstone found that compressive strength data was essentially independent of sample geometry down to sample loading surfaces as small as 0.5 -inch square. Such small sizes allowed for multiple samples per test article and more efficient use of test samples. The platen displacement rate was also studied, and a rate of 0.05 inches per minute was settled on as the standard. Load transfer was found to be successfully accomplished by simply attaching $3 \mathrm{M}$ packaging tape to the loaded faces of the foam. This eliminated the need for time-consuming polymer composite or metal facesheet attachment as had been standardized previously.

The following sections summarize the properties of "green" and calcined foams made from each of the coal precursors at a variety of foaming temperature and pressure conditions. The nomenclature used in these tables includes:

Date: date of foam production at Touchstone Research Laboratory, Reactor: $\quad$ Parr Instruments reactors "A" and "B;" they are identical, $\mathrm{P}: \quad$ inert gas (nitrogen) pressure, in psi, T: $\quad$ foaming process temperature, in ${ }^{\circ} \mathrm{C}$, dmf: $\quad$ mass loss during foaming, in $\%$, which may include moisture loss, dlc: dimensional (length) change during calcining, in $\%$ of foam basis, dmc: mass loss during calcining, in $\%$ of foam basis, rf: $\quad$ density ( $\mathrm{r}$ is for $\rho$ ) of "green" foam article, in $\mathrm{g} / \mathrm{cm}^{3}$, rc: $\quad$ density of calcined foam article, in $\mathrm{g} / \mathrm{cm}^{3}$,

Yc: $\quad$ Young's modulus in compression of calcined foam article, in psi, Sc: $\quad$ ultimate strength in compression of calcined foam article, in psi, Yg: $\quad$ Young's modulus in compression of "green" foam article, in psi, Sg: $\quad$ ultimate strength in compression of "green" foam article, in psi,

Discussion of these data, as well as graphical presentations of (1) stress-strain curves, and (2) property changes with foaming temperature and pressure follow the summary table for each coal. In all graphs, the red points indicate calcined foam data, the green indicate "green" foam

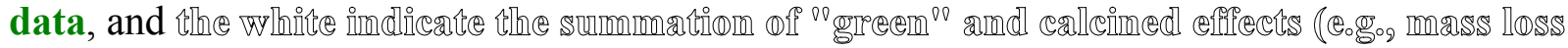
ore lineare shrainolkage). 
CPCPC Final Technical Report

January 2001

\section{Coal}

Table 11. Mechanical and physical properties of "green" and calcined 610 coal

$\begin{array}{cccccccccccccc}\text { Date } & \mathbf{R} & \mathbf{P} & \mathbf{T} & \mathbf{d m f} & \mathbf{d l c} & \mathbf{d m c} & \mathbf{d m} & \mathbf{r f} & \mathbf{r c} & \mathbf{Y c} & \mathbf{S c} & \mathbf{Y g} & \mathbf{S g} \\ & & & & & & & & & & & & & \\ 04 / 17 / 00 & \text { A } & 500 & 425 & 16.43 & -11.89 & 17.17 & 30.77 & 0.4358 & 0.5521 & 1.55 \mathrm{E}+05 & 2169 & 2.69 \mathrm{E}+04 & 353 \\ 04 / 07 / 00 & \text { A } & 500 & 450 & 17.12 & -11.97 & 18.12 & 32.14 & 0.3740 & 0.4569 & 1.03 \mathrm{E}+05 & 1349 & 2.23 \mathrm{E}+04 & 308 \\ 04 / 06 / 00 & \text { A } & 500 & 475 & 18.61 & -11.39 & 15.19 & 30.97 & 0.3418 & 0.4083 & 9.20 \mathrm{E}+04 & 886 & 2.72 \mathrm{E}+04 & 371 \\ 04 / 03 / 00 & \text { A } & 500 & 500 & 19.33 & -11.12 & 12.69 & 29.57 & 0.2650 & 0.3525 & 5.19 \mathrm{E}+04 & 632 & 1.73 \mathrm{E}+04 & 210 \\ 04 / 13 / 00 & \text { B } & 500 & 525 & 19.94 & -10.20 & 12.71 & 30.11 & 0.2879 & 0.3442 & 6.76 \mathrm{E}+04 & 679 & 1.47 \mathrm{E}+04 & 299 \\ & & & & & & & & & & & & & \\ 05 / 05 / 00 & \text { A } & 100 & 475 & 18.24 & -10.09 & 11.93 & 27.99 & 0.3558 & 0.3921 & 1.70 \mathrm{E}+04 & 221 & 2.28 \mathrm{E}+04 & 229 \\ 05 / 01 / 00 & \text { A } & 200 & 475 & 20.34 & -10.47 & 13.02 & 30.71 & 0.2967 & 0.3685 & 1.94 \mathrm{E}+04 & 340 & 3.83 \mathrm{E}+03 & 107 \\ 05 / 02 / 00 & \text { A } & 300 & 475 & & -11.31 & 15.79 & & 0.3600 & 0.4338 & 6.95 \mathrm{E}+04 & 846 & 1.40 \mathrm{E}+04 & 221 \\ 04 / 06 / 00 & \text { A } & 500 & 475 & 18.61 & -11.39 & 15.19 & 30.97 & 0.3418 & 0.4083 & 9.20 \mathrm{E}+04 & 886 & 2.72 \mathrm{E}+04 & 371\end{array}$

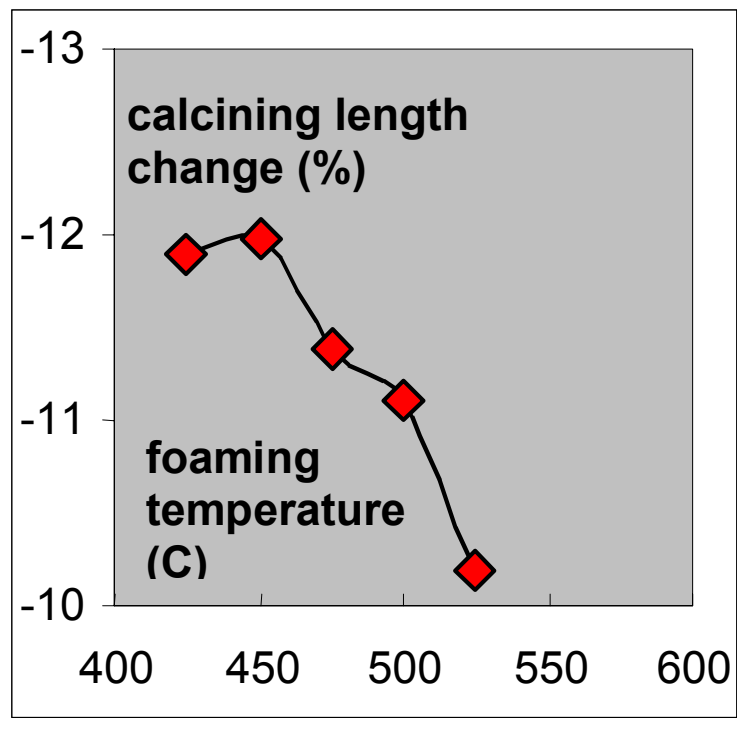

Figure 12. Calcining length change with foaming temperature (610)

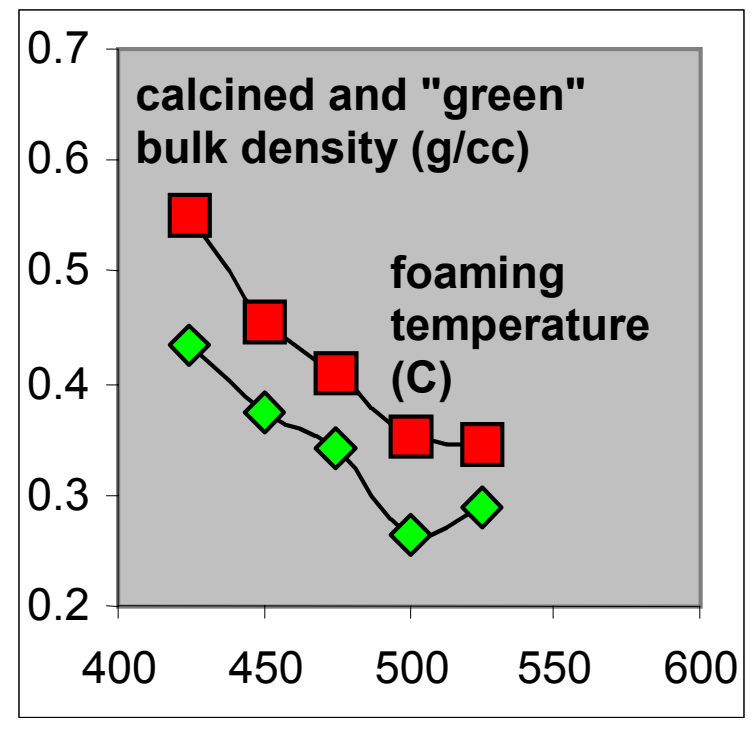

Figure 13. Bulk density (calcined and "green") with foaming temperature (610) 


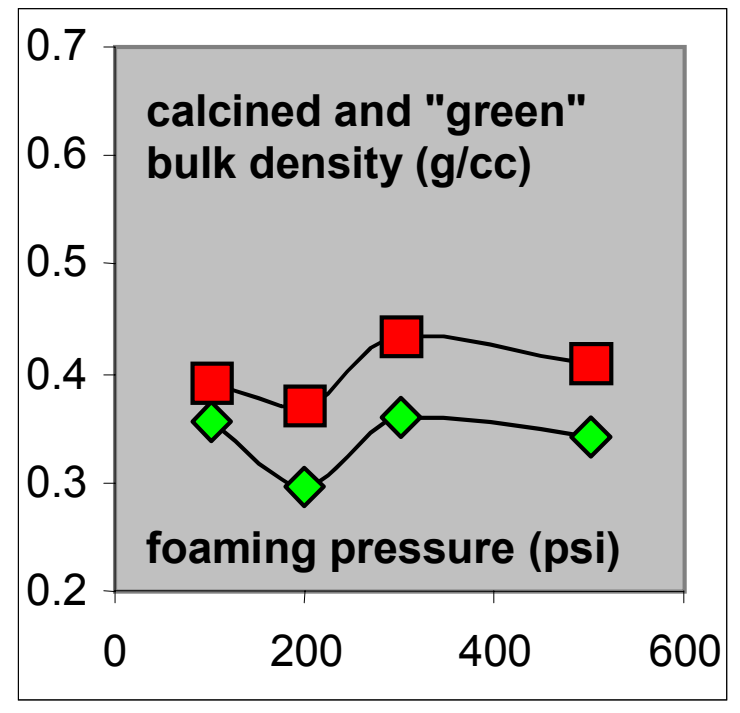

Figure 14. Bulk density (calcined and "green") with foaming pressure (610)

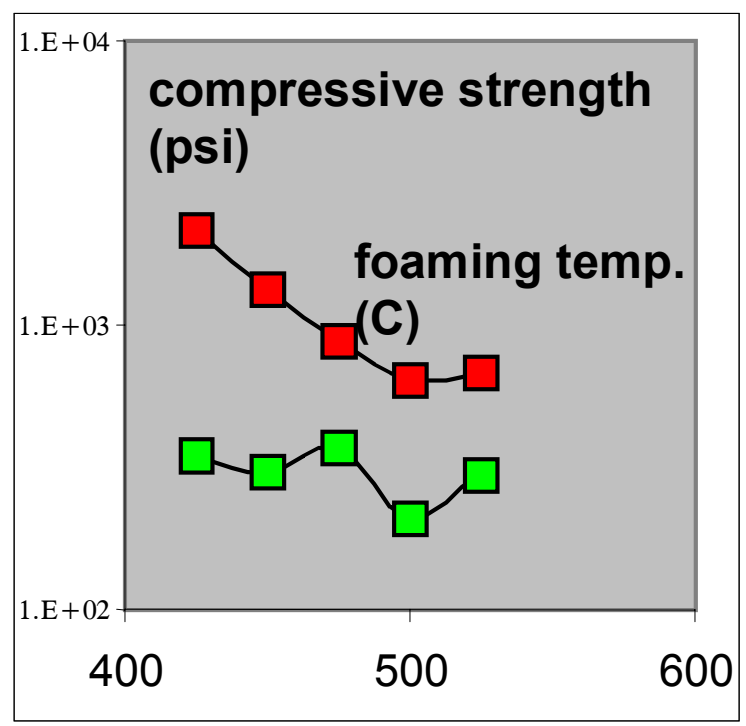

Figure 16. Compressive strength (calcined and "green") with foaming temperature (610)

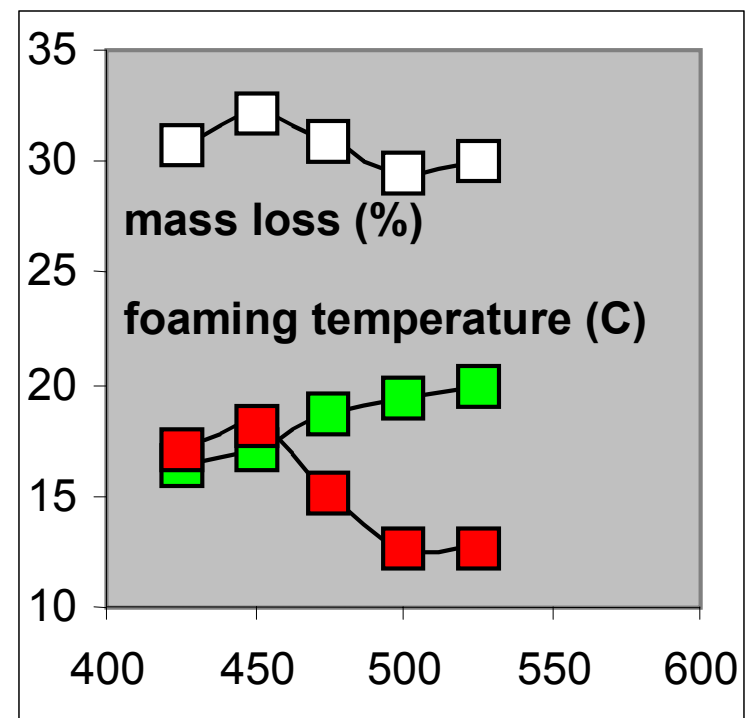

Figure 15. Mass loss (calcined, "green," and total) with foaming temperature (610)

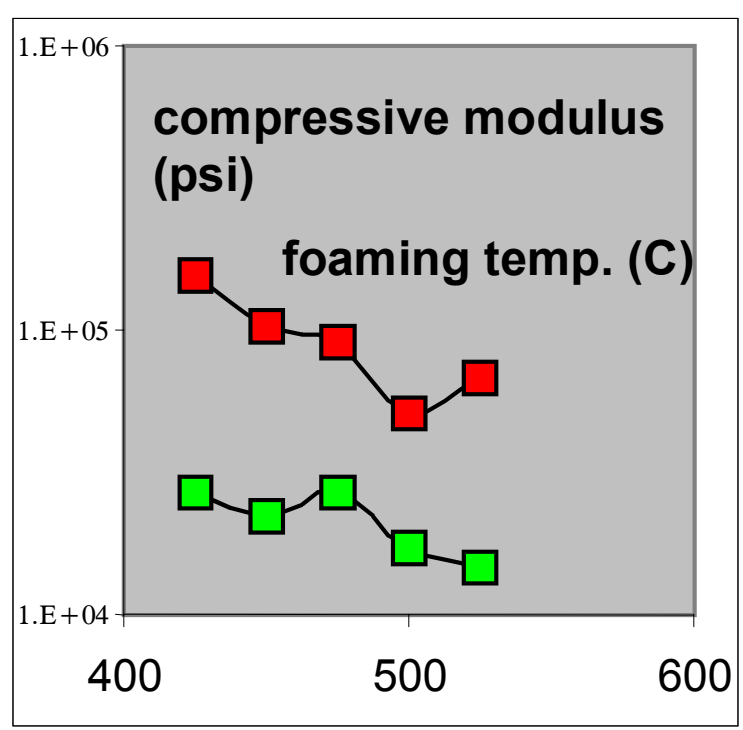

Figure 17. Compressive modulus (calcined and "green") with foaming temperature (610) 


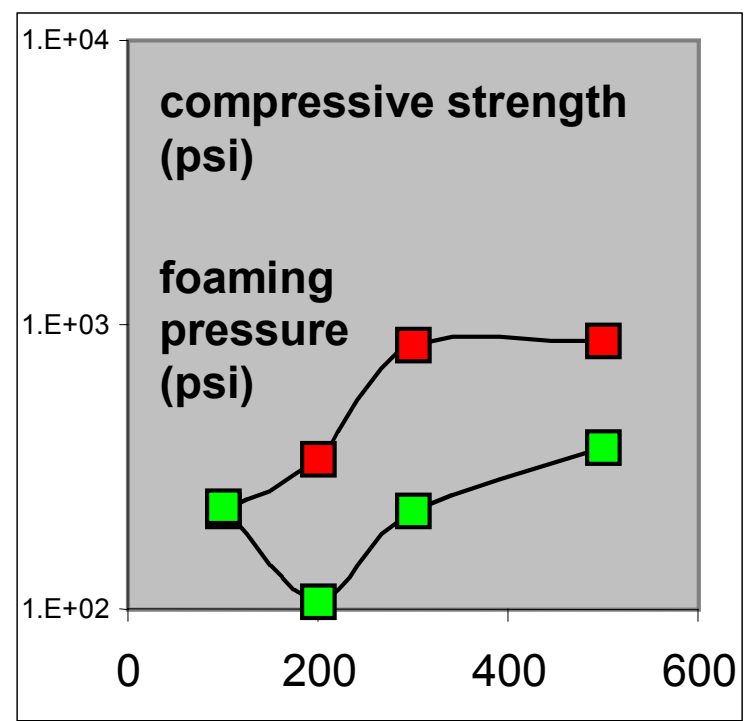

Figure 18. Compressive strength (calcined and "green") with foaming pressure(610)

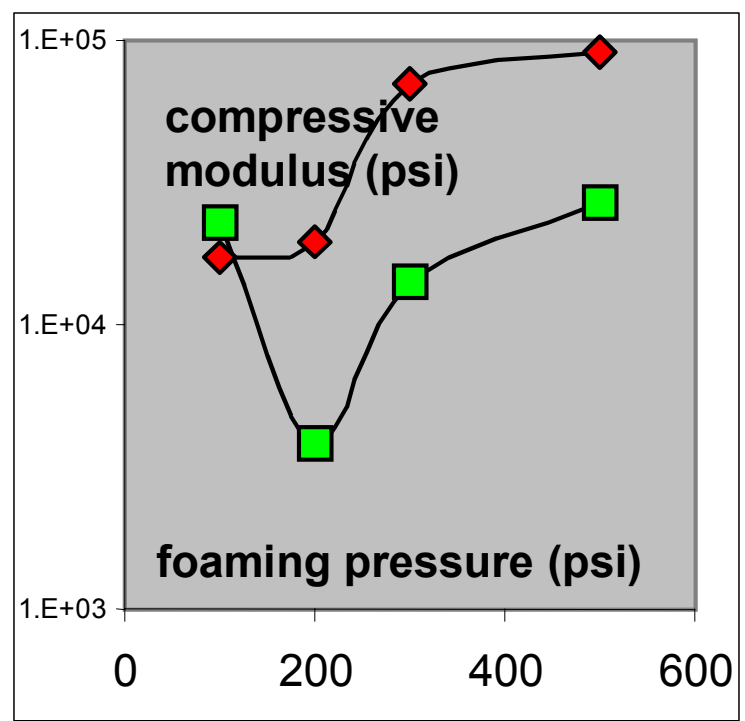

Figure 19. Compressive modulus (calcined and "green") with foaming pressure (610)

\section{$\underline{1060 \text { Coal }}$}

Table 12. Mechanical and physical properties of "green" and calcined 1060 coal, which is simply another shipment of 610 coal that was mislabeled

\begin{tabular}{|c|c|c|c|c|c|c|c|c|c|c|c|c|c|}
\hline Date & R & P & T & dmf & dlc & dmc & dm & rf & rc & Yc & Sc & Yg & Sg \\
\hline & & & & & & & & & & & & & \\
\hline $04 / 07 / 00$ & A & 500 & 450 & 18.89 & -12.06 & 16.08 & 31.93 & 0.3673 & 0.4621 & $1.34 \mathrm{E}+05$ & 2022 & $1.14 \mathrm{E}+04$ & 401 \\
\hline $04 / 06 / 00$ & A & 500 & 475 & 19.55 & -11.75 & 14.62 & 31.32 & 0.3105 & 0.4130 & $9.71 \mathrm{E}+04$ & 1340 & $1.57 \mathrm{E}+04$ & 374 \\
\hline $04 / 04 / 00$ & A & 500 & 500 & 21.19 & -11.49 & 13.36 & 31.72 & 0.2940 & 0.3916 & $7.23 \mathrm{E}+04$ & 1169 & $1.47 \mathrm{E}+04$ & 359 \\
\hline $04 / 13 / 00$ & B & 500 & 525 & 21.56 & -10.61 & 11.17 & 30.32 & 0.2858 & 0.3678 & $7.65 \mathrm{E}+04$ & 1136 & $1.43 \mathrm{E}+04$ & 381 \\
\hline
\end{tabular}




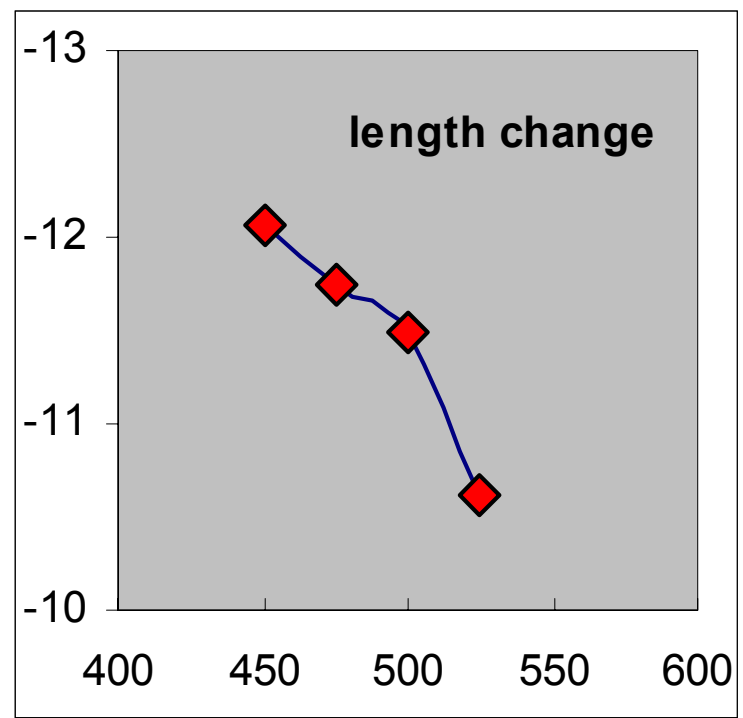

Figure 20. Calcining length change with foaming temperature (1060)

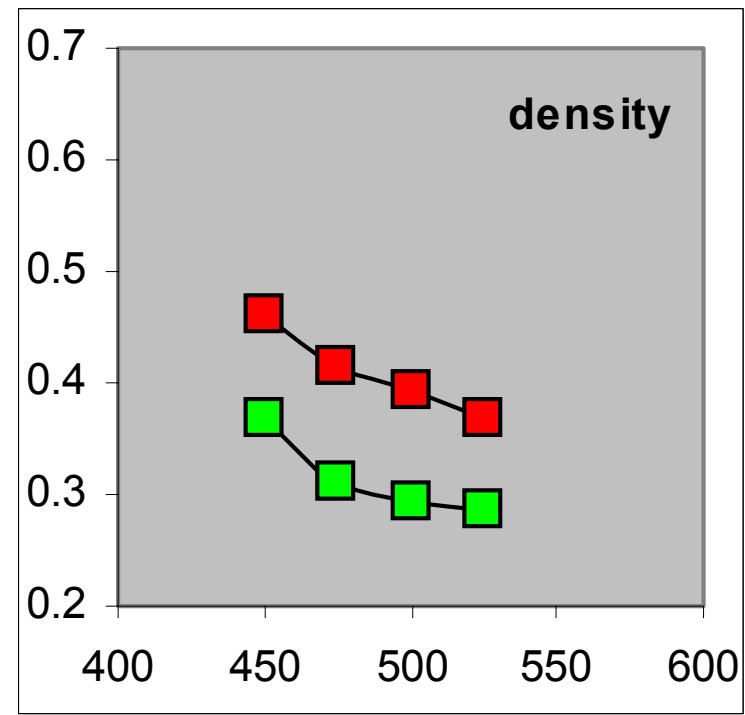

Figure 21. Bulk density (calcined and "green") with foaming temperature (1060)

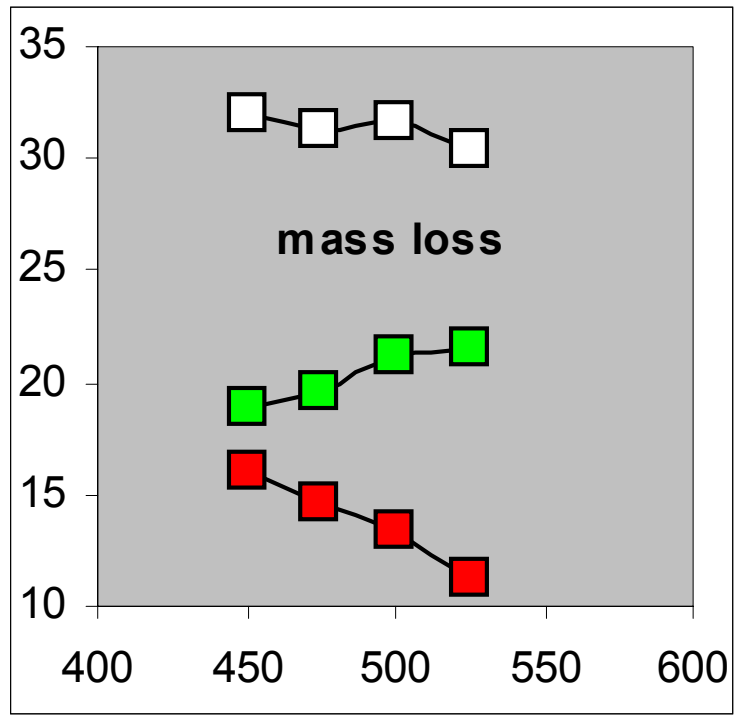

Figure 22. Mass loss (calcined, "green," and total) with foaming temperature (1060) 


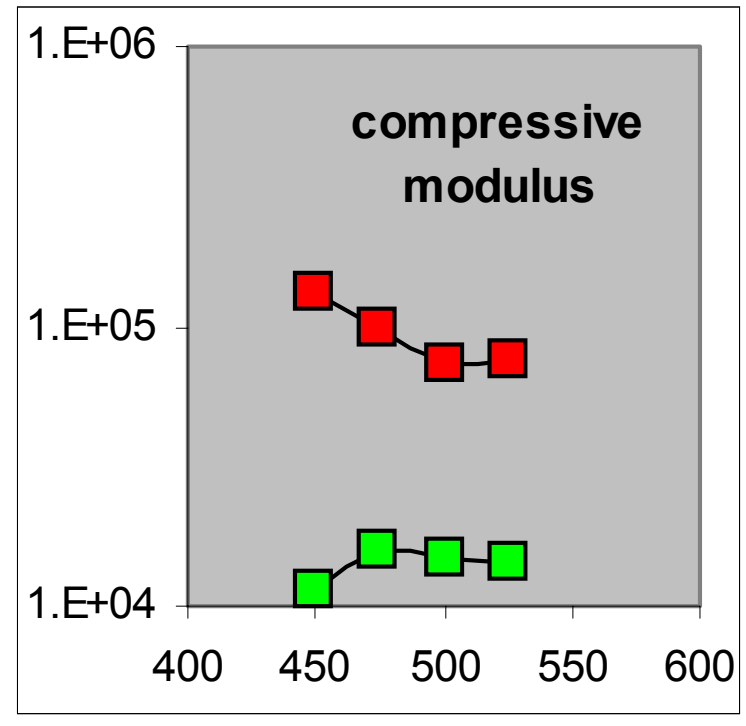

Figure 23. Compressive strength (calcined and "green") with foaming temperature (1060)

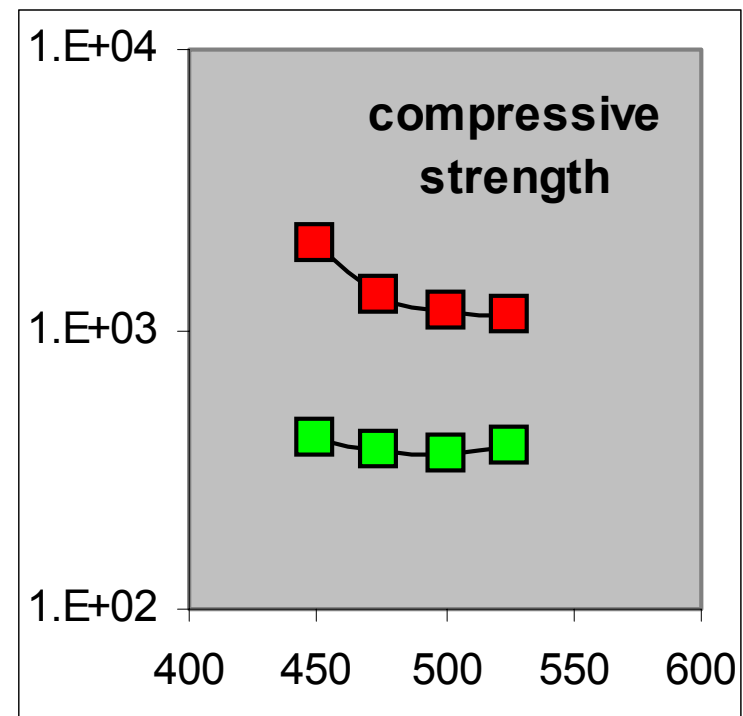

Figure 24. Compressive modulus (calcined and "green") with foaming temperature (1060)

\section{$\underline{603 \text { Coal }}$}

Table 13. Mechanical and physical properties of "green" and calcined 603 coal

$\begin{array}{cccccccccccccc}\text { Date } & \mathbf{R} & \mathbf{P} & \mathbf{T} & \mathbf{d m f} & \mathbf{d l c} & \mathbf{d m c} & \mathbf{d m} & \mathbf{r f} & \mathbf{r c} & \mathbf{Y c} & \mathbf{S c} & \mathbf{Y g} & \mathbf{S g} \\ & & & & & & & & & & & & & \\ 04 / 17 / 00 & \text { A } & 500 & 425 & 16.48 & -12.42 & 17.31 & 30.93 & 0.5157 & 0.6484 & 1.35 \mathrm{E}+05 & 2361 & 6.70 \mathrm{E}+04 & 682 \\ 04 / 10 / 00 & \text { A } & 500 & 450 & 17.59 & -12.17 & 15.60 & 30.44 & 0.3933 & 0.5151 & 1.86 \mathrm{E}+05 & 2999 & 1.98 \mathrm{E}+04 & 476 \\ 04 / 05 / 00 & \text { B } & 500 & 475 & 19.83 & -11.83 & 14.18 & 31.20 & 0.3498 & 0.4366 & 1.09 \mathrm{E}+05 & 1800 & 3.03 \mathrm{E}+04 & 564 \\ 04 / 03 / 00 & \text { B } & 500 & 500 & 20.79 & -11.41 & 12.96 & 31.05 & 0.3263 & 0.4051 & 6.98 \mathrm{E}+04 & 1458 & 2.41 \mathrm{E}+04 & 503 \\ 04 / 14 / 00 & \text { B } & 500 & 525 & 20.51 & -11.21 & 12.13 & 30.15 & 0.3201 & 0.3935 & 8.23 \mathrm{E}+04 & 1269 & 2.16 \mathrm{E}+04 & 459 \\ & & & & & & & & & & & & & \\ 05 / 05 / 00 & \text { A } & 100 & 475 & 22.39 & -10.43 & 11.91 & 31.63 & & 0.6441 & 5.05 \mathrm{E}+04 & 927 & & \\ 05 / 01 / 00 & \text { A } & 200 & 475 & 20.04 & -10.39 & 11.48 & 29.22 & 0.4132 & 0.5292 & 4.65 \mathrm{E}+04 & 784 & 7.00 \mathrm{E}+03 & 205 \\ 05 / 02 / 00 & \text { A } & 300 & 475 & & -11.74 & 15.21 & & 0.3959 & 0.5258 & 1.17 \mathrm{E}+05 & 1440 & 3.24 \mathrm{E}+04 & 395 \\ 04 / 05 / 00 & \text { B } & 500 & 475 & 19.83 & -11.83 & 14.18 & 31.20 & 0.3498 & 0.4366 & 1.09 \mathrm{E}+05 & 1800 & 3.03 \mathrm{E}+04 & 564\end{array}$




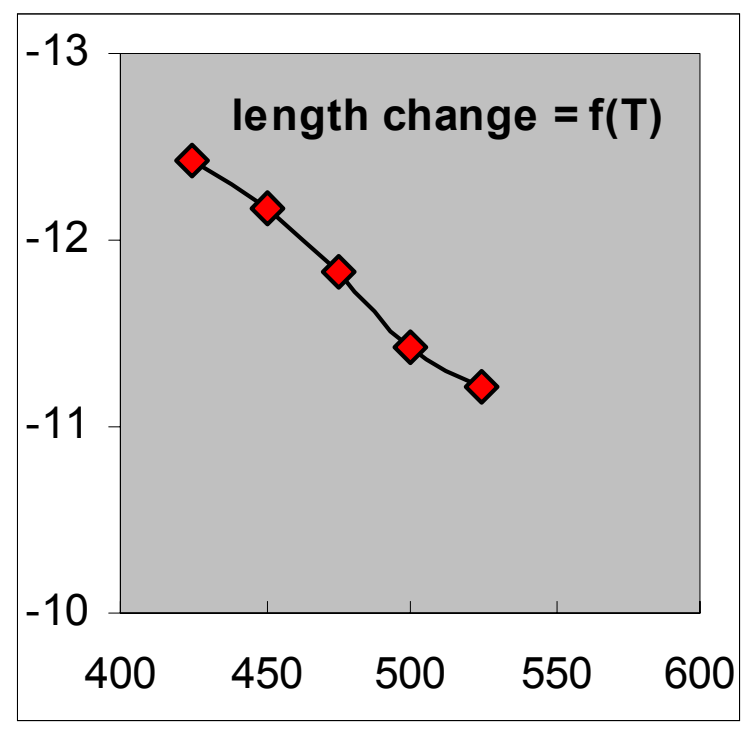

Figure 25. Calcining length change with foaming temperature (603)

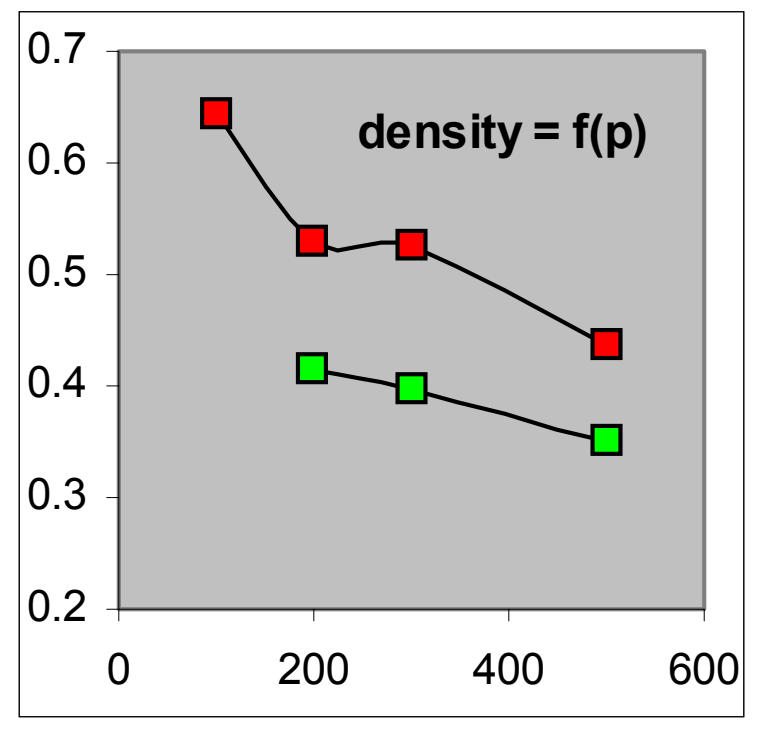

Figure 27. Bulk density (calcined and "green") with foaming pressure (603)

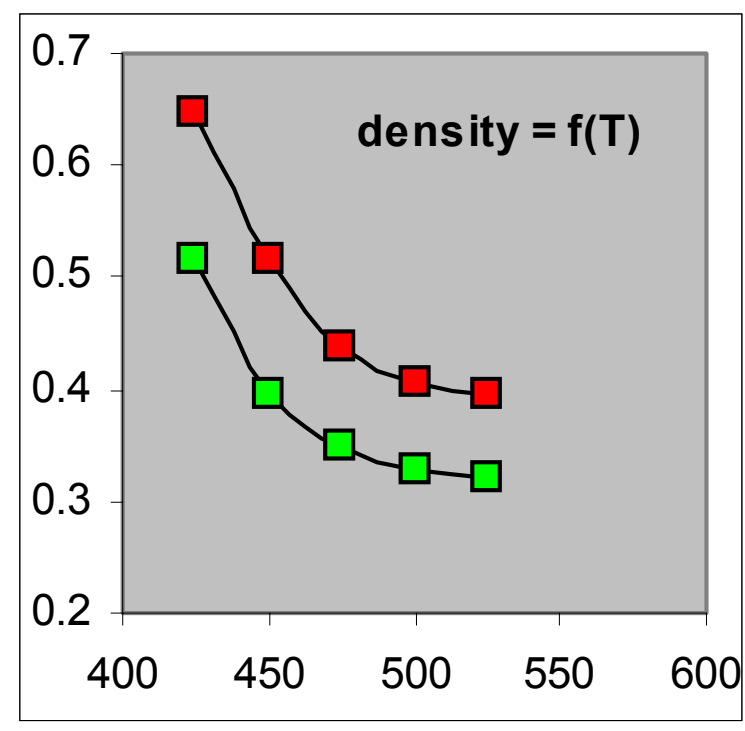

Figure 26. Bulk density (calcined and "green") with foaming temperature (603)

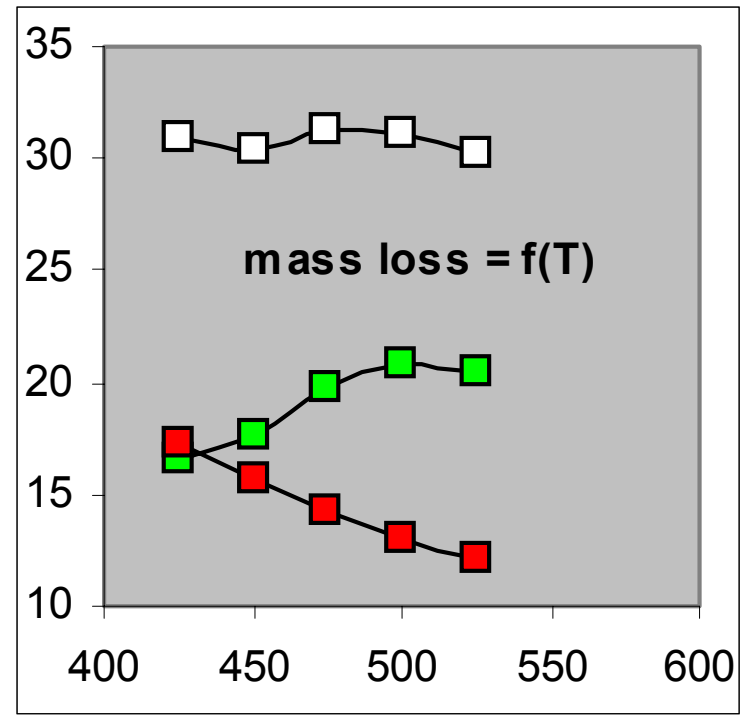

Figure 28. Mass loss (calcined, "green," and total) with foaming temperature (603) 


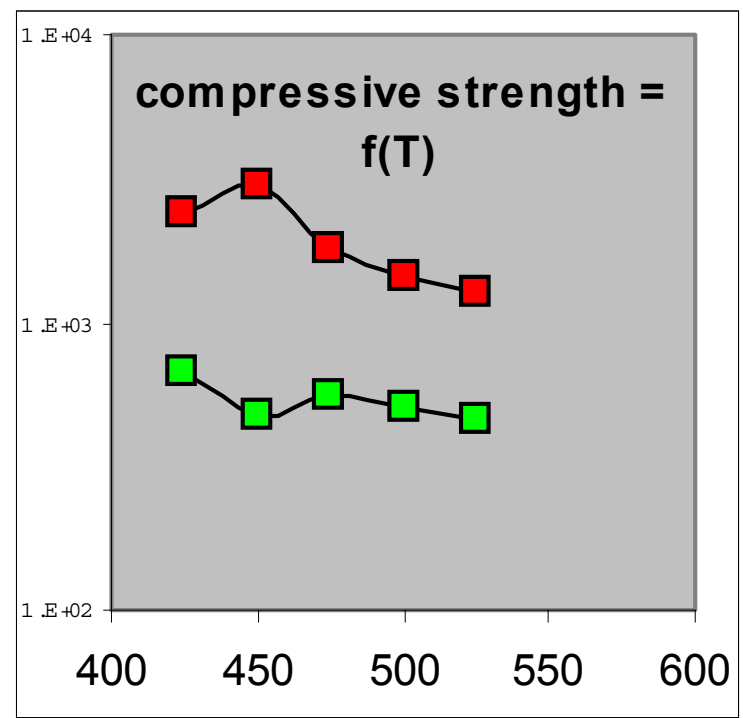

Figure 29. Compressive strength (calcined and "green") with foaming temperature (603)

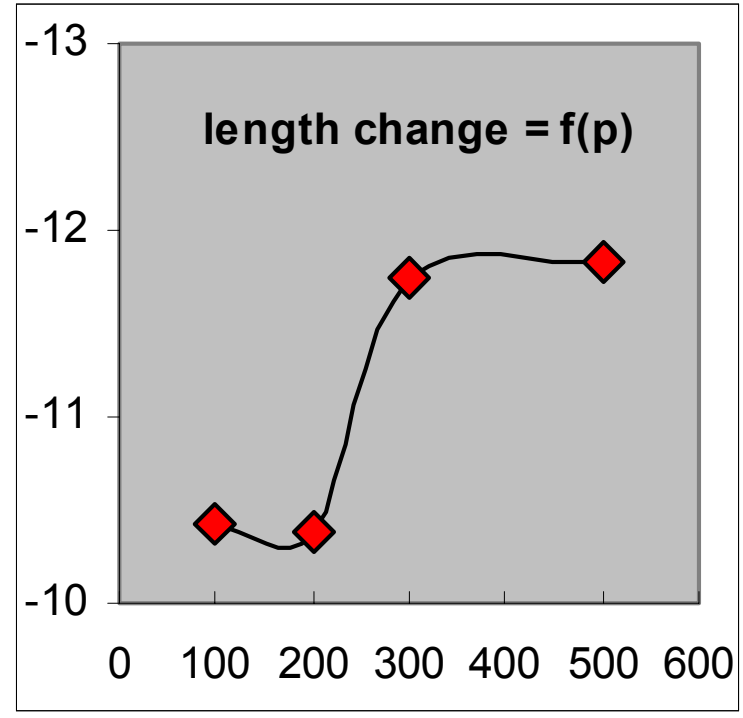

Figure 31. Calcining length change with foaming pressure (603)

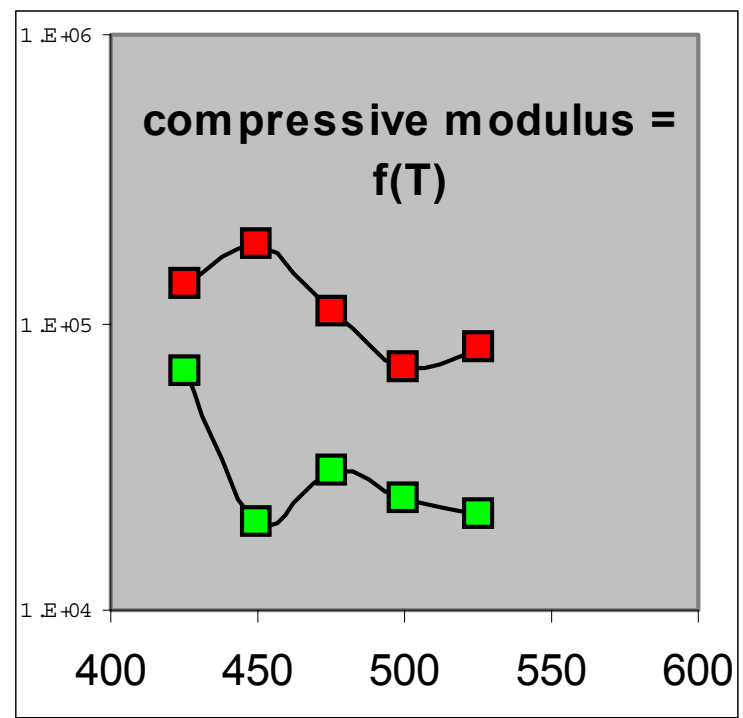

Figure 30. Compressive modulus (calcined and "green") with foaming temperature (603)

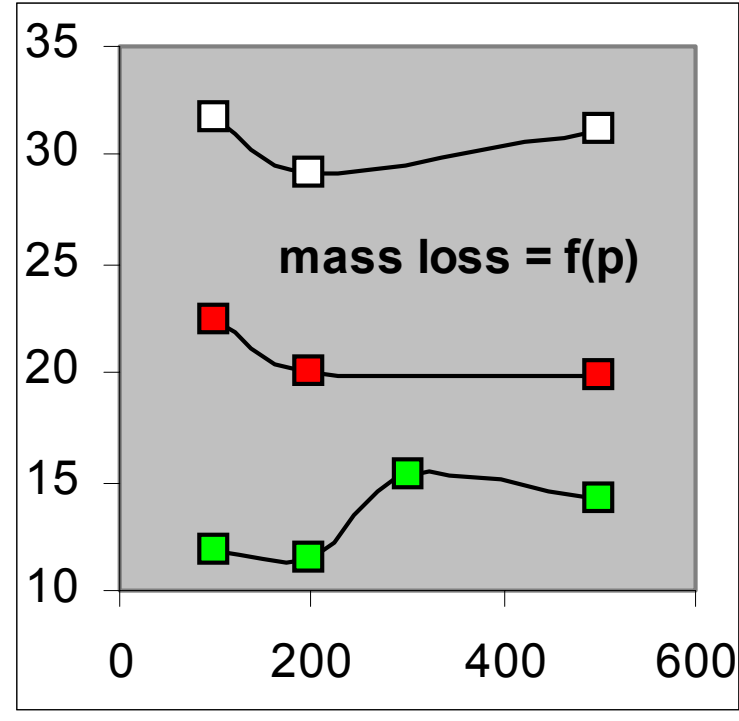

Figure 32. Mass loss (calcined, "green," and total) with foaming pressure (603) 


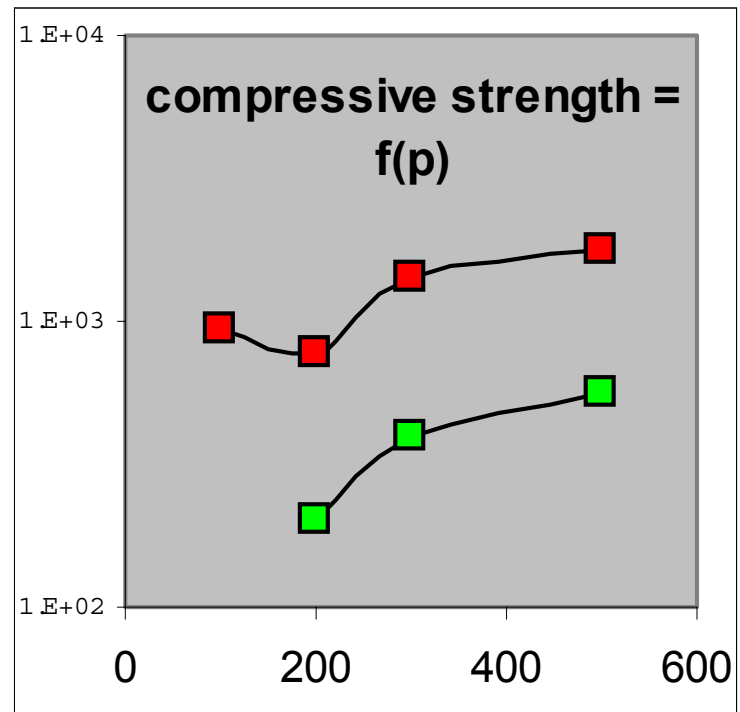

Figure 33. Compressive strength (calcined and "green") with foaming pressure(603)

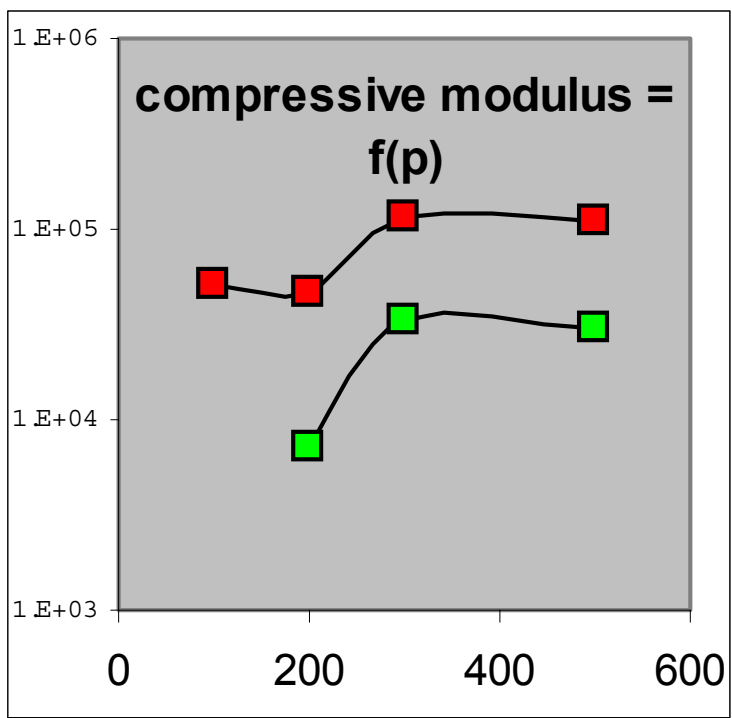

Figure 34. Compressive modulus (calcined and "green") with foaming pressure (603)

\section{$\underline{710 \text { Coal }}$}

Table 14. Mechanical and physical properties of "green" and calcined 710 coal

\begin{tabular}{|c|c|c|c|c|c|c|c|c|c|c|c|c|c|}
\hline Date & R & P & T & dmf & dlc & dmc & dm & rf & rc & Yc & Sc & Yg & Sg \\
\hline & & & & & & & & & & & & & \\
\hline $04 / 10 / 00$ & A & 500 & 450 & 17.52 & -11.56 & 15.78 & 30.53 & 0.5163 & 0.6683 & $2.14 \mathrm{E}+05$ & 3013 & $4.90 \mathrm{E}+04$ & 807 \\
\hline $04 / 05 / 00$ & B & 500 & 475 & 18.86 & -11.04 & 14.06 & 30.27 & 0.4177 & 0.5258 & $9.75 \mathrm{E}+04$ & 1320 & $1.65 \mathrm{E}+04$ & 374 \\
\hline $04 / 03 / 00$ & A & 500 & 500 & 16.91 & -10.77 & 12.68 & 27.44 & 0.3822 & 0.4718 & $1.02 \mathrm{E}+05$ & 2027 & $3.24 \mathrm{E}+04$ & 700 \\
\hline $04 / 14 / 00$ & B & 500 & 525 & 19.21 & -10.74 & 12.21 & 29.07 & 0.3611 & 0.4490 & $1.23 \mathrm{E}+05$ & 1603 & $2.67 \mathrm{E}+04$ & 588 \\
\hline
\end{tabular}




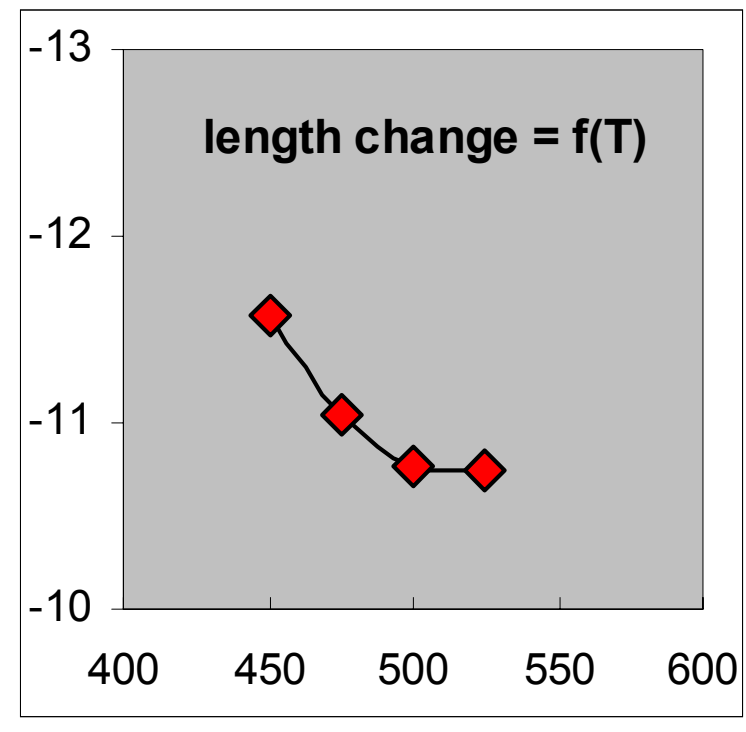

Figure 35. Calcining length change with foaming temperature (710)

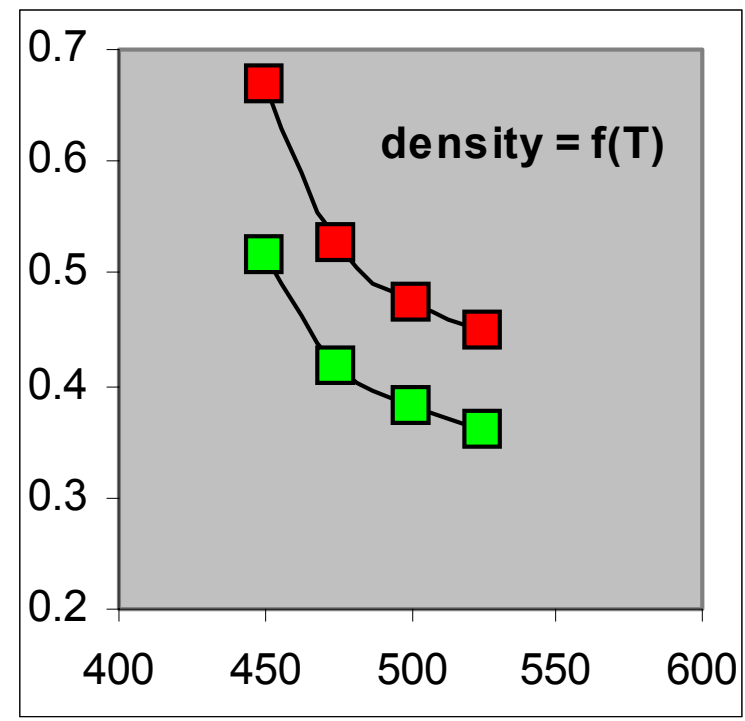

Figure 36. Bulk density (calcined and "green") with foaming temperature (710)

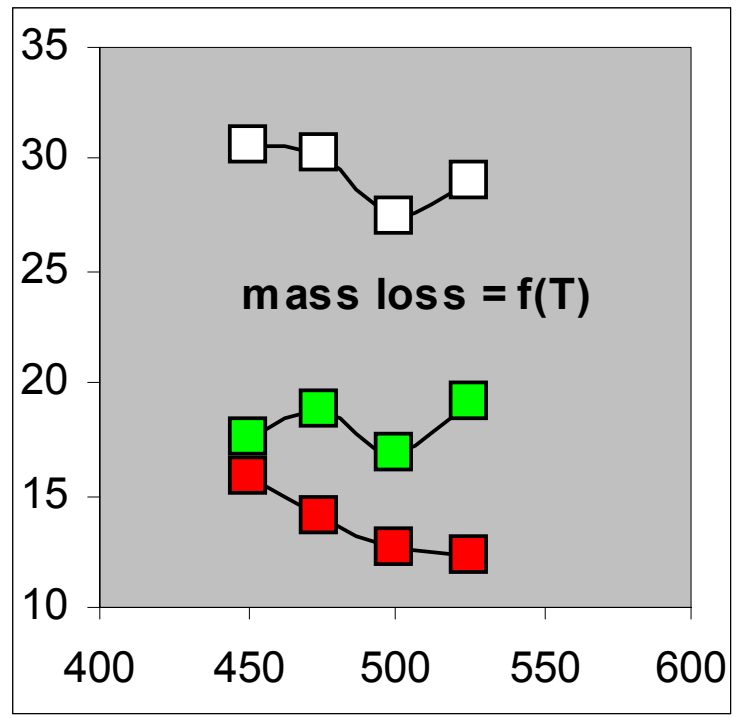

Figure 37. Mass loss (calcined, "green," and total) with foaming temperature (710) 


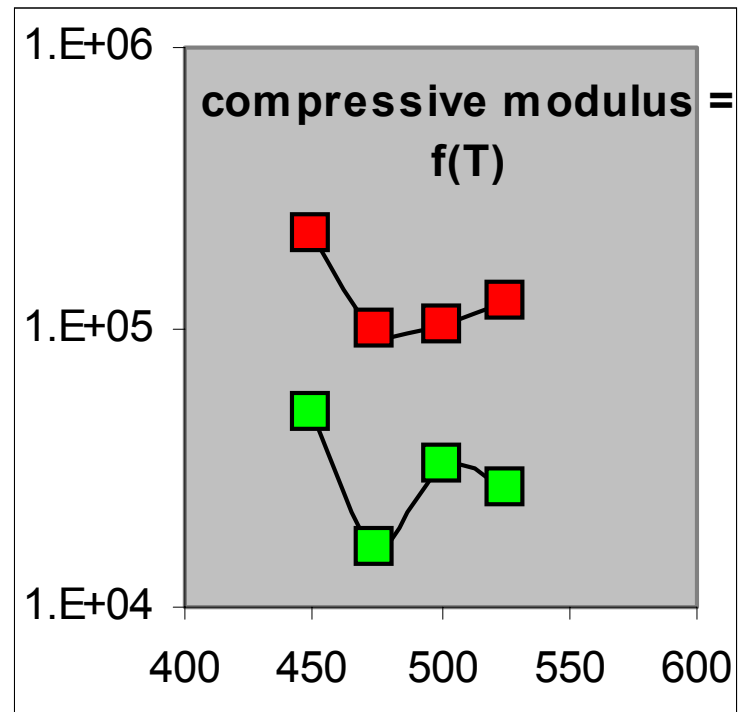

Figure 38. Compressive strength (calcined and "green") with foaming temperature (710)

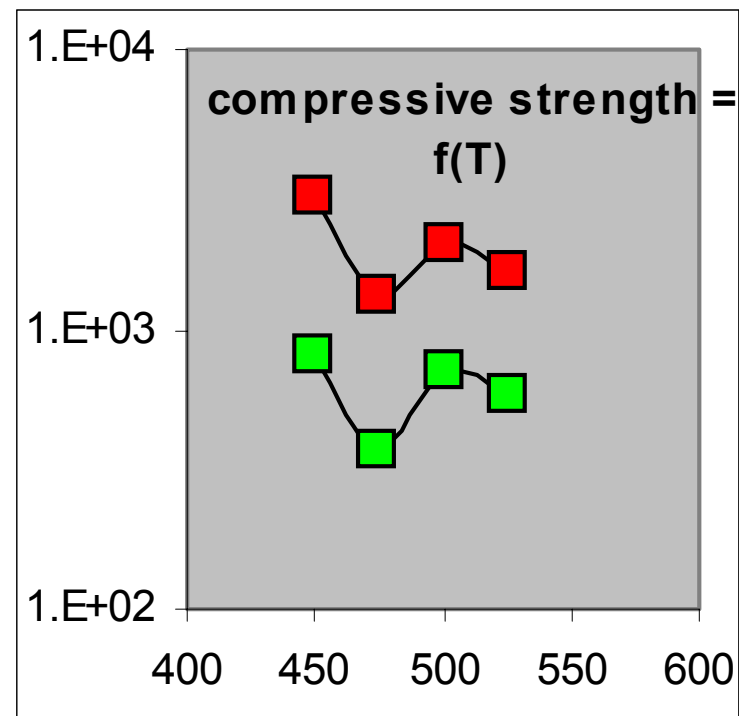

Figure 39. Compressive modulus (calcined and "green") with foaming temperature (710)

\section{Coal}

Table 15. Mechanical and physical properties of "green" and calcined 715 coal

\begin{tabular}{|c|c|c|c|c|c|c|c|c|c|c|c|r|r|}
\hline Date & $\mathbf{R}$ & $\mathbf{P}$ & $\mathbf{T}$ & $\mathbf{d m f}$ & $\mathbf{d l c}$ & $\mathbf{d m c}$ & $\mathbf{d m}$ & $\mathbf{\text { ff }}$ & $\mathbf{r c}$ & Yc & Sc & Yg & Sg \\
\hline & & & & & & & & & & & & & \\
\hline $04 / 14 / 00$ & A & 500 & 450 & 13.82 & -10.55 & 17.49 & 28.89 & 0.9272 & 1.0848 & $3.26 \mathrm{E}+04$ & 1292 & $1.13 \mathrm{E}+04$ & 483 \\
\hline $04 / 05 / 00$ & A & 500 & 475 & 16.08 & -10.36 & 16.38 & 29.82 & 0.9579 & 1.1491 & $1.10 \mathrm{E}+05$ & 3758 & $4.88 \mathrm{E}+04$ & 1728 \\
\hline $04 / 03 / 00$ & B & 500 & 500 & 16.55 & -9.90 & 14.54 & 28.68 & 0.9226 & 1.0890 & $1.20 \mathrm{E}+05$ & 4502 & $8.51 \mathrm{E}+04$ & 2356 \\
\hline $04 / 10 / 00$ & B & 500 & 525 & 16.45 & -9.76 & 14.06 & 28.20 & 0.8946 & 1.0487 & $1.35 \mathrm{E}+05$ & 4522 & $6.12 \mathrm{E}+04$ & 1842 \\
\hline
\end{tabular}




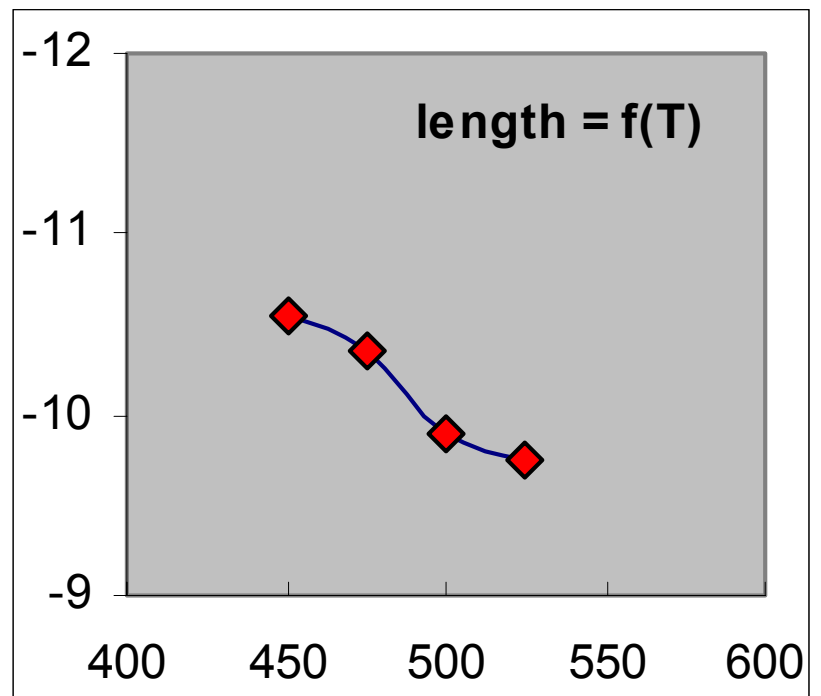

Figure 40. Calcining length change with foaming temperature (715)

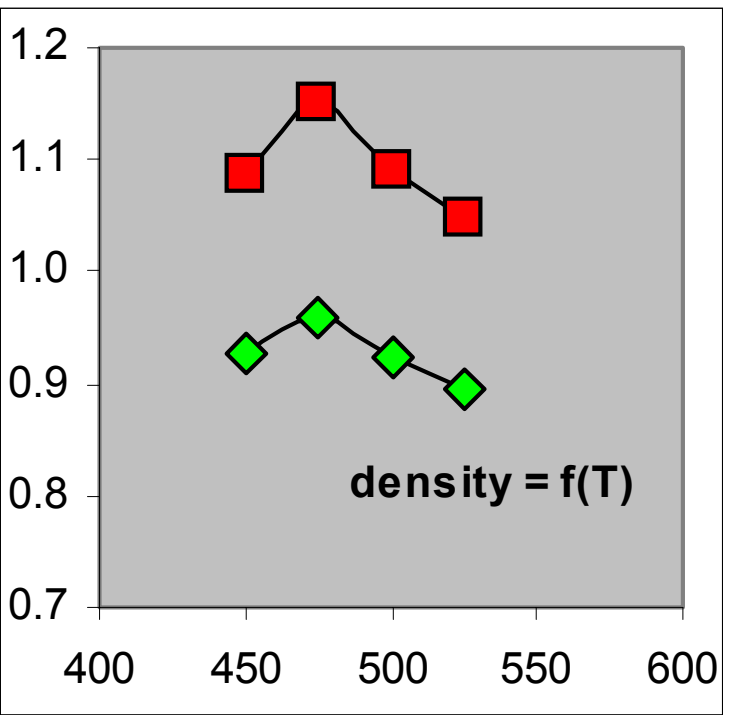

Figure 41. Bulk density (calcined and "green") with foaming temperature (715)

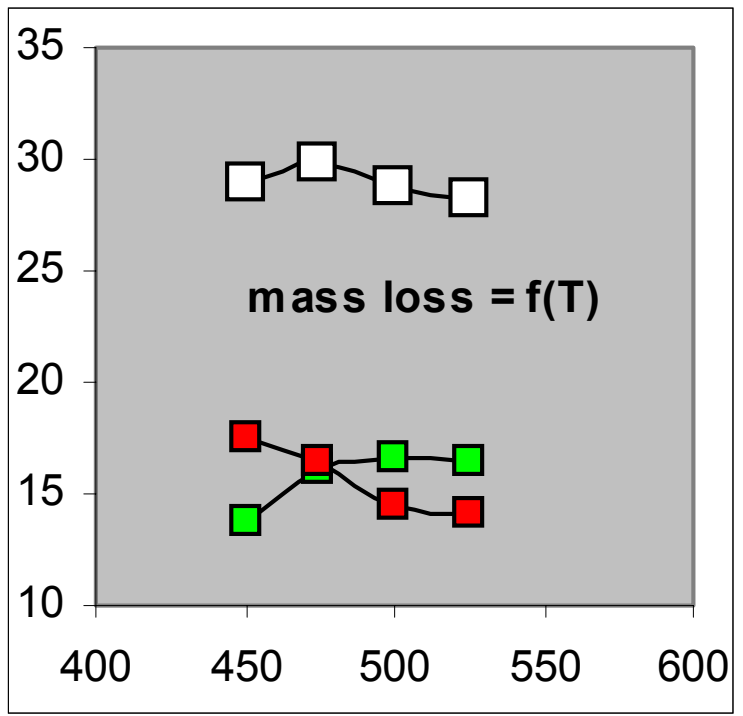

Figure 42. Mass loss (calcined, "green," and total) with foaming temperature (715) 


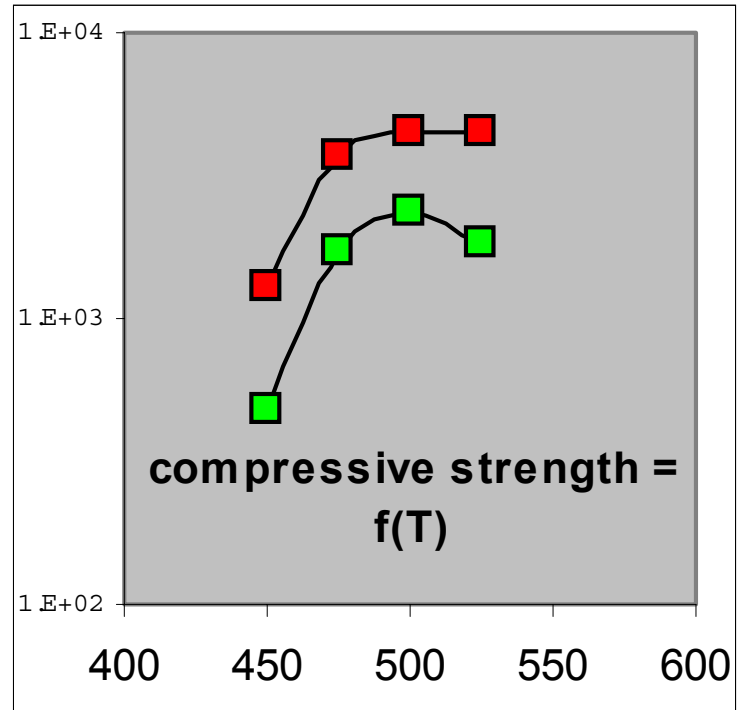

Figure 43. Compressive strength (calcined and "green") with foaming temperature (715)

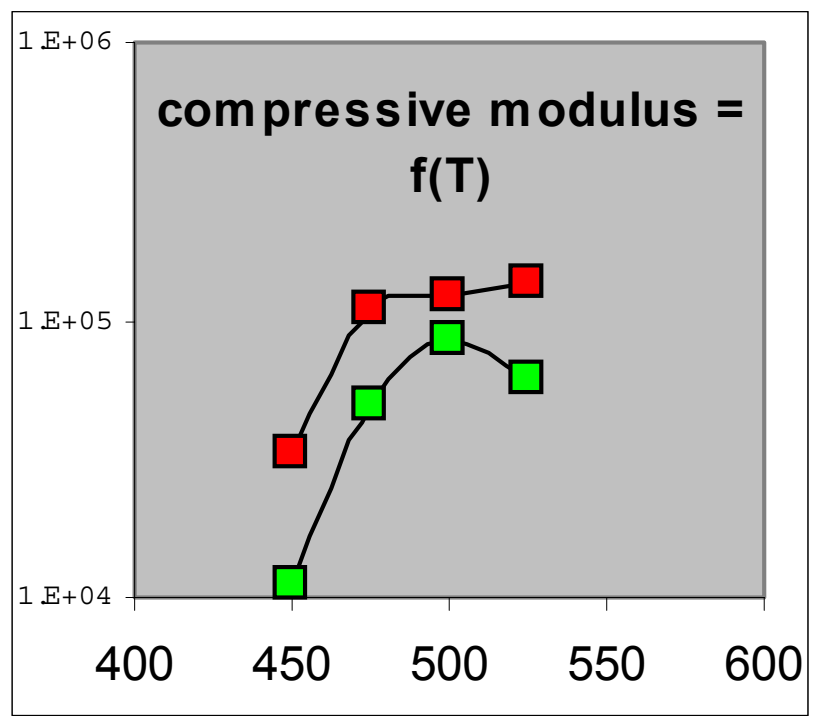

Figure 44. Compressive modulus (calcined and "green") with foaming temperature (715)

\section{$\underline{720 \text { Coal }}$}

No foam was produced from this coal. It did not, under any temperature or pressure combination, sinter fully or produce foam.

\section{$\underline{725 \text { Coal }}$}

Table 16. Mechanical and physical properties of "green" and calcined 725 coal

\begin{tabular}{|c|c|c|c|c|c|c|c|c|c|c|c|c|c|}
\hline Date & $\mathbf{R}$ & $\mathbf{P}$ & $T$ & dmf & dlc & dmc & $\mathrm{dm}$ & $\mathbf{r f}$ & re & Yc & Sc & $\mathbf{Y g}$ & Sg \\
\hline 04 & $\mathrm{~A}$ & 00 & 425 & .31 & 11.16 & 49 & .65 & 50 & 2239 & $1.04 \mathrm{E}+$ & 3821 & $\overline{04}$ & 1383 \\
\hline $04 / 18 / 00$ & $\mathrm{~A}$ & 500 & 450 & 16.36 & -11.13 & 16.20 & 29.91 & 0.6590 & 0.8169 & $1.35 \mathrm{E}+05$ & 2880 & $6.55 \mathrm{E}+04$ & 927 \\
\hline $04 / 19 / 00$ & $\mathrm{~B}$ & 500 & 475 & 17.41 & -10.85 & 14.95 & 29.75 & 0.6304 & 0.7575 & $2.22 \mathrm{E}+05$ & 3009 & $7.76 \mathrm{E}+04$ & 1042 \\
\hline $04 / 18 / 00$ & $\mathrm{~B}$ & 500 & 500 & 18.36 & -10.64 & 14.35 & 30.07 & 0.4781 & 0.5967 & $1.08 \mathrm{E}+05$ & 2750 & $5.28 \mathrm{E}+04$ & 914 \\
\hline $05 / 01 / 00$ & B & 500 & 525 & 16.68 & -9.88 & 11.91 & 26.61 & 0.4721 & 0.5806 & $1.57 \mathrm{E}+05$ & 2804 & $5.63 \mathrm{E}+04$ & 1039 \\
\hline $04 / 27 / 00$ & B & 500 & 550 & 20.06 & -9.28 & 10.48 & 28.43 & 0.4454 & 0.5561 & $1.08 \mathrm{E}+05$ & 2536 & $5.52 \mathrm{E}+04$ & 804 \\
\hline
\end{tabular}




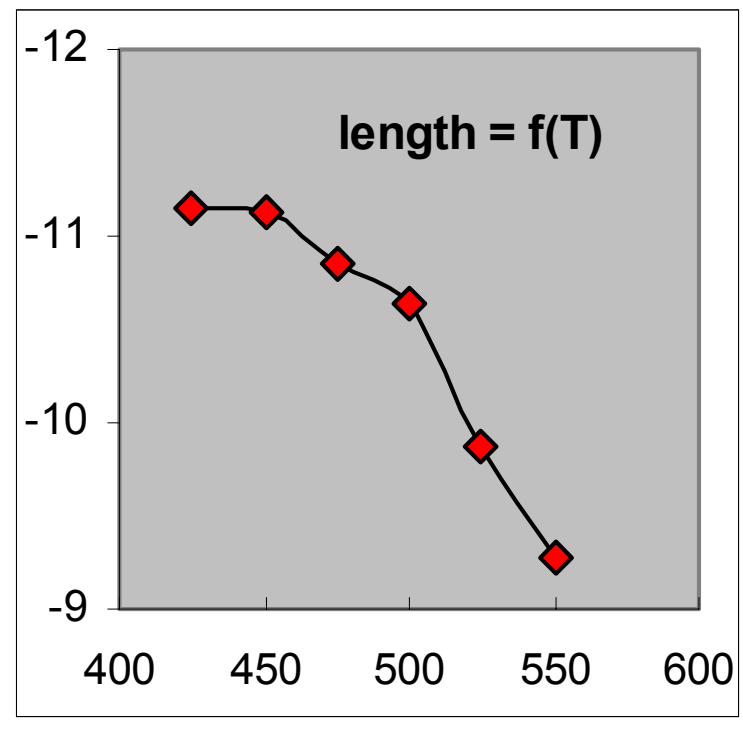

Figure 45. Calcining length change with foaming temperature (725)

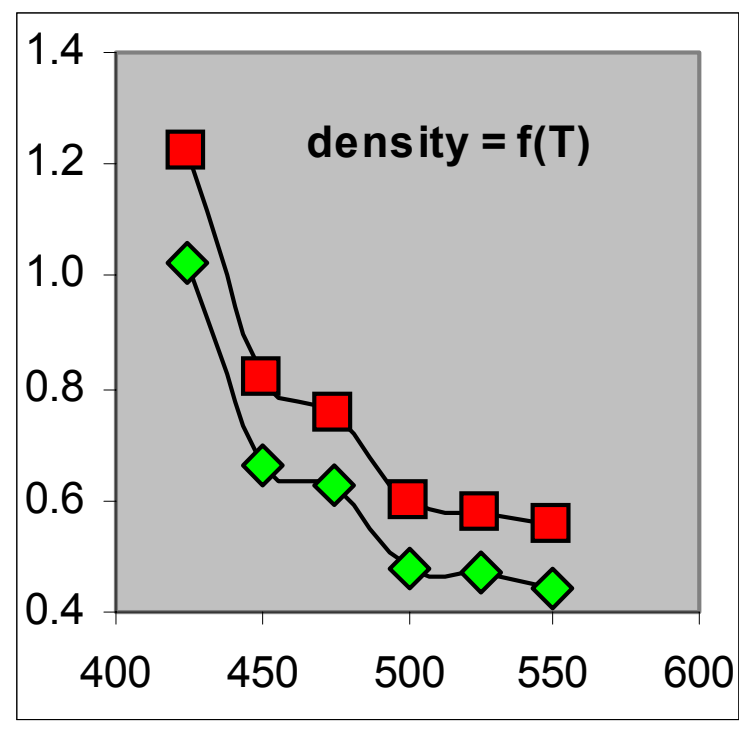

Figure 46. Bulk density (calcined and "green") with foaming temperature (725)

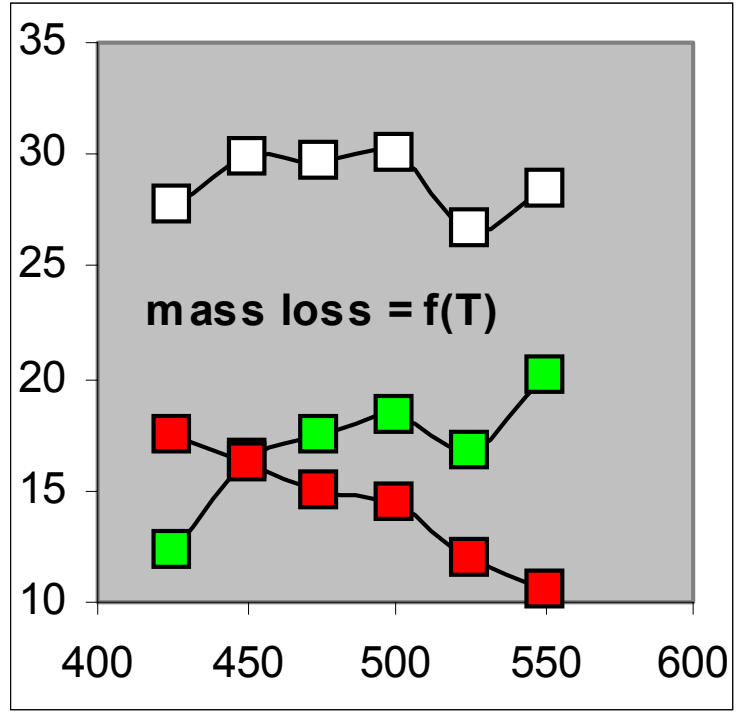

Figure 47. Mass loss (calcined, "green," and total) with foaming temperature (725) 


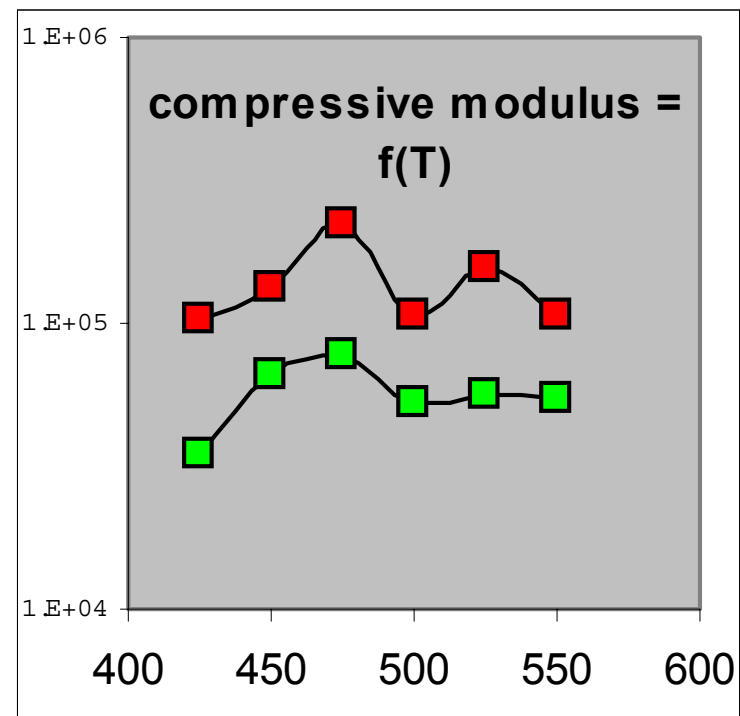

Figure 48. Compressive strength (calcined and "green") with foaming temperature (725)

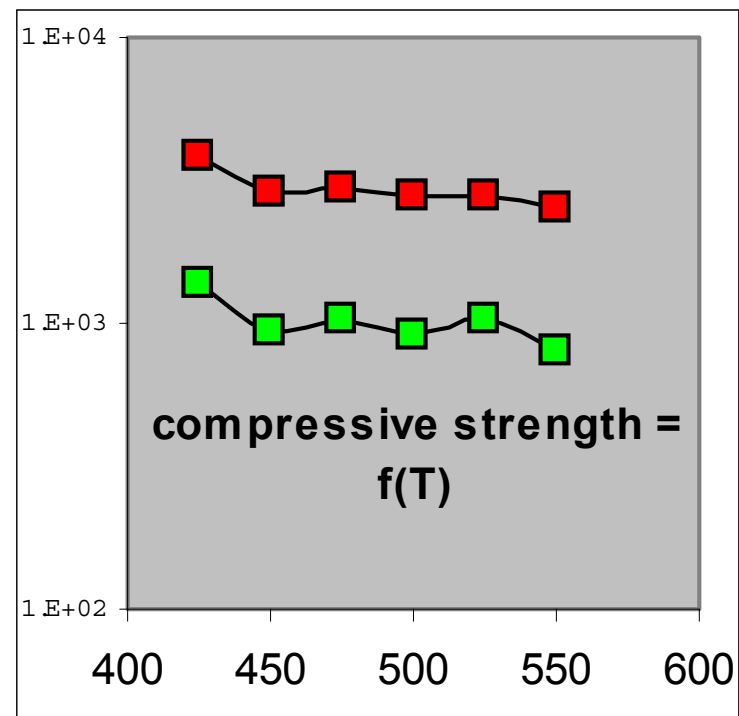

Figure 49. Compressive modulus (calcined and "green") with foaming temperature (725)

\section{$\underline{729 \text { Coal }}$}

Table 17. Mechanical and physical properties of "green" and calcined 729 coal

\begin{tabular}{|c|c|c|c|c|c|c|c|c|c|c|c|r|r|}
\hline Date & $\mathbf{R}$ & $\mathbf{P}$ & $\mathbf{T}$ & $\mathbf{d m f}$ & $\mathbf{d l c}$ & $\mathbf{d m c}$ & $\mathbf{d m}$ & $\mathbf{\text { } f}$ & $\mathbf{~ c}$ & $\mathbf{Y c}$ & $\mathbf{S c}$ & Yg & Sg \\
\hline & & & & & & & & & & & & & \\
\hline $04 / 21 / 00$ & A & 500 & 425 & 16.02 & -11.44 & 16.80 & 30.12 & 0.5525 & 0.6873 & $1.60 \mathrm{E}+05$ & 3318 & $5.31 \mathrm{E}+04$ & 588 \\
\hline $04 / 18 / 00$ & A & 500 & 450 & 17.47 & -11.76 & 16.49 & 31.08 & 0.4288 & 0.5305 & $1.53 \mathrm{E}+05$ & 2058 & $4.10 \mathrm{E}+04$ & 560 \\
\hline $04 / 19 / 00$ & B & 500 & 475 & 18.86 & -11.10 & 14.79 & 30.86 & 0.4066 & 0.5118 & $9.52 \mathrm{E}+04$ & 1828 & $3.66 \mathrm{E}+04$ & 493 \\
\hline $04 / 18 / 00$ & B & 500 & 500 & 20.39 & -10.85 & 13.49 & 31.13 & 0.3814 & 0.4887 & $7.71 \mathrm{E}+04$ & 1512 & $3.17 \mathrm{E}+04$ & 460 \\
\hline 05/01/00 & B & 500 & 525 & 20.43 & -10.26 & 11.04 & 29.21 & 0.3917 & 0.4825 & $1.09 \mathrm{E}+05$ & 1472 & $3.78 \mathrm{E}+04$ & 513 \\
\hline $04 / 27 / 00$ & B & 500 & 550 & 20.46 & -9.92 & 10.48 & 28.79 & 0.3872 & 0.4546 & $6.93 \mathrm{E}+04$ & 1001 & $2.53 \mathrm{E}+04$ & 424 \\
\hline & & & & & & & & & & & & & \\
\hline $05 / 05 / 00$ & A & 100 & 475 & 18.98 & -9.99 & 11.68 & 28.45 & 0.6606 & 0.7377 & & & $4.55 \mathrm{E}+04$ & 1204 \\
\hline $05 / 01 / 00$ & A & 200 & 475 & 18.07 & -10.25 & 12.34 & 28.18 & 0.5447 & 0.6402 & $1.48 \mathrm{E}+05$ & 1729 & $6.18 \mathrm{E}+04$ & 910 \\
\hline $05 / 02 / 00$ & A & 300 & 475 & & -10.61 & 13.92 & & 0.5695 & 0.7078 & $3.56 \mathrm{E}+04$ & 2143 & $3.66 \mathrm{E}+04$ & 1088 \\
\hline $04 / 19 / 00$ & B & 500 & 475 & 18.86 & -11.10 & 14.79 & 30.86 & 0.4066 & 0.5118 & $9.52 \mathrm{E}+04$ & 1828 & $3.66 \mathrm{E}+04$ & 493 \\
\hline
\end{tabular}




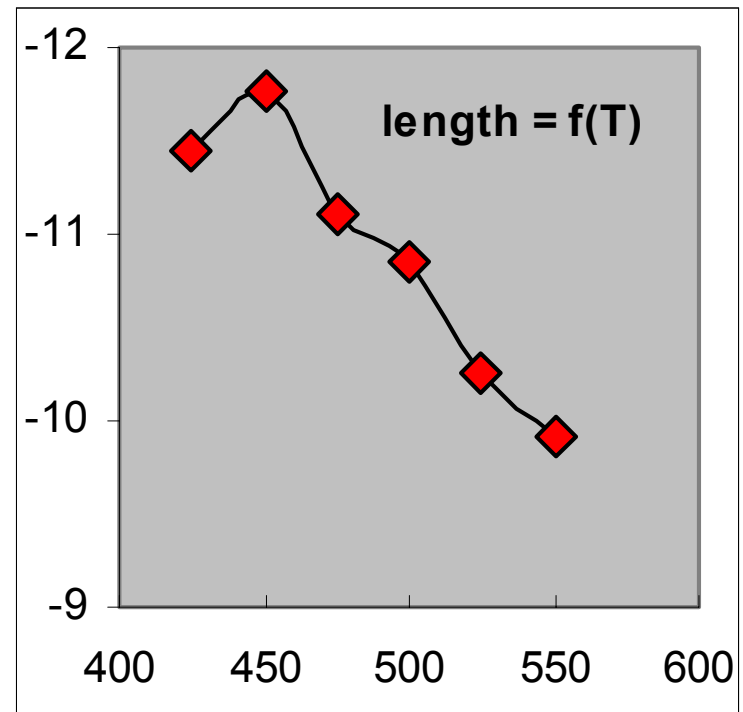

Figure 50. Calcining length change with foaming temperature (729)

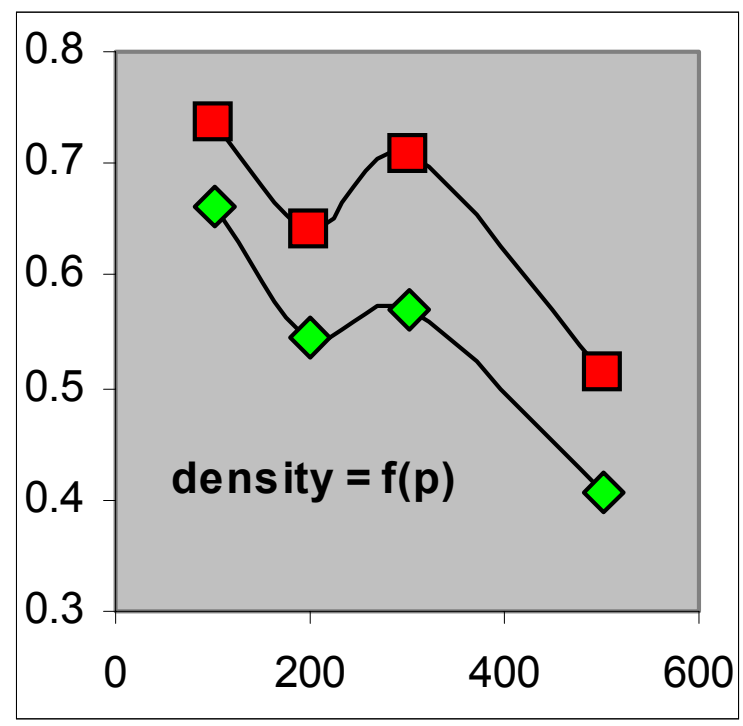

Figure 52. Bulk density (calcined and "green") with foaming pressure (729)

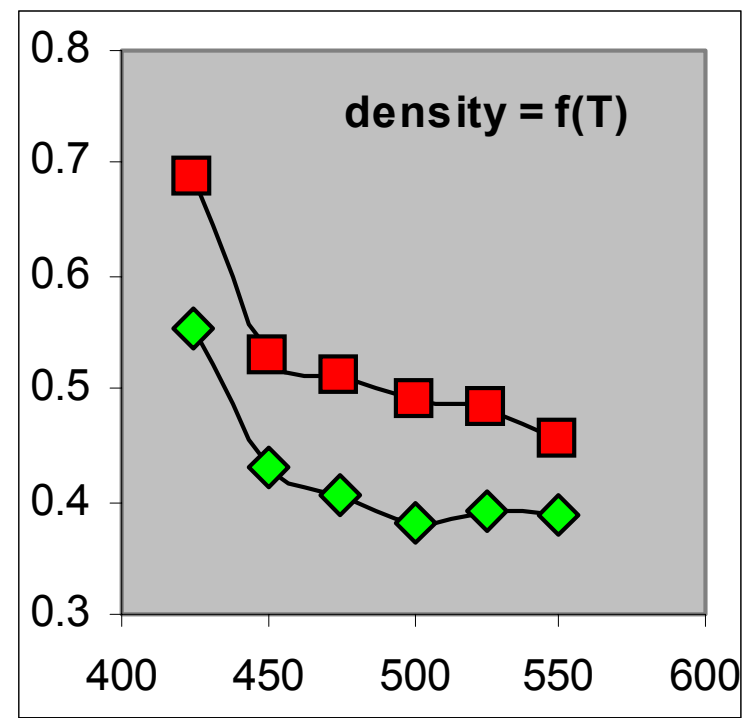

Figure 51. Bulk density (calcined and "green") with foaming temperature (729)

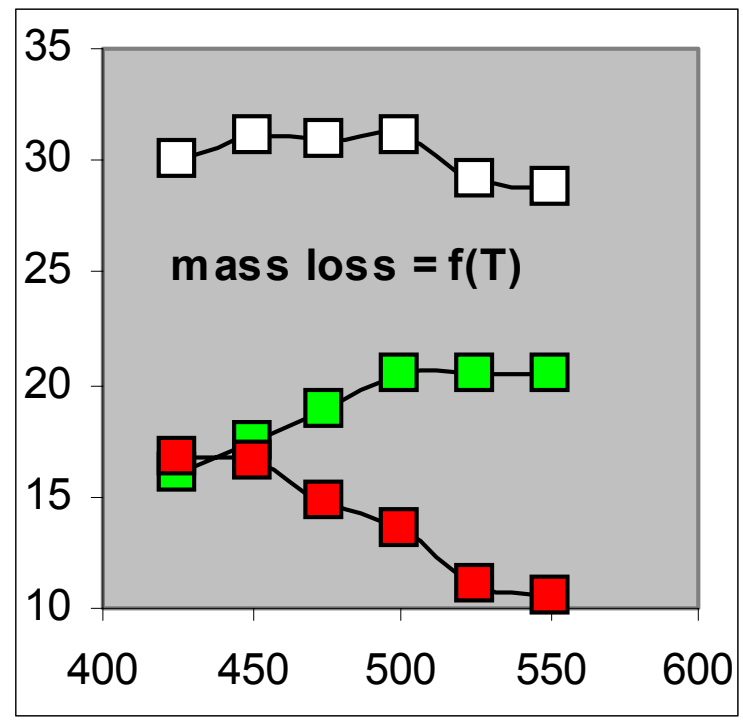

Figure 53. Mass loss (calcined, "green," and total) with foaming temperature (729) 


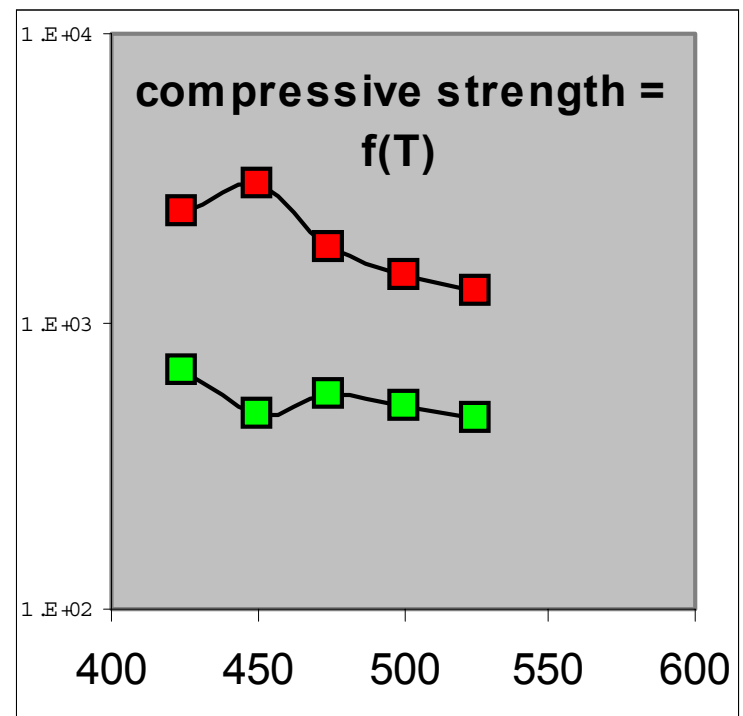

Figure 54. Compressive strength (calcined and "green") with foaming temperature (729)

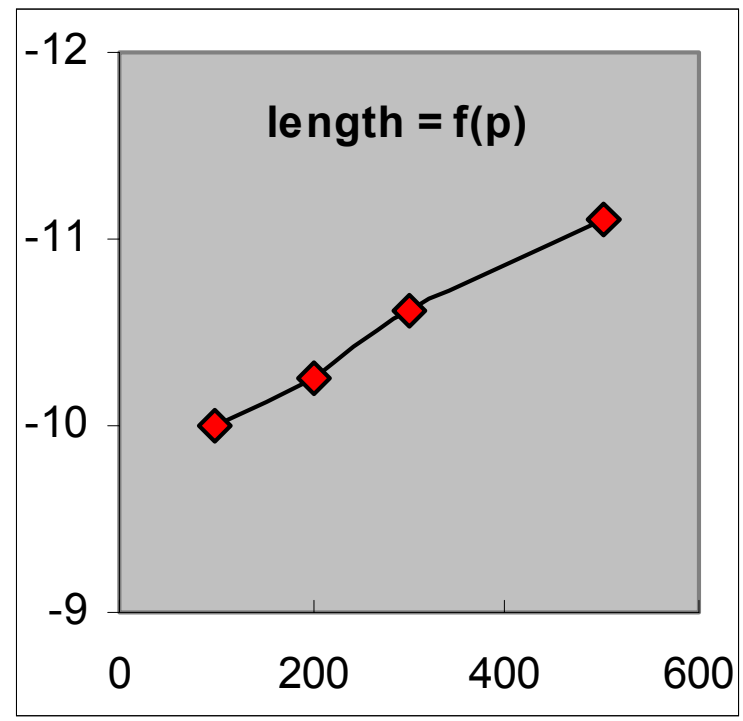

Figure 56. Calcining length change with foaming pressure (729)

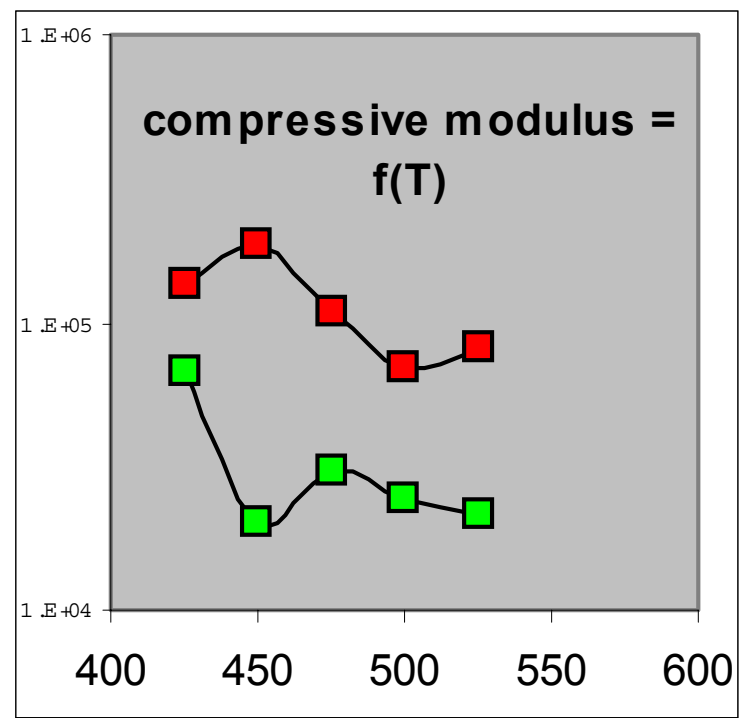

Figure 55. Compressive modulus (calcined and "green") with foaming temperature

(729)

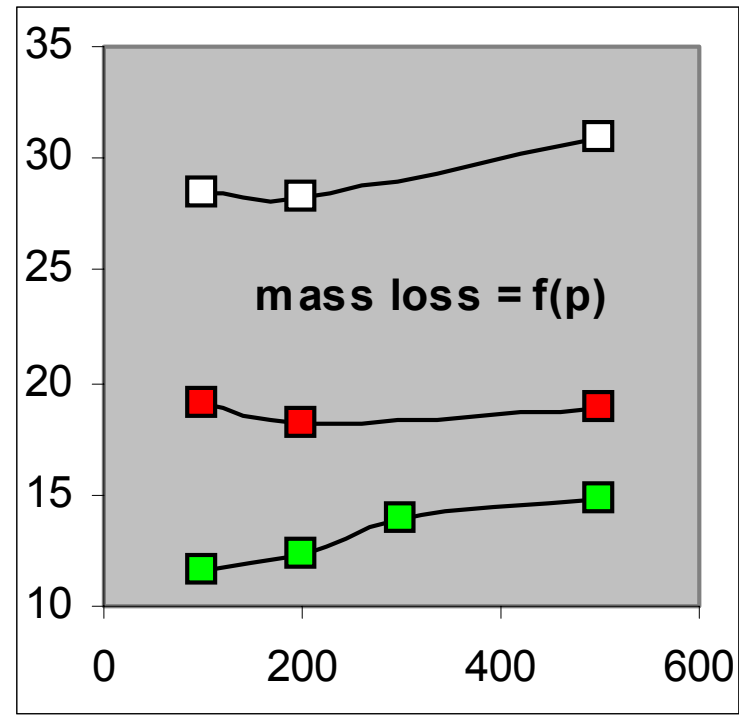

Figure 57. Mass loss (calcined, "green," and total) with foaming pressure (729) 


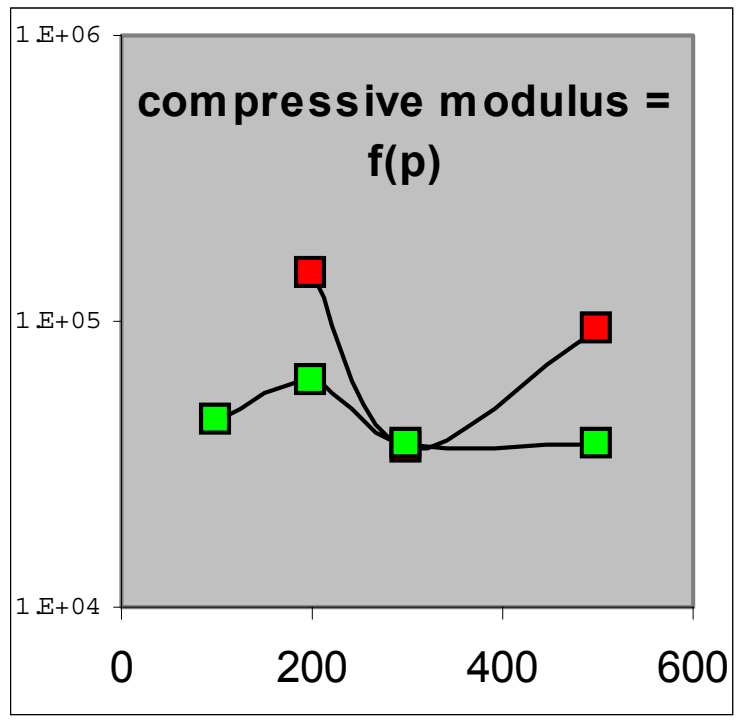

Figure 58. Compressive modulus (calcined and "green") with foaming pressure (729)

\section{$\underline{731 \text { Coal }}$}

Table 18. Mechanical and physical properties of "green" and calcined 731 coal

\begin{tabular}{|c|c|c|c|c|c|c|c|c|c|c|c|c|r|}
\hline Date & fac & $\mathrm{P}$ & $\mathrm{T}$ & $\mathrm{dmf}$ & $\mathrm{dlc}$ & $\mathrm{dmc}$ & $\mathrm{dm}$ & $\mathrm{rf}$ & $\mathrm{rc}$ & $\mathrm{Yc}$ & $\mathrm{Sc}$ & $\mathrm{Yg}$ & $\mathrm{Sg}$ \\
\hline & & & & & & & & & & & & & \\
\hline $04 / 13 / 00$ & $\mathrm{~A}$ & 500 & 450 & 3.37 & -9.08 & 12.23 & 15.19 & 0.9575 & 1.1364 & $4.00 \mathrm{E}+04$ & 1448 & $1.60 \mathrm{E}+04$ & 392 \\
\hline $04 / 06 / 00$ & $\mathrm{~B}$ & 500 & 475 & 5.67 & -9.92 & 10.11 & 15.20 & 1.0322 & 1.2214 & $3.79 \mathrm{E}+05$ & 7464 & $1.44 \mathrm{E}+05$ & 2942 \\
\hline $04 / 04 / 00$ & $\mathrm{~A}$ & 500 & 500 & 5.40 & -9.59 & 9.94 & 14.80 & 0.5774 & 0.7492 & $1.28 \mathrm{E}+05$ & 3762 & $7.40 \mathrm{E}+04$ & 1162 \\
\hline $04 / 07 / 00$ & $\mathrm{~B}$ & 500 & 525 & 6.66 & -9.01 & 8.70 & 14.78 & 0.5268 & 0.6313 & $1.18 \mathrm{E}+05$ & 4682 & $9.73 \mathrm{E}+04$ & 1862 \\
\hline $04 / 17 / 00$ & $\mathrm{~B}$ & 500 & 550 & 8.15 & -8.97 & 8.80 & 16.23 & 0.5165 & 0.6131 & $2.43 \mathrm{E}+05$ & 4182 & $8.87 \mathrm{E}+04$ & 1662 \\
\hline & & & & & & & & & & & & & \\
\hline $04 / 24 / 00$ & B & 0 & 500 & 5.88 & -9.66 & 9.52 & 14.84 & 0.7382 & 0.8916 & $1.69 \mathrm{E}+05$ & 3447 & $6.77 \mathrm{E}+04$ & 1292 \\
\hline & & & & & & & & & & & & & \\
\hline ?4/2/2000 & B & 500 & 500 & 4.79 & -9.74 & 10.93 & 15.19 & 1.2199 & 1.4539 & $2.25 \mathrm{E}+05$ & 5383 & $1.02 \mathrm{E}+05$ & 2906 \\
\hline
\end{tabular}




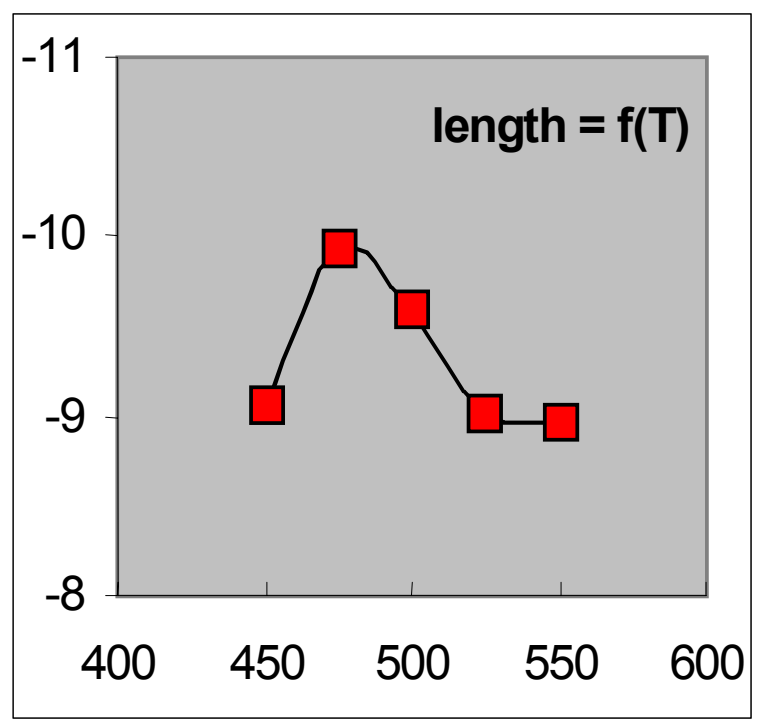

Figure 59. Calcining length change with foaming temperature (731)

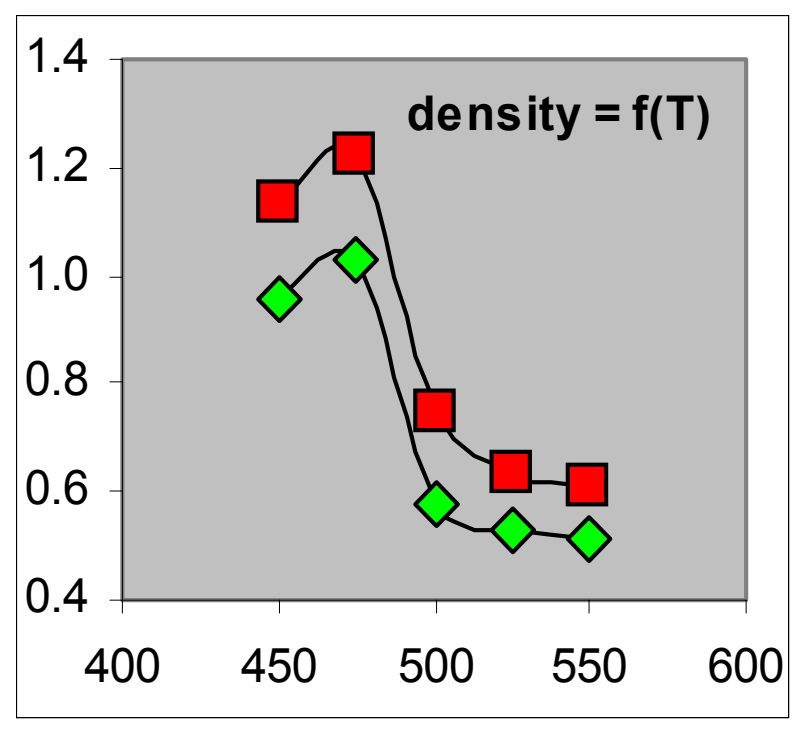

Figure 60. Bulk density (calcined and "green") with foaming temperature (731)

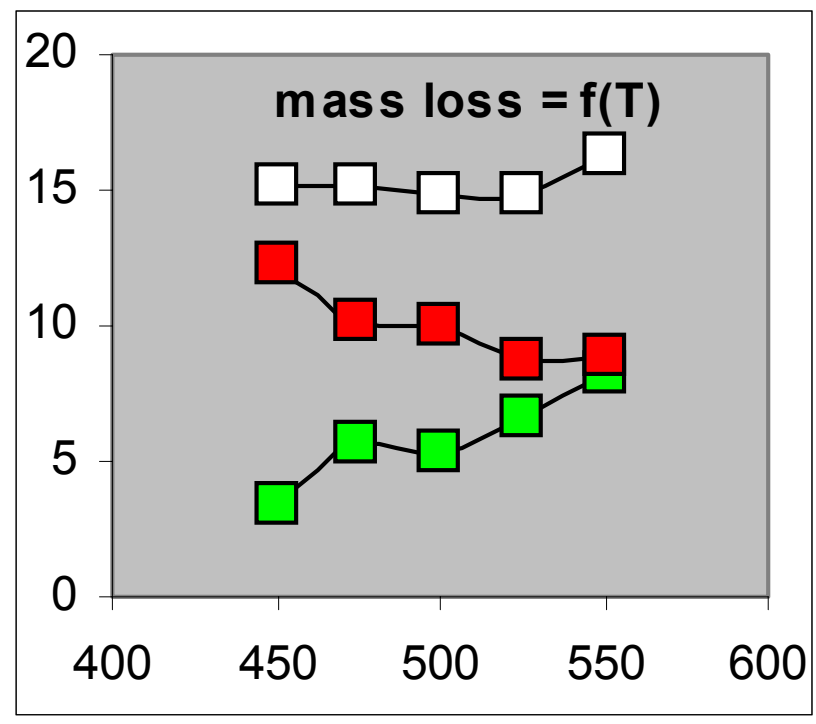

Figure 61. Mass loss (calcined, "green," and total) with foaming temperature (731) 


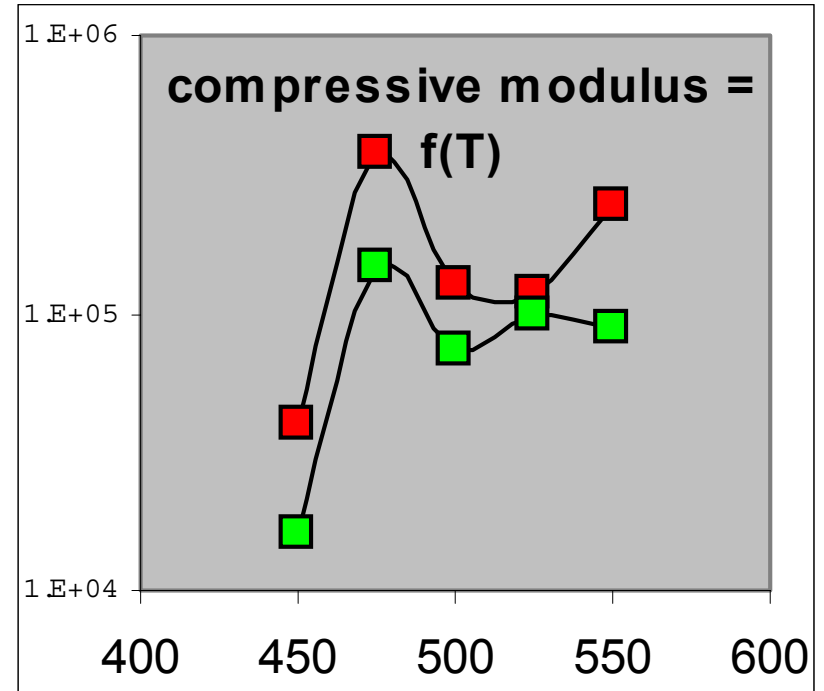

Figure 62. Compressive strength (calcined and "green") with foaming temperature (731)

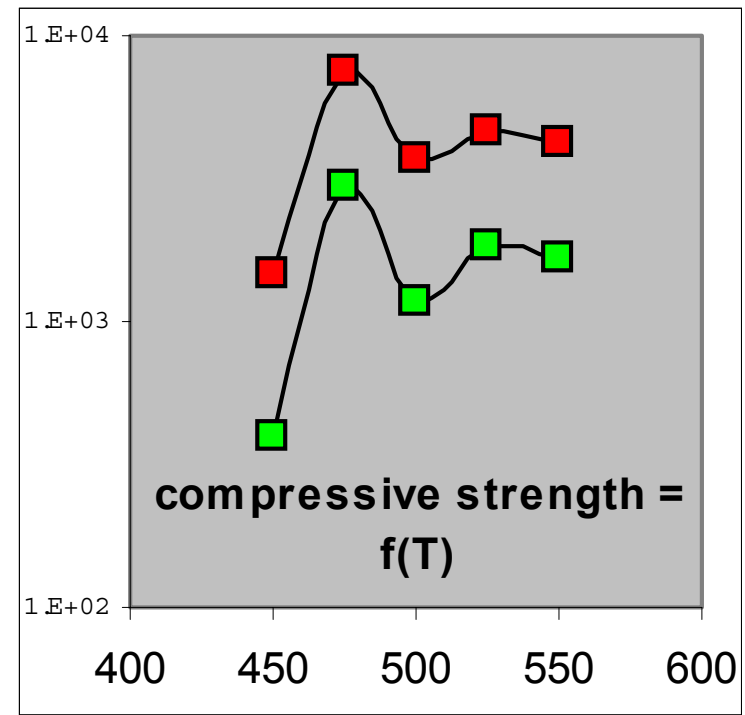

Figure 63. Compressive modulus (calcined and "green") with foaming temperature (731)

\section{Coal}

Table 19. Mechanical and physical properties of "green" and calcined 735 coal 
CPCPC Final Technical Report

January 2001

\begin{tabular}{|c|c|c|c|c|c|c|c|c|c|c|c|c|r|}
\hline Date & zac & $\mathrm{P}$ & $\mathrm{T}$ & $\mathrm{dmf}$ & $\mathrm{dlc}$ & $\mathrm{dmc}$ & $\mathrm{dm}$ & rf & $\mathrm{rc}$ & $\mathrm{Yc}$ & $\mathrm{Sc}$ & $\mathrm{Yg}$ & $\mathrm{Sg}$ \\
\hline & & & & & & & & & & & & & \\
\hline $04 / 13 / 00$ & $\mathrm{~A}$ & 500 & 450 & 3.34 & -9.07 & 12.44 & 15.36 & 1.1503 & 1.3728 & $8.39 \mathrm{E}+04$ & 3595 & $4.75 \mathrm{E}+04$ & 1282 \\
\hline $04 / 06 / 00$ & $\mathrm{~B}$ & 500 & 475 & 6.43 & -10.07 & 10.11 & 15.89 & 0.4742 & 0.5885 & $2.15 \mathrm{E}+05$ & 4145 & $3.97 \mathrm{E}+04$ & 974 \\
\hline $04 / 04 / 00$ & $\mathrm{~B}$ & 500 & 500 & 6.59 & -10.05 & 10.03 & 15.97 & 0.4693 & 0.5732 & $1.86 \mathrm{E}+05$ & 3816 & $6.29 \mathrm{E}+04$ & 1194 \\
\hline $04 / 07 / 00$ & $\mathrm{~B}$ & 500 & 525 & 6.91 & -9.44 & 9.45 & 15.71 & 0.4557 & 0.5508 & $1.58 \mathrm{E}+05$ & 3200 & $7.63 \mathrm{E}+04$ & 1374 \\
\hline $04 / 17 / 00$ & $\mathrm{~B}$ & 500 & 550 & 7.22 & -9.37 & 9.65 & 16.17 & 0.4230 & 0.5262 & $9.25 \mathrm{E}+04$ & 2447 & $5.15 \mathrm{E}+04$ & 1073 \\
\hline & & & & & & & & & & & & & \\
\hline $04 / 24 / 00$ & $\mathrm{~B}$ & 0 & 500 & 5.92 & -10.22 & 9.78 & 15.12 & 0.2754 & 0.3479 & $2.05 \mathrm{E}+04$ & 502 & $8.29 \mathrm{E}+03$ & 192 \\
\hline & & & & & & & & & & & & & \\
\hline$? 4 / 2 / 2000$ & $\mathrm{~B}$ & 500 & 500 & 5.20 & -10.02 & 10.14 & 14.81 & 0.4917 & 0.6044 & $3.46 \mathrm{E}+04$ & 1088 & $3.99 \mathrm{E}+04$ & 543 \\
\hline
\end{tabular}

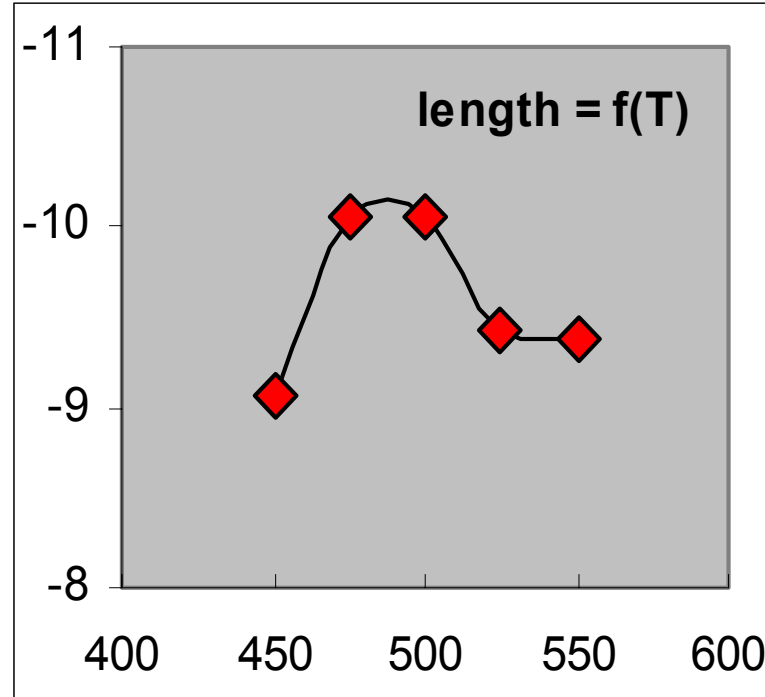

Figure 64. Calcining length change with foaming temperature (735)

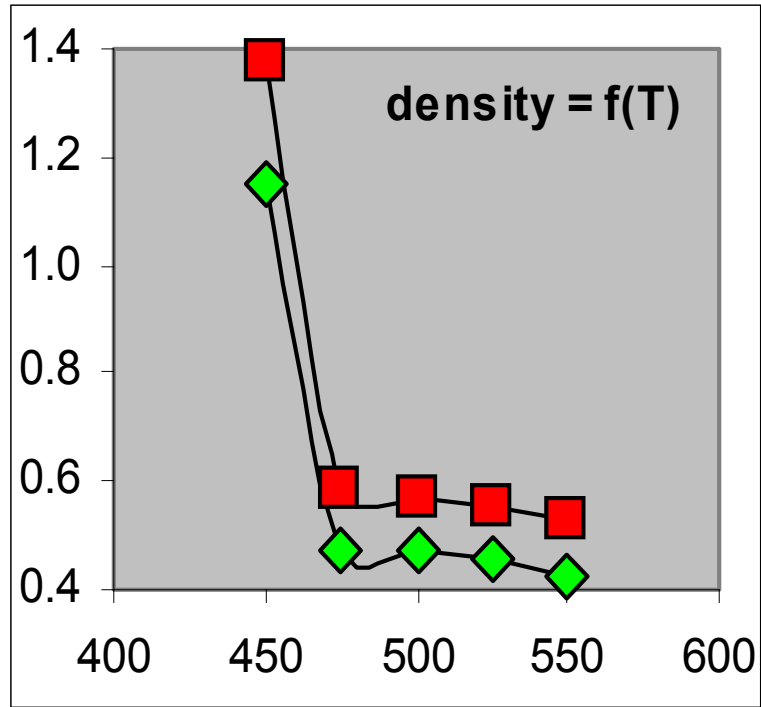

Figure 65. Bulk density (calcined and "green") with foaming temperature (735)

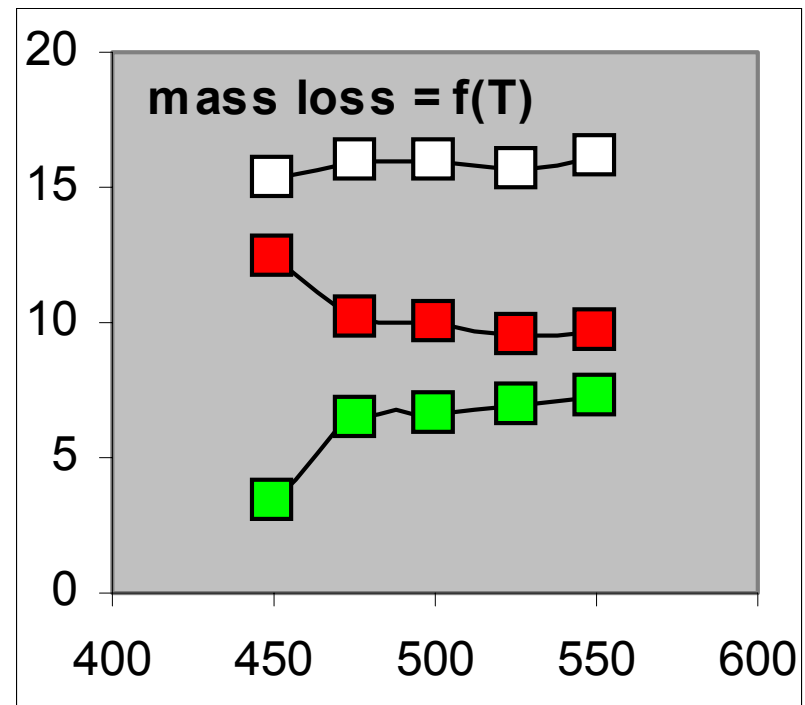

Figure 66. Mass loss (calcined, "green," and total) with foaming temperature (735) 


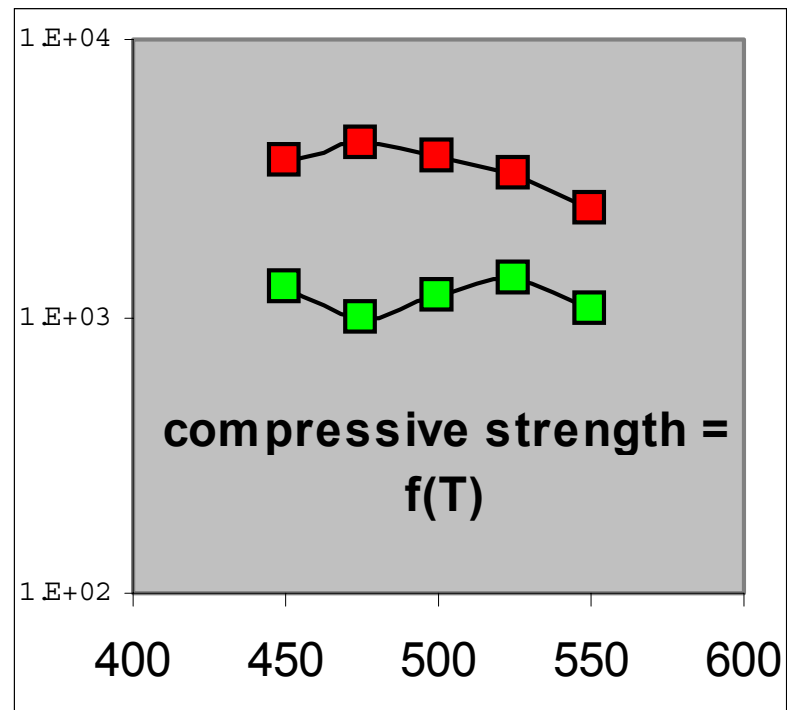

Figure 67. Compressive strength (calcined and "green") with foaming temperature (735)

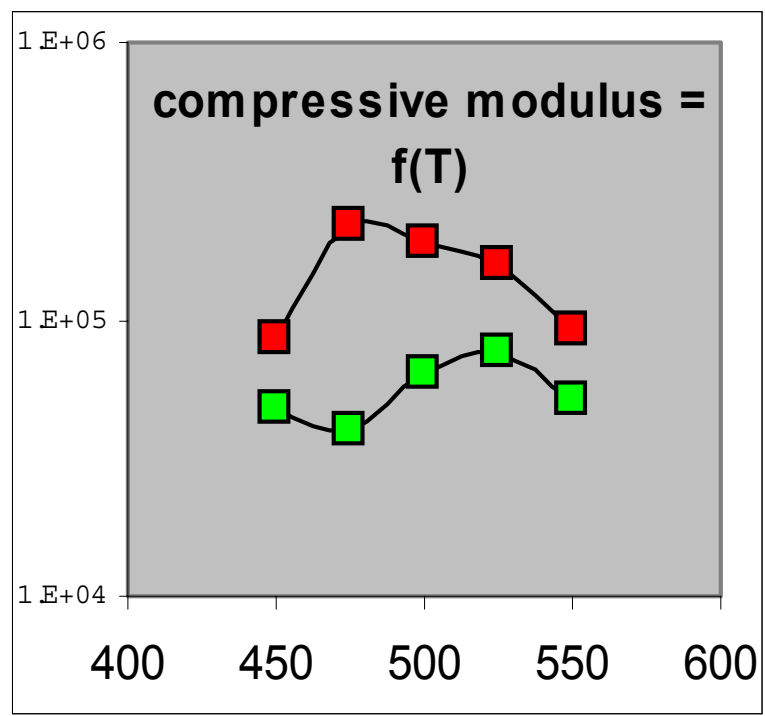

Figure 68. Compressive modulus (calcined and "green") with foaming temperature (735)

\section{Coal}

Table 20. Mechanical and physical properties of "green" and calcined 800 coal

\begin{tabular}{|c|c|c|c|c|c|c|c|c|c|c|c|r|r|}
\hline Date & zact & $\mathrm{P}$ & $\mathrm{T}$ & $\mathrm{dmf}$ & $\mathrm{dlc}$ & $\mathrm{dmc}$ & $\mathrm{dm}$ & rf & rc & Yc & Sc & Yg & Sg \\
\hline & & & & & & & & & & & & & \\
\hline $04 / 17 / 00$ & $\mathrm{~A}$ & 500 & 425 & 2.62 & -10.31 & 13.73 & 15.99 & 0.9011 & 1.1129 & $3.93 \mathrm{E}+04$ & 1138 & $9.15 \mathrm{E}+03$ & 237 \\
\hline 04/10/00 & A & 500 & 450 & 3.94 & -10.45 & 12.17 & 15.63 & 1.0221 & 1.2901 & $1.43 \mathrm{E}+05$ & 4960 & $8.17 \mathrm{E}+04$ & 1120 \\
\hline $04 / 05 / 00$ & B & 500 & 475 & 6.26 & -10.45 & 11.28 & 16.83 & 0.4419 & 0.5479 & $1.79 \mathrm{E}+05$ & 4142 & $6.33 \mathrm{E}+04$ & 945 \\
\hline $04 / 04 / 00$ & B & 500 & 500 & 8.02 & -10.00 & 10.29 & 17.48 & 0.4097 & 0.5052 & $2.11 \mathrm{E}+05$ & 3228 & $5.09 \mathrm{E}+04$ & 1075 \\
\hline $04 / 14 / 00$ & B & 500 & 525 & 6.75 & -9.63 & 10.80 & 16.82 & 0.3859 & 0.4708 & $1.67 \mathrm{E}+05$ & 2381 & $4.65 \mathrm{E}+04$ & 1018 \\
\hline $04 / 17 / 00$ & B & 500 & 550 & 10.16 & -9.43 & 9.95 & 19.10 & 0.3787 & 0.4707 & $8.90 \mathrm{E}+04$ & 2431 & $4.96 \mathrm{E}+04$ & 1009 \\
\hline & & & & & & & & & & & & & \\
\hline $04 / 24 / 00$ & B & 0 & 500 & 8.54 & -10.49 & 10.60 & 18.24 & 0.2640 & 0.3486 & $4.47 \mathrm{E}+04$ & 681 & $1.86 \mathrm{E}+04$ & 202 \\
\hline & & & & & & & & & & & & & \\
\hline$? 4 / 2 / 2000$ & B & 500 & 500 & 5.80 & -10.92 & 11.28 & 16.43 & 0.4497 & 0.5605 & $1.69 \mathrm{E}+05$ & 4450 & $5.70 \mathrm{E}+04$ & 967 \\
\hline
\end{tabular}




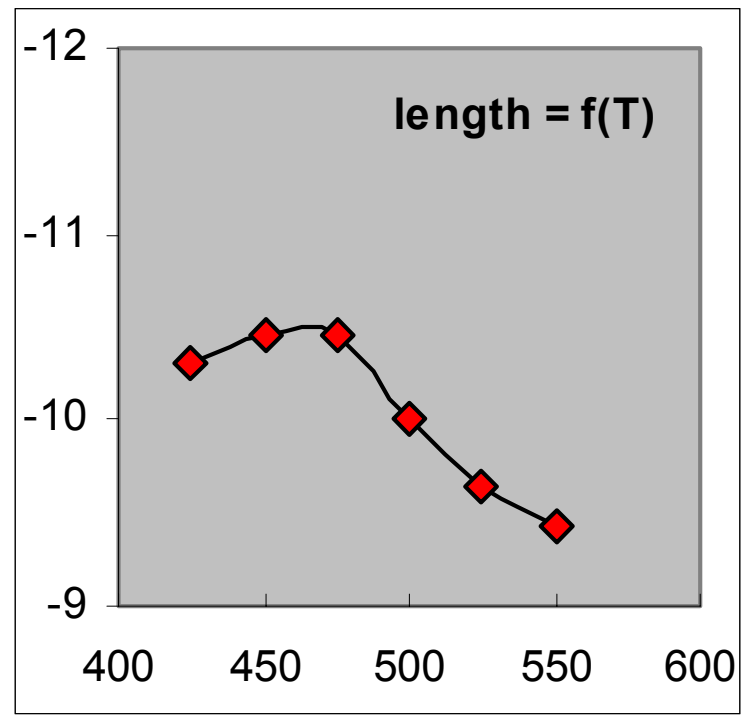

Figure 69. Calcining length change with foaming temperature (800)

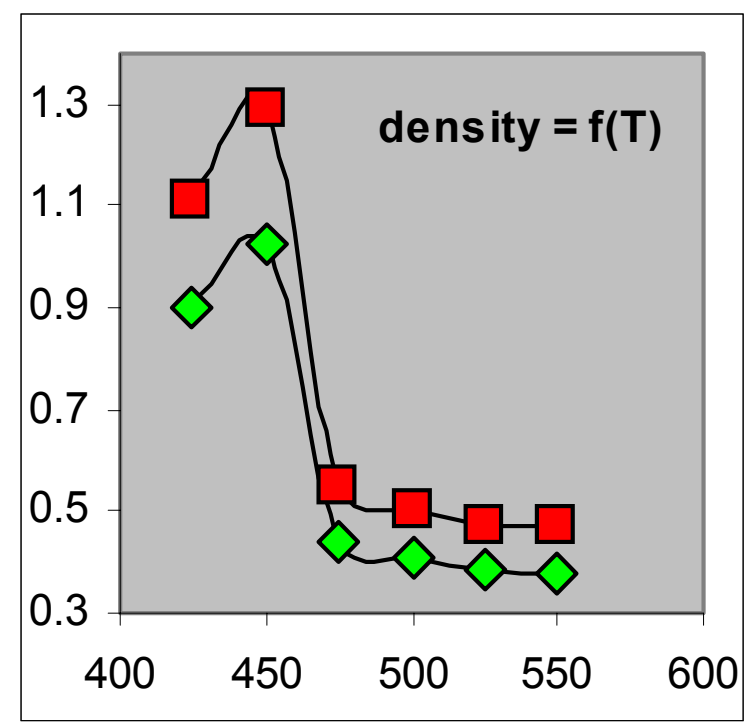

Figure 70. Bulk density (calcined and "green") with foaming temperature (800)

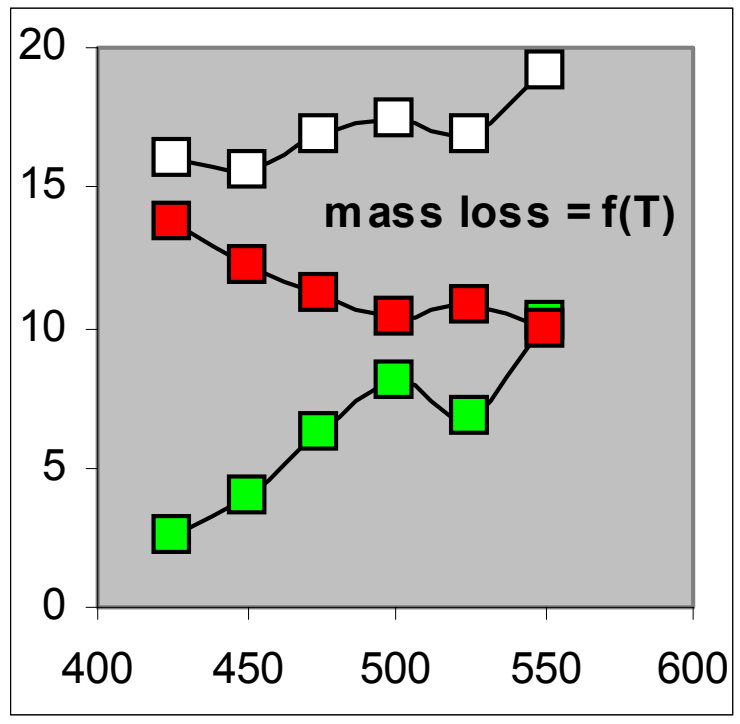

Figure 71. Mass loss (calcined, "green," and total) with foaming temperature (800) 


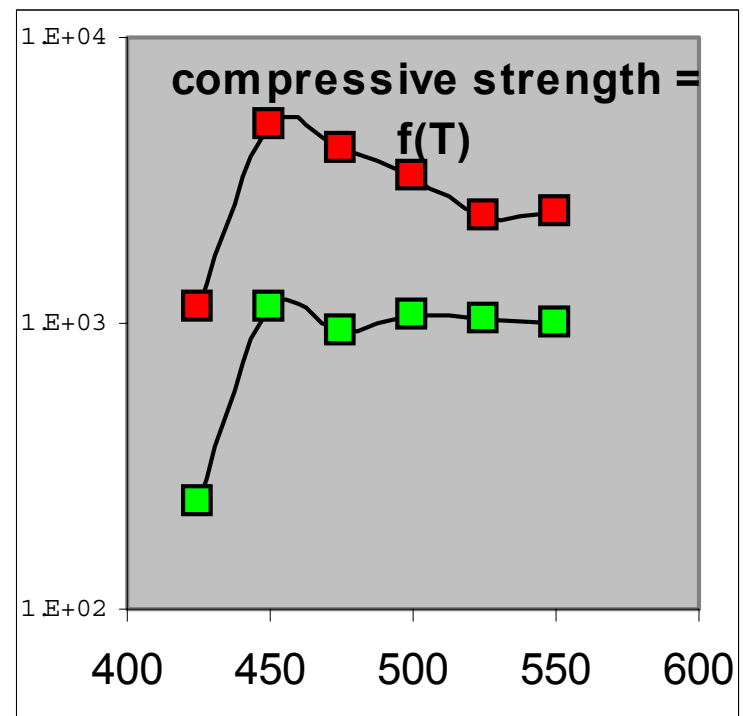

Figure 72. Compressive strength (calcined and "green") with foaming temperature (800)

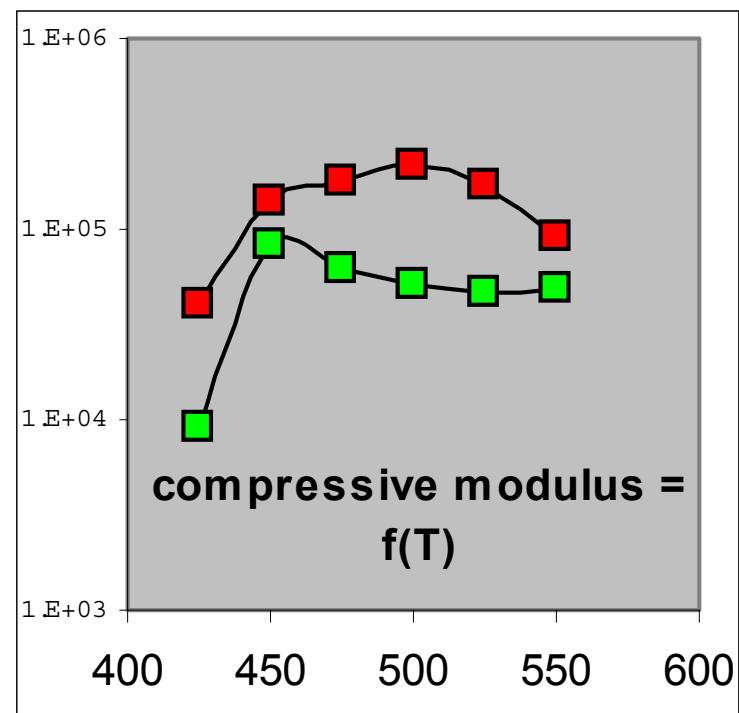

Figure 73. Compressive modulus (calcined and "green") with foaming temperature (800)

\section{Coal}

Table 21. Mechanical and physical properties of "green" and calcined 801 coal

\begin{tabular}{|c|c|c|c|c|c|c|c|c|c|c|c|c|c|}
\hline Date & zac & $\mathrm{P}$ & $\mathrm{T}$ & $\mathrm{dmf}$ & $\mathrm{dlc}$ & $\mathrm{dmc}$ & $\mathrm{dm}$ & if & rc & Yc & Sc & Yg & Sg \\
\hline 04/14/00 & $\mathrm{A}$ & 500 & 450 & 5.51 & & 1piece & & & & & & & \\
\hline 04/05/00 & $\mathrm{A}$ & 500 & 475 & 7.21 & & 1 piece & & & & & & & \\
\hline 04/04/00 & $\mathrm{B}$ & 500 & 500 & 8.40 & -9.91 & 13.23 & 20.51 & 0.8130 & 0.985161 & $4.70 \mathrm{E}+03$ & 190 & $2.06 \mathrm{E}+03$ & 110 \\
\hline $04 / 10 / 00$ & $\mathrm{~B}$ & 500 & 525 & 8.50 & -9.52 & 13.58 & 20.93 & 0.8451 & 1.028847 & $1.15 \mathrm{E}+04$ & 399 & $6.48 \mathrm{E}+03$ & 242 \\
\hline
\end{tabular}

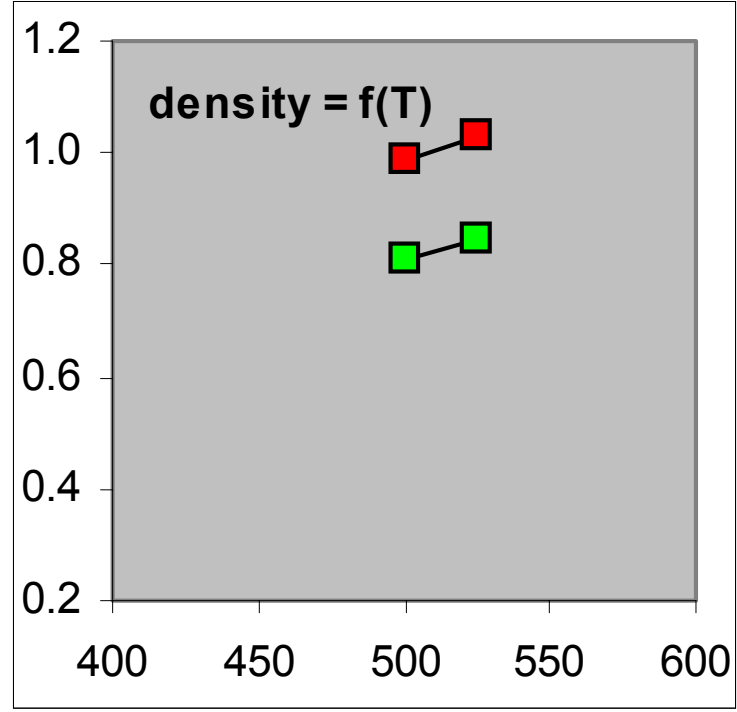

Figure 74. Bulk density (calcined and "green") with foaming temperature (801)

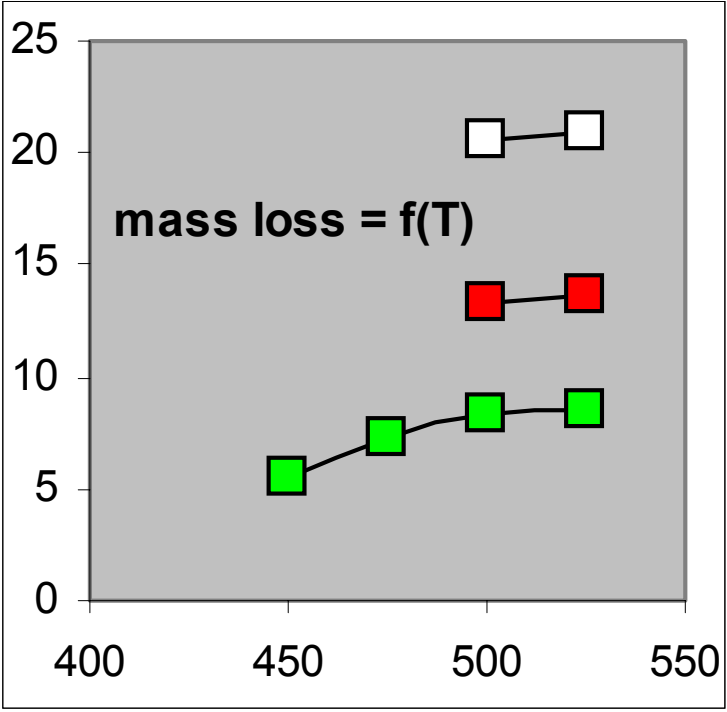

Figure 75. Mass loss (calcined, "green," and total) with foaming temperature (801) 


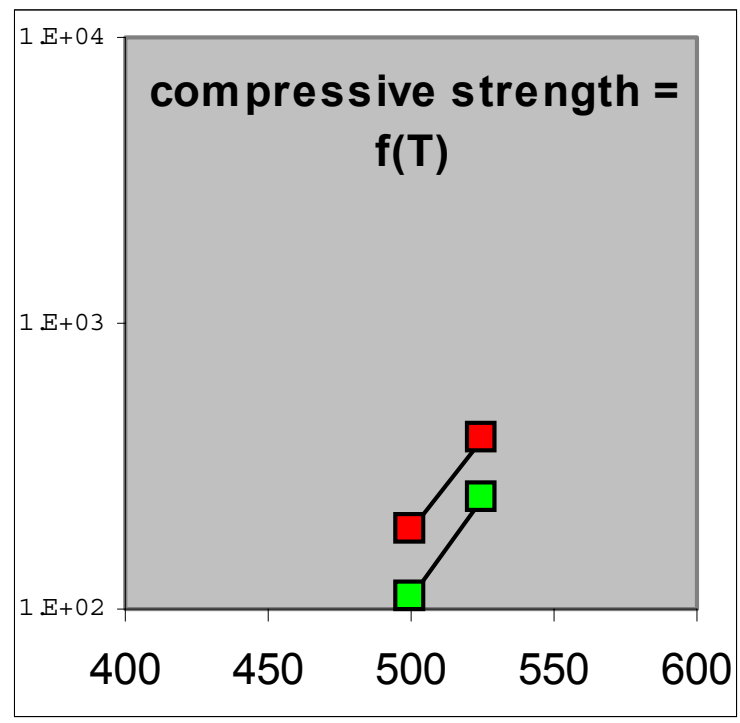

Figure 76. Compressive strength (calcined and "green") with foaming temperature (801)

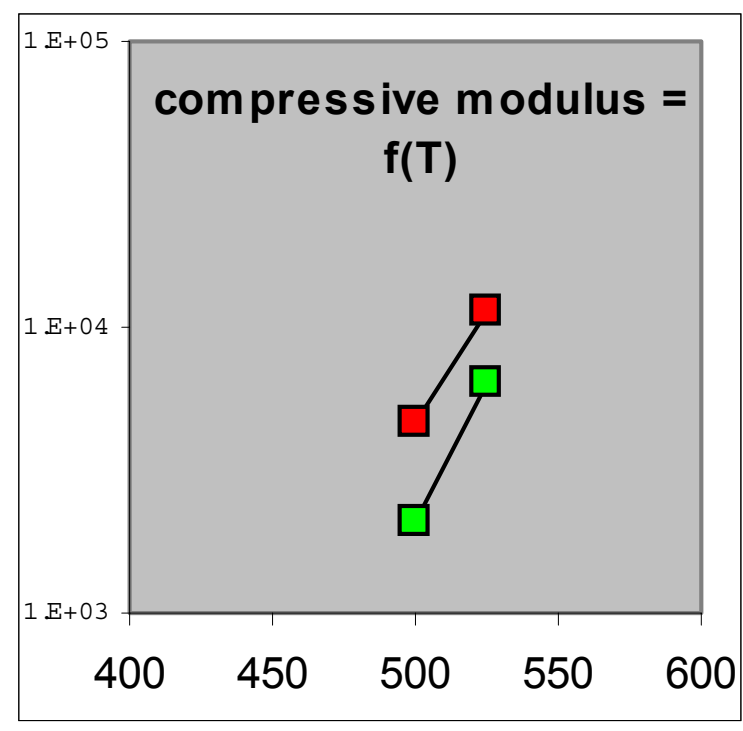

Figure 77. Compressive modulus (calcined and "green") with foaming temperature (801)

\section{0 (POW) Coal}

Table 22. Mechanical and physical properties of "green" and calcined $900(\mathrm{POW})$ coal

\begin{tabular}{|c|c|c|c|c|c|c|c|c|c|c|c|c|c|}
\hline Date & zac & $\mathrm{P}$ & $\mathrm{T}$ & $\mathrm{dmf}$ & $\mathrm{dlc}$ & $\mathrm{dmc}$ & $\mathrm{dm}$ & rf & rc & Yc & Sc & Yg & Sg \\
\hline & & & & & & & & & & & & & \\
\hline $04 / 07 / 00$ & A & 500 & 450 & 10.53 & -12.04 & 14.15 & 23.19 & 0.5104 & 0.6610 & $2.54 \mathrm{E}+05$ & 4623 & $3.40 \mathrm{E}+04$ & 703 \\
\hline 04/06/00 & A & 500 & 475 & 12.29 & -11.69 & 12.50 & 23.25 & 0.4285 & 0.5628 & $1.93 \mathrm{E}+05$ & 2881 & $3.48 \mathrm{E}+04$ & 792 \\
\hline $04 / 04 / 00$ & A & 500 & 500 & 13.90 & -11.38 & 11.62 & 23.91 & 0.3857 & 0.4974 & $1.26 \mathrm{E}+05$ & 2393 & $3.85 \mathrm{E}+04$ & 752 \\
\hline $04 / 13 / 00$ & B & 500 & 525 & 12.32 & -10.80 & 10.04 & 21.12 & 0.3621 & 0.4737 & $1.31 \mathrm{E}+05$ & 2071 & $3.45 \mathrm{E}+04$ & 708 \\
\hline
\end{tabular}




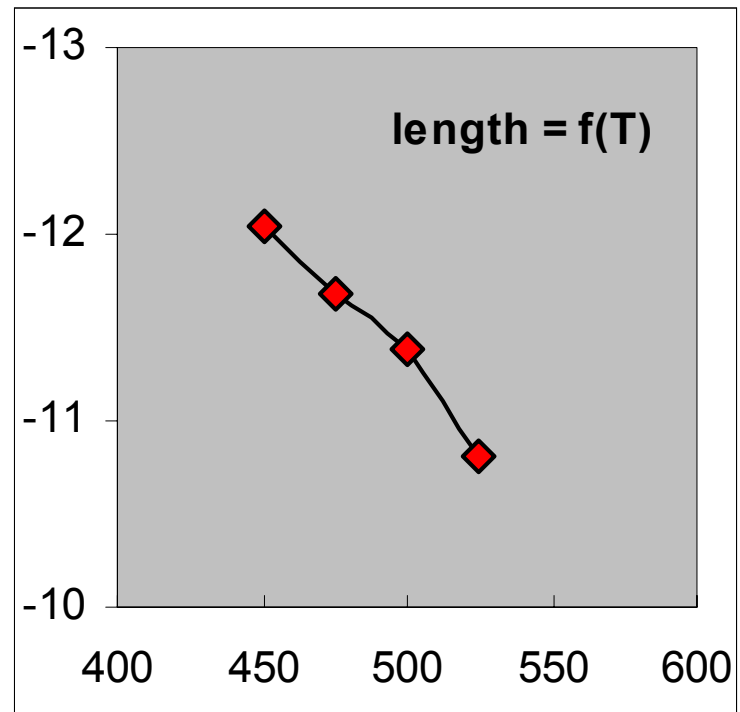

Figure 78. Calcining length change with foaming temperature (900)

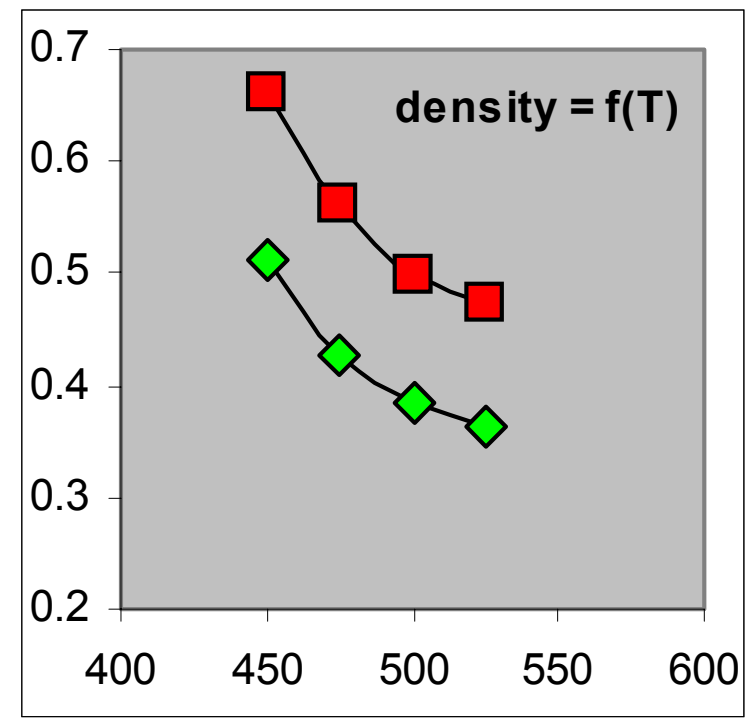

Figure 79. Bulk density (calcined and "green") with foaming temperature (900)

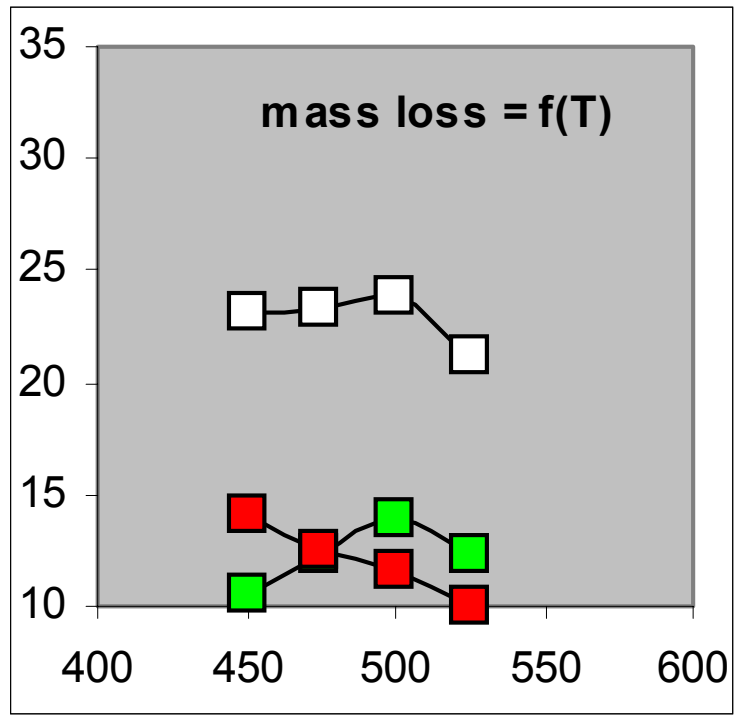

Figure 80. Mass loss (calcined, "green," and total) with foaming temperature (900) 


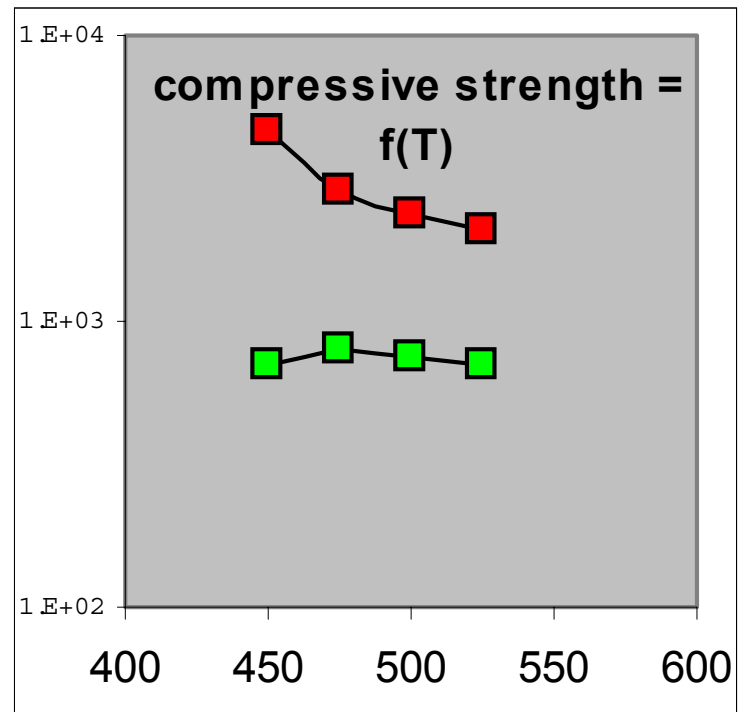

Figure 81. Compressive strength (calcined and "green") with foaming temperature (900)

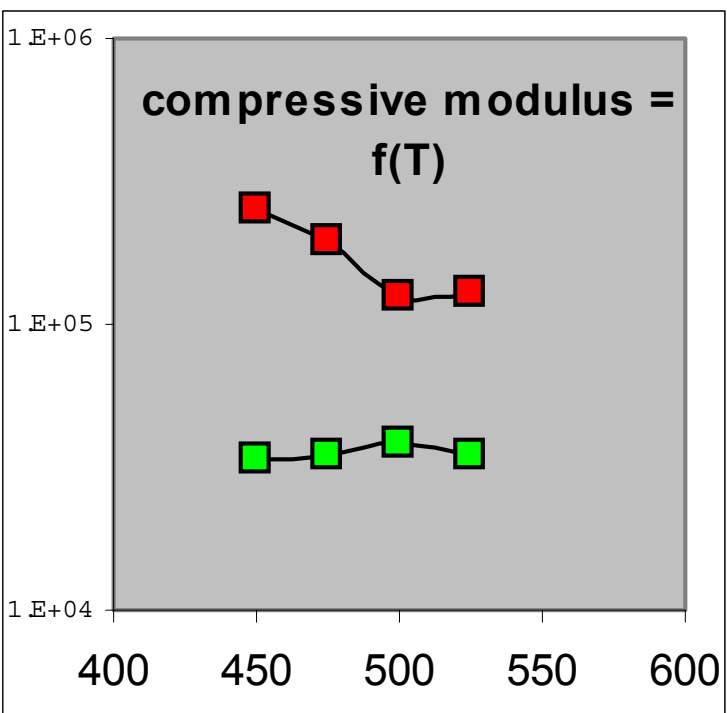

Figure 82. Compressive modulus (calcined and "green") with foaming temperature (900)

\section{TASK 6.0 GRAPHITIZATION}

Coals 610, POW (a.k.a. 900, in this study), 729, and 800 were selected, based on the quality of foam that they produced, for further study. For each, two identical 5.0-inch diameter disks were produced and calcined to $1050^{\circ} \mathrm{C}$. These disks were then quartered so that they would fit in the chamber of a Thermal Technologies "Astro" graphite resistance furnace for graphitization. Graphitization took place at the facilities of Pittsburgh Materials Technology, Inc. (PMTI; Large, PA). A sample of each of the coal foams was stacked in the vertical cylindrical hot zone (approximately 30-inches diameter by 6.0-inches length) of the furnace, atop a graphite hearth and separated by flexible graphite foils. The graphitization process went as follows:

- carbon foam samples loaded into hot zone and furnace sealed by means of three knurled screws,

- furnace shell water cooling system started,

- furnace evacuated by roughing pump and then pressurized with helium to 2 to 5 psi gage pressure (this cycle is repeated three times),

- furnace filled to 2 to 5 psi helium,

- heating profile started, with heating rate set at $20^{\circ} \mathrm{C}$ per minute to an ultimate temperature selected from $1800,2000,2200,2400$, and $2600^{\circ} \mathrm{C}$,

- furnace held at ultimate temperature for 30 minutes,

- furnace turned off and allowed to cool without a controlled rate, and

- furnace pressure vented and samples removed. 
Graphitized samples were subjected to (1) X-ray diffraction analysis, (2) mechanical testing, and (3) physical testing to determine the effects of high temperature treatment on these different

materials. The interplanar spacing, or spacing between the $(00,2)$ crystal planes for graphite, is an important descriptor of crystal order. This spacing is 3.44 Angstroms for "turbostratic," or disordered graphite with random $(00,2)$ plan orientation, and 3.354 Angstroms for perfectly ordered graphite, with an ABAB stacking sequence. A "degree of graphitization" is also defined, expressed by a lever-rule calculation of the fraction of graphite material based upon a material's $(00,2)$ spacing relative to that of graphite and disordered graphite. This value is only defined between 0 and 1 ; higher $\mathrm{d}(00,2)$ values that that for disordered graphite are possible - with strain, heteroatom inclusion, etc. - but negative degree of graphitization values are meaningless.

Crystallite size can also be calculated from the breadth of multiple orders of the same reflections (peaks), after separation of instrumental and strain broadening terms, and application of Scherrer's Law. The determination of two crystallite dimensions is possible. The first is Lc, the stack height, which is the crystallite size in the direction normal to the $(00,2)$ planes, and is determined from the breadths of $(00,2),(00,4),(00,6)$, etc. types of reflections. This indicates the height of a stack of $(00,2)$ planes ordered in the ABAB stacking sequence. La, the coherence length, is more difficult to define, but is related to the diameter or breadth of graphite planes. The planes are actually very large in dimension, but La indicates distances between wrinkles, dislocations, and other such features that scatter X-rays, rather than the breadth of a discrete, disk-like solid. La correlates well with transport properties, like thermal and electrical conductivity, as the conducting phonons and electrons are scatter at these crystal imperfections in similar fashion as do X-rays - though not at exactly the same degree. La, then, can be correlated with the mean-free-paths of phonons, for example, in the prediction of thermal conductivity.

Raw X-ray diffraction scans are presented in Appendix B, along with a description of the method employed to calculate crystalline parameters. The following tables and graphs summarize these data; curves are color-coded with respect to coal precursor. 
CPCPC Final Technical Report

January 2001

Table 23. Crystal properties of coal foams after graphitization to temperatures between 1600 and $2600^{\circ} \mathrm{C}$

\begin{tabular}{|c|c|c|c|c|c|c|}
\hline Raw Material & Heat Treatment & $\begin{array}{c}d(002) \\
\text { Angstroms }\end{array}$ & $g$ & $\begin{array}{l}\text { Stack Height } \\
\text { (Angstroms) }\end{array}$ & $\begin{array}{l}\text { Coherence Length } \\
\text { (Angstroms) }\end{array}$ & $\begin{array}{l}\text { La/Lo } \\
\text { Ratio }\end{array}$ \\
\hline A & 1600 & 3.4812 & -0.4790 & 41.3 & 31.2 & 0.76 \\
\hline \multirow[t]{5}{*}{610} & 1800 & 3.4549 & -0.1727 & 49.6 & 39.5 & 0.80 \\
\hline & 2000 & 3.4368 & 0.0375 & 71.9 & 43.1 & 0.60 \\
\hline & 2200 & 3.4335 & 0.0757 & 73.4 & 44.0 & 0.60 \\
\hline & 2400 & 3.4365 & 0.0403 & 70.8 & 129.5 & 1.83 \\
\hline & 2600 & 3.4338 & 0.0724 & 72.1 & 647.4 & 8.98 \\
\hline $\bar{B}$ & 1600 & 3.4779 & -0.4411 & 41.0 & 16.8 & 0.41 \\
\hline \multirow[t]{5}{*}{729} & 1800 & 3.4612 & -0.2470 & 53.1 & 18.2 & 0.34 \\
\hline & 2000 & 3.4424 & -0.0275 & 81.5 & 38.1 & 0.47 \\
\hline & 2200 & 3.4315 & 0.0984 & 94.9 & 82.0 & 0.86 \\
\hline & 2400 & 3.4389 & 0.0125 & 91.1 & 33.9 & 0.37 \\
\hline & 2600 & 3.4312 & 0.1019 & 95.5 & 100.0 & 1.05 \\
\hline $\bar{C}$ & 1600 & 3.4629 & -0.2667 & 51.7 & 35.0 & 0.68 \\
\hline \multirow[t]{5}{*}{ POW } & 1800 & 3.4485 & -0.0993 & 65.1 & 12.4 & 0.19 \\
\hline & 2000 & 3.4360 & 0.0460 & 117.5 & 33.7 & 0.29 \\
\hline & 2200 & 3.4278 & 0.1416 & 141.2 & 202.6 & 1.44 \\
\hline & 2400 & 3.4101 & 0.3479 & 150.5 & 39.7 & 0.26 \\
\hline & 2600 & 3.4238 & 0.1878 & 155.1 & 46.4 & 0.30 \\
\hline $\mathrm{D}$ & 1600 & 3.4550 & -0.1739 & 56.0 & 27.1 & 0.48 \\
\hline \multirow[t]{5}{*}{800} & 1800 & & & & & \\
\hline & 2000 & 3.4340 & 0.0693 & 130.9 & 67.1 & 0.51 \\
\hline & 2200 & & & & & \\
\hline & 2400 & 3.4315 & 0.0988 & 187.9 & 315.5 & 1.68 \\
\hline & 2600 & 3.4309 & 0.1063 & 184.7 & 311.5 & 1.69 \\
\hline MIT & 2600 & 3.3804 & 0.6926 & 338.5 & 556.1 & 1.64 \\
\hline
\end{tabular}


$d(00,2)$ Spacing with Heat Treatment

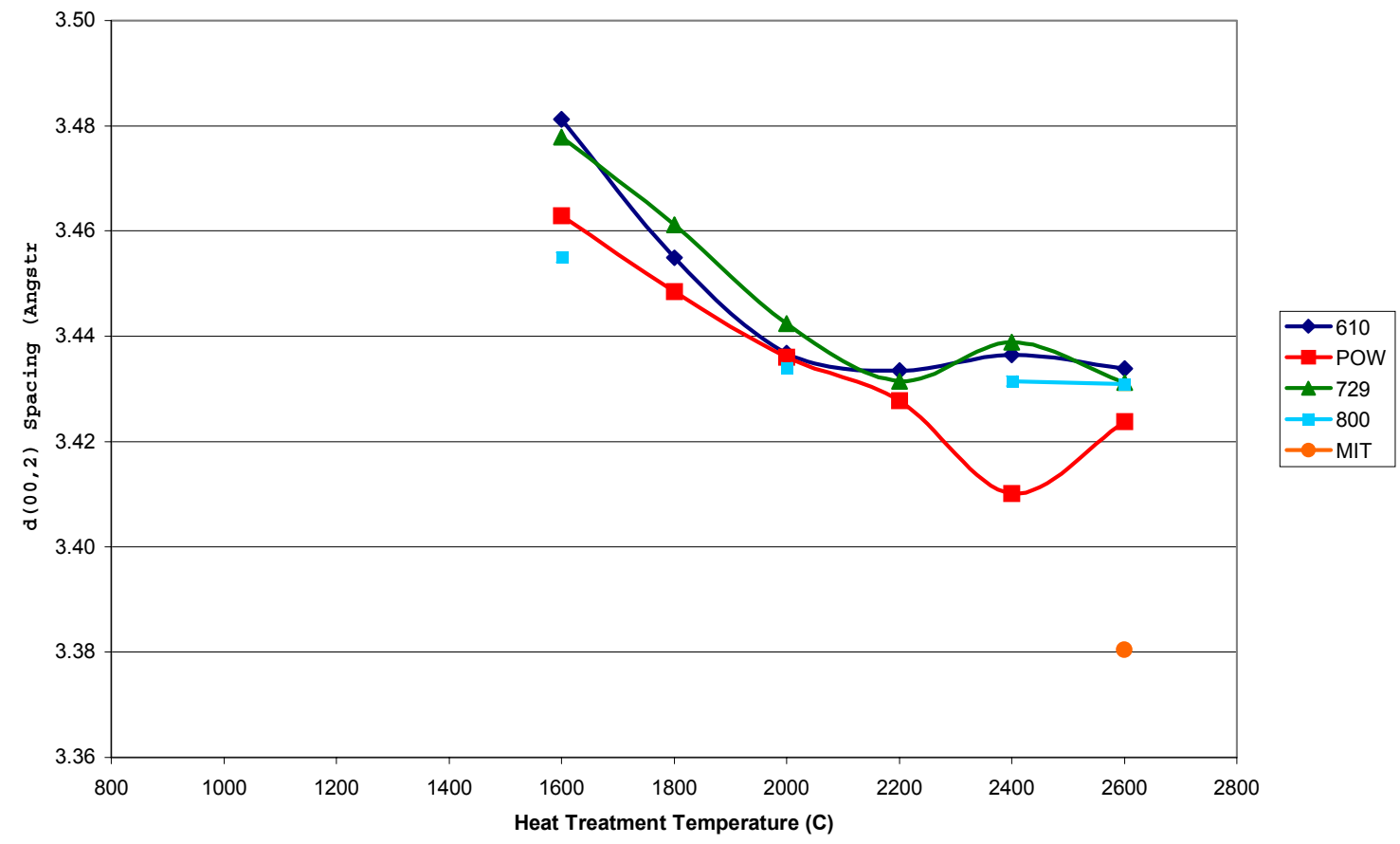

Figure 83. Interplanar spacing $(d(00,2))$ in Angtroms for graphitized coal foams

Degree of Graphitization with Heat Treatment

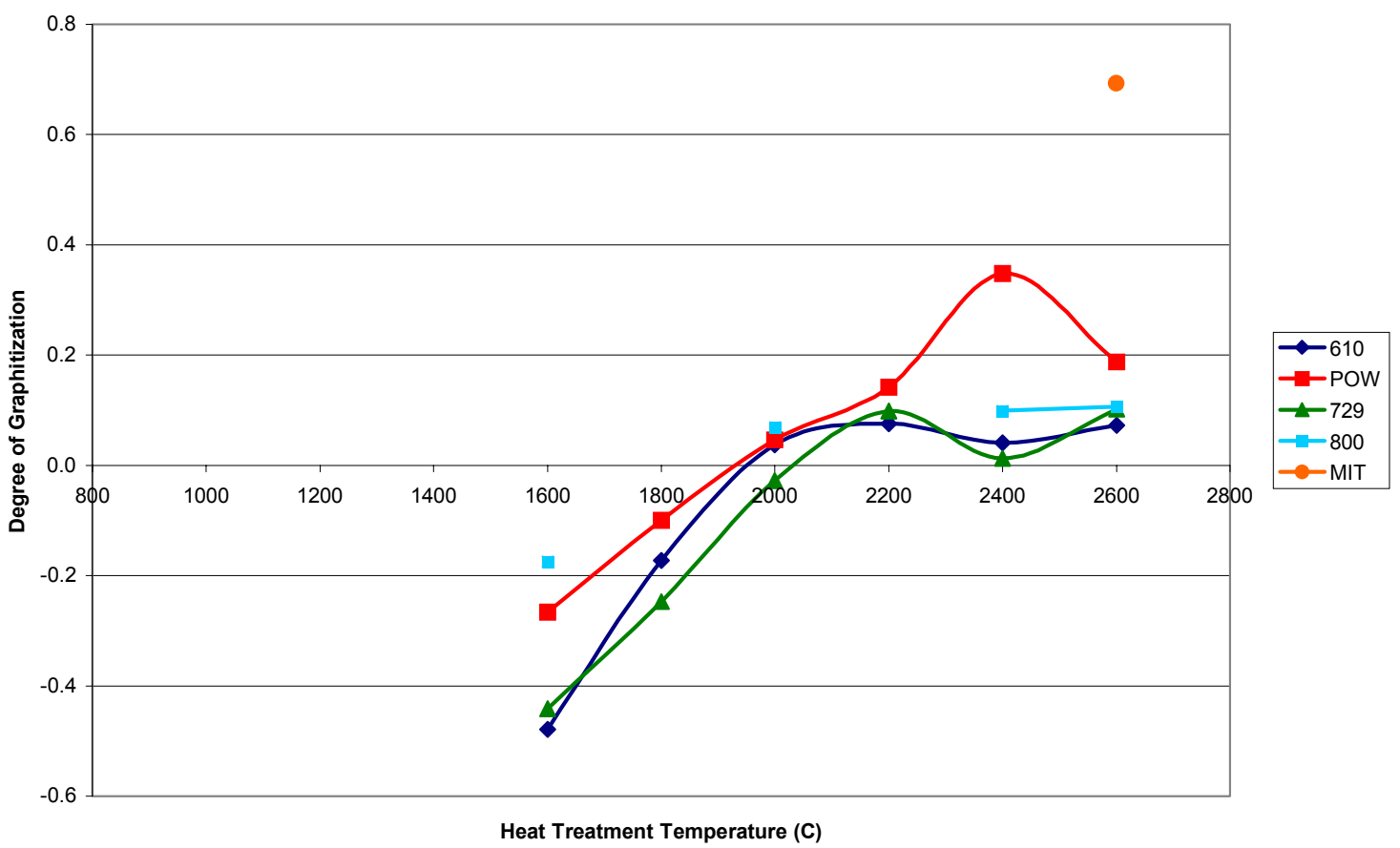

Figure 84. Degree of graphitization, calculated from d(002,), for coal foams 
Stack Height, Lc, with Heat Treatment

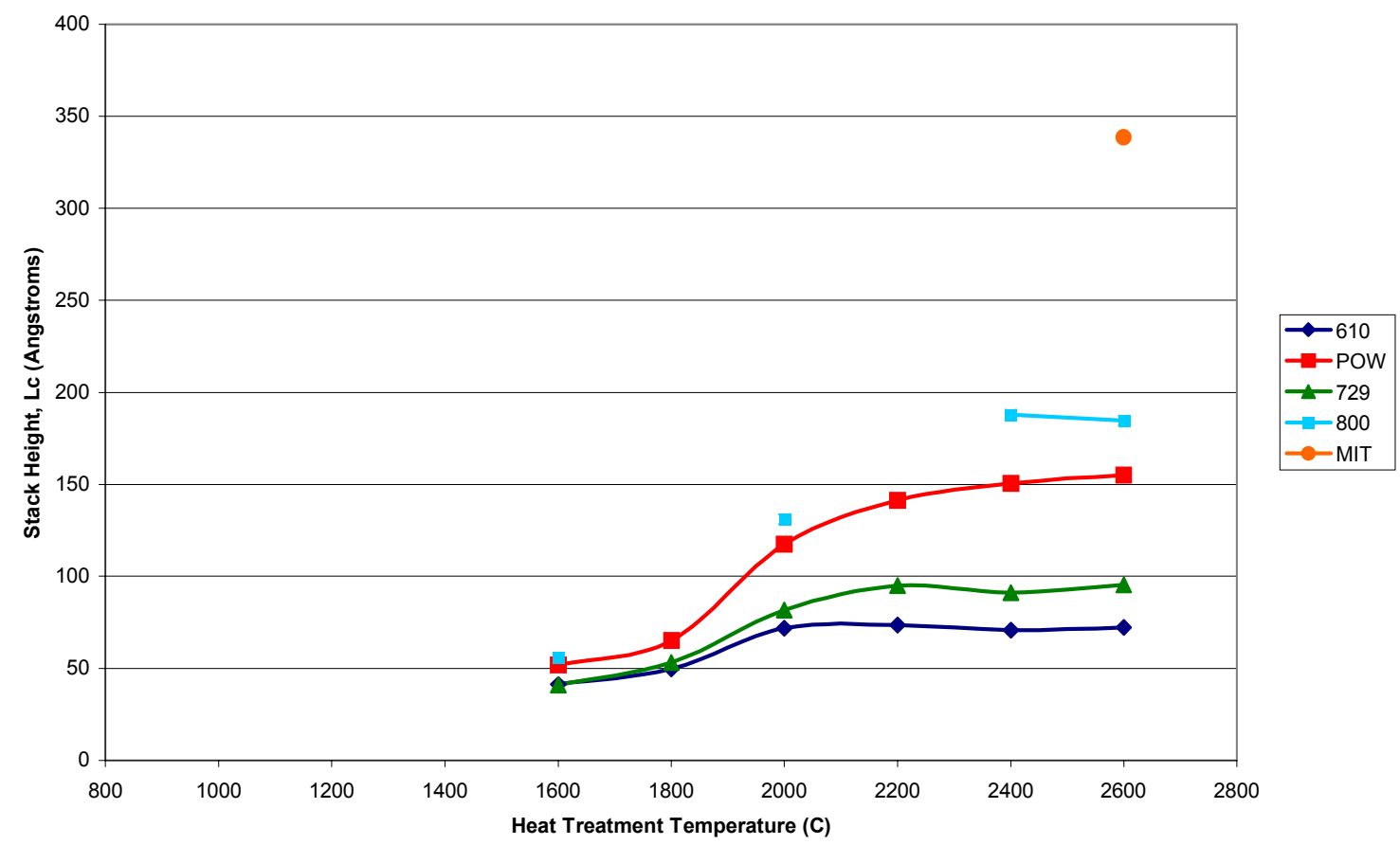

Figure 85. Stack Height (Lc) for graphitized coal foams

Coherence Length, La, with Heat Treatment

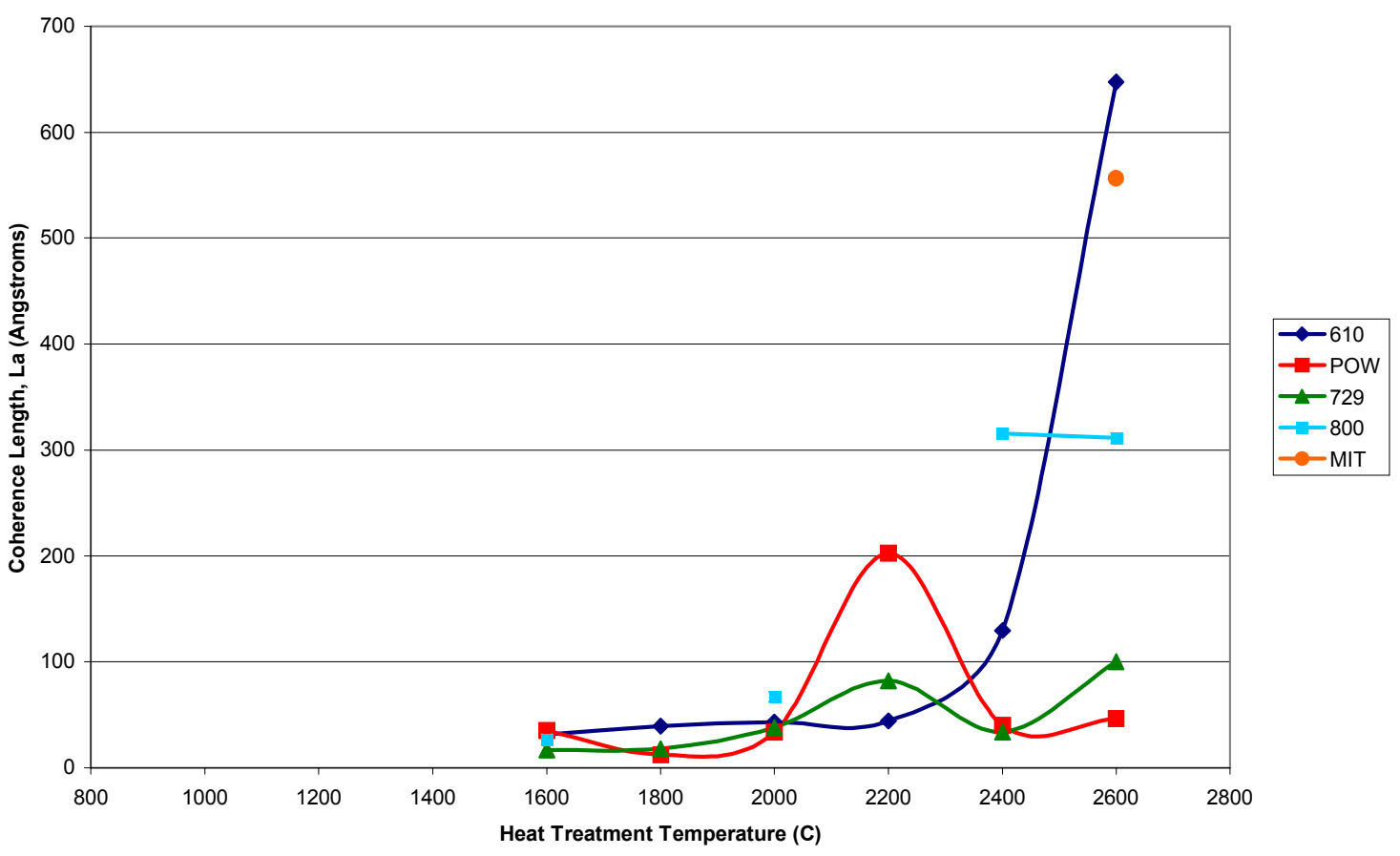

Figure 86. Coherence Length (La) for graphitized coal foams 
Crystal Aspect Ratio with Heat Treatment

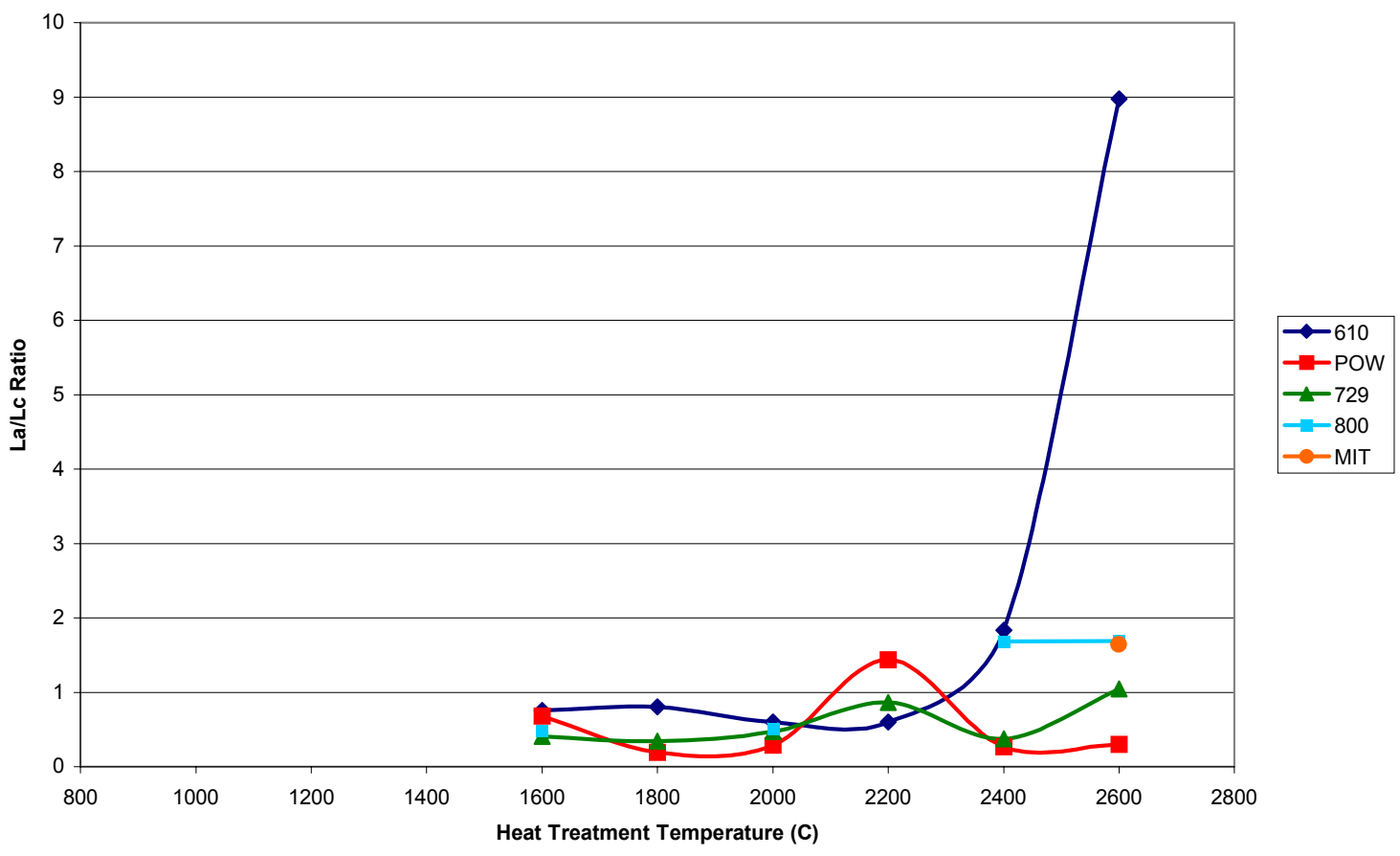

Figure 87. Crystallite aspect ratio (ratio of La to Lc) for graphitized coal foams 
CPCPC Final Technical Report

January 2001

\section{Table 24. Mechanical and physical properties of coal foams graphitized over a range of temperatures}

\begin{tabular}{|c|c|c|c|c|c|c|c|c|c|c|}
\hline Raw Material & Heat Treatment & $\begin{array}{c}\text { Bulk Density } \\
(\mathrm{g} / \mathrm{cc})\end{array}$ & $\begin{array}{c}\text { COV } \\
\text { on Density }\end{array}$ & $\begin{array}{c}\text { Mass Change } \\
(\%, \text { rel. to } 1050)\end{array}$ & $\begin{array}{c}\text { Dimension Change } \\
(\%, \text { rel. to 1050) }\end{array}$ & $\begin{array}{l}\text { Solid Density } \\
(\mathrm{g} / \mathrm{cc})\end{array}$ & Porosity & $K$ & $\begin{array}{c}\text { E, compressive } \\
(p s i)\end{array}$ & $\begin{array}{c}S, \text { compressive } \\
\text { (psi) }\end{array}$ \\
\hline \multirow[t]{7}{*}{610} & 1050 & 0.3758 & 0.0033 & $0.00 \%$ & $0.00 \%$ & 1.9033 & 0.794 & 3.85 & 56,200 & 1,158 \\
\hline & 1600 & 0.3755 & 0.0002 & $5.98 \%$ & $2.25 \%$ & 1.9156 & 0.796 & 3.90 & 52,900 & 1,171 \\
\hline & 1800 & 0.3629 & 0.0034 & $9.55 \%$ & $2.65 \%$ & 1.9188 & 0.801 & 4.03 & 59,300 & 1,134 \\
\hline & 2000 & 0.3682 & 0.0045 & $12.03 \%$ & $3.30 \%$ & 1.9355 & 0.800 & 4.00 & 53,300 & 986 \\
\hline & 2200 & 0.3526 & 0.0018 & $17.04 \%$ & $4.13 \%$ & 1.9065 & 0.807 & 4.18 & 44,100 & 873 \\
\hline & 2400 & 0.3714 & 0.0076 & $13.95 \%$ & $4.20 \%$ & 1.9738 & 0.810 & 4.26 & 23,900 & 900 \\
\hline & 2600 & 0.3629 & 0.0011 & $16.22 \%$ & $4.07 \%$ & 1.9495 & 0.811 & 4.29 & 40,600 & 877 \\
\hline \multirow[t]{7}{*}{ POW } & 1050 & 0.3973 & 0.0004 & $0.00 \%$ & $0.00 \%$ & 1.9208 & 0.793 & 3.83 & 87,800 & 1,425 \\
\hline & 1600 & 0.3897 & 0.0066 & $2.86 \%$ & $2.39 \%$ & 2.0266 & 0.810 & 4.26 & 57,500 & 829 \\
\hline & 1800 & 0.3891 & 0.0033 & $5.06 \%$ & $2.41 \%$ & 2.0353 & 0.810 & 4.26 & 54,000 & 958 \\
\hline & 2000 & 0.3707 & 0.0016 & $8.86 \%$ & $2.35 \%$ & 2.0691 & 0.820 & 4.56 & 36,700 & 802 \\
\hline & 2200 & 0.3658 & 0.0029 & $11.48 \%$ & $3.11 \%$ & 2.0648 & 0.822 & 4.62 & 48,900 & 710 \\
\hline & 2400 & 0.3787 & 0.0010 & $13.21 \%$ & $3.86 \%$ & 2.0369 & 0.814 & 4.38 & 32,700 & 839 \\
\hline & 2600 & 0.3945 & 0.0060 & $10.47 \%$ & $3.78 \%$ & 2.0647 & 0.807 & 4.18 & 50,200 & 914 \\
\hline \multirow[t]{7}{*}{729} & 1050 & 0.5588 & 0.0065 & $0.00 \%$ & $0.00 \%$ & 1.9059 & 0.709 & 2.44 & 152,000 & 3,097 \\
\hline & 1600 & 0.5093 & 0.0023 & $9.98 \%$ & $2.82 \%$ & 1.9891 & 0.745 & 2.92 & 87,300 & 2,729 \\
\hline & 1800 & 0.5045 & 0.0033 & $13.62 \%$ & $3.56 \%$ & 2.0062 & 0.747 & 2.95 & 109,000 & 2,571 \\
\hline & 2000 & 0.4990 & 0.0065 & $16.81 \%$ & $4.10 \%$ & 1.9923 & 0.752 & 3.03 & 108,000 & 1,865 \\
\hline & 2200 & 0.4886 & 0.0078 & $19.64 \%$ & $4.63 \%$ & 1.9731 & 0.755 & 3.08 & 97,100 & 1,646 \\
\hline & 2400 & 0.5048 & 0.0036 & $19.95 \%$ & $4.63 \%$ & 1.9878 & 0.747 & 2.95 & 78,900 & 1,688 \\
\hline & 2600 & 0.4694 & 0.0000 & $20.18 \%$ & $4.34 \%$ & 1.9436 & 0.758 & 3.13 & 75,800 & 1,480 \\
\hline \multirow[t]{7}{*}{800} & 1050 & 0.4905 & 0.0000 & $0.00 \%$ & $0.00 \%$ & 1.9854 & 0.753 & 3.05 & 132,000 & 2,384 \\
\hline & 1600 & 0.4836 & 0.0004 & $3.50 \%$ & $1.58 \%$ & 2.0950 & 0.769 & 3.33 & 85,400 & 1,588 \\
\hline & 1800 & & & & & & & & & \\
\hline & 2000 & 0.4568 & 0.0093 & $8.27 \%$ & $1.65 \%$ & 2.1228 & 0.782 & 3.59 & 75,100 & 1,089 \\
\hline & 2200 & & & & & & & & & \\
\hline & 2400 & 0.4624 & 0.0066 & $8.99 \%$ & $1.84 \%$ & 2.1345 & 0.781 & 3.57 & 54,000 & 1,026 \\
\hline & 2600 & 0.4581 & 0.0015 & $8.82 \%$ & $1.45 \%$ & 2.1252 & 0.784 & 3.63 & 47,300 & 986 \\
\hline
\end{tabular}


Foam Bulk Density with Heat Treatment

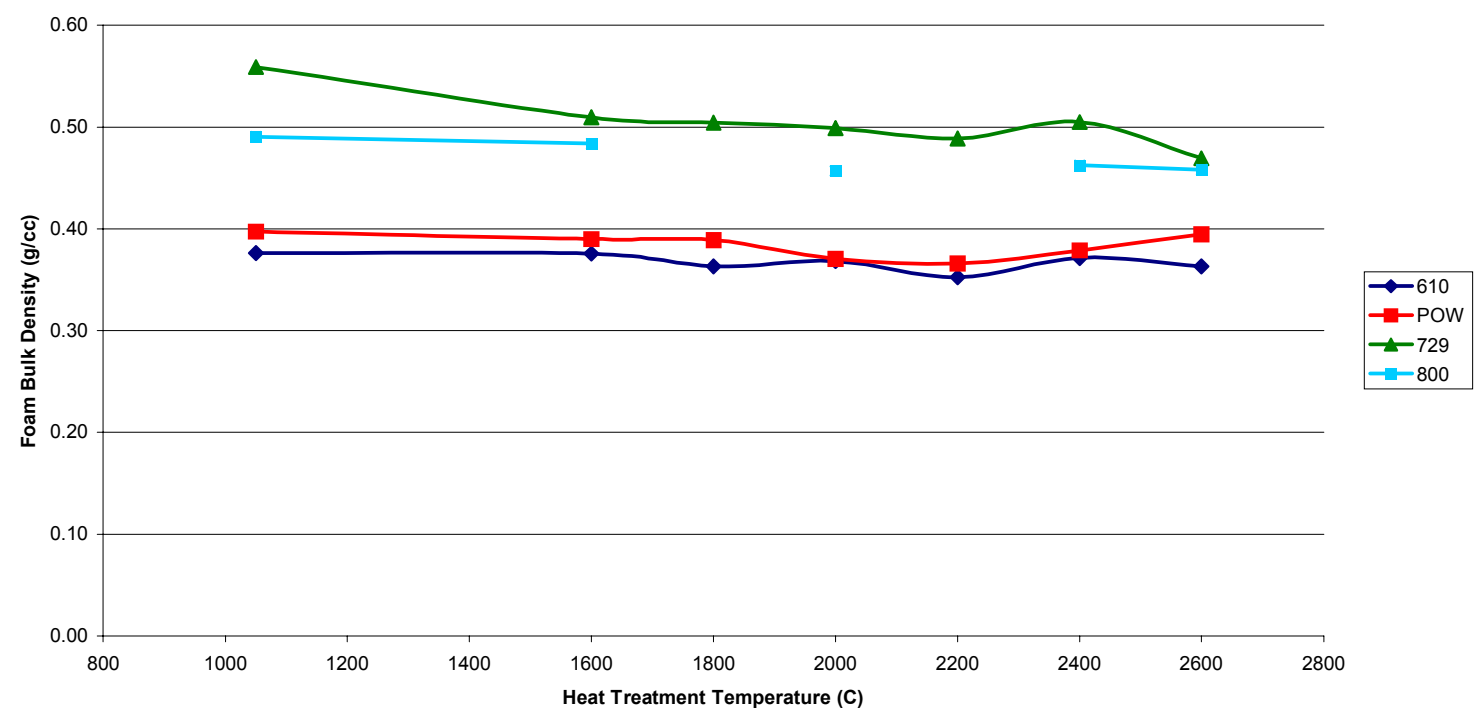

Figure 88. Graphitzed foam bulk density versus heat treatment temperature

Foam Solid Density with Heat Treatment

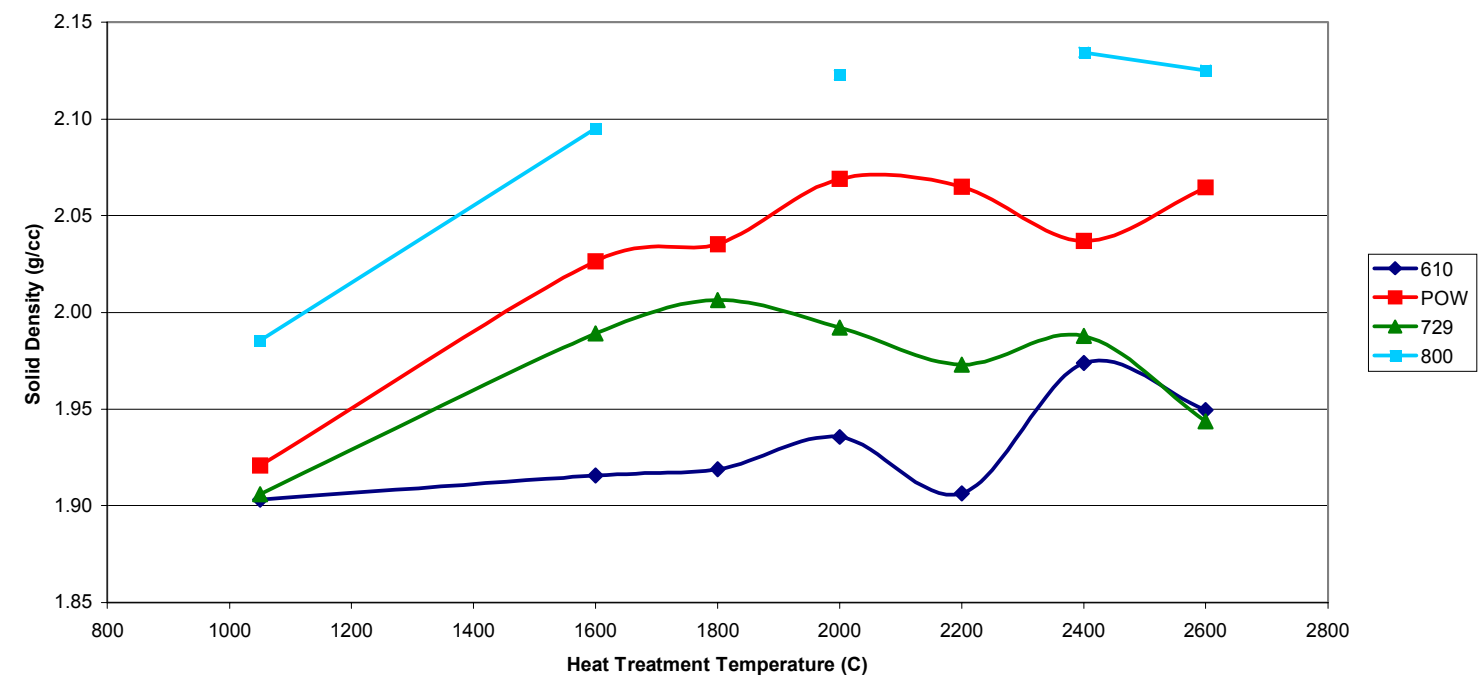

Figure 89. Graphitized foam true (solid) density, as determined by helium pycnometry 
Foam Porosity with Heat Treatment

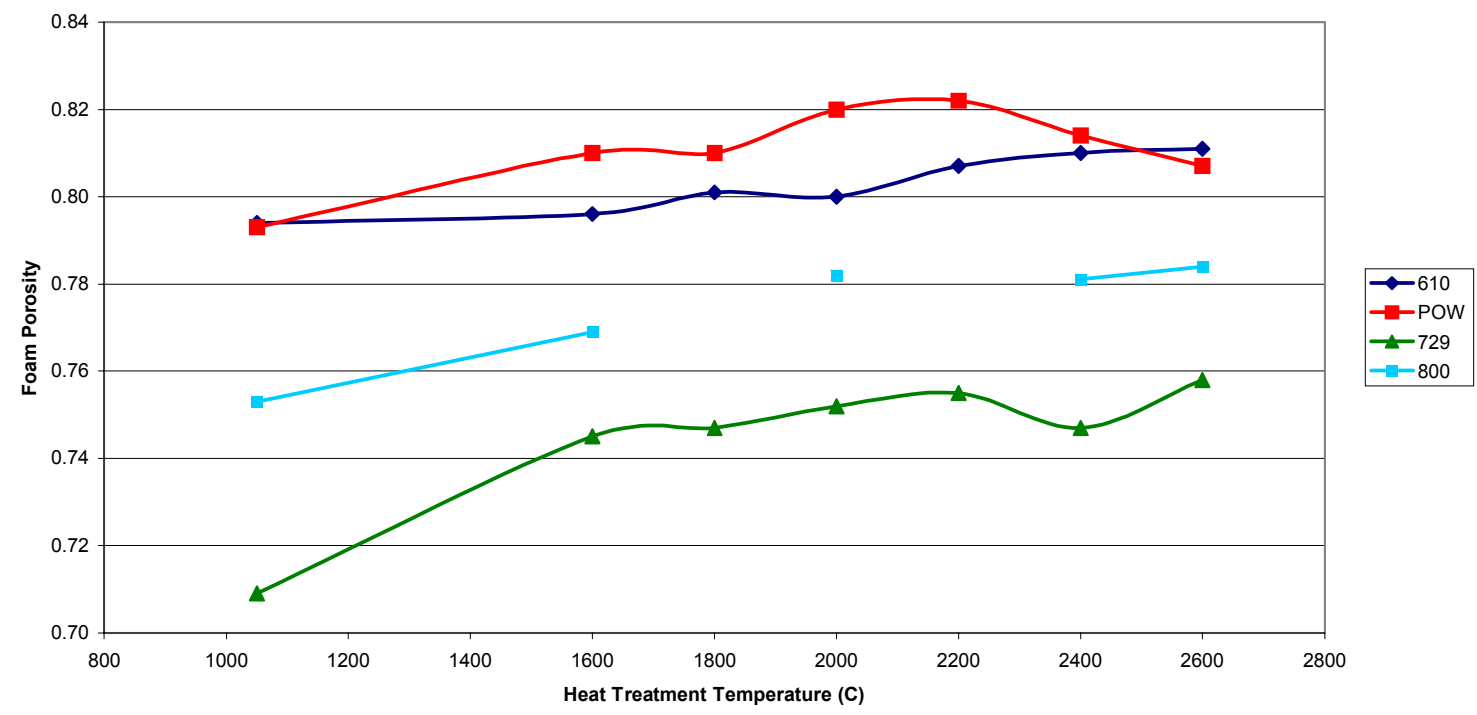

Figure 90. Graphitized foam porosity, as calculated from bulk and tue (solid) density

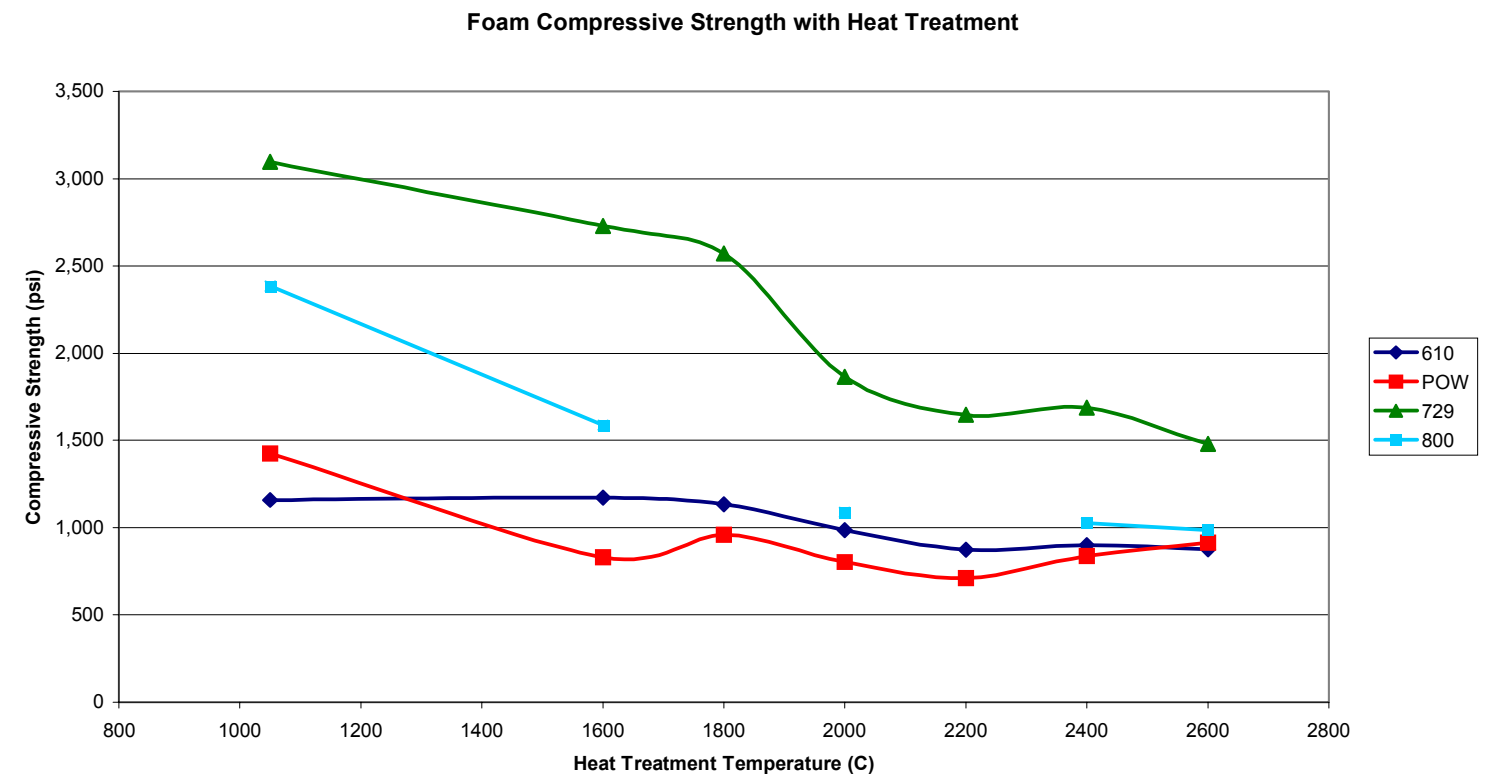

Figure 91. Graphitized foam compressive strength 


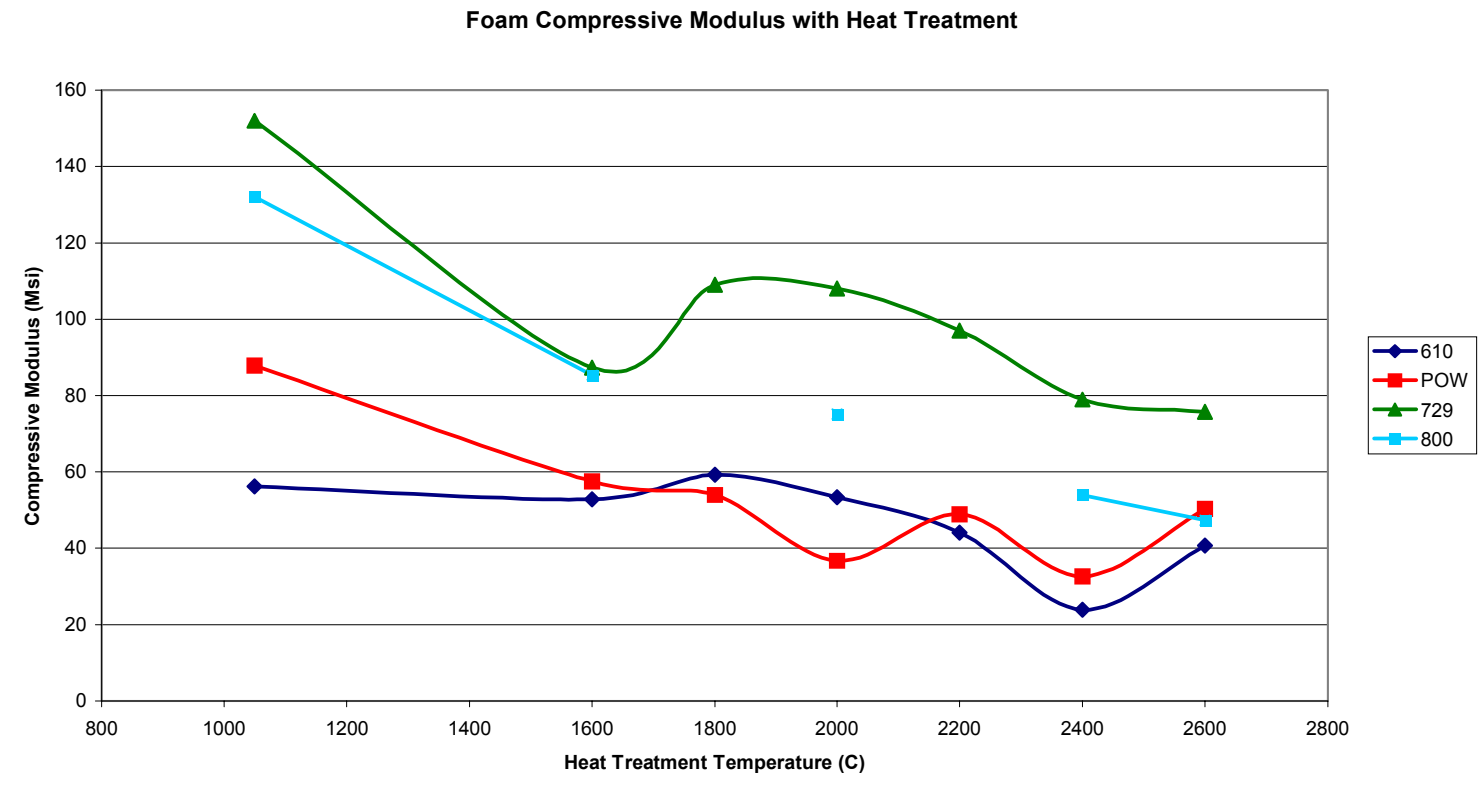

Figure 89. Graphitized foam compressive modulus

\section{TASK 7.0 CHARACTERIZATION OF FOAM STRUCTURE AND MORPHOLOGY}

All carbon foam articles were characterized, in both the "green" and calcined states, by optical microscopy. Examples of "green" and calcined foam structures, in the form of photographs of diametric cuts of the foam articles are shown for coals 610 and 800 in Appendix A. These photos trace the development of foam cellular structure with increase in foaming temperature. Other data was collected to characterize the foams, including density (pycnometry) and mercury porosimetry. These were summarized under the previous task.

\section{TASK 8.0 MODELING}

Touchstone currently is developing mathematical models, based on these data, to aid in process development.

\section{TASK 9.0 REPORTING}

This document serves as the final technical report for this effort. The author wold like to thank the Consortium for Premium Carbon Product from Coal (CPCPC) for their support of this practical study of the foaming process as is related to coal precursors. This effort has allowed Touchstone to improve its understanding of

- which coals are potential foaming precursors and why,

- how the foam structure develops in coals as functions of temperature, time, and pressure, 
- methods for rapid characterization of new candidate precursors and the process alterations that they might require in order to produce high-quality foams,

- the mechanical and physical properties of foams in the "green" and calcined states,

- how different precursors develop graphitic crystal structures during high temperature heat treatment,

- the roles of sulfur and ash on the graphitization behavior of different precursors, and

- how mechanical properties can be tailored through high temperature heat treatment.

This data have, by no means, been thoroughly examined, and these data will continue to be referenced as Touchstone develops and commercializes the carbon foam process. Touchstone has also expanded its use of coals to include multiple materials from the coals studied under this effort in Touchstone's pilot-scale production efforts.

\section{Additional Progress}

Touchstone would like to add a description of additional program made in the Fall of 2000 toward the manufacturing scale-up of coal-based carbon foams, further illustrating the importance of this research effort toward process understanding and the momentum behind commercialization of coal-based foams.

In July, 2000, Touchstone installed a pilot-scale facility to produce carbon foam panels at dimensions of up to 24-inches square. It includes

- pilot-scale autoclave (34-inches internal diameter x 42 -inches working length; $550^{\circ} \mathrm{C}$ and 500 psi operating capability), fabricated by Ionics, Inc.,

- Bolttech hydraulic stud tensioners (5) and hydraulic pump to apply the $120,000 \mathrm{ft}-\mathrm{lbs}$ required for each of the 20 autoclave flange bolts,

- stainless steel shelving, molds, tooling, and cans for foaming and calcining processes,

- gas supply and pressure control equipment,

- calcination furnace (32-inches cube; $1200^{\circ} \mathrm{C}$ maximum temperature, with potential for inert atmosphere control), fabricated by Hy-Tech Sales,

- Holmes coal crusher and pulverizer,

- Cleveland Vibratory Co. vibratory table for molding loading control,

- hydraulic lift for furnace loading,

- workbenches and tools, and

- a heated external shed for raw material storage and staging.

A photograph of the pilot area, during its construction, is shown in Figure 90. 


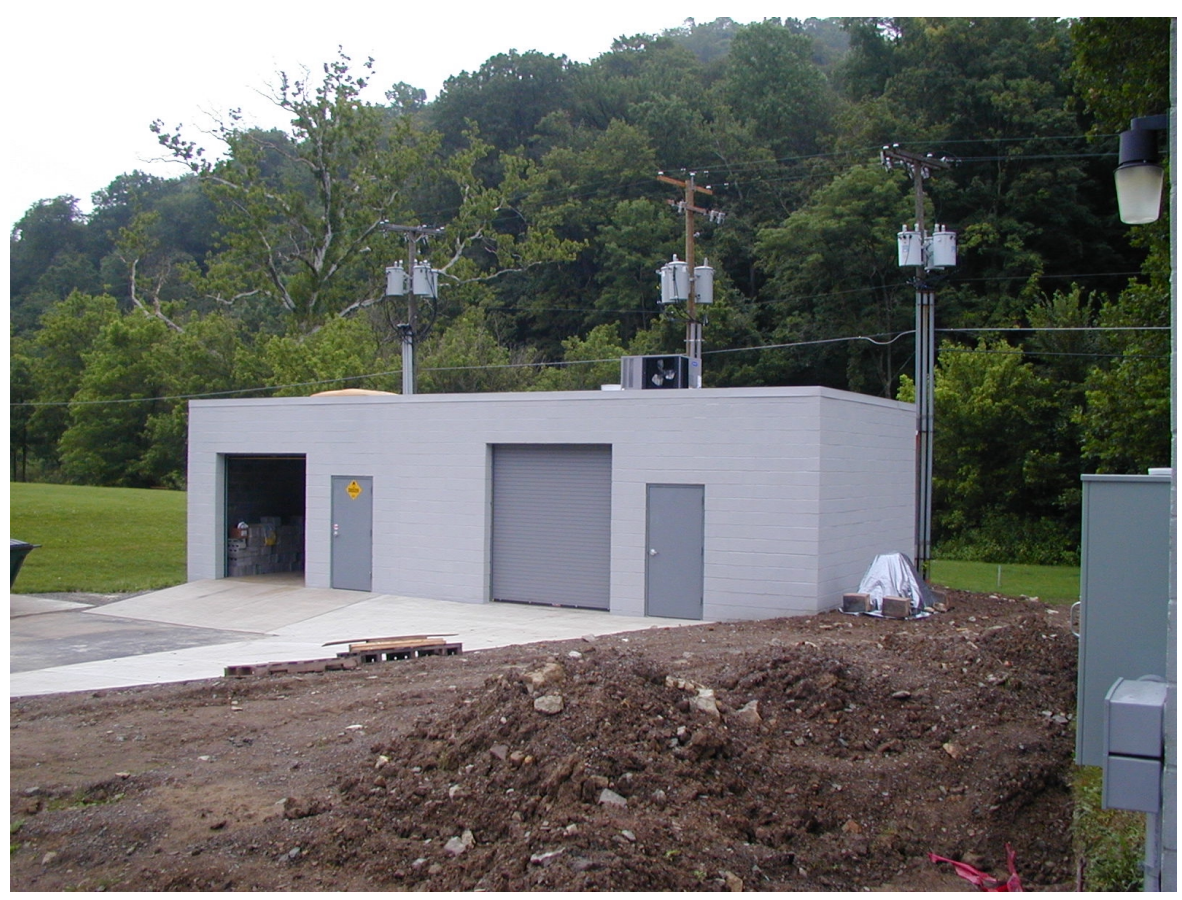

Figure 90. Carbon foam pilot area, under construction

This area was intended for use to (1) verify scale-up potential of the carbon foam technology beyond laboratory equipment, and (2) support carbon foam production until a larger facility could be completed. Touchstone currently is preparing to build a 12,000 square foot pilot production facility that will support production of wallboard size panels (4-feet by 8-feet), starting in spring 2001. Based on findings from this pilot area, larger autoclave, furnace, finishing, and material handling equipment has been specified.

The autoclave is shown in Figure 91, during installation, and in Figure 92, loaded for service. It is heated by six mineral-filled band heaters, each consisting of three $120^{\circ}$ arcs that are bolted together and supply 18,000 watts. Within about three months, the major difficulties related to scale-up of the foaming process from laboratory reactors to the pilot-scale (up to 24-inch panels) had been identified and addressed. Examples of large (typically 12-inch, 16-inch, and 20-inch breadth by 1 - to 3 -inch thickness) disk and rectangular articles just after removal from the foaming reactor are shown in Figures 93 and 94. After heat treatment, they can be machined, as illustrated in Figures 95 through 98, to remove surface defects (Figure 95), produce demonstration articles (such as the tongue-and-groove joint in Figure 96), produce large components (Figure 97), or produce specimens for mechanical and physical tests (Figure 98). 


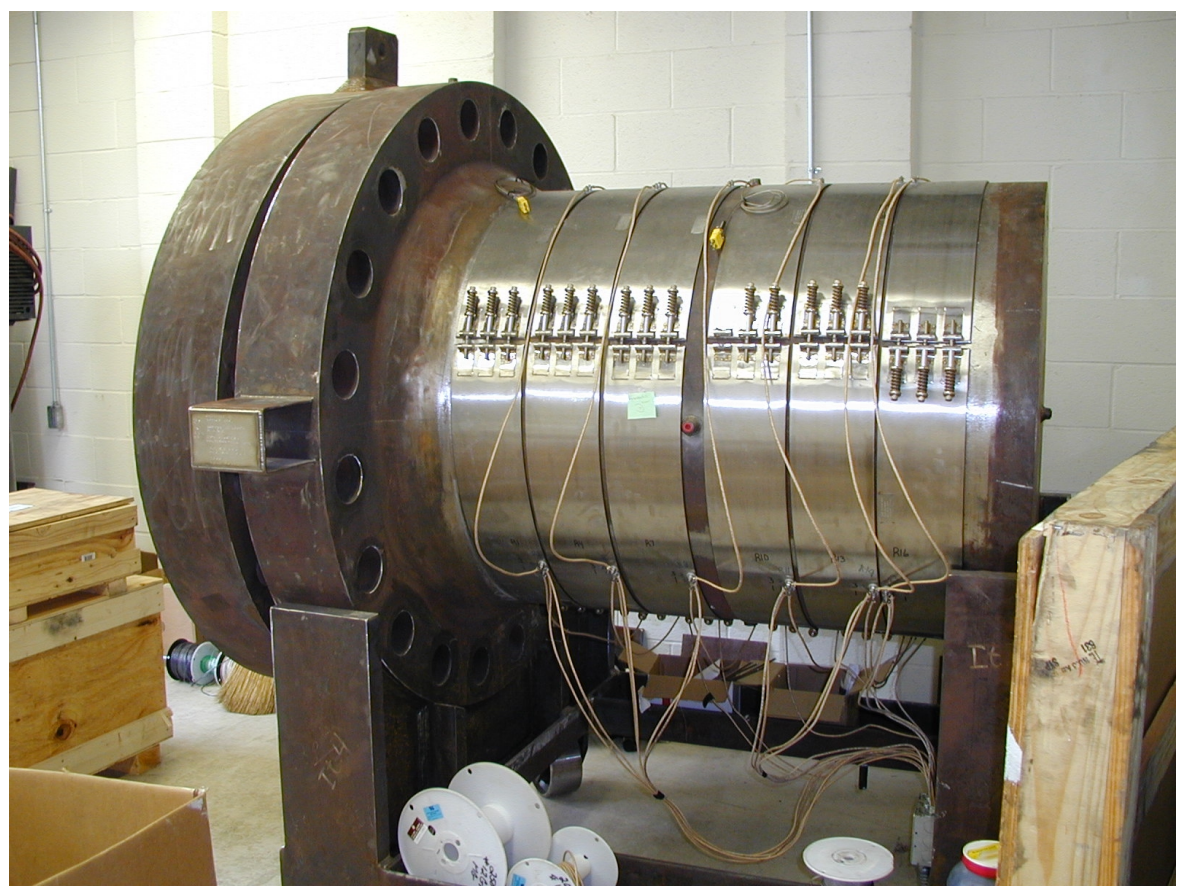

Figure 91. Foaming process autoclave during installation

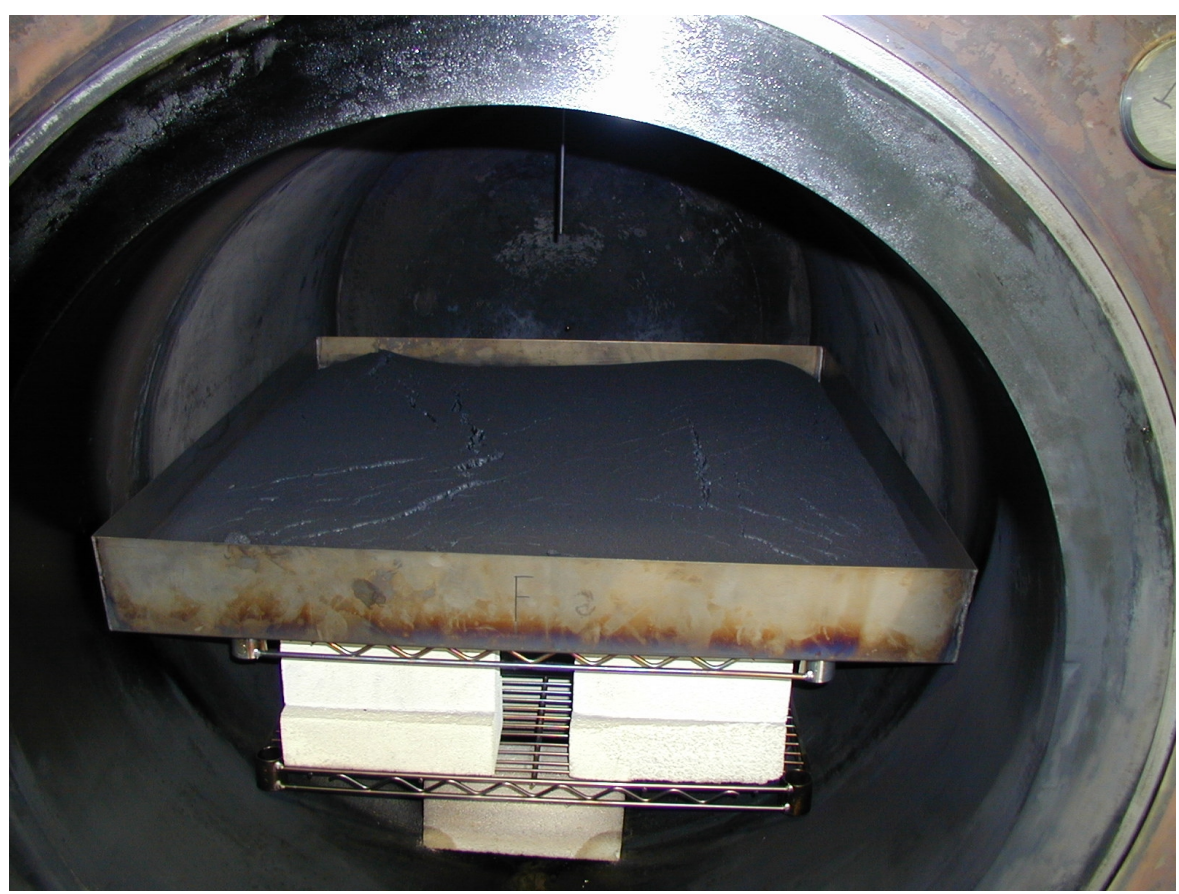

Figure 92. Pilot-scale reactor loaded for service 


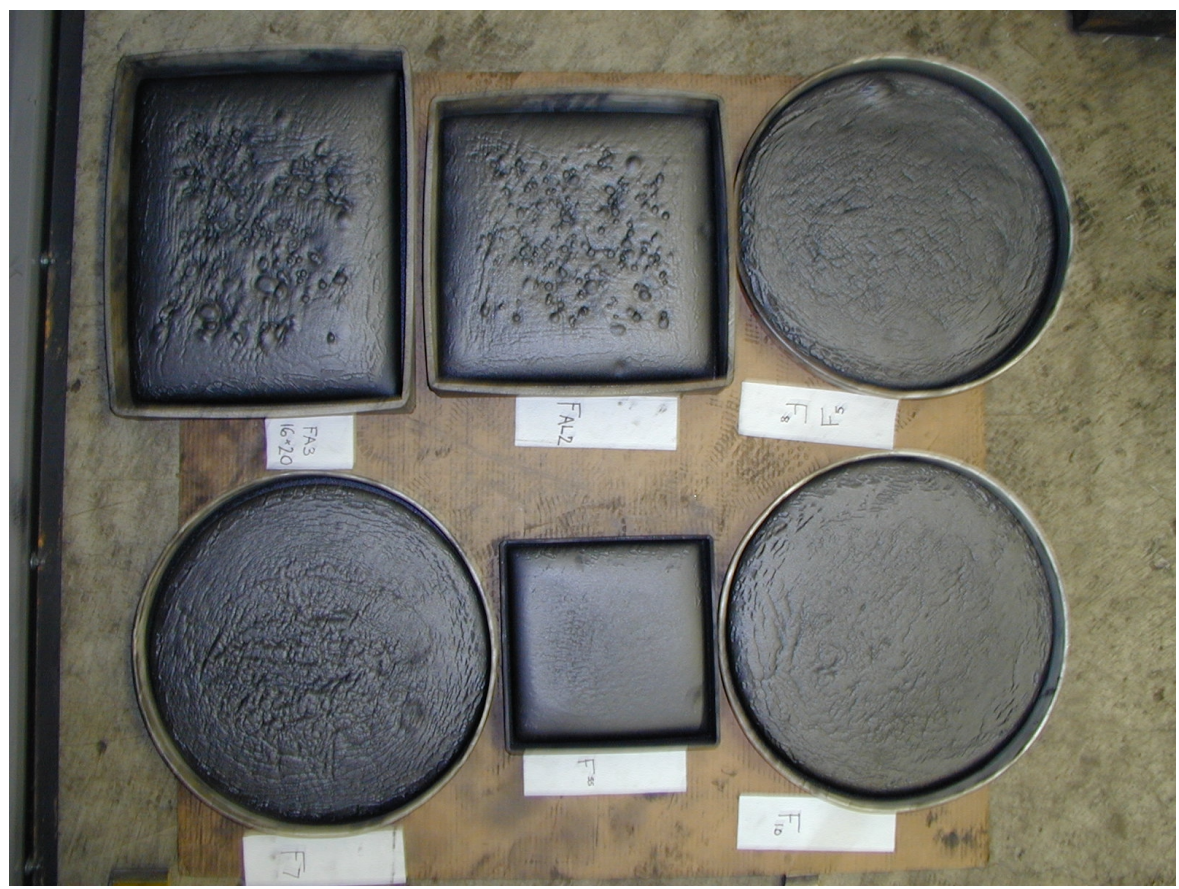

Figure 93. Six successful panels from a single foam production trial

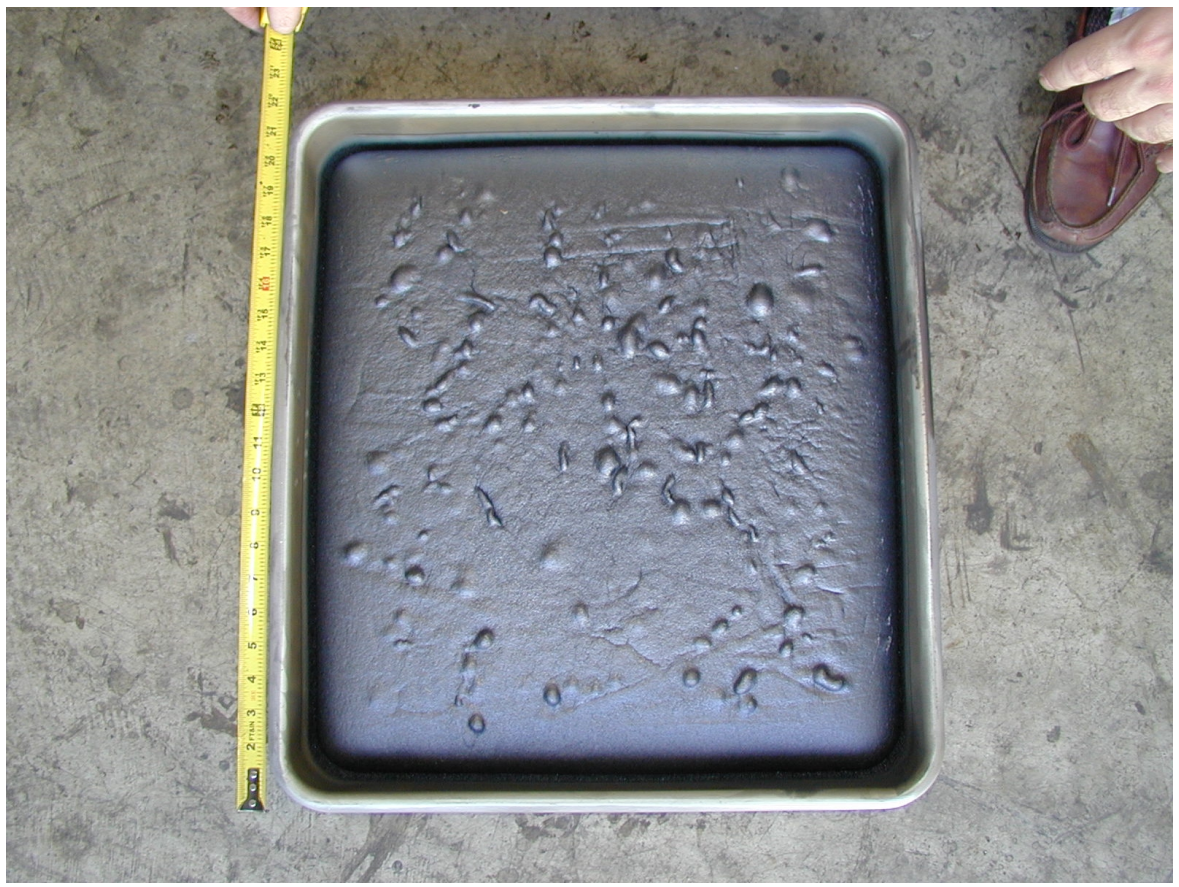

Figure 94. Close-up of 20-inch by 16-inch by 3-inch carbon foam panel, showing surface defects that are easily removed by milling 


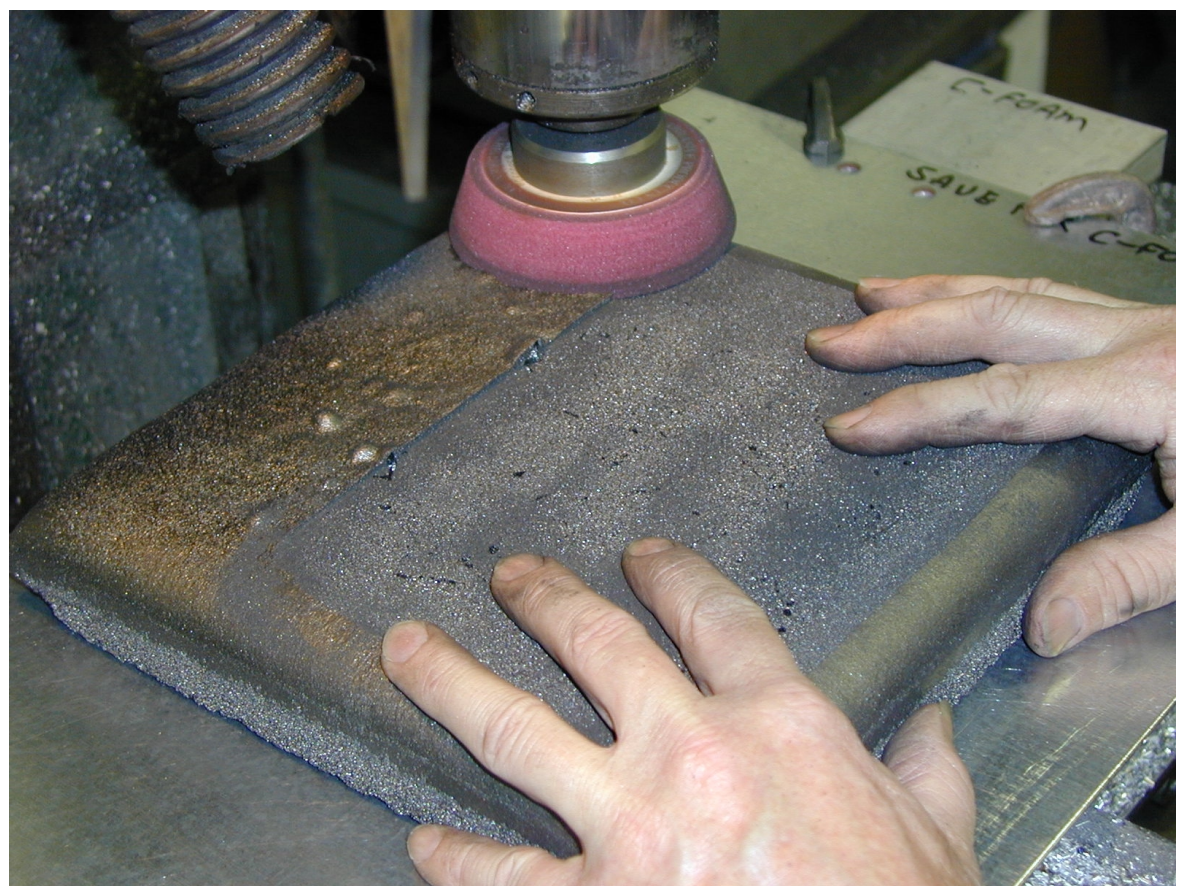

Figure 95. Removal of surface defects by milling with a diamond media cup wheel

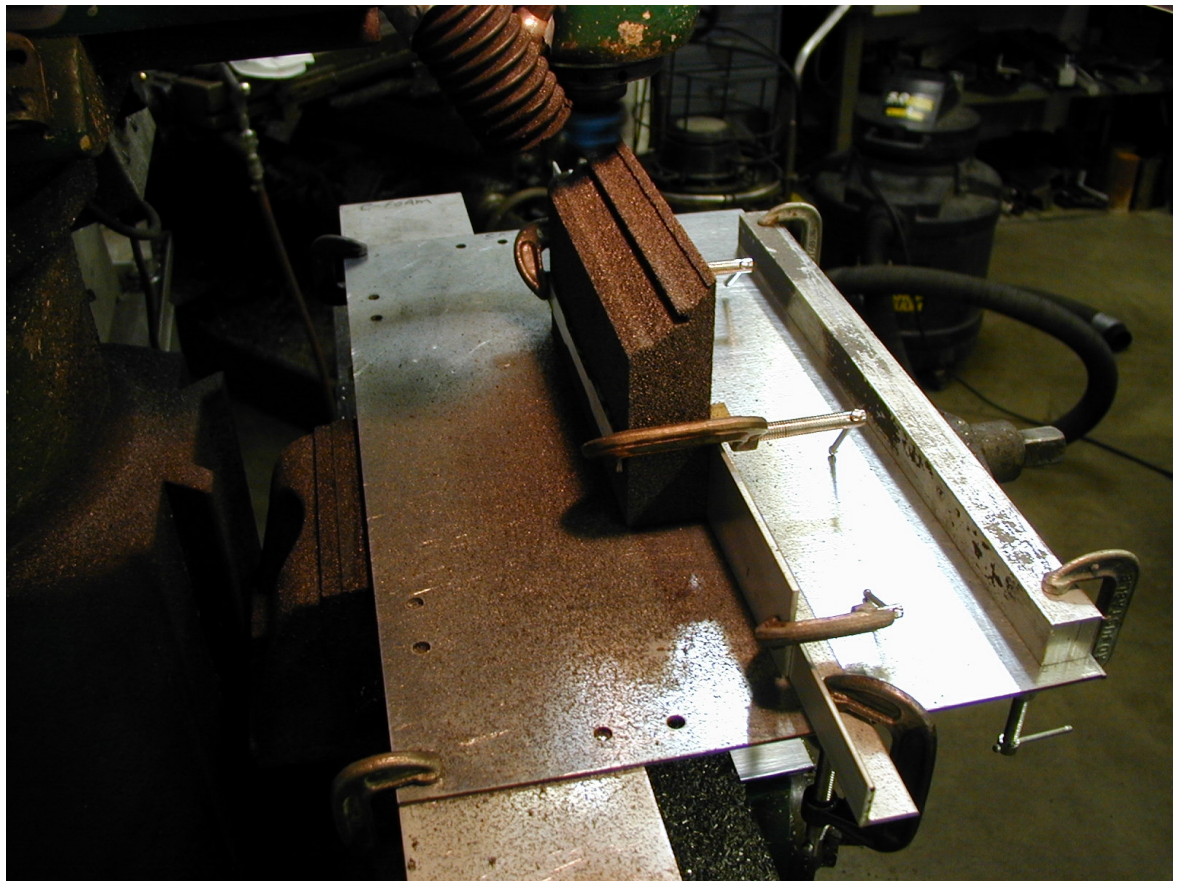

Figure 96. Routed complex tongue-and-groove corner joint specimen on milling table 


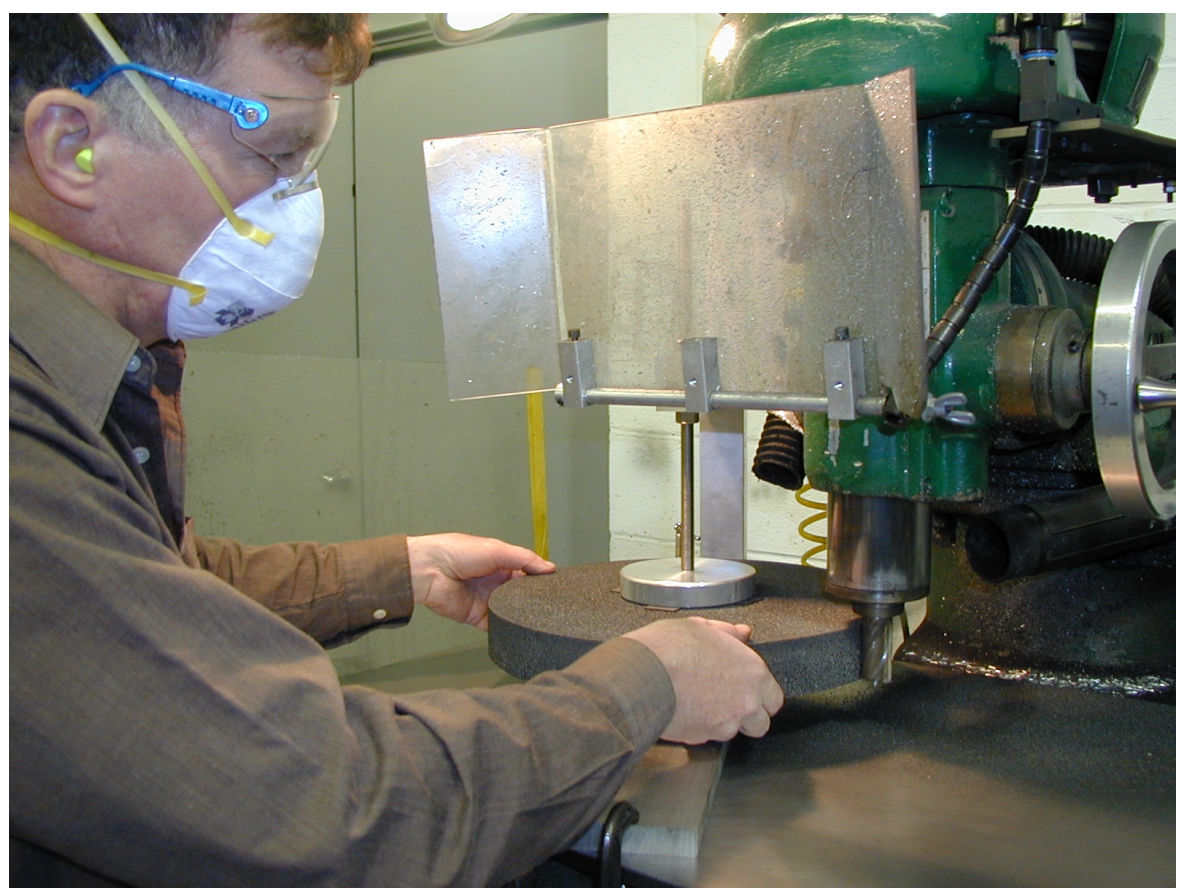

Figure 97. Milling a calcined carbon foam panel to specified shape/size

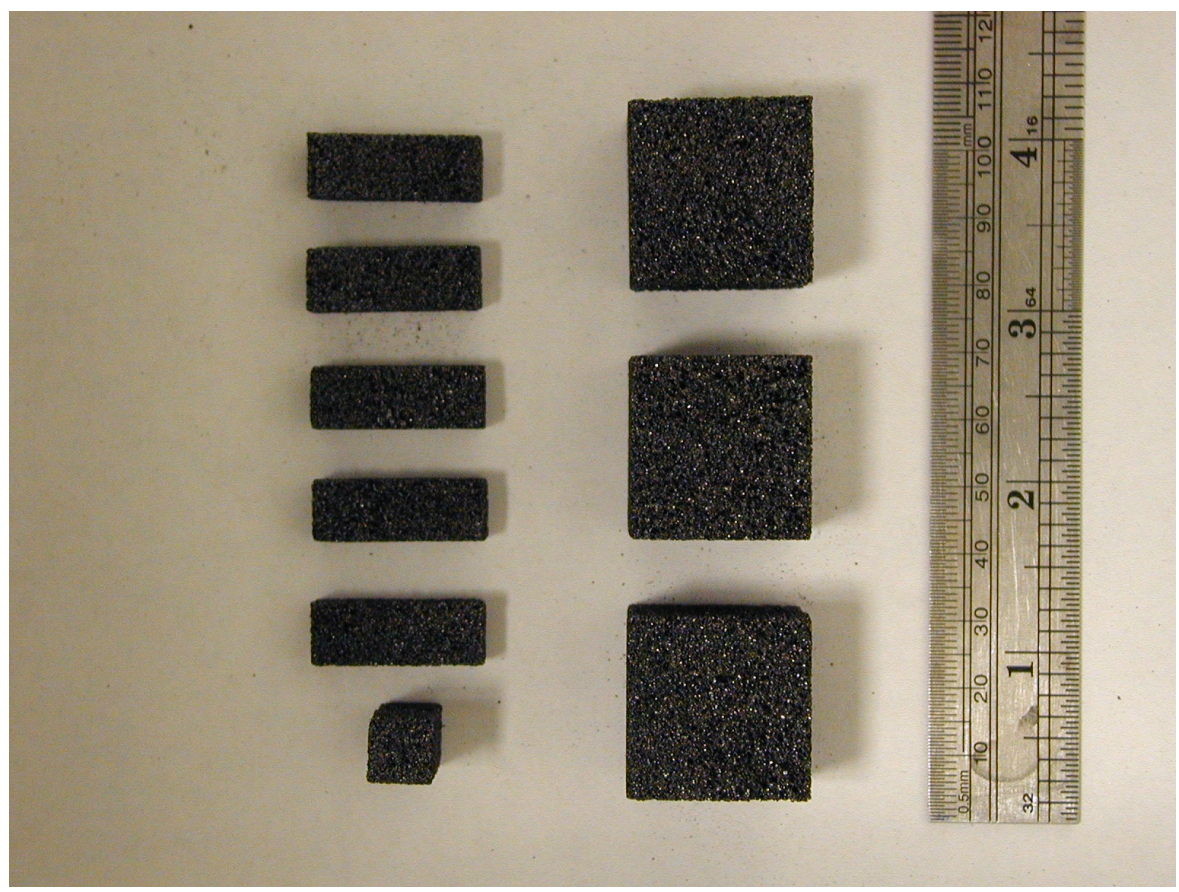

Figure 98. Tensile and physical test specimens cut from larger panel 


\section{Appendix A.}

\section{Photos of "Green" and Calcined 610 and 800 Carbon Foam Structures}




\section{Coal - Calcined Foam Structures}

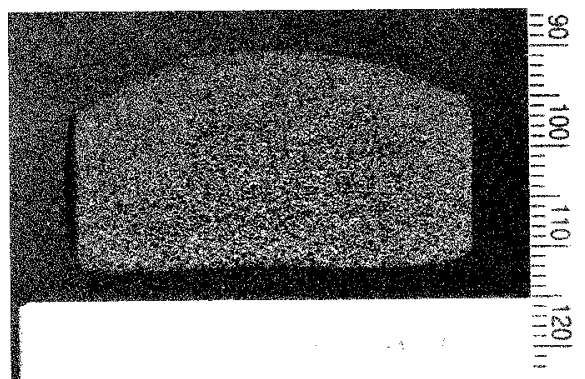

foamed at 500 psi and $425^{\circ} \mathrm{C}$, calcined to $1050^{\circ} \mathrm{C}$

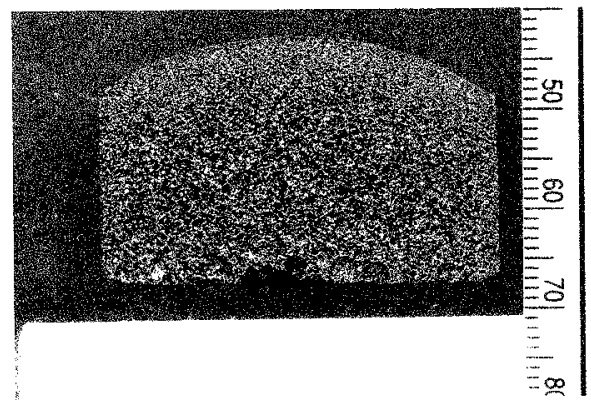

foamed at 500 psi and $450^{\circ} \mathrm{C}$, calcined to $1050^{\circ} \mathrm{C}$

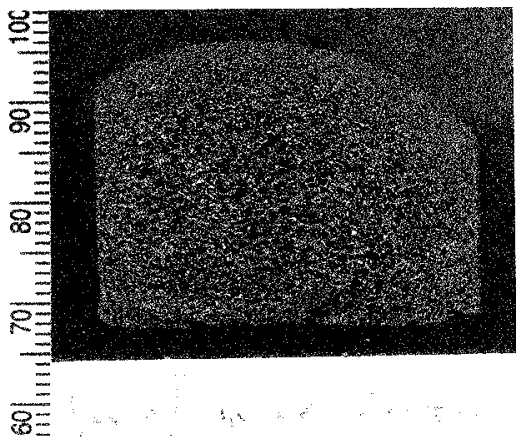

foamed at 500 psi and $475^{\circ} \mathrm{C}$, calcined to $1050^{\circ} \mathrm{C}$

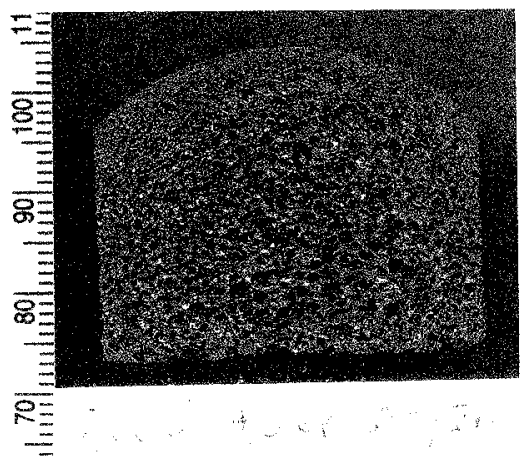

foamed at 500 psi and $500^{\circ} \mathrm{C}$, calcined to $1050^{\circ} \mathrm{C}$ 


\section{Coal - Calcined foam Structures}

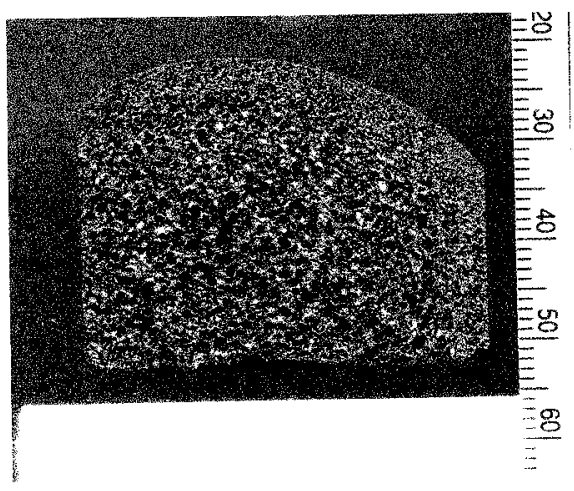

foamed at 500 psi and $525^{\circ} \mathrm{C}$, calcined to $1050^{\circ} \mathrm{C}$ 


\section{Coal - Calcined roam Structures}

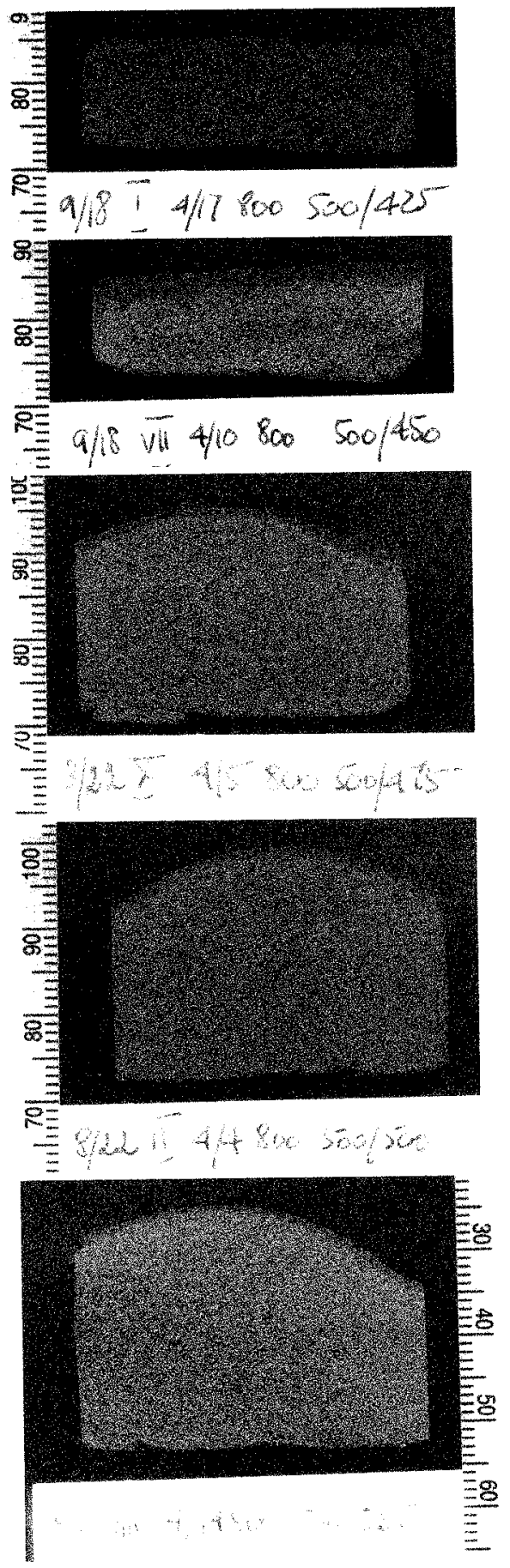

foamed at $500 \mathrm{psi}$ and $425^{\circ} \mathrm{C}$, calcined to $1050^{\circ} \mathrm{C}$

foamed at $500 \mathrm{psi}$ and $450^{\circ} \mathrm{C}$, calcined to $1050^{\circ} \mathrm{C}$

foamed at $500 \mathrm{psi}$ and $475^{\circ} \mathrm{C}$, calcined to $1050^{\circ} \mathrm{C}$

foamed at 500 psi and $500^{\circ} \mathrm{C}$, calcined to $1050^{\circ} \mathrm{C}$

foamed at 500 psi and $525^{\circ} \mathrm{C}$, calcined to $1050^{\circ} \mathrm{C}$ 


\section{Coal - Calcined Foam Structures}

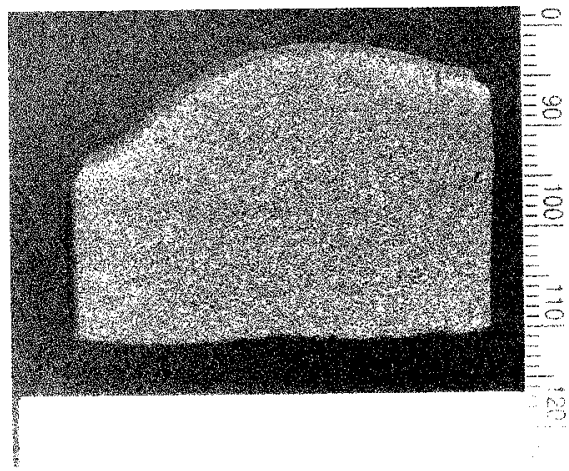

foamed at 500 psi and $550^{\circ} \mathrm{C}$, calcined to $1050^{\circ} \mathrm{C}$ 


\section{Appendix B.}

\section{X-Ray Diffraction Scans for Graphitized Samples and Method Employed for Analysis}




\section{Key to X-ray Diffraction Scans}

The four coals for which the structural changes that occur during graphitization were studied were labeled as follows:
A $=610$ coal,
$\mathrm{B} \quad=729$ coal,
$\mathrm{C} \quad=$ POW coal, and
$\mathrm{D}=800$ coal.

For each coal, samples heat-treated to different ultimate temperatures are noted as

$\begin{array}{ll}1 & =1600^{\circ} \mathrm{C}, \\ 2 & =1800^{\circ} \mathrm{C}, \\ 3 & =2000^{\circ} \mathrm{C}, \\ 4 & =2200^{\circ} \mathrm{C}, \\ 5 & =2400^{\circ} \mathrm{C}, \text { and } \\ 6 & =2600^{\circ} \mathrm{C},\end{array}$

with the exception of lot D (800 coal), for which less calcined foam was available. For lot D, then, the samples are noted as

$\begin{array}{ll}1 & =1600^{\circ} \mathrm{C}, \\ 2 & =2000^{\circ} \mathrm{C}, \\ 3 & =2400^{\circ} \mathrm{C}, \text { and } \\ 4 & =2600^{\circ} \mathrm{C} .\end{array}$

Thus, sample A1 was 610 coal foam graphitized to $1600^{\circ} \mathrm{C}$ and sample $\mathrm{C} 5$ was POW coal foam graphitized to $2400^{\circ} \mathrm{C}$.

For each lot (A-D, plus foam made from Mitsubishi ARA24 resin graphitized to $2600^{\circ} \mathrm{C}$ and labeled "Lot $\mathrm{M}$ "), the first page is a summary and shows the X-ray diffraction scan for each of the samples of that lot. Subsequent pages show individual scans of (1) the raw intensity versus

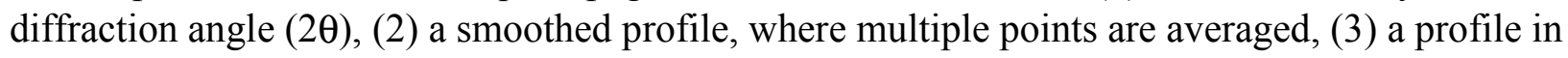
which the background has been subtracted, (4) a profile in which the K $\alpha$ components of the copper incident X-radiation have been separated, and (5) a peak line graph. 


\section{X-ray Diffraction Analysis Method}

The following is a summary of the techniques employed to analyze X-ray diffraction data, and for the determination of crystallite size and other parameters.

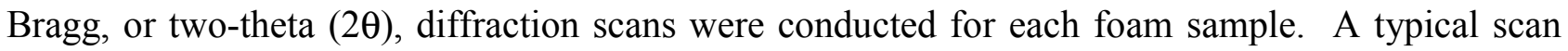
involved scanning the angular range of 22 to $85^{\circ}$ two-theta at a scan rate of $0.25^{\circ}$ per minute. When greater precision was required for a-directional crystallite size measurements, the scan range was reduced to $6^{\circ}$ symmetrically surrounding the diffraction peak of interest and the diffractometer was operated in step-scan mode. The step increment was chosen to be $0.025^{\circ}$ and the count time at each increment was 10 seconds. In both cases, the X-ray source was operated at a voltage of $40 \mathrm{kV}$ and a tube current of $30 \mathrm{~mA}$, while the solid state detector was operated at a negative bias of $1000 \mathrm{mV}$.

Foam samples were ground to a fine powder by ceramic mortar and pestal and/or vibratory mill, and placed in the powder diffraction holder. While it has been shown that lengthy ball-milling affects the crystal structure of carbons, the "light" grinding employed during this study was considered to have negligible influence. Step scans employing $0.025^{\circ}$ steps and 10 seconds per step were used to scan the angular ranges corresponding to the (0002), (1010), (0004), and (1120) diffraction peaks. The same information concerning interplanar spacing, crystallite size, and strain could be obtained, but, of course, (0002) orientation could not be measured.

The intensity-diffraction angle spectrum contained the diffraction pattern of the fiber sample in addition to a diffuse background. A number of factors contributed to the background, including Compton-modified scattering, non-monochromatic radiation (both bremsstrahlung and Ka2), and absorption. Fortunately, the background could be subtracted by a routine by the diffractometer software. The same routine also removed all peak doublets due to the $\mathrm{K}_{\alpha 2}$ component of the incident radiation, and applied the Lorentz-polarization factor to the measured intensities.

Analysis of an individual peak meant first fitting a split-Pearson VII profile to the intensity data and determining the angular location and full-width-at-half-maximum, $\beta$. The Pearson VII profile, which has the form

$$
\mathrm{I}_{\mathrm{n}, \mathrm{k}}=\frac{2 \sqrt{m} \Gamma\left(2^{1 / m}-1\right)}{\pi \Gamma(m-0.5) \beta_{k}}\left[1+\frac{4\left(2^{1 / m}-1\right)}{\beta_{k}^{2}}\left(2 \theta_{n}-2 \theta_{k}\right)^{2}\right]^{-m},
$$

was chosen for two reasons: (1) it allows the exponent to be modified, giving the model one degree of freedom more than either the Gaussian and Cauchy models, which have the forms

$$
\begin{gathered}
\mathrm{I}_{\mathrm{n}, \mathrm{k}}=\frac{2 \sqrt{\ln 2}}{\beta_{k}} \exp \left[\frac{-4 \ln 2}{\beta_{k}^{2}}\left(2 \theta_{n}-2 \theta_{k}\right)^{2}\right] \text { and } \\
\mathrm{I}_{\mathrm{n}, \mathrm{k}}=\frac{\sqrt{4}}{\beta_{k}}\left[1+\frac{4(\sqrt{2}-1)}{\beta_{k}^{2}}\left(2 \theta_{n}-2 \theta_{k}\right)^{2}\right]^{-1},
\end{gathered}
$$




\section{CPCPC Final Technical Report}

January 2001

respectively, and (2) when used in the split form, a diffraction peak is modeled as a composite of two Pearson VII peaks. The latter feature is especially pertinent to carbons, because their low absorption gives rise to asymmetric peaks, skewed toward higher angles. From this type of analysis, four parameters could be used to describe each diffraction peak. They were the Pearson VII exponents for each side of the peak (indicating Gaussian or Cauchy profile character), the angular position of the intensity maximum, and the full-width-at-half-maximum, $\beta$.

To perform the calculation of lattice constant, crystallite size, and lattice strain from these parameters, one additional correction was necessary. That correction is the angular shift and peak broadening due to imperfections in the machine. As discussed earlier, finite source and detector slit widths, non-monochromatic radiation, and imperfect diffraction geometry leads to errors in angular measurement and finite peak breadth, even for large, nearly-perfect crystals. Therefore, a strain-free reference material having precisely-known lattice constants and large crystal size was scanned at the same conditions as the fiber samples during each group of diffraction experiments. The material chosen for this work was silicon reference material NBS-640b, a strain-free powder of greater than $5 \mathrm{~mm}(50,000 \mathrm{~A})$ crystal size. Because of limits in resolution of peak breadths for materials with an average crystal size of greater than $1000 \mathrm{~A}$, the peak width for this material should have been negligible. Any measured broadening was due to the instrument.

The lattice constants of the graphite-like crystals were found by determining the lattice constant for several orders of the same reflection and extrapolating to $20=180^{\circ}$. Typically, the lattice constant is plotted versus $\cos ^{2} \theta$, the intercept being the true lattice constant. However, no high angle $(2 \theta>$ $90^{\circ} \mathrm{C}$ ) reflections were present for the fiber samples and a different extrapolation function was required. The Nelson-Riley function (NRF), having the form

$$
\mathrm{NRF}=\frac{\cos ^{2} \theta}{\sin \theta}+\frac{\cos ^{2} \theta}{\theta}
$$

was developed for materials having few high angle peaks and low absorption. The true lattice constant is the intercept of this extrapolation to $\mathrm{NRF}=0$, and the slope gives a measure of the uniform lattice strain. If the slope is negative, the low-orders of a given reflection underestimate the unit cell dimension and the crystal is said to be in "compression". On the other hand, a positive slope indicates "tensile" strain, with the low-orders overestimating the lattice constant. Thus, the sign of this slope gave the predominant sense of strain in the crystallites that comprise the foam.

Next, the instrumental breadth was subtracted from the breadths of the carbon fiber peaks. Its contribution was assumed to be Gaussian because the exponent of the Pearson VII profile found for the silicon reference peaks was around 10. The instrumental breadth ( $\left.\beta_{\text {instrumental }}\right)$ then was subtracted from the measured breadth $\left(\beta_{\text {measured }}\right)$ by the formula

$$
\beta_{\text {sample }}=\sqrt{\beta_{\text {measured }}^{2}-\beta_{\text {instrumental }}^{2}},
$$

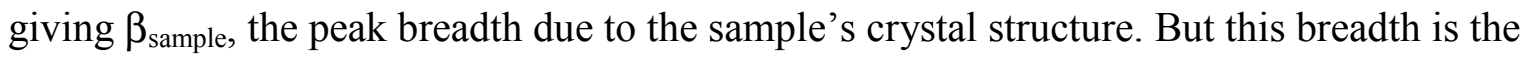
summation of two terms: the breadth due to finite crystallite size, and the breadth due to nonuniform strain (or distribution of interplanar spacings). The sample breadth then can be written 


$$
\beta_{\text {sample }}=\beta_{\text {strain }}+\beta_{\text {crystallite size, }}
$$

where both the strain and crystallite size components are assumed to be Cauchy in character. This was reasonable as the Pearson VII exponents for these samples were found to be in the range of 1 to 4. Substituting the relationships of breadth to non-uniform strain and crystallite size into the above equation gives

$$
\beta_{\text {sample }}=S \tan \theta+\frac{K \lambda}{L_{(h k i l)} \cos \theta},
$$

where $\mathrm{S}$ is proportional to the lattice strain, $\mathrm{K}$ is the Scherrer constant, $\lambda$ is the wavelength of the incident $\mathrm{X}$-radiation, and $\mathrm{L}_{(\mathrm{hki})}$ is the crystallite dimension perpendicular to the crystal plane being studied. Multiplying this equation by $\cos \theta$ gives

$$
\beta_{\text {sample }} \cos \theta=S \sin \theta+\frac{K \lambda}{L_{(h k i l)}} .
$$

$\mathrm{S}$ and $\mathrm{L}_{\text {(hkil) }}$ were determined by plotting $\beta_{\text {sample }} \cos \theta$ versus $\sin \theta$. The slope is $\mathrm{S}$ and the intercept is $\mathrm{KL}_{(\mathrm{hki})}$. So that the crystallite size could be calculated by substituting the appropriate value of Scherrer's constant, K, and the incident calculated from the full peak width, including both tails of the planar spacing distribution, it is equal to twice the lattice strain. The sense of stain, $\varepsilon=S / 2$ would be unknown, if not for the previous lattice constant calculation. Typically, it is assumed that the $\varepsilon$ is predominantly either tensile or compressive, as determined by the slope of the lattice constant extrapolation. If the non-uniform strain were due to bending in a direction parallel to the (hkil) plane being considered, there would always exist a region under tensile strain and a region under compression strain, separated by an axis of zero strain. Then, there would be no diffraction peak shift, and S could not be assumed to be predominantly tensile or compressive. However, if a crystallite exists so that localized stresses (e.g., thermal stresses at grain walls) cause a distribution of (hkil) spacings bounded by the true d(hkil), both peak shift and peak broadening will be observed. Then, the sign of the Nelson-Riley extrapolation gives the tensile or compressive sense of the strain, and its magnitude can be estimated from peak broadening. In truth, S is a measure of strain broadening, given that the average crystallite has been strained preferentially in a given sense.

The value of $\mathrm{K}$ used in the general case is 0.89 . However, for turbostratic carbons with random stacking of two-dimensionally perfect layers, Warren's random layer diffraction theory dictates a value of 1.84 for $\mathrm{K}$ in the case of (hki0) diffraction lines. In this study, K(hki0) was allowed to decrease from 1.84 to 0.89 as layer stacking becomes more perfect. Using Franklin's definition of the degree of graphitization,

$$
p=1-g^{2},
$$

where $g$ is 
CPCPC Final Technical Report

January 2001

$$
g=\frac{3.44-d(0002)}{2.44-3.354} .
$$

The appropriate value of $\mathrm{K}$ for (hki0) diffraction lines was determined from

$$
\mathrm{K}=0.89+(1.84-0.89) \mathrm{p} .
$$




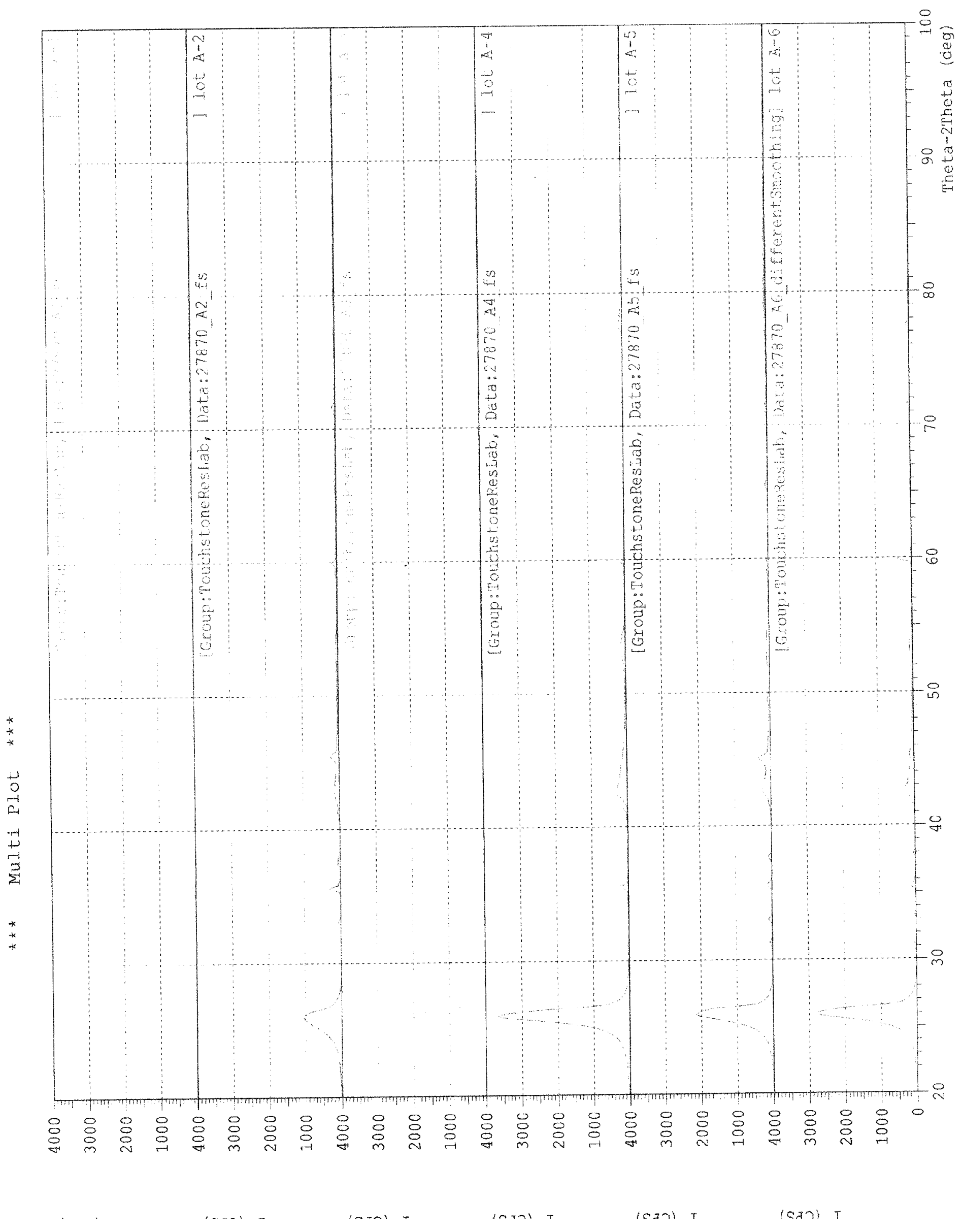


Group Name

Data Name

: Houcnstonekeshas

Eile Name

: $27870 \mathrm{~A} 1 \mathrm{fs}$

Sample Name

Comment

: 27870 A1 Es.PKR

Lot A-1

- Graphite foam

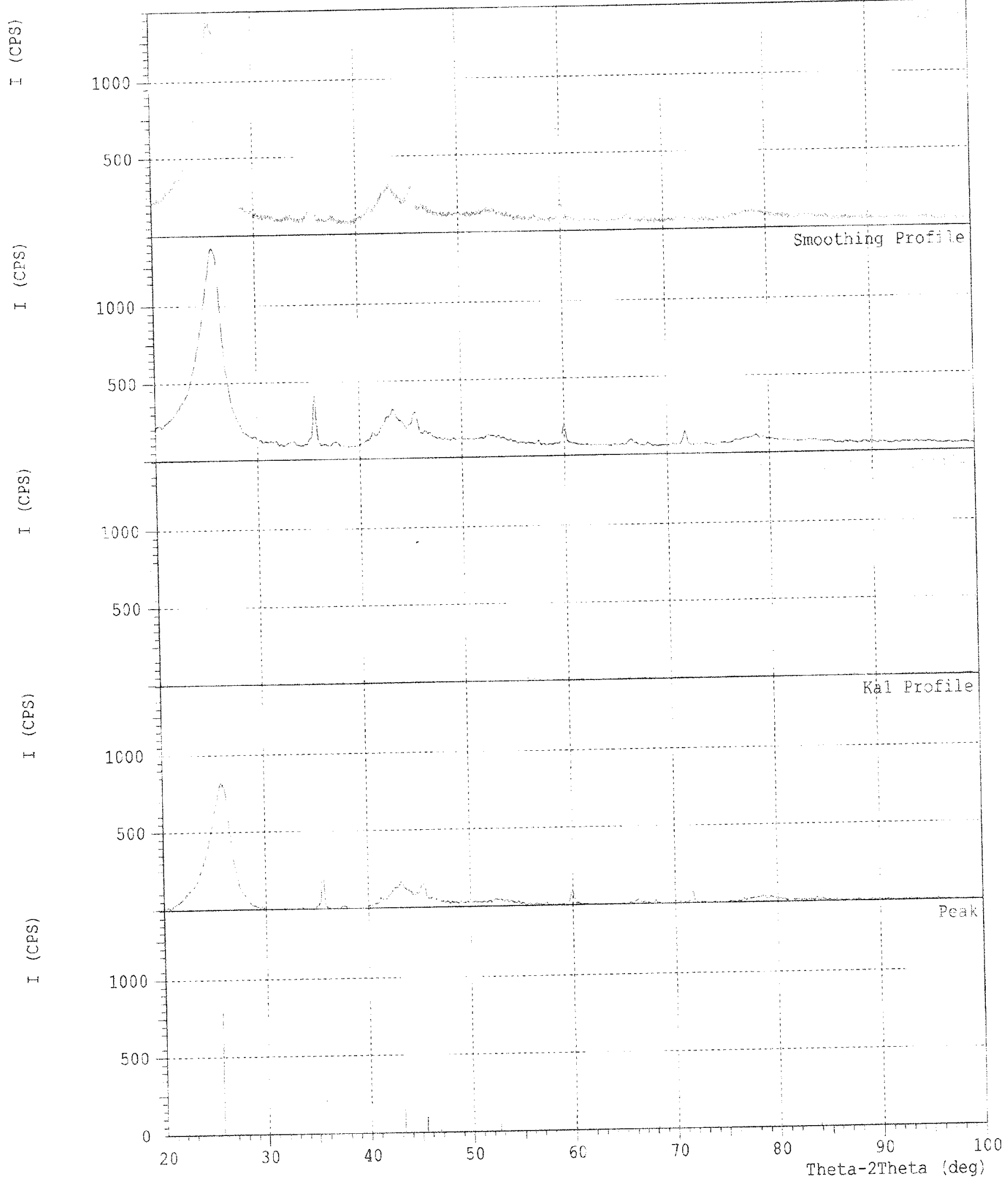




$\begin{array}{ll}\text { Group Name } & \text { TouchstoneResLab } \\ \text { Data Name } & : 27870 \text { A2 fs } \\ \text { Eile Name } & : 27870 \text { A2 Is.PKR } \\ \text { Sample Name : lot A-2 } \\ \text { Comment }\end{array}$

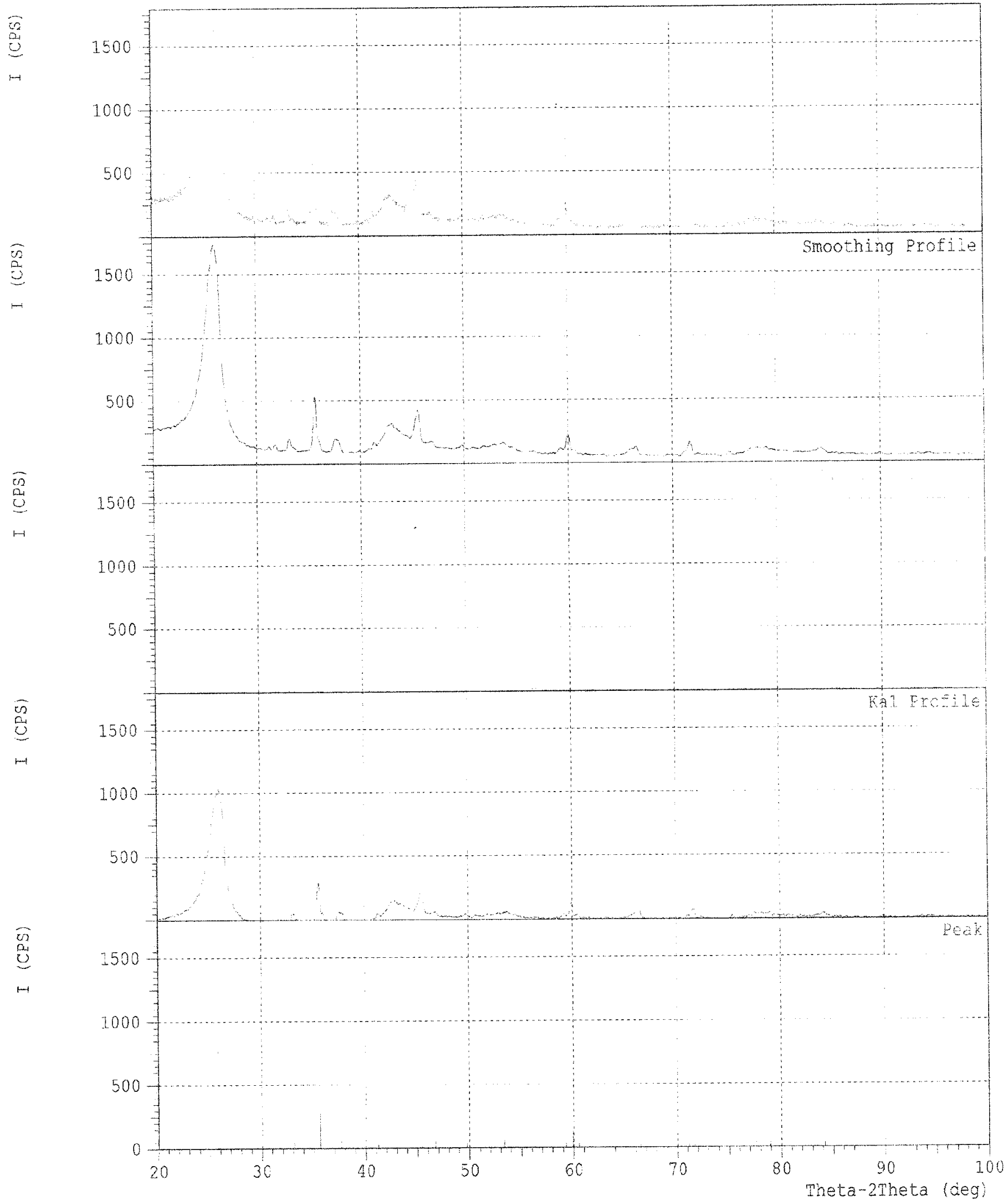




\section{** Basic Data Process}

sroup Name

Jata Name

Tile Name

Sample Name

somment
- Touchstoneresluab

27870 A3 ts

: 27870 A3 fs.PKR

$: \operatorname{lot} A-3$

- Graphite foam

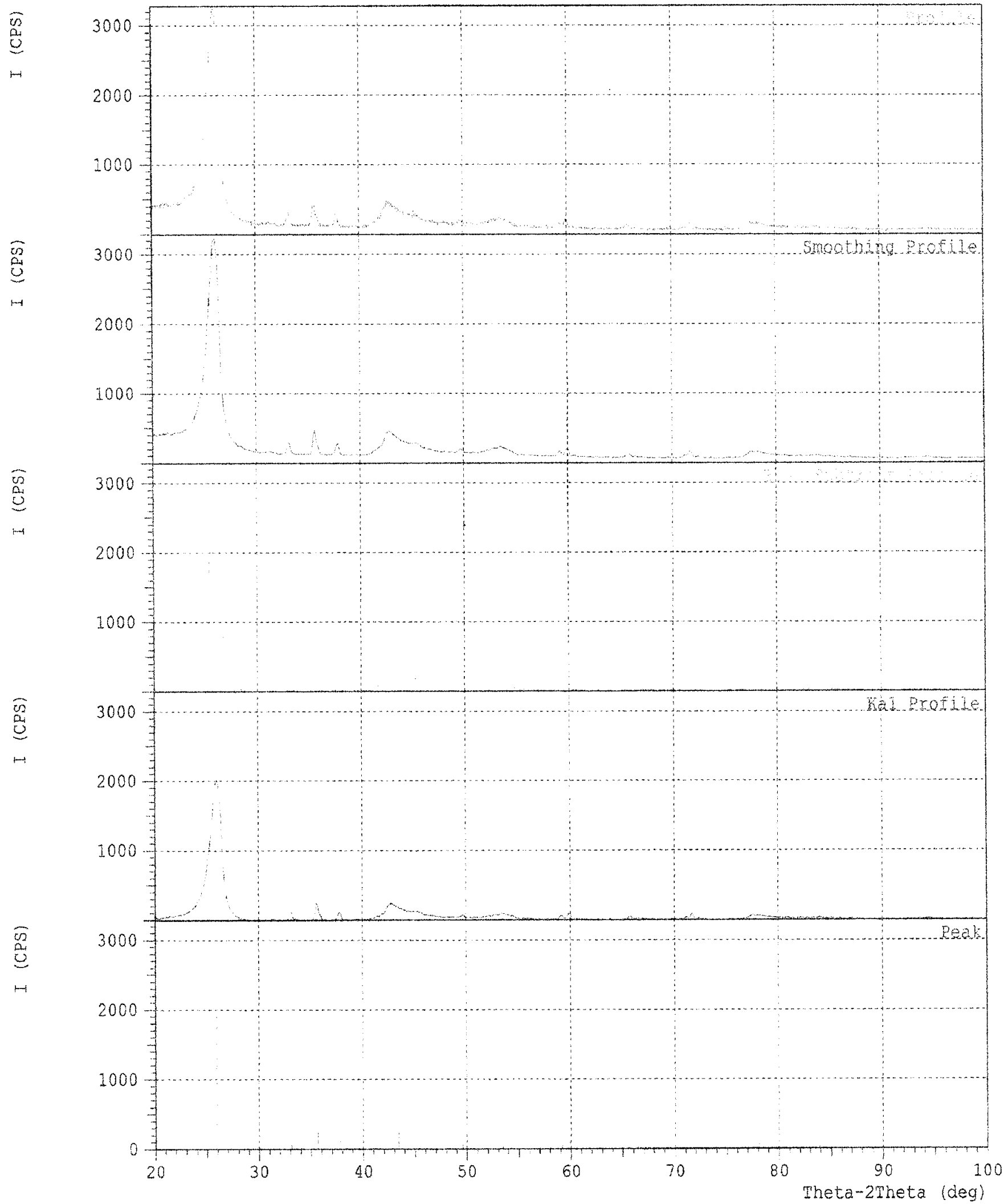


Group Name : TouchstoneRestab

Data Name : $27870 \mathrm{~A} 4$ fs

Eile Name : $27870 \mathrm{~A} 4$ fs.PKR

Sample Name: lot $\mathrm{A}-4$

Comment : Graphite foam

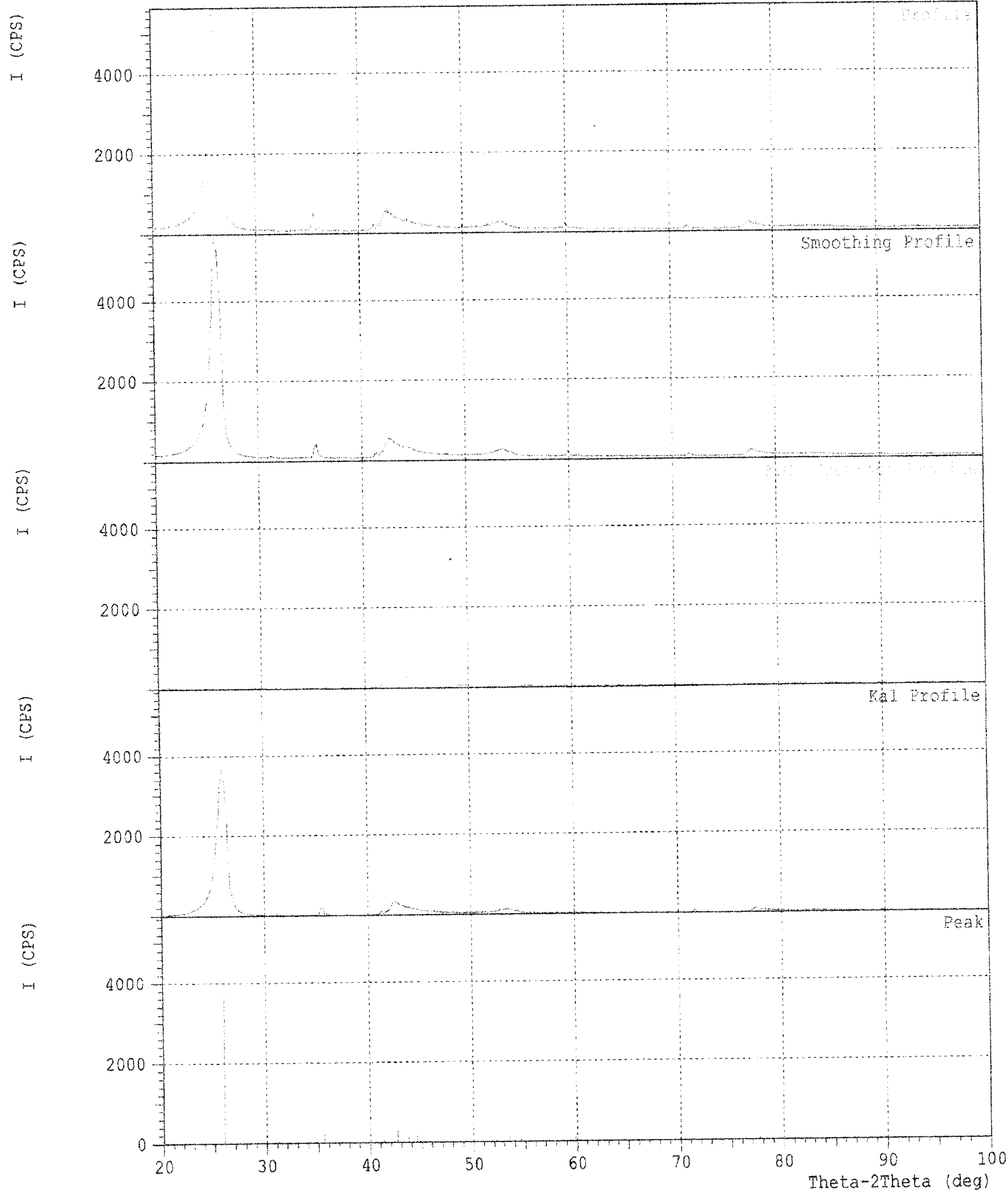




Group Name : TouchstoneRestab
Data Name : 27870 As fs
Eile Name : $27870 \mathrm{AS}$ fs.PKR
Sample Name: lot A-5
Comment: : Graphite foam

sis

$\underline{\omega}$

H

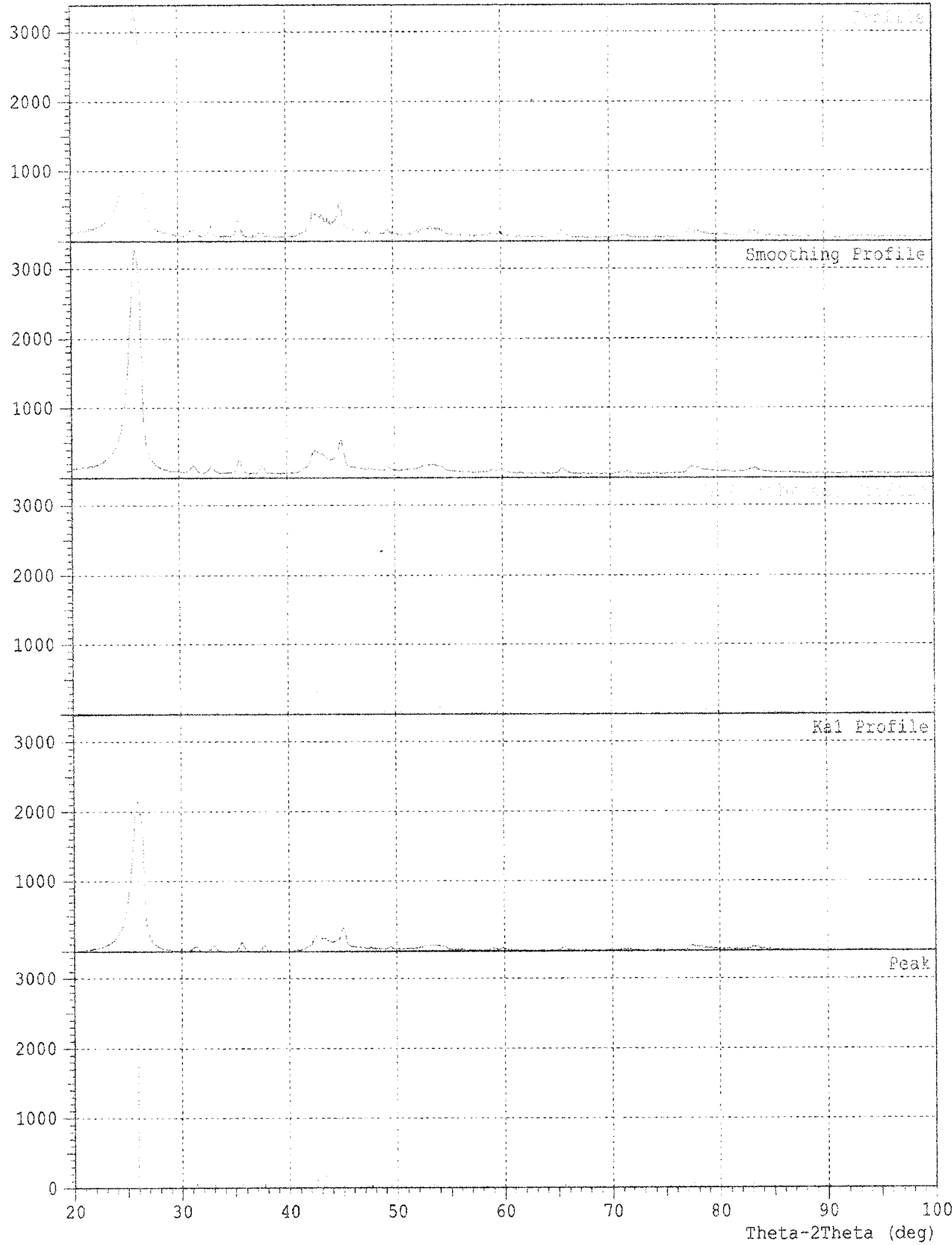




$\begin{array}{ll}\text { Group Name } & \text { TouchstoneResLab } \\ \text { Data Name : } 27870 \text { A6 fs } \\ \text { File Name : } 27870 \text { A6 fS.PKR } \\ \text { Sample Name: lot A-6 - } \\ \text { Comment : Graphite Foam }\end{array}$

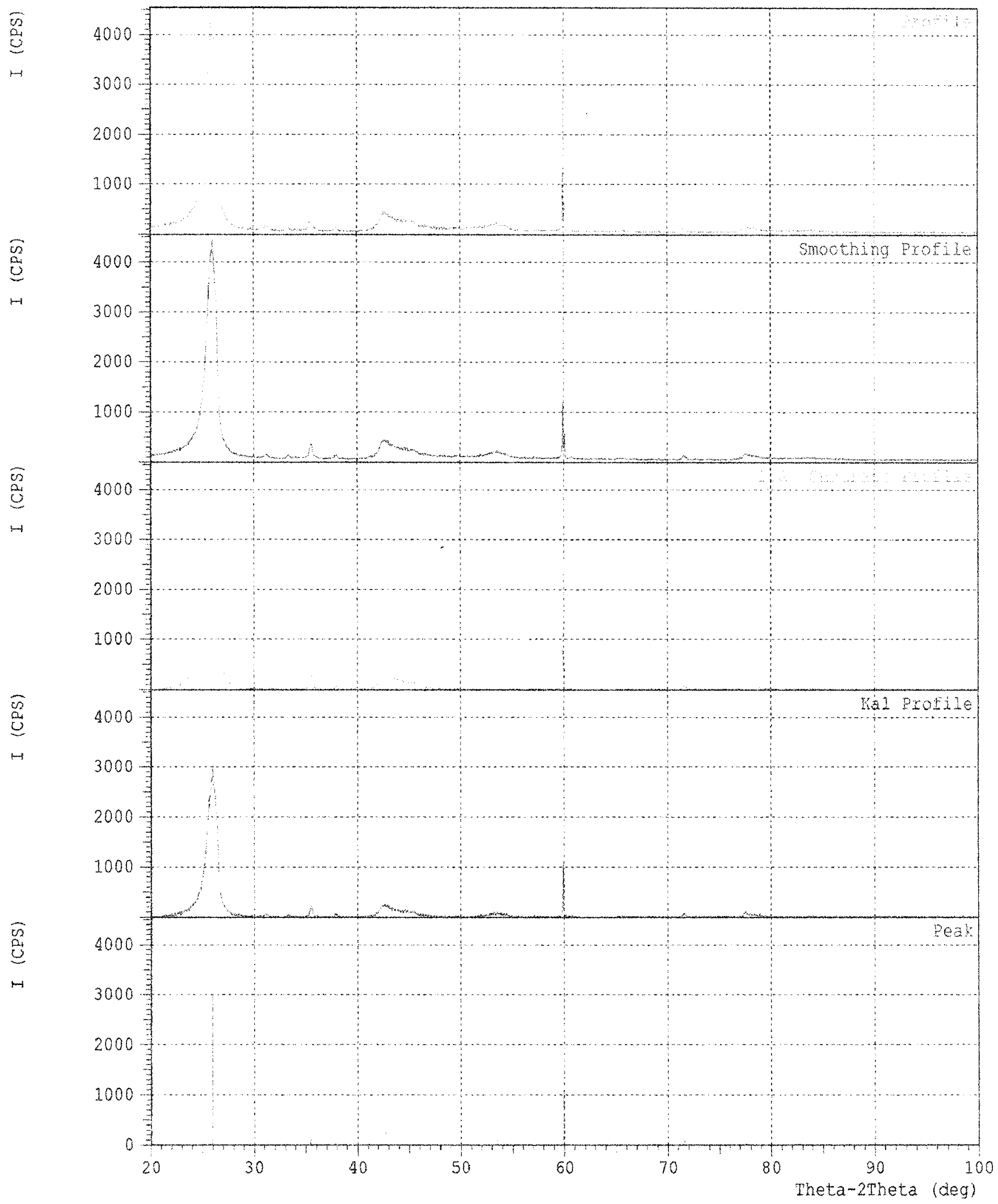




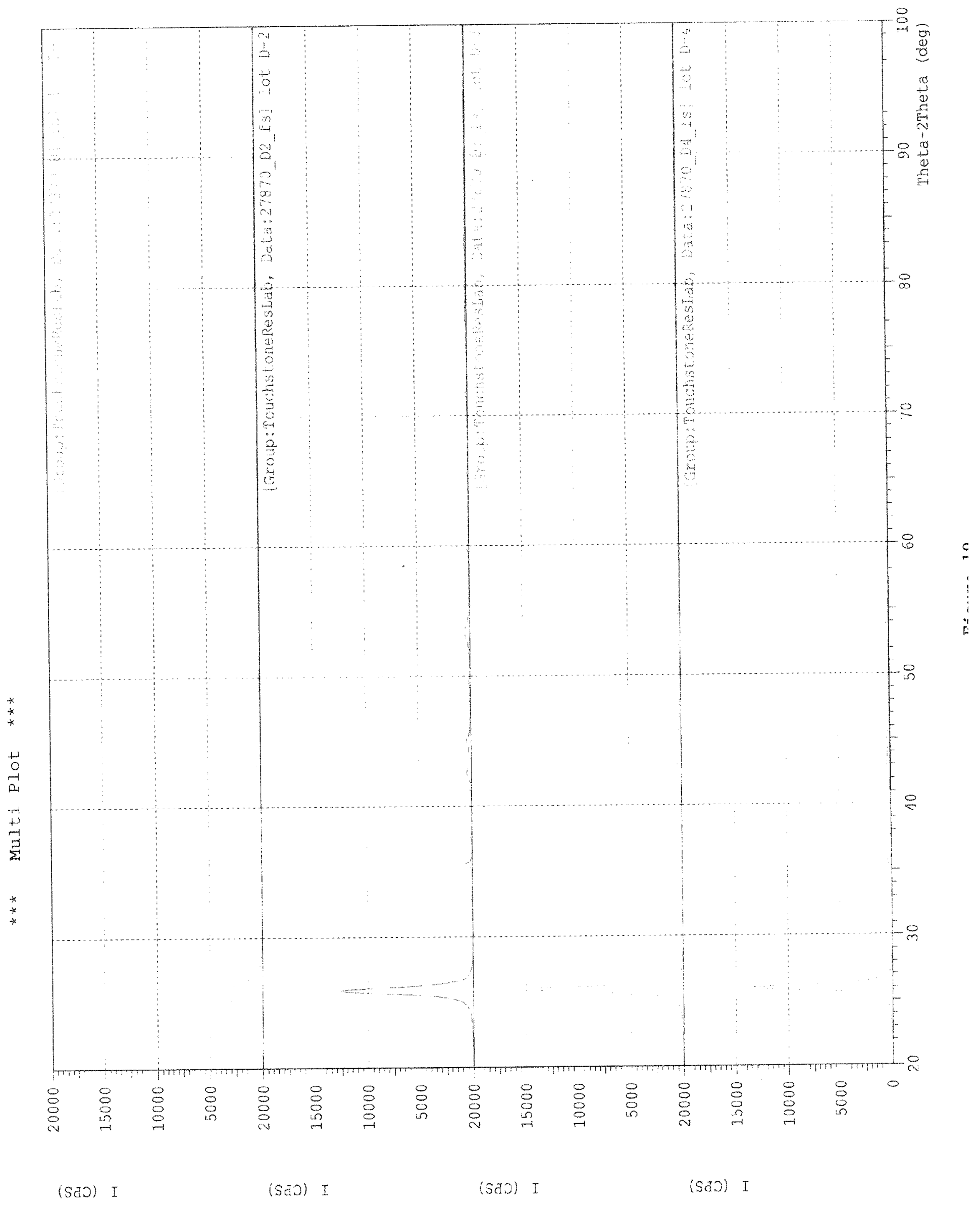



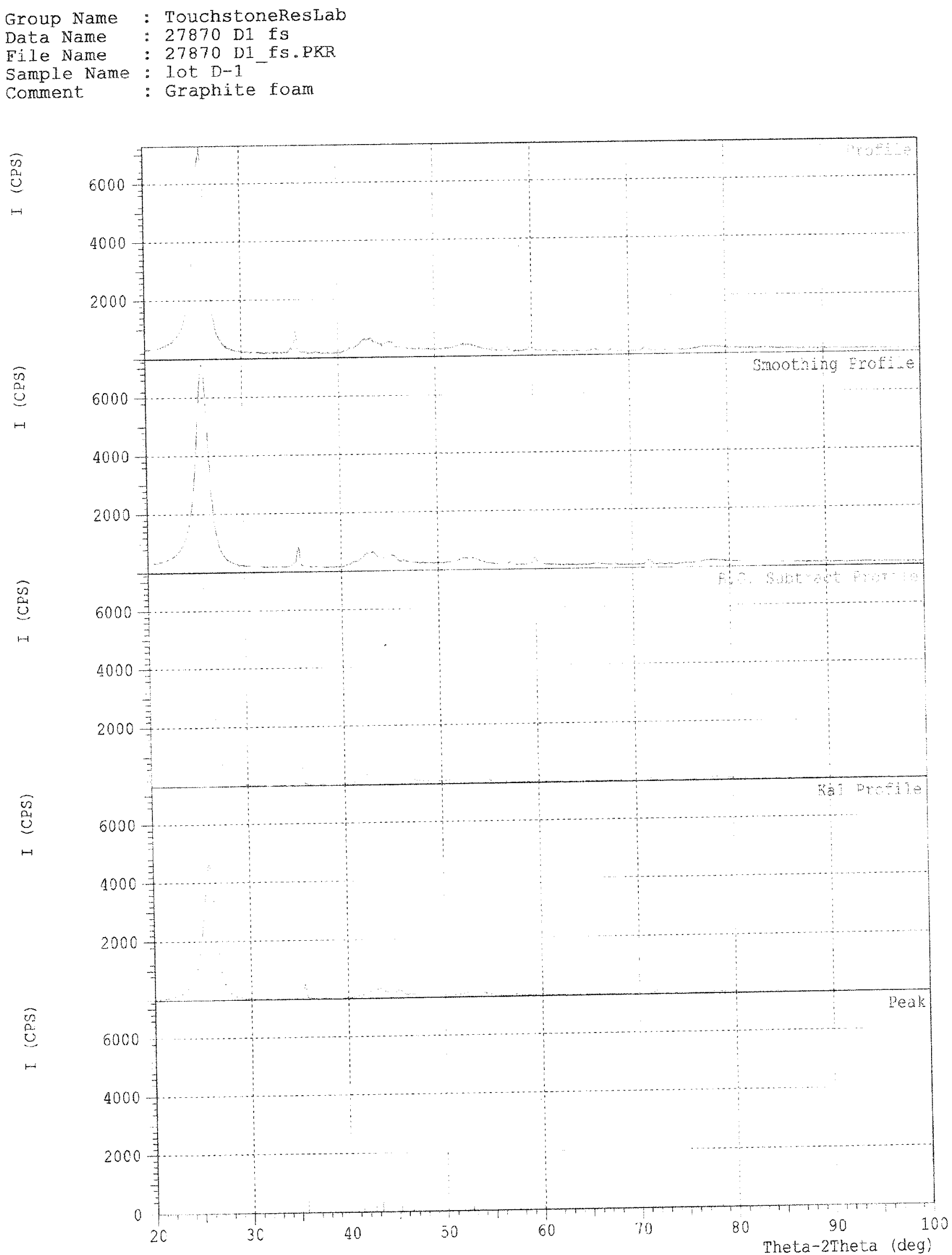


Group Name: 1oucnstunenesuan
Data Name : 27870 D2 fs
File Name : 27870 D2 fs.PKR
Sample Name: 10t D-2
Comment

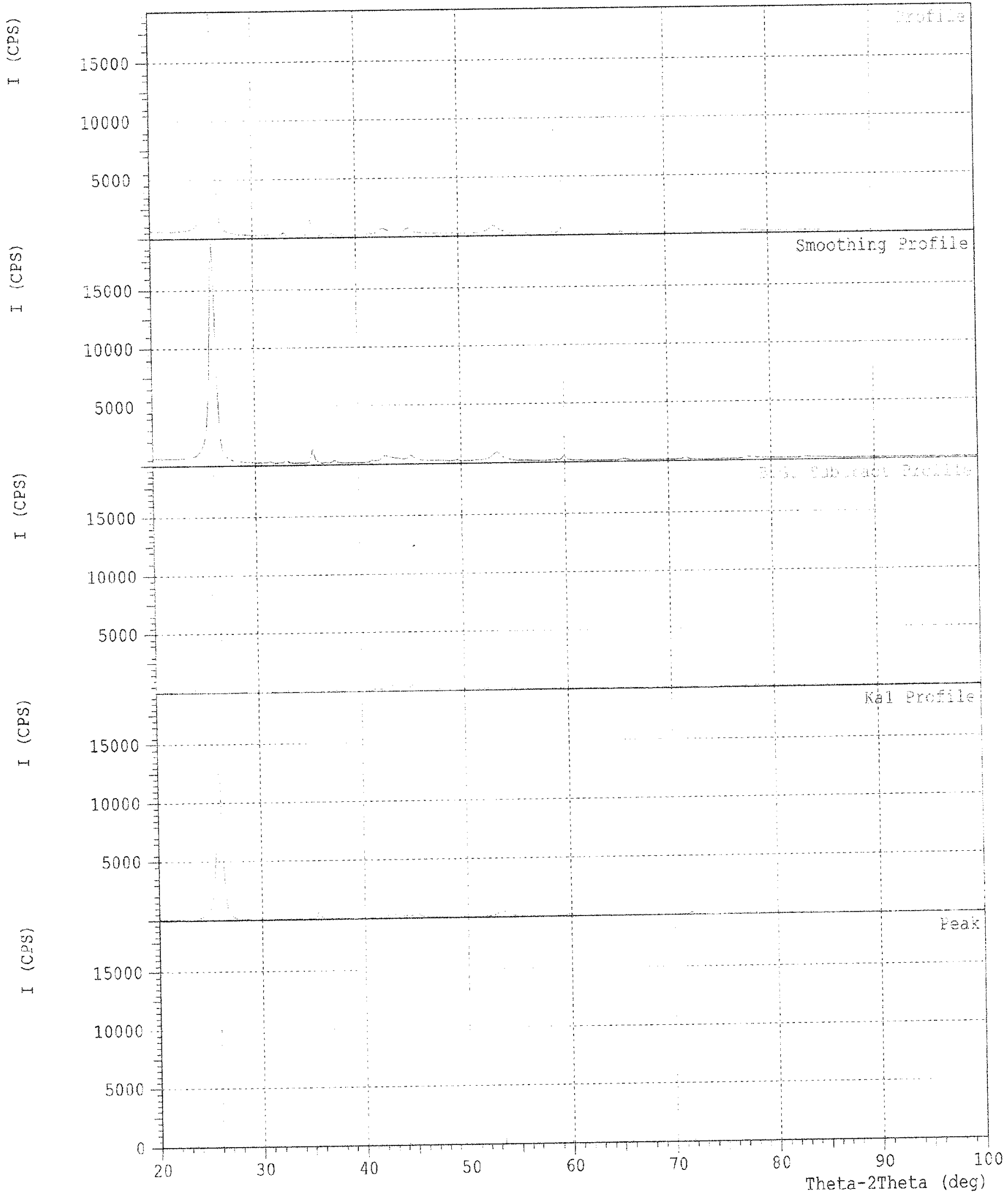




$\begin{array}{ll}\text { Group Name } & \text { TouchstoneResLab } \\ \text { Data Name } & : 27870 \text { D3 fS } \\ \text { File Name } & : 27870 \text { D3 fS.PKR } \\ \text { Sample Name : lot D-3 - } \\ \text { Comment }\end{array}$

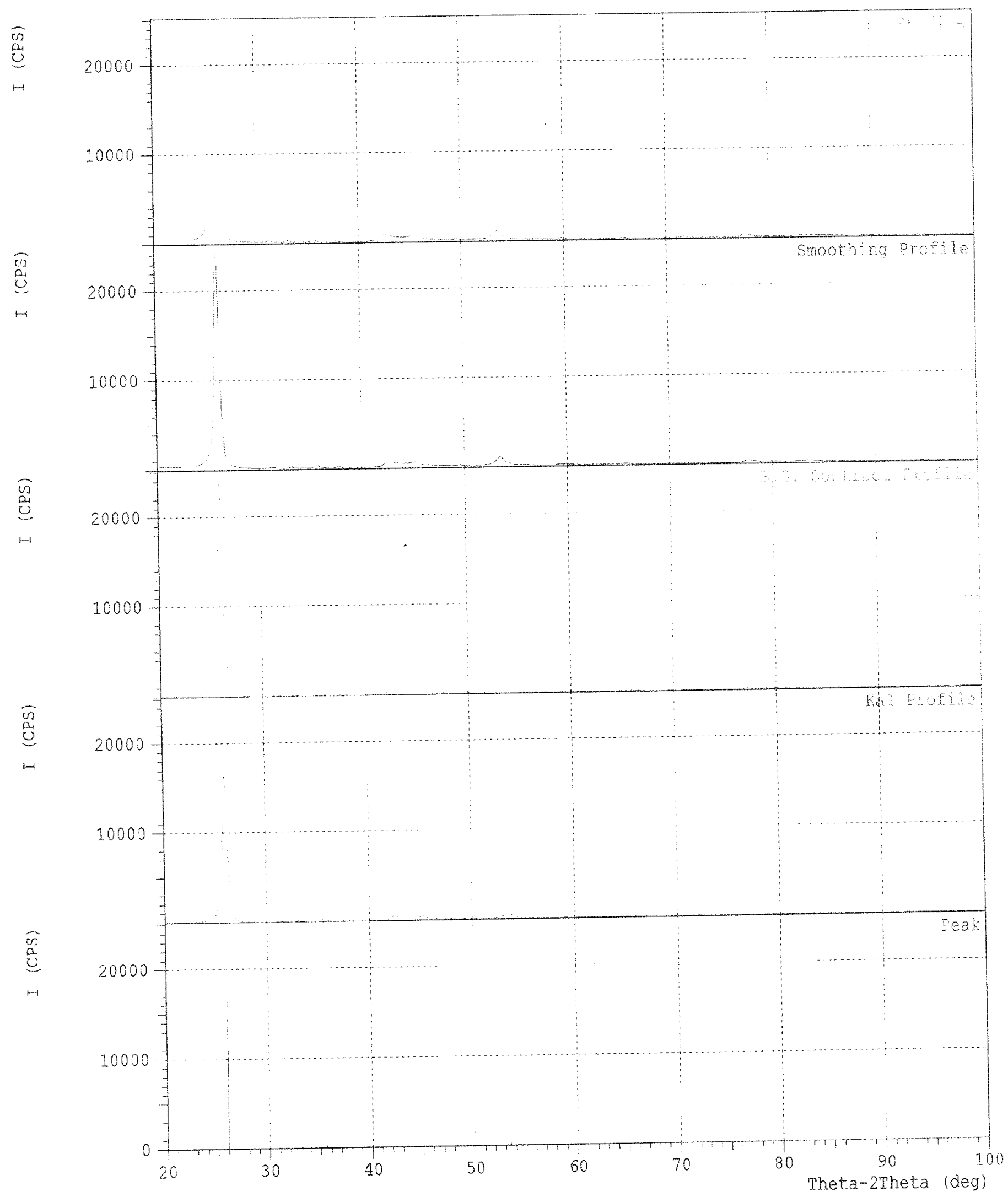



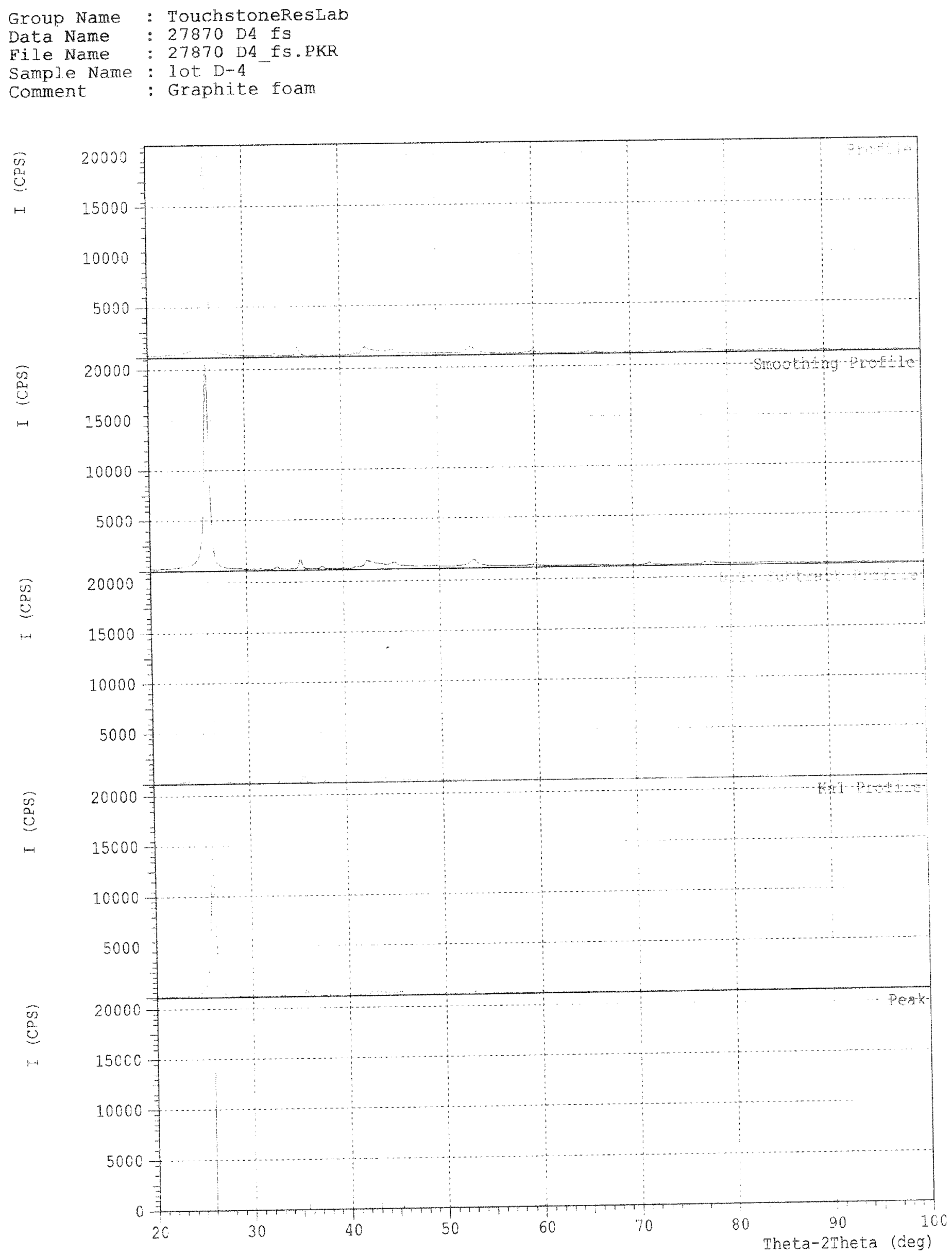


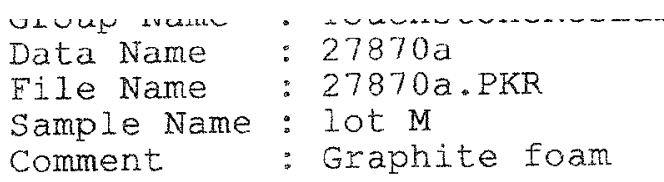

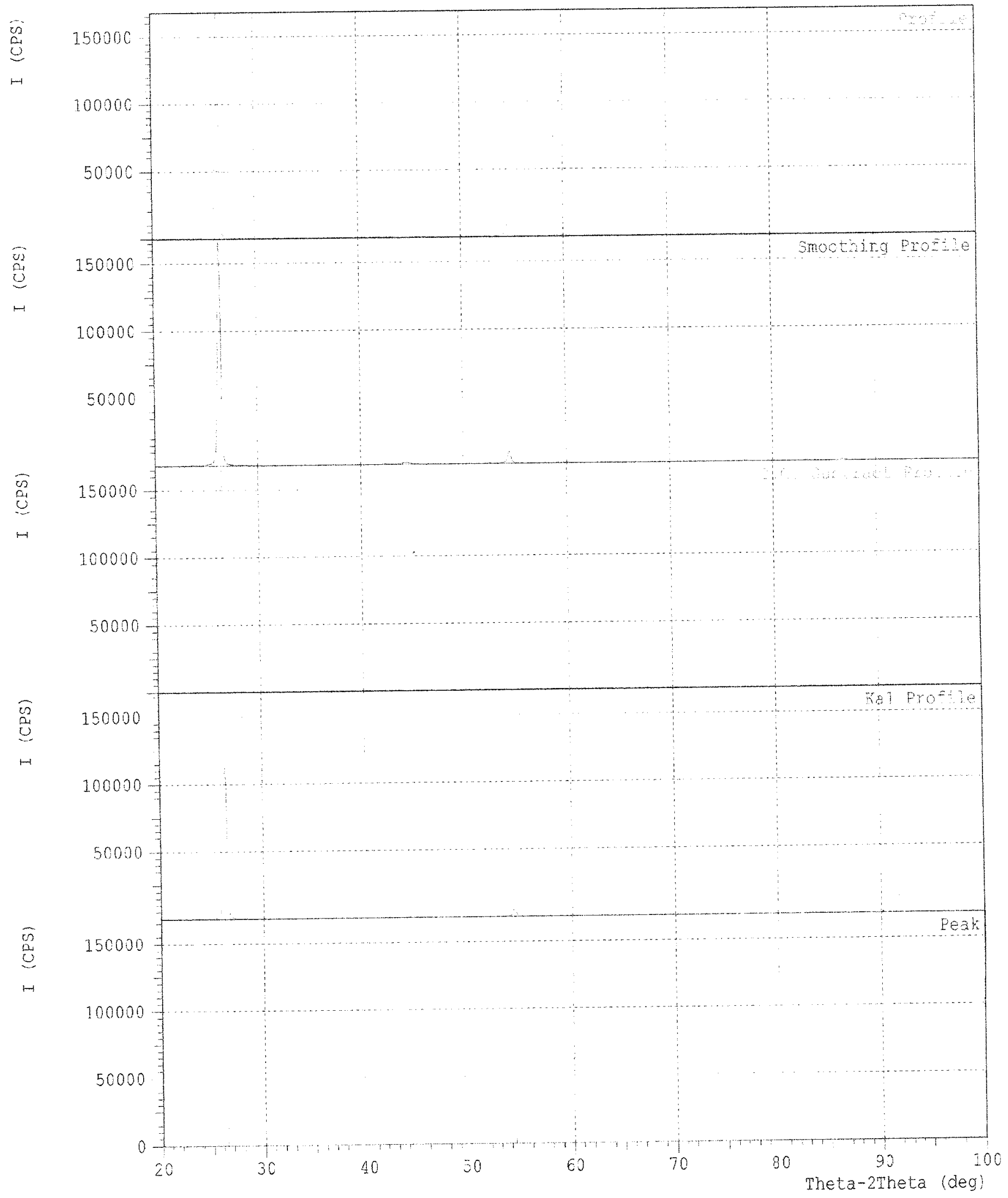




\title{
Development of Binder Pitches from Direct Coal Liquefaction and Coal-Tar Pitch Blends
}

\author{
FINAL REPORT
}

Report Period Start Date: January 1, 2000

Report Period End Date: June 30, 2001

\author{
Report Prepared by \\ Peter G. Stansberry \\ \& \\ John W. Zondlo
}

Department of Chemical Engineering

College of Engineering and Mineral Resources

P. O. Box 6102

West Virginia University

Morgantown, WV 26506-6102

Report Issued

June 30, 2001

DOE Award Number DE-FC26-98FT40350

Other Contributor

Robert H. Wombles

Koppers Industries, Inc.

1005 William Pitt Way

Pittsburgh, PA 15238-1362 


\section{DISCLAIMER}

This report was prepared as an account of work sponsored by an agency of the United States Government. Neither the United States Government nor any agency thereof, nor any of their employees, makes any warranty, expressed or implied, or assumes any legal liability or responsibility for the accuracy, completeness, or usefulness of any information, apparatus, product, or process disclosed, or represents that its use would not infringe privately owned rights. Reference herein to any specific commercial product process, or service by trade name, trademark, manufacturer, or otherwise does not necessarily constitute or imply its endorsement, recommendation, or favoring by the United States Government or any agency thereof. The views and opinions of authors expressed herein do not necessarily state or reflect those of the United States Government or any agency thereof. 


\begin{abstract}
Binder pitches are essential ingredients in the manufacture of carbon anodes. Although considerable work has focused on combining petroleum-derived materials with conventional coal-tar pitches, relatively little effort has been directed toward using solvent extracts from coal as feedstocks for blending. In this project, researchers from West Virginia University and Koppers Industries, Inc. studied the effects of pitches developed by solvent extraction of coal. The coal-derived extract pitch was mixed with conventional coal-tar pitch in quantities sufficient to form laboratory-scale anodes. Formulations with a standard petroleum and coal-tar pitch were used as controls. The binder pitches, green and baked anodes were then subjected to a battery of standard tests. The results of using solvent-extracted coal pitch on anode characteristics including thermal conductivity, electrical resistivity, compressive strength, air permeability, bulk density, etc., were determined and found to be equivalent to those for conventional coaltar binder pitches.
\end{abstract}




\section{TABLE OF CONTENTS}

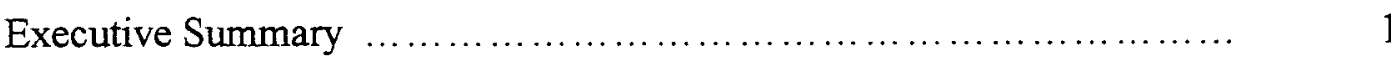

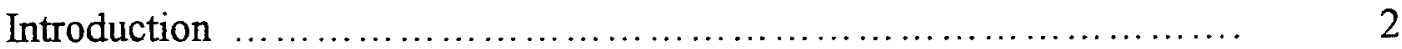

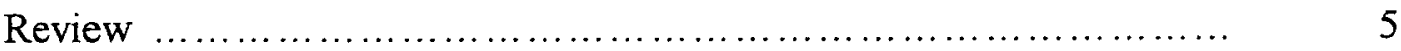

Experimental .................................................. 8

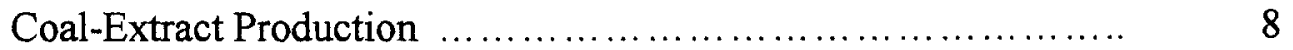

Pilot Anode Fabrication ................................... 10

Other Characterizations ................................... 11

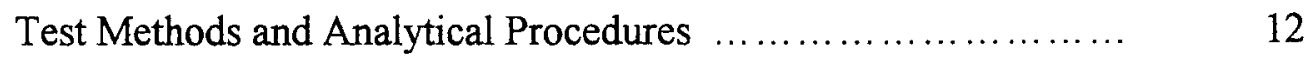

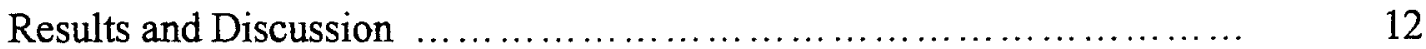

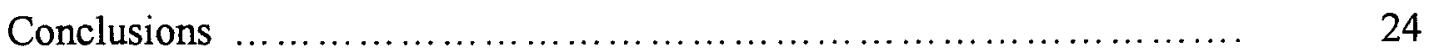

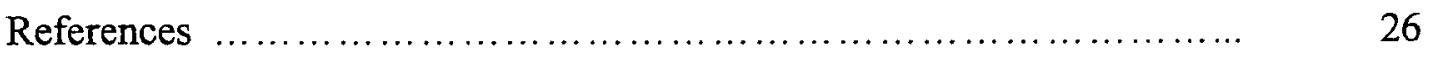

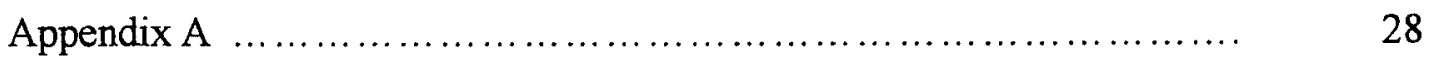

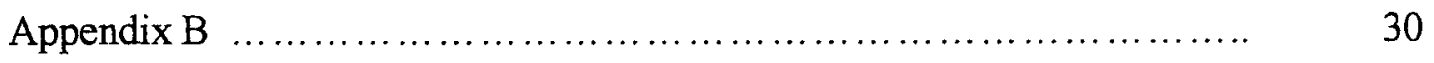

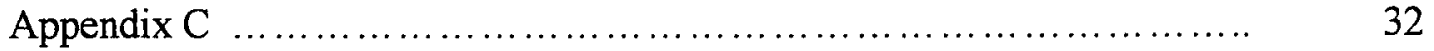

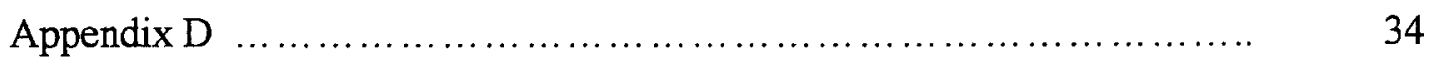

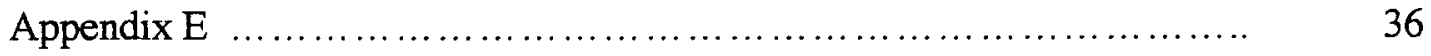




\section{LIST OF TABLES}

1 Yield of Materials from the Production of Metallurgical Coke ...... 3

2 North American Binder Pitch Demand ........................... 3

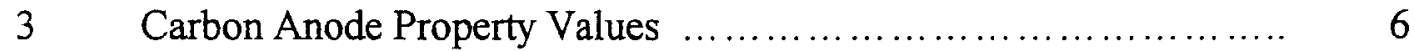

4 Comparison of Petroleum/Coal-Tar Pitch Blend and Coal-Tar

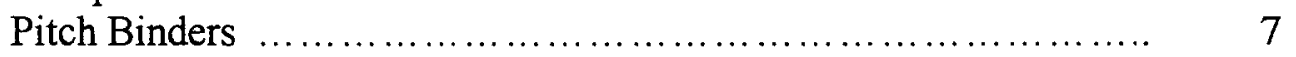

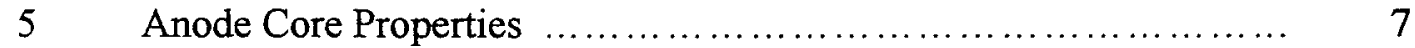

$6 \quad$ Properties of Arch Coal (PSOC 3001) .......................... 9

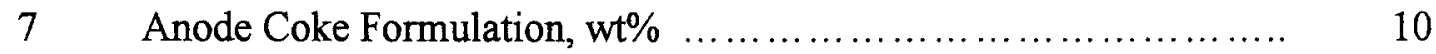

$8 \quad$ Test Methods for Measuring Pitch Properties $\ldots \ldots \ldots \ldots \ldots \ldots \ldots \ldots . \ldots \ldots$

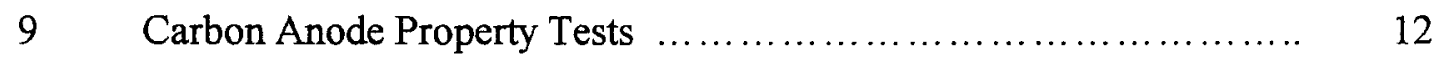

10 Effects of Reaction Conditions on Product Yield and Pitch Properties

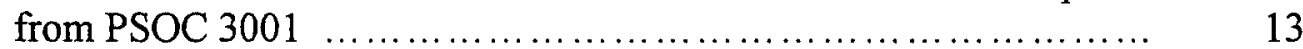

11 Properties of Pitches and Their Blends $\ldots \ldots \ldots \ldots \ldots \ldots \ldots \ldots \ldots \ldots \ldots$

12 Elemental Composition and Aromaticity of Binder Pitches $\ldots \ldots \ldots \ldots . \quad 14$ 


\section{LIST OF FIGURES}

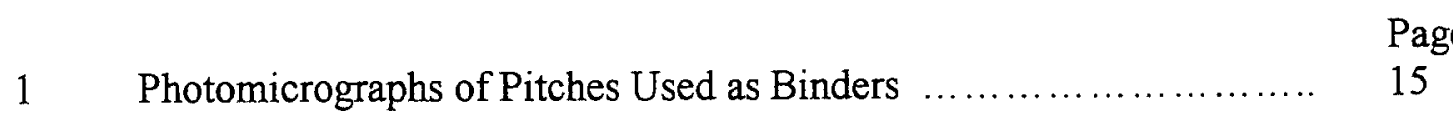

2 Optical Photomicrographs of Pitch Cokes …................... 16

3 Viscosity of Raw Pitches and Blends at $140^{\circ} \mathrm{C} \ldots \ldots \ldots \ldots \ldots \ldots \ldots \ldots \ldots$

4 Viscosity of Raw Pitches and Blends at $160^{\circ} \mathrm{C} \ldots \ldots \ldots \ldots \ldots \ldots \ldots \ldots \ldots$

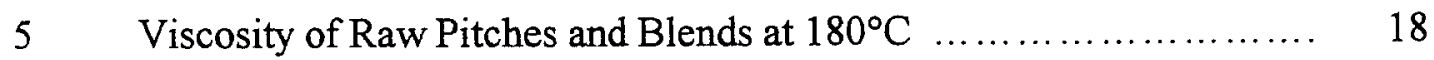

6 Green Anode Apparent Density vs. Binder Composition .............. 19

$7 \quad$ Baked Apparent Density vs. Binder Composition $\ldots \ldots \ldots \ldots \ldots \ldots \ldots \ldots . . \ldots \ldots$

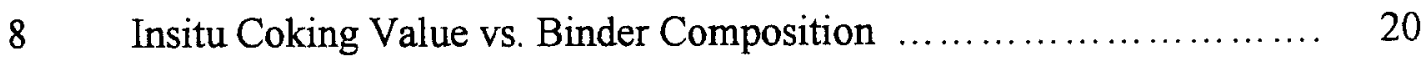

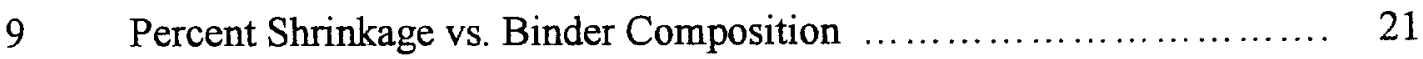

10 Core Apparent Density vs. Binder Composition $\ldots \ldots \ldots \ldots \ldots \ldots \ldots \ldots . \ldots \ldots \ldots \ldots$

11 Core Electrical Resistivity vs. Binder Composition $\ldots \ldots \ldots \ldots \ldots \ldots \ldots \ldots . \ldots \ldots$

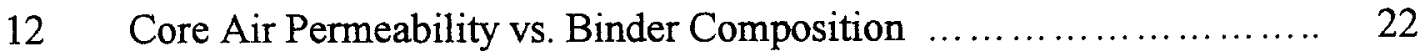

13 Core Compressive Strength vs. Binder Composition ................. 23

14 Coefficient of Thermal Expansion vs. Binder Composition ............ 23

15 Core Thermal Conductivity vs. Binder Composition ................. 24 


\section{EXECUTIVE SUMMARY}

A bituminous coal supplied by Arch Coal, Incorporated was converted into a pitch-like material by thermal hydrogenation. Following reaction, unconverted coal and mineral matter were removed from the coal-derived pitch by solvent extraction using N-methyl pyrrolidone (NMP). Reaction conditions were varied in order to produce a product suitable for blending with a conventional coal-tar pitch. Blends of the conventional coaltar pitch and coal-extract pitch were made at 50:50 and 85:15 wt:wt proportion by melt mixing in a heated vessel.

The pitches were combined with sized calcined petroleum coke and butt material, formed into laboratory anodes, and baked to $1100^{\circ} \mathrm{C}$ under an inert atmosphere. Formulations with a standard petroleum (SPP) and coal-tar pitch (SCTP) were used as controls. The coal-extract material and its blends, as well as the petroleum and conventional coal-tar pitch were analyzed for softening point temperature, toluene and quinoline solubility, coking value, ash content, along with other appropriate tests. In addition, green and baked laboratory anodes were also subjected to a standard battery of tests. Where possible, testing methods followed ASTM protocols.

The results of this project demonstrate that pitches derived from coal extracts offer the potential as additives to conventional coal-tar pitches for use as binders in anode fabrication. Though the coal-extract pitches were not optimal, they performed very well. Additional work should be conducted to extend the range of binder content in order to determine the more effective binder level for the pitch blends. Finally, the properties of 
the coal-extract pitches should be optimized to perform effectively as additives to conventional binder pitches.

\section{INTRODUCTION}

The development of coal tars and metallurgical coke is inextricably related. For instance, in 1894 , sixty by-product coke ovens for the production of the main product, blast furnace coke, and the recovery of evolved volatiles first appeared in the United States in Johnstown, PA. Crude tars from these types of ovens began to be refined as pitch feedstocks by the year 1915. The demand for the production of iron and steel and the need for dyes, explosives, and coal chemicals increased until about the middle of the 20th century when the number of by-product coke ovens peaked to over 16,000. In 1952, approximately 80 million tons of metallurgical coke were produced by this technology. However, for a variety of reasons, the production of metallurgical coke in the United States has continually decreased since about the $1960 \mathrm{~s}$. A recent projection places the annual production of metallurgical coke at slightly over 18 million tons by the year 2002 .

Associated with the decline in coke production is also the decline in valuable by-products and coal tars. Table 1 shows typical yields of the materials generated by the carbonization of coal in a modern recovery coke battery. As can be seen, the yield of tar from coal is only about $4 \mathrm{wt} \%$. The tar is processed further by distillation to produce roughly $50 \mathrm{wt} \%$ distillate oils and $50 \mathrm{wt} \%$ bottoms material called coal-tar pitch. Although the yield of coal-tar pitch amounts to about $2 \mathrm{wt} \%$ based on the initial charge of 
coal, it is the preferred raw material for use as a binder in the fabrication of carbon electrodes and anodes because of its desirable properties.

Table 1 Yield of Materials from the Production of Metallurgical Coke

\begin{tabular}{|c|c|}
\hline Yield from 1 ton of coal & Weight, $\%$ \\
\hline 1520 lbs coke & 76 \\
\hline 78 lbs tar & 4 \\
\hline 20 lbs light oil & 1 \\
\hline 20 lbs ammonium sulfate & 1 \\
\hline 280 lbs gas & 14 \\
\hline 80 lbs other & 4 \\
\hline Total 1998 lbs & $100 \%$ \\
\hline
\end{tabular}

Unfortunately, North America is currently a net importer of coal-tar and pitch feedstocks. Consequently, producers and consumers of these materials are becoming more concerned about the growing domestic sourcing shortfall. Table 2 provides figures for recent and anticipated demand of coal-tar binder pitch for North America. The trend in the tar deficit is expected to increase further as the number of operating by-product recovery coke ovens in the United States dwindles.

Table 2 North American Binder Pitch Demand (1000 metric tons)

\begin{tabular}{|c|c|c|c|c|c|}
\hline Year & 1995 & 1997 & 1999 & $\underline{2001}$ & $\underline{2003}$ \\
\hline $\begin{array}{l}\text { Aluminum } \\
\text { Industry }\end{array}$ & 597 & 666 & 708 & 679 & 701 \\
\hline $\begin{array}{l}\text { Commercial } \\
\text { Carbon }\end{array}$ & 95 & 95 & 95 & 95 & 95 \\
\hline Miscellaneous & $\underline{140}$ & 127 & 118 & $\underline{91}$ & $\underline{91}$ \\
\hline Total & 832 & 888 & 921 & 865 & 887 \\
\hline $\begin{array}{l}\text { Crude Tar } \\
\text { Required }\end{array}$ & 1,602 & 1,711 & 1,774 & 1,666 & 1,706 \\
\hline $\begin{array}{l}\text { Crude Tar } \\
\text { Available }\end{array}$ & 1,316 & 1,302 & 1,077 & $\underline{990}$ & 929 \\
\hline Tar Deficit & 286 & 409 & 697 & 676 & 777 \\
\hline
\end{tabular}


To ameliorate domestic coal-tar supplies, industrial pitch producers have given considerable attention to blending petroleum pitches together with traditional coal-tar binders. Tests conducted with the petroleum/coal-tar blends in anode manufacturing have indicated adequate performance, but comparatively little effort has been directed toward blending coal-extract feedstocks. To a large extent, a major impediment to a wider application of coal as a source for carbon products is the presence of inherent inorganic matter in the coal. These contaminants adversely affect most practical aspects of coal utilization, particularly for carbon precursors. In this regard, West Virginia University researchers have shown that coal can be converted into a wide variety of pitch precursors each one with a chosen slate of characteristics and properties. One feature of the process involves prehydrogenation of coal followed by extraction using the dipolar, aprotic solvent N-methyl pyrrolidone (NMP). This solvent has been shown to be highly effective for substantially reducing the inorganic, ash-forming matter in coal-derived materials.

Thus the objective of this project is to determine the utility of coal prehydrogenation and solvent extraction in the production of binder pitch additives or extenders. The coalextract pitch was blended with conventional coal-tar pitch and laboratory carbon anodes were fabricated. The research was a successful collaboration between West Virginia University and Koppers Industries, Inc. in which WVU was responsible for the development of the coal extracts, preparation of the blends, and the characterization of the pitches. Koppers used the coal extracts produced by WVU to fashion, machine, and evaluate the test anodes. 


\section{REVIEW}

Prebaked carbon anodes for the production of aluminum metal by Hall molten-salt electrolysis are a complex aggregate made by combining, forming, and baking calcined petroleum coke, butt material, and coal-tar pitch. Typical anode formulations call for 80$90 \mathrm{wt} \%$ coke filler and $10-20 \mathrm{wt} \%$ binder pitch. Ideally the anode carbon is oxidized to carbon dioxide in the electrochemical reaction at a rate of $0.334 \mathrm{~kg}$ per $\mathrm{kg}$ of aluminum, though the actual consumption rate will range from 0.400 to $0.500 \mathrm{~kg}$ per $\mathrm{kg}$ of aluminum. Because the carbon anode is a necessary reactant in aluminum production, a large quantity of calcined coke and coal-tar pitch is used in the United States. Currently, approximately 2,000,000 tons of calcined petroleum coke and 746,000 tons of coal-tar pitch are utilized domestically in the rendering of aluminum.

A carbon anode will exhibit acceptable performance only if the primary ingredients meet certain requirements. The calcined petroleum coke, inter alia, must be of a minimal graphene crystal structure, display a certain optical texture, and possess a proper level of porosity. Also, undesirable impurities such as vanadium, nickel, and sulfur in the petroleum cokes can impact negatively the quality of aluminum metal manufacture. In Table 3 are provided some of the more important characteristics that a carbon anode should possess in order to function properly. Additional information on the characterization and performance of carbon anodes can be found in the literature. ${ }^{(1-8)}$ 
Table 3 Carbon Anode Property Values ${ }^{(5)}$

\begin{tabular}{|c|c|}
\hline Property & Range \\
\hline Baked Density & $1.40-1.65 \mathrm{~g} / \mathrm{cm}^{3}$ \\
\hline Electrical Resistivity & $50-75 \mu \Omega-\mathrm{m}$ \\
\hline Compressive Strength & $34-49 \mathrm{MPa}$ \\
\hline Bending Strength & $6-8 \mathrm{MPa}$ \\
\hline Young s Modulus & $78-98 \times$ Xending Strength \\
\hline Coefficient of Thermal Expansion & $3.5-5.0 \times 10^{-6} /{ }^{\circ} \mathrm{C}$ \\
\hline Thermal Conductivity & $3.5-5.5 \mathrm{~W} / \mathrm{m}^{\circ} \mathrm{C}$ \\
\hline
\end{tabular}

Coal-tar pitch from the high-temperature coking of coal is generally agreed by industrial consumers to be the material best suited for use as a binder. ${ }^{(9-11)}$ Binders are characterized by softening point temperature, solubility in various solvents (e.g., toluene and quinoline), aromaticity, coking value, and viscosity. ${ }^{(12,13)}$ Softening point is important in the specification required by end users while the solubility characteristics provide nominal information on molecular weight distribution and the content of solids known as quinoline insolubles or QI. Aromaticity is related to the reactivity of the pitch to form mesophase and to coking value; proper viscosity ensures adequate mixing and wetting of the filler material by the binder. Although helpful, tests on binder pitches conducted under laboratory conditions are useful for screening and quality control assessment. Nevertheless, judgments as whether a particular binder will perform as expected are best made after test anodes have been fabricated and evaluated under prescribed conditions.

The primary function of binder pitch is to fuse the coke filler into a mechanically stable monolith and to provide electrically conductive linkages among the filler particles. The optimum amount of pitch required in the mix is determined when a maximum in 
properties such as baked density and crush strength or a minimum in electrical resistivity are achieved.

Several researchers have reported on the use of petroleum pitch alone or the addition of heavy aromatic petroleum fractions to conventional coal-tar pitch as binders. ${ }^{(14-18)}$ Positive results were observed in pilot scale anode evaluations with a binder consisting of $15 \mathrm{wt} \%$ petroleum-based feedstock. ${ }^{(14)}$ The properties of the blend and coal-tar pitch control were virtually identical as shown in Table 4. There were also no significant differences between pilot scale and the control anodes when the binder blend was used, Table 5.

Table 4 Comparison of Petroleum/Coal-Tar Pitch Blend and Coal-Tar Pitch Binders ${ }^{(14)}$

\begin{tabular}{|l|c|c|}
\hline \multicolumn{1}{|c|}{ Property } & Blend & Coal-Tar Pitch \\
\hline Softening Point, ${ }^{\circ} \mathrm{C}$ & 110.5 & 110.2 \\
\hline TI, $\mathrm{wt} \%$ & 26.4 & 27.2 \\
\hline QI, $\mathrm{wt} \%$ & 12.1 & 13.2 \\
\hline Beta Resin, $\mathrm{wt} \%$ & 14.3 & 14.0 \\
\hline Coking Value, $\mathrm{wt} \%$ & 55.8 & 57.1 \\
\hline Ash, $\mathrm{wt} \%$ & 0.22 & 0.19 \\
\hline Density, $\mathrm{g} / \mathrm{cm}^{3}$ & 1.32 & 1.33 \\
\hline Sulfur, $\mathrm{wt} \%$ & 0.76 & 0.61 \\
\hline
\end{tabular}

Table 5 Anode Core Properties ${ }^{(14)}$

\begin{tabular}{|l|c|c|}
\hline \multicolumn{1}{|c|}{ Property } & Binder Blend & Coal-Tar Pitch \\
\hline Baked Density, $\mathrm{g} / \mathrm{cm}^{3}$ & 1.54 & 1.55 \\
\hline Electrical Resistivity, $\mu \Omega \mathrm{m}$ & 66 & 64 \\
\hline $\mathrm{CO}_{2}$ Reactivity, $\mathrm{wt} \%$ & 93.6 & 93.6 \\
\hline Air Reactivity, $\mathrm{wt} \%$ & 84.7 & 86.2 \\
\hline Air Permeability, $\mathrm{nPm}$ & 0.47 & 0.46 \\
\hline Thermal Conductivity, $\mathrm{W} / \mathrm{mK}$ & 2.70 & 2.64 \\
\hline
\end{tabular}


Further testing of pilot anodes with a binder consisting of up to $40 \mathrm{wt} \%$ the petroleum additive proved that there are benefits to the blend in terms of increased coking value and crush strength as well as reduced electrical resistivity at the lower blend composition.

Recent studies on petroleum-enhanced coal-tar pitches have demonstrated positive synergisms. ${ }^{(17)}$ Results for coal-tar pitch blends with up to $50 \mathrm{wt} \%$ petroleum-based materials showed similar or superior anode performance over the coal-tar or petroleum pitch alone. These observations lead to the conclusion that there are opportunities to improve binder pitch properties by exploiting the positive characteristics of individual raw materials going into the blend.

Very little work has been directed toward the examination of coal extracts as blending feedstocks to conventional coal-tar pitches. ${ }^{(19)}$ Similar to petroleum additives, indications are that coal extracts can also exert positive synergies when used as a component in carbon anode formulations.

\section{EXPERIMENTAL}

\section{Coal-Extract Production}

The Pennsylvania State University in concert with the Consortium for Premium Carbon Products from Coal (CPCPC) supplied about 18kg of a bituminous coal from Arch Coal, Incorporated. The coal is given the designation PSOC 3001. Some characteristics of the coal are shown in Table 6. 
Table 6 Properties of Arch Coal (PSOC 3001)

\begin{tabular}{ccccc}
\hline \multicolumn{2}{c}{ Moisture, wt \% as received } & Ash, wt \% dry & \multicolumn{2}{c}{ Volatile Matter, wt \% dry } \\
1.79 & & 7.36 & & 31.57 \\
\hline Carbon & Hydrogen & Nitrogen & Sulfur & Oxygen \\
wt $\%$ dry & wt $\%$ dry & wt $\%$ dry & wt $\%$ dry & by difference \\
80.31 & 4.56 & 1.41 & 0.71 & 5.65 \\
\hline Vitrinite & Liptinite & Inertinite & Mineral Matter \\
vol $\% \mathrm{mf}$ & vol $\% \mathrm{mf}$ & vol $\% \mathrm{mf}$ & vol $\% \mathrm{mf}$ \\
57.2 & 8.3 & & 30.3 & 4.2 \\
\hline
\end{tabular}

The coal was ground in a hammer mill to about 20 mesh (Tyler sieve) top size and then dried in a vacuum oven overnight at $100^{\circ} \mathrm{C}$ to remove excess moisture. The dried coal was then sealed in $4 \mathrm{~L}$ glass bottles and stored in a refrigerator until ready for use.

Coal-derived pitches were produced in batches by placing $600 \mathrm{~g}$ of coal along with $1.5 \mathrm{~L}$ of tetralin into a 1 gal bolted-closure autoclave. The reactor was purged of air with hydrogen gas and then pressurized to 400 psig with molecular hydrogen at room temperature. The reactor contents were stirred while heating and brought to either 400 or $450^{\circ} \mathrm{C}$ for times of 1 or 2 hours. Depending on the reaction conditions, the pressure would rise to between 1,200 and 2,000psig during processing. Following reaction, the reactor was cooled to room temperature and vented. The products were washed out with N-methyl pyrrolidone (NMP) and collected in a 10L flask. The unreacted tetralin and NMP were then removed by rotary evaporation. Three liters of NMP were added to the flask and agitated for 2 hours at $110^{\circ} \mathrm{C}$. Afterward, the mixture was transferred to $750 \mathrm{~mL}$ centrifuge bottles and centrifuged for 1 hour at 2000 times the force of gravity (2000G) to separate unconverted coal and other insoluble material. The supernatant liquid was decanted and placed in a rotary evaporator device to remove the NMP. Finally, the coalderived pitch was vacuum dried at about $150^{\circ} \mathrm{C}$. 
Koppers Industries, Inc. supplied 5gal of a standard coal-tar pitch (SCTP). Two blends of SCTP and the WVU pitch were prepared in the appropriate proportions by combining each material in a heated vessel at about $130-140^{\circ} \mathrm{C}$ while being constantly stirred for 30min. Heat was removed from the vessel and the blend allowed to cool while still being stirred until the mixture became very viscous. The pitch blend was removed as a thick paste and placed on metal pans to cool and solidify. The material was crushed to pass a 1/4in-sieve and sealed in plastic containers. About $5 \mathrm{~kg}$ of each blend were prepared and delivered to Koppers for their testing and anode fabrication.

Pitch blends involving a standard coal-tar pitch and a standard petroleum pitch were prepared by Koppers at 50:50 and 85:15 wt:wt compositions. These blends were also used as binders in the fabrication of test anodes and were used as controls.

\section{Pilot Anode Fabrication}

Pilot anodes were formed into $10.2 \mathrm{~cm}$ diameter by $15.2 \mathrm{~cm}$ long cylinders using a vibration technique, baked, and evaluated. Sized petroleum coke was premixed according to a standard anode coke formulation shown in Table 7.

Table 7 Anode Coke Formulation, wt $\%$

\begin{tabular}{c|c|c|c}
\hline Coarse & Fines & Intermediate & Butts \\
\hline 31.5 & 37.0 & 14.6 & 16.9 \\
\hline
\end{tabular}

The binder level for the anode formulations ranged from 14.0 up to 16.0 at $1.0 \mathrm{wt} \%$ increments. The pitch and coke were added cold to a $155-165^{\circ} \mathrm{C}$ preheated mixer before transferring to a mold set to a temperature of $150^{\circ} \mathrm{C}$. Typical vibraforming conditions 
were conducted at about $50 \mathrm{~Hz}$ through an amplitude of $0.6 \mathrm{~cm}$. Baking of the green anodes was accomplished in a three-zone, horizontal furnace under a blanket of nitrogen. The baking profile was $10^{\circ} \mathrm{C} / \mathrm{hr}$ to $600^{\circ} \mathrm{C} ; 25^{\circ} \mathrm{C} / \mathrm{hr}$ from $600^{\circ} \mathrm{C}$ to $1160^{\circ} \mathrm{C}$; hold at $1160^{\circ} \mathrm{C}$ for $14 \mathrm{hr}$; cool to room temperature. The final internal bake temperature of the baking retort was approximately $1100^{\circ} \mathrm{C}$. After baking, $5 \mathrm{~cm}$ diameter cores were cut for testing and evaluation.

\section{Other Characterizations}

Samples of pitch were converted to green coke using a coking method developed at WVU. This was accomplished by placing about $1 \mathrm{~g}$ of material into a tared ceramic crucible fitted with a cover. The crucible was then inserted into a slightly larger crucible, covered with coke breeze, and heated in a temperature programmable furnace to $600^{\circ} \mathrm{C}$ at $5^{\circ} \mathrm{C} /$ min with a soak time at $600^{\circ} \mathrm{C}$ for two hours. After cooling, coke yield was determined before embedding the specimen in epoxy resin in preparation for optical microscopy under polarized light. Conventional polishing techniques were followed prior to microscopy.

Viscosity measurements were conducted using a Brookfield LVDV III programmable rheometer equipped with a high-temperature Thermosel heating unit. About 10g of pitch were placed into the sample cup and heated to above the softening point temperature of the pitch before rheological determination. In all cases during the experiment, the pitch was protected from air by a nitrogen purge to prevent oxidation. 


\section{Test Methods and Analytical Procedures}

The test methods used to characterize the binder pitch materials are listed in Table 8 .

Koppers is a known leader in the development and establishment of carbon anode testing methods. The typical tests conducted by Koppers are provided in Table 9. Wherever possible, testing methods followed statistical process control principles.

Table 8 Test Methods for Measuring Pitch Properties

\begin{tabular}{|c|c|}
\hline Characterization & Method \\
\hline Softening Point, ${ }^{\circ} \mathrm{C}$ & ASTM D3104 \\
\hline Toluene Insolubles, $\mathrm{wt} \%$ & ASTM D 4072 or Soxhlet Extraction \\
\hline Quinoline Insolubles, $\mathrm{wt} \%$ & ASTM D 2318 or Soxhlet Extraction \\
\hline$\beta$-Resin, $\mathrm{wt} \%$ & TI - QI \\
\hline Conradson Carbon Residue, $\mathrm{wt} \%$ & ASTM D189 \\
\hline Density, $\mathrm{g} / \mathrm{cm}^{3}$ & ASTM D4892 \\
\hline Ash Content, $\mathrm{wt} \%$ & ASTM D2415 \\
\hline Viscosity, $\mathrm{cP}$ & Brookfield Viscometry \\
\hline $\mathrm{C}, \mathrm{H}, \mathrm{N}, \mathrm{S}$ Content, $\mathrm{wt} \%$ & CE Instruments Model 1112 \\
\hline Coke Structure & Polarized-Light Microscopy \\
\hline Aromaticity Index & Fourier-Transform Infrared Spectroscopy \\
\hline
\end{tabular}

Table 9 Carbon Anode Property Tests

\begin{tabular}{|c|c|}
\hline Test & Unit \\
\hline Apparent Density & $\mathrm{g} / \mathrm{cm}^{3}$ \\
\hline Air Permeability & $\mathrm{NPm}$ \\
\hline Electrical Resistivity & $\mu \Omega \mathrm{m}$ \\
\hline Compressive Strength & $\mathrm{MPa}$ \\
\hline Coefficient of Thermal Expansion & $10^{-6} /{ }^{\circ} \mathrm{C}$ \\
\hline Thermal Conductivity & $\mathrm{W} / \mathrm{m}-\mathrm{K}$ \\
\hline
\end{tabular}

\section{RESULTS AND DISCUSSION}

A few preliminary reactions were conducted to determine the conditions that would produce a material with a Mettler softening point temperature near $110^{\circ} \mathrm{C}$ and a coke 
yield of about $50 \mathrm{wt} \%$. Table 10 provides some of the results of the screening experiments.

Table 10 Effects of Reaction Conditions on Product Yield and Pitch Properties from PSOC 3001

\begin{tabular}{cccc}
\hline Reaction Conditions & Pitch Yield $^{1}$ & Coke Yield $^{2}, \mathrm{wt} \%$ & Softening Point, ${ }^{\circ} \mathrm{C}$ \\
\hline $400^{\circ} \mathrm{C}$ & & 58 & 131.3 \\
2 Hours & 66 & 45 & 116.0 \\
\hline $450^{\circ} \mathrm{C}$ & 63 & 48 & 83.0 \\
1 Hour & 51 & & \\
\hline $450^{\circ} \mathrm{C}$ & &
\end{tabular}

The data indicate that as reaction severity increases the yield of pitch product decreases. The decease in yield is probably because of the greater amount of lighter distillate materials generated at the higher temperatures or longer reaction times, which would be lost during work up. The dramatic drop in softening point temperature and the general decrease in coking value support this observation. Based on these results it was decided to process the remaining coal at $450^{\circ} \mathrm{C}$ for 1 hour. Runs were repeated until about $5 \mathrm{~kg}$ of pitch were produced.

Table 11 provides characteristics of the various binder pitches which were tested in this study. The measurements depicted in Table 11 indicate that the softening point temperature and coking value for the coal-extract, coal-extract/coal-tar blend, and petroleum pitch are within the range found for conventional coal-tar binder pitch. Quinoline insoluble matter is naturally low for the WVU pitch and SPP because of their origin, though the amount of toluene insolubles in the former is significantly greater than the latter. 
Table 11 Properties of Pitches and Their Blends

\begin{tabular}{|c|c|c|c|c|c|}
\hline & & & SCTP:WVU & SCTP:WVU & \\
\hline & WVU Pitch & SCTP & $50: 50$ & $85: 15$ & SPP \\
\hline Mettler SP ${ }^{\circ} \mathrm{C}$ & 116.0 & 109.4 & 111.1 & 107.8 & 112.0 \\
\hline Conradson & & & & & \\
\hline Carbon, wt $\%$ & 52.7 & 57.8 & 57.6 & 56.1 & 46.9 \\
\hline QI, wt $\%$ & nil & 13.1 & $6.6^{*}$ & $11.1^{*}$ & 0.1 \\
\hline TI, wt $\%$ & 19.8 & 30.3 & $25.1^{*}$ & $28.7^{*}$ & 3.2 \\
\hline$\beta$-Resin, $\mathrm{wt}^{\mathrm{t}} \%$ & 19.8 & 14.4 & 18.5 & 17.6 & 3.1 \\
\hline $\begin{array}{l}\text { Ash Content } \\
\mathrm{wt} \%\end{array}$ & 0.03 & 0.07 & 0.08 & 0.11 & 0.03 \\
\hline Density, $\mathrm{g} / \mathrm{cm}^{3}$ & 1.24 & 1.34 & 1.28 & 1.33 & 1.22 \\
\hline
\end{tabular}

Table 12 reports elemental composition, atomic carbon-to-hydrogen ratio, and an aromaticity index for the standard coal-tar pitch, WVU pitch, and their blends. The aromaticity index was determined using Fourier-transform infrared spectroscopy. The index is simply the ratio of the integrated peak areas of the spectral regions associated with the aromatic-carbon-hydrogen to the sum of the aromatic-carbon-hydrogen and aliphatic-carbon-hydrogen stretching frequencies.

Table 12 Elemental Composition and Aromaticity of Binder Pitches

\begin{tabular}{|l|c|c|c|c|}
\hline Element, wt\% & SCTP & WVU Pitch & $\begin{array}{c}\text { SCTP:WVU } \\
50: 50\end{array}$ & $\begin{array}{c}\text { SCTP:WVU } \\
85: 15\end{array}$ \\
\hline $\mathrm{C}$ & 93.46 & 86.85 & 89.50 & 90.79 \\
\hline $\mathrm{H}$ & 4.34 & 5.88 & 5.03 & 4.50 \\
\hline $\mathrm{N}$ & 2.32 & 2.85 & 2.62 & 2.81 \\
\hline $\mathrm{S}$ & 0.71 & --- & 0.74 & 0.78 \\
\hline $\mathrm{C} / \mathrm{H}$ atomic & 1.79 & 1.23 & 1.48 & 1.68 \\
\hline $\mathrm{IR} \mathrm{index,}$ & 0.81 & 0.12 & 0.29 & 0.56 \\
$\mathrm{H}_{\mathrm{ar}} /\left(\mathrm{H}_{\mathrm{al}}+\mathrm{H}_{\mathrm{ar}}\right)$ & & & & \\
\hline
\end{tabular}

Because the coal volatiles are subjected to high temperatures within the coke battery, coal-tar pitch is highly aromatic as evidenced by its high carbon and low hydrogen 
content, high $\mathrm{C} / \mathrm{H}$ atomic ratio, and large IR index value. The coal-extract pitch contains considerably more hydrogen, though all pitch materials are rather high in nitrogen content.

Samples of the standard coal-tar pitch and WVU pitch were mounted in epoxy resin and polished to a smooth surface for examination by optical microscopy. Figure 1 shows the photomicrographs of the optical features displayed by the two materials. Notice that the coal-tar pitch is not simply a mixture of aromatic molecules but also contains a variety of insoluble solids such as cenospheres, mineral inclusions, and other materials insoluble in quinoline (QI). In contrast, the pitch developed by WVU is virtually free of solids visible by optical microscopy.

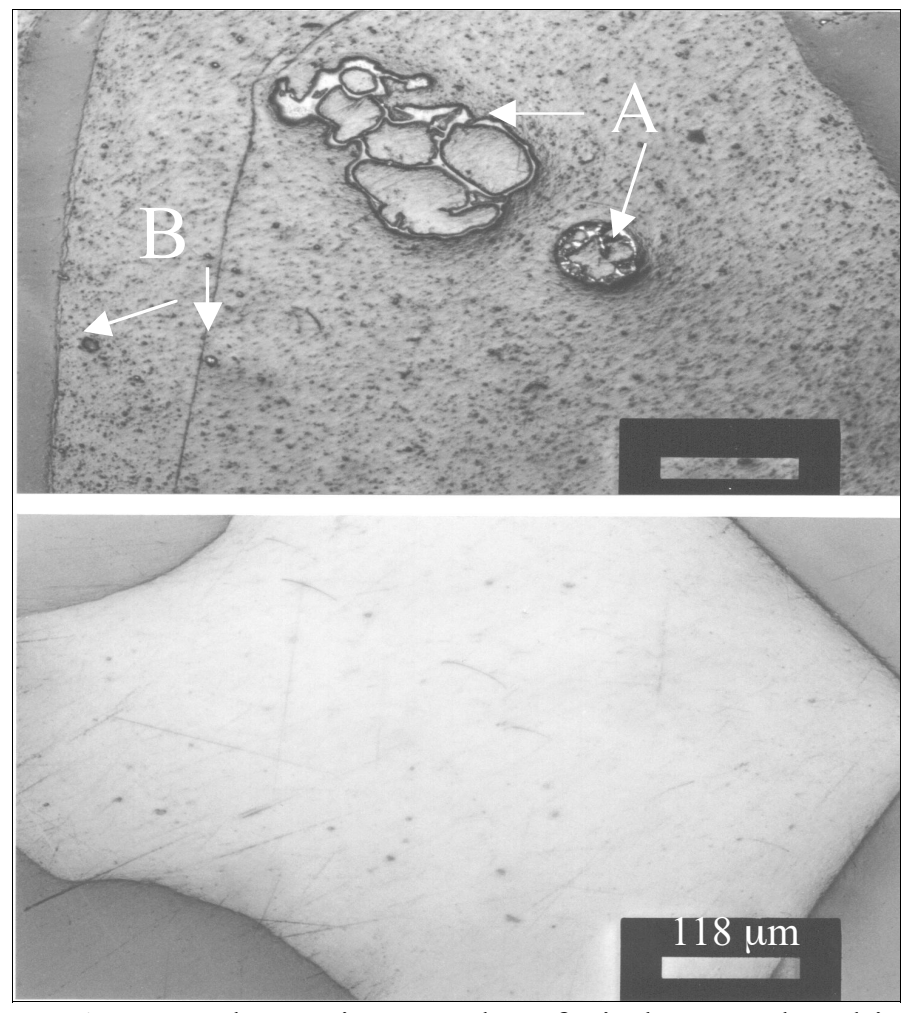

Figure 1. Photomicrographs of pitches used as binders. Top: SCTP; A, cenospheres; B, other quinoline insoluble material. Bottom: WVU pitch with no visible quinoline insoluble solids. 
The standard coal-tar pitch and WVU pitch were also converted into green coke using the WVU coke procedure. Figure 2 shows the optical texture developed by the SCTP and WVU pitches.
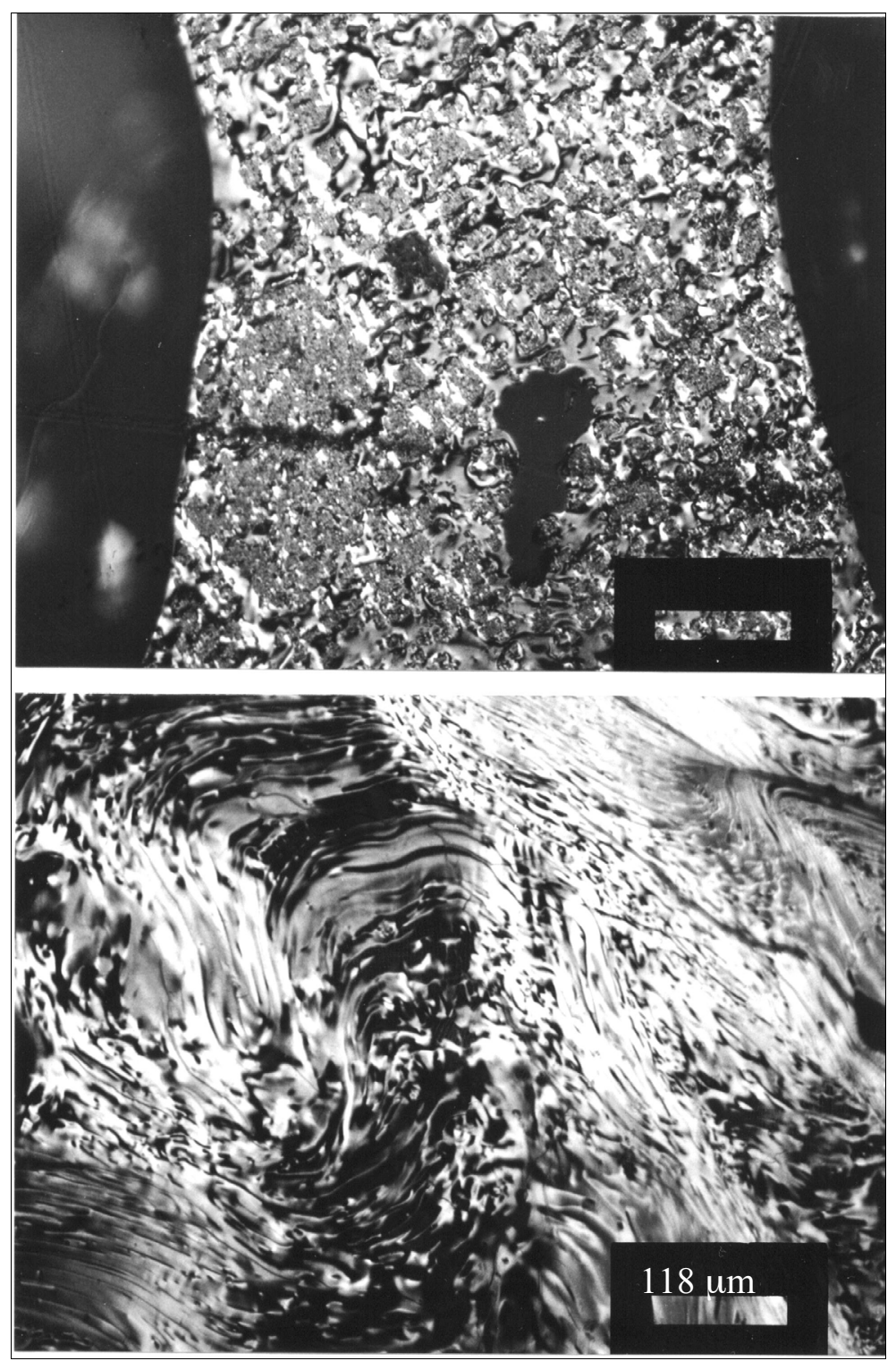

Figure 2. Optical photomicrographs of pitch cokes. Top: SCTP; Bottom: WVU Pitch 
Notice that the optical texture exhibited by the pitch cokes is dramatically different. The SCTP sample underwent restricted mesophase development because of the presence of QI material. On the other hand, since no QI was present, the WVU pitch underwent extensive mesophase transformation forming regions of long-range molecular order. The SCTP should also show this long-range order had the QI been removed prior to carbonization.

Viscosity measurements of the pitches were conducted on a Brookfield Model LVDV III programmable rheometer. Figures 3, 4, and 5 show the results at 140,160 and $180^{\circ} \mathrm{C}$, respectively.

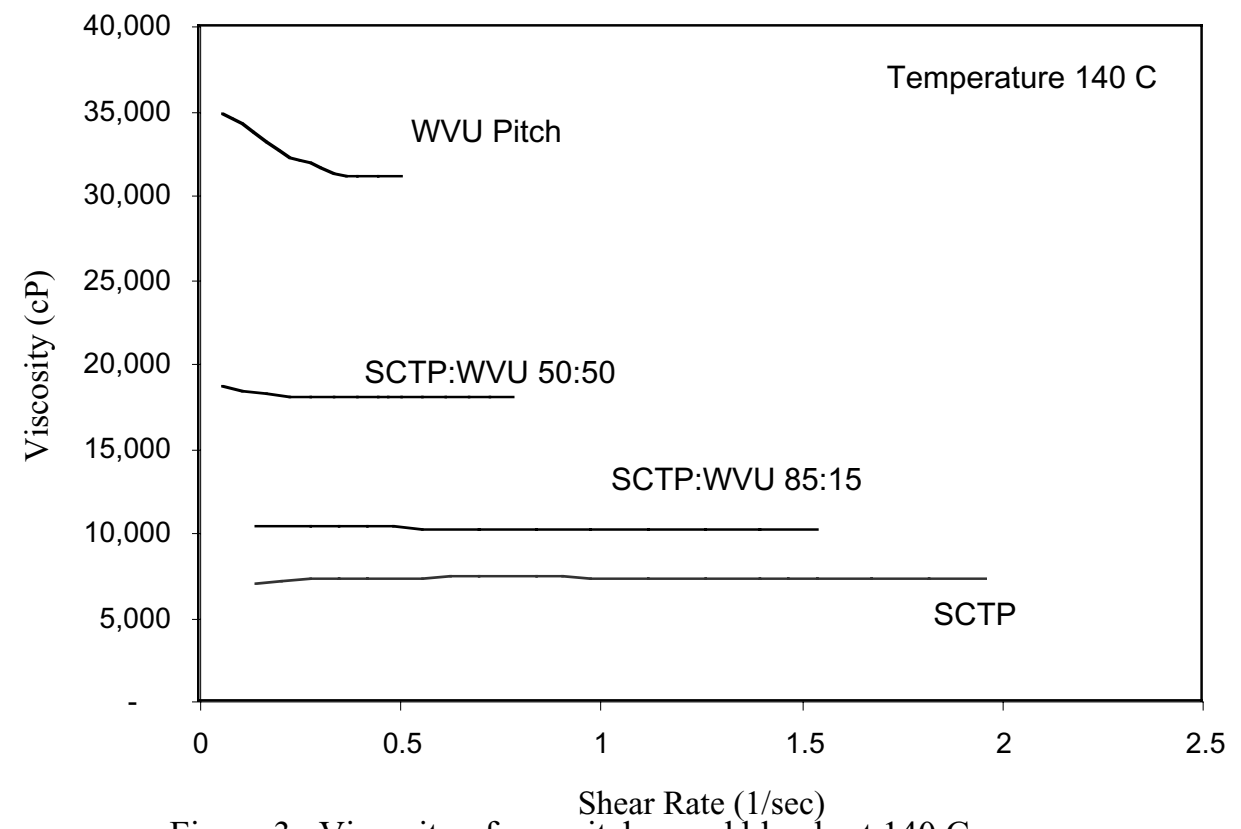

Figure 3. Viscosity of raw pitches and blends at $140 \mathrm{C}$. 


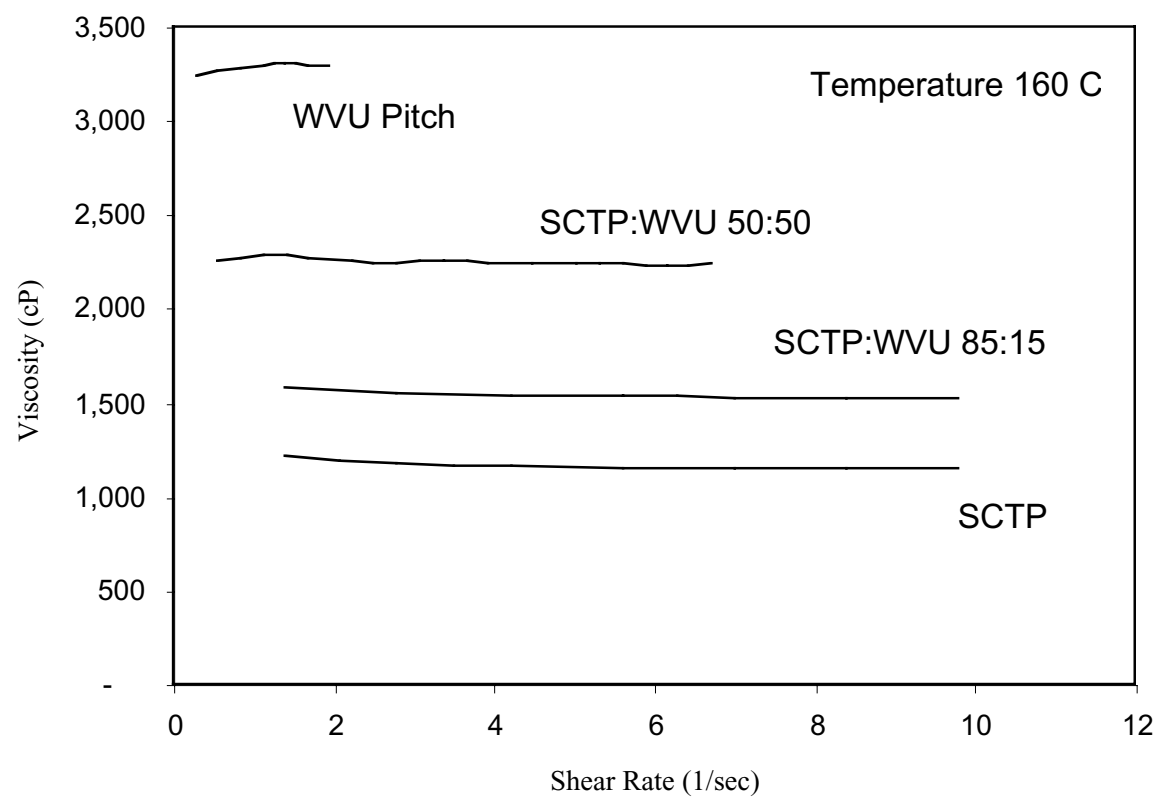

Figure 4. Viscosity of raw pitches and blends at $160 \mathrm{C}$.

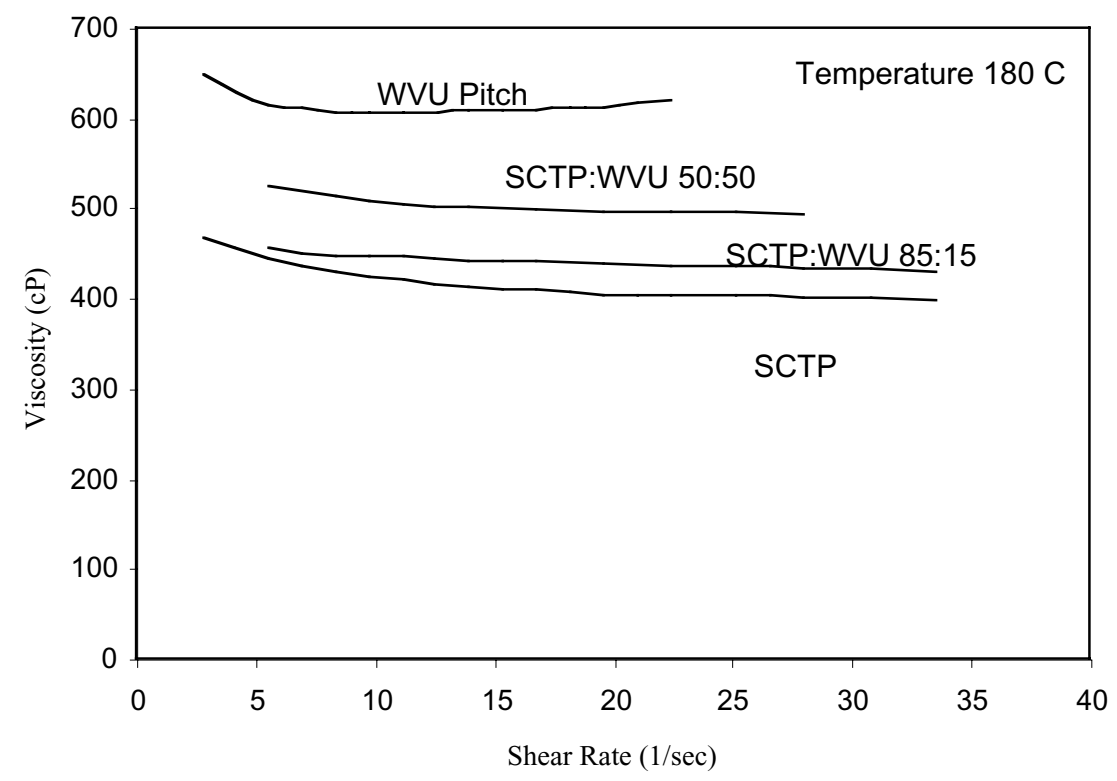

Figure 5. Viscosity of raw pitches and blends at $180 \mathrm{C}$.

At all temperatures investigated, the viscosity of the WVU pitch is higher than the SCTP. The viscosities of the blends exhibit intermediate values at each temperature, with the viscosity decreasing as the proportion of SCTP increases. Higher viscosity exhibited by 
the WVU pitch could be due, in part, to higher molecular weight species as suggested by its higher softening point temperature and beta resin content, Table 11. Higher viscosities could affect the wetting and penetration characteristics of pitch during mixing with anode coke. However, this did not seem to be a significant performance factor in the laboratory test anode analyses, discussed below.

The raw data accumulated for the green and baked anodes as well as the core specimens are provided an appendixes A through E. The results of the analyses are depicted graphically in Figures 6 through 15. For similar binder formulations, the overall trend in density changes for the baked apparent density tracks that for the core materials, with the core densities being somewhat higher. Whether with the coal extract or petroleum pitch, the 50:50 blends resulted in an essentially similiar core density at the $16 \mathrm{wt} \%$ binder content. Nevertheless, a synergism may be present when using either the WVU or petroleum pitch at the $85: 15$ blend composition since the core densities are significantly greater than the coal-tar pitch control alone.
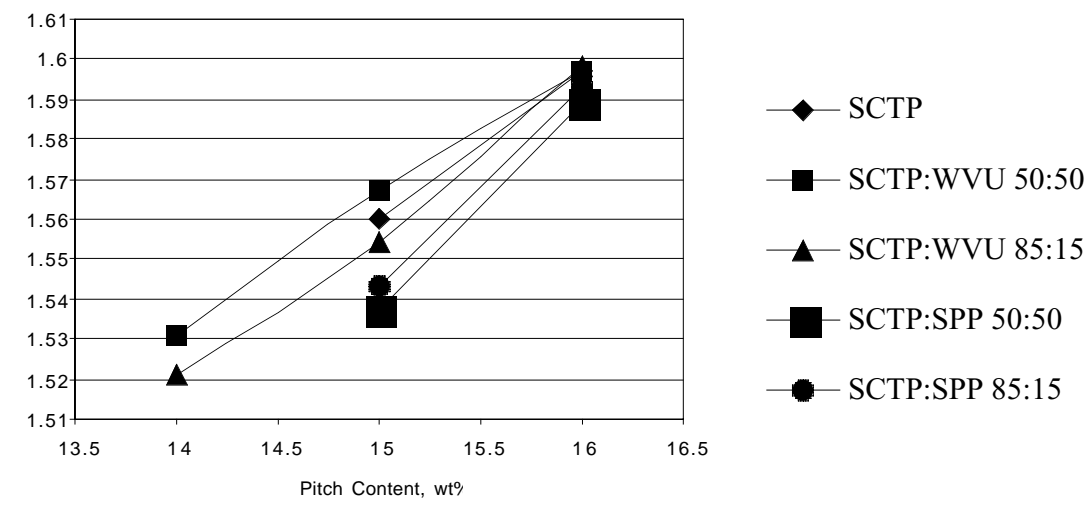

Figure 6 Green anode apparent density vs. binder composition 


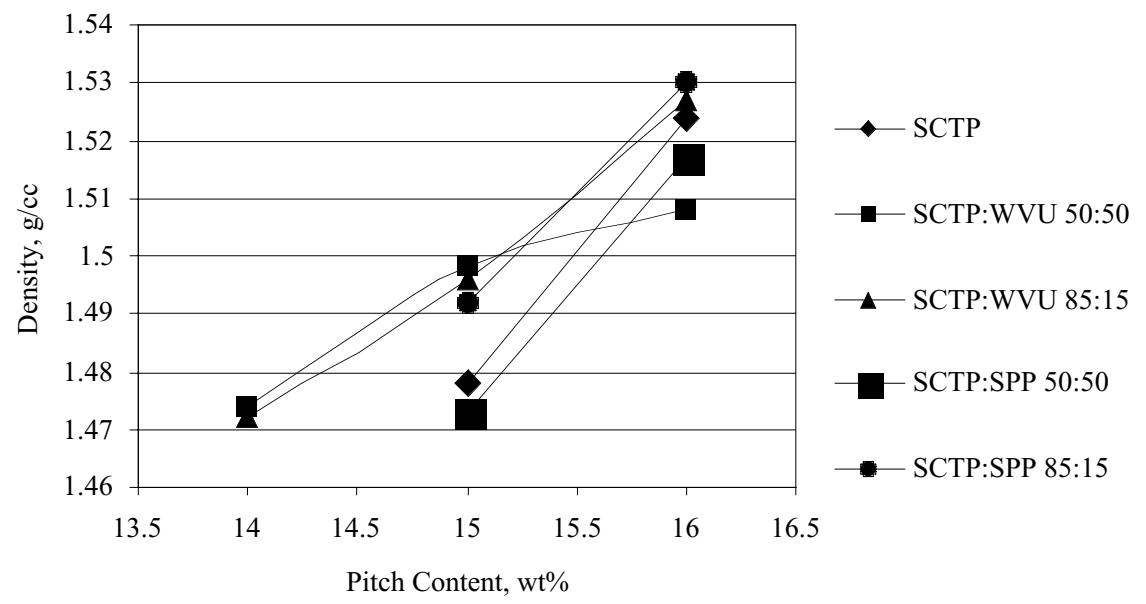

Figure 7 Baked apparent density vs. binder composition.

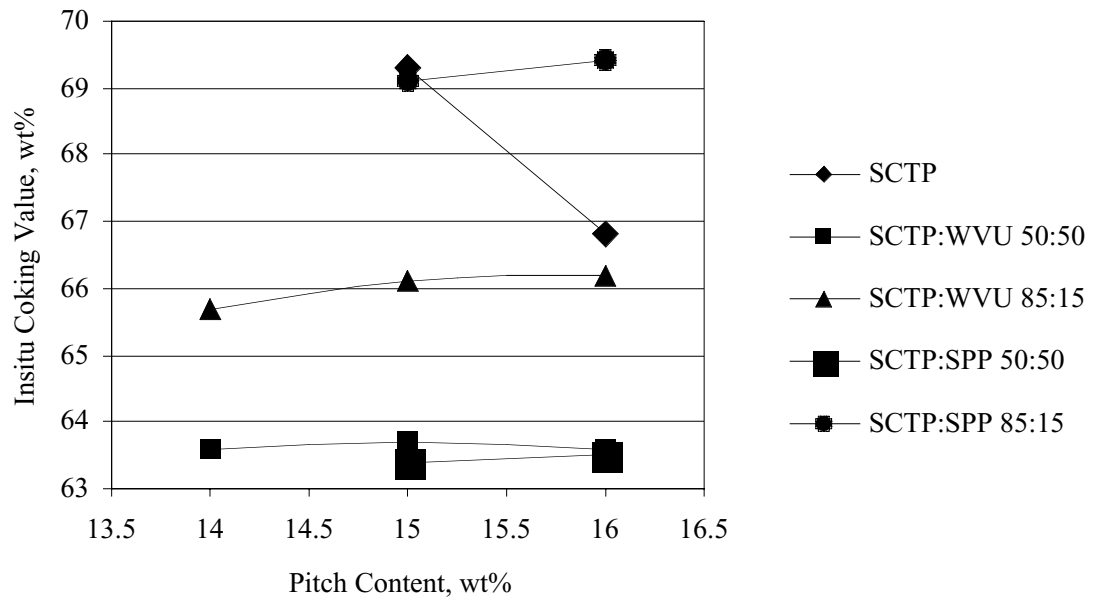

Figure 8 Insitu coking value vs. binder composition. 

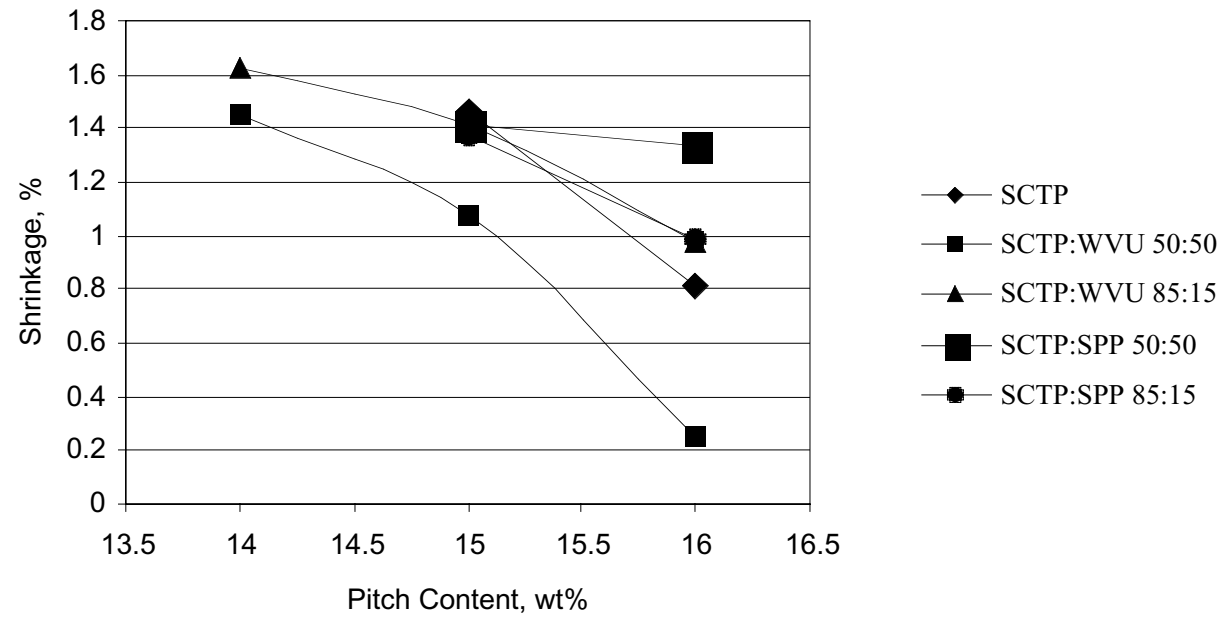

Figure 9 Percent shrinkage vs. binder compositior

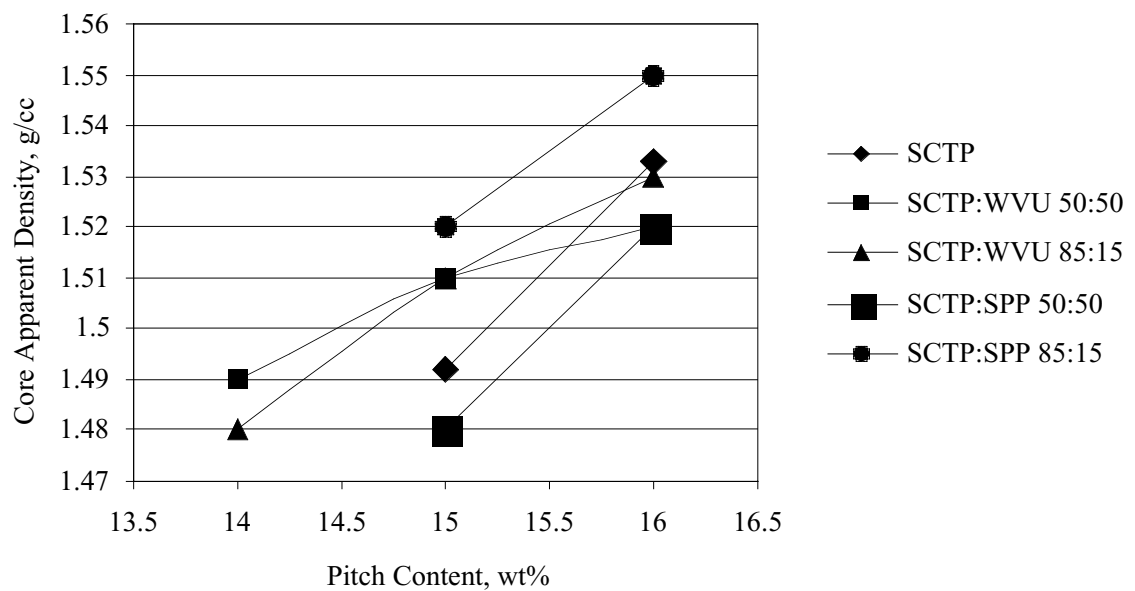

Figure 10 Core apparent density vs. binder composition. 


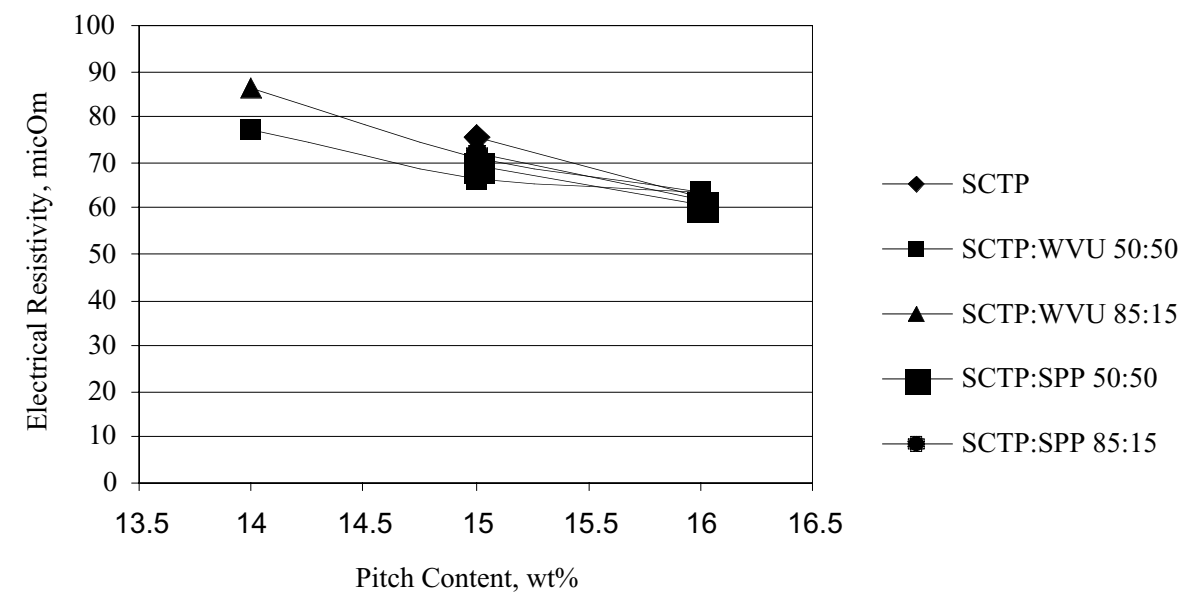

Figure 11 Core electrical resistivity vs. binder composition.

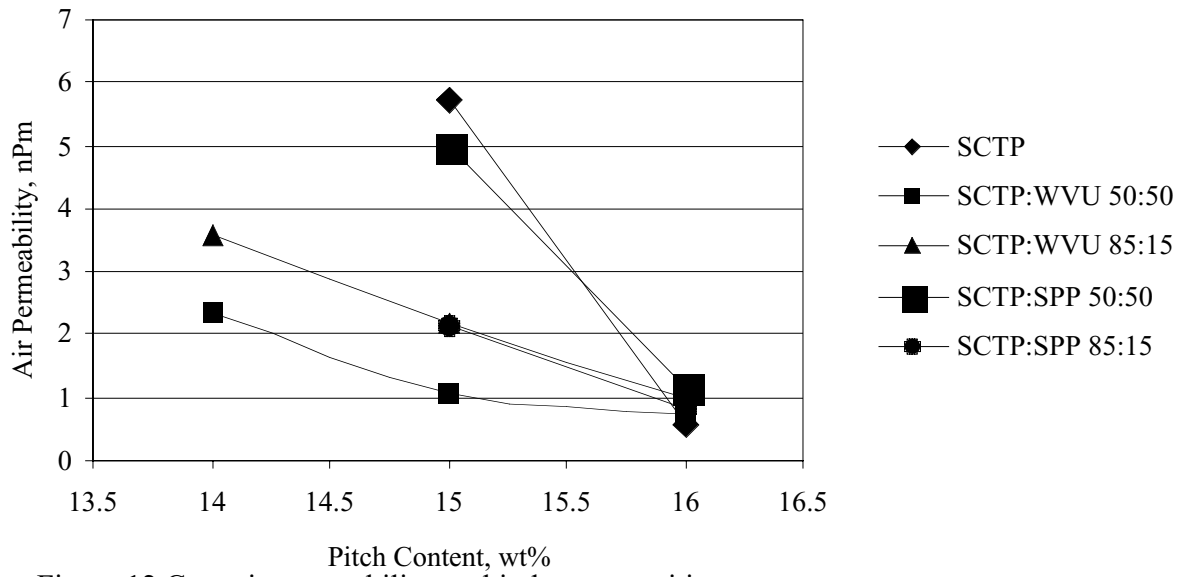

Figure 12 Core air permeability vs. binder composition. 


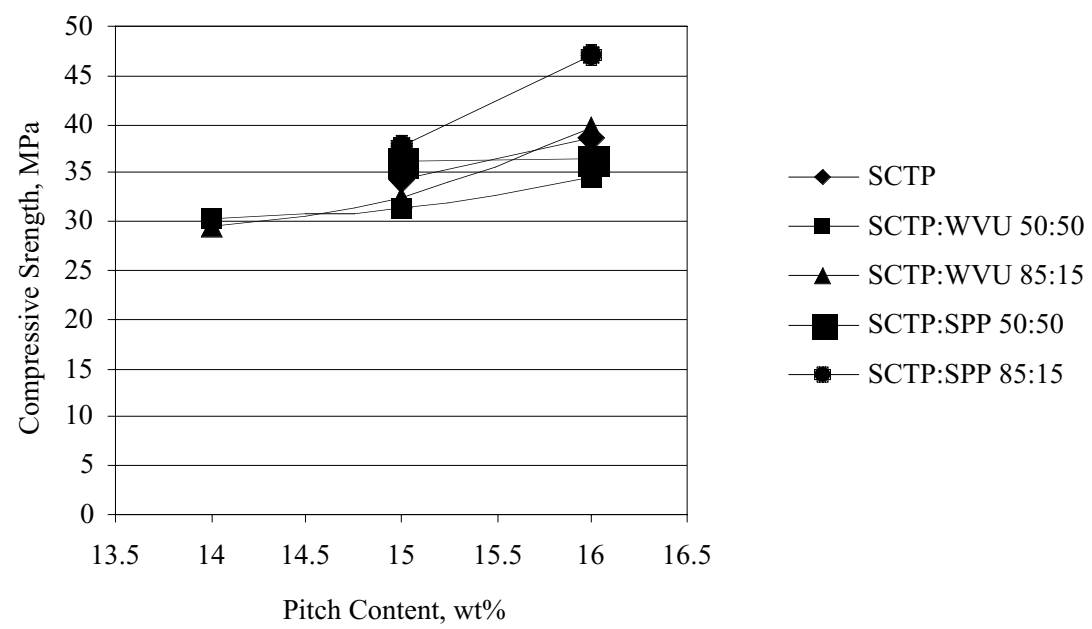

Figure 13 Core compressive strength vs. binder composition.

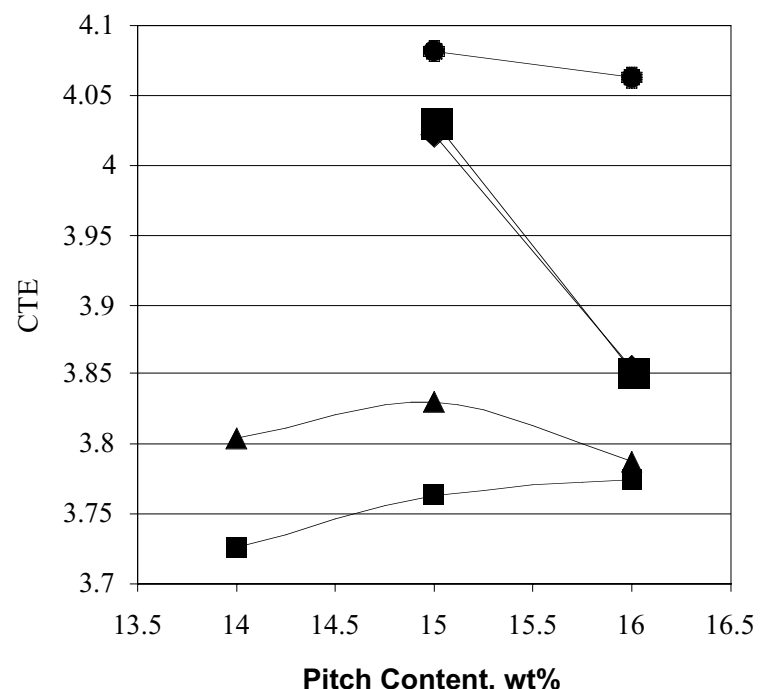

$$
\begin{aligned}
& \longrightarrow \text { SCTP } \\
& \square \text { SCTP:WVU 50:50 } \\
& \square \text { SCTP:WVU 85:15 } \\
& - \text { SCTP:SPP 50:50 } \\
& - \text { SCTP:SPP 85:15 }
\end{aligned}
$$

Figure 14 Coefficient of thermal expansion vs. binder composition. 


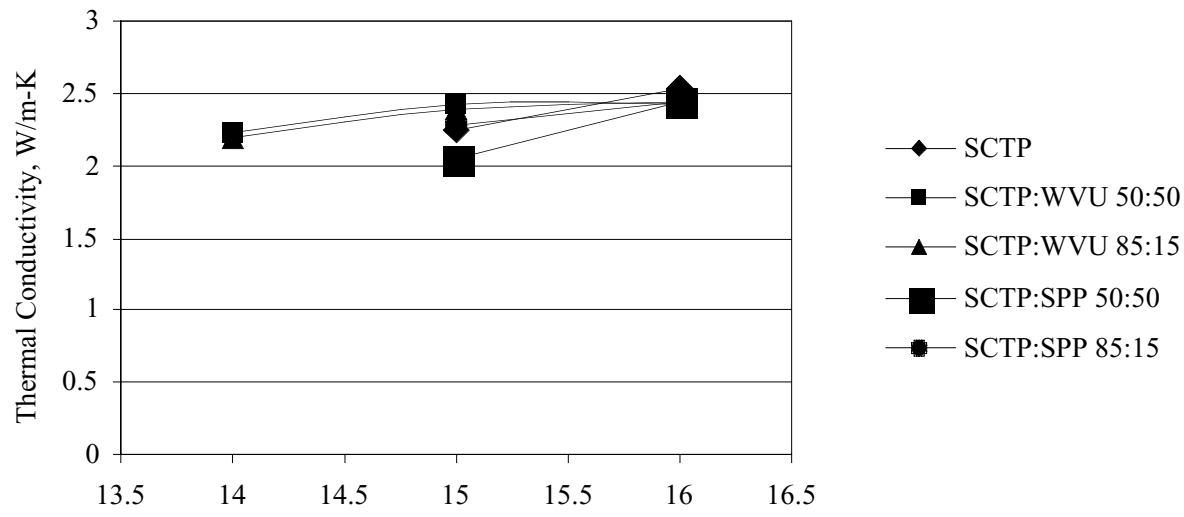

Figure 15 Core thermal conductivity vi vi binder composition.

The electrical resistivity values at the $15 \mathrm{wt} \%$ binder level remained relatively constant between about 67 and $72 \mu \Omega \mathrm{m}$, except for the coal-tar pitch control with a value over $75 \mu \Omega \mathrm{m}$, Figure 11. Increasing the binder content to $16 \mathrm{wt} \%$ decreased resistivity for all anode cores to approximately $60 \mu \Omega \mathrm{m}$. Crush strength is displayed in Figure 13. The most dramatic effects on anode properties were observed for changes in the coefficient of thermal expansion, Figure 14. The addition of coal extracts to the standard coal-tar pitch at the 85:15 composition was more successful in reducing dimensional changes than the coal-tar pitch/petroleum 50:50 composition.

\section{CONCLUSION}

The results obtained in this project indicate that coal-extracts perform very well when used as a blending material with conventional coal-tar pitch. For the most part, the trends in anode properties upon going from 14 to $16 \mathrm{wt} \%$ binder level for the coal extracts track those for the conventional coal-tar pitch and its blends with the petroleum pitch. 
Important characteristics attributed to the coal-extract blends as a function of binder level include a reduction in shrinkage after baking, increase in core density, decrease in electrical resistivity and air permeability.

The use of coal extracts as binder pitch additives is encouraging and show promise as effective blending agents. Moreover, it should be emphasized that the coal extracts produced in this project were not optimized in any way and as such represent an initial attempt to derive products of high value from coal. 


\section{REFERENCES}

1) Heintz, E. A. Carbon 34, 699 (1996).

2) Marsh, $\mathrm{H}$ and Fiorino, K., In Introduction to Carbon Technologies; Marsh, H, Heintz, E. A., and Rodriguez-Reinoso, F., Eds; University of Alicante: Spain, 1997; pp. 537-560.

3) Mantell, C. L., In Carbon and Graphite Handbook; Robert E. Krieger Publishing Company: Huntington, NY, 1979.

4) Hutcheon, J. M., In Modern Aspects of Graphite Technology; Blackman, L. C. F., Ed; Academic Press: New York, 1970; pp. 49-78.

5) Jones, S. S. and Bart, E. F. Light Metals, 611 (1990).

6) Rhedey, P. J. and Nadkarni, S. K. Light Metals, 859 (1984).

7) Heintz, E. A. Carbon 33, 817 (1995).

8) Belitskus, D. Light Metals, 557 (1989).

9) Ball, D. R. Carbon 16, 205 (1978).

10) Krupinski, K. C. and Windfelder, J. J. Ironmaking Conference Proceedings 1992.

11) Darney, A., In Industrial Carbon and Graphite; Society of Chemical Industry: London, 1958; 152-161.

12) King, L. F., In Analytical Methods for Coal and Coal Products Volume II; Karr, C., Ed; Academic Press: New York, 1978; 535-559.

13) Nair, C. S. B., In Analytical Methods for Coal and Coal Products Volume II; Karr, C., Ed; Academic Press: New York, 1978; 495-533.

14) McHenry, E. R. Light Metals, 543 (1997).

15) Newman, J. W Light Metals, 503 (1980).

16) King L. F. and Robertson, W. D. Carbon 47, 197 (1968).

17) Turner, N. R., Alsop, S. H., Malmros, O., Whittle, D., Hansen, B. E., Stenby, E. H., and Andersen, S. I. Light Metals, 565 (2001).

18) Perez, M., Garcia, G. R., Menendez, R., and Romero, E. Light Metals, 573 (2001). 
19) Stansberry, P. G., Zondlo, J. W., and Wombles, R. H. Light Metals, 581 (2001). 


\section{APPENDIX A}

Standard Coal-Tar Pitch Pilot Anodes

\begin{tabular}{|c|c|c|c|c|c|c|}
\hline $\begin{array}{c}\text { Sample } \\
\text { No. }\end{array}$ & $\begin{array}{c}\text { Koppers } \\
\text { Sample } \\
\text { No. }\end{array}$ & $\begin{array}{l}\text { Pitch } \\
\mathrm{Wt} \%\end{array}$ & $\begin{array}{l}\text { Block } \\
\text { GAD } \\
(\mathrm{g} / \mathrm{cc})\end{array}$ & $\begin{array}{l}\text { Block } \\
\text { BAD } \\
(\mathrm{g} / \mathrm{cc})\end{array}$ & $\begin{array}{c}\text { InSitu } \\
\mathrm{CV} \\
\mathrm{Wt} \%\end{array}$ & $\begin{array}{c}\text { Shrinkage } \\
\%\end{array}$ \\
\hline A149 & C98-824 & 15 & 1.536 & 1.486 & 69.1 & 1.441 \\
\hline A150 & C98-825 & 15 & 1.527 & 1.478 & 69.3 & 1.451 \\
\hline A151 & C98-826 & 15 & 1.523 & 1.478 & 70.2 & 1.560 \\
\hline A152 & C98-827 & 15 & 1.528 & 1.474 & 68.1 & 1.334 \\
\hline A153 & C98-828 & 15 & 1.524 & 1.476 & 69.8 & 1.446 \\
\hline A154 & C98-829 & 15 & 1.520 & 1.473 & 69.3 & 1.555 \\
\hline Avg. & & & 1.526 & 1.478 & 69.3 & 1.465 \\
\hline W1 & 20001310 & 16 & 1.591 & 1.520 & 66.5 & 0.955 \\
\hline $\mathrm{W} 2$ & 20001311 & 16 & 1.607 & 1.523 & 66.5 & 0.155 \\
\hline W3 & 20001312 & 16 & 1.597 & 1.529 & 67.0 & 1.092 \\
\hline W4 & 20001313 & 16 & 1.592 & 1.524 & 67.1 & 1.053 \\
\hline Avg. & & & 1.597 & 1.524 & 66.8 & 0.814 \\
\hline
\end{tabular}

Standard Coal-Tar Pitch Anode Cores

\begin{tabular}{|c|c|c|c|c|c|c|c|c|c|}
\hline $\begin{array}{c}\text { Sample } \\
\text { No. }\end{array}$ & $\begin{array}{c}\text { Pitch } \\
\mathrm{Wt} \%\end{array}$ & $\begin{array}{c}\text { Core } \\
\text { BAD } \\
(\mathrm{g} / \mathrm{cc})\end{array}$ & $\begin{array}{c}\text { ER } \\
(\mu \Omega \mathrm{m})\end{array}$ & $\begin{array}{c}\text { Air } \\
\text { Perm. } \\
(\mathrm{nPm})\end{array}$ & $\begin{array}{c}\text { Crush } \\
\text { Streng. } \\
(\mathrm{MPa})\end{array}$ & $\begin{array}{c}\text { Mod. } \\
\text { Elast. } \\
(\mathrm{MPa})\end{array}$ & $\begin{array}{c}\text { Flex. } \\
\text { Streng. } \\
\text { Stress } \\
(\mathrm{MPa})\end{array}$ & $\begin{array}{c}\mathrm{CTE} \\
10^{-6} /{ }^{\circ} \mathrm{C} \\
@ 300^{\circ} \mathrm{C}\end{array}$ & $\begin{array}{c}\text { Thermal } \\
\text { Conduct. } \\
(\mathrm{W} / \mathrm{mK})\end{array}$ \\
\hline $\mathrm{C} 98-824$ & 15 & 1.50 & 74.3 & 5.03 & & & 2.40 & 4.036 & 2.31 \\
\hline $\mathrm{C} 98-825$ & 15 & 1.49 & 84.0 & & 34.07 & 1897.9 & & & \\
\hline $\mathrm{C} 98-826$ & 15 & 1.50 & 73.1 & 6.47 & & & 1.74 & 4.026 & 2.15 \\
\hline $\mathrm{C} 98-827$ & 15 & 1.48 & 73.8 & & 36.86 & 2154.4 & & & \\
\hline $\mathrm{C} 98-828$ & 15 & 1.50 & 73.2 & 5.69 & & & 2.40 & 4.005 & 2.28 \\
\hline $\mathrm{C} 98-829$ & 15 & 1.49 & 75.1 & & 31.97 & 1206.9 & & & \\
\hline
\end{tabular}

\begin{tabular}{|c|c|c|c|c|c|c|c|c|c|}
\hline Count & 6 & 6 & 3 & 3 & 3 & 3 & 3 & 3 \\
\hline Avg. & 1.492 & 75.6 & 5.73 & 34.30 & 1753.1 & 2.18 & 4.022 & 2.25 \\
\hline Std.Dev. & 0.005 & 4.2 & 0.72 & 2.45 & 490.1 & 0.38 & 0.016 & 0.09 \\
\hline
\end{tabular}




\section{APPENDIX A \\ (CONTINUED)}

Standard Coal-Tar Pitch Anode Cores

\begin{tabular}{|c|c|c|c|c|c|c|c|c|c|c|}
\hline $\begin{array}{c}\text { Sample } \\
\text { No. }\end{array}$ & $\begin{array}{l}\text { KII } \\
\text { No. }\end{array}$ & $\begin{array}{l}\text { Pitch } \\
\mathrm{Wt} \%\end{array}$ & $\begin{array}{l}\text { Core } \\
\text { BAD } \\
(\mathrm{g} / \mathrm{cc})\end{array}$ & $\begin{array}{c}\text { ER } \\
(\mu \Omega \mathrm{m})\end{array}$ & $\begin{array}{c}\text { Air } \\
\text { Perm. } \\
(\mathrm{nPm})\end{array}$ & $\begin{array}{l}\text { Crush } \\
\text { Streng. } \\
\text { (MPa) }\end{array}$ & $\begin{array}{l}\text { Mod. } \\
\text { Elast. } \\
\text { (MPa) }\end{array}$ & $\begin{array}{c}\text { Flex. } \\
\text { Streng. } \\
\text { Stress } \\
(\mathrm{MPa})\end{array}$ & $\begin{array}{c}\mathrm{CTE} \\
10^{-6} /{ }^{\circ} \mathrm{C} \\
@ 300^{\circ} \mathrm{C}\end{array}$ & $\begin{array}{l}\text { Thermal } \\
\text { Conduct. } \\
\text { (W/mK) }\end{array}$ \\
\hline W1 & & 16 & 524 & 633 & 0.70 & 35 & 323.8 & 8.53 & 3.955 & 2.54 \\
\hline W & $\begin{array}{l}2000 \\
1311\end{array}$ & 16 & & & & & & 7.44 & 860 & \\
\hline W3 & $\begin{array}{l}2000 \\
1312\end{array}$ & 16 & 1.539 & 61.9 & 0.42 & 41.72 & 3706.2 & 6.19 & 3.864 & 2.52 \\
\hline W4 & $\begin{array}{l}2000 \\
1313 \\
\end{array}$ & 16 & 1.535 & 62.9 & 0.38 & 36.23 & 3165.8 & 6.92 & 3.736 & 2.45 \\
\hline
\end{tabular}

\begin{tabular}{|c|c|c|c|c|c|c|c|c|c|}
\hline Count & & 4 & 4 & 4 & 4 & 4 & 4 & 4 & 4 \\
\hline Avg. & & 1.533 & 62.5 & 0.58 & 38.50 & 2683.4 & 7.27 & 3.854 & 2.53 \\
\hline Std.Dev. & & 0.007 & 0.6 & 0.22 & 3.06 & 1024.5 & 0.99 & 0.090 & 0.06 \\
\hline
\end{tabular}


APPENDIX B

Standard Coal-Tar Pitch:WVU Pitch 85:15

\begin{tabular}{|c|c|c|c|c|c|c|}
\hline $\begin{array}{c}\text { Sample } \\
\text { No. }\end{array}$ & $\begin{array}{c}\text { Koppers } \\
\text { Sample } \\
\text { No. }\end{array}$ & $\begin{array}{c}\text { Pitch } \\
\mathrm{Wt} \%\end{array}$ & $\begin{array}{c}\text { Block } \\
\text { GAD } \\
(\mathrm{g} / \mathrm{cc})\end{array}$ & $\begin{array}{c}\text { Block } \\
\text { BAD } \\
(\mathrm{g} / \mathrm{cc})\end{array}$ & $\begin{array}{c}\text { InSitu } \\
\mathrm{CV} \\
\mathrm{Wt} \%\end{array}$ & $\begin{array}{c}\text { Shrinkage } \\
\%\end{array}$ \\
\hline W1 & 20001314 & 14 & 1.523 & 1.479 & 66.3 & 1.841 \\
\hline W2 & 20001315 & 14 & 1.524 & 1.470 & 65.2 & 1.334 \\
\hline W3 & 20001316 & 14 & 1.522 & 1.474 & 65.6 & 1.759 \\
\hline W4 & 20001317 & 14 & 1.516 & 1.467 & 66.0 & 1.576 \\
\hline & & & & & & \\
\hline Avg. & & & 1.521 & 1.472 & 65.7 & 1.627 \\
\hline
\end{tabular}

\begin{tabular}{|c|c|c|c|c|c|c|}
\hline W9 & 20001318 & 15 & 1.551 & 1.497 & 66.7 & 1.564 \\
\hline W10 & 20001319 & 15 & 1.560 & 1.495 & 65.7 & 1.016 \\
\hline W11 & 20001320 & 15 & 1.556 & 1.497 & 66.0 & 1.340 \\
\hline W12 & 20001321 & 15 & 1.547 & 1.494 & 66.2 & 1.703 \\
\hline & & & & & & \\
\hline Avg. & & & 1.554 & 1.496 & 66.1 & 1.406 \\
\hline
\end{tabular}

\begin{tabular}{|c|c|c|c|c|c|c|}
\hline W13 & 20001322 & 16 & 1.591 & 1.520 & 66.5 & 0.908 \\
\hline W14 & 20001323 & 16 & 1.604 & 1.531 & 66.7 & 0.790 \\
\hline W15 & 20001324 & 16 & 1.604 & 1.536 & 65.7 & 1.275 \\
\hline W16 & 20001325 & 16 & 1.593 & 1.521 & 65.9 & 0.961 \\
\hline & & & & & & \\
\hline Avg. & & & 1.598 & 1.527 & 66.2 & 0.983 \\
\hline
\end{tabular}

Standard Coal-Tar Pitch:WVU Pitch 85:15 ANODE CORES

\begin{tabular}{|c|c|c|c|c|c|c|c|c|c|c|}
\hline $\begin{array}{c}\text { Sample } \\
\text { No. }\end{array}$ & $\begin{array}{l}\text { KII } \\
\text { No. }\end{array}$ & $\begin{array}{l}\text { Pitch } \\
\mathrm{Wt} \%\end{array}$ & $\begin{array}{l}\text { Core } \\
\text { BAD } \\
(\mathrm{g} / \mathrm{cc})\end{array}$ & $\begin{array}{c}\text { ER } \\
(\mu \Omega \mathrm{m})\end{array}$ & $\begin{array}{c}\text { Air } \\
\text { Perm. } \\
(\mathrm{nPm})\end{array}$ & $\begin{array}{l}\text { Crush } \\
\text { Streng. } \\
(\mathrm{MPa})\end{array}$ & $\begin{array}{l}\text { Mod. } \\
\text { Elast. } \\
\text { (MPa) }\end{array}$ & $\begin{array}{c}\text { Flex. } \\
\text { Streng. } \\
\text { Stress } \\
(\mathrm{MPa})\end{array}$ & $\begin{array}{c}\mathrm{CTE} \\
10^{-6} /{ }^{\circ} \mathrm{C} \\
@ 300^{\circ} \mathrm{C}\end{array}$ & $\begin{array}{l}\text { Thermal } \\
\text { Conduct. } \\
(\mathrm{W} / \mathrm{mK})\end{array}$ \\
\hline W5 & $\begin{array}{l}2000 \\
1314\end{array}$ & 14 & 1.484 & 83.1 & 4.21 & 28.48 & 1752.8 & 1.97 & 3.658 & 2.16 \\
\hline W6 & $\begin{array}{l}2000 \\
1315 \\
\end{array}$ & 14 & 1.481 & 88.0 & 3.04 & 29.62 & 1956.9 & 1.99 & 3.953 & 2.17 \\
\hline W7 & $\begin{array}{l}2000 \\
1316\end{array}$ & 14 & 1.481 & 84.4 & 4.10 & 29.52 & 1904.5 & 2.59 & 3.873 & 2.20 \\
\hline W8 & $\begin{array}{l}2000 \\
1317 \\
\end{array}$ & 14 & 1.483 & 88.9 & 3.02 & 30.15 & 1661.7 & 2.33 & 3.731 & 2.27 \\
\hline Count & & & 4 & 4 & 4 & 4 & 4 & 4 & 4 & 4 \\
\hline Avg. & & & 1.482 & 86.1 & 3.59 & 29.44 & 1819.0 & 2.22 & 3.804 & 2.20 \\
\hline Std.Dev. & & & 0.002 & 2.8 & 0.65 & 0.70 & 136.0 & 0.30 & 0.134 & 0.05 \\
\hline
\end{tabular}




\section{APPENDIX B \\ (CONTIUNED)}

\begin{tabular}{|c|c|c|c|c|c|c|c|c|c|c|}
\hline $\begin{array}{c}\text { Sample } \\
\text { No. }\end{array}$ & $\begin{array}{l}\text { KII } \\
\text { No. }\end{array}$ & $\begin{array}{l}\text { Pitch } \\
\mathrm{Wt} \%\end{array}$ & $\begin{array}{l}\text { Core } \\
\text { BAD } \\
(\mathrm{g} / \mathrm{cc})\end{array}$ & $\begin{array}{c}\text { ER } \\
(\mu \Omega \mathrm{m})\end{array}$ & $\begin{array}{c}\text { Air } \\
\text { Perm. } \\
(\mathrm{nPm})\end{array}$ & $\begin{array}{l}\text { Crush } \\
\text { Streng. } \\
(\mathrm{MPa})\end{array}$ & $\begin{array}{l}\text { Mod. } \\
\text { Elast. } \\
(\mathrm{MPa})\end{array}$ & $\begin{array}{c}\text { Flex. } \\
\text { Streng. } \\
\text { Stress } \\
(\mathrm{MPa})\end{array}$ & $\begin{array}{c}\mathrm{CTE} \\
10^{-6} /{ }^{\circ} \mathrm{C} \\
@ 300^{\circ} \mathrm{C}\end{array}$ & $\begin{array}{l}\text { Thermal } \\
\text { Conduct. } \\
(\mathrm{W} / \mathrm{mK})\end{array}$ \\
\hline W9 & $\begin{array}{l}2000 \\
1318\end{array}$ & 15 & 1.508 & 72.2 & 2.26 & 33.03 & 1627.4 & 3.74 & 3.868 & 2.38 \\
\hline W10 & $\begin{array}{l}2000 \\
1319\end{array}$ & 15 & 1.510 & 70.1 & 1.82 & 32.30 & 1708.3 & 2.33 & 3.827 & 2.44 \\
\hline W11 & $\begin{array}{l}2000 \\
1320\end{array}$ & 15 & 1.508 & 70.6 & 2.24 & 34.28 & 2253.8 & 4.83 & 3.775 & 2.39 \\
\hline W12 & $\begin{array}{l}2000 \\
1321 \\
\end{array}$ & 15 & 1.504 & 71.6 & 2.35 & 30.29 & 1291.8 & 2.82 & 3.851 & 2.35 \\
\hline
\end{tabular}

\begin{tabular}{|c|l|c|c|c|c|c|c|c|c|c|}
\hline Count & & & 4 & 4 & 4 & 4 & 4 & 4 & 4 & 4 \\
\hline Avg. & & & 1.482 & 71.1 & 2.17 & 32.47 & 1720.3 & 3.43 & 3.830 & 2.39 \\
\hline Std.Dev & & & 0.002 & 0.9 & 0.24 & 1.67 & 398.7 & 1.10 & 0.040 & 0.04 \\
\hline
\end{tabular}

\begin{tabular}{|c|c|c|c|c|c|c|c|c|c|c|}
\hline W13 & $\begin{array}{l}2000 \\
1322\end{array}$ & 16 & 1.525 & 65.2 & 1.85 & 38.92 & 1346.1 & 5.85 & 3.777 & 2.34 \\
\hline W14 & $\begin{array}{l}2000 \\
1323 \\
\end{array}$ & 16 & 1.535 & 62.7 & 0.88 & 41.03 & 2121.3 & 7.81 & 3.758 & 2.39 \\
\hline W15 & $\begin{array}{l}2000 \\
1324 \\
\end{array}$ & 16 & 1.538 & 62.0 & 0.46 & 40.88 & 1857.8 & 7.08 & 3.776 & 2.57 \\
\hline W16 & $\begin{array}{l}2000 \\
1325 \\
\end{array}$ & 16 & 1.530 & 64.0 & 0.82 & 37.33 & 2083.4 & 4.82 & 3.837 & 2.46 \\
\hline
\end{tabular}

\begin{tabular}{|c|c|c|c|c|c|c|c|c|c|c|}
\hline Count & & & 4 & 4 & 4 & 4 & 4 & 4 & 4 & 4 \\
\hline Avg. & & & 1.532 & 63.5 & 1.00 & 39.54 & 1852.1 & 6.39 & 3.787 & 2.44 \\
\hline Std.Dev & & & 0.006 & 1.4 & 0.60 & 1.76 & 356.9 & 1.32 & 0.034 & 0.10 \\
\hline
\end{tabular}




\section{APPENDIX C}

Standard Coal-Tar Pitch:WVU Pitch 50:50

\begin{tabular}{|c|c|c|c|c|c|c|}
\hline $\begin{array}{c}\text { Sample } \\
\text { No. }\end{array}$ & $\begin{array}{c}\text { Koppers } \\
\text { Sample } \\
\text { No. }\end{array}$ & $\begin{array}{c}\text { Pitch } \\
\mathrm{Wt} \%\end{array}$ & $\begin{array}{c}\text { Block } \\
\text { GAD } \\
(\mathrm{g} / \mathrm{cc})\end{array}$ & $\begin{array}{c}\text { Block } \\
\text { BAD } \\
(\mathrm{g} / \mathrm{cc})\end{array}$ & $\begin{array}{c}\text { InSitu } \\
\mathrm{CV} \\
\mathrm{Wt} \%\end{array}$ & $\begin{array}{c}\text { Shrinkage } \\
\%\end{array}$ \\
\hline $\mathrm{W} 17$ & 20001326 & 14 & 1.531 & 1.476 & 64.3 & 1.450 \\
\hline $\mathrm{W} 18$ & 20001327 & 14 & 1.532 & 1.476 & 63.4 & 1.531 \\
\hline W19 & 20001328 & 14 & 1.537 & 1.478 & 62.4 & 1.497 \\
\hline W20 & 20001329 & 14 & 1.523 & 1.467 & 64.3 & 1.335 \\
\hline & & & & & & \\
\hline Avg. & & & 1.531 & 1.474 & 63.6 & 1.453 \\
\hline
\end{tabular}

\begin{tabular}{|c|c|c|c|c|c|c|}
\hline W21 & 20001330 & 15 & 1.568 & 1.502 & 64.7 & 1.141 \\
\hline W22 & 20001331 & 15 & 1.562 & 1.494 & 63.9 & 1.121 \\
\hline W23 & 20001332 & 15 & 1.577 & 1.500 & 63.0 & 0.685 \\
\hline W24 & 20001333 & 15 & 1.561 & 1.496 & 63.4 & 1.333 \\
\hline & & & & & & \\
\hline Avg. & & & 1.567 & 1.498 & 63.7 & 1.070 \\
\hline
\end{tabular}

\begin{tabular}{|c|c|c|c|c|c|c|}
\hline W25 & 20001334 & 16 & 1.603 & 1.506 & 64.0 & -0.278 \\
\hline W26 & 20001335 & 16 & 1.592 & 1.505 & 62.9 & 0.484 \\
\hline W27 & 20001336 & 16 & 1.599 & 1.509 & 63.3 & 0.270 \\
\hline W28 & 20001337 & 16 & 1.595 & 1.511 & 64.1 & 0.514 \\
\hline & & & & & & \\
\hline Avg. & & & 1.597 & 1.508 & 63.6 & 0.247 \\
\hline
\end{tabular}

\section{ANODE CORES}

\begin{tabular}{|c|c|c|c|c|c|c|c|c|c|c|}
\hline $\begin{array}{c}\text { Sample } \\
\text { No. }\end{array}$ & $\begin{array}{l}\text { KII } \\
\text { No. }\end{array}$ & $\begin{array}{l}\text { Pitch } \\
\mathrm{W}{ }^{\circ} \%\end{array}$ & $\begin{array}{l}\text { Core } \\
\text { BAD } \\
(\mathrm{g} / \mathrm{cc})\end{array}$ & $\begin{array}{c}\text { ER } \\
(\mu \Omega \mathrm{m})\end{array}$ & $\begin{array}{c}\text { Air } \\
\text { Perm. } \\
(\mathrm{nPm})\end{array}$ & $\begin{array}{l}\text { Crush } \\
\text { Streng. } \\
\text { (MPa) }\end{array}$ & $\begin{array}{l}\text { Mod. } \\
\text { Elast. } \\
\text { (MPa) }\end{array}$ & $\begin{array}{c}\text { Flex. } \\
\text { Streng. } \\
\text { Stress } \\
(\mathrm{MPa})\end{array}$ & $\begin{array}{c}\mathrm{CTE} \\
10^{-6} /{ }^{\circ} \mathrm{C} \\
@ 300^{\circ} \mathrm{C}\end{array}$ & $\begin{array}{l}\text { Thermal } \\
\text { Conduct. } \\
\text { (W/mK) }\end{array}$ \\
\hline W17 & $\begin{array}{l}2000 \\
1326\end{array}$ & 14 & 1.490 & 76.3 & 1.95 & 31.43 & 2176.9 & 2.45 & 3.596 & 2.23 \\
\hline W18 & $\begin{array}{l}2000 \\
1327\end{array}$ & 14 & 1.487 & 77.0 & 2.02 & 31.13 & 2047.4 & 3.47 & 3.630 & 2.17 \\
\hline W19 & $\begin{array}{l}2000 \\
1328 \\
\end{array}$ & 14 & 1.488 & 76.0 & 2.45 & 29.86 & 1832.2 & 3.17 & 3.862 & 2.25 \\
\hline W20 & $\begin{array}{l}2000 \\
1329 \\
\end{array}$ & 14 & 1.485 & 79.9 & 2.95 & 29.10 & 1912.9 & 2.70 & 3.816 & 2.27 \\
\hline
\end{tabular}

\begin{tabular}{|c|l|c|c|c|c|c|c|c|c|c|}
\hline Count & & & 4 & 4 & 4 & 4 & 4 & 4 & 4 & 4 \\
\hline Avg. & & & 1.488 & 77.3 & 2.34 & 30.38 & 1992.4 & 2.95 & 3.726 & 2.22 \\
\hline Std.Dev. & & 0.002 & 1.8 & 0.46 & 1.09 & 151.7 & 0.46 & 0.133 & 0.07 \\
\hline
\end{tabular}


APPENDIX C

(CONTIUNED)

Standard Coal-Tar Pitch:WVU Pitch 50:50

ANODE CORES

\begin{tabular}{|c|c|c|c|c|c|c|c|c|c|c|}
\hline W21 & $\begin{array}{c}2000 \\
1330\end{array}$ & 15 & $\begin{array}{c}1.51 \\
1\end{array}$ & 64.9 & 1.14 & 34.07 & 1740.2 & 7.91 & 3.770 & 2.52 \\
\hline W22 & $\begin{array}{c}2000 \\
1331\end{array}$ & 15 & $\begin{array}{c}1.50 \\
1\end{array}$ & 68.0 & 1.76 & 32.64 & 1475.5 & 5.35 & 3.661 & 2.32 \\
\hline W23 & $\begin{array}{c}2000 \\
1332\end{array}$ & 15 & $\begin{array}{c}1.50 \\
6\end{array}$ & 66.4 & 0.69 & 30.96 & 925.8 & 5.34 & 3.879 & 2.38 \\
\hline W24 & $\begin{array}{c}2000 \\
1333\end{array}$ & 15 & $\begin{array}{c}1.50 \\
8\end{array}$ & 66.6 & 0.70 & 28.23 & 650.9 & 4.35 & 3.740 & 2.49 \\
\hline
\end{tabular}

\begin{tabular}{|c|c|c|c|c|c|c|c|c|c|c|}
\hline Count & & & 4 & 4 & 4 & 4 & 4 & 4 & 4 & 4 \\
\hline Avg. & & $\begin{array}{c}1.50 \\
6\end{array}$ & 66.5 & 1.07 & 31.48 & 1198.1 & 5.74 & 3.763 & 2.43 \\
\hline Std.Dev & & $\begin{array}{c}0.00 \\
4\end{array}$ & 1.3 & 0.50 & 2.51 & 498.1 & 1.52 & 0.090 & 0.09 \\
\hline
\end{tabular}

\begin{tabular}{|c|c|c|c|c|c|c|c|c|c|c|}
\hline W25 & $\begin{array}{c}2000 \\
1334\end{array}$ & 16 & $\begin{array}{c}1.51 \\
9\end{array}$ & 63.7 & 0.69 & 33.24 & 2798.2 & 7.60 & 3.757 & 2.36 \\
\hline W26 & $\begin{array}{c}2000 \\
1335\end{array}$ & 16 & $\begin{array}{c}1.51 \\
2\end{array}$ & 66.3 & 0.70 & 34.62 & 1503.0 & 5.59 & 3.803 & 2.42 \\
\hline W27 & $\begin{array}{c}2000 \\
1336\end{array}$ & 16 & $\begin{array}{c}1.52 \\
5\end{array}$ & 62.9 & 0.96 & 38.88 & 3485.4 & 8.43 & 3.746 & 2.40 \\
\hline W28 & $\begin{array}{c}2000 \\
1337\end{array}$ & 16 & $\begin{array}{c}1.51 \\
6\end{array}$ & 62.7 & 0.56 & 31.52 & 986.0 & 5.98 & 3.789 & 2.54 \\
\hline
\end{tabular}

\begin{tabular}{|c|c|c|c|c|c|c|c|c|c|c|}
\hline Count & & & 4 & 4 & 4 & 4 & 4 & 4 & 4 & 4 \\
\hline Avg. & & $\begin{array}{c}1.51 \\
8\end{array}$ & 63.9 & 0.73 & 34.56 & 2193.2 & 6.90 & 3.774 & 2.43 \\
\hline Std.Dev & & $\begin{array}{c}0.00 \\
6\end{array}$ & 1.6 & 0.16 & 3.14 & 1150.3 & 1.34 & 0.027 & 0.08 \\
\hline
\end{tabular}




\section{APPENDIX D}

Standard Coal-Tar Pitch:Standard Petroleum Pitch 50:50 Pilot Anodes

\begin{tabular}{|c|c|c|c|c|c|c|}
\hline $\begin{array}{c}\text { Sample } \\
\text { No. }\end{array}$ & $\begin{array}{c}\text { Koppers } \\
\text { Sample } \\
\text { No. }\end{array}$ & $\begin{array}{c}\text { Pitch } \\
\mathrm{Wt} \%\end{array}$ & $\begin{array}{c}\text { Block } \\
\text { GAD } \\
(\mathrm{g} / \mathrm{cc})\end{array}$ & $\begin{array}{c}\text { Block } \\
\text { BAD } \\
(\mathrm{g} / \mathrm{cc})\end{array}$ & $\begin{array}{c}\text { InSitu } \\
\mathrm{CV} \\
\mathrm{Wt} \%\end{array}$ & $\begin{array}{c}\text { Shrinkage } \\
\%\end{array}$ \\
\hline A125 & C98-705 & 15 & 1.543 & 1.477 & 63.4 & 1.298 \\
\hline A126 & C98-706 & 15 & 1.534 & 1.473 & 63.5 & 1.556 \\
\hline A127 & C98-707 & 15 & 1.535 & 1.469 & 62.7 & 1.323 \\
\hline A128 & C98-708 & 15 & 1.537 & 1.476 & 63.8 & 1.524 \\
\hline A129 & C98-709 & 15 & 1.534 & 1.470 & 63.6 & 1.325 \\
\hline A130 & C98-710 & 15 & 1.517 & 1.463 & 65.9 & 1.612 \\
\hline & & & & & & \\
\hline Avg. & & & 1.537 & 1.473 & 63.4 & 1.41 \\
\hline & & 16 & 1.595 & 1.525 & 64.2 & 1.411 \\
\hline A113 & C98-693 & 16 & 1.598 & 1.522 & 63.5 & 1.172 \\
\hline A114 & C98-694 & 16 & 1.594 & 1.515 & 62.3 & 1.108 \\
\hline A115 & C98-695 & 16 & 1.581 & 1.511 & 63.9 & 1.455 \\
\hline A116 & C98-696 & 16 & 1.578 & 1.510 & 63.8 & 1.564 \\
\hline A117 & C98-697 & 16 & 1.577 & 1.509 & 63.7 & 1.540 \\
\hline A118 & C98-698 & 16 & & & & \\
\hline & & & 1.589 & 1.509 & 63.5 & 1.34 \\
\hline Avg. & & & & & \\
\hline
\end{tabular}

Standard Coal-Tar Pitch:Standard Petroleum Pitch 50:50 Anode Cores

\begin{tabular}{|c|c|c|c|c|c|c|c|c|c|}
\hline $\begin{array}{c}\text { Sample } \\
\text { No. }\end{array}$ & $\begin{array}{l}\text { Pitch } \\
\mathrm{Wt} \%\end{array}$ & $\begin{array}{l}\text { Core } \\
\text { BAD } \\
(\mathrm{g} / \mathrm{cc})\end{array}$ & $\begin{array}{c}\text { ER } \\
(\mu \Omega m)\end{array}$ & $\begin{array}{c}\text { Air } \\
\text { Perm. } \\
(\mathrm{nPm})\end{array}$ & $\begin{array}{l}\text { Crush } \\
\text { Streng. } \\
\text { (MPa) }\end{array}$ & $\begin{array}{l}\text { Mod. } \\
\text { Elast. } \\
(\mathrm{MPa})\end{array}$ & $\begin{array}{l}\text { Flex. } \\
\text { Streng. } \\
\text { Stress } \\
(\mathrm{MPa})\end{array}$ & $\begin{array}{c}\mathrm{CTE} \\
10^{-6} /{ }^{\circ} \mathrm{C} \\
\left(a, 300^{\circ} \mathrm{C}\right.\end{array}$ & $\begin{array}{l}\text { Thermal } \\
\text { Conduct. } \\
(\mathrm{W} / \mathrm{mK})\end{array}$ \\
\hline C98-705 & 15 & 1.490 & 68.2 & & 38.81 & 1987.8 & 2.41 & 4.031 & \\
\hline C98-706 & 15 & 1.480 & 68.0 & & 38.33 & 2176.4 & & & \\
\hline C98-707 & 15 & 1.484 & 67.9 & 5.18 & & & 3.07 & 4.033 & 1.86 \\
\hline C98-708 & 15 & 1.475 & 70.7 & 3.74 & & & & & 2.23 \\
\hline C98-709 & 15 & 1.468 & 71.3 & 6.00 & & & & & \\
\hline C98-710 & 15 & 1.477 & 68.5 & & 33.88 & 2048.8 & & & \\
\hline
\end{tabular}

\begin{tabular}{|c|c|c|c|c|c|c|c|c|c|}
\hline Count & 6 & 6 & 3 & 3 & 3 & 2 & 2 & 2 \\
\hline Avg. & 1.48 & 69.3 & 4.97 & 36.27 & 2071.0 & 2.74 & 4.032 & 2.05 \\
\hline Std.Dev. & & 0.01 & 1.4 & 1.14 & 2.37 & 96.2 & 0.47 & 0.001 & 0.09 \\
\hline
\end{tabular}




\section{APPENDIX D \\ (CONTINUED)}

Standard Coal-Tar Pitch:Standard Petroleum Pitch 50:50 Anode Cores

\begin{tabular}{|c|c|c|c|c|c|c|c|c|c|}
\hline $\begin{array}{c}\text { Sample } \\
\text { No. }\end{array}$ & $\begin{array}{c}\text { Pitch } \\
\mathrm{Wt} \%\end{array}$ & $\begin{array}{c}\text { Core } \\
\text { BAD } \\
(\mathrm{g} / \mathrm{cc})\end{array}$ & $\begin{array}{c}\text { ER } \\
(\mu \Omega \mathrm{m})\end{array}$ & $\begin{array}{c}\text { Air } \\
\text { Perm. } \\
(\mathrm{nPm})\end{array}$ & $\begin{array}{c}\text { Crush } \\
\text { Streng. } \\
(\mathrm{MPa})\end{array}$ & $\begin{array}{c}\text { Mod. } \\
\text { Elast. } \\
(\mathrm{MPa})\end{array}$ & $\begin{array}{c}\text { Flex. } \\
\text { Streng. } \\
\text { Stress } \\
(\mathrm{MPa})\end{array}$ & $\begin{array}{c}\mathrm{CTE} \\
10^{-6} /{ }^{\circ} \mathrm{C} \\
\left(0300^{\circ} \mathrm{C}\right.\end{array}$ & $\begin{array}{c}\text { Thermal } \\
\text { Conduct. } \\
(\mathrm{W} / \mathrm{mK})\end{array}$ \\
\hline $\mathrm{C} 98-693$ & 16 & 1.52 & 59.9 & 1.03 & & & 6.03 & 3.950 & 2.59 \\
\hline $\mathrm{C} 98-694$ & 16 & 1.52 & 60.5 & & 44.17 & 2507.0 & & & \\
\hline $\mathrm{C} 98-695$ & 16 & 1.52 & 60.2 & 1.18 & & & 4.05 & 3.844 & 2.25 \\
\hline $\mathrm{C} 98-696$ & 16 & 1.52 & 61.3 & & 43.45 & 2583.4 & & & \\
\hline $\mathrm{C} 98-697$ & 16 & 1.52 & 62.3 & 1.34 & & & 2.90 & & 2.49 \\
\hline $\mathrm{C} 98-698$ & 16 & 1.51 & 60.7 & & 21.66 & 2918.6 & & 4.081 & \\
\hline
\end{tabular}

\begin{tabular}{|c|c|c|c|c|c|c|c|c|c|}
\hline Count & 6 & 6 & 3 & 3 & 3 & 3 & 3 & 3 \\
\hline Avg. & 1.52 & 60.9 & 1.16 & 38.50 & 2669.7 & 4.33 & 3.852 & 2.44 \\
\hline Std.Dev. & & 0.00 & 0.8 & 0.16 & 12.68 & 219.0 & 1.58 & 0.109 & 0.17 \\
\hline
\end{tabular}




\section{APPENDIX E}

Standard Coal-Tar Pitch:Standard Petroleum Pitch 85:15 Pilot Anodes

\begin{tabular}{|c|c|c|c|c|c|c|}
\hline $\begin{array}{c}\text { Sample } \\
\text { No. }\end{array}$ & $\begin{array}{c}\text { Koppers } \\
\text { Sample } \\
\text { No. }\end{array}$ & $\begin{array}{l}\text { Pitch } \\
\mathrm{Wt} \%\end{array}$ & $\begin{array}{l}\text { Block } \\
\text { GAD } \\
(\mathrm{g} / \mathrm{cc}) \\
\end{array}$ & $\begin{array}{l}\text { Block } \\
\text { BAD } \\
(\mathrm{g} / \mathrm{cc}) \\
\end{array}$ & $\begin{array}{c}\text { InSitu } \\
\mathrm{CV} \\
\mathrm{Wt} \% \\
\end{array}$ & $\begin{array}{c}\text { Shrinkage } \\
\%\end{array}$ \\
\hline A234 & C98-1174 & 15 & 1.521 & 1.483 & 67.5 & 2.445 \\
\hline A235 & C98-1175 & 15 & 1.554 & 1.486 & 65.3 & 0.845 \\
\hline A236 & C98-1176 & 15 & 1.542 & 1.497 & 73.8 & 1.039 \\
\hline A237 & C98-1177 & 15 & 1.550 & 1.496 & 69.1 & 1.174 \\
\hline A238 & C98-1178 & 15 & 1.547 & 1.498 & 69.9 & 1.337 \\
\hline A239 & C98-1179 & 15 & 1.549 & 1.490 & 69.7 & 0.810 \\
\hline Avg. & & & 1.543 & 1.492 & 69.1 & 1.37 \\
\hline A222 & C98-1161 & 16 & 1.601 & 1.538 & 69.6 & 0.977 \\
\hline A223 & C98-1162 & 16 & 1.592 & 1.533 & 68.7 & 1.408 \\
\hline A224 & C98-1163 & 16 & 1.594 & 1.531 & 69.6 & 0.938 \\
\hline A225 & C98-1164 & 16 & 1.592 & 1.521 & 70.0 & 0.373 \\
\hline A226 & C98-1165 & 16 & 1.588 & 1.529 & 68.9 & 1.271 \\
\hline A227 & C98-1166 & 16 & 1.590 & 1.531 & 69.8 & 1.201 \\
\hline Avg. & & & 1.593 & 1.530 & 69.4 & 0.99 \\
\hline
\end{tabular}

Standard Coal-Tar Pitch:Standard Petroleum Pitch 85:15 Anode Cores

\begin{tabular}{|c|c|c|c|c|c|c|c|c|c|}
\hline $\begin{array}{c}\text { Sample } \\
\text { No. }\end{array}$ & $\begin{array}{l}\text { Pitch } \\
\mathrm{Wt} \%\end{array}$ & $\begin{array}{l}\text { Core } \\
\text { BAD } \\
(\mathrm{g} / \mathrm{cc})\end{array}$ & $\begin{array}{c}\text { ER } \\
(\mu \Omega m)\end{array}$ & $\begin{array}{c}\text { Air } \\
\text { Perm. } \\
(\mathrm{nPm})\end{array}$ & $\begin{array}{l}\text { Crush } \\
\text { Streng. } \\
\text { (MPa) }\end{array}$ & $\begin{array}{l}\text { Mod. } \\
\text { Elast. } \\
(\mathrm{MPa})\end{array}$ & $\begin{array}{l}\text { Flex. } \\
\text { Streng. } \\
\text { Stress } \\
(\mathrm{MPa})\end{array}$ & $\begin{array}{c}\mathrm{CTE} \\
10^{-6} /{ }^{\circ} \mathrm{C} \\
\left(a, 300{ }^{\circ} \mathrm{C}\right.\end{array}$ & $\begin{array}{l}\text { Thermal } \\
\text { Conduct. } \\
(\mathrm{W} / \mathrm{mK})\end{array}$ \\
\hline A234 & 15 & 1.529 & 70.3 & 1.80 & & & 3.20 & 4.140 & 2.29 \\
\hline A235 & 15 & 1.517 & 71.7 & & 39.29 & & & & \\
\hline A236 & 15 & 1.509 & 72.1 & 2.79 & & & 2.89 & 3.985 & 2.22 \\
\hline A237 & 15 & 1.520 & 72.9 & & 34.35 & & & & \\
\hline A238 & 15 & 1.512 & 72.7 & 1.79 & & & 2.35 & 4.138 & 2.37 \\
\hline A239 & 15 & 1.513 & 71.6 & & 39.88 & & & & \\
\hline
\end{tabular}

\begin{tabular}{|c|c|c|c|c|c|c|c|c|c|}
\hline Count & 6 & 6 & 3 & 3 & & 3 & 3 & 3 \\
\hline Avg. & 1.48 & 69.3 & 2.13 & 37.84 & & 2.81 & 4.081 & 2.29 \\
\hline Std.Dev. & & 0.01 & 1.4 & 0.58 & 3.04 & & 0.43 & 0.100 & 0.08 \\
\hline
\end{tabular}




\section{APPENDIX E \\ (CONTINUED)}

Standard Coal-Tar Pitch:Standard Petroleum Pitch 85:15 Anode Cores

\begin{tabular}{|c|c|c|c|c|c|c|c|c|c|}
\hline $\begin{array}{c}\text { Sample } \\
\text { No. }\end{array}$ & $\begin{array}{c}\text { Pitch } \\
\mathrm{Wt} \%\end{array}$ & $\begin{array}{c}\text { Core } \\
\text { BAD } \\
(\mathrm{g} / \mathrm{cc})\end{array}$ & $\begin{array}{c}\text { ER } \\
(\mu \Omega \mathrm{m})\end{array}$ & $\begin{array}{c}\text { Air } \\
\text { Perm. } \\
(\mathrm{nPm})\end{array}$ & $\begin{array}{c}\text { Crush } \\
\text { Streng. } \\
(\mathrm{MPa})\end{array}$ & $\begin{array}{c}\text { Mod. } \\
\text { Elast. } \\
(\mathrm{MPa})\end{array}$ & $\begin{array}{c}\text { Flex. } \\
\text { Streng. } \\
\text { Stress } \\
(\mathrm{MPa})\end{array}$ & $\begin{array}{c}\mathrm{CTE} \\
10^{-6} /{ }^{\circ} \mathrm{C} \\
\left(0300^{\circ} \mathrm{C}\right.\end{array}$ & $\begin{array}{c}\text { Thermal } \\
\text { Conduct. } \\
(\mathrm{W} / \mathrm{mK})\end{array}$ \\
\hline $\mathrm{A} 222$ & 16 & 1.55 & 62.2 & 1.80 & & & 3.20 & 4.140 & 2.29 \\
\hline $\mathrm{A} 223$ & 16 & 1.55 & 62.2 & & 39.29 & & & & \\
\hline $\mathrm{A} 224$ & 16 & 1.54 & 62.9 & 2.79 & & & 2.89 & 3.985 & 2.22 \\
\hline $\mathrm{A} 225$ & 16 & 1.55 & 61.6 & & 34.35 & & & & \\
\hline $\mathrm{A} 226$ & 16 & 1.54 & 61.3 & 1.79 & & & 2.35 & & 2.37 \\
\hline $\mathrm{A} 227$ & 16 & 1.54 & 61.4 & & 39.88 & & & 4.138 & \\
\hline
\end{tabular}

\begin{tabular}{|c|c|c|c|c|c|c|c|c|c|}
\hline Count & 6 & 6 & 3 & 3 & & 3 & 3 & 3 \\
\hline Avg. & 1.55 & 61.9 & 2.13 & 37.84 & & 2.81 & 4.081 & 2.29 \\
\hline Std.Dev. & 0.01 & 0.6 & 0.58 & 3.04 & & 0.43 & 0.100 & 0.08 \\
\hline
\end{tabular}

